\title{
Phantasma Indien
}

\section{Zur Indienrezeption um 1800}

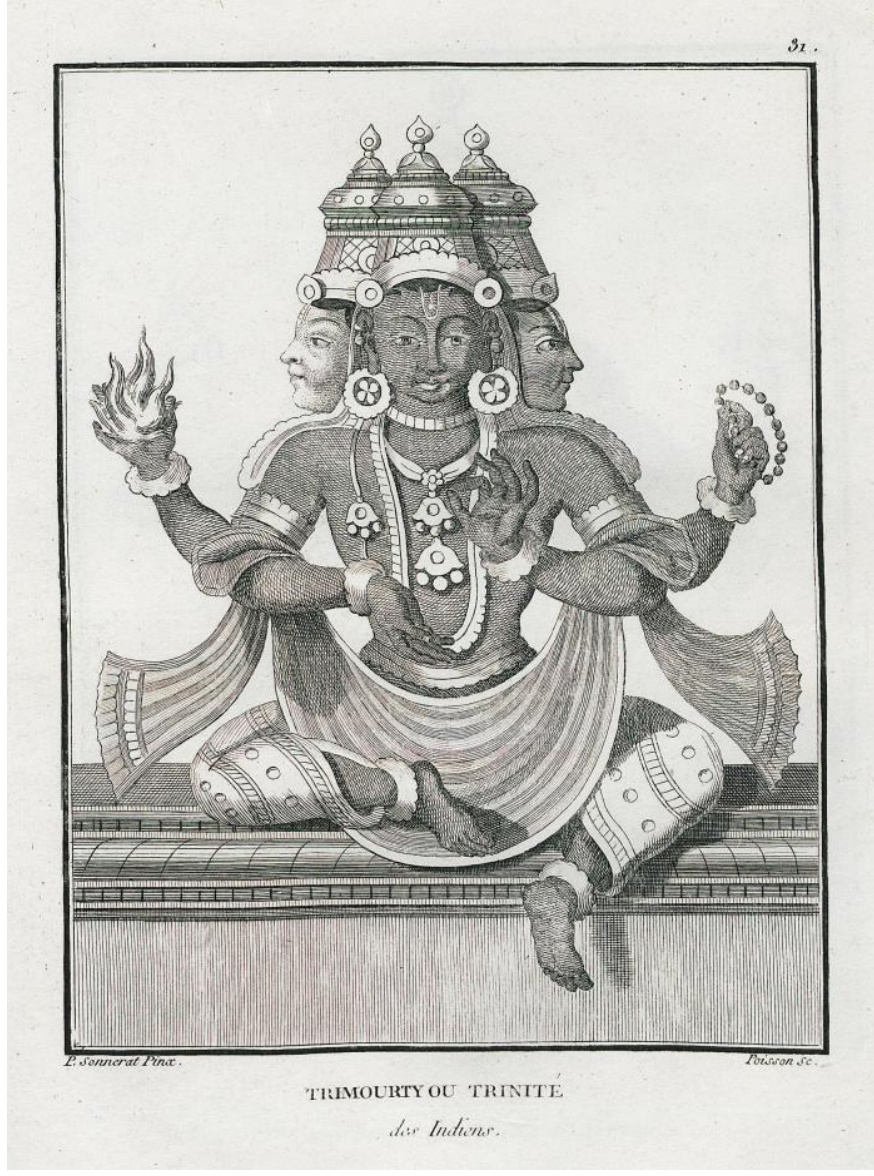

Dissertation

zur Erlangung des philosophischen Doktorgrades

an der Philosophischen Fakultät der Georg-August-Universität Göttingen vorgelegt von

Merle Otte

aus Henstedt-Ulzburg

Göttingen 2020 
Erstgutachter: Prof. Dr. Gerhard Lauer

Zweitgutachter: Prof. Dr. Marian Füssel

Datum der mündlichen Prüfung: 16.12.2020

Fassung September 2021

Abbildung Titelseite:

„Trimourti ou Trinité des Indiens“ aus Sonnerat, Pierre.: Voyages aux Indes orientales et la Chine, Fait par ordre du Roi, depuis 1774 jusqu'en 1781. Band 5. Collection de planches pour servir au Voyage aux Indes Orientales et a la Chine. Paris 1806, Pl. 31 (https://digi.ub.uniheidelberg.de/diglit/sonnerat1806bd5/0045)

Die Abbildung zeigt die indische Trimūrti (die Einheit der Götter Brahmā, Viṣṇu und Śiva). 


\section{Inhalt}

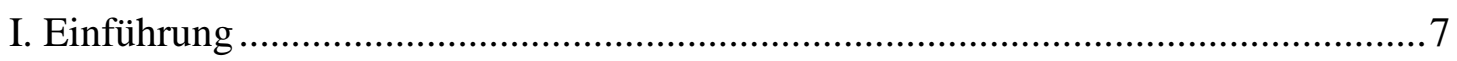

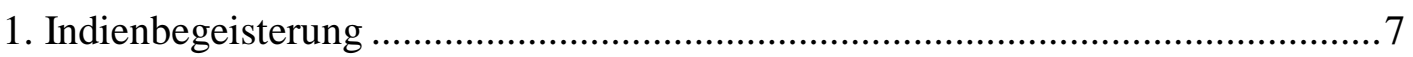

2. Überblick über die bisherige Forschung ......................................................... 10

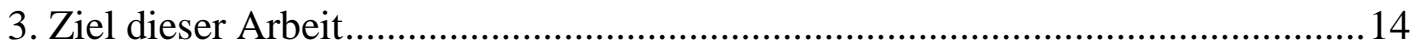

4. Diskursanalyse oder Begriffsgeschichte - Fragen der methodischen

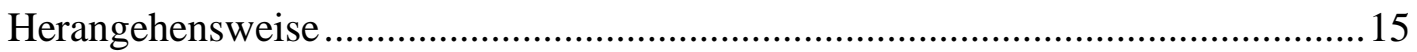

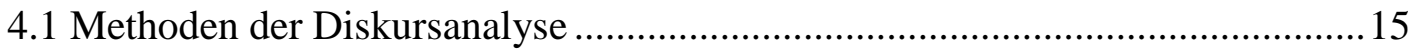

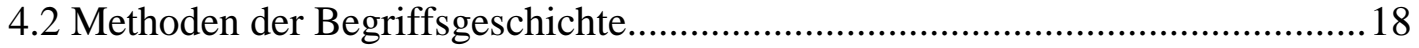

4.3 Historische Semantik und Argumentationsanalyse ......................................... 19

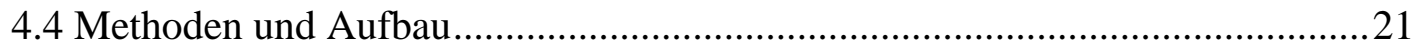

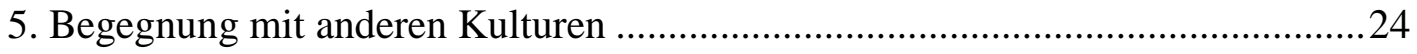

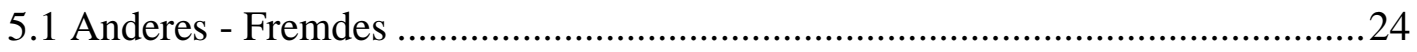

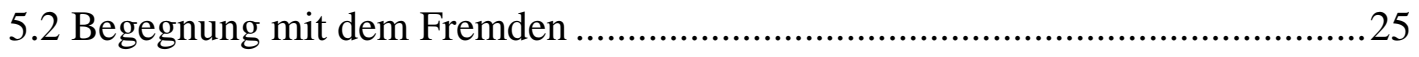

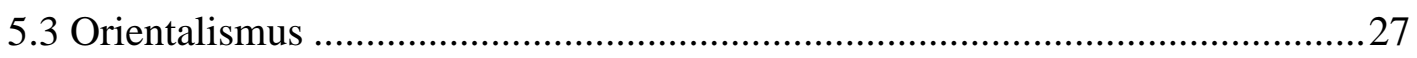

5.4 Einstellungen zum Anderen/Fremden um 1800 ............................................. 32

6. Indienkenntnisse und -vorstellungen im Mittelalter und in der frühen Neuzeit.. 35

6.1 Europäische Vorstellungen von Indien im Mittelalter ......................................35

6.2 Zwischen Handel und Mission - Indien und Europa in der frühen Neuzeit...... 37

7. Kolonialismus und Wissenschaft - Europa und Indien Ende des 18. Jahrhunderts

7.1 Europäische Handelskompanien in Indien .....................................................42

7.2 Paradigmenwechsel - die Entdeckung des klassischen Indiens ........................45

7.3 Die Ausgangslage im deutschsprachigen Raum ...........................................49

II. Indien in Sachtexten - Themen, Thesen, Bilder ....................................................55

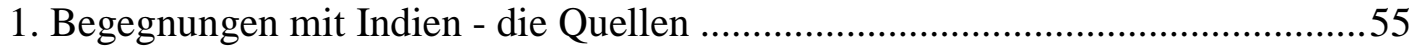

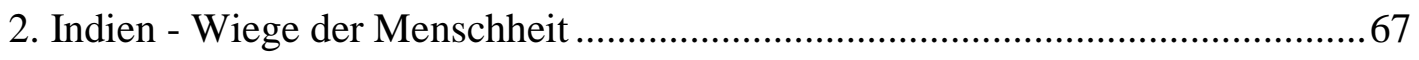

3. Kolonialismus und Kastenwesen - das gegenwärtige Indien ..............................89

3.1 Der indische Subkontinent - Geographie, Flora und Fauna ............................... 89 
3.3 Despotismus und Kastenwesen - die indische Regierungs- und Gesellschaftsform

3.4 Witwenverbrennung und Bajaderen - die Stellung der Frau.

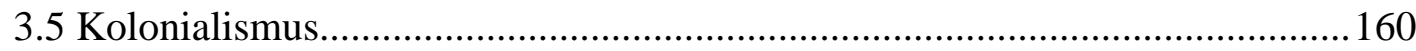

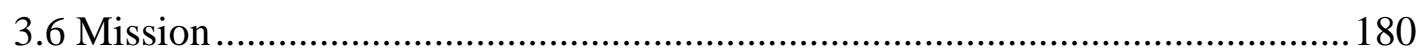

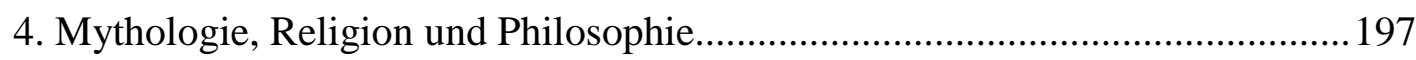

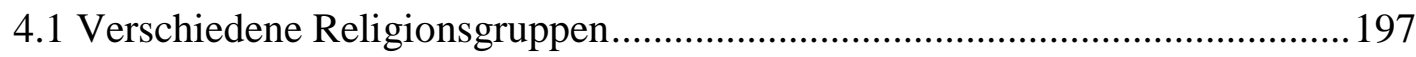

4.2 Die Suche nach mythologischen Gemeinsamkeiten ...................................203

4.3 Götter und Seelenwanderung - die Grundzüge indischer Religion.................2217

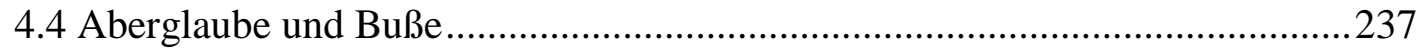

5. Literatur, Kunst und Wissenschaften ........................................................243

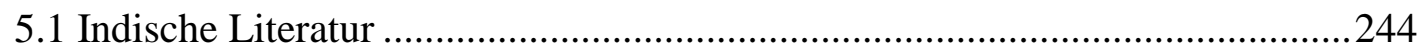

5.2 Indische Kunst, Bildhauerei und Architektur..............................................2. 261

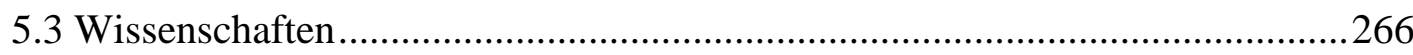

6. Sanskrit und die Entstehung der Indologie ...............................................22

6.1 Sanskrit und die vergleichende Sprachwissenschaft..................................271

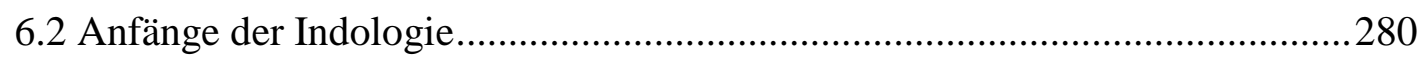

7. Indien als lebendes Museum - eine Zwischenbilanz ......................................284

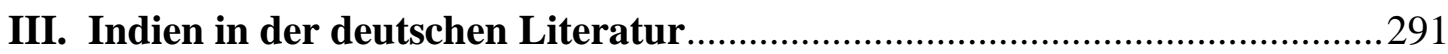

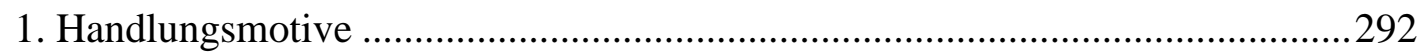

1.1 Rettung einer Witwe/eines Menschenopfers ...............................................2292

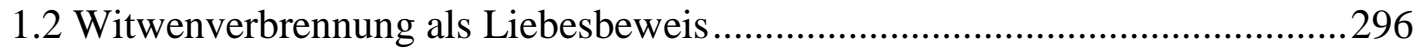

1.3 Liebe zwischen Indern und Europäern ......................................................298

1.4 Konflikte aus dem Begehren einer Frau...................................................... 301

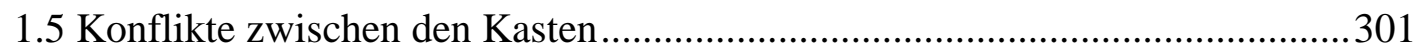

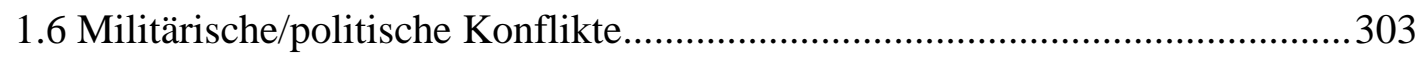

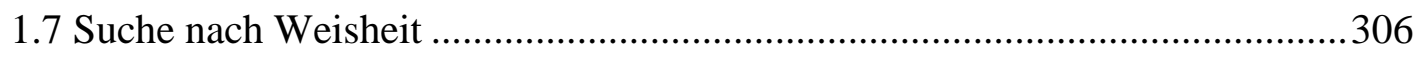

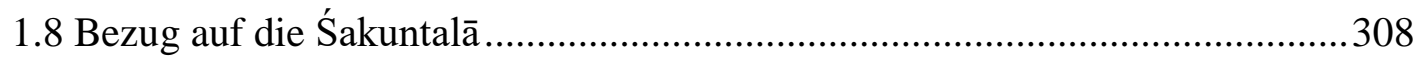




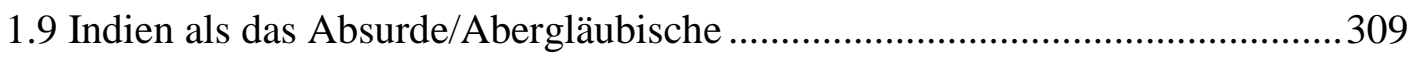

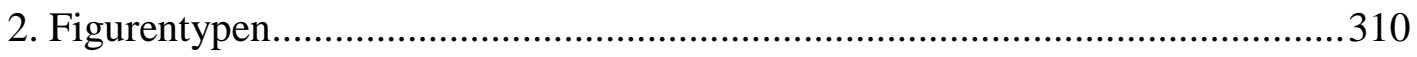

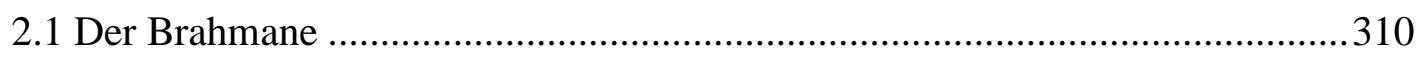

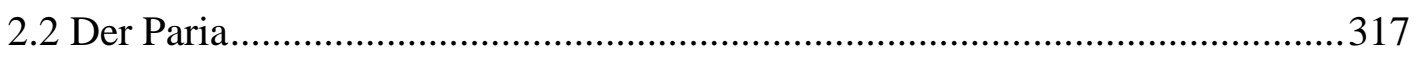

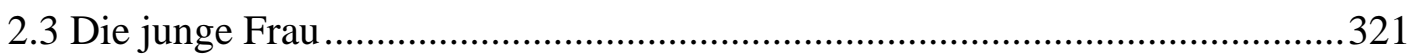

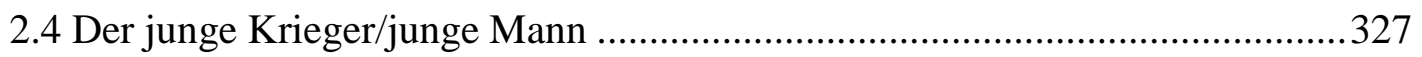

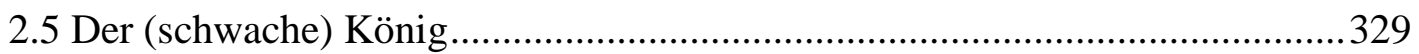

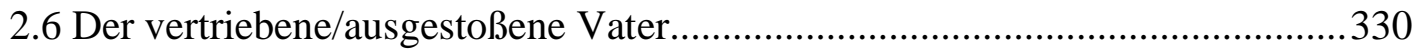

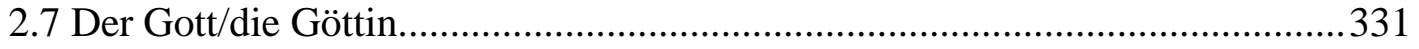

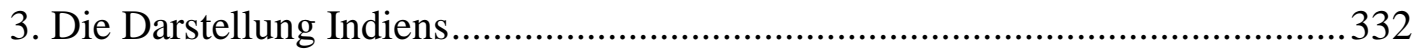

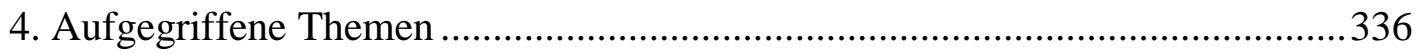

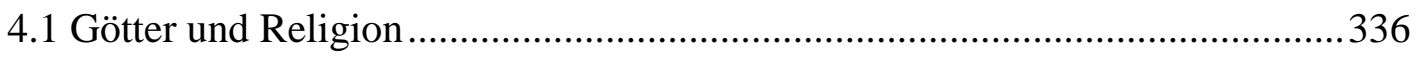

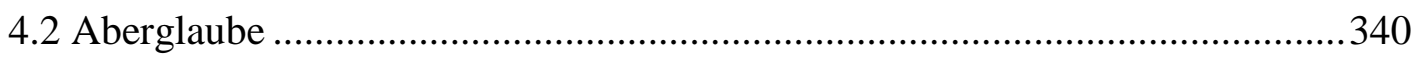

4.3 Vergangene Herrlichkeit/fehlende Entwicklung ........................................... 342

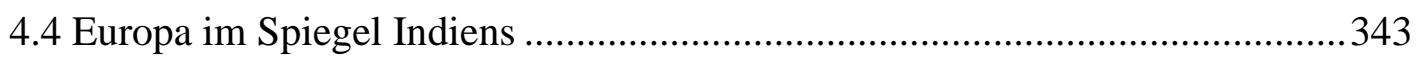

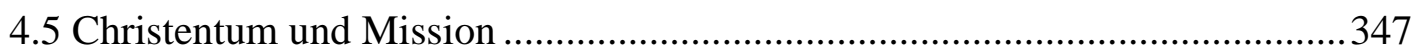

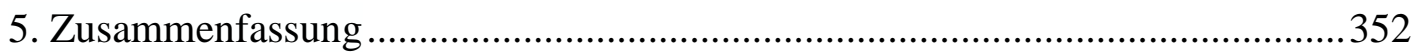

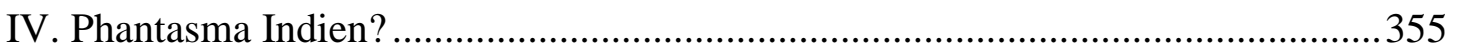

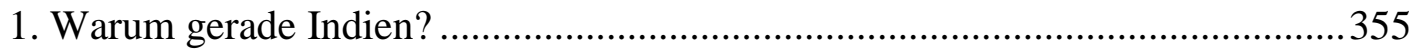

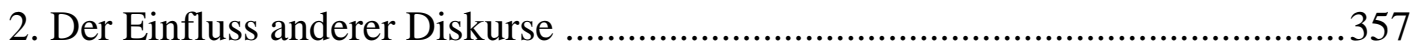

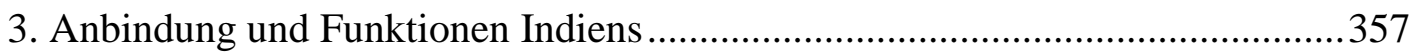

4. Paradigmenwechsel: Distanz und Differenz ................................................. 361

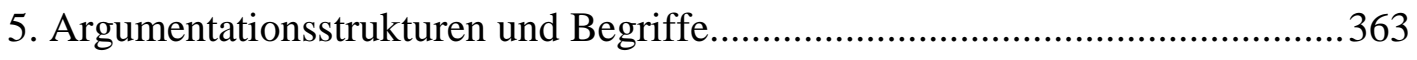

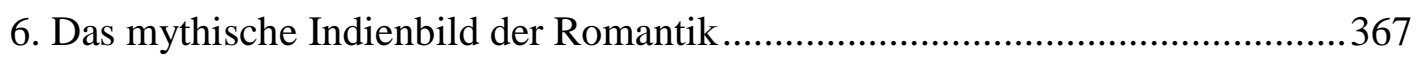

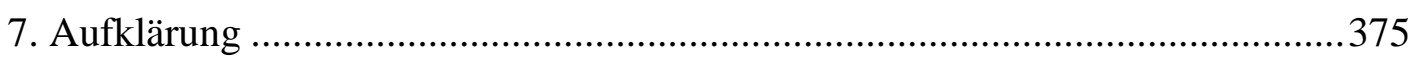

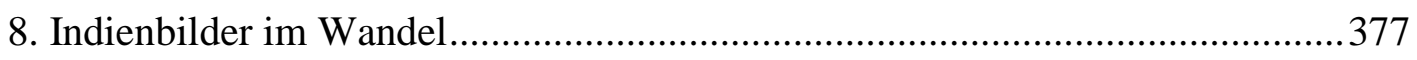

9. Orientalismus und die besondere Rolle der deutschen Indienrezeption .............379

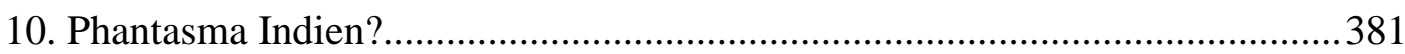


11. Resümee 384

Primärliteratur 389

Sekundärliteratur. 400

Internetseiten 414 


\section{Einführung}

\section{Indienbegeisterung}

Indien - welche Bilder und Vorstellungen kann allein die Nennung dieses Wortes hervorrufen: Man denkt an prächtige Bauwerke, an Mönche und Einsiedler, an farbenfrohe Märkte und vieles mehr. Indien steht für viele für das Exotische, das reizvolle Fremde. Reiseveranstalter werben noch immer mit Slogans wie „Traumhafte Märchenwelten im Land der Maharajas“"1, „,märchenhafte Welt wie aus „Tausend-undeiner-Nacht“‘“2, „,märchenhafte(r) Reichtum““3. Auch die Vorstellung von einer ehemals sehr hoch stehenden Kultur im Kontrast zu der jetzt verbreiteten Rückständigkeit, Armut und gesellschaftlichen Ungerechtigkeit ist weit verbreitet. Eindrucksvoll schildert Kamakshi Murti, wie sie selbst diese Stereotypen 1965 aus dem Mund eines Beamten des Ausländeramtes zu hören bekam: „Das war mal ein hochzivilisiertes Volk, die Inder. Ich hab“ irgendwo gelesen von indo-arisch und dergleichen - wir haben eine gemeinsame Tradition. Sie werden sicher hierbleiben wollen. Die schreckliche Armut bei Ihnen, der Aberglaube, die Witwenverbrennung, Kinderehen." 4 Diese Vorstellungen und Bilder, die oft mit Indien assoziiert werden, sind keineswegs neu. Einige stammen bereits aus der Antike, andere verbreiteten sich seit Ende des 18. Jahrhunderts. In dieser Zeit lösten der Orient allgemein und insbesondere die neu entdeckte Kultur Indiens in Europa und gerade auch im deutschsprachigen Raum eine große Faszination aus. ${ }^{5}$ Doch auch wer diese Begeisterung für die indische Kultur nicht teilte, konnte doch oft nicht umhin, ihr mit einem gewissen Interesse zu begegnen. Ein wichtiger Auslöser für diese Begeisterung war das indische Drama Śakuntalā, das Georg Forster mit seiner Übersetzung aus dem Englischen 1791 schlagartig bekannt machte. Goethe redet noch 40 Jahre später von „Enthusiasmus“ und einem „überschwenglichen Eindruck““6, wenn er sich an seine erste Lektüre dieses Dramas erinnert.

\footnotetext{
${ }^{1}$ http://www.tourvital.de/tvrproduct/DEL01AA/?gclid=CLyfuqfJ-8gCFQs6GwodyRIJwQ (Stand 06.11.2015)

${ }^{2}$ http://www.indien-reise.com/ (Stand 06.011.2015)

${ }^{3}$ https://www.chamaeleon-reisen.de/Asien/Indien/Thar (Stand 06.11.2015)

${ }^{4}$ Murti, Kamakshi: India. The Seductive and Seduced „Other“ of German Orientalism. Westport, London 2001, S. 1, Übersetzung S. 8f.

${ }^{5}$ Welche Ausmaße die Begeisterung für alles Exotische und vor allem Orientalische annahm (nicht nur in der Literatur, Kunst und Musik, sondern z.B. auch in der Mode) veranschaulicht Anke Schmitt in Schmitt, Anke: Der Exotismus in der deutschen Oper zwischen Mozart und Spohr. Hamburg 1988 (Hamburger Beiträge zur Musikwissenschaft; 36), S. 53-67.

${ }^{6}$ Goethe, Johann Wolfgang: Die letzten Jahre. Briefe, Tagebücher und Gespräche von 1823 bis zu Goethes Tod. Teil II: Vom Dornburger Aufenthalt 1828 bis zum Tode. Herausgegeben von Horst Fleig. Frankfurt a.M. 1993 (Goethe, Johann Wolfgang: Sämtliche Werke. Briefe Tagebücher und Gespräche), S. 318f. (Brief an Chézy Oktober 1830)
} 
Natürlich gab es auch vor dieser Übersetzung bereits Texte, die sich mit dem Thema Indien auseinandersetzten. Dies geschah zunächst vor allem in der Form von Reiseberichten. Im Zuge der Ausbreitung der englischen East India Company auf dem Subkontinent kamen dann immer mehr Informationen über die indische Kultur nach Europa und zwar nicht nur anhand von Beobachtungen, sondern - und das war neu auch in Form von Übersetzungen indischer Originaltexte. Diese wurden im deutschsprachigen Raum zunächst aber nur von einem relativ kleinen Personenkreis rezipiert. Erst die Śakuntalā-Übersetzung Forsters lenkte die Aufmerksamkeit weiterer Kreise auf die alte indische Kultur. Auch Herder trug zu dem steigenden Interesse an Indien bei. Er hatte schon in den 1780er Jahren in seinen „Ideen zur Philosophie der Geschichte der Menschheit“ ein größtenteils sehr positives Bild von Indien als Paradies und Entstehungsort der Menschheit entworfen, das in der Forschung oft als phantastisch im Sinne von erfunden, mythisch bezeichnet wurde. ${ }^{7}$ Dieses von Herder gezeichnete Indienbild war vor allem auch für einige der Romantiker prägend, die der indischen Kultur besonders euphorisch begegneten und hohe Erwartungen an sie hatten. Sie versprachen sich von Indien wichtige Impulse zur Erneuerung der europäischen Kultur. Diese Euphorie bekam allerdings im Zuge der wissenschaftlichen Beschäftigung mit Indien oftmals einen empfindlichen Dämpfer. Und auch wo dies nicht geschah, stellte doch die Etablierung der Indologie als universitärer Lehr- und Forschungsbereich einen wichtigen Einschnitt dar. Indien verlor allmählich den Reiz des Neuen und wurde in der Wissenschaft zu einem möglichen Feld der persönlichen Profilierung. Neben dieser Neuausrichtung einiger Autoren und Wissenschaftler auf das klassische Indien richtete sich das Interesse der Mehrheit der Autoren und Leser aber nach wie vor auch auf das zeitgenössische Indien, vor allem auf das politische Geschehen und ökonomische und gesellschaftliche Aspekte.

Die verschiedenen Indienbilder, die sich aus diesem Spannungsfeld ergeben, sind das Thema der vorliegenden Arbeit, wobei der zeitliche Rahmen durch die oben genannten Ereignisse der Śakuntalā-Übersetzung sowie der wissenschaftlichen Etablierung des Fachs Indologie Ende der 1820er Jahre grob abgesteckt wird. Die ŚakuntalāÜbersetzung ist dabei nur ein - sehr markanter - Teil eines Wandels in der europäischen Wahrnehmung Indiens, der mit der Entdeckung der klassischen indischen Kultur Ende

\footnotetext{
${ }^{7}$ Vgl. z.B. Willson, A. Leslie: A mythical image: The ideal of India in German Romanticism. Durham 1964.
} 
des 18. Jahrhunderts einhergeht. Gleichzeitig ist diese Zeit der Beginn einer Entwicklung, bei der das europäische Selbstverständnis immer mehr ein exklusives wird, das das moderne Europa gegenüber den übrigen (als nicht modern empfundenen) Kulturen abgrenzt. Durch die Entstehung von Fächern wie der Indologie verlagert sich Ende der 1820er Jahre die wissenschaftliche Erforschung asiatischer Kulturen aus Fächern wie Geschichte, Soziologie, politische Theorie in ein eigenes Fachgebiet und wird dadurch nun in noch stärkerem Maße einer gemeinsamen Vergleichsebene mit Europa entzogen. ${ }^{8}$

Da die intensive (wissenschaftliche) Beschäftigung und das große Interesse an diesem Land sich erst um 1800 entwickelten und nicht schon eine längere Tradition besaßen (wie z.B. im Falle der chinesischen oder osmanischen Kultur), lassen sich an diesem Beispiel die verschiedenen Möglichkeiten des Umgangs mit einer noch unbekannten Kultur besonders gut untersuchen. Die Entdeckung der klassischen indischen Texte, die vielen Zeitgenossen als eine orientalische Renaissance erschien ${ }^{9}$, bot sowohl die Möglichkeit, die bisherigen Kenntnisse über die Entwicklung der Menschheit und die Entstehung der Kultur zu erweitern und gegebenenfalls zu modifizieren, als auch eigene Vorstellungen und Vorannahmen durch die fremden Zeugnisse zu bestätigen bzw. auf die andere Kultur zu projizieren. Dabei wurden viele bereits aus der Antike stammende Topoi weiter tradiert, andere entstanden neu. Die Bilder Indiens, die um 1800 entworfen wurden, sind auch deshalb von Interesse, weil auch heute noch - wie einleitend bereits angedeutet - viele dieser Topoi und Themen eng mit dem Begriff Indien verbunden sind. Noch immer erstreckt sich die Wahrnehmung Indiens zwischen dem (mitunter mitleidigen) Blick auf ein aus europäischer Sicht in vielerlei Hinsicht noch unterentwickeltes Land und der Idealisierung als Ort der Träume, Wunder und religiösen Erfüllung. Dabei stehen sich zwei Diskurse gegenüber, die sich mit dem Diskurs über das zeitgenössische Indien um 1800 (vor allem in Reiseberichten) und dem romantischen Diskurs über Weisheit und Wissen des alten Indiens vergleichen lassen: auf der einen Seite die Berichterstattung über das gegenwärtige Indien zwischen Tradition und Moderne, Armut und Fortschritt und auf der anderen Seite spirituelle

8 Vgl. Osterhammel, Jürgen: Die Entzauberung Asiens. Europa und die asiatischen Reiche im 18. Jahrhundert. München 1998, S.377-382

${ }^{9}$ Vgl. z.B. Schwab, Raymond: The Oriental Renaissance. Europe's Rediscovery of India and the East, 1680-1880. New York 1984, S. 13-15 
Traditionen vom Yoga in immer neuen Varianten ${ }^{10}$ bis hin zu Diskussionen über den sogenannten „Wohlfühlbuddhismus“. ${ }^{11}$ Und auch das Wunderbare und Fremde der indischen Kultur fasziniert noch immer. Das spiegelt sich sogar in dem Artikel über Indien des digitalen Brockhaus wider und zwar in den Bildern zu dem ansonsten sachlichen Artikel. Diese bilden entweder die Armut von Teilen der Bevölkerung ab oder zeigen die aus europäischer Sicht besonders fremden Aspekte der indischen Religion und Kultur (wie z.B. Schlangenbeschwörer, Badende im Ganges, heilige Kühe, Götterfiguren). ${ }^{12}$ Und Anushka Gokhale zeigt in ihrer Untersuchung in Reiseberichten deutschsprachiger Autoren der letzten Jahre Sichtweisen auf, die bereits um 1800 das Bild von Indien prägten. Dazu gehören z.B. die Wahrnehmung der indischen Kultur als etwas der Vergangenheit Angehörendes, nicht auf der gleichen Zeitebene Liegendes oder die Projektion von etwas Mythischem auf Indien. ${ }^{13}$ Dieses Fortführen von Themen, Bildern und Zuschreibungen ist auch ein Grund, weshalb eine Untersuchung der Entstehung dieser Vorstellungen von Bedeutung ist, da sie zu einem tieferen Verständnis der heutigen Sicht auf den Subkontinent beitragen kann.

\section{2. Überblick über die bisherige Forschung}

Die Forschung hat sich vor allem innerhalb der Germanistik hinsichtlich der Beschäftigung mit Indien lange auf die Untersuchung einzelner Autoren oder Werke zumeist in relativ kurzen Artikeln und oft auch nicht allein auf Indien, sondern allgemein auf den Orient bezogen - konzentriert. So gibt es Abhandlungen z.B. zu den mythologischen Arbeiten Creuzers und Görres' ${ }^{14}$, zu August Wilhelm Schlegel und den

\footnotetext{
${ }^{10}$ Interessanterweise werden der indischen Kultur in diesem Kontext auch heute noch Merkmale zugeschrieben, die - wie wir noch sehen werden - bereits um 1800 als typisch indisch galten, wie z.B. die hohe Toleranz, die Gleichmütigkeit, die Suche nach Wahrheit. Sogar der Einfluss von Topographie und Klima auf die Kultur werden betont (vgl. https://wiki.yoga-vidya.de/Indien; Stand 07.05.2019).

${ }^{11}$ Wie bereits ein kurzer Blick in eine Google-Suche zeigt, dient dieser Begriff der Abwertung bestimmter als nicht authentisch angesehener Formen des Buddhismus in westlichen Ländern. Immer wieder wird entweder betont, dass die eigene spirituelle Praxis kein „Wohlfühlbuddhismus“ sei, oder Anbieter von Seminaren oder Büchern zum Thema Buddhismus werden als Anhänger eines solchen diskreditiert (vgl. z.B. die ersten Einträge zu diesem Begriff (Stand: 07.05.2019) https://www.buddhaland.de/forum/thread/8966-schubladen-denkfaulheit-und-aversion/; http://www.buddha-vs.de/Buecher/Meditation; https://katholisches.info/2014/06/24/gewalttaetigerbuddhismus-vatikan-besorgt-wegen-papstbesuch/).

${ }^{12}$ Vgl. https://brockhaus.de/ecs/enzy/article/indien (Stand 07.05.2019)

${ }^{13}$ Vgl. Gokhale, Anushka: Indien erzählen. Eine Studie zur deutschsprachigen Reiseliteratur. Würzburg 2011

${ }^{14}$ Vgl. z.B.: Kocziszky, Éva: Das Konzept und die Rolle des Orients in Creuzers Werk im Vergleich zu Görres. In: 200 Jahre Heidelberger Romantik. Herausgegeben von Friedrich Strack. Berlin u.a. 2008, S. 299-320; Michelsen, Peter: Der Sog der Mythe : zu Johannes Joseph von Görres 'Mythengeschichte der
} 
Kontroversen hinsichtlich der historisch-vergleichenden Sprachwissenschaft sowie der Übersetzungstheorie ${ }^{15}$, zu Wilhelm von Humboldt, Hegel und der Auseinandersetzung über die Bhagavad-Gita ${ }^{16}$, zu Friedrich Schlegel und die Bedeutung Indiens für das

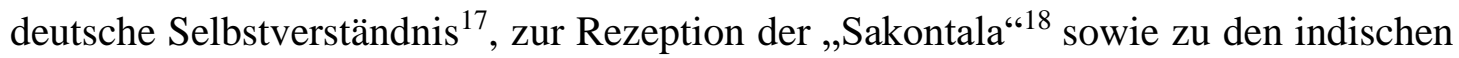

asiatischen Welt'. In: Heidelberg im säkularen Umbruch. Traditionsbewußtsein und Kulturpolitik um 1800. Hrsg. von Friedrich Strack. Stuttgart 1987, S. 444-65.

${ }^{15}$ Vgl. z.B.: Bhatti, Anil: August Wilhelm Schlegels Indienrezeption und der Kolonialismus. In: Lehmann, Jürgen u.a. (Hg): Konflikt Grenze Dialog. Kulturkontrastive und interdisziplinäre Textzugänge. Festschrift für Horst Turk zum 60. Geburtstag. Frankfurt a.M. 1997, S. 185-205; Czapla, Ralf Georg: Annäherungen an das ferne Fremde. August Wilhelm Schlegels Kontroverse mit Friedrich Rückert und Franz Bopp über die Vermittlung von indischer Religion und Mythologie. In: RückertGesellschaft :: Jahrbuch der Rückert-Gesellschaft e.V. 17 (2008), S. 131-141; Grotsch, Klaus: Das Sanskrit und die Ursprache. Zur Rolle des Sanskrit in der Konstitutionsphase des historischvergleichenden Sprachwissenschaft. In: Theorien vom Ursprung der Sprache. Hrsg. von Joachim Gessinger und Wolfert von Rahden. 2. Bd. Berlin/New York 1988, S. 85-121; Guthke, Karl S.: Benares am Rhein - Rom am Ganges. Die Begegnung von Orient und Okzident im Denken A. W. Schlegels. In: Jb des FdH (1978), S. 396-419; Mueller-Vollmer, Kurt: Mutter Sanskrit und die Nacktheit der Südseesprachen: Das Begräbnis von Humboldts Sprachwissenschaft. In: Athenäum 1 (1991), S. 109133; Poltermann, Andreas: Den Orient übersetzen. Europäisches Zivilisationsmodell und die Aneignung orientalischer Weisheit. Zur Debatte zwischen den Gebrüdern Schlegel, Humboldt und Goethe. In: Kulturelle Identität. Deutsch-indische Kulturkontakte in Literatur, Religion und Politik. Herausgegeben von Anil Bhatti und Horst Turk. Berlin 1997, S. 67-103

${ }^{16}$ Vgl. z.B.: Bergunder, Michael: Die Bhagavadgita im 19. Jahrhundert. Hindismus, Esoterik und Kolonialismus. In: Bergunder, Michael (Hg.): Westliche Formen des Hinduismus in Deutschland. Eine Übersicht. Halle 2006 (Neue Hallesche Berichte. Quellen und Studien zur Geschichte und Gegenwart Südindiens; 6), S. 187-211; Gipper, Helmut: Verstehen als sprachlicher Annäherungsprozeß. Am Beispiel des Begriffes Yoga in der indischen Bhagavad Gita und der Diskussion zwischen A. W. Schlegel, S. A. Langlois, W. v. Humboldt und G. W. Hegel. In: Sprachwissenschaft 12:1 (1987), S. $24-$ 44; Herling, Bradley L.: The German Gìtā. Hermeneutics and Discipline in the German Reception of Indian Thought, 1778-1831. New York u. London 2006; Maillard, Christine: La "Bhagavad gîtâ": fortune(s) d'un texte en Allemagne de 1785 à 1825; les points de vue de Herder, A. W. Schlegel, W. v. Humboldt et Hegel. In: L'Orient dans la culture allemande aux XVIIIe et XIXe siècles. Actes du colloque organisé par le Centre d'Études Germaniques et Scandinaves (LIRA) de l'Université Nancy 2 (9 et 10 décembre 2004) / ouvrage publié sous la dir. de Philippe Alexandre. Nancy 2007, S. 131-143; Marchignoli, Saverio: Canonizing an Indian Text? A.W. Schlegel, W. von Humboldt, Hegel, and the Bhagavadgítá. In: McGetchin, Douglas (Hg.): Sanskrit and ,Orientalism'. Indology and Comparative Linguistics in Germany, 1750-1958. Delhi 2004, S. 245-270; Menze: Das indische Altertum in der Sicht Wilhelm von Humboldts und Hegels. In: Welt und Wirkung von Hegels Ästhetik. Herausgegeben von Annette Gethmann-Siefert und Otto Pöggeler. Bonn 1986, S. 245-294

${ }^{17}$ Vgl. z.B. Dusche, Michael: Friedrich Schlegel's Writings on India. Reimagining Germany as Europe's True Oriental Self. In: Hodkinson, James u.a. (Hg.): Deploying Orientalism in Culture and History. From Germany to Central and Eastern Europe. Rochester N.Y. 2013, S. 31-54; TzorefAshkenazi, Chen: Der romantische Mythos vom Ursprung der Deutschen. Friedrich Schlegels Suche nach der indogermanischen Verbindung. Göttingen 2009 (Schriftenreihe des Minerva Instituts für deutsche Geschichte der Universität Tel Aviv; 29)

${ }^{18}$ Vgl. z.B. Grenzmann, Ludger: Zur frühen deutschsprachigen Rezeption von Georg Forsters Sakontala-Übertragung von 1791. In: Hellfaier, Detlev u.a. (Hg): Der wissenschaftliche Bibliothekar. Festschrift für Werner Arnold. Wiesbaden 2009, S. 231-256; Karyekar, Madhuvanti: Fostering aesthetic tolerance through literary translation. Georg Forster's Śakuntalā. In: Cho, Joanne Miyang u.a. (Hg.): Transcultural Encounters between Germany and India. Kindred spirits in the nineteenth and twentieth centuries. London u. New York, S. 13-24; Steiner, Gerhard: Kalidasas Sakontala oder die deutsche Entdeckung Indiens. In: Rasmussen, Detlef (Hg.): Der Weltumsegler und seine Freunde Georg Forster als gesellschaftlicher Schriftsteller der Goethezeit. Tübingen 1988, S. 59-69 
bzw. orientalischen Einflüssen im Werk verschiedener Autoren ${ }^{19}$. In Bezug auf Goethe gibt es überwiegend Arbeiten zu seinem Orientbild, wie es durch den West-östlichen Divan vermittelt wird, jedoch nur wenig zu seinem Verhältnis zu Indien ${ }^{20}$. Neben diesen Einzeluntersuchungen liegen einige Überblicksdarstellungen zur Indienrezeption vor, die aber oft einen sehr weiten Zeitraum umfassen und daher nur kurz auf die Zeit um 1800 eingehen. ${ }^{21}$ Oder aber sie analysieren hauptsächlich einen

${ }^{19}$ Vgl. z.B.: Birus, Hendrik: Der „Orientale“ Jean Paul. Versuch über Goethes Vergleichung. In: Jahrbuch der Jean-Paul-Gesellschaft 20 (1985), S. 103-126; Bosse, Anke: Orientalismus im Frühwerk Ludwig Tiecks. In: Ludwig Tieck. Literaturprogramm und Lebensinszenierung im Kontext seiner Zeit. Herausgegeben von Walter Schmitz. Tübingen 1997, S. 43-62; Dallet-Mann, Véronique: "Nur das Wilde, Große, Glänzende gefällt mir": l'orient de Karoline von Günderrode. In: L'Orient dans la culture allemande aux XVIIIe et XIXe siècles. Actes du colloque organisé par le Centre d'Études Germaniques et Scandinaves (LIRA) de l'Université Nancy 2 (9 et 10 décembre 2004) / ouvrage publié sous la dir. de Philippe Alexandre. Nancy 2007, S. 61-72; Doering, Sabine: Persien im Märkischen Sand. Kleists Bild vom Orient. In: Kleist-Jahrbuch 1996, S. 171-186; Espagne, Geneviève: Orient-Bezüge in Jean Pauls „Hesperus“. In: Goer, Charis u. Hofmann, Michael (Hg.): Der Deutschen Morgenland. Bilder des Orients in der deutschen Literatur und Kultur von 1770 bis 1850. München 2008, S. 117-136; Frank, Alexa: Sanftes Gefühl und stille Tiefe der Seele. Herders Indien. Würzburg 2009; Germana, Nicholas: India and Hegel's ,scientific“ method in the Phenomenology of Spirit. In: Cho, Joanne Miyang u.a. (Hg.): Transcultural Encounters between Germany and India. Kindred spirits in the nineteenth and twentieth centuries. London u. New York 2014, S. 25-36; Gosh, Pranabendra Nath: Johann Gottfried Herder's Image of India. In: Heinz Mode u. H.-J. Peuke (Hg.): Indien in der deutschen literarischen Tradition. Halle 1979, S. 4-17; Hilliard, Kevin F.: Orient und Mythos: Karoline von Günderrode. In: Frauen: MitSprechen, MitSchreiben. Beiträge zur literatur- und sprachwissenschaftlichen Frauenforschung. Herausgegeben von Marianne Henn. Stuttgart 1997, S. 244-255; Maillard, Christine: Beobachter, Weggenosse, Pionier. Herder und die Anfänge der europäischen Indologie. In: Cultura tedesca: revista semestrale 24 (2003), S. 49-62; Rommel, Gabriele (Hg.): Novalis und der Orient. Katalog der Ausstellung im Novalis-Schloß Oberwiederstedt; [vom 30. August 2007 bis zum 31. August 2008]. Wiederstedt 2007; Polaschegg, Andrea: Im Schatten der Pyramide. Achim von Arnims Ordnung des Orients. In: Regionalität und Fremde. Literarische Konstellationen, Visionen und Konzepte im deutschsprachigen Mitteleuropa. Herausgegeben von András F. Balogh, in Verbindung mit Magdolna Orosz. Berlin 2007, S. 89-102; Schmitz-Emans, Monika: Orientalisches bei Jean-Paul. In: Orientdiskurse in der deutschen Literatur. Herausgegeben von Klaus-Michael Bogdal. Bielefeld 2007, S. 81-123; Tautz, Birgit: Wackenroder's 'Ein wunderbares morgenländisches Mährchen von einem nackten Heiligen'. Autopoiesis of world, rhetoric of "the Orient". In: Monatshefte für deutschsprachige Literatur und Kultur 95 (2003), N.1, S. 59-75; Tekinay, Alev: Zum Orient-Bild Bettine von Arnims und der jüngeren Romantik. In: Arcadia 16 (1982), H. 1, S. 47-49

${ }^{20}$ Dazu gehören z.B.: Bell, David: Goethe's Orientalism. In: Nicholas Boyle und John Guthrie (Hg.): Goethe and the English-Speaking World. Essays from the Cambridge Symposium for his 250th Anniversary. Rochester 2020, S. 199-212; Däbritz, Walther: Anregungen aus der indischen Mythologie in Goethes Dichtung. In: Goethe N.F. 20 (1958), S. 99- 117; Kratzsch, Siegfried: Goethe und Indien. In: Indien in der deutschen literarischen Tradition. Herausgegeben von Heinz Model und HansJoachim Peuke. Halle 1979, S. 18-31; Lauer, Gerhard: Goethes indische Kuriositäten. In: Kunz, Edith Anna u.a. (Hg.): Figurationen des Grotesken in Goethes Werken. Bielefeld 2012, S. 159-179; Mommsen, Katharina: „Indisches“ im West-östlichen Divan. In: Goethe. Jahrbuch der GoetheGesellschaft. N.F. 22 (1960), S. 294-297; Pille, René-Marc: À la fracture du classicisme et du romantisme. L'Inde, sujet de discorde entre Goethe et Friedrich Schlegel. In: La fascination de l'Inde en Allemagne 1800-1933. Herausgegeben von Marc Cluet. Rennes 2004, S. 25-45

${ }^{21}$ Vgl. z.B. Amman, Ludwig: Östliche Spiegel. Ansichten vom Orient im Zeitalter seiner Entdeckung durch den deutschen Leser 1800-1850. Hildesheim 1989; Cie'slik, Boleslaw: Das Bild Indiens in der deutschen Literatur von der Aufklärung bis zum Zweiten Weltkrieg. In: Colloquia Germanica Stetinensia 4 (1995), S. 153-162; Cowan, Robert: The Indo-German Identification. Reconciling South Asian Origins and European Destinies, 1765-1885. Rochester 2010 (Studies in German Literature Linguistics and Culture; 86); Durzak, Manfred: Indien - Wahrnehmungen in einem Spielgelkabinett. 
Bereich des vielfältigen Themengebietes. Sie haben also z.B. einen rein literaturwissenschaftlichen Blick (Indien als Motiv innerhalb der deutschen Literatur), interessieren sich für die Anfänge der Indologie und sind dabei eher sprachwissenschaftlich ausgerichtet, analysieren bildliche Darstellungen, setzen sich mit der Mission auseinander oder konzentrieren sich auf weitere Themen. ${ }^{22}$ Hinzu

In: Durzak, Manfred (Hg.): Bilder Indiens in der deutschen Literatur. Frankfurt a.M. 2011, S. 7-12; Flüchter, Antje: ,Aus den fürnembsten indianischen Reisebeschreibungen zusammengezogen'. Knowledge about India in early modern Germany. In: Huigen, Siegfried u.a. (Hg.): The Duch Trading Companies as Knowledge Networks. Leiden u. Boston 2010, S. 337-356; Ganeshan, Vridhagiri: Das Eigene und das Fremde in der Indienbegegnung deutscher Schriftsteller. In: Hardt, Dietrich (Hg.): Fiktion des Fremden. Erkundung kultureller Grenzen in Literatur und Publizistik. Frankfurt a.M. 1994, S. 161-179; Glasenapp, Helmut von: Das Indienbild deutscher Denker. Stuttgart 1960; Halbfass, Wilhelm: Indien und Europa. Perspektiven ihrer geistigen Begegnung. Basel u. Stuttgart 1981; Inden, Ronald B.: Imagining India. 2. Aufl. London 2000; Koch, Gerhard: Deutschlands literarisches Indienbild. Zur Indienrezeption der deutschen Literatur von den Anfängen bis zum Beginn des 20. Jahrhunderts. In: German studies in India 11 (1987), S. 175-183 und 12 (1988), S. 2-14; Leifer, Walter: Indien und die Deutschen. 500 Jahre Begegnung und Partnerschaft. Tübingen und Basel 1969; Rothermund, Dietmar: The German Intellectual Quest for India. Delhi 1986; Schwab, Raymond: The Oriental Renaissance. Europe's Rediscovery of India and the East, 1680-1880. New York 1984; Windisch, Ernst: Geschichte der Sanskrit-Philologie und Indischen Altertumskunde. Berlin 1992 ${ }^{22}$ Vgl. z.B. Behler: Das Indienbild der deutschen Romantik. In: Germanisch-Romanische Monatsschrift N.F. 18 (1968), S. 21-37; Chakkalakal, Silvy: Deutsch-indische Figurationen. Der bildhafte Stil der Ethnographie um 1800. In: Füssel, Marian u.a. (Hg.): Historische Anthropologie. Kultur, Gesellschaft, Alltag. 22 (2014. Heft 2, S. 250-277; Dalmia-Lüderitz, Vasudha: Die Aneignung der vedischen Vergangenheit. Aspekte der frühen deutschen Indien-Forschung. In: Zeitschrift für Kulturaustausch 37 (1987), 3. Vj.: Utopie-Projektion-Gegenbild, S. 434-443; De Zoysa, Asoka: "Blutrünstige Braminen am heiligen Strome". Indienbilder in der deutschen Unterhaltungsliteratur zwischen Aufklärung und Restauration. Frankfurt am Main u.a. 1997; Fischer, Wolfdietrich: Die Wahrnehmung des Orients in der deutschen Literatur der ersten Hälfte des 19. Jahrhunderts. In: Jahrbuch der Rückert-Gesellschaft e.V. 17 (2008), S. 59-72; Flüchter, Antje: Bajadere und Sati. Bilder der Inderin im deutschsprachigen Diskurs der Frühen Neuzeit. In: Ineichen, Martina u.a. (Hg.): Gernder in Trans-it. Transkulturelle und transnationale Perspektiven. Beiträge der 12. Schweizerischen Tagung für Geschlechtergeschichte. Zürich 2009, S. 159-170; Hemron, Anand Sebeyan: Transmission of knowledge by christian missionarie among the indigenous people of central-Eastern India in the 19th century. In: Heyden, Ulrich van der u. Feldtkeller, Andreas (Hg.): Missionsgeschichte als Geschichte der Globalisierung von Wissen. Transkulturelle Wissensaneignung und -vermittlung durch christliche Missionare in Afrika und Asien im 17., 18. und 19. Jahrhundert. Stuttgart 2012, S. 155-171; Hoffmann, Paul: Der indische und der deutsche Geist von Herder bis zur Romantik. Eine literarhistorische Darstellung. Tübingen 1915; Jolles, Frank: India in England and Germany during the 18th century, - a synthesis? In: German studies in India 9 (1985), S. 191-204; Jürgens, Janco: German Indology avant la lettre: The Experiences of the Halle Missionaries in Southern India, 1750-1810. In: Douglas T. McGetchin u.a. (Hg.): Sanskrit and ,Orientalism'. Indology and Comparative Linguistics in Germany, 1750-1958. New Delhi 2004, S. 41-82; Maillard, Christine: „Indomanie“ um 1800: ästhetische, religiöse und ideologische Aspekte. In: Goer, Charis u. Hofmann, Michael (Hg.): Der Deutschen Morgenland. Bilder des Orients in der deutschen Literatur und Kultur von 1770 bis 1850 . München 2008, S. 67-83; Mangold, Sabine: Eine "weltbürgerliche Wissenschaft". Die deutsche Orientalistik im 19. Jahrhundert. Stuttgart 2004; Michaels, Axel: Wissenschaft als Einheit von Religion, Philosophie und Poesie. Die Indologie als frühromantisches Projekt einer ganzheitlichen Wissenschaft. In: Romantische Wissenspoetik. Die Künste und die Wissenschaften um 1800. Herausgegeben von Gabriele Brandstetter und Gerhard Neumann. Würzburg 2004, S. 325-340; Remy, Artur F. J.: The Influence of India and Persia on the Poetry of Germany. New York 1901; Schröder, Ulrike: Religion, Kaste und Ritual. Christliche Mission und tamilischer Hinduismus in Südindien im 19. Jahrhundert. Halle 2009 (Neue Hallesche Berichte. Quellen und Studien zur Geschichte und Gegenwart Südindiens. Im Auftrag der Franckeschen Stiftungen zu Halle. Herausgegeben von Michael Bergunder und Helmut Obst; 8); Somerfeld, Susanne: Indienschau und Indiendeutung romantischer Philosophen. Diss. Zürich 
kommen Arbeiten, die in der Folge Saids den Orientalismus in literarischen oder wissenschaftlichen Darstellungen untersuchen. Diese Arbeiten widmen sich aber vor allem dem islamisch geprägten Orient (weniger Indien) und sie untersuchen ebenfalls oft größere Zeitspannen. ${ }^{23}$

Zusammenfassend kann man also sagen, dass es zu dem Thema der Beschäftigung mit Indien im deutschsprachigen Raum um 1800 auf der einen Seite Überblicksdarstellungen (oft im Rahmen einer viel weiter gefassten Arbeit) gibt sowie auf der anderen Seite viele Untersuchungen zu Einzelaspekten, die jedoch lediglich einen Ausschnitt aus einem sehr viel komplexeren und umfangreicheren Geflecht unterschiedlicher Themen und Diskurse darstellen. Eine Darstellung des Zusammenhangs der Indienbegeisterung der klassisch-romantischen Welt in all ihren Aspekten steht also noch aus. Es fehlt damit eine Untersuchung, welche Bedeutung und Funktionen Indien für diese so zentrale Epoche der deutschen Kulturgeschichte hatte.

\section{Ziel dieser Arbeit}

In dieser Arbeit möchte ich der Frage nachgehen, welche Bedeutung und Funktion Indien für die Zeit von ca. 1791 bis zum Ende der 1820er Jahre in diesbezüglichen Diskursen im deutschsprachigen Raum hatte, welche Bilder und Vorstellungen mit diesem Begriff bzw. diesem Begriffsfeld verbunden waren, welche Themen im Vordergrund standen und welche Strategien es zum Umgang mit der anderen und zunächst fremden Kultur und deren Anbindung an die eigene Kultur gab. Die Fragestellung dieser Arbeit zielt also weniger darauf, die Indienvorstellungen eines oder mehrerer Autoren bis ins kleinste Detail zu rekonstruieren, sondern die einzelnen Diskurse zum Thema Indien (z.B. über die indische Sprache, die indische Philosophie und Religion, die indische Literatur, aber auch über die zeitgenössische indische

1943; Trepp, Anne-Charlott: „Daher entsteht so viel naturhistorisches Unheil“. Wissens- und Kulturtransfer zwischen Indien und Europa. Die Halleschen Missionsberichte. In: Beck, Andreas u. Kaminski, Nicola (Hg.): Literatur der Frühen Neuzeit und ihre kulturellen Kontexte. Bochumer Ringvorlesung im Sommersemester 2011. Frankfurt a. M. 2012, S. 229-255; Willson: A Mythical Image; Windisch, Ernst: Geschichte der Sanskrit-Philologie und Indischen Altertumskunde. Berlin 1992; Zhang, Chunjie: German Indophilia, Feminity, and Transcultural Symbiosis around 1800. In: Fuechtner, Veronika u. Rhiel, Mary (Hg.): Imagining Germany Imagining Asia. Essays in AsianGerman Studies. new York 2013, S. 204-219

${ }^{23}$ Vgl. z.B. Bhatti, Anil: Der deutsche Indiendiskurs. Ambivalenzen im deutschen Orientalismus des neunzehnten Jahrhunderts. In: German Studies in India. Aktuelle Beiträge aus der indischen Germanistik in Indien. München 2006, S. 23-38; Murti, Kamakshi: India. The Seductive and Seduced „Other" of German Orientalism. Westport, London 2001 (Contributions in Comperative Colonial Studies; 39); Pollock, Sheldon: Indology, Power, and the Case of Germany. In: Macfie, A. L. (Hg.): Orientalism. A Reader. Edinburgh 2000, S. 302-323 
Gesellschaft) zu untersuchen. Auch das kann nicht bis in kleinste Details geschehen. Vielmehr wird es vor allem um die Fragen gehen, welche Themen aufgegriffen werden, welche Thesen vertreten werden und wie die Argumentationen aufgebaut sind. Welche Bilder von Indien werden dabei entworfen? Werden alte Bilder aufgegriffen und weitergeführt oder werden sie verändert? Gibt es eine bewusste Auseinandersetzung mit ihnen? Gibt es Themen und Bilder, die in der Auseinandersetzung mit unterschiedlichen Aspekten der indischen Kultur diskursübergreifend von Bedeutung sind? Welchen Einfluss anderer zeitgenössischer Diskurse gibt es. Eng damit verbunden ist auch die Frage, warum gerade Indien eine solche Aufmerksamkeit zuteil wird und wie die neu entdeckte indische Kultur an die eigene Kultur angebunden wird. Dient die indische Kultur nur als Projektionsfläche eigener Vorstellungen und als Symbol eigener Sehnsüchte (wie es von der Forschung z.T. vermutet wurde) oder wird ernsthaft versucht, durch die Beschäftigung mit Indien das eigene Wissen und vielleicht auch Weltbild zu erweitern?

\section{Diskursanalyse oder Begriffsgeschichte - Fragen der methodischen Herangehensweise}

Aufgrund der Fragestellung, die sich eben nicht allein auf die konkreten Ansichten einzelner Autoren oder Texte, sondern auf Muster der Wahrnehmung, Deutung und Aneignung der fremden Kultur richtet, sowie auch aufgrund der großen Datenmenge in dem durch die Fragestellung vorgegebenen Textkorpus ist es in dieser Arbeit nicht möglich, sich methodisch auf rein literaturwissenschaftlich-hermeneutische Methoden zu beschränken, bei denen einzelne Texte im Fokus des Interesses stehen. Vielmehr ist eine Herangehensweise zu wählen, die es ermöglicht, große Textmengen zu untersuchen, indem sie ihr Augenmerk auf textübergreifende Einheiten wie Diskurse, Aussagen, Argumentationsstrukturen, Begriffe richtet. In Frage kommen dabei besonders Methoden der Diskursanalyse oder der Begriffsgeschichte.

\subsection{Methoden der Diskursanalyse}

Diskursanalytische Ansätze gehen davon aus, dass die Wahrnehmung der Wirklichkeit immer schon sprachlich geprägt und dass das gesamte Wissen einer Zeit so der Ordnung von Diskursen unterworfen ist. Jenseits der Sprache und der Diskurse gibt es diesem Verständnis nach kein (für uns erfahrbares) objektives Wissen. 
bestimmten Bedeutungsmustern aus, erkennen bestimmte Sichtweisen auf diese Umwelt als Wissen an [...] und objektivieren Elemente zu einer Wirklichkeit, der man nicht mehr ansehen kann, dass sie historisch entstanden und alles andere als naturnotwendig ist. 24

Nicht der Einzelne produziert hier Wissen durch seine eigene freie Kreativität, sondern er ist in seinem Denken immer schon an die im Diskurs zur Sprache kommende Wirklichkeitsauffassung gebunden. ${ }^{25}$ Der Begriff des Diskurses findet in unterschiedlichen Disziplinen Verwendung, wobei es jedoch an einer einheitlichen Definition mangelt. Foucault, an den sich viele dieser Ansätze anlehnen, bezeichnet mit diesem Begriff eine Menge von Aussagen über bestimmte Gegenstände oder Gegenstandsbereiche, die jeweils in verschiedenen konkreten Aussageereignissen (Foucault nennt sie auch Äußerungen) vorliegen können und die dem gleichen Formationssystem angehören bzw. eine hohe Regelmäßigkeit aufweisen. ${ }^{26}$ Diskursanalytische Ansätze fragen nach dem Entstehen und Wirken dieser Diskurse. Ziel ist es, die „Möglichkeitsbedingung(en)“627 von Aussagen zu untersuchen. Denn diese werden durch verschiedene „Prozeduren der Ausschließung ${ }^{“ 28}$ kontrolliert und eingeschränkt. Dazu gehören laut Foucault Verbote, die Entgegensetzung von Vernunft und Wahnsinn und der Gegensatz von Wahrem und Falschem. Aber auch Regeln, die von bestimmten (wissenschaftlichen) Disziplinen vorgegeben werden sowie die Begrenzung der Sprecher, deren Aussage innerhalb eines Diskurses von den anderen Diskursteilnehmern anerkannt wird, grenzen die Möglichkeitsbedingungen von Aussagen ein. Die Diskursanalyse möchte daher die „Regelhaftigkeit“ einer „Serie“ von „Ereignissen“ ${ }^{29}$ untersuchen und Regelmäßigkeiten in scheinbar Ungleichem

\footnotetext{
${ }^{24}$ Landwehr: Historische Diskursanalyse. Frankfurt. a.M. 2008, S. $18 f$.

${ }^{25}$ Vgl. Busse, Dietrich: Historische Semantik: Analyse eines Programms. Stuttgart 1987, S. 225

${ }^{26}$ Vgl. Klawitter, Arne/Ostheimer, Michael: Literaturtheorie - Ansätze und Anwendungen. Göttingen 2008, S. 162; Keller, Reiner: Diskursforschung. Eine Einführung für SozialwissenschaftlerInnen. 2. Auflage. Wiesbaden 2004, S. 63; Busse: Historische Semantik, S. 224; Busse, Dietrich: Historische Diskurssemantik. Ein linguistischer Beitrag zur Analyse gesellschaftlichen Wissens. In: Sprache und Literatur 86, 2 (2000), S. 29-53, hier S. 40; Busse, Dietrich: Begriffsgeschichte oder Diskursgeschichte? Zu theoretischen Grundlagen und Methodenfragen einer historisch-semantischen Epistemologie. In: Dutt, Carsten (Hg.): Herausforderungen der Begriffsgeschichte. Heidelberg 2003, S. 17-38, hier S. 23; Busse, Dietrich: Diskurs - Sprache - Gesellschaftliches Wissen. Perspektiven einer Diskursanalyse nach Foucault im Rahmen einer Linguistischen Epistemologie. In: Busse, Dietriche/Teubert, Wolfgang: Linguistische Diskursanalyse: neue Perspektiven. Wiesbaden 2013, S.147-185, hier S. 150; Foucault, Michel: Archäologie des Wissens. Frankfurt a. M. 1981, S. 138f.,144, 153, 156, 167f., 170

${ }^{27}$ Foucault, Michel: Die Ordnung des Diskurses. Mit einem Essay von Ralf Konersmann. Frankfurt a. M. 10. Auflage 2007, S. 35

${ }^{28}$ Foucault: Die Ordnung des Diskurses, S. 11

${ }^{29}$ Foucault: Die Ordnung des Diskurses, S. 35; vgl. auch Foucault: Archäologie des Wissens, S. 205207
} 
sowie Brüche in scheinbar Gleichem identifizieren. Warum wird zu einer bestimmten Zeit eine bestimmte Aussage gemacht, eine andere aber nicht? Was konnte zu einer Zeit überhaupt gesagt werden, welche Aussagen befanden sich innerhalb der geltenden Wahrheit? Welches (unbewusst) vorausgesetzte Wissen liegt einer Aussage zu Grunde? Welche diskursübergreifenden „Episteme“ ${ }^{30}$, also allgemeine Erkenntnisstrukturen, lenkten das Denken einer Epoche? Die Diskurse haben auch mit Macht zu tun. Aussagen, die nicht mit dem bisher im Rahmen des Diskurses Gesagten übereinstimmen, werden kaum als wahr anerkannt werden. ${ }^{31}$. Analysiert wird also die Menge der $\mathrm{zu}$ einer diskursiven Formation gehörenden Aussagen, ihre Formationsregeln und die Art und Weise, wie sie als Machtmittel fungieren. ${ }^{32}$

Die Ansätze der Diskursanalyse haben den Vorteil, dass sie, indem sie auf Aussagen als kleinsten Einheiten basieren, den Inhalt vieler Texte erfassen und vergleichen können. Ein gewichtiger Nachteil ist allerdings, dass aufgrund der Auffassung, dass nicht ein individueller Autor eigene originäre Texte verfasst, sondern dass das, was er überhaupt sagen kann, durch die herrschenden Diskurse begrenzt und geordnet wird, die einzelnen Texte und Autoren völlig in den Hintergrund treten. Dadurch finden nicht nur sprachliche Bilder und Metaphern kaum Beachtung, sondern es bleiben auch individuelle Besonderheiten der Autoren und Texte weitgehend unberücksichtigt, obwohl sich durch „das Nebeneinander verschiedener diskursiver Formationen, durch die Konkurrenz von Verknüpfungsmöglichkeiten [...] zahlreiche individuelle Positionierungsmöglichkeiten“ ${ }^{33}$ ergeben. Daher ist oft kritisiert worden, dass man Gefahr laufe, dem Diskurs ontischen Charakter zuzusprechen und ihm die Rolle des handelnden Subjekts zuzuschreiben. Diskurse aber sind keine real existierenden Gegebenheiten, sondern lediglich ein vom Forscher eingesetztes Analyseinstrument, ein für eine bestimmte Fragestellung und Forschungsperspektive geschaffenes Konstrukt. Diskursanalyse selbst ist ein Diskurs über Diskurse und so ebenfalls den Regeln eines Diskurses unterworfen, also keineswegs so objektiv, wie es oft den

\footnotetext{
${ }^{30}$ Foucault: Archäologie des Wissens, S. 272

${ }^{31}$ Vgl. Foucault: Die Ordnung des Diskurses, S. 11, -13, 22-26, 35; Busse: Historische Diskurssemantik, S. 41; Busse: Begriffsgeschichte oder Diskursgeschichte, S. 24f.; Landwehr: Historische Diskursanalyse, S. 70, 92

${ }^{32} \mathrm{Vgl}$. Füssel, Merian u. Neu, Tim: Diskursforschung in der Geschichtswissenschaft. In: Angermüller, Johannes u.a. (Hg.): Diskursforschung. Ein interdisziplinäres Handbuch. Band 1: Theorien,

Methodologien und Kontroversen. Bielefeld 2014, S. 145-161, hier S. 152

${ }^{33}$ Landwehr: Historische Diskursanalyse, S. 94
} 
Anschein erweckt. Schon die Fragestellung und die Korpusauswahl sowie die Herausarbeitung der Aussagen unterliegen der Interpretation des Forschers. ${ }^{34}$

\subsection{Methoden der Begriffsgeschichte}

Ein anderer Ansatz, an dem man sich methodisch orientieren könnte, ist die von Reinhart Koselleck begründete Begriffsgeschichte. Koselleck versucht anhand des Bedeutungswandels sogenannter Grundbegriffe, Umbrüche im Denken der Menschen herauszuarbeiten. Unter Grundbegriffen versteht er Begriffe, die als Konzentration vieler Bedeutungsgehalte angesehen werden können, deren Inhaltsseite nicht einfach durch eine konkrete Bedeutung abgebildet werden kann. Solche Grundbegriffe können z.B. Staat oder Freiheit sein. Diese Begriffe sind unverzichtbar und unersetzbar, aber sie sind auch hoch umstritten, da jeder sie mit anderem Inhalt füllt. Diese Methode ist für meine Arbeit vor allem insofern reizvoll, als Koselleck für den Anbruch der Moderne um 1800 eine Sattelzeit annimmt, in der sich die Begriffe und damit auch das Denken der Menschen sehr stark ändern. Aus zuvor verbreiteten Erfahrungsregistraturbegriffen, also aus Begriffen, die aus konkreten Erfahrungen gewonnenes Wissen bündelten, würden Erfahrungsstiftungsbegriffe und schließlich Erwartungsbegriffe, die auf keinerlei konkreten Erfahrungen mehr beruhten, sondern die Erwartungen auf erst in der Zukunft zu machende Erfahrungen projizierten. Ein markantes Beispiel dafür seien Neubildungen auf -ismus. Das Denken richte sich also immer stärker auf die Zukunft, was Koselleck als Verzeitlichung bezeichnet. Weiterhin beschreibt er die von ihm angenommene Sattelzeit mit den Begriffen der Demokratisierung (Grundbegriffe seien weiteren Gesellschaftsschichten zugänglich geworden), der Ideologisierbarkeit (höhere Anfälligkeit für Ideologien durch zunehmende Abstraktheit der Begriffe) und den Zwang zur Politisierung. ${ }^{35}$ Hinsichtlich des Konzepts der Sattelzeit ist allerdings kritisiert worden, dass Koselleck seine ganze

\footnotetext{
${ }^{34}$ Vgl. Busse: Begriffsgeschichte oder Diskursgeschichte, S. 28; Busse, Dietrich/Teubert, Wolfgang: Ist Diskurs ein sprachwissenschaftliches Objekt? Zur Methodenfrage der historischen Semantik. In: Busse, Dietrich u.a. (Hg.): Begriffsgeschichte und Diskursgeschichte. Methodenfragen und Forschungsergebnisse der historischen Semantik. Opladen 1994, S. 10-28, hier S. 16; Busse: Historische Semantik, S. 73; Landwehr: Historische Diskursanalyse, S. 20f., 98, 171; Keller: Diskursforschung, S. 61.

${ }^{35}$ Vgl. Koselleck, Reinhart: Die Geschichte der Begriffe und Begriffe der Geschichte. In: Dutt, Carsten (Hg.): Herausforderungen der Begriffsgeschichte. Heidelberg 2003, S. 3-16, S. 5, 9-11; Koselleck, Reinhart: Begriffsgeschichten. Studien zur Semantik und Pragmatik der politischen und sozialen Sprache. Frankfurt a.M. 2010, S. 66-70, 84f.; Schultz, Heiner: Begriffsgeschichte und Argumentationsgeschichte. In: Koselleck, Reinhart (Hg.): Historische Semantik und Begriffsgeschichte. Stuttgart 1979, S. 43-74, hier S. 44-46
} 
Theorie der Begriffsgeschichte von dieser Umbruchzeit her konzipiere und dann auf vorhergehende Epochen übertrage. ${ }^{36}$

Diese Methode würde die Aufmerksamkeit auf Kontinuitäten und Wandel in den mit dem Thema Indien verbundenen Begriffen lenken. Sie hat allerdings auch mehrere Nachteile: So wurde kritisiert, dass die zu strikte Orientierung an Leitbegriffen, deren Definition und Auswahlkriterien nie genau angegeben werden konnten, den Blick auf begriffskonstitutive Elemente in Texten, die diesen Leitbegriff selbst nicht enthalten, sowie auf den argumentativen bzw. diskursiven Kontext dieser Begriffe verstelle. Die Begriffsgeschichte komme über eine Ideengeschichte kaum hinaus. ${ }^{37}$ Ein ganz praktisches Problem stellt zudem dar, dass sich zu dem Thema Indien nur schwer Begriffe herausarbeiten lassen, die für eine Betrachtung nach den Methoden der Begriffsgeschichte in Frage kommen und die dann insgesamt ein anschauliches Bild der Vorstellungen von Indien um 1800 zeichnen können.

\subsection{Historische Semantik und Argumentationsanalyse}

In den letzten Jahren verbreitet sich in der Forschung immer mehr die Ansicht, dass Begriffsgeschichte und Diskursanalyse sich gar nicht so diametral entgegenstehen, wie es zuvor immer behauptet wurde, sondern dass sie sich vielmehr gegenseitig bedingen und ergänzen. So fehle der Diskursanalyse der Bezug zum konkreten Sprachgebrauch und den konkreten Texten, wohingegen die Begriffsgeschichte nicht einzelne Begriffe analysieren solle, sondern Begriffsnetze bzw. Begriffe als „minimale Kristallisationskerne von Diskursen“38. Auch Koselleck selbst stellt später fest, dass man den Kontext der einzelnen Begriffe samt ihrer jeweiligen Gegenbegriffe und

\footnotetext{
${ }^{36}$ Vgl. Stollberg-Rilinger: Einleitung. In: Stollberg-Rilinger (Hg.): Ideengeschichte. Stuttgart 2010, S. 7-42, hier S. 26

${ }^{37}$ Vgl. Busse: Historische Semantik, S. 11, 39; Busse, Dietrich: Begriffsgeschichte - Diskursgeschichte - Linguistische Epistemologie, Bemerkungen zu den theoretischen und methodischen Grundlagen einer Historischen Semantik in philosophischem Interesse anlässlich einer Philosophie der „Person“. In: Alexander Haardt und Nikolaj Plotnikov (Hg.): Diskurse der Personalität. Die Begriffsgeschichte der $>$ Person< aus deutscher und russischer Perspektive. München 2008, S. 115-142, hier S. 118; Schultz: Begriffsgeschichte und Argumentationsgeschichte, S. 67f.; Wiehl, Reiner: Begriffsgeschichte zwischen theoretischem Mangel und theoretischem Überschuss. Philosophische Fußnoten zur historischen Semantik. In: Dutt, Carsten (Hg.): Herausforderungen der Begriffsgeschichte. Heidelberg 2003, S. 81101, hier S. 81f.

${ }^{38}$ Linke, Angelika: Begriffsgeschichte - Diskursgeschichte - Sprachgebrauchsgeschichte. In: Dutt, Carsten (Hg.): Herausforderungen der Begriffsgeschichte. Heidelberg 2003, S. 39-49, hier S. 40, vgl. auch S. 39-34; vgl. auch Busse/Teubert: Ist Diskurs ein sprachwissenschaftliches Objekt, S. 13; Busse: Begriffsgeschichte oder Diskursgeschichte, S. 17; Schultz: Begriffsgeschichte und Argumentationsgeschichte, S. 67-69
} 
Nebenbegriffe deutlich stärker berücksichtigen müsse und dass sich der Übergang zur Diskursanalyse damit von selbst ergebe. ${ }^{39}$ Mehrere Autoren haben Vorschläge zur Verbindung dieser beiden Forschungsansätze unterbreitet. Einer der bekanntesten ist Dietrich Busses Konzept einer historischen Semantik, bei der nicht einzelne Begriffe, sondern semantische Felder und Beziehungsgefüge von Begriffen im Fokus der Untersuchung stehen. Die historische Semantik will Bewusstseinsgeschichte sein, die - auf den epistemischen Kontext achtend - durch eine Analyse der Bedeutungsveränderungen Bewusstseinsveränderungen erkennen möchte. Dabei wird der Begriff als interpretatorische Funktion durch Diskurs ersetzt. Unter Diskurs versteht Busse dabei einen „Sektor der Sprache“ mit „Querbeziehungen von Begriffen, Sätzen, Äußerungseinheiten, der durch einen inhaltlichen Zusammenhang strukturiert ist ${ }^{\star 40}$. Diese auch als Diskurssemantik bezeichnete Methode soll sich - anders als Foucault es tut - mit den „Konstitutions- bzw. Realisierungsbedingungen von Sinn ${ }^{\text {“41 }}$ befassen, der immer an den einzelnen kommunikativen Akt gebunden bleibe. Konkret sollen Serien von Äußerungen herausgearbeitet werden sowie die Regelmäßigkeit bestimmter Verwendungen und Kontexte bestimmt und die Verwendungsregeln sowie deren epistemische und diskursive Möglichkeitsbedingungen rekonstruiert werden. Als eine mögliche Vorgehensweise erwähnt Busse unter anderem eine Argumentationsanalyse, wobei er sich gegen eine Beschränkung dieses Begriffs auf konkrete Situationen und Sprechergruppen ausspricht, wie Schultz sie vorschlägt, da sonst die personenübergreifenden „Argumentationsstrukturen“ aus dem Blick gerieten. ${ }^{42}$ Den Vorschlag der Argumentationsanalyse greift Wengeler auf. Konkret nutzt Wengeler den von Kienpointner entwickelten Topos-Katalog, füllt aber die dort aufgeführten allgemeinen Formprinzipien (Schlussregeln der Argumentation) mit konkreten Inhalten aus dem entsprechenden Diskurs. Auf diese Weise entsteht eine „Typologie themenbzw. kontextspezifischer Argumentationsmuster ${ }^{\text {‘43 }}$, wobei keine konkreten Argumente verglichen werden, sondern Schlussregeln bzw. Topoi, denn diese können besser in kontextabstrakter Form formuliert werden. Je nachdem wie gelöst vom Kontext

\footnotetext{
${ }^{39}$ Vgl. Koselleck: Begriffsgeschichten, S. 101

${ }^{40}$ Busse: Historische Semantik, S. 95

${ }^{41}$ Busse: Historische Semantik, S. 263

${ }^{42}$ Vgl. Busse: Historische Semantik, S. 97; vgl. auch Schultz: Begriffsgeschichte und Argumentationsgeschichte, S. 67-72

${ }^{43}$ Wengeler, Martin: Historische Diskurssemantik als Analyse von Argumentationstopoi. In: Busse, Dietrich/Teubert, Wolfgang: Linguistische Diskursanalyse: neue Perspektiven. Wiesbaden 2013, S. 189-215, hier S. 196
} 
formuliert wird, lassen sich mehr oder weniger viele Schlussregeln unterscheiden. Diese so herausgearbeiteten Topoi lassen sich dann auch hinsichtlich ihres quantitativen Vorkommens untersuchen. ${ }^{44}$

\subsection{Methoden und Aufbau}

Auch bei meiner Arbeit werde ich Methoden der Diskursanalyse und der Begriffsgeschichte verbinden, indem ich die die verschiedenen Argumentationsmuster der einzelnen (Sub-)Diskurse über Aspekte der indischen Kultur untersuche. Dabei werden im Rahmen einer Grobanalyse zunächst einzelne Aussagen, die den spezifischen Diskurs bilden, untersucht werden. Anhand dieser Aussagen sollen Themen des Diskurses näher beschrieben (worüber redet man eigentlich, wenn man über Indien spricht?), die Verknüpfungen zwischen den Aussagen analysiert (welche Aussagenkomplexe treten häufig zusammen auf, welche nicht? Gibt es isoliert voneinander bestehende Diskursstränge?) und gegebenenfalls das zeitliche Erscheinen und eventuelle wieder Abebben bestimmter Themen herausgearbeitet werden. Interessant ist es auch zu untersuchen, wie häufig bestimmte Aussagen auftreten und welche Aussagen besonders umstritten sind (weil sie ideologisch aufgeladen sind und sich bestimmte Positionen unversöhnlich gegenüberstehen oder weil es einfach kaum belastbare Daten, aber viele Theorien gibt). Zu klären ist ebenfalls, welche anderen Diskurse der Zeit Einfluss auf die Aussagen und Argumentationsstrukturen des Indiendiskurses haben (geht es wirklich um Indien oder wird am Beispiel Indien stellvertretend ein anderer Themenkomplex bearbeitet?).

Die Ergebnisse dieser Analyse der thematischen und zeitlichen Struktur der einzelnen Diskurse sollen anhand von ausgewählten Einzeltexten beispielhaft dargestellt werden. In dieser Feinanalyse kann der Blick auf die Einbettung der einzelnen Argumente und Aussagen in den Text sowie auf die Herangehensweise bei der Vermittlung fremder und mitunter zunächst vielleicht unverständlicher Aspekte der indischen Kultur gerichtet werden. Auch die dabei verwendeten Bilder und Stilmittel können bei der Untersuchung gegebenenfalls berücksichtigt werden.

\footnotetext{
${ }^{44}$ Vgl. Wengeler: Historische Diskurssemantik, S. 191-198; Wengeler, Martin: „Gastarbeiter sind auch Menschen“. Argumentationsanalyse als diskursgeschichtliche Methode. In: Sprache und Literatur 86,2 (2000), S. 54-69, hier S. 57-60
} 
In einem ersten Schritt werden so die Möglichkeit und Vielfalt dessen, was um 1800 in (wissenschaftlichen oder populären) Sachtexten mit dem Begriff Indien verbunden werden konnte, welche Bilder von Indien entworfen wurden und welche Themen anhand des Beispiels Indien diskutiert worden sind, aufgezeigt. In einem zweiten Schritt sollen dann die literarischen Bearbeitungen des Themas untersucht werden. Hierbei soll aufgezeigt werden, in welchen Textgattungen Indien vor allem eine Rolle spielt, welche Handlungsmuster, Szenerien und Personentypen vorkommen und ob sich diese bestimmten Typologien zuordnen lassen. Dabei wird es vor allem um die Fragen gehen, welche Aspekte des breitgefächerten Themas Indien überhaupt zur literarischen Bearbeitung herangezogen werden und wie sich die Darstellung dieser Aspekte von derjenigen der Sachtexte unterscheidet.

Bei der Analyse der einzelnen (Sub-)Diskurse zum Thema Indien fällt sehr schnell auf, dass bestimmte Begriffe, Themen und Themenfelder immer wieder eine wichtige Rolle spielen, und zwar (sub-)diskursübergreifend und in den verschiedensten Zusammenhängen und Funktionen und mit ganz unterschiedlicher Bewertung. Diese Begriffe und Themenfelder dienen häufig als Argumente in einer Schlussregel (Stützungsbegriffe) oder wecken sofort eine ganze Kette an Assoziationen (Assoziationsbegriffe), stehen also quasi pars pro toto für den ganzen Themenkomplex Indien oder doch zumindest einen großen Teil davon. Während letztere verständlicherweise themengebunden sind (was nicht heißt, dass sie nicht auch auf andere Themen übertragen werden können; dann sieht man ihnen ihre Herkunft aber deutlich an), zählen zu der ersten Kategorie Begriffe, die nicht unmittelbar aus dem Themenfeld Indien stammen. Da all diese Begriffe und Begriffsfelder eine besondere Bedeutung für alle Subdiskurse zum Thema Indien haben, möchte ich sie während der einzelnen Untersuchungen im Blick behalten und am Ende zusammenfassend kurz darstellen.

Abschließend soll in einem Rückblick auf die Ergebnisse der Untersuchungen den Fragen nachgegangen werden, warum gerade Indien eine solche Aufmerksamkeit erhielt, welche Hoffnungen und Erwartungen mit der Rezeption der indischen Kultur verbunden wurden und welche Indienbilder sich um 1800 gegenüberstanden.

Auch wenn es seinen Reiz hätte, ein wirklich umfassendes Bild der Indienwahrnehmung um 1800 quer durch alle Gesellschaftsschichten und Gruppen zu 
zeichnen, so wäre dies doch allein aufgrund der großen, kaum zu bearbeitenden Menge an Quellenmaterial sowie der Schwierigkeit, für bestimmte Schichten und Gruppen eine ausreichend repräsentative Anzahl an zugänglichen Quellen zu finden, ein praktisch kaum durchführbares Unterfangen. Aus diesen Gründen wie auch aus dem Anliegen heraus, Texte $\mathrm{zu}$ untersuchen, die möglichst in einem engen Diskurszusammenhang stehen, konzentriere ich mich bei der Zusammenstellung des konkreten Textkorpus auf Texte aus dem literarischen und wissenschaftlichen Umfeld im deutschsprachigen Raum. Auf die Einbeziehung von Alltagsquellen, die die Ansichten anderer Gesellschaftsschichten widerspiegeln könnten, werde ich weitestgehend verzichten, auch wenn mit großer Wahrscheinlichkeit angenommen werden kann, dass die in den ausgewählten Texten diskutierten Vorstellungen von Indien keinesfalls die Ansichten der großen Mehrheit der Bevölkerung darstellen. Diese zu untersuchen (gerade im Hinblick auf die Unterschiede und Gemeinsamkeiten zu bzw. mit den wissenschaftlich diskutierten Themen) wäre sicherlich ein interessantes und erhellendes Projekt, ist aber im Rahmen dieser Arbeit nicht zu leisten. Auch wird nur Textmaterial, jedoch keine Bildquellen für die Untersuchung herangezogen werden. Aufgrund der sehr großen Menge an wissenschaftlicher Literatur zu Indien wird eine Auswahl aus verschiedenen Textgattungen beispielhaft untersucht werden. Ergänzt wird diese durch eine Auswahl wichtiger Zeitschriftenartikel, die in den für dieses Thema und in diesen Kreisen relevanten Zeitschriften publiziert wurden.

Die Auswahl der Texte für die Feinanalyse orientiert sich an verschiedenen Parametern. Da sie eine möglichst große Breite der in den Texten des Diskurses thematisierten Inhalte und Meinungen abdecken sollen, ihre Vergleichbarkeit aber dennoch gegeben bleiben sollte, werden neben besonders bedeutsamen (weil Neues einführenden oder viel diskutierten und zitierten) Texten Ausschnitte mit einer sehr ähnlichen (minimale Kontrastierung) bzw. einer sich möglichst stark unterscheidenden Argumentationsstruktur (maximale Kontrastierung) herangezogen. ${ }^{45}$

\footnotetext{
${ }^{45}$ Vgl. zu dem Konzept der minimalen und maximalen Kontrastierung Keller: Diskursforschung, S. $87 \mathrm{f}$.
} 


\section{Begegnung mit anderen Kulturen}

\subsection{Anderes - Fremdes}

Die Rezeption Indiens im deutschsprachigen Raum stellt eine Begegnung mit einer anderen, zumindest in großen Teilen auch fremden Kultur dar. Diese Unterscheidung zwischen dem Begriff der anderen und dem Begriff der fremden Kultur wird in der Forschung oft außer Acht gelassen, ist aber insofern von Bedeutung, als eine andere Kultur nicht zwangsläufig auch als fremd empfunden werden muss und umgekehrt Fremdes nicht immer Teil einer anderen Kultur sein muss, sondern auch innerhalb der eigenen Kultur existieren kann. In der Forschung gibt es dazu verschiedene begriffliche Vorschläge und Differenzierungen: Andrea Polaschegg unterscheidet zwischen einer Dichotomie der Differenz (das Eigene vs. das Andere; es geht um Identität) und einer Dichotomie der Distanz (das Vertraute vs. das Fremde; es geht um Verstehen). ${ }^{46} \mathrm{Sie}$ weist außerdem darauf hin, dass kulturelle Fremdheit nicht nur durch räumliche Distanz entstehe, sondern gerade in der Zeit um 1800 vor allem auch eine Frage zeitlicher Distanz sei. ${ }^{47}$ Michael Hofmann und Iulia-Karin Patrut definieren das kulturell Andere durch die Verschiedenheit vom Eigenen. Fremdheit ist für sie „Alterität mit einer intensiven Erfahrung der Differenz ${ }^{\text {“48 }}$. Dietrich Krusche unterscheidet zwar nicht klar zwischen Anderem und Fremden, aber er beschreibt verschiedene Bedeutungen des Begriffs ,fremd“, die der Differenzierung zwischen Anderem und Fremden ähneln: Das Fremde, das - wie er betont - keine Eigenschaft eines Objekts sei, sondern ein Verhältnis des Subjekts zum Objekt, könne das vom Eigenen einfach nur Unterschiedene meinen, das dazu Komplementäre, das davon Ausgeschlossene oder das Unvergleichliche. ${ }^{49}$ In der Terminologie Polascheggs wäre ersteres das Andere, letzteres das Fremde. Ähnlich verfährt auch Bernhard Waldenfels, wenn er die Bedeutungen des Begriffs ,fremd“ aufteilt in ein Äußeres (vs. das Innere), etwas einem

\footnotetext{
${ }^{46}$ Vgl. Polaschegg, Andrea: Der andere Orientalismus. Regeln deutsch-morgenländischer Imagination im 19. Jahrhundert. Berlin 2005, S. 41-43

${ }^{47}$ Vgl. Polaschegg, Andrea: Athen am Nil oder Jerusalem am Ganges? Der Streit um den kulturellen Ursprung um 1800. In: Böhm, Alexandra / Sproll, Monika (Hg.): Fremde Figuren. Alterisierungen in Kunst, Wissenschaft und Anthropologie um 1800. Würzburg 2008, S. 41-65, hier S.42f.; Diese Unterscheidung hatte bereits Hume getroffen, wobei er zu beobachten meinte, dass Distanz in der Zeit schwieriger vorzustellen sei als Distanz im Raum, vgl. Osterhammel, Jürgen:

Distanzerfahrung. Darstellungsweisen des Fremden im 18. Jahrhundert. In: Hans-Joachim König u.a. (Hg.): Der europäische Beobachter außereuropäischer Kulturen. Zur Problematik der Wirklichkeitswahrnehmung. Berlin 1989, S. 9-42, hier S. 9

${ }^{48}$ Hofmann, Michael u. Patrut, Iulia-Karin: Einführung in die interkulturelle Literatur. Darmstadt 2015, S. 7f.

${ }^{49}$ Vgl. Krusche, Dietrich: Literatur und Fremde. Zur Hermeneutik kulturräumlicher Distanz. München 1985, S. 14
} 
Anderen Angehöriges (vs. das Eigene) und etwas Fremdartiges, Unheimliches (vs. das Vertraute) ${ }^{50}$ Norbert Mecklenburg führt eine Dreigliederung der Begriffe anhand der Wahrnehmungsperspektive ein: Von Differenz spricht er, wenn die Andersartigkeit in analytischer Rede aus der Sicht eines unbeteiligten Beobachters beschrieben wird; erfolgt die Beschreibung jedoch aus der Mitspieler-Perspektive in hermeneutischer Rede, so bezeichnet er dies als Fremdheit. Während Differenz eine Skala von identisch über ähnlich/unähnlich bis zu nichtidentisch beschreibe, sei Fremdheit eine Deutung der Differenz. Den Begriff der Alterität möchte er, anders als z.B. Polaschegg, dann verwenden, wenn in der kulturwissenschaftlichen Arbeit beide Perspektiven, sowohl die des unbeteiligten Beobachters als auch die des Mitspielers, bewusst gehalten werden sollen. ${ }^{51}$ Da die Ansätze Krusches und Waldenfels', zwischen verschiedenen Aspekten des Begriffes „fremd“ zu unterscheiden, diese Unterschiede nicht immer eindeutig begrifflich kenntlich machen, und da die Definition der Alterität nach Mecklenburg den meisten gängigen Definitionen nicht entspricht, werde ich mich in dieser Arbeit - sofern nicht anders angegeben - an der Begrifflichkeit Polascheggs orientieren.

\subsection{Begegnung mit dem Fremden}

So unterschiedlich die eben vorgestellten Definitionen und Bezeichnungen von Anderem und Fremdem sein mögen, eines haben sie alle gemeinsam: die Feststellung, dass das räumlich oder zeitlich Andere mit einer Erfahrung von Fremdheit einhergehen kann. Interessant sind dabei zwei Beobachtungen von Mecklenburg: Er unterscheidet zunächst zwischen dem kognitiv Fremden (Unbekannten, Unerkannten) und dem normativ Fremden (etwas gilt aufgrund von sozialen Normen als nicht zugehörig). Das heißt, damit das Andere als fremd empfunden wird, muss es entweder unbekannt sein und dadurch unvertraut bzw. auch unverständlich. Oder es muss aus normativen Gründen abgelehnt werden. Wichtig ist dabei seine zweite Beobachtung, dass sich Fremdheit sowohl auf nahe, als auch auf entfernte Punkte der Differenz-Skala beziehen könne und dass es gerade das objektiv Ähnliche sei, das häufig als fremd empfunden werde. $^{52}$

\footnotetext{
${ }^{50}$ Vgl. Waldenfels, Bernhard: Grundmotive einer Phänomenologie des Fremden. Frankfurt a.M. 2006, S. 111 f.

${ }^{51}$ Vgl. Mecklenburg, Norbert: Das Mädchen aus der Fremde. Germanistik als interkulturelle Literaturwissenschaft. München 2008, S. $215 f$.

52 Vgl. Mecklenburg: Das Mädchen aus der Fremde, S. $215 f$.
} 
Bei der Frage, wie das Andere erfasst und ggf. als fremd wahrgenommen wird, ist die aktive Rolle der Einbildungskraft von großer Bedeutung. Das Subjekt muss ein Ganzes, das es normalerweise nur in fragmentarischen Ausschnitten wahrnehmen und erleben kann (sei es durch eigene, perspektivisch begrenzte Sinneseindrücke, sei es durch lückenhaftes Quellenmaterial), erst aktiv für sich als Ganzes formen. ${ }^{53}$ Dabei greift es auf durch andere vermittelte oder aus ähnlichen Zusammenhängen vertraute Bilder zurück und ist daher bereits vor dem ersten Zusammentreffen mit der anderen Kultur vorgeprägt. Verfestigen und vereinfachen sich kollektive Bilder von anderen Kulturen, kann man von Stereotypen sprechen. Stereotype werden zumeist ohne kritische Infragestellung der Inhalte von vielen Menschen immer wieder unverändert kommuniziert und sind auch Tatsachen und Argumenten kaum noch zugänglich. Außerdem sind sie häufig mit bestimmten Gefühlen wie z.B. Angst verbunden. Norbert Mecklenburg differenziert hinsichtlich der Bilder und Stereotype noch weiter: Vorurteile oder Klischees entstünden, wenn sich die Stereotypen auf bloße Meinungen oder Redensarten reduzierten; als Stereotypenbündel bezeichnet er die Kombination aufeinander bezogener Stereotypen. Für die Beschäftigung mit Kulturkontakten besonders wichtig seien auch Projektionen. Von diesen spreche man, wenn Eigenes Anderem zugeschrieben werde, wenn man z.B. in der anderen Kultur eigene Vorstellungen, Diskussionen oder Riten zu erkennen glaube. Von Phantasmen könne man sprechen, wenn die im Kopf erzeugten Bilder kaum noch auf wirklichen Erfahrungen fußten. ${ }^{54}$ Inwieweit auch die Rezeption und Darstellung der indischen Kultur um 1800 auf solchen Projektionen oder Phantasmen beruhte, soll unter anderem in dieser Arbeit untersucht werden.

Das Eigene und das Andere werden in Beziehung zueinander und in Abgrenzung voneinander konstruiert. Dabei geschieht es immer wieder, dass die Anderen durch „falsche Zuschreibungen zu einem nicht mehr verstehbaren Fremden“ 55 gemacht werden. Die (bewusste) Abgrenzung ist aber nur eine Möglichkeit des Verhältnisses von Anderem/Fremdem und Eigenem. Ottfried Schäffter führt in seiner

\footnotetext{
${ }^{53}$ Vgl. Osterhammel: Distanzerfahrung, S. 10

${ }^{54}$ Vgl. Mecklenburg: Das Mädchen aus der Fremde, S. 239f.

${ }^{55}$ Marschall, Wolfgang: Verfremdung und autonome Konstitution. Zur Kategorie der Fremden im Denken des aufgeklärten Jahrhunderts. In: Schuster, Meinhard (Hg.): Die Begegnung mit dem Fremden. Wertungen und Wirkungen in Hochkulturen vom Altertum bis zur Gegenwart. Stuttgart u. Leipzig 1996 (Colloquium Rauricum; 4), S. 245-261, hier S. 247
} 
Zusammenstellung von Facetten des Fremdseins neben dieser Möglichkeit, das Fremde als Gegenbild zu deuten, noch folgende weitere Facetten auf: das Fremde als Resonanzboden des Eigenen (indem man im Anderen Eigenes erkennt, beginnt die Fremdheit zu schwinden), das Fremde als Ergänzung und positive Erweiterung des Eigenen und das Fremde als das Komplementäre (das Fremde wird in seiner Fremdheit anerkannt und respektiert). ${ }^{56}$

Bei der Art und Weise, wie in einem Text das Fremde an das Vertraute angebunden und wie mit ihm umgegangen wird, lassen sich folgende Haupttendenzen unterscheiden: 1) Die Anbindung geschieht durch Verweis auf Ähnlichkeiten in der eigenen Kultur oder anderen bekannten Kulturen. 2) Die Anbindung geschieht durch das Herausarbeiten der Gegensätze, Schaffen des ganz Anderen. 3) Unterschiede werden hervorgehoben; das Eigene ist zwar das Bessere, aber das Andere ist so aus bestimmten Gründen und wird daher als solches anerkannt. 4) Die Anbindung geschieht durch die Wertschätzung des Anderen, das als solches anerkannt und gleichgestellt wird. 5) Im Anderen wird eine Bestätigung der eigenen Anschauungen gesucht/gesehen. 6) Das Andere wird nur als Bild für etwas Eigenes gebraucht. 7) Das Andere wird überhöht und idealisiert. 8) Im Anderen werden Kenntnisse über allgemeinere Themen (z.B. Vorzeit, religiöse Wahrheit etc.) gesucht. Da diese Kategorien sowohl Formen der Anbindung als auch der Bewertung sowie der Intention für die Beschäftigung mit anderen Kulturen umfassen, kann ein und derselbe Text natürlich mehreren Kategorien zugleich angehören.

\subsection{Orientalismus}

Die Forschung zur Rezeption des Orients wurde durch das 1978 erschienene Buch „Orientalism“ von Edward Said nachhaltig beeinflusst. Seine Thesen und Methoden wurden aber auch auf andere Beispiele von Kulturkontakt übertragen. ${ }^{57}$ In seinem Buch beschreibt Said die Konstruktion des Orients durch den Westen als eine besondere Form des „othering“. „Othering“ bedeutet, dass das Andere auf sein Anderssein

\footnotetext{
${ }^{56}$ Vgl. Hofmann u. Patrut: Einführung in die interkulturelle Literatur, S. 12

${ }^{57}$ Es gibt sogar Übertragungen auf intrakulturelle Phänomene; so beschreibt z.B. Manuel Borutta die Orientalisierung des deutschen Katholizismus, vgl. Borutta, Manuel: Der innere Orient:

Antikatholizismus als Orientalismus in Deutschland, 1781-1924. In: Juneja, Monica u. Pernau, Margrit (Hg.): Religion und Grenzen in Indien und Deutschland. Auf dem Weg zu einer transnationalen Historiographie. Göttingen 2008, S. 245-274
} 
festgelegt wird. Es muss den der anderen Kultur von außen zugeschriebenen Merkmalen entsprechen und wird, ist dies nicht ausreichend der Fall, kritisiert, nicht seinem Anderssein zu genügen. ${ }^{58}$ Der Westen erschaffe sich ein imaginäres Bild vom Orient, indem er von einer ontologischen und epistemologischen Unterscheidung zwischen Okzident und Orient ausgehe und diesen auf sein Anderssein festlege. Der Orient werde dabei essentialisiert und als eine einheitliche, homogene Größe aufgefasst, die statisch und unveränderlich sei. ${ }^{59}$ Es werde davon ausgegangen, dass der Osten sich nicht selbst repräsentieren könne und daher vom Westen repräsentiert werden müsse. Denn aufgrund seiner kulturellen Überlegenheit könne nur der Westen die Relikte der vergangenen klassischen Zivilisation des Orients richtig deuten und rekonstruieren. Der gegenwärtige Orient werde dabei - wenn er denn überhaupt Beachtung finde - als dekadent angesehen, weshalb auch die orientalischen Akademiker selbst kaum Gehör fänden. ${ }^{60}$ Die durch den Westen geschaffenen Repräsentationen beruhten weniger auf tatsächlichen Beobachtungen orientalischer Kulturen, sondern vielmehr auf Traditionen, Institutionen und Konventionen, also auf kollektiven Bildern und Stereotypen. ${ }^{61}$ Dabei sei zu beobachten, dass der Westen das Bild des Osten als sein genaues Gegenstück entwerfe, so dass ganze Reihen von „binären Oppositionsketten“ ${ }^{\prime 62}$ entstünden. Indem der Osten als irrational, verkommen, kindlich, weiblich und anders beschrieben werde, könne sich der Westen selbst in Abgrenzung zum Osten als rational, tugendhaft, mündig, männlich und normal darstellen. ${ }^{63}$ Diese Entgegensetzung von Ost und West diene aber nicht allein der Konstruktion einer europäischen Identität, sondern auch der Schwächung und Herabsetzung des Orients, über den auf diese Weise Macht ausgeübt werden könne. ${ }^{64}$

Die Thesen Saids sind in der Forschung häufig übernommen und auf andere Bereiche übertragen worden. Sie haben aber auch scharfe Kritik erfahren. Dabei werden einige Hauptkritikpunkte immer wieder vorgebracht: Said sei nicht eindeutig in seiner Definition des Orientalismus und in der Festlegung eines zeitlichen Beginns. So

\footnotetext{
${ }^{58}$ Vgl. Mecklenburg: Das Mädchen aus der Fremde, S. 137

${ }^{59}$ Vgl. Said, Edward W.: Orientalism. London 2003, S. $96 f$.

${ }^{60}$ Vgl. Said: Orientalism, S. 21, 52, 79, 121, 233

${ }^{61}$ Vgl. Said: Orientalism, S. 21f., 69

${ }^{62}$ Kurz, Isolde: Vom Umgang mit dem anderen. Die Orientalismus-Debatte zwischen Alteritätsdiskurs und interkultureller Kommunikation. Würzburg 2000, S. 14

${ }^{63}$ Vgl. Said: Orientalism, S. 40

${ }^{64}$ Vgl. Said: Orientalism, S. 2f.
} 
beschreibe er zwar das 18. Jahrhundert als Beginn des Orientalismus, spreche dann aber auch vom Orientalismus der Antike. Das widerspreche nicht nur dem Ansatz Foucaults (auf den sich Said beruft), da dieser vor dem 16. Jahrhundert nicht von Diskursen spreche, sondern führe auch dazu, dass er Diskurse verschiedener Epochen zu einem großen „orientalischen Metadiskurs(...)“ 65 zusammenfasse und dadurch Veränderungen innerhalb der Diskurse nicht wahrnehme und epistemologische Brüche übersehe. Außerdem richte er seine Quellenauswahl an dieser Vorannahme eines Metadiskurses aus, indem er Texte, die diese Annahme nicht stützten, außer Acht lasse. Anders als Foucault es getan hatte, konstruiere er den Orientdiskurs nicht anhand von möglichst breitgefächertem Quellenmaterial, sondern auf der Grundlage einiger weniger, anscheinend entsprechend seiner Ziele ausgesuchter bekannter Texte. ${ }^{66}$ Auch einige historische Fakten passe Said seiner These von der Macht des Wissens über den Orient an: So verlege er den eigentlichen Beginn der wissenschaftlichen Erforschung des Orients in das England und Frankreich der Zeit der Kolonialisierungen, obwohl die orientalischen Studien zu diesem Zeitpunkt dort bereits gut etabliert gewesen seien. ${ }^{67}$ Außerdem beachte er nicht, dass gerade der islamische Orient, auf den sich Said in seiner Untersuchung fast ausschließlich beruft, keinesfalls immer der Macht des Westens unterlegen war, sondern lange Zeit selbst im Westen als Gefahr angesehen und entsprechend rezipiert wurde (vgl. z.B. das Osmanische Reich). Der Beginn der Auseinandersetzung mit der islamischen Welt sei also keineswegs mit der Ausübung oder dem Gewinn von Macht verbunden gewesen. Anders läge der Fall im von Said kaum beachteten Indien, das wissenschaftlich wirklich erst im Zuge der Kolonialisierung entdeckt worden sei. ${ }^{68}$

Noch wichtiger als einige von Said verfälschte Fakten sind meiner Ansicht nach allerdings zwei weitere in der Forschung kritisierte Probleme, die sich aus Saids starker Orientierung seiner Methoden an dem von ihm intendierten Ergebnis ergeben: Erstens entsteht aus der Zusammenfassung von Texten verschiedenster Epochen in einen

\footnotetext{
${ }^{65}$ Polaschegg: Der andere Orientalismus, S. 30f.

${ }^{66}$ Vgl. Ahmad, Aijaz: Between Orientalism an Historicism. In: Macfie, A.L. (Hg.): Orientalism. A Reader. Edinburgh 2000, S. 285-297, hier S. 287f., 291; Kurz: Vom Umgang mit dem anderen, S. 21, 172f.; Jalal al-'Azm, Sadik: Orientalism and Orientalism in Reverse. In: Macfie, A.L. (Hg.): Orientalism. A Reader. Edinburgh 2000, S. 217-238, hier S. 218f.; Polaschegg: Der andere Orientalismus, S. 30f.; Arens, Katherine: Said's Colonial Fantasies: How Orientalism marginalizes eighteenth-centaury Germans. In: Herder Jahrbuch 7 (2004), S. 11-29, hier S. 18

${ }^{67}$ Vgl. Lewis, Bernhard: The Question of Orientalism. In: Macfie, A.L (Hg.): Orientalism. A Reader. Edinburgh 2000, S. 249-270, hier S. 258

${ }^{68}$ Vgl. Lewis: The Question of Orientalism, S. 259-261; Polaschegg: Der andere Orientalismus, S. 31
} 
durchgängigen homogenen Diskurs ein Bild vom Westen, das ähnlich essentialisiert und okzidentalisiert ist, wie Said es den Orientalisten hinsichtlich des Orients vorwirft. Der Orientdiskurs war aber sowohl für die islamischen Kulturen als auch für Indien wie im Verlauf der Arbeit deutlich werden wird - nicht einheitlich und zwar weder synchron (es gab Gegenstimmen und unterschiedliche Sichtweisen) noch diachron (es gab Brüche und Veränderungen in der Zeit). Außerdem stellt Said anhand der frz. und engl. Orientalisten gewonnene Ergebnisse als „den“ europäischen Orientalismus dar, ohne auf mögliche Besonderheiten anderer Länder einzugehen. ${ }^{69}$ Doch nicht nur der Westen wird durch Said zu einem einheitlichen statischen Gebilde, auch die den Orientalisten vorgeworfene Homogenisierung des Orients setzt Said in gewisser Weise fort, wenn er seinen Orient zunächst auf die islamische Kultur begrenzt und somit aus dem Rezeptionskontext reißt, dann aber wiederum die so gewonnenen Ergebnisse auf den Orient allgemein überträgt. Und zweitens bleibt Said widersprüchlich in seiner Bewertung der festgestellten Repräsentation des Ostens durch den Westen. Denn er betont einerseits, dass es ihm nicht um die Richtigkeit der Repräsentation gehe, sondern um das Wie der Darstellung, ${ }^{70}$ und dass es bei dem Bemühen, andere Kulturen zu verstehen, zwangsläufig zur Entstehung von Bildern, zu Schematisierung und Repräsentation komme. ${ }^{71}$ Andererseits aber kritisiert er sowohl die Inhalte der westlichen Orientbilder als auch die Tatsache der Repräsentation als solche, in der er westliche Machtansprüche manifestiert sieht. Die Kritik an dem Inhalt der Repräsentationen impliziert, dass es neben der von Said beschriebenen Konstruktion des Orients einen außerdiskursiv erfahrbaren Orient geben müsste, anhand dessen über die Richtigkeit der Bilder entschieden werden könnte. Das aber widerspricht sowohl Foucaults Ansichten als auch seinen eigenen Annahmen. Wenn alles Kulturelle, so wie wir es wahrnehmen, konstruiert ist und uns nur durch Bilder zugänglich, dann kann auch ein möglicherweise außerdiskursiv existierender Orient nicht als Maßstab für die Richtigkeit von Orientbildern gelten (da er eben ,,an sich“ nicht wahrnehmbar ist) bzw. es gäbe nur viele einzelne Dinge, die jedoch ohne das sie umfassende Konzept des Orients nicht als ein Ganzes, als eine Einheit erschienen. Und durch die Kritik an der

\footnotetext{
${ }^{69}$ Vgl. Ahmad: Between Orientalism and Historicism, S. 289; vgl. auch King, Richard: Orientalism and Religion. Postcolonial theory, India and "the mystic East". London u. New York 1999, S. 116; Kurz: Vom Umgang mit dem anderen, S. 172, 179; Mecklenburg: Das Mädchen aus der Ferne, S. 249251

${ }^{70}$ Vgl. Said: Orientalism, S. 21

${ }^{71}$ Vgl. Jalal al'-Azm: Orientalim and Orientalism in Reverse, S. 221
} 
Repräsentation als solche stellt Said diese, sofern sie den Orient betrifft, als etwas Besonderes, bestimmten Machtstrukturen Geschuldetes dar. Doch wenn alles Kulturelle konstruiert und nur über Bilder erfahrbar ist, muss das auch für den Orient gelten und ist damit der Normalfall und keine Besonderheit des Orientalismus. ${ }^{72}$ Dass die Konstruktion des Orients an sich kein Sonderfall ist, zeigt sich auch darin, dass es ebenso stereotype Bilder vom Westen oder anderen Gegenden der Welt gibt und zwar nicht nur durch den Westen, sondern auch durch andere Kulturen. Eine besondere Form dieser Bilder ist ein Phänomen, das Sadik Jalal al'Azm als „orientalism in reverse“73 bezeichnet: die bewusste Nutzung westlicher Orientbilder durch die Träger der betroffenen Kulturen selbst, z.B. um eigene Vorteile herauszustellen, vor allem aber auch um die eigene kulturelle Identität zu festigen und nach außen abzugrenzen. Die von außen zugeschriebenen Bilder werden übernommen und stolz als Merkmale der eigenen Kultur präsentiert. Ein weiterer Kritikpunkt an Saids Thesen betrifft das angenommene Verhältnis zwischen orientalistischer Forschung und den Machtverhältnissen, wie sie sich z.B. im Kolonialismus äußern. So zeigt z.B. Ludwig Amman, dass Said zwar Recht damit hatte, dass negative Urteile über den Orient zur Rechtfertigung der Kolonialpolitik dienen konnten, aber sie seien „kein hinreichender Grund und noch nicht einmal notwendige Bedingung kolonialistischer Politik ${ }^{674}$.

Zusammenfassend kann man sagen, dass Said zwar wichtige Denkanstöße gegeben hat, in vielen Bereichen aber unzulässig verallgemeinert. So war es sicher wichtig und richtig darauf aufmerksam zu machen, dass die Erforschung anderer Kulturen immer mit Bildern und Repräsentationen zu tun hat, die zu Stereotypen werden können, die mit bestimmten Absichten oder politischen Zielen verbunden sein können. Daraus zu schließen, dass nur die Träger einer Kultur selbst diese erforschen sollten, ist aber sicherlich keine Option. Verständlicherweise gibt es zwischen Kulturen des Orients und denen des Westens größere Differenzen als zwischen zwei Kulturen des gleichen Kulturkreises. Und diese Differenzen können und dürfen auch beschrieben werden. Denn wie David Bell es formuliert: die Annahme kultureller Differenz muss nicht gleich die Annahme von fundamentaler oder ontologischer Differenz bedeuten. ${ }^{75}$

\footnotetext{
${ }^{72}$ Vgl. Jalal al'-Azm: Orientalism and Orientalism in Reverse, S. 221f.; Polaschegg: Der andere Orientalismus, S. 33f.

${ }^{73}$ Jalal al'-Azm: Orientalism and Orientalism in Reverse, S. 231

${ }^{74}$ Amman: Östliche Spiegel, S. 44

${ }^{75}$ Vgl. Bell, David: Goethe's Orientalism, In: Nicholas Boyle und John Guthrie (Hg.): Goethe and the English-Speaking World. Essays from the Cambridge Symposium for his 250th Anniversary.

Rochester 2002, S. 199-212, hier S. 205f.
} 
Gerade in der Zeit um 1800 entstand durch die Entwicklung Europas hin zur Moderne ein immer stärker werdendes Gefühl für (vielleicht zunächst noch nicht greifbare) Unterschiede, über deren Ursachen spekuliert wurde. Indem die europäische Kultur sich in der Moderne grundlegend wandelte und diese Veränderungen auch bewusst durchlebte, wurden z.B. die orientalischen Kulturen zumindest in Teilen zunehmend als fremd empfunden. Diese Fremdheitserfahrung ist das Spezifische in dem Verhältnis des Westens zum Orient, nicht jedoch die Wahrnehmung von bloßer Differenz. ${ }^{76}$ Vielleicht ist es sinnvoll, sich bei der Frage nach dem Orientalismus konkreter Texte an dem von Osterhammel vorgeschlagenen Fragenkatalog $\mathrm{zu}$ orientieren, um gegenüber Saids Verallgemeinerungen zu einer differenzierteren Beurteilung zu kommen: Worin genau wird das unterscheidende Merkmal zwischen Osten und Westen gesehen? Wurde diese Differenz als Überlegenheit/Unterlegenheit bewertet? Wurde eine Möglichkeit gesehen, die Differenz zu überwinden oder galt sie als natürlich gegeben und dadurch unveränderlich? Durch welche Strategien (z.B. der Ausgrenzung, Abwehr, Assimilation) sollte dem Fremden der Schrecken genommen werden ${ }^{77}$

\subsection{Einstellungen zum Anderen/Fremden um 1800}

Um 1800 waren große Teile des europäischen Diskurses über außereuropäische Kulturen mehr als je zuvor von dem Wunsch, den Anderen verstehen zu wollen, geprägt. Dabei sollten die Anderen auch selbst zu Wort kommen, was ein Grund für die vermehrten Übersetzungstätigkeiten war. Diese Texte sowie die Ergebnisse von Untersuchungen zu anderen Kulturen wurden europaweit kommuniziert, übersetzt und kommentiert. Hans-Jürgen Lüsebrink spricht sogar von einer Art europäischer Gelehrtenrepublik. ${ }^{78}$

Die Diskurse über das Andere/Fremde wurden nun im Vergleich zu früheren Ansätzen auf ein „schärferes theoretisches Niveau“79 gehoben. Dabei lassen sich bei allen Unterschieden der theoretischen Positionen zwei Hauptlinien erkennen. Wolfgang Marschall bezeichnet sie als integratives Entwicklungsdenken und Kulturrelativismus.

\footnotetext{
${ }^{76}$ Vgl. Polaschegg: Der andere Orientalismus, S. 56; Lütt: Einleitung. In: Zeitschrift für Kulturaustausch 37.Jg/3. Vj. (Utopie - Projektion - Gegenbild. Indien in Deutschland) (1987), S. 391393, hier S. 393

${ }^{77}$ Vgl. die Zusammenstellung der Fragen bei Mecklenburg: Das Mädchen aus der Ferne, S. 252

${ }^{78}$ Vgl. Lüsebrink, Hans-Jürgen: Von der Faszination zur Wissenssystematisierung: die koloniale Welt im Diskurs der europäischen Aufklärung. In: Lüsebrink, Hans-Jürgen (Hg.): Das Europa der Aufklärung und die außereuropäische koloniale Welt, S. 9-18, hier S. 10 f.

${ }^{79}$ Marschall: Verfremdung und autonome Konstitution, S. 249
} 
Bei ersterem werde davon ausgegangen, dass alle Kulturen im Prinzip die gleiche Entwicklung durchliefen und entsprechend ihres Entwicklungsstands auf einer Entwicklungsskala angeordnet werden können. Diese Entwicklung werde größtenteils als ein Fortschritt von einem dem Tierischen ähnlichen Urzustand bis hin zu den europäischen Zivilisationen als Höhepunkt der Entwicklung gedacht. Da die sogenannten Edlen Wilden ${ }^{80}$ noch auf einer Entwicklungsstufe verweilten, die die europäischen Kulturen bereits durchlaufen hätten, könne man an jenen auch die Kindheit der eigenen Kultur studieren. Es gehörten aber auch Konzepte eines Goldenen Zeitalters dazu, dessen Weisheit auf einem höheren Entwicklungsstand wieder erlangt werden solle. Wie wir später sehen werden, sind solche Vorstellungen gerade auch bei der Rezeption der indischen Kultur durch die Romantiker von besonderer Bedeutung. Anders als die Entwicklungsdenker gingen die Kulturrelativisten nicht von einer gradlinigen Entwicklung aller menschlichen Kulturen und einer daraus sich ergebenden hierarchischen Gliederung aus, sondern erachteten alle Kulturen als gleich wertvoll. Diese Ansicht sei allerdings deutlich weniger stark verbreitet gewesen. Marschall vermutet, dass der Optimismus des Entwicklungsdenkens diesem Vortrieb gegeben habe. ${ }^{81}$ Ein bekannter Vertreter des Entwicklungsdenkens war z.B. Hegel, aber auch

\footnotetext{
${ }^{80}$ Der Topos des Edlen Wilden spielt auch in der Zeit um 1800 eine Rolle, im Indiendiskurs allerdings eher am Rande, da Indien vor allem als alte Hochkultur rezipiert wurde; in einigen literarischen Texten gibt es allerdings Anspielungen auf diesen Topos, auf die an entsprechender Stelle eingegangen werden wird; zu dem Topos des Edlen Wilden allgemein vgl. z.B. Kaufmann, Stefan u. Haslinger, Peter: Einleitung: Der Edle Wilde - Wendungen eines Topos. In: Fludernik, Monika u.a. (Hg.): Der Alteritätsdiskurs des Edlen Wilden. Exotismus, Anthropologie und Zivilisationskritik am Beispiel eines europäischen Topos. Würzburg 2002, S. 13-30 und Fludernik, Monika: Der „Edle Wilde“ als Kehrseite des Kulturprogressivismus. In: Fludernik, Monika u.a. (Hg.): Der Alteritätsdiskurs des Edlen Wilden. Exotismus, Anthropologie und Zivilisationskritik am Beispiel eines europäischen Topos. Würzburg 2002, S. 157-175

${ }^{81}$ Vgl. Marschall: Verfremdung und autonome Konstitution, S. 249-252; vgl. auch Jürgen Osterhammel, der statt von Entwicklungsdenkern von Stadientheoretiker spricht, vgl. Osterhammel: Distanzerfahrung, S. 34f.
} 
Schiller dachte in eine ähnliche Richtung. Forster ${ }^{82}$, vor allem aber Herder ${ }^{83}$ neigten zu kulturrelativistischen Ansichten. ${ }^{84}$

Um 1800 war die Beschäftigung mit dem Fremden darüber hinaus auch von großer Bedeutung für den Beginn der ästhetischen Moderne. Auch hier ging es in der Auseinandersetzung mit dem Fremden (sei es in Form der Begegnung mit anderen Kulturen, sei es in Form der Entdeckung von Anderem innerhalb der eigenen Kultur) in großem Maße um die Definition oder Erneuerung/Erweiterung des Eigenen. ${ }^{85}$ In Bezug auf Kunst und Literatur beschränkte sich der Einfluss der (Kunst/Literatur der) anderen Kultur nicht auf die inhaltlich-thematische Seite, sondern erstreckte sich auch auf die formale Ebene. Viele zentrale ästhetische Elemente gerade der Romantik bildeten sich im Kontakt mit anderen Kulturen (z.B. die Arabeske durch die Begegnung mit orientalischer Kunst). ${ }^{86}$

\footnotetext{
${ }^{82}$ Forster geht davon aus, dass alle Kulturen von lokalen Gegebenheiten geprägt seien und somit verschiedene Ausprägungen des Menschlichen. Sie alle eine die Fähigkeit, ähnliche Gefühle zu erleben. Diese grundlegende emotionale Gemeinsamkeit zeige sich bei allen sonstigen Unterschieden auch in den verschiedenen Literaturen, deren Rezeption somit die Toleranz anderer Kulturen sowie die Erweiterung des eigenen Verständnisses des Humanen fördern könne (vgl. Karyekar, Madhuvanti: Fostering aesthetic tolerance through literary translation. Georg Forster's Śakuntalā. In: Cho, Joanne Miyang u.a. (Hg.): Transcultural Encounters between Germany and India. Kindred spirits in the nineteenth an twentieth centuries. London u. New York 2014, S. 13-24, hier S. 19-21).

${ }^{83}$ Herder betont die Gleichwertigkeit der verschiedenen Kulturen, deren So-Sein auch von klimatischen Bedingungen geprägt sei. Man könne und dürfe die verschiedenen Völker nicht miteinander vergleichen, da sie zu unterschiedlich seien. Vorstellungen von niederen und höheren Kulturen entstünden durch den strengen Vergleich, vor allem mit der von vielen als Vorbild angesehenen Antike. Diese kulturrelativistischen Ansichten verbindet er allerdings mit einer Art Entwicklungsdenken, indem er zwar nicht seine eigene Zeit und Kultur als Höhepunkt einer linearen Entwicklung ansieht, aber die Blütejahre verschiedener Kulturen bestimmten Altersstufen der Menschheit zuordnet: So entspreche der Orient der Kindheit der Menschheit, das alte Ägypten der Knabenzeit, die Griechen dem Jüngling, die Römer dem Mannesalter. Anschließend seien die rauen Menschen des Nordens gekommen. Herder versucht, europäische Errungenschaften zwar als einen Entwicklungsschritt darzustellen, diese Darstellung aber mit der Anerkennung und Wertschätzung der einzelnen Völker und Kulturen als eigenständige Größen zu vereinen (vgl. Herder, Johann Gottfried: Ideen zur Philosophie der Geschichte der Menschheit. Darmstadt 1966, S. 407f.; Herder: Auch eine Philosophie der Geschichte zur Bildung der Menschheit. Frankfurt a.M. 1967, S. 38-51) 84 Der Begriff der Kulturrelativisten spielt auch in einem anderen Zusammenhang eine Rolle. So bezeichnet man hinsichtlich der Frage, inwieweit ein Verstehen einer anderen Kultur überhaupt möglich sei, die Position, kulturelles Verstehen sei prinzipiell nicht möglich, als kulturrelativistisch. Die andere Kultur müsse in ihrer Andersheit anerkannt werden, da Verstehensversuche der Gefahr unterliefen, Macht über die andere Kultur auszuüben. Im Gegensatz dazu gehen Universalisten davon aus, dass es genügend Gemeinsamkeiten zwischen den verschiedenen Kulturen gebe, auf deren Grundlage ein Verstehen möglich sei (vgl. Mecklenburg: Das Mädchen aus der Fremde, S. 44f.) ${ }^{85} \mathrm{Vgl}$. Böhm, Alexandra u. Sproll, Monika: Einleitung. In: Böhm, Alexandra und Sproll, Monika (Hg.): Fremde Figuren. Alterisierungen in Kunst, Wissenschaft und Anthropologie um 1800. Würzburg 2008, S. 7-26, hier S. 7f.

${ }^{86}$ Vgl. Böhm u. Sproll: Einleitung, S. 11f.
} 


\section{Indienkenntnisse und -vorstellungen im Mittelalter und in der frühen Neuzeit}

Bevor die Rezeption der indischen Kultur um 1800 in ihren Facetten untersucht werden soll, möchte ich kurz einen Blick auf die im Mittelalter und der frühen Neuzeit verbreiteten Indienbilder werfen. Denn diese beeinflussten die Vorstellungen, vor deren Hintergrund die Autoren um 1800 begannen, sich mit dem Thema Indien auseinanderzusetzen.

\subsection{Europäische Vorstellungen von Indien im Mittelalter}

Da die Handelsbeziehungen, die die Römer nach Indien unterhalten hatten, nach dem Zusammenbruch des Römischen Reiches abgebrochen waren und ein erneuter Zugang zu Indien aufgrund der muslimischen Eroberungen kaum möglich war, beruhte das Wissen, welches Europa im Mittelalter von Indien besaß, auf antiken Quellen. In den muslimischen Gebieten hatte man zwar Kontakt zu Indien und daher auch genauere Kenntnisse über die dortige Kultur, doch diese Berichte wurden in Europa anscheinend nicht oder kaum rezipiert. ${ }^{87}$ Allerdings fanden einige Märchen und Geschichten, z.B. die Sage von Barlaam und Josaphat oder auch Fabeln aus dem Pañcatantra ihren Weg aus Indien nach Europa, wo sie jedoch aufgrund von zwischengeschalteten Übersetzungen aus dem Arabischen nicht als ursprünglich indisch erkannt wurden. ${ }^{88}$ So war das mittelalterliche Indienbild geprägt von den in antiken Texten vermittelten Ansichten, die sich zwischen direkt beobachteten Erfahrungen und phantastischen Vorstellungen erstreckten. Besonders bekannt war das vierbändige Werk „Indica“ von Megasthenes. ${ }^{89}$ Er berichtet detailliert über Klima, Flora und Fauna, aber auch über die Sitten und Gebräuche der Inder, ausgeschmückt mit „märchenhafte(n) Einsprengsel(n)“ “. ${ }^{90}$ Märchenhafte Elemente sind auch im etwas älteren Indienbuch des Ktesias zu finden. Er beschreibt Indien als sagenhaft reiches Wunderland, das von seltsamen Menschen und Tieren, z.B. von Schattenfüßlern, Mundlosen und anderen bewohnt werde. ${ }^{91}$ Diese Geschichten wurden im Mittelalter kaum in Frage gestellt,

\footnotetext{
${ }^{87} \mathrm{Vgl}$. Sedlar, Jean W.: India in the Mind of Germany. Schelling, Schopenhauer and their Times. Washington D.C. 1982, S. VII, 1; Halbfass, Wilhelm: Indien und Europa. Perspektiven ihrer geistigen Begegnung. Basel u. Stuttgart 1981, S. 34, 37

${ }^{88}$ Vgl. Leifer, Walter: Indien und die Deutschen. 500 Jahre Begegnung und Partnerschaft. Tübingen und Basel 1969, S. 16; Halbfass: Indien und Europa, S. 34; Gregor, Helmut: Das Indienbild des Abendlandes (bis zum Ende des 13. Jahrhunderts). Wien 1964, S. 7

${ }^{89} \mathrm{Vgl}$. Leifer: Indien und die Deutschen, S. 13; Sedlar: India in the Mind of Germany, S. VII; Willson: A mythical image, S. 3-7; Halbfass: Indien und Europa, S. 26f., 34

${ }^{90}$ Koch: Deutschlands literarisches Indienbild, S. 177

${ }^{91}$ Vgl. Koch: Deutschlands literarisches Indienbild, S. 177; Halbfass: Indien und Europa, S. $23 f$.
} 
sondern eher noch weiter ausgeschmückt. Indien galt als exotisches Land der Wunder, das einerseits unermesslich reich (vor allem an Gold, Silber, Edelsteinen und Gewürzen) sei, andererseits aber von seltsamen Wesen und Monstern bevölkert werde. Diese wurden jedoch zunächst als Teil der göttlichen Schöpfung angesehen und als solche akzeptiert. Erst später wurden sie mit negativen Attributen versehen. ${ }^{92}$

Sowohl in der Antike als auch im Mittelalter wurde darüber hinaus über Bereiche der indischen Kultur berichtet, die auch später immer wieder eine Rolle spielten: Askese und Religionsübungen der Brahmanen, deren vegetarische Lebensweise sowie der Glauben an die Reinkarnation, Witwenverbrennung und Kastenwesen. Dabei galten die Inder im Mittelalter zwar vor allem als Heiden (also als das Gegenteil zum Eigenen), wurden in einigen Texten aber (wie in der Antike auch) als weise Asketen idealisiert. Ein Ziel der späteren geistlichen Literatur war es zu zeigen, dass wichtige Ideale des Christentums bereits vor Christi Geburt präfiguriert waren. Hier kommt in einigen Fällen bereits der später so wichtige Gedanke der engen Naturverbundenheit der Inder ins Spiel, die ihnen natürliche Tugenden und intuitive Weisheit ermöglicht habe. Man entdeckte jedoch nicht nur christliche Ideale unter den indischen Heiden, sondern es gab auch Gerüchte von der Existenz christlicher, auf den Apostel Thomas zurückgeführter Gemeinden in Indien. Gesteigert wurde diese Vorstellung durch die Legende des Reichs des Priesters Johannes, die im 12. Jahrhundert entstanden ist und schnell bekannt wurde. Einflussreich wurde vor allem ein in der Mitte des Jahrhunderts entstandener Brief, den der Priester Johannes vorgeblich an den Kaiser von Byzanz geschickt haben soll und in dem das indische Reich des Priesters als Land der Wunder und als paradiesischer Gottesstaat geschildert wird. Auch das irdische Paradies wurde auf dem Subkontinent verortet. ${ }^{93}$ Auch das kann als eine Form der Idealisierung gelten.

\footnotetext{
92 Vgl. Leifer: Indien und die Deutschen, S. 13-16; Sedlar: India in the Mind of Germany, S. 1-3; Willson: A mythical image, S. 6-8; Dharampal-Frick, Gita: Indien im Spiegel deutscher Quellen der Frühen Neuzeit (1500-1750). Studien zu einer interkulturellen Konstellation. Tübingen 1994, S. 125128; Halbfass: Indien und Europa, S. 24, 34; Mitter, Partha: Much maligned monsters. A history of European reactions to Indian art. Chicago und London 1992, S. 8f.; Gregor: Das Indienbild des Abendlandes, S. 51f.; Ganeshan: Das Eigene und das Fremde in der Indienbegegnung deutscher Schriftsteller, S. 167

${ }^{93}$ Vgl. Dharampal-Frick: Indien im Spiegel deutscher Quellen, S. 316; Leifer: Indien und die Deutschen, S. 23, 30; Sedlar: India in the Mind of Germany, S. 2; Halbfass: Indien und Europa, S. 35; Kragl, Florian: Die Weisheit des Fremden. Studien zur mittelalterlichen Alexandertradition. Mit einem allgemeinen Teil zur Fremdheitswahrnehmung. Bern u.a. 2005, S. 108, 115f., 152, 203-206, 245f., 251f., 313-316; Mitter: Much maligned monsters, S. 49; Gregor: Das Indienbild des Abendlandes, S. 12f., 39, 84-89; Lederle, Julia: Mission und Ökonomie der Jesuiten in Indien. Intermediäres Handesln am Beispiel der Malabar-Provinz im18. Jahrhundert. Wiesbaden 2009 (Studien zu Außereuropäischen Christentumsgeschichte (Asien, Afrika, Lateinamerika; 14), S. 86, 88
} 
Literarisch schlugen sich die geschilderten Vorstellungen von Indien vor allem in den im Mittelalter sehr beliebten Alexanderromanen nieder. Die Erzählung von Alexanders Zug nach Osten unterlag im Laufe der Zeit immer wieder Veränderungen. Fast immer werden jedoch die der Welt entsagenden indischen Weisen dem nach weltlicher Macht strebenden Alexander kontrastierend entgegengesetzt. Auch der sagenhafte Priester Johannes wird in der mittelalterlichen Literatur thematisiert (z.B. im Parzival). Dabei nimmt sein weit entferntes Reich den Charakter einer kaum fassbaren, idealen Gegenwelt an. Auch in den Herzog-Ernst-Dichtungen wird Indien thematisiert, wobei zwar monströse Fabelwesen als die bösen Anderen gezeichnet werden, es zwischen den europäischen und den indischen Adligen aber fast keine Unterschiede gibt; selbst sprachliche Grenzen scheinen nicht zu existieren. Die Zuordnung zu einem gemeinsamen gesellschaftlichen Stand impliziert für den mittelalterlichen Betrachter auch eine gemeinsame höfische Kultur. ${ }^{94}$

Festzuhalten ist, dass bereits in der Antike Indien mit bestimmten Themen und Attributen verbunden wird, die im Mittelalter weiter fortgeführt und auch später immer wieder von Bedeutung sein werden. Zu diesen Typisierungen gehören die Weisheit und asketische Lebensweise der Brahmanen, die Lokalisierung des Paradieses in Indien, der unermessliche Reichtum sowie das Exotische und Monströse des fremden und weit entfernten Landes, das Ausdruck findet in den Vorstellungen von fabelhaften Völkern, aber auch in fremden Traditionen wie der Witwenverbrennung. Gerade weil es kaum Zugang zu Informationen über Indien gab, konnte der Begriff Indien immer wieder als - wie Walter Leifer es nennt - eine Art „Zaubername“ fungieren, der stellvertretend für Reichtum und Glück stehen konnte. ${ }^{95}$

\subsection{Zwischen Handel und Mission - Indien und Europa in der frühen Neuzeit}

Obwohl Marco Polo im Zuge seiner im 13. Jahrhundert unternommenen Chinareise auch über Indien berichtet hatte, ${ }^{96}$ eröffnete erst Vasco Da Gamas Entdeckung des

\footnotetext{
${ }^{94}$ Vgl. Kragl: Die Weisheit des Fremden, S. 112-114, 117-119, 167, 202f.; vgl. auch Krusche: Literatur und Fremde, S. 20-22

${ }^{95}$ Vgl. Leifer: Indien und die Deutschen, S. 15

${ }^{96}$ Marco Polo bezieht sich zwar nicht auf literarische Muster, wie sie aus den Alexanderromanen bekannt sind, aber auch in seiner Beschreibung Indiens finden sich die oben bereits beschriebenen typischen Themen und Motive wie z.B. die Enthaltsamkeit der Brahmanen, ihre vegetarische Lebensweise, ihre Naturverbundenheit und auch ihre Nacktheit. Neu bei ihm ist dagegen die
} 
Seewegs nach Indien 1498 neue Möglichkeiten des Zugangs zu Indien. Diese wurden von europäischer Seite vor allem aus zwei Beweggründen genutzt: Handel und Mission. Mit der Errichtung eines portugiesischen Stützpunktes in Indien 1505 fanden immer mehr direkte Informationen über Indien (vor allem in der Form von Reise- oder Missionsberichten) ihren Weg nach Europa. ${ }^{97}$ In der Qualität der nun zahlreicher werdenden Berichte über Indien spiegelte sich jedoch wider, dass fehlende Sprachkenntnisse ein tieferes Verständnis der anderen Kultur in der Regel verhinderten (nur der visuell zugängliche Teil der Sitten und Bräuche konnte anfangs geschildert werden) und dass das Interesse an dem neu entdeckten Land häufig auf bestimmte Bereiche beschränkt war. Für Händler und Soldaten waren das vor allem geographische Kenntnisse sowie Informationen über Waren und Handelsmöglichkeiten. Ein weiterer Grund für die häufig nur oberflächlichen Beschreibungen der indischen Kultur in Reiseberichten von Kaufleuten und Seeleuten war deren räumlich und zeitlich sehr begrenzter Aufenthalt in verschieden indischen Häfen. Hinzu kam, dass die Wahrnehmung vieler Reisender durch die vertrauten, seit der Antike überlieferten Stereotypen geprägt wurde, vor deren Hintergrund die neuen Eindrücke interpretiert wurden. Die Beobachtungen wurden zunächst in den vertrauten Diskurs eingeordnet. ${ }^{98}$ Dennoch lässt sich feststellen, dass nun, wo das Wissen über Indien plötzlich ganz konkrete Vorteile bei Handel und Eroberung, später auch bei der Mission brachte, das Interesse an empirisch nachweisbaren Fakten und genauen Beobachtungen gegenüber den alten Stereotypen die Oberhand gewann bzw. diese umdeutete. ${ }^{99}$ Dabei war Indien vor allem als Objekt der (wirtschaftlichen) Eroberung von Interesse. Das, was innerhalb des Diskurses über Indien gewusst und gesagt werden konnte, wurde so schrittweise erweitert.

Im Gegensatz zu den Händlern und Soldaten hatten die Missionare sowohl genügend Zeit als auch das Interesse, sich eingehender mit der indischen Vorstellungswelt zu beschäftigen, denn sie machten die Erfahrung, dass für eine erfolgreiche Mission genauere Kenntnisse der Kultur der zu missionierenden Völker Voraussetzung waren.

\footnotetext{
Erwähnung eines Rinderkultes (vgl. Kragl: Die Weisheit des Fremden, S. 281f.). Seine Berichte fanden allerdings deutlich weniger Beachtung als die herkömmlichen Berichte mit den vertrauten Bildern; jenen wurde sogar weniger Glauben geschenkt als diesen, weshalb sie das bisherige Indienbild kaum verändern konnten (vgl. Koch: Deutschlands literarisches Indienbild, S. 177 und Krusche: Literatur und Fremde, S. 23).

${ }^{97}$ Vgl. Koch: Deutschlands literarisches Indienbild, S. 178

${ }^{98} \mathrm{Vgl}$. Sedlar: India in the Mind of Germany, S. VII, 5; Willson: A mythical image, S. 8; DharampalFrick: Indien im Spiegel deutscher Quellen, S. 61; Mitter: Much maligned monsters, S. 2

${ }^{99}$ Vgl. Koch: Deutschlands literarisches Indienbild, S. 178f.
} 
Besonders im 16. und beginnenden 17. Jahrhundert standen einem tieferen Verständnis jedoch auch hier die fehlenden Sprachkenntnisse im Wege. Da viele Brahmanen ihr Wissen nicht an Außenstehende weitergeben wollten, konnte erst im 17. Jahrhundert der Jesuit Roberto de Nobili gründlichere Kenntnisse im Sanskrit erwerben. Einige Missionare lernten allerdings die jeweiligen Sprachen und Dialekte der Gegend, in der sie sich aufhielten, und konnten so mit den Einwohnern kommunizieren. Dennoch gab es vor 1780 bei den Missionaren nur wenig Interesse an Sprachkenntnissen, die über das für die Kommunikation notwendige Maß hinausgingen. Auch für die Sitten und religiösen Gebräuche der Inder interessierten sie sich zunächst eher weniger. ${ }^{100}$ Obwohl in der Mitte des 16. Jahrhunderts die Aufmerksamkeit für exotische Mythologien erstarkte (vor allem an Ägypten und an den Hieroglyphen, die als heilige, in die tiefsten Geheimnisse der ägyptischen Religion einführende Schrift gedeuteten wurden) und obwohl die zur Verfügung stehenden Informationen zunahmen, gab es bis ins 17. Jahrhundert hinein kaum Versuche einer systematischen Darstellung der indischen Kultur und Religion. Auch die Beschäftigung mit Sanskrit weitete sich erst in der ersten Hälfte des 18. Jahrhunderts weiter aus. Einige der Missionare begannen, Sammlungen indischer Texte zusammenzustellen - oft jedoch weniger aus Sympathie für die Sache, sondern eher aus dem Antrieb heraus, die Brahmanen bei den Missionierungsversuchen mit Argumenten aus ihrer eigenen Vorstellungswelt zu überzeugen. Auch sollten Darstellungen bestimmter Teile der indischen Kultur (wie z.B. die aus Sicht der Europäer schädliche Rolle des Kastenwesens) dazu dienen, die Missions- und Kolonisationsbestrebungen zu rechtfertigen. Aus dieser anfangs zweckgebundenen Beschäftigung mit indischen Texten und Lehren konnte dann allerdings auch echtes Interesse erwachsen. ${ }^{101}$

Nachdem die Dänen in dem Wunsch, die Inder auf weniger gewaltsame Weise zu bekehren, als es z.B. die Portugiesen taten, in Tranquebar eine Mission errichtet hatten, kamen auch einige deutsche Missionare dorthin. Einer der bekanntesten unter ihnen war Bartholomäus Ziegenbalg (1682-1719), ein Schüler Franckes. Er erwarb sehr gründliche Kenntnisse des Tamilischen und beschäftigte sich intensiv mit religiösen

\footnotetext{
${ }^{100}$ Vgl. Jürgens, Hanco: German Indology avant la lettre: The Experiences of the Halle Missionaries in Southern India, 1750-1810. In: Douglas T. McGetchin u.a. (Hg.): Sanskrit and 'Orientalism'. Indology and Comparative Liguistics in Germany, 1750-1958. New Delhi 2004, S. 41-82, hier S. 57f.

${ }^{101}$ Vgl. Sedlar: India in the Mind of Germany, S. 5-9; Willson: A mythical image, S. 23; DharampalFrick: Indien im Spiegel deutscher Quellen, S. 178f.; Halbfass: Indien und Europa, S. 53-59; Mitter: Much maligned monsters, S. 27, 48, 50
} 
und philosophischen Vorstellungen der Tamilen. Seine Berichte blieben allerdings lange unveröffentlicht, denn Francke war der Ansicht, dass die Missionare die Heiden bekehren, nicht aber deren Lehren in Europa verbreiten sollten. Dieses Schicksal von Schriften war kein Einzelfall: Die Aufzeichnungen des ersten europäischen Sanskritkenners, Roberto de Nobili, gerieten in den Archiven der Jesuiten in Vergessenheit, und auch die erste in einer europäischen Sprache verfasste SanskritGrammatik des Jesuiten Heinrich Roth (ca. 1660) wurde nicht publiziert. Erst nachdem sich ab 1780 die Einstellung der Missionare zum Hinduismus zu wandeln begann, wurden auch Ziegenbalgs Schriften als Informationsquelle wieder entdeckt und zumindest ein Inhaltsverzeichnis veröffentlicht. ${ }^{102}$

Doch welches Bild entwarfen die Händler und Missionare der frühen Neuzeit von Indien? Während einige der im 19. Jahrhundert immer wiederkehrenden Motive wie das des asiatischen Despoten noch völlig fehlten, hatten sich, vor allem im 16. Jahrhundert, noch viele Vorstellungen des Mittelalters erhalten, die nun aber z.T. umgedeutet wurden. So galt Indien immer noch als reiches, fruchtbares Land, das oft (nun vor allem metaphorisch) als Paradies bezeichnet wurde. Auch Vorstellungen von phantastischen Monstern und fremdartigen Geschöpfen fanden sich - vor allem auch auf Bildern - bis ins 17. Jahrhundert hinein. Neben den bereits aus der Antike bekannten Erzählungen von phantastischen Völkern waren es nun allerdings vor allem indische Götter, die mit Hilfe der Kategorie des Monströsen beschrieben und dargestellt wurden. ${ }^{103}$ Erst mit der Verbreitung einer empirisch-kausalen Weltsicht bemühte man

\footnotetext{
${ }^{102}$ Vgl. Leifer: Indien und die Deutschen, S. 51f., 54, 63, 72; Sedlar: India in the Mind of Germany, S. 7-10; Dharampal-Frick: Indien im Spiegel deutscher Quellen, S. 89-91, 104, 237; Halbfass: Indien und Europa, S. 63, 69; Mitter: Much maligned monsters, S. 51; Jürgens: German Indology avant la lettre, S. $60 \mathrm{f}$.

${ }^{103}$ Die Tradition, die indischen Götter als Monster oder Dämonen darzustellen, speiste sich aus zwei Quellen: Zum einen projizierten die ersten Reisenden die aus den griechischen Texten vertrauten Schilderungen von (z.T. mehrarmigen) Monstern, die es in Indien geben solle, auf die Götterbilder, die sie in Indien sahen. Zum anderen galten heidnische Götter nach frühester christlicher Lehre als dämonisch und vom Teufel geschaffen. Und so wurden dementsprechend von europäischen Malern Attribute der bekannten heidnischen (also der griechischen und römischen) Götter wie Ziegenbart und Hufe zur Abbildung des Teufels verwendet. Die indischen Götter wurden nun einfach als weitere Variante dieser teuflischen heidnischen Götter interpretiert und z.T. ebenfalls mit den nun als typisch geltenden Teufelsmerkmalen versehen (z.B. wurden sie mit Hörnern und Klauen dargestellt). Die indischen „Monster“ und Fabelwesen wurden seit dem Ende des 16. Jahrhunderts nicht mehr wie zuvor als gleichberechtigter Teil der Schöpfung Gottes und als Beweis für seine Macht angesehen, sondern als Zeichen für Unglück und Unheil. Diese Darstellungsweise indischer Götter galt auch dann noch lange als authentisch, als bereits immer mehr Reisende sich ein eigenes Bild von den Götterfiguren machen konnten; denn die ersten Darstellungen dieser Art beeinflussten die nachfolgenden stark (vgl. Mitter: Much maligned monsters, S. 4-26)
} 
sich um authentischere Abbildungen der indischen Götter, und Monster und Fabelwesen wurden - wenn sie überhaupt noch thematisiert wurden - als Kuriositäten geschildert, die vor allem der Unterhaltung der Leser dienen sollten. ${ }^{104}$ Aus dem bisherigen Diskurs vertraute Wahrnehmungs- und Interpretationsmuster wurden also zunächst übernommen, dann in ihrer Bedeutung herabgesetzt oder auf andere Bereiche übertragen und schließlich durch neue Deutungsmuster ersetzt. Doch auch jenseits von Berichten über monströse oder kuriose Wesen und Bräuche betrachteten die Europäer Indien häufig vor dem Hintergrund bestimmter Schemata und Ansichten, in die sie das Erfahrene einzupassen suchten. So idealisierten z.B. die Humanisten aufgrund ihrer Vorstellung eines goldenen Zeitalters die Brahmanen als im Einklang mit der Natur lebende Weise und lobten deren naive Unschuld. Diese positive Konnotation wurde jedoch später durch eine Deutung ersetzt, die in der Lebensweise der indischen Asketen das Fehlen von Kultur und Zivilisation ausmachte. Vergleichbar mit der mittelalterlichen Entdeckung christlicher Ideale in Indien führte auch im 16. Jahrhundert die Projektion von eigenen Vorstellungen und bekannten Deutungsmustern auf die andere Kultur dazu, dass der Hinduismus als solcher häufig kaum erkannt, sondern - wie Wilhelm Halbfass es ausdrückt - als Form eines unterdrückten Christentums angesehen wurde. So gab es im 16. Jahrhundert Texte, die davon ausgingen, dass auch Indien teil an einer Uroffenbarung gehabt habe, deren Überlieferung aber verdorben sei und an deren Ende - als dessen verzerrtes Bild - die als heidnisch betrachtete Religion stehe. Die Vorstellung einer nichtchristlichen, aber dennoch hochstehenden Kultur war innerhalb des Diskurses über andere Religionen zunächst nicht denkbar. Daher wurde versucht, das Beobachtete mit innerhalb des Diskurses zur Verfügung stehenden Kategorien zu interpretieren. Erst mit zunehmender Kenntnis der indischen Religion wurde man sich ihrer Andersartigkeit bewusst. Nun wurde sie zumeist anhand christlicher Maßstäbe in negativer Weise beurteilt. ${ }^{105}$ Eine Änderung setzte im Zuge der Aufklärung und des sich verbreitenden Toleranzdenkens ein: Die Beobachtung und Beschreibung der indischen Kultur geschah immer stärker unter einem um Neutralität bemühten Blickwinkel, so dass es im 18. Jahrhundert vermehrt positive und wohlwollende Berichte über Indien gab. Viele Autoren machten

\footnotetext{
${ }^{104}$ Als Kuriosität konnte auch die Witwenverbrennung erzählt werden, sie wurde allerdings auch (nach einer vorausgehenden Phase der Idealisierung in Anlehnung an Märtyrer- und Heiligenlegenden) vermehrt kritisiert.

${ }^{105}$ Vgl. Dharampal-Frick: Indien im Spiegel deutscher Quellen, S. 48, 121-133, 136-140, 278, 312f., 320; Halbfass: Indien und Europa, S. 25, 29, 52
} 
freilich in ihren Werken ihre Verwunderung über die für sie unerwarteten positiven Erfahrungen und Einsichten deutlich. ${ }^{106}$

Obwohl in der frühen Neuzeit durch den nun ermöglichten direkten Kontakt mit Indien eine intensivere Beschäftigung mit der indischen Kultur einsetzte, die das antike Wissen durch eigene empirische Beobachtungen ergänzte oder umdeutete und so den Diskurs über Indien mit der Zeit veränderte, lebten viele der bereits aus der Antike stammenden Vorstellungen von Indien fort: die Weisheit und Tugend der Brahmanen, der Reichtum des Landes, die Naturverbundenheit der Inder. Diese im Mittelalter stereotyp gebrauchten Bilder wurden nun zwar durch die erweiterten Kenntnisse mit konkreterem Inhalt gefüllt, blieben aber als Themen, die zu dem Diskurs Indien unbedingt dazugehörten und die daher in einer Abhandlung über Indien zu erwarten waren, erhalten. Obwohl man sich in Teilen auch mit der alten Kultur Indiens beschäftigte, galt die Hauptaufmerksamkeit sowohl der Händler als auch der Missionare in der frühen Neuzeit dem gegenwärtigen, nicht dem vergangenen Indien. Man wandte sich der anderen Kultur vor allem aus praktischen Gründen (Handel oder Mission) zu, weniger aus rein wissenschaftlichem Interesse. Dem entspricht, dass die andere Kultur als mit der eigenen Kultur auf der gleichen zeitlichen (oder zumindest einer ähnlichen) Entwicklungsstufe befindlich wahrgenommen wurde.

7. Kolonialismus und Wissenschaft - Europa und Indien Ende des 18. Jahrhunderts

\subsection{Europäische Handelskompanien in Indien}

Während Portugal im 17. Jahrhundert nach und nach an Einfluss auf dem indischen Subkontinent verlor, konnten die niederländische Vereenigde Oost-Indische

\footnotetext{
${ }^{106}$ So ging es auch Ziegenbalg, der berichtete, dass es ihm selbst zunächst wie den meisten Europäern gegangen sei: Er sei mit der Vorstellung nach Indien gekommen, dass die heidnischen Tamilen ein barbarisches Volk ohne Gelehrsamkeit und Moral seien. Auch habe er sich nicht vorstellen können, dass sie eine regelmäßige Sprache haben. Erst über das durch die Sprachkenntnisse ermöglichte Studium ihrer Texte und durch zahlreiche Gespräche sei er zu der Erkenntnis gelangt, dass sie Gesetze besitzen und in den philosophischen Disziplinen, die in Europa als wichtig erachtet wurden, bewandert seien. Für Ziegenbalg war die Einsicht in die Tugend und Sittlichkeit der Tamilen auch insofern von Bedeutung, als dies ihm Beweis dafür war, dass eine Bekehrung möglich sei. Er äußerte darüber hinaus die Ansicht, dass die Tamilen in Hinsicht von Tugend und Moral sogar einigen Christen als Vorbild dienen könnten und dass ein Grund für die Weigerung der Inder, zum Christentum überzutreten, möglicherweise in der aus indischer Sicht abschreckenden Lebensweise der Europäer in Tranquebar liege (vgl. Leifer: Indien und die Deutschen, S. 55f., Dharampal-Frick: Indien im Spiegel deutscher Quellen, S. 354, 369f.)
} 
Compagnie, vor allem aber die englische East India Company durch den immer stärkeren Verfall des Mogulreiches ihr Einflussgebiet und ihre Besitztümer ausweiten. Die Kämpfe z.B. gegen die Marathen in Zentralindien und die Herrscher des expandierenden südindischen Mysore, Haidar Ali und sein Sohn Tipu Sultan ${ }^{107}$, wurden in England als Verteidigungskriege inszeniert, da gezielte Eroberungen durch den India Act eigentlich untersagt waren und auch nicht direkt im Interesse der Direktoren der Company lagen. ${ }^{108}$ Auch im deutschsprachigen Raum wurden sie mit Interesse verfolgt und fanden in verschiedenen Berichten Erwähnung. Etwa um die Jahrhundertwende änderte sich die eher zurückhaltende Einstellung gegenüber Eroberungskriegen, da sich immer mehr die Auffassung verbreitete, dass erfolgreicher Handel politische Kontrolle bedinge. Als Ergebnis war bis 1818 der größte Teil Indiens in britischer Hand. ${ }^{109}$ Dabei fanden „die entscheidenden Expansionsschübe (...) zwischen 1798 und 1805 und noch einmal 1817 bis 1819 statt $^{\star 110}$, also genau in dem Untersuchungszeitraum dieser Arbeit. Die veränderten Machtverhältnisse wirkten sich auch auf die Einstellung der Europäer zu Indien aus. Während europäische Händler in der frühen Neuzeit auf das Wohlwollen der indischen Herrscher angewiesen waren und daher Indien größtenteils als zwar

\footnotetext{
${ }^{107}$ Nachdem der General Haidar Ali Khan gegen den Raja von Mysore geputscht hatte, dehnte er mit Hilfe eines modernen Heeres die Macht Mysores immer weiter aus. Dabei kam es 1767-69 zu einem ersten Krieg zwischen Haidar Ali und den Briten, wobei die Briten empfindliche Niederlagen erlitten, die ihre Herrschaft bedrohten. Den 1780 begonnenen zweiten Krieg gegen die Briten führte nach dem Tod Haider Alis dessen Sohn Tipu Sultan weiter, bis er als Folge eines Separatfriedens seiner französischen Verbündeten mit den Briten 1784 ebenfalls Frieden schließen musste. 1790 kam es erneut zu einem Krieg zwischen Mysore auf der einen und den Briten, Nizam und Marathen auf der anderen Seite, der nach großen Verlusten Mysores 1792 endete. (vgl. S. Förster: Die mächtigen Diener der East-India-Company, S. 50-52, 98-102, 154; Rothermund, Dietmar: Carl August Schlegel's Military Geography of the Carnatic. In: Ahuja, Ravi u. Christof-Füchsle, Martin (Hgg.): A Great War in South India. German Accounts of the Anglo-Myysore Wars, 1766-1799, S. 79-91, hier S. 80) ${ }^{108}$ Die Ausbeutung Bengalens durch die von Korruption und kostspieligen Kriegen geprägte Herrschaft der East India Company, die nicht nur großes Leid bei den Menschen vor Ort auslöste, sondern deren Folgen der Company auch wirtschaftlich große Verluste zufügten, führten $1773 \mathrm{zu}$ sogenannten „Regulating Act“", der die Gewährung von Staatskrediten an eine stärkere Kontrolle der Company durch die britische Regierung bzw. eines eingesetzten Generalgouverneurs knüpfte. Diese Kontrolle wurde im India Act von 1784 weiter verstärkt. Zudem wurde das Führen von Angriffskriegen ausdrücklich verboten. Das Spannungsfeld zwischen Handelsinteressen und Territorialherrschaft blieb allerdings bestehen und auch Kriege wurden weiterhin geführt (vgl. Förster: Die mächtigen Diener der East-India-Company, S. 60-65). Förster führt das unter anderem auf ,die Mehrheit der politischen und militärischen Angestellten der Company in Indien (zurück), die durchgehend ein expansionistisches Vorgehen propagierte und ihre Linie mit Hilfe der ihr gewogenen Generalgouverneure Lord Wellesley und Lord Hastings gegen den Widerstand der Company-Führung und meist hinter dem Rücken der Regierung in London auch durchsetzen konnte. (Förster: Die mächtigen Diener der East-IndiaCompany, S. 22).

${ }^{109}$ Vgl. Reinhard, Wolfgang: Die Unterwerfung der Welt. Globalgeschichte der europäischen Expansion 1415-2015. München 2016, S. 263-278; Rothermund, Dietmar: Geschichte Indiens. Vom Mittelalter bis zur Gegenwart. München 2002 (Wissen in der Beck’schen Reihe; 2194), S. 49-52, $56 f$.

${ }^{110}$ Förster, Stig: Die mächtigen Diener der East India Company. Ursachen und Hintergründe der britischen Expansionspolitik in Südasien, 1793 - 1819. Stuttgart 1992, S. 11
} 
anders, aber durchaus ebenbürtig oder in einigen Bereichen sogar überlegen ansahen, ${ }^{111}$ führten die wachsende Macht der Europäer sowie das aufkommende Entwicklungsdenken dazu, dass die Europäer sich mehr und mehr als von den anderen Kulturen unterschiedene Elite der menschlichen Entwicklung ansahen.

Der Aufbau einer Territorialherrschaft stellte die East India Company vor neue Herausforderungen: Waren ihre Mitarbeiter bislang in erster Linie auf Handel hin ausgebildet worden, so mussten sie sich nun mit Verwaltungsaufgaben und Rechtsprechung auseinandersetzen. Dazu waren Kenntnisse der indischen Sprachen und Kultur von entscheidender Bedeutung. Da der Generalgouverneur von Bengalen, Hastings, bei der Verwaltung auf bereits bestehenden Strukturen aufbauen und zur Sicherung der Herrschaft die Inder nach indischen Prinzipien regieren wollte (anstatt wie einige forderten - in allen Bereichen englisches Recht einzuführen), standen die englischen Richter und Beamten vor der Herausforderung herauszufinden, wie denn das traditionelle Regierungs- und Rechtswesen in Indien genau aussah. Diese Aufgabe erwies sich als problematisch, da Sanskrit noch im 18. Jahrhundert vielen als Geheimsprache ähnlich der Hieroglyphen galt, deren Geheimnisse die Brahmanen für sich behielten. Die von den Engländern im Besitz der Brahmanen vermuteten traditionellen Gesetzestexte ${ }^{112}$ waren so den Europäern, die zumeist Persisch, die offizielle Sprache der Großmoguln, oder zeitgenössische indische Sprachen und Dialekte lernten, nicht ohne weiteres zugänglich. Man war also zunächst auf Aussagen der Brahmanen angewiesen. Auf diese Art und Weise entstand 1776 der „Code of Gentoo Law", der auf einer persischen Zusammenfassung mündlicher Erläuterungen von Brahmanen basierte, die von Halhed ins Englische übersetzt wurde. Dieses Werk wurde aufgrund seiner Entstehung von vielen als nicht authentisch kritisiert. Auch William Jones, der als Richter in Kalkutta tätig war und daher ein Interesse an der indischen Rechtspraxis hatte, lobte zwar Halheds Bemühungen, war aber dennoch der Ansicht, dass man dringend den indischen Originaltext brauche. Jones, der bereits ein bekannter Orientalist und Kenner des Persischen und Arabischen war, begann 1785 mit

\footnotetext{
${ }^{111}$ Vgl. Flüchter, Antje: ,Religions, Sects, and Heresy“. Religion on the Indian Subcontinent in Early Modern German Texts. In: Krämer, Martin u.a. (Hg.): Labeling Self and Other in Historical Contacts between Religious groups. Leipzig 2010 (Comparativ; 20,4), S. 58-74, hier S. 61

112 Die Engländer gingen davon aus, dass es in Indien mindestens zwei alte kodifizierte Rechtssysteme geben müsse: ein muslimisches und eines der Hindus. Diese wollte man nun ausfindig machen und wenn nötig die (verdorbene) alte Form wieder rekonstruieren (vgl. Cohn, Bernhard S.: Colonialism and its forms of knowledge. The British India. Princeton 1996, S. 27-29).
} 
Hilfe eines indischen Grammatiklehrers, Sanskrit zu lernen (die früheren Versuche einiger Missionare, Sanskrit zu lernen, waren den Engländern anscheinend nicht bekannt). Aus dem zunächst rein praktischen Interesse an der Sprache wurde bald echte Faszination. ${ }^{113}$

\subsection{Paradigmenwechsel - die Entdeckung des klassischen Indiens}

Das auf der Suche nach indischen Rechtstexten begonnene Studium des Sanskrit führte nicht nur bei Jones zu einem von direktem praktischen Nutzen unabhängigen wissenschaftlichen Interesse, das seinen Ausdruck in der 1784 gegründeten „Asiatick Society of Bengal" fand. Der Austausch der Forscher innerhalb der Society und ab 1788 auch in der nun erscheinenden Zeitschrift „Asiatick Researches“ ermöglichte erstmals ein systematisches Studium der indischen Kultur und Literatur. Die Aufmerksamkeit der Forscher richtete sich nun nicht mehr nur auf das gegenwärtige Indien sowie auf klimatische, geologische oder auch historische und politische Gegebenheiten, sondern man wurde sich der Bedeutung der indischen literarischen und philosophischen Tradition bewusst. Der Indiendiskurs wurde so um ein weites Spektrum erweitert. Damit veränderten sich sowohl das, was über Indien gewusst und gesagt werden konnte, als auch die Interpretationsmuster. In kurzer Zeit erschien eine Reihe von Übersetzungen aus indischen Originaltexten, die bald auch in ganz Europa Bekanntheit erlangten: 1785 übersetzte Wilkins die Bhagavadgītā und 1787 den Hitopadeśa; von Jones erschienen 1789 die literarischen Werke Śakuntalā und Gītagovinda sowie 1796 Manus Gesetzbuch (Manusmṛti). ${ }^{114}$ Indien begann sich in der Wahrnehmung der Europäer von einem Land des Reichtums und der Wunder zu einer alten Hochkultur zu wandeln bzw. die Motive des Reichtums und des Wunderbaren wurden auf die Schriftkultur Indiens ausgedehnt und um weitere Motive erweitert.

Diese Erweiterung des Indiendiskurses und die damit verbundene Neuausrichtung des Interesses war bemerkenswert und erstreckte sich bald auch auf Europa. So schrieb Michaelis noch 1779, man möge doch bitte keine poetischen oder philosophischen Texte übersetzen, sondern historische und geographische Abhandlungen. Nur sechs

\footnotetext{
${ }^{113}$ Vgl. Sedlar: India in the mind of Germany, S. 14f.; Halbfass: Indien und Europa, S. 78; Cohn: Colonialism, S. 20f, 25-29, 60-66; Salus, Peter H: Preface. In: Sir William Jones. A reader. Edited with Introduction and Notes by Satya S. Pachori. Foreword by Rosanne Rocher and a Preface by Peter H. Salus. Delhi 1993, S. 3-10, S. 3f.; zu Jones, Wilkins, Colebrooke vgl. Windisch: Geschichte der Sanskrit-Philologie und indischen Altertumskunde, S. 22-36

${ }^{114}$ Vgl. Halbfass: Indien und Europa, S. 77f.
} 
Jahre später hatte er seine Meinung diesbezüglich grundlegend geändert und fragte sogar danach, ob nicht ein Brahmane nach Europa kommen und die Veden übersetzen könne. Diese Entdeckung klassischer indischer Texte galt einigen als zweite (orientalische) Renaissance. Zwar waren auch zuvor schon indische Texte nach Europa gelangt, aber da aufgrund mangelnder Sanskritkenntnisse niemand diese Texte lesen konnte, gerieten sie schnell in Vergessenheit, so dass sogar die Existenz der Veden noch Ende des 18. Jahrhunderts angezweifelt werden konnte, obwohl bereits 1731 ein relativ vollständiges Exemplar Paris erreicht hatte. Das, was man zuvor über die nicht direkt beobachtbaren Aspekte der indischen Kultur wusste, stammte entweder aus persischen Übersetzungen indischer Texte oder aus mündlicher Unterweisung durch Brahmanen. ${ }^{115}$ Da man nicht in der Lage war, die vorgefundenen Texte einer kritischen Untersuchung $\mathrm{zu}$ unterziehen, wurden immer wieder auch defekte oder neuere Schriften für sehr alt und bedeutend gehalten. ${ }^{116}$ Indem sich die Sanskritkenntnisse der Europäer erweiterten, war man immer weniger auf nicht überprüfbare Sekundärübersetzungen aus dem Persischen angewiesen. Dennoch ist es gerade eine 1801/1802 aus dem Persischen angefertigte lateinische Übersetzung der Upanișaden, der Oupnek'hat von Anquetil-Duperron, die trotz ihres oft kritisierten anachronistischen Charakters als Sekundärübersetzung für das europäische Interesse von großer Bedeutung war (z.B. durch die positive Aufnahme durch Arthur Schopenhauer $\left.{ }^{117}\right) .{ }^{118}$

\footnotetext{
${ }^{115}$ Vgl. Sedlar: India in the Mind of Germany, S. 9, 13f.; Cohn: Colonialism, S. 25; Jürgens: German Indology, S. 66

${ }^{116}$ Bekanntestes Beispiel dafür ist der 1778 bekannt gewordene l'Ezour-Vedam, den besonders Voltaire als Beweis dafür lobte, dass in Indien die ursprüngliche, auf Rationalität gegründete Religion zu Hause sei. Obwohl es bereits zuvor kritische Stimmen gab, konnte erst 1822 eindeutig gezeigt werden, dass es sich beim l'Ezour-Vedam keineswegs um einen alten hinduistischen Text, sondern vielmehr um eine - wohl durch die Jesuiten veranlasste - Zusammenstellung von Texten handelte. Diese sollten dazu dienen, den Polytheismus mit Hilfe von älteren Lehren der Veden zu diskreditieren, um so einen Zugang für die Lehren des Christentums zu öffnen. Trotz dieser frühen Zweifel wurde er bis ins beginnende 19. Jahrhundert hinein immer wieder zitiert (vgl. Sedlar: India in the mind of Germany, S. 16; Windisch: Geschichte der Sanskrit-Philologie und indischen Altertumskunde, S. 8-10; Reinhard: Die Unterwerfung der Welt, S. 661; Schwab: The Oriental Renaissance, S. 153-155).

${ }^{117}$ Inwieweit Schopenhauers Philosophie von indischem Denken beeinflusst ist, ist eine viel diskutierte Frage und vor allem deswegen interessant, weil es hier nicht nur um die Beurteilung indischen Denkens geht, sondern um einen konkreten Einfluss. Da diese Frage aber eine detaillierte Auseinandersetzung mit Schopenhauers Philosophie erfordert, ist sie für die Zielsetzung dieser Arbeit zu weitgehend und wird daher nicht näher untersucht. Einen guten ersten Überblick über die Forschung zu diesem Thema findet sich in Bhatawadekar, Sai: Claims and disclaimers. Schopenhauer and the cross-cultural comperative enterprise. In: Cho, Joanne Miyang u.a. (Hg.): Transcultural Encounters between Germany and India. Kindred spirits in the nineteenth and twentieth centuries. London u. New York 2014, S. 37-51.

${ }^{118} \mathrm{Vgl}$. Sedlar: India in the mind of Germany, S. 15f. ; Halbfass: Indien und Europa, S. 80; Glasenapp, Helmut von: Das Indienbild deutscher Denker. Stuttgart 1960, S. 25
} 
Ein Motiv der Aufklärung für die Beschäftigung mit der klassischen indischen Kultur war der deistische Versuch zu beweisen, dass alle Religionen aus einer universellen Offenbarung der Vernunft herrührten. Diese natürliche Religion sei im Laufe der Zeit durch Aberglauben entstellt worden. Während man die Spuren dieser ursprünglichen Religion zunächst in China zu finden hoffte, richtete sich die Aufmerksamkeit bald auch auf Indien, wobei besonders auf den Kontrast zwischen den als degeneriert angesehenen zeitgenössischen Formen des Hinduismus und seinen vermuteten monotheistischen Ursprüngen hingewiesen wurde. Wie noch zu zeigen sein wird, war diese Entgegensetzung von den reinen Ursprüngen der indischen Religion und den entstellten zeitgenössischen Formen auch später noch ein sehr beliebtes Thema. Hier zeigt sich deutlich, wie durch den Einfluss eines neuen Diskurses innerhalb Europas, der mit Indien zunächst nichts direkt zu tun hatte, auch der Indiendiskurs erweitert und in eine neue Richtung gelenkt werden konnte.

Mit dem Diskurs über die Ursprünge der Religion hängt ein anderer eng zusammen, nämlich die Frage nach der Priorität der biblischen Offenbarung. Sowohl Voltaire als auch Langlès wandten sich gegen die Vorstellung, dass alle guten Eigenschaften und Bräuche Asiens nur Reste der biblischen Offenbarung seien. Voltaire setzte die Behauptung, dass vielmehr die christliche auf der ursprünglicheren indischen Religion beruhe, dagegen. Diese Frage, wer wen beeinflusst hat, wurde auch auf dem Gebiet des weltlichen Wissens gestellt: Ist das indische oder das griechische Wissen älter? In diesen Diskursen der Aufklärung galt das Interesse allerdings nicht Indien als solchem, sondern es war nur ein Beispiel, anhand dessen verschiedene Themen (über die natürliche Religion, über die Ursprünge der Kultur, über die Verdunklung der Vernunft) untersucht und veranschaulicht werden konnten. Dementsprechend basierte der Zugang dieser Autoren zur indischen Kultur in weitaus geringerem Maße auf detaillierten Kenntnissen, sondern war oberflächlicher und spekulativer. ${ }^{119}$ Sie gaben für den weiteren Verlauf des Indiendiskurses aber wichtige Impulse.

Ein weiterer Anstoß, sich mit Indien zu beschäftigen, kam von Seiten des im 18. Jahrhunderts aufkommenden Konzepts der Universal- oder Menschheitsgeschichte. Wissenschaftler wie Schlözer oder Meiners ging es dabei nicht darum,

\footnotetext{
${ }^{119}$ Vgl. Halbfass: Indien und Europa, S. 70-74; Mitter: Much maligned monsters, S. 115-120; zu Voltaire vgl. z.B. Cowan, Robert: The Indo-German Identification. Rochester 2010 (Studies in German Literature Linguistics and Culture; 86), S. 37
} 
Einzelgeschichten summarisch zusammenzuführen, sondern ihre Absicht war es, durch einen Vergleich der verschiedenen Völker und Kulturen eine Geschichte der Menschheit zu schreiben, die zur Erklärung des gegenwärtigen Seins der Menschheit beitragen könne. ${ }^{120}$ In diesem Konzept war Indien zwar ebenfalls nur eine Kultur unter vielen, aber dennoch lieferte auch dieser Diskurs Deutungsmuster, die sich auf das Indienbild um 1800 auswirkten. ${ }^{121}$

Die Mitglieder der Asiatic Society beschäftigten sich z.T. mit ähnlichen Themen wie die Aufklärer und Deisten, gingen z.B. wie diese davon aus, dass die indische Kultur altertümlich und ursprünglich sei. Jones und die anderen interessierten sich dabei besonders für die Frage, ob die europäischen Kulturen gemeinsame Wurzeln mit der indischen Kultur hätten und ob dieser gemeinsame Ursprung in Indien selbst oder woanders zu suchen sei. Große Bedeutung hatte diese Frage vor allem in zwei Gebieten: der Mythologie und der Sprachwissenschaft. Während die schon früher beobachteten Ähnlichkeiten zwischen Sanskrit und den alten europäischen Sprachen zur Theorie des Sprachwandels und einer gemeinsamen Sprachfamilie ausgearbeitet wurden, suchte man die Mythologien verschiedener Völker nach Gemeinsamkeiten und Ähnlichkeiten $\mathrm{ab}$ und führte auch sie auf gemeinsame Ursprünge zurück. Dabei wurden immer wieder indische Götter mit griechischen (vor allem Dionysos) und ägyptischen (Osiris) auf synkretistische Weise gleichgesetzt. Ähnliche Vergleiche finden sich auch im Bereich der Philosophie (z.B. ist Duperron der Ansicht, in den indischen philosophischen Texten spinozistische Ansätze entdeckt zu haben). Die These von den gemeinsamen Ursprüngen der indischen und der europäischen Kulturen ist ein weiteres typisches Thema, das auch im Folgenden immer wiederkehrt. Dabei war das unvorstellbar hohe Alter, das man den indischen kulturellen Zeugnissen zuschrieb, von großer Bedeutung. Denn wie Andrea Polaschegg feststellt, ist es um 1800 gerade die zeitliche (nicht räumliche) Distanz, die kulturelle Fremdheit erschafft und die zur Klärung des Eigenen wichtigen Fragen aufwirft. Interessant ist, dass diese zeitliche Distanz im Falle Indiens

\footnotetext{
${ }^{120}$ Vgl. Fuchs, Konrad u. Raab, Heribert: Wörterbuch der Geschichte. 13. Auflage. München 2002, S. 860; Lotter, Friedrich: Christoph Meiners und die Lehre von der unterschiedlichen Wertigkeit der Menschenrassen. In: Geschichtswissenschaft in Göttingen. Eine Vorlesungsreihe. Herausgegeben von Hartmut Boockmann und Hermann Wellenreuther. Göttingen1987, S. 30-75, hier S. 46

${ }^{121}$ Diese Entwicklung entspricht der von Koselleck beobachteten Entstehung von Kollektivsingularen, die nicht mehr nur Erfahrungen reflektieren, sondern diese auf Gegenwart und Zukunft beziehen und auf einen Wandel zielen. Aus den Einzelgeschichten verschiedener Völker wird die Weltgeschichte bzw. Menschheitsgeschichte, aus den Menschen wird die Menschheit. Auch Indien wird damit aus dem Bereich des lediglich Beobachteten herausgehoben und in einen weiteren Rahmen gestellt (vgl. Koselleck: Begriffsgeschichte, S. 66f.)
} 
nicht nur gegenüber den alten kulturellen Zeugnissen empfunden wurde, sondern auch hinsichtlich des zeitgenössischen Indiens. Diesem wurde häufig jeglicher Fortschritt abgesprochen, so dass dort die alten Traditionen noch immer lebendig zu sein schienen (wenn auch vielleicht in etwas degenerierter Form). Indien wurde für die europäischen Beobachter eine Art lebendes Museum, wie Cohn es nennt. Daher versprach man sich von den oben genannten Vergleichen der Mythologien unter anderem auch Aufschlüsse über die nicht mehr direkt erlebbaren antiken Kulturen. ${ }^{122}$ Damit einher geht ein wachsendes Gefühl der europäischen Überlegenheit und Verschiedenheit von Indien. ${ }^{123}$

\subsection{Die Ausgangslage im deutschsprachigen Raum}

Anders als z.B. England oder Frankreich hatten die deutschsprachigen Länder keinen intensiven direkten Kontakt zu Indien und die Autoren daher nur erschwerten Zugriff auf indische Quellen. Zunächst waren sie auf Reiseberichte und (vor allem englische) Übersetzungen indischer Texte angewiesen. Dennoch konnte zu dem Zeitpunkt, als Forsters Übersetzung der Śakuntalā die Begeisterung für die indische Kultur auch im deutschsprachigen Gebiet bei einem größeren Leserkreis weckte und wenig später eine intensive wissenschaftliche Beschäftigung mit der indischen Kultur begann, bereits auf viele Informationen $\mathrm{zu}$ dem Thema zurückgegriffen werden. Hinsichtlich der Informationsmöglichkeiten und Qualität des Quellenmaterials sollte man unterscheiden zwischen der Zeit vor den ersten englischen Übersetzungen von Sanskrittexten bzw. dem Erscheinen der „Asiatick Researches“ und der Zeit danach. ${ }^{124}$ Das würde eine Zäsur Ende der 1780er Jahre bedeuten und sich somit in etwa mit dem Beginn der in der vorliegenden Arbeit zu behandelnden Zeit decken (der Beginn der breiteren Rezeption indischer Texte seit dem Erscheinen der „Sakontala“ 1791).

Ein Blick in Zedlers 1735 erschienenes „Grosses vollständiges Universal-Lexicon Aller Wissenschaften und Künste (...)“ ermöglicht einen Einblick in das Indienbild, das vor diesem Einschnitt verbreitet war. Es zeigt neben den typischen Themen und Bildern, die beim Thema Indien erwartet wurden, sehr schön die Verbindung von alten, wenig genauen Vorstellungen mit neueren Berichten und Erkenntnissen sowie Einflüsse

\footnotetext{
${ }^{122}$ Vgl. Cohn: Colonialism, S. 78f.; Halbfass: Indien und Europa, S. 78f., 83; Mitter: Much maligned monsters, S. 83; Polaschegg: Athen am Nil, S. 43, 52

${ }^{123}$ Vgl. Tzoref-Ashkenazi: German Soldiers in India, S. 137

${ }^{124}$ Vgl. Ghosh, Pranabendra Nath: Johann Gottfried Herder's Image of India. In: Heinz Mode und H.-J. Peuke (Hg.): Indien in der deutschen literarischen Tradition. Halle 1979, S. 4-17, hier S. 10; Jolles: India in England and Germany during the 18th century, S. 197
} 
christlicher Vorstellungen auf die Interpretation des Gesehenen/Gehörten. So wird auch hier der indische Reichtum betont. Die Inder seien stark, aber sehr faul und die meisten gingen nackt. Sie seien dem Krieg ergeben und darin auch geschickt. Von der Geschichte Indiens wird berichtet, dass es darüber nur einige Fabeln gebe. Präziser werden die Angaben erst bei der Beschreibung der europäischen Aktivitäten in Indien. Hinsichtlich der Religion findet sich hier bereits die Unterscheidung zwischen dem Volk, das viele Götter (und Teufel) anbete, und den Verständigen, die nur ein höchstes Wesen verehrten. Dem alten Verständnis, es würden Teufel angebetet, werden Beschreibungen von drei Hauptgöttern gegenübergestellt. In diese neueren Kenntnisse mischen sich aber auch hier wieder aus dem Christentum übernommene Ansichten wie die von Himmel und Hölle, auch wenn sie durch die Erklärung, die Inder glaubten, dass die Seelen erst nach dem letzten Gericht dorthin gelangten, problemlos mit dem Konzept der Seelenwanderung vereint werden. ${ }^{125}$

Was aber sind die Quellen, auf die sich Autoren vor den späten 1780er Jahren berufen konnten? Für Herder waren das neben antiken Quellen vor allem Werke von Indienreisenden wie die von Bernier, Macintosh, Dow, Holwell, Olearius, Rogerius, Baldeus, Niebuhr und Sonnerat. ${ }^{126}$ Auf Rogerius, Baldeus, Niebuhr und Sonnerat berief sich auch Goethe, der darüber hinaus auch Dapper las. ${ }^{127}$ Diese Texte waren sehr bekannt und werden daher auch anderen Autoren als Informationsquelle gedient haben.

Rogerius’ Werk „De Open Deure tot het Verborgen Heydendom“ von 1651 war einer der umfangreichsten Berichte der Zeit, der sich vor allem dadurch auszeichnete, dass er als einer der ersten nicht nur über Flora, Fauna und geographische Begebenheiten berichtete, sondern erste detaillierte Einblicke in Sitten und Bräuche der Hindus gewährte. Denn Rogerius hatte das Glück gehabt, einen Brahmanen zu treffen, der bereit gewesen war, ihn zu unterrichten. So finden sich in seinem Text Berichte über das Kastenwesen, über das Leben der Brahmanen und ihren Glauben, über wichtige Feste, über Witwenverbrennungen sowie einige Götterfabeln. Er berichtete auch kurz über das Konzept der Seelenwanderung und fügte eine erste Übersetzung eines

\footnotetext{
${ }^{125}$ Vgl. Zedler, Johann Heinrich: Grosses vollständiges Universal-Lexicon (...). Halle u. Leipzig 1735, Sp. 635-642

${ }^{126}$ Vgl. Jolles: India in England and Germany, S. 197; Michaels: Wissenschaft als Einheit, S. 327

${ }^{127}$ Vgl. Kade-Luthra, Veena: Einleitung. In: Kade-Luthra, Veena (Hg.): Sehnsucht nach Indien. Ein Lesebuch von Goethe bis Grass. München 1991, S. 9-37, hier S. 10f.
} 
indischen Textes, die Sprüche Bhartṛharis, ein, die der Brahmane für ihn angefertigt hatte. $^{128}$

Ein anderes viel beachtetes Werk ist Sonnerats „Voyages aux Indes“ aus dem Jahr 1782. Es bot eine der detailliertesten Darstellungen der indischen Religion und Mythologie. Sonnerat sah in Indien die Wiege der Menschheit. Und wie viele andere spätere Autoren vertrat er die Auffassung, dass die indische Kultur zwar eine alte hohe Zivilisation sei, die aber nicht nur kaum Fortschritte gemacht habe, sondern vielmehr degeneriert sei. Gründe dafür sah er in dem indischen Despotismus und dem Klima. ${ }^{129}$ Auch die Frömmigkeit des einfachen Volkes sah Sonnerat als verkommen und dem Aberglauben verfallen an, denn hinter den vielen Götterfiguren stehe ursprünglich der Glaube an ein einziges höchstes Wesen und hinter den Traditionen des Volkes eine reine Sittenlehre. ${ }^{130}$ Sonnerat lieferte mit seinen Nacherzählungen indischer Götterfabeln auch die Anregungen für Goethes indische Balladen. ${ }^{131}$ Georg Forster bemängelt in seiner 1783 erschienen Rezension von Sonnerats Text, dass dieser zwar von den weisen Indern spricht und deren reine Philosophie lobe, dann aber vor allem den Aberglauben des einfachen Volkes schildere. Außerdem nehme Sonnerat dem Leser die Möglichkeit, selbst zu urteilen, indem er es für ihn tue. Interessant ist an der Rezension Forsters auch, dass er immer wieder betont, dass Sonnerat in vielen Punkten ähnlich wie andere Reiseberichte schreibe und dabei wenig Neues schildere, sondern altbekannte Dinge berichte. Hier wird einerseits deutlich, wie viel Wissen über Indien auch vor dem Bekanntwerden der Originaltexte bereits verfügbar war (Sonnerat beschreibt ja viele Themen), aber andererseits auch, wie welche Einschränkungen dieses Wissen dennoch aufwies, welche Verbreitung bestimmte Themen und Ansichten erlangten und wie sehr das Verlangen nach neuem Wissen von Bedeutung war. ${ }^{132}$ Sonnerats Text soll in den folgenden Untersuchungen immer mal wieder als Vergleichstext für die Zeit kurz vor Gründung der Asiatic Society herangezogen werden.

\footnotetext{
${ }^{128}$ Vgl. Windisch: Geschichte der Sanskrit-Philologie, S. 2f.; Jolles: India in England an Germany, S. 197

${ }^{129}$ Vgl. Mitter: Much maligned monsters, S. $115 \mathrm{f}$.

${ }^{130}$ Vgl. Windisch: Geschichte der Sanskrit-Philologie, S. 17f.

${ }^{131}$ Vgl. Däbritz, Walther: Anregungen aus der indischen Mythologie in Goethes Dichtung. In: Goethe N.F. 20 (1958), S. 99-117, hier S. 109

${ }^{132}$ Vgl. Forster, Georg. Rezensionen. Bearbeitet von Horst Fiedler. Berlin 1977 (Georg Forsters

Werke. Sämtliche Schriften, Tagebücher, Briefe; 11), S. 49, 51, 53, 57
} 
Weniger für konkretes Wissen über Indien, aber umso mehr für die Vorstellungen und Konnotationen, die mit diesem Land verbunden waren, stellte Herder eine wichtige Quelle dar. Denn seine Sicht hat das spätere Indienbild vor allem der Romantiker nachhaltig geprägt. Herder hatte sich schon früh im Rahmen seiner Suche nach Volkspoesie $^{133}$ auch mit Indien beschäftigt. Herders Indienbild ist von der Forschung lange nur als idealisiertes und unkritisches Phantasiegebilde beschrieben worden. ${ }^{134}$ Diese Beschreibung wird Herder allerdings nicht in allen Aspekten gerecht. Natürlich war auch er zunächst auf antike Berichte und Informationen aus Reiseberichten angewiesen, was sich in der Qualität seiner Beschreibungen widerspiegelt. Da er aber die neuesten Informationen der Indienforschung rezipierte, die „Asiatick Researches“ sowie auch Übersetzungen indischer Texte las und auch zu deren Verbreitung und Bekanntmachung beitrug, muss man seine frühen Texte zu Indien von den späteren unterschieden. Dabei gelangte er im Rahmen des Möglichen zu einem relativ tiefen Verständnis indischen Denkens, auch wenn er dabei nicht frei von Idealisierungen blieb. ${ }^{135}$

Herder differenzierte erstmals in seinen ab 1784 erschienenen „Ideen zur Philosophie der Geschichte der Menschheit“" zwischen den einzelnen orientalischen Kulturen und berichtete in einem eigenen Abschnitt auch über Indien. Darin beschrieb er Indien (vor allem Kaschmir) als Wiege der Menschheit und Paradies der Welt, das fruchtbar und klimatisch für die Entwicklung der Menschen sehr positiv sei. Auch viele kulturelle Errungenschaften stammten aus Indien. Die Inder sind bei Herder also, auch wenn sie die Kindheit der Menschheit darstellten, keineswegs mit dem Konzept des Edlen Wilden zu verwechseln. Herder beschrieb die Inder als schön, sanftmütig, unschuldig,

\footnotetext{
${ }^{133} \mathrm{Zu}$ Herders Konzept der Volkspoesie und seiner Hoffnung, deren Sinnlichkeit in die moderne, verstandesgeprägte Welt zu integrieren und so zur Bildung des Menschen beizutragen vgl. z.B. Stemmrich-Köhler, Barbara: Zur Funktion der orientalischen Poesie bei Goethe, Herder, Hegel. Exotische Klassik und ästhetische Systematik in den "Noten und Abhandlungen zu besserem Verständnis des West-östlichen Divans" Goethes, in Frühschriften Herders und in Hegels Vorlesungen zur Ästhetik. Frankfurt a.M. u.a. 1992

${ }^{134}$ Vgl. z.B. Hoffmann: Der indische und der deutsche Geist, S. 5f.; Hoffmann schreibt, dass Herder Indien nicht nach den bekannten Reiseberichten schildere, sondern aufgrund ,seiner Vorstellung vom goldenen Zeitalter" (S. 5); vgl. auch Michaels: Wissenschaft als Einheit von Religion, Philosophie und Poesie, S. 328f.; Michaels begründet Herders idealisierendes Indienbild mit dessen tiefer Sehnsucht nach einem unschuldigen, unverdorbenen Land (S. 328).

${ }^{135}$ Vgl. Ghosh: Johann Gottfried Herder's Image of India, S. 5-7, 9; Frank, Alexa: Sanftes Gefühl und stille Tiefe der Seele. Herders Indien. Würzburg 2009, S. 14, 132
} 
ruhig, duldsam, tolerant, leidenschaftslos und gebildet. Durch ihre Friedfertigkeit seien sie allerdings Opfer des Despotismus geworden. Auch sei ihr reiner Glauben mit Aberglauben durchsetzt, da der Sinn der eigentlich symbolisch gemeinten Bilder und Riten verloren gegangen sei. Die Lehre der Seelenwanderung habe viel Gutes, aber auch viel Schlechtes gebracht, da sie wahres Mitgefühl verhindere. Herder sprach sich in diesem Text auch deutlich gegen die Vorstellung verschiedener Menschenrassen aus und bezog Stellung gegen die Sklaverei. ${ }^{136}$ Er entwarf Indien demnach bereits in seinen frühen Werken nicht ausschließlich als Repräsentant eines goldenen Zeitalters, sondern betrachtete einige Aspekte durchaus kritisch. ${ }^{137}$

Indien war Ende des 18. Jahrhunderts also mit verschiedenen Konnotationen verbunden und wurde in unterschiedlichen Diskurszusammenhängen thematisiert. So spielten bereits aus dem Mittelalter stammende Stereotype wie die naive Unschuld und enge Naturverbundenheit der Inder, die Weisheit der Brahmanen sowie der unermessliche Reichtum des Landes immer noch eine Rolle. Man kann sogar sagen, dass einige dieser alten Motive durch die Hinwendung zur alten indischen Kultur Ende des 18. Jahrhunderts (z.B. bei Herder und später den Autoren der Romantik) wieder an Anziehungskraft gewannen, nachdem zuvor häufig die hohe europäische Zivilisation von einer vermeintlich niedriger stehenden indischen Kultur abgegrenzt wurde. Man kann allerdings nicht sagen, dass die eine Deutung die andere abgelöst hätte. Denn auch während der Aufklärung gab es Stimmen, die die hohe Moral und Tugend der Inder lobend hervorhoben. Und auch nach 1800 gab es viele Autoren, die aufgrund ihres Fortschrittsdenkens von einer steten Entwicklung der Menschheit ausgingen und Indien dabei einen deutlich niedrigeren Platz zuwiesen als der eigenen Kultur. Auch in Fragen der Religion standen sich verschiedene Positionen gegenüber. Auf der einen Seite wurde die Mission der Heiden gefordert (vor allem auch in pietistischen Kreisen), auf der anderen Seite gab es deistische Bestrebungen zu beweisen, dass alle Religionen durch Verfall und Aberglauben entstellte Reste einer universellen Offenbarung der Vernunft seien und daher das Christentum nicht über den anderen Religionen stehe.

\footnotetext{
${ }^{136}$ Vgl. Herder: Ideen zur Philosophie der Geschichte der Menschheit, S. 160f., 183, 199, 246, 254, 257, 259, 293f.

${ }^{137}$ Vgl. auch Maillard, Christine: Beobachter, Weggenosse, Pionier: Herder und die Anfänge der europäischen Indologie. In: Cultura tedesca: revista semestrale 24 (2003), S. 49-62, hier S. 52; Maillard hält fest, dass Indien für Herder im Gegensatz zur Romantik kein „Ort bedingungsloser Identifikation“ und seine Rezeption nicht ,indomanisch“ sei (S. 52).
} 
Mit dem Beginn der wissenschaftlichen Erforschung Indiens durch die Asiatic Society in den 1780er Jahren sowie im Zuge der eifrig diskutierten Frage nach dem Ursprung der Menschheit, der menschlichen Kultur, der Sprache usw. kam es in der Wahrnehmung Indiens dennoch zu einer Art Wendepunkt: In der frühen Neuzeit galt das Hauptinteresse dem gegenwärtigen Indien, das als zeitgenössisches Land empfunden wurde, das zwar anders, aber nicht grundlegend fremd war. Einige Aspekte der indischen Kultur konnten zwar als exotisch oder kurios gelten, die meisten wurden jedoch einfach als Varianten des Eigenen interpretiert. So war das Kastenwesen eben eine andere Form der Ständeordnung. Diese Wahrnehmung Indiens änderte sich deutlich, als die Vorstellung von der stetigen zeitlichen Entwicklung der Menschheit immer mehr Gewicht erhielt - sei es als ersehnter Fortschritt zu mehr Zivilisation, sei es als kritisierte Abkehr von einer ursprünglichen Natürlichkeit. Indem diese geschichtsphilosophische Deutung die zuvor dominierenden religiösen und moralphilosophischen Deutungsmuster ablöste, richtete sich die Aufmerksamkeit verstärkt auf das hohe Alter der indischen Kultur, von der man sich nun Aufschlüsse über die Anfänge der Menschheit versprach. Indien wurde so mehr und mehr von einem exotischen Nachbarn zu einer Art lebendem Museum. Die ausgeprägte Wahrnehmung historischer Distanz führte dazu, dass Indien immer mehr als grundlegend fremd empfunden wurde: entweder in negativer Hinsicht als rückständig oder aber - positiv konnotiert - als Vertreter einer naiven Kindlichkeit. ${ }^{138} \mathrm{Zu}$ Beginn dieser Umbruchsituation beginnt sich das Interesse an Indien im deutschsprachigen Raum durch Forsters Übersetzung der Śakuntalā auf einen größeren Kreis auszuweiten. Und genau diese Indienbilder dieses Umbruchs und des Beginns der wissenschaftlichen Beschäftigung mit Indien sollen im Folgenden untersucht werden.

\footnotetext{
${ }^{138}$ Vgl. Dharampal-Frick: Indien im Spiegel deutscher Quellen, S. 180f.; Polaschegg: Der andere Orientalismus, S. 134f., 195
} 


\section{Indien in Sachtexten - Themen, Thesen, Bilder}

\section{Begegnungen mit Indien - die Quellen}

Nachdem Ende des 18. Jahrhunderts das Interesse an asiatischen Kulturen und insbesondere auch an Indien spürbar gestiegen ist, begegnen Leser in Europa bei ihrer Lektüre immer häufiger Themen, Texten und Bildern aus dem indischen Kontext. Das gilt auch für Menschen, die aufgrund fehlenden Interesses nicht gezielt danach suchen. Denn außer in wissenschaftlichen Abhandlungen zu Indien (z.B. in speziellen Fachartikeln) finden indische Themen und bildliche Darstellungen auch Eingang in allgemeinere Journale wie z.B. Cottas Morgenblatt für die gebildeten Stände oder auch in das Journal für Luxus und Moden. Sogar in Volkskalendern wie dem Hinkenden Boten kann man Indien begegnen. Darüber hinaus ist Indien immer wieder Handlungsort von Dramen oder Opern und spielt auch in anderen literarischen Werken eine Rolle. Welches Bild oder welche Bilder aber werden den Lesern vermittelt? Was sind typische Assoziationen, die um 1800 mit dem Begriff Indien verbunden sind? Welche Themen werden angesprochen? Diesen Fragen möchte ich in den nächsten beiden Hauptteilen dieser Arbeit nachgehen. Dabei möchte ich mich im ersten Hauptteil ausschließlich mit Sachtexten befassen und die literarischen Texte in einem zweiten Hauptteil gesondert untersuchen, da sie sich hinsichtlich der Funktionen, die das Thema Indien in ihnen wahrnimmt, von den Sachtexten unterscheiden. Da es um 1800 kaum direkte Kontakte zwischen Indien und dem deutschsprachigen Raum gibt, sind die Vorstellungen, die man sich dort von Indien macht, sehr stark von den Texten vor allem englischer oder französischer Autoren geprägt. Daher habe ich in meine Untersuchung diese Texte ebenfalls mit einbezogen, sofern sie in deutscher Übersetzung vorliegen und daher auch von einer größeren deutschsprachigen Leserschaft rezipiert werden können.

Die Texte, die ich hier unter der allgemeinen Bezeichnung Sachtexte zusammengefasst habe, gehören selbstverständlich ebenfalls sehr unterschiedlichen Kategorien von Texten an. Dazu gehören die in einem wissenschaftlichen Kontext erschienenen Artikel oder Monographien, die immer noch sehr beliebten Reiseberichte sowie auf Informationen aus Reiseberichten beruhende Darstellungen, Berichte einiger Missionare, Lexikonartikel und Artikel in Journalen mit breitgefächertem Inhalt. Diese Unterschiede sollte man bei der Interpretation der Textausschnitte im Bewusstsein haben, da sie allein schon aufgrund der unterschiedlichen Lesergruppen, die 
angesprochen werden, anders mit dem Thema Indien umgehen und andere Ziele in ihrer Darstellung verfolgen. Dennoch ähneln sich die Texte in ausreichendem Maße, so dass sie durchaus miteinander verglichen werden können. Denn so unterschiedlich die Textsorten sein mögen, gelten ihre Informationen doch - anders als die der literarischen Texte - als sachlich-wissenschaftlich und damit eher als objektiv, auch wenn bereits vielen zeitgenössischen Lesern klar ist, dass die Autoren mit ihrer Darstellung eigene Ziele verfolgen, vor deren Hintergrund die Aussagen der Texte kritisch hinterfragt werden sollten. ${ }^{139}$

Besonders bei Berichten aus dem Kontext der Mission stößt man bei Lesern und Rezensenten immer wieder auf dieses kritische Bewusstsein für eine mögliche Voreingenommenheit und Parteilichkeit der berichtenden Missionare, die die indische Kultur vor dem Hintergrund ihres Glaubens und ihrer Missionsbestrebungen betrachten. Andererseits ist es für die Missionare - anders als für andere Indienreisende - für ihre Arbeit von großer Bedeutung, sich „nicht auf oberflächliche Beobachtungen wirtschaftlicher oder ethnographischer Art“ zu beschränken, sondern „sich gründlich mit fremden Kulturen auseinander(zu)setzen“140. Die Missionsberichte unterscheiden sich voneinander vor allem hinsichtlich zweier Kriterien: der Kenntnisse des Berichtenden (vor allem inwieweit er indische Sprachen beherrscht und somit nicht nur auf seine Beobachtungen angewiesen ist, sondern direkten Zugang zu Informationen der Einheimischen hat) sowie seiner Einstellung gegenüber der indischen Kultur bzw. der Einstellung der ihn entsendenden Einrichtung. Je besser seine Sprachkenntnisse sind und je offener er für die andere Kultur ist, desto mehr Informationen finden sich auch über Bereiche der indischen Kultur, die nicht allein durch eigene sinnliche Beobachtung erfahren werden können, sondern der Lektüre indischer Texte oder der Einweisung durch indische Gelehrte bedürfen. So beschreiben z.B. Ziegenbalg und Paulinus a Sancto Bartholomaeo ausführlich einzelne indische Gottesvorstellungen und

\footnotetext{
${ }^{139}$ Auf eine Untersuchung bildlicher Darstellungen Indiens werde ich im Rahmen dieser Arbeit verzichten, da das Quellenmaterial dann zu heterogen geworden wäre. Wie ergiebig eine solche Untersuchung indes sein kann, zeigt z.B. Chakkakakal in ihrer Analyse bildlicher Darstellungen vor dem Hintergrund der Ethnoraphie um 1800 (vgl. Chakkalakal, Silvy: Deutsch-indische Figurationen. Der bildhafte Stil der Ethnographie um 1800. In: Füssel, Marian u.a. (Hg.): Historische Anthropologie. Kultur, Gesellschaft, Alltag. 22 (2014). Heft 2, S. 250-277).

${ }^{140}$ Reinhard, Wolfgang: Bornierter Blick? Gegenseitige Wahrnehmung von Europäern und Asiaten im 17. und 18. Jahrhundert. In: Liebau, Heike u.a. (Hg.): Mission und Forschung. Translokale Wissensproduktion zwischen Indien und Europa im 18. und 19. Jahrhundert. Halle 2010, S. 3-20, hier S. 3
} 
auch Werke der indischen Literatur, wohingegen in den Halleschen Missionsberichten vor allem die Erlebnisse der Missionare im Mittelpunkt stehen. Einige der ausführlicheren Missionsberichte ähneln den Reiseberichten, natürlich erweitert um die religiöse Komponente, und werden vermutlich auch ähnlich rezipiert. Für die vorliegende Arbeit wurden folgende Missionsberichte ausführlicher untersucht: „Briefe über den Zustand des Christentums in Indien“141 von Jean Dubois, der in etwa 30 Jahre lang in Indien als katholischer Missionar tätig war, ${ }^{142}$ „Des Fra Paolino da San Bartolomeo Reise nach Ostindien“ ${ }^{143}$ des Karmelitermönchs Paulinus a Sancto Bartholomaeo, der neben seinem Bericht aus Indien auch Abhandlungen über die

\footnotetext{
${ }^{141}$ Dubois's Briefe über den Zustand des Christenthums in Indien, in welchen die Bekehrung der Hindus als unausführbar dargestellt wird. Aus dem Englischen übersetzt mit Anmerkungen und erläuternden Nachträgen von D. A. G. Hoffmann nebst einer Vorrede von D. Joh. Friedr. Röhr. Neustadt a.d. Orla 1824

142 Jean-Antoine Dubois kam 1792 über die Missions Étrangères als katholischer Missionar nach Südindien, wo er bis 1823 blieb. Er setzte sich mit den Sitten, Bräuchen und der Religion der dort lebenden Menschen auseinander und lernte die dortige Sprache Tamil. Er gehörte also wie viele Missionare nicht zu den Sanskrit-Gelehrten und Entdeckern der klassischen indischen Kultur, wie sie sich vor allem in Bengalen in der Asiatic Society einen Namen gemacht haben. Mit der Tamilliteratur war er dagegen vertraut. Vor allem aber versuchte er, das Vertrauen der Bewohner zu erlangen, wobei er viele Einblicke in ihre Kultur erhielt. Die Ergebnisse dieser Beobachtungen und Studien fasste er in seiner zum Teil vom Jesuitenpater Coeurdoux übernommenen Abhandlung „Description of the character, manners, and customs of the people of India“ zusammen, die von der East India Company als so wichtig erachtet wurde, dass sie 1807 von ihr gekauft und einige Jahre später veröffentlicht wurde. In den hier untersuchten „Briefen“ setzte sich Dubois mit der Möglichkeit bzw. Unmöglichkeit einer Bekehrung von Indern höherer Kasten auseinander (vgl. Müller, Friedrich Max: Vorwort. In: Dubois, Jean Antoine: Leben und Riten der Inder. Kastenwesen und Hinduglaube in Südindien um 1800. Auf Grundlage der französischen und englischen Ausgaben von 1825 und 1906 übersetzt und herausgegeben von Thomas Kohl. Mit den Anmerkungen, Korrekturen und der Biographie von Henry k: Beauchamp sowie dem Vorwort von Friedrich Max Müller aus der dritten englischen Auflage von 1906. Mit Karten, Abbildungen, einem Register und einem Verzeichnis der wichtigsten Sanskritbegriffe sowie einem Essay „Dubois, Coeurdoux und die Jesuiten in Südindien“. Bielefeld 2002, S. 13f.; Beachamp, Henry K: Vorwort des Herausgebers. In: Dubois, Jean Antoine: Leben und Riten der Inder. Kastenwesen und Hinduglaube in Südindien um 1800. Auf Grundlage der französischen und englischen Ausgaben von 1825 und 1906 übersetzt und herausgegeben von Thomas Kohl. Mit den Anmerkungen, Korrekturen und der Biographie von Henry k: Beauchamp sowie dem Vorwort von Friedrich Max Müller aus der dritten englischen Auflage von 1906. Mit Karten, Abbildungen, einem Register und einem Verzeichnis der wichtigsten Sanskritbegriffe sowie einem Essay „Dubois, Coeurdoux und die Jesuiten in Südindien“. Bielefeld 2002, S. 15-36, hier S. 16, 18f., 25f.; Kohl, Thomas: Dubois, Coeurdoux und die Jesuiten in Südindien. In: Dubois, Jean Antoine: Leben und Riten der Inder. Kastenwesen und Hinduglaube in Südindien um 1800. Auf Grundlage der französischen und englischen Ausgaben von 1825 und 1906 übersetzt und herausgegeben von Thomas Kohl. Mit den Anmerkungen, Korrekturen und der Biographie von Henry k: Beauchamp sowie dem Vorwort von Friedrich Max Müller aus der dritten englischen Auflage von 1906. Mit Karten, Abbildungen, einem Register und einem Verzeichnis der wichtigsten Sanskritbegriffe sowie einem Essay „Dubois, Coeurdoux und die Jesuiten in Südindien“. Bielefeld 2002, S. 577-588, hier S. 577f.). ${ }^{143}$ Des Fra Paolino da San Bartolomeo Reise nach Ostindien. Aus dem Französischen. Mit Anmerkungen von Johann Reinhold Forster. Berlin 1798 (Magazin von merkwürdigen neuen Reisebeschreibungen, aus fremden Sprachen übersetzt und mit erläuternden Anmerkungen begleitet; 15)
} 
indische Götterlehre und die indische Sprache verfasst hat, ${ }^{144}$ „M. Perrin’s Reise durch Hindostan“ ${ }^{\text {"145 }}$ sowie die „Neuere Geschichte der Evangelischen Missions-Anstalten zur Bekehrung der Heiden in Ostindien“146 über die frühen 1790er Jahre.

Reiseberichte waren auch vor 1800 schon sehr verbreitet. In der Aufklärung waren sie sogar eine der beliebtesten Gattungen, die sowohl viel gelesen als auch produziert wurde. ${ }^{147}$ Auch als die Belletristik sie nach 1800 in ihrer Popularität langsam ablöste, waren sie dennoch immer noch sehr beliebt und einflussreich. Sie liegen für Indien meistens in Form von Übersetzungen vor oder werden gleich im Original rezipiert, denn deutschsprachige Reisende sind in Indien zu dieser Zeit selten. ${ }^{148}$ Grundlage der in ihnen enthaltenen Informationen sind neben angelesenem Wissen vor allem eigene Beobachtungen sowie Mitteilungen von Indern oder anderen Indienreisenden. Sie umfassen zumeist Angaben zu Geographie, Klima, Botanik und Zoologie Indiens, zu den politischen Geschehnissen der letzten Jahre (vor allem zu kriegerischen Auseinandersetzungen zwischen Indern und europäischen Händlern bzw. Kolonialisten), sowie zu (beobachteten) Festen, Riten und gesellschaftlichen Strukturen

${ }^{144}$ Paulinus a Sancto Bartholomaeo lebte von 1748 bis 1806 und hieß mit bürgerlichem Namen Philipp Weszdin. Er stammte aus einer austrokroatischen Bauernfamilie und wuchs in Niederösterreich auf. Auf eigenen Wunsch kam er 1776 als Missionar nach Südindien, wo er bis 1789 tätig war und sich intensiv nicht nur mit Sankskrit, sondern auch mit dem südindischen Malabarischen beschäftigte. Seine Kenntnisse des Malabarischen waren so gut, dass er auch Texte in dieser Landessprache schrieb. Auch nach seiner Rückkehr nach Europa widmete er sich weiter der Indologie. Er wurde zunächst Professor für orientalische Sprachen am Collegio San Pancrazio, später dann Studienpräfekt am Collegio Urbano der Propagandakongregation und veröffentlichte zahlreiche indologische Abhandlungen (vgl. Vogel, Claus: Die Anfänge des westlichen Studiums der altindischen Lexikographie.Opladen/Wiesbaden 1999, S. 7-11)

${ }^{145}$ M. Perrin's Reise durch Hindostan und Schilderung der Sitten, Einwohner, Natur-Producte und Gebräuche dieses Landes nach einem sechzehnjährigen Aufenthalte daselbst. Nach dem Französischen bearbeitet von Theodor Hell. Wien 1811; Jean-Charles Perrin kam 1777 als Missionar nach Indien, wo er acht Jahre blieb. Er lernte die Tamulische Sprache und und reiste viel durch das Land (vgl. Göttingische gelehrte Anzeigen unter der Aufsicht der königl. Gesellschaft der Wissenschaften. Der erste Band auf das Jahr 1808. 37. Stück. Göttingen 1808, S. 361-365)

${ }^{146}$ Schulze, Johann Ludwig (Hg.): Neuere Geschichte der Evangelischen Missions-Anstalten zu Bekehrung der Heiden in Ostindien. Vierter Band. Halle 1796; Knapp, Georg Christian (Hg.): Neuere Geschichte der Evangelischen Missions-Anstalten zu Bekehrung der Heiden in Ostindien. 5. Band. Halle 1804

${ }^{147}$ Vgl. D’Aprile, Iwan-Michelangelo u. Siebers, Winfried: Das 18. Jahrhundert. Zeitalter der Aufklärung. Berlin 2008, S. 117

${ }^{148}$ In der frühen Neuzeit gab es einige deutschsprachige Reisende, die als Angestellte der niederländischen Vereenigde Oost-Indische Compagnie (zumeist als Soldaten) nach Indien fuhren. Einige von ihnen verfassten nach ihrer Rückkehr Reiseberichte, die meisten in relativ günstigen und damit für eine größere Bevölkerungsgruppe erschwinglichen Drucken erschienen, aber selten eine zweite Auflage erfuhren. Sie dienten vor allem dazu, die Neugierde auf Neuigkeiten aus der weiten Welt zu befriedigen (vgl. Flüchter, Antje: ,Aus den fürnembsten indianischen Reisebeschreibungen zusammengezogen'. Knowledge about India in early modern Germany. In: Huigen, Seigfried u.a. (Hg.): The Dutch Trading Companies as Knowledge Networks. Leiden u. Boston 2010, S. 337-356, hier S. 338-341, 344) 
Indiens. Sachliche Darstellungen, die oft auf angelesenem Wissen beruhen, wechseln sich mit anschaulichen Berichten eigener Erlebnisse ab. Das Hauptaugenmerk ist überwiegend auf das zeitgenössische Indien sowie die letzten Jahrzehnte der Kolonialgeschichte gerichtet. Die klassische Kultur des alten Indiens, die in einigen Kreisen im deutschsprachigen Raum viel Bewunderung erfuhr, wird eher am Rande erwähnt oder anhand von Darstellungen in bekannten europäischen Werken beschrieben. Etwas anders ist es bei Reisenden, die sich intensiver mit einer der indischen Sprachen beschäftigt haben und ihr Interesse explizit auch auf diese Themen richten. Wie auch bei den Missionsberichten hängt die inhaltliche Ausrichtung und vor allem auch die Deutung und Bewertung des Beobachteten sehr von den persönlichen Einstellungen und Interessen des Autors ab. Sie liefern daher einerseits Zeugnisse aus erster Hand, sind andererseits aber deutlich subjektiv gefärbt. Was Ludwig Ammann für Reiseberichte über den Orient allgemein feststellt, gilt auch für die Berichte über Indien: Diese stellen aufgrund der subjektiven Färbung eine uneinheitliche Textgruppe dar und können sich vor allem hinsichtlich ihrer Bewertung Indiens stark voneinander unterscheiden. Manchmal wechseln sich Zustimmung und Ablehnung einzelner Aspekte der indischen Kultur sogar innerhalb ein und desselben Berichts ab. Ammann beobachtet in ihnen deutlich mehr positive Urteile über den Orient als in entsprechenden Lexikonartikeln, auch wenn die ablehnenden Wertungen insgesamt überwiegen. ${ }^{149}$ Ein ähnliches Nebeneinander von Ablehnung und Anerkennung lässt sich auch für Reiseberichte über Indien beobachten. Ob auch hier die negativen Stellungnahmen überwiegen, wird allerdings noch $\mathrm{zu}$ untersuchen sein. Die Reiseberichte sollen sowohl der Information als auch der Unterhaltung der Leser dienen und entfalten ihren Reiz vor allem auch in der Möglichkeit der Selbstbetrachtung im Spiegel des Fremden - sowohl in der Form von Selbstbestätigung als auch Selbstkritik. ${ }^{150}$ Auch wenn es von den Reisenden nicht immer explizit thematisiert wird, liefern sie doch immer wieder auch Hinweise auf ihre eigene Kultur. ${ }^{151}$ Durch bereits vor Beginn der Reise angelesenes Wissen sowie durch die im Zuge der Literarisierung der Gattung entstehenden Erzählschemata war die Wahrnehmung des

\footnotetext{
${ }^{149}$ Vgl. Ammann: Östliche Spiegel, S. 51f.

${ }^{150}$ Vgl. Ammann: Östliche Spiegel, S. 68

${ }^{151}$ Vgl. Kuczynski, Ingrid: Verunsicherung und Selbstbehauptung - der Umgang mit dem Fremden in der englischen Reiseliteratur des 18. Jahrhunderts. In: Fuchs, Anne u. Harden, Theo (Hg.): Reisen im Diskurs. Modelle der literarischen Fremderfahrung von den Pilgerberichten bis zur Postmoderne.

Tagungsakten des internationalen Symposiums zur Reiseliteratur University College Dublin vom 10.12. März 1994. Heidelberg1995, S.55-70, hier S. 55
} 
für die Reisenden eigentlich noch Unbekannten bereits durch Vorannahmen und (stereotype) Bilder gelenkt. Die Auswahl des zu Berichtenden orientiert sich sowohl an den Konventionen der Gattung als auch an den Erwartungen der Leser, unterhalten und unterrichtet zu werden. ${ }^{152}$ Obwohl den Reiseberichten eine so große Aufmerksamkeit zuteil wird und sie auch in großer Zahl vorliegen, so dass ihr Einfluss auf das Indienbild des späten 18. und frühen 19. Jahrhunderts nicht zu unterschätzen ist, wurden sie von der Forschung für die späte Neuzeit nicht mehr in dem Maße als Quelle genutzt, wie das noch für die Erforschung der frühen Neuzeit der Fall war. Stattdessen lag der Fokus oftmals auf der Rekonstruktion eines Herder und der Romantik zugeschriebenen mystischen Indienbildes. Die Reiseberichte stellen aber auch nach Erscheinen der Asiatic Researches noch eine wichtige Informationsquelle für deutsche Autoren dar. Aufgrund der großen Fülle an unterschiedlichen Reiseberichten war es notwendig, für diese Arbeit eine Auswahl zu treffen. Näher untersucht wurden: Das Sammelwerk „Neueste Beiträge zur Kunde von Indien“, herausgegeben von T.F. Ehrmann ${ }^{153}$ (darin besonders die „Briefe eines italienischen Reisenden“ ${ }^{\prime 154}$ in Band 3) ${ }^{155}$, der Bericht des im Dienste der East India Company stehenden George Forster „Reise aus Bengalen

\footnotetext{
${ }^{152}$ Vgl. auch D’Aprile u. Siebers: Das 18. Jahrhundert, S. 118

153 Theophil Friedrich Ehrmann (1762-1811) war Jurist und ein bekannter Herausgeber von Reiseberichten (vgl. Ehrmann, Theophil Friedrich. In: Allgemeine Deutsche Biographie 5 (1877), S. 721 [Online-Version]; URL: https://www.deutsche-biographie.de/pnd115368337.html\#adbcontent) ${ }^{154}$ Hinter dem unbekannten italienischen Reisenden verbirgt sich der italienische Arzt, Soldat, Kaufmann und Schriftsteller Lazzaro Papi (1763-1834). Papi, der in Pisa Chirurgie studiert hatte, reiste 1792 als Schiffsarzt nach Kalkutta. Nachdem er in Travancore den mahārājan Rāma Varmma von einer schweren Krankheit geheilt hatte, bat Papi ihn um die Möglichkeit einer militärischen Laufbahn bei seinen Truppen. Die folgenden Jahre diente er als Offizier des mit den Engländern verbündeten Rāma Varmma und kämpfte in dieser Funktion an Seiten der Engländer auch gegen Tipu Sultan. Nach dem Krieg wurde er nach Malabar versetzt. Aus gesundheitlichen Gründen kehrte er 1801/02 nach Italien zurück. Aufgrund der oftmals lückenhaften Informationen über Indien entschloss sich Papi, Briefe aus Indien, die eigentlich für einen Freund bestimmt waren, 1802 zunächst anonym zu veröffentlichen. Die Texte Papis zeichnen sich durch dessen Kenntnisse verschiedener Regionen Indiens aus, die auf seinen langjährigen eigenen Erfahrungen beruhen. Seine Beurteilungen der indischen Kultur sind geprägt von Ideen der Spätaufklärung, die sich häufig gegen die in seinen Augen irrationale Ausrichtung indischer Traditionen und Religiosität richten und häufig antiklerikale Züge aufweisen. Er weist aber immer wieder auch auf positive Aspekte hin und versucht Erklärungen für zunächst kaum verständliche Beobachtungen zu finden. Obwohl Papi aufgrund seiner Tätigkeit engen Kontakt zu den englischen Truppen hat, äußert er durchaus scharfe Kritik an dem Vorgehen der East India Company und das von den Engländern errichtete politische System. Zudem richtet er sein Augenmerk immer wieder auch auf die wirtschaftlichen und sozialen Probleme der Inder (vgl. Panattoni, Emanuela: Il Malabar nelle „Lettere sulle Indie Orientali“ di Lazzaro Papi. In: Indologica Taurinensia 2 (1974), S. 199-233, hier S. 199-204; Festa, Aldo: Giudizi e considerazioni sulla Compagnia delle Indie dalle „Lettere“ di Lazzaro Papi. In: Rivista delle Colonie 16 (1942), 6, S. 548-552, hier S. 548-550

${ }^{155}$ Ehrmann, Theophil Friedrich (Hg.): Neueste Beiträge zur Kunde von Indien. Aus dem Englischen und Italienischen. Weimar 1806
} 
nach England“'156, die Beschreibungen des Malers Hodges ${ }^{157}$ sowie die Ausführungen des englischen Lords Georg Viscount Valentia. ${ }^{158}$

Eine Untergruppe der Reiseberichte stellen Briefe und Berichte von Soldaten dar, die vor allem im Auftrag der East India Company in Indien stationiert waren. Darunter waren auch viele Soldaten aus Hannover, die seit 1782/83 die englischen Truppen in Indien unterstützten. Sie stellen neben einigen Missionsberichten eine der wenigen deutschen Quellen dar, die auf eigener Anschauung beruhen. Diese Gruppe von Texten unterscheidet sich durch einige Merkmale von anderen Formen von Reiseberichten. Vor allem die Briefe, die in Zeitungen und Zeitschriften erscheinen, sind deutlich weniger von Konventionen und Diskursen der Reiseberichte geprägt und orientieren sich stärker an den eigenen Erlebnissen im zeitgenössischen Indien. Typische Elemente wie z.B. die Witwenverbrennung, die - wie wir noch sehen werden - in Reiseberichten über Indien nicht fehlen dürfen, spielen in den Berichten der Soldaten kaum eine Rolle bzw. beruhen, sofern sie doch aufgegriffen werden, deutlich stärker auf eigenen

\footnotetext{
${ }^{156}$ Forster, Georg: Reise aus Bengalen nach England, durch die nördlichen Theile von Hindostan, durch Kaschemir, Afganistan, Persien und Rußland. Aus dem Englischen übersetzt, und mit Anmerkungen begleitet von C. Meiners. Erster Theil. Zürich 1796; George Forster (1752-1791) war ein Beamter der East India Company. Von 1782-1784 reiste er zusammen mit lokalen Kaufleuten über Land von Kalkutta u.a. über Kaschmir, Persien und Russland nach Europa. Dabei durchquerte er Gegenden, die in Europa noch weitgehend unbekannt waren. 1787 kehrte er nach Indien zurück, um dort im Auftrag von Lord Cornwallis Bündnisse mit anderen indischen Fürsten gegen Tipu Sultan zu schmieden. Er starb 1791 am Hof des Raja Raghoji Bhonsla in Nagpur (vgl. Lima Martins, Luciana de: George Forster. In: Oxford Dictionary of National Biography. [Online-Version]; URL: https://www.oxforddnb.com/view/10.1093/ref:odnb/9780198614128.001.0001/odnb-9780198614128e-9907?rskey=sMOoQ7\&result=1)

${ }^{157}$ Hodges, Wilhelm: Reisen durch Ostindien während der Jahre 1780, 1781, 1782 und 1783. Aus dem Englischen. Hamburg 1793 (Neuere Geschichte der See- und Land-Reisen; 6); William Hodges (17441797) war ein englischer Landschaftsmaler. Von 1772-1775 begleitete er James Cook auf dessen Weltreise, um das Gesehene in seinen Bildern zu dokumentieren. Nachdem seine Frau, die er nach seiner Rückkehr nach England geheiratet hatte, im Kindbett verstorben war, suchte Hodges sein Glück in Indien. 1780 erreichte er Madras. Finanziell unterstützt von der East India Company reiste er drei Jahren durch Nordindien, wobei er auch Abstecher ins Landesinnere unternahm und viele Zeichnungen anfertigte (vgl. Stuebe, Isabel Combs: The Life and Works of William Hodges. New York u. London 1979, S. 2f., 15-19, 43f.).

${ }^{158}$ Georg Viscount Valentia's und Heinrich Salt's Reisen nach Indien, Ceylon, dem rothen Meere, Abyssinien und Ägypten, in den Jahren 1802, 1803, 1804, 1805 u. 1806. Aus dem Englischen im Auszuge übersetzt und mit einigen Anmerkungen begleitet von Friedrich Ruhs. Weimar 1811; Henry Salt (1780-1827) wollte zunächst Porträtmaler werden, doch er merkte bald, dass sein Talent keinen größeren Erfolg in diesem Bereich versprach. Als Sekretär und Zeichner begleitete er Georg Viscount Valentia 1802 auf dessen Reise nach Indien, Ceylon und ans Rote Meer. 1805 wurde er von ihm nach Abessinien geschickt. Über Ägypten reiste er 1806 nach England zurück. 1809 kehrte er im Auftrag der britischen Regierung nach Abessinien zurück. 1815 wurde er Generalkonsul von Ägypten (vgl. Manley, Deborah u. Rée, Peta: Henry Salt. In: Oxford Dictionary of National Biography. [OnlineVersion]; URL: https://www.oxforddnb.com/view/10.1093/ref:odnb/9780198614128.001.0001/odnb9780198614128-e-24563?rskey=TiiJeA\&result=8).
} 
Erfahrungen und Beobachtungen als auf überlieferten Merkmalen. Hinzu kommt, dass die Berichte und Briefe, die zwar zum Teil erst später und damit innerhalb des hier gewählten Untersuchungszeitraums veröffentlicht wurden, von der Wandlung der Indienwahrnehmung um 1800 noch relativ unberührt geblieben sind. Die Soldaten begegnen Indien weniger als einer alten Hochkultur als einem zeitgenössischen Gegenüber. ${ }^{159}$ Für diese Arbeit wurden „Briefe über Ost-Indien“ ${ }^{160}$ von Best und „Briefe auf einer Reise von Stade nach Madras in Ostindien und aus Ostindien geschrieben nach Stade“161 von Scharnhorst untersucht.

Die subjektive Färbung, die typisch für die Berichte der Reisenden sind, sollte bei Lexikonartikeln im Prinzip eine weniger große Rolle spielen (auch wenn das im konkreten Fall durchaus anders sein kann). Lexikonartikel sind insofern von Interesse für diese Arbeit, als davon auszugehen ist, dass sie den Wissensstand der Zeit abbilden, der als einigermaßen sicher gilt und über den ein möglichst großer Konsens erzielt wurde. ${ }^{162}$ Zumindest werden Informationen aus Lexika vom Leser normalerweise als relativ gesichert wahrgenommen. Außerdem sollten sie angesichts der geforderten Kürze nur diejenigen Aspekte über Indien enthalten, die als besonders wichtig und berichtenswert gelten, und erlauben somit bereits eine erste Gewichtung dieser Aspekte hinsichtlich der Frage, was als Grundwissen über Indien und seine Kultur gilt. Für diese Arbeit wurden die Ausgaben von 1809 und 1815 der späteren Brockhaus-Enzyklopädie herangezogen. Schlägt man unter dem Begriff Ostindien nach, so erfährt man in der Ausgabe von 1809 zunächst, dass Indien ein merkwürdiges Land sei, dessen Kenntnisse durchaus notwendig seien, das aber so verwirrend sei, dass vieles immer noch im Dunkeln liege. Anschließend werden die geographische Lage und politische Einteilung Indiens sowie seine Bodenschätze ausführlich beschrieben. Auch die Besitzungen der Europäer in Indien werden detailliert aufgelistet. Es folgt ein Abschnitt zu der Geschichte Indiens seit Alexander, wobei es fast ausschließlich um die verschiedenen Eroberungen Indiens durch andere Völker geht. Anschließend wird die Regierungsverfassung Indiens beschrieben. Die verschiedenen Einwohner und

\footnotetext{
${ }^{159}$ Vgl. Tzoref-Ashkenazi, Chen: German Soldiers in Colonial India. London 2014, S. 1, 33, 96, 99, $111,122,135,137$,

${ }^{160}$ Best, C. C.: Briefe über Ost-Indien, das Vorgebirge der guten Hoffnung und die Insel St. Helene. Herausgegeben von Karl Gottlob Küttner. Leipzig 1807

${ }^{161}$ Briefe auf einer Reise von Stade nach Madras in Ostindien und aus Ostindien geschrieben nach Stade von einem churhannöverschen Capitain der Infanterie. Bremen 1789

162 Vgl. Ammann: Östliche Spiegel, S. 24
} 
Sprachen Indiens werden nur sehr kurz aufgezählt. Die Religion der Hindus wird wieder ausführlicher beschrieben, wobei immer wieder das Dunkle und das Verworrene dieser Religion betont werden. Anschließend wird das Kastensystem erläutert. Der Artikel schließt mit einem Blick auf Wissenschaften und Literatur Indiens (Śakuntalā) und einigen Anmerkungen zum Charakter der Hindus. ${ }^{163}$ Bei dem Artikel „Hindustan“ in der Ausgabe von 1815 fehlt die Betonung der noch großen Unwissenheit über Indien. Er beginnt sofort mit Angaben zur Geographie, Geologie, dem Klima sowie Flora und Fauna. Nach einer kurzen Aufzählung der neueren Eroberer wird ausführlich das Gesellschaftssystem mit den verschiedenen Kasten dargestellt. Anschließend werden die indische Religion und der Charakter der Inder sowie einige indische Sitten beschrieben (die Vielweiberei sowie die Witwenverbrennung). Nach einem kurzen Hinweis auf indische Wissenschaften geht der Autor ausführlich auf indische Handelsgüter sowie auf die Geschichte der Eroberungen des Landes ein. Abschließend beschreibt er einige bedeutende indische Städte, wobei sich die Bedeutung des Ortes daran bemisst, inwieweit er für Handel oder Militärpolitik der Europäer wichtig ist. ${ }^{164}$ Die Themen, die den Autoren der Lexikonartikel wichtig erschienen, ähneln sich in beiden Ausgaben sehr. ${ }^{165}$ Auffallend ist, dass - abgesehen von der Beschreibung der indischen Religion - das Hauptaugenmerk auf Themenbereiche gerichtet ist, die für die europäische Indienpolitik von aktuellem Interesse waren oder sind. Um die indische Kultur geht es nur am Rande. Auch die Geschichte Indiens spielt nur als Geschichte der Eroberungen eine Rolle.

Ähnlich sieht es bei der hier stellvertretend untersuchten historisch-politischen Zeitschrift „Minerva“ aus. Die meisten der im Untersuchungszeitraum erschienenen Artikel beschäftigen sich mit den konkreten Erfahrungen der Europäer in Indien (Kriege, Handel, zeitgenössische indische Geschichte und Politik, Mission). Selbst ein Artikel, deren Titel auch andere Themen vermuten lässt wie „Beyträge zur Kenntniß

\footnotetext{
${ }^{163} \mathrm{Vgl}$. Conversations-Lexikon oder kurzgefasstes Handwörterbuch für die in der gesellschaftlichen Unterhaltung aus den Wissenschaften und Künsten vorkommenden Gegenstände. Band 3. Amsterdam 1809, S. 326-337

${ }^{164}$ Conversations-Lexicon oder encyclopädisches Handwörterbuch für gebildete Stände. Band 4. Dritte Auflage. Leipzig und Altenburg 1815, S. 715-720

${ }^{165}$ Auch Ammann stellt für verschiedene Lexikoneinträge zum Orient allgemein fest, dass sie ein sehr ähnliches Bild vermitteln. Dabei spielten die Topoi der orientalischen Leidenschaftlichkeit, Despotie und Indolenz eine wichtige Rolle. Zur Leidenschaftlichkeit gehörten auch Grausamkeit und Wollust sowie niedrige Affektkontrolle, zum Despotismus auch der Vorwurf der Sklaverei und Unfreiheit des Individuums. Hinzu komme die Kritik am Schicksal der orientalischen Frau (vgl. Ammann: Östliche Spiegel, S. 24-27).
} 
der Länder und Völker im Nordwestlichen Indien“"166, beschäftigt sich in erster Linie mit militärischen Fragen.

Artikel in nicht fachspezifischen, eher populären Zeitschriften und Journalen weisen ein breiteres Themenspektrum auf. Aber auch hier überwiegen, wie bereits bei den Reiseberichten, Themen, die verschiedene Aspekte des zeitgenössischen Indiens betreffen, also vor allem bestimmte Riten und Gebräuche, gesellschaftliche Einrichtungen wie das Kastenwesen, sowie Berichte zur neueren Geschichte. Texte über das alte Indien finden sich dagegen vorwiegend in wissenschaftlichen Publikationen. Beispielhaft für die nicht fachspezifischen Zeitschriften und Journale wurden das „Journal für Literatur, Kunst, Luxus und Mode“ sowie Cottas „Morgenblatt für gebildete Stände“ untersucht. Das „Journal für Literatur, Kunst, Luxus und Mode“ widmet sich in den Jahren von 1795 bis 1829 in mindestens elf Artikeln dem indischen Subkontinent, wobei der Schwerpunkt getreu dem Titel der Zeitschrift einerseits auf Berichten über indische Feste, Sitten und (Luxus-)Güter sowie andererseits auf literarischen Bearbeitungen des Themas durch europäische Autoren liegt. ${ }^{167}$ Das Interesse gilt also nicht unbedingt dem Verständnis der Besonderheiten der indischen Kultur und des indischen Denkens, sondern in erster Linie dienen die Texte der Unterhaltung und der Befriedigung der Neugierde auf fremde Welten. Auch in Cottas Morgenblatt finden sich einige Artikel, die auf die Freude am Fremden, Kuriosen und Spektakulären zielen und eine gewisse Sensationslust befriedigen. ${ }^{168}$ Daneben gibt es weitere Artikel, die sich mit dem zeitgenössischen Indien beschäftigen. Wie bereits das „Journal für Literatur, Kunst, Luxus und Mode“ weist auch Cottas Morgenblatt als zweiten großen Schwerpunkt die Literatur auf, wobei hier nicht die deutschen Bearbeitungen des Themas Indien überwiegen, sondern Übersetzungen oder

\footnotetext{
${ }^{166}$ Beyträge zur Kenntnis der Länder und Völker im Nordwestlichen Indien. In: Minerva. Ein Journal historischen und politischen Inhalts 59 (1806), S. 193-241

${ }^{167} \mathrm{Vgl}$. zu den Festen und Gütern die Artikel über englische Equipagen in London und Calcutta 12 (1795), über das Jahresfest der Thronbesteigung des Groß-Moguls 20 (1805), über kostbare Tücher aus Kaschmir 24 (1809); vgl. zu Sitten und Charakter der Hindus die Artikel über den Charakter der Hindus 32 (1817) und über die Sitten der Hindus 33 (1818); vgl. zu den literarischen Texten die Artikel über Gitagovinda 31 (1816), über den Paria von de la Vigne und die Oper Jessonda von Spohr 38 (1823)

${ }^{168}$ Vgl. z.B. die Artikel über Witwenverbrennungen in Nr. 109 (1807), Nr. 121 (1819), Nr. 147 (1821), Nr. 41 (1824) und Nr. 243 (1827), über verschiedene Jagden in Nr. 209 (1808), Nr. 147/148 (1812), Nr. 284 (1813) und Nr. 189 (1820), über Gaukler und Fakire in Nr. 154 (1809), Nr. 123/127 (1816), Nr. 274 (1817) und Nr. 168 (1821) sowie über indische Feste in Nr. 108 (1810), Nr. 4 (1814), Nr. 21 (1816), Nr. 81 (1818), Nr. 82 (1818) und Nr. 56 (1824)
} 
Übertragungen indischer Werke ins Deutsche bzw. Berichte über indische Literatur. Diese Zeitschrift enthält darüber hinaus aber auch Artikel, die sich mit anderen Aspekten des klassischen Indiens auseinandersetzen, vor allem mit Religion und Mythos. Cottas Morgenblatt bringt in dem Zeitraum zwischen 1807 und 1829 mehr als 80 Artikel, die sich in irgendeiner Weise mit dem Thema Indien beschäftigen. Auffallend ist dabei, dass sich in chronologischer Hinsicht keinerlei Häufungen oder thematische Schwerpunkte erkennen lassen. In einigen Jahren gibt es kaum Artikel zu Indien, in anderen ausgesprochen viele, aber Jahre mit viel oder wenig Artikeln folgen nicht aufeinander, sondern scheinen relativ wahllos verteilt zu sein. ${ }^{169}$ Die Häufung von Artikeln im Jahr 1808 könnte man vielleicht noch mit dem Erscheinen des sehr umstrittenen Buchs „Über Sprache und Weisheit der Indier“ von Friedrich Schlegel in Zusammenhang bringen, aber zum einen lässt sich die noch größere Anzahl an Indienartikeln 1821 auf diese Weise nicht erklären und zum anderen weisen andere Journale für diese Jahre keine speziellen Anstiege an Artikeln über Indien auf. Auch thematisch lassen sich keine besonderen Schwerpunkte zu bestimmten Zeiten erkennen. Man kann also anhand der Befunde aus den untersuchten Zeitschriften nicht ableiten, dass sich das Interesse zunächst auf diese, später auf jene Themen richtete.

Auch die in der zu untersuchenden Zeit erschienenen Monographien zu Indien, wie sie z.B. in dem „Handbuch der deutschen Literatur seit der Mitte des achtzehnten Jahrhunderts“ zusammengetragen sind ${ }^{170}$ oder wie sie sich in den Rezensionen der Allgemeinen Literaturzeitung widerspiegeln, lassen keine zeitlichen und thematischen Häufungen erkennen. Über den gesamten Zeitraum finden sich immer wieder die für die Monographien typischen Themen und Textsorten wie z.B. Reiseberichte, Berichte über aktuelle politische Ereignisse und Kriege der Kolonialmächte, Abhandlungen zu mythologischen Vorstellungen der Inder sowie immer wieder auch Übersetzungen und Übertragungen indischer Texte, zunächst auch aus zeitgenössischen indischen Sprachen wie dem Tamilischen, später vor allem aus dem Sanskrit. Um so interessanter wird es sein zu untersuchen, ob und inwieweit sich zeitliche Veränderungen in einigen

\footnotetext{
${ }^{169}$ Insgesamt lässt sich aber anscheinend ein starker Anstieg von Artikeln zu Themen des Orients allgemein seit kurz nach 1800 feststellen, mit einem Höhepunkt Ende der 20er, Anfang der 30er Jahre (vgl. Ammann: Östliche Spiegelungen, S. 4)

${ }^{170}$ Vgl. Ersch, Johann Samuel: Handbuch der deutschen Literatur seit der Mitte des achtzehnten Jahrhunderts bis auf die neueste Zeit, systematisch bearbeitet und mit den nöthigen Registern versehen. Neue mit verschiedenen Mitarbeitern besorgte Ausgabe. Zweiter Band enthaltend I. Literatur der Jurisprodenz und Politik mit Einschluss der Kameralwissenschaften. II. Literatur der schönen Künste. Leipzig 1840 sowie Vierter Band enthaltend Geschichte und deren Hülfswissenschaften. Leipzig 1827
} 
Details der Darstellung und Bewertung dieser Themen finden lassen. Werden möglicherweise zwar dieselben Themen immer wieder behandelt, aber mit unterschiedlicher Ausrichtung und Herangehensweise?

Während sich die Reiseberichte und Artikel in populären Journalen bevorzugt mit Aspekten des zeitgenössischen Indiens auseinandersetzen und an den religiösen Vorstellungen entweder die fremdartig erscheinende Götterwelt oder aber die sinnlich wahrnehmbaren Riten und Feste interessieren, liegt der Schwerpunkt wissenschaftlicher Artikel häufig woanders. Noch mehr als die populären Artikel widmen sie sich der indischen Literatur. Hinzu kommen Themengebiete, die in den anderen Textsorten weniger verbreitet sind wie Abhandlungen zu indischen Sprachen und zu verschiedenen Bereichen indischer Wissenschaft. Sowohl die Sprache als auch die Mythologie, die ebenfalls häufig thematisiert wird, interessieren hier weniger hinsichtlich ihrer spannenden Andersartigkeit. Vielmehr werden die (historischen) Gemeinsamkeiten mit anderen europäischen Sprachen und Mythologien betont. Zeitschriften, die sich auf das Thema Asien bzw. Indien spezialisiert haben und die für diese Arbeit untersucht wurden, sind vor allem das „Asiatische Magazin“ von Klaproth ${ }^{171}$, die „Indische Bibliothek“ von August Wilhelm Schlegel ${ }^{172}$ sowie die Übersetzungen der „Asiatick Researches“. Dabei handelt es sich zum einen um eine Zusammenstellung verschiedener Artikel der ersten beiden Bände der „Asiatick Researches“ durch Johann Kleuker ${ }^{173}$ und zum anderen um einige Artikel der Bände sechs und sieben, die Ehrmann in seinen „Neuste(n) Beiträgen zur Kunde von Indien“ zusammengestellt hat. ${ }^{174}$ Die Zeitschrift „Fundgruben des Orients“ ${ }^{175}$ wurde nicht näher herangezogen, da sie sich vor allem mit der persischen und arabischen Kultur beschäftigt und nur sehr wenig zu Indien enthält. Obwohl sie allesamt einen wissenschaftlichen Anspruch haben, unterscheiden sich die genannten Zeitschriften durchaus voneinander hinsichtlich ihrer Ausrichtung und Zielsetzung. Während z.B.

\footnotetext{
${ }^{171}$ Vgl. Asiatisches Magazin. Hrsg. von Julius Klaproth. Weimar 1802

${ }^{172}$ Vgl. Indische Bibliothek. Herausgegeben von August Wilhelm Schlegel. 1. Band Bonn 1823, 2. Band Bonn 1827

${ }^{173}$ Vgl. Abhandlungen über die Geschichte und Alterthümer, die Künste, Wissenschaften und Literatur die Künste, Wissenschaften und Literatur Asiens von Sir William Jones und andern Mitgliedern der im Jahr 1784 zu Calcutta in Indien errichteten gelehrten Gesellschaft. Aus dem Englischen übersetzt von Johann Christian Fick, Lehrer am ill. Gymnasium zu Erlangen, durchgesehen, und mit Anmerkungen, ausführlichen Erläuterungen und Zusätzen bereichert von D. Johann Friedrich Kleuker. 1. Band Riga 1795, 2. Band Riga 1795, 3. Band Riga 1797

${ }^{174}$ Vgl. Ehrmann (Hg.): Neueste Beiträge zur Kunde von Indien

${ }^{175}$ Vgl. Fundgruben des Orients. Bearbeitet durch eine Gesellschaft von Liebhabern. Wien 1809
} 
das „Asiatische Magazin“ vor allem über neue Erkenntnisse über asiatische Kulturen unterrichten möchte, setzt sich Schlegel in seiner deutlich später erscheinenden Indischen Bibliothek in einem weitaus größeren Maße mit den Methoden und Problemen der noch neuen Wissenschaft der Indologie auseinander.

\section{Indien - Wiege der Menschheit}

Ein wichtiger Topos, auf den man in den verschiedenen Texten über Indien immer wieder stößt und der in der Zeit um 1800 als Allgemeinplatz gelten kann, ${ }^{176}$ ist die Annahme, in Asien und speziell in Indien liege die Wiege der Menschheit und der menschlichen Kultur. Indien stelle somit die Kindheit der Menschheit dar. Viele Texte setzen sich direkt mit diesem Topos auseinander, andere spielen nur indirekt durch die immer wiederkehrende Betonung des immens hohen Alters der indischen Kultur, Sprache, Literatur darauf an.

Der Topos von Indien als der Wiege der Menschheit findet sich um 1800 in verschiedenen Deutungszusammenhängen, die man grob zwei unterschiedlichen Richtungen zuordnen kann. So stehen sich die Annahme eines stetigen Fortschritts der Menschheit und die Vorstellung eines verlorenen Goldenen Zeitalters gegenüber. Während für viele der Autoren die indische Kindheit der Menschheit ein ungebildetes und wenig zivilisiertes Zeitalter darstellt, symbolisiert gerade für die Autoren der Romantik die Kindheit allgemein und somit auch die Kindheit der Menschheit eine harmonische Zeit des intuitiven und auch naiven Eins-Seins mit der Natur, mit dem Göttlichen, eine Zeit, in der Poesie, Philosophie und Wissen noch nicht getrennt waren. Vertreter des Fortschrittsdenkens zollen Indien oft zwar Anerkennung als Ursprungsland der Kultur, aber man sieht die eigene Zivilisation als sowohl dem alten Indien als auch dem zeitgenössischen Indien überlegen an. In den Augen vieler Autoren steht Indien auf einer anderen Zeit- und Entwicklungsstufe als die europäische Kultur, da es keine der europäischen Kulturen vergleichbare Entwicklung zur Moderne erlebt habe. ${ }^{177}$ Aber auch für die romantischen Autoren befindet sich Indien auf einer anderen

\footnotetext{
${ }^{176}$ Vgl. Ammann: Östliche Spiegel, S. 31f.

${ }^{177}$ In dem Diskurs der Aufklärung über die Einheit der Menschheit kann die daraus abgeleitete Gleichheit der Menschen nur mit den beobachteten Unterschieden in Einklang gebracht werden, indem von einer prinzipiell gleichen Ausstattung der Menschen ausgegangen wird, die sich aber je nach äußeren Einflüssen unterschiedlich oder auch kaum entwickelt habe (vgl. Meyer, Annette: Die Epoche der Aufklärung. Berlin 2010, S. 92)
} 
Stufe als die eigene Kultur, nur ist hier die hierarchische Gliederung der Kulturen nicht so eindeutig wie bei den Entwicklungsdenkern. Denn während in ihren Augen die moderne Zivilisation die ursprüngliche Einheit zerstört habe, habe sich in Indien durch die fehlende Entwicklung einiges der alten goldenen Zeit erhalten, weshalb sich viele aus Indien zumindest Impulse für eine Erneuerung der eigenen Kultur erhoffen. ${ }^{178}$

Die These, dass in Indien nicht nur die Menschheit, sondern auch die menschliche Zivilisation und Kultur entstanden seien, kann entweder religiös-biblisch oder säkularwissenschaftlich begründet werden, wobei die säkular-wissenschaftliche Begründung die religiös-biblische nach und nach immer mehr ablöst. In den ersteren Bereich gehören z.B. Argumente, die sich auf die biblischen Schilderungen des im Osten gelegenen irdischen Paradieses beziehen (bereits im Mittelalter verorteten viele das irdische Paradies in Indien) oder aber auf die Höhe der indischen Berge, die während der Sintflut aus den Wassermassen ragten. Säkular-wissenschaftlich wird vor allem mit Hinweisen auf das hohe Alter der indischen Kultur sowie die klimatisch optimalen Bedingungen für die Entstehung menschlichen Lebens argumentiert.

So verbreitet die These, dass Indien die Wiege der Menschheit sei, auch ist, ist sie doch keineswegs unumstritten. Auch andere Länder sind als Ursprungsort der Menschheit im Gespräch. Dabei erfolgt die Suche nach der Herkunft der Menschheit immer auch vor dem Hintergrund der eigenen Kultur als Zielpunkt und wird so zu einer Suche nach dem Ursprung der eigenen Kultur und Zivilisation. Dazu passt, dass gerade nicht die Völker, die in einem rousseauschen Sinne als Naturvölker gelten könnten, in die engere Auswahl kommen, sondern durchweg frühe Hochkulturen. Das waren zunächst die Hebräer und Griechen, dann kamen Ägypter und Perser und etwas später auch die Inder hinzu. ${ }^{179}$

Gerade zu Beginn der intensiven Beschäftigung mit Indien wird immer wieder um die bereits in der Antike aufgeworfene Frage gerungen, ob ursprünglich indisches Wissen die griechische und ägyptische Kultur beeinflusst habe (z.B. ob Pythagoras' Lehren

\footnotetext{
${ }^{178}$ Vgl. dazu auch Ammann: Östliche Spiegel, S. 31-33; Schmitz-Emans: Monika: Einführung in die Literatur der Romantik. Darmstadt 2004, S. 38; Behler: Das Indienbild der deutschen Romantik, S. 2124; Maráthe, Mandakini: Spiegelungen Indiens in der deutschen Literatur des XIX. Jahrhunderts. Wien 1965, S. 17, 32f.; Michaels: Wissenschaft als Einheit, S: 328-330; Pille: À la fracture du classicisme et du romantisme, S. 29f.; Willson: A mythical image, S. 84

${ }^{179}$ Vgl. Polaschegg: Athen am Nil oder Jerusalem am Ganges? S. 47-52; Mitter: Much maligned monsters, S. 189-191
} 
indischen Ursprungs sind) oder ob umgekehrt die indische Kultur auf die griechische oder ägyptische zurückzuführen ist. Dabei lässt sich im 18. Jahrhundert ein Umbruch beobachten: Während nun die These von den indischen Ursprüngen der Kultur immer beliebter wird, waren Autoren des 17. Jahrhunderts größtenteils der Ansicht, dass die Wurzeln der europäischen Kultur im Westen lägen und verwiesen vor allem auf Ägypten. ${ }^{180}$

Obwohl bereits die alten Griechen Vermutungen anstellten, dass die Menschheit in Indien entstanden sei und die Quellen einzelner philosophischer Ideen dort verorteten und obwohl Autoren wie Rogerius, Holwell, Sonnerat und Voltaire ${ }^{181}$ diese Vermutungen teilten, wird die Entstehung der These von Indien als der Wiege der Menschheit immer wieder Herder zugeschrieben. Dieser hat sie jedoch nicht „erfunden“, allerdings sicherlich sehr zu ihrer Popularität beigetragen. ${ }^{182}$ Bereits in seinen „Ideen zur Philosophie der Geschichte der Menschheit“ verortete Herder den Ursprung der Menschheit in Asien, genauer auf den hohen indischen Bergen, und begründete das zum einen mit der Höhe der Berge, die das Wasser der Sintflut nicht bedecken konnte, zum anderen aber auch mit den regen organischen Kräften dort. Ein weiterer Hinweis sei auch die große Vielzahl unterschiedlicher Tierarten, die in diesem Gebiet vorkommen. ${ }^{183}$ Er benutzte also sowohl Argumente aus dem religiös-biblischen Bereich als auch aus einem eher säkular-wissenschaftlichen. Dabei ging es Herder in erster Linie allerdings nicht darum, explizit Indien als Ursprung der Menschheit

\footnotetext{
${ }^{180}$ LaCroze begründete Ähnlichkeiten zwischen der ägyptischen und der indischen Kultur mit der These, dass Indien eine ägyptische Kolonie gewesen sei. Auch Kircher ging davon aus, dass die Inder ihr Wissen aus Ägypten erlangt hätten, aber er übertrug auch die Vorstellung von den ägyptischen Hieroglyphen als Geheimschrift des heiligsten Wissens auf Indien und sah nun im Sanskrit eine heilige Sprache, die die Weisheiten der Inder enthalte. Dapper sah dagegen die Wurzeln indischen Denkens in Griechenland: Die Inder hätten Bücher von Pythagoras gehabt, einige hielten sogar Brahmā für Pythagoras. (Vgl. Sedlar: Indien in the Mind of Germany, S. 12f.; Willson: A mythical image, S. 24f., Dharampal-Frick: Indien im Spiegel deutscher Quellen, S. 341; zur antiken Herleitung einzelner Aspekte der griechischen Philosophie aus Indien vgl. Halbfass: Indien und Europa, S. 13-22; Dapper, Olfert: Asia / oder Ausführliche Beschreibung Des Reichs des Grossen Mogols Und eines grossen Theils von Indien. Nürnberg 1681, S. 17)

${ }^{181}$ Voltaire ging es dabei allerdings nicht um Indien als solches, sondern er stellt sich wie andere Deisten mit seinem Verweis auf das alte indische religiöse Denken gegen die These, dass alles Positive, was sich in Asien finden lasse, lediglich (verfälschte) Überbleibsel der jüdisch-christlichen Offenbarung seien. (vgl. Halbfass: Indien und Europa, S. 73f.; Herling: The German Gītā, S. 61; Mitter: Much maligned monsters, S. 191f.)

${ }^{182}$ Vgl. Frank: Sanftes Gefühl und stille Tiefe der Seele, S. 61, 65-68; Halbfass: Indien und Europa, S. 13-15, 21f., 29f.

183 Vgl. Herder: Ideen zur Philosophie der Geschichte der Menschheit, S. 254; das Argument, dass die hohen Berge Indiens als erstes wieder frei von Wasser gewesen seien, führt auch Klaußner an, der aber auch die Nähe zum Kaukasus als der Urheimat der Menschen betont (vgl. Klaußner: Die Hindus. In Neue Litteratur und Völkerkunde 1 (1791), S. 508-527, hier S. $209 f$.
} 
auszumachen, sondern seine z.T. paradiesischen Bilder Indiens sind Teil eines umfassenderen Diskurses, der im Folgenden kurz dargestellt werden soll.

Die Berichte von fremden Völkern warfen in der zweiten Hälfte des 18. Jahrhunderts die Frage auf, wie sich die Vorstellung von der Einheit der Menschheit, die biblisch durch die Schöpfungsgeschichte oder aber auch philosophisch aus physiologischen Gemeinsamkeiten oder einer allen Menschen gemeinen Seele und Vernunft abgeleitet werden konnte, mit den berichteten äußerlichen und kulturellen Unterschieden in Einklang bringen lasse. Dadurch kam Fragen nach der Entstehung und Entwicklung der Menschheit eine immense Bedeutung zu: War die Menschheit in einem eher tierischen Zustand entstanden und hatte sich dann immer höher entwickelt? Stammten alle Völker von einem Urahnen ab (Monogenese) oder gab es verschiedene Stammväter (Polygenese)? Wie haben sich bei Annahme einer Monogenese die Unterschiede zwischen den Völkern entwickelt? Stehen bei Annahme einer Polygenese einige Völker hierarchisch niedriger als andere? Sind sie vielleicht sogar den Affen näher als andere? Die These, dass alle Völker von einem einzigen Ursprungsvolk ausgingen (Monogenese), war zu Beginn biblisch geprägt und wurde bis ins späte 18. Jahrhundert häufiger vertreten als die entsprechende Gegenthese der Polygenese.

Sehr bekannt war die nicht mehr biblisch, sondern wissenschaftlich argumentierende Klimatheorie Buffons. Diese bereits in der Antike aufgestellte These der „Determiniertheit der Menschen durch klimatische und physisch-geographische Bedingungen“"184 diente zunächst zur Begründung der eigenen Überlegenheit, wurde von Buffon dann aber zur Erklärung der menschlichen Vielfalt herangezogen. Dabei ging er von einem ursprünglichen Menschentypus aus, der im Zuge seiner Verbreitung über die ganze Welt verschiedenen klimatischen und geographischen Einflüssen ausgesetzt gewesen sei und sich dementsprechend verändert und angepasst habe. Da diese neuen Merkmale schließlich erblich (aber doch nicht gänzlich unumkehrbar) geworden seien, seien verschiedene Menschenvarietäten entstanden, die sich aber nur graduell, z.B. durch die Hautfarbe, voneinander unterschieden. Für andere Autoren waren diese Unterschiede dagegen weniger graduell, sondern so signifikant, dass sie

\footnotetext{
${ }^{184}$ Hoorn, Tanja van: Dem Leibe abgelesen. Georg Forster im Kontext der physischen Anthropologie des 18. Jahrhunderts. Tübingen 2004, S. 26
} 
von verschiedenen Rassen oder gar Arten sprachen. ${ }^{185}$ Herder vertrat sehr entschieden die Thesen der Monogenese und Gleichwertigkeit aller Menschen. Beobachtete (z.B. klimatisch bedingte) Unterschiede sollten als solche anerkannt und nicht bewertet oder verändert werden. Allerdings war er selbst in dieser Hinsicht auch nicht immer ganz konsequent. ${ }^{186}$

Diese Fragen spielen auch in der Abolitionsbewegung eine wichtige Rolle. Zwar weist z.B. der entschiedene Gegner der Sklaverei Georg Forster darauf hin, dass die Europäer auch dann Schwarze grausam unterdrücken würden, wenn bewiesen wäre, dass alle Menschen verwandt und „Brüder“ seien. Das zeige sich allein daran, dass sie „über ihre weißen Mitmenschen ebenso despotisch“ herrschten. ${ }^{187}$ Andere jedoch wie z.B. Blumenbach versuchen, die enge Verwandtschaft und Ebenbürtigkeit der Menschen gegen die Sklaverei ins Feld zu führen. Auf der anderen Seite nutzen Befürworter der Sklaverei wie Christoph Meiners vermeintliche angeborene Ungleichheiten zur Legitimierung der Unterdrückung Schwarzer. ${ }^{188}$

Nicht nur der Diskurs über die Frage nach der Entstehung der Menschheit fördert die Verknüpfung Indiens mit etwas Ursprünglichem. Aus dem Kontext der neuen geschichtlichen Ausrichtung des Denkens und der Anthropologie stammen auch die eng damit verbundenen Diskurse über die Anfänge der Sprache sowie der Religion. Auch die romantische Suche nach einer ursprünglichen Einheit von Poesie, Religion und Wissenschaft sowie die Frage nach der Herkunft und Entstehung der eigenen Kultur spielen in dieses Thema mit hinein.

\footnotetext{
${ }^{185}$ Vgl. Mitte: Much maligned monsters, S. 190; Lauer, Gerhard: Über Menschen, Schweine und andere Rassen. Die Varietäten der Menschen und ihre zoologischen Kritik in der gelehrten Literatur des 18. Jahrhunderts. In: Gantet, C. u. Schock, F. (Hg.): Zeitschriften, Journalismus und gelehrte Kommunikation im 18. Jahrhundert. Festschrift für Thomas Habel. Bremen 2004, S. 221-232, hier S. 221f., 224f.; Hoorn: Dem Leibe abgelesen, S. 25-32

${ }^{186}$ Vgl. Herder: Ideen zur Philosophie der Geschichte der Menschheit, S. 178f., 190-195; vgl. zu Herder vor allem auch Frank: Sanftes Gefühl und stille Tiefe der Seele, S. 42-48

${ }^{187}$ Forster, Georg: Noch etwas über die Menschenracen. In: Forster, Therese (Hg.): Georg Forster's sämmtliche Schriften. Bd. 4: Kleine Schriften. Leipzig 1843, S. 280-306, hier S. 304f.; vgl. auch Lentz, Sarah: „Wer helfen kann, der helfe!“ Deutsche SklavereigegnerInnen und die atlantische Abolitionsbewegung, 1780-1860. Göttingen 2020 (Veröffentlichungen des Instituts für Europäische Geschichte Mainz; 261), S. 95; Forster wandte sich seit seiner Weltumseglung mit Cook immer wieder gegen Rassismus und die Überheblichkeit der Europäer gegenüber anderen Kulturen (vgl. Steiner, Gerhard: Kalidasas Sakontala oder die deutsche Entdeckung Indiens. In: Rasmussen, Detlef (Hg.): Der Weltumsegler und seine Freunde - Georg Forster als gesellschaftlicher Schriftsteller der Goethezeit.Tübingen 1988, S. 59-69, hier S.62).

${ }^{188}$ Vgl. Lentz: ,Wer helfen kann, der helfe!“, S. 61, 80-107 (insbesondere S. 91-93)
} 
Ein wichtiger Aspekt des Diskurses über Indien als Wiege der Menschheit ist die Idealisierung des alten Indiens als Goldenes Zeitalter der menschlichen Kindheit, wie die Darstellung in Müllers ${ }^{189}$ „Glauben, Wissen und Kunst der alten Hindus [...]“zeigt:

\begin{abstract}
Wir haben oben gesagt, daß wenige der heutigen gelehrten Forscher, und nur jene, welchen es ehrlicher Weise um Wahrheit zu thun ist, dahin übereinstimmen; Hindostan sey die Urwiege der Menschheit; das Mutterland alles Glaubens, alles Wissens und aller Kunst. Die bedeutenden Fortschritte in den Sprachen dieses Wunderlandes, besonders in der Gelehrtensprache, der Sanskrita, der ältesten Menschensprache welche wir kennen, haben uns mit der wunderbar hohen Ausbildung dieses merkwürdigen Erdetheiles bekannt gemacht, und das besonders in neuern Zeiten mit so glücklichem Fleisse gesteigerte Studium der vergleichenden Sprachenkunde, so wie der philosophisch vergleichenden Länder- und Völkerkunde haben die Ahnung einer alten, für uns primitiven Urheimath aller Menschenkultur in Hindostan, so wie die Verdunkelung einer vorsündfluthlichen, von daher in unerloschenem Glimmer noch lebenden Offenbarung [...] zu Wahrscheinlichkeit erhoben [...]. [...] jene Weisheit, sage ich, welche Pythagoras, und, freilich nach Mißbrauch hinkehrend, Pyrrho mit wohl vielen andern Griechen aus Indien in ihr Vaterland verpflanzt haben, sie war das Erbe der von uns in ihrer Weisheitstiefe bewunderten Vorwelt [...]. ${ }^{190}$
\end{abstract}

Müller bezeichnet Indien nicht nur als Wiege, sondern in besonderer Betonung der Ursprünglichkeit als „Urwiege“ der Menschheit, von wo aus Glauben, Wissen und Kunst ausgegangen seien. Diese „Urheimath“ sei „für uns“ primitiv, womit Müller aber weniger etwas geistig Unterentwickeltes meint (wie Hegel), sondern etwas Ursprüngliches, das noch nicht von der modernen Zivilisation verändert wurde. Indem er diesen ersten Ursprung mit einer „,vorsündfluthlichen“ Offenbarung verbindet, wird deutlich, dass er in den ersten Anfängen in Indien eine Art Goldene Zeit sieht, die in Teilen verloren gegangen sei (,Verdunklung“), in Teilen aber überliefert wurde und neu entdeckt werden könne (,unerloschenem Glimmer“). Spuren dieser ursprünglichen, von Gott dem Menschen offenbarten Weisheit fänden sich auch bei Pythagoras und anderen Griechen, die die indischen Lehren übernommen hätten.

\footnotetext{
${ }^{189}$ Nikolaus Müller (1770-1851) war ein Maler und Literat. In seiner Geburtsstadt Mainz schloss er sich den Mainzer Jakobinern an und war in verschiedenen Ausschüssen tätig. Nach der Kapitulation der Stadt ging er zunächst nach Paris. 1798 gründete er in Mainz eine Zeichenschule und wurde 1802 Professor für Zeichenkunst und Ästhetik. Ab 1800 begann er, sich für orientalische und indische Dichtung und Mythologie zu interessieren und stützte sich dabei vor allem auf Herder, Creuzer und Hammer-Purgstall (vgl. Rösch, Gertrud Maria, "Müller, Nikolaus" in: Neue Deutsche Biographie 18 (1997), S. 460 f. [Online-Version]; URL: https://www.deutschebiographie.de/pnd117608122.html\#ndbcontent; Kosch, Wilhelm: Deutsches Literaturlexikon. Biographisches und bibliographisches Handbuch. Zweiter Band. Kosegarten - Zyrl. Halle 1930, Sp. 1641

${ }^{190}$ Müller, Niklas: Glauben, Wissen und Kunst der alten Hindus in ursprünglicher Gestalt und im Gewande der Symbolik mit vergleichenden Seitenblicken auf die Symbolmythe der berühmten Völker der alten Welt, mit hieher gehöriger Literatur und Linguistik. Erster Band. Mainz 1822, S. XI, XIX
} 
Müller sieht also kulturelle Unterschiede zwischen der alten indischen Kultur und der Moderne, aber er deutet sie nicht im Sinne einer fortschreitenden Entwicklung hin zur Vervollkommnung, sondern als Verlust einer ursprünglichen Vollkommenheit. Müller erhofft sich von dem Studium der alten indischen Kultur nicht nur Impulse für eine Erneuerung der eigenen Kultur, sondern geradezu die Wiedererweckung des verlorenen heiligen Wissens. Das aber beinhaltet hohe Ansprüche an die Wissenschaft, die zunächst den gefundenen Schatz als solchen erkennen muss (was sie Müllers Empfinden nach noch nicht getan hat) und dann die Aufgabe hat, ihn in seiner verdunkelten Urform aus dem Vorgefundenen herauszuarbeiten. ${ }^{191}$ Diese Hoffnung auf Erneuerung des Eigenen durch das der Menschheit ursprünglich nicht fremde, uns aber verlorengegangene Andere verbindet Müller mit einer Kritik an der eigenen „Zwergige(n), geschnürte(n) und geschminkte(n) “192 Gegenwart, die sich weise dünke, aber nur „Schattenidolen“ anhänge, die Sinne verwirre, das Gemüt bedrücke und die Menschen so blende, dass sie nicht merkten, wie es um sie stehe. ${ }^{193}$ Müller, der von sich selbst schreibt, er sei kein Sanskritgelehrter, knüpft sein Indienbild an so hohe Erwartungen, dass man durchaus von einer Überhöhung und Idealisierung des Anderen mit gleichzeitiger Kritik am Eigenen sprechen kann.

Anklänge einer Idealisierung des ursprünglichen asiatischen Wissens finden sich auch bei Matthias Claudius ${ }^{194}$. Er stellt 1802 in dem Aufsatz „Eine asiatische Vorlesung“ zunächst fest, dass die Wissenschaften aus Asien nach Europa gekommen seien und nicht umgekehrt. ${ }^{195}$ Die aus Asien stammenden „Urkenntnisse“ hätten sich mit den Wanderungen der Menschen in alle Welt verbreitet, seien dabei aber immer mehr

\footnotetext{
${ }^{191}$ Vgl. Müller: Glauben, Wissen und Kunst der alten Hindus, S. XVIf. („,Der Geist des Brahmanismus will gleichsam aus seinen verschütteten Tempeltrümmern [...] herausbeschworen seyn, und wenn er dem Nekromanten in unvermoderten Binden und Hüllen erscheint, dann muß dieser dieselben geduldig, sorgsam und verständig ablösen, daß das Heilige auch nackt und rein vor seinen gewürdigten Blicken erschienen möge [...] um mit seinem Erwachen ein neues strahlendes Leben in die Gegenwart einzuführen, und die erneuen Rennbahnen nach der Urwiege unsers Seyns, zum Troste und zur Freude der Menschheit, zu ebnen und zu beleuchten.")

${ }^{192}$ Müller: Glauben, Wissen und Kunst der alten Hindus, S. XVII

${ }^{193}$ Vgl. Müller: Glauben, Wissen und Kunst der alten Hindus, S. XVII

${ }^{194}$ Matthias Claudius (1740-1815) stammte aus einer holsteinischen Pastorenfamilie. Er studierte zunächst Theologie und anschließend Rechts- und Kameralwissenschaften, allerdings ohne einen Abschluss zu machen. Der Verleger und Übersetzer J. Bode vermittelte ihm 1771 die Redaktion des „Wandsbecker Bothe“. Durch die Beiträge bekannter Autoren sowie seine eigenen Texte erlangte die kleine Zeitung in literarischen Kreisen einige Bekanntheit (vgl. Roedl, Urban, "Claudius, Matthias" in: Neue Deutsche Biographie 3 (1957), S. 266-267 [Online-Version]; URL: https://www.deutschebiographie.de/pnd118521098.html\#ndbcontent).

${ }^{195}$ Vgl. Claudius, Matthias: Eine asiatische Vorlesung. In: ASMUS omnia SECUM portans, oder Sämmtlich Werke des Wandsbecker Bothen. 7. Teil. Wandsbeck 1802, S. 1-62, hier S. 7
} 
verwittert. ${ }^{196}$ Die biblische Überlieferung nimmt bei Claudius aber doch einen höheren Rang ein:

\begin{abstract}
Die wahre Religion und das Geschlecht der Menschen ist in Asien entstanden; die Quelle ihrer Urkenntnisse sprudelte in Asien zuerst, und man sieht hier rund um an den Büschen und Steinen noch die dicken Tropfen hängen. Die Bibel gibt uns Nachricht von der Schöpfung der Welt, von dem Fall und der Verführung des Menschen durch das Prinzipium des Bösen, von den ersten Menschen-Geschlechtern, von der Sündfluth, von der Zerstreuung der Menschen und Völker u.s.w. Und all diese große Begebenheiten, welche die Christliche Religion zum Theil voraussetzt und zum Theil darauf sich gründet, hallen in den ältesten Schriften der Asiatischen Nationen wieder. ${ }^{197}$
\end{abstract}

Es folgen Vergleiche der Schilderungen von Schöpfung und Sintflut in verschiedenen Texten der unterschiedlichsten asiatischen Kulturen. Claudius, der sich in seinem „Wandsbecker Bothen“ mit verschiedenen Aspekten und Themen des Christentums beschäftigt, sieht in Asien also nicht nur den Entstehungsort der Menschen, sondern auch der Wissenschaft und - was ihn besonders interessiert - der wahren Religion. Wichtig ist festzuhalten, dass er von Asien allgemein spricht und keineswegs von Indien allein. Das Bild von der Quelle, deren Spuren noch zu finden seien, impliziert, dass die Quelle des Wissens nun anscheinend versiegt ist und auch die Tropfen, die man hier und dort noch findet (vor allem natürlich möglichst dicht an der Quelle), auch über kurz oder lang verdunsten werden. Es geht also nicht um eine fortschreitende Entwicklung, sondern um das Aufspüren der letzten Tropfen des fast Verlorenen. Mit diesem alten asiatischen Wissen, dessen Spuren noch in den alten Überlieferungen zu finden sind, wird das Wissen verglichen, das für Claudius als Christ hohe Autorität besitzt: das der Bibel. Die beobachteten Gemeinsamkeiten sind für ihn ein Beweis für die Richtigkeit der biblischen Erzählungen. Es geht Claudius also weniger um genaue Kenntnisse der asiatischen Kulturen, sondern darum, die Bibel in Zeiten, in denen sie als Quelle der Wahrheit immer mehr in Frage gestellt wird, als genau eine solche zu bestätigen. Das Andere dient also in erster Linie der Bestätigung des Eigenen. Dabei wird das Andere vielleicht nicht als gleichberechtigt, aber doch als sehr wichtig anerkannt. Deutlich wird das z.B. auch durch die Wortwahl „wiederhallen“ statt „nachhallen“, das eine zeitliche Hierarchisierung vermeidet.

\footnotetext{
${ }^{196}$ Claudius: Eine asiatische Vorlesung, S. 22

${ }^{197}$ Claudius: Eine asiatische Vorlesung, S. 7
} 
Während der Textausschnitt von Müller nicht nur ein Beispiel für eine Idealisierung Indiens, sondern auch für die Funktionalisierung Indiens zur Kritik an der eigenen Kultur ist, zeigt sich an dem Ausschnitt von Claudius noch ein anderer wichtiger Aspekt dieses Themas: die Vorstellung, dass die alte indische Hochkultur im zeitgenössischen Indien nur noch in Spuren zu finden sei. Von einem solchen Verfall geht auch Ehrmann aus:

\begin{abstract}
So wie man in Asien, eigentlich nur auf einigen Inseln, wahre barbarischrohe Wilde, den Amerikanischen ähnlich findet, so giebt es in diesem Erdheile auch keine einzige Nation mehr, welche auf gleich hoher Stufe der Kultur mit den aufgeklärteren Europäern stände, ob gleich derselbe die Wiege der Künste und Wissenschaften war, und in Hindustan, Persien und Sina vorzüglich, schon in jenen frühen Zeiten, welchen die Europäer noch in düstre Unwissenheit und Barbarei versunken waren, Künste und Wissenschaften hoch aufgeblüht waren, wie wir noch jetzt sehen. Aber diese Asiaten blieben entweder gedankenlos und mechanisch auf der bereits erstiegenen Stufe oder sie sanken während der Zerrüttungen dieses Erdtheils, wieder tiefer zurück, und die schnell emporgestiegenen Europäer überflügelten sie! ${ }^{198}$
\end{abstract}

Auch bei Ehrmann ist wie bei Claudius nicht speziell Indien, sondern Asien allgemein Wiege der Künste und Wissenschaften. Aber während es Claudius um Ähnlichkeiten, gegenseitige Beeinflussungen sowie die Ausbreitung des Wissens geht, betont Ehrmann die Überlegenheit der zwar später entstandenen, dann aber um so schneller sich entwickelnden europäischen Kultur. Obwohl er ein Gegner der Sklaverei ist und sich in seinen Schriften auch entsprechend kritisch äußert, ${ }^{199}$ ist sein Denken dennoch von einem hierarchisierenden Menschenbild geprägt: Auf der einen Seiten stehen die barbarischen Wilden (die amerikanischen Völker), auf der anderen die aufgeklärten Europäer und dazwischen die ehemals hochstehenden Asiaten.

Eine Möglichkeit, Indien gleichzeitig als für die Frühgeschichte der Menschheit bedeutende Hochkultur anzuerkennen, es aber dennoch nicht als die Urwiege zu idealisieren, zeigt sich in der Ansicht Johann Arnold Kannes ${ }^{200}$, der davon ausgeht, dass

\footnotetext{
${ }^{198}$ Ehrmann, Theophil Friedrich (Hg.): Neuste Kunde von Asien. Erster Band. Asien überhaupt, WestAsien und Mittel-Asien. Weimar 1811 (Neueste Länder- und Völkerkunde. Ein geographisches Lesebuch für alle Stände; 10), S. 32f.

${ }^{199}$ Vgl. Lentz: „Wer helfen kann, der helfe!“”, S. 59 (Fußnote 15)

${ }^{200}$ Johann Arnold Kanne (1773-1824) begann zunächst ein Studium der Theologie, wechselte aber bald zur klassischen Philologie. Diese Spannung zwischen Wissenschaft und (pietistisch geprägter) Religion war auch für sein weiteres Leben bestimmend. Sein wissenschaftliches Interesse galt mythologischen und sprachvergleichenden Forschungen, aber er schrieb auch humoristische und satirische Texte. Seine Abhandlungen zur Mythologie waren geprägt von Versuchen, über etymologische Vergleiche eine Urmythe zu rekonstruieren, Sie wiesen neben geschichtsmetaphysischen Deutungen aber auch starken
} 
sich in Indien die ursprüngliche, göttliche Erkenntnis, der eine Urglaube, am reinsten erhalten habe, wenngleich auch hier nicht in der ursprünglichen Form. Denn auch die überlieferte indische Lehre sei nur abgeleitet von der Lehre des ersten Stammvolkes. Die Frage, ob dieses Stammvolk in Indien gelebt habe oder nicht, lässt Kanne offen. ${ }^{201}$

Ein weiteres häufig diskutiertes Thema ist die bereits angesprochene Frage, ob es eine indische Kolonie in Ägypten gegeben habe oder eine ägyptische in Indien und wer dadurch von wem kulturell beeinflusst worden sein könnte. Die Beantwortung dieser Frage ist durchaus umstritten. Creuzer ${ }^{202}$ möchte sich nicht genau festlegen, aber während er für These der Vermittlung ägyptischen Wissens durch eine indische Priesterkolonie in Ägypten verschiedene Quellen und eine indische Sage, die diese These zu stützen scheint, angibt, so sagt er über die gegenteilige Variante lediglich, dass neuere Forscher wie Jones ihr zuzustimmen scheinen. ${ }^{203}$ Für Creuzer scheint die genaue Beantwortung der Frage, wer wen gelehrt hat, weniger wichtig zu sein als die Feststellung, dass es Beeinflussungen gab und daher Vergleiche beider Kulturen zulässig seien. ${ }^{204}$

\footnotetext{
christlichen Einfluss auf (vgl. Elschenbroich, Adalbert, "Kanne, Johann Arnold" in: Neue Deutsche Biographie 11 (1977), S. 105-107 [Online-Version]; URL: https://www.deutschebiographie.de/pnd118776665.html\#ndbcontent).

${ }^{201}$ Vgl. Kanne, Johann Arnold: Pantheum der Ältesten Naturphilosophie, die Religion aller Völker. Tübingen 1811, S. 5f.; zu Kanne vgl. Willson: A mythical image, S. 104f.

${ }^{202}$ Georg Friedrich Creuzer (1771-1858) studierte zunächst Theologie und Philosophie, später wechselte er zu Philologie und Literaturgeschichte. Ab 1804 war er Professor für Philologie und alte Geschichte in Heidelberg, wo er Kontakte mit den Heidelberger Romantikern Brentano und Arnim hatte. Bekannt ist auch seine Beziehung zu Caroline von Günderrode. In seiner Auseinandersetzung mit den Mythologien verschiedener Völker ging er vor einem neuplatonischen und christlichen Hintergrund von einer monotheistischen Uroffenbarung aus, deren Spuren sich - eingekleidet in Symbole - in den alten Mythen (auch den Griechischen) finden lassen (vgl. Dammann, Oswald, "Creuzer, Friedrich" in: Neue Deutsche Biographie 3 (1957), S. 414 f. [Online-Version]; URL: https://www.deutsche-biographie.de/pnd118677330.html\#ndbcontent; Kocziszky, Eva: Das Konzept und die Rolle des Orients in Creuzers Werk im Vergleich zu Görres. In: Heidelberger Jahrbücher; Strack, Friedrich (Hg.): 200 Jahre Heidelberger Romantik 51 (2007/8), S. 299-320, hier S. 303-305, 31; Jamme, Christoph: „Göttersymbole“. Friedrich Creuzer als Mythologe und seine philosophische Wirkung. In: Heidelberger Jahrbücher 51 (2007), S. 487- 498, hier S. 491)

${ }^{203}$ Vgl. Creuzer, Friedrich: Symbolik und Mythologie der alten Völker, besonders der Griechen. In Vorträgen und Entwürfen. Leipzig und Darmstadt. 1. Band 1810, S. 276

${ }^{204}$ Auch in einem 1819 in dem Journal für Luxus und Moden erschienenen Artikel lässt der Autor die Frage, wer wen beeinflusst haben könnte, auch nach einem ausführlichen Vergleich der ägyptischen und indischen Kultur, offen. Er hält lediglich fest, dass es Verbindungen zwischen beiden Ländern gegeben haben müsse (vgl. Jomard: Parallele zwischen den Alterthümern von Indien und denen von Ägypten.. In: Journal für Literatur, Kunst, Luxus und Mode 34 (1819), S. 728-744, S. 743f.). Auch Heeren will die Frage, ob die Inder Kolonien in Ägypten gehabt hätten, offen lassen, hält sie aber aufgrund der Ähnlichkeiten zwischen den Kulturen für nicht unwahrscheinlich (vgl. Heeren, Arnold Hermann Ludwig: Ideen über die Politik, den Verkehr und den Handel der vornehmsten Völker der alten Welt. Erster Theil. Zweyte Abtheilung. Upsala 1818, S. 499).
} 
Claudius und der englische Angestellte der East India Company, George Forster, gehen davon aus, dass die indische Kultur die ägyptische beeinflusst habe und nicht umgekehrt. Ihre Begründungen dafür unterscheiden sich aber fundamental. Während Forster seine These damit begründet, dass die Inder auf ihre eigene Kultur konzentriert seien, Indien nicht verließen und daher keine Gelegenheit zum Kulturaustausch gehabt hätten und es auch für die These einer ägyptischen Kolonie in Indien keine Beweise gebe ${ }^{205}$ geht Claudius davon aus, dass Ägypten eine indische Kolonie gewesen sei. ${ }^{206}$ Wichtiger als ein möglicher Einfluss auf die ägyptische Kultur ist Claudius allerdings die Frage, ob die Inder indirekt über Ägypten auch die alttestamentarischen Texte geprägt haben könnten. Diese Frage verneint er jedoch deutlich. ${ }^{207}$

Eine andere These für die Verflechtungen der alten Kulturen wird in einem Artikel in Cottas Morgenblatt vertreten:

\begin{abstract}
Was wir Menschen sind und haben, scheint nach seinen ersten Keimen aus Indien zu stammen. Wissenschaftliche Kenntnisse sind dort früher, als in irgend einem Lande der bekannten Erde; kein Land hat so alte Nationalsagen, keines so frühe Religionsinstitute, keines so frühe Beobachtungen des Himmels. Was sich unter einem glücklichen Himmel zuerst entwickelt hat, das scheint darauf durch wandernde Stämme in das westliche Asien getragen worden zu seyn. Doch ist es in dem Lande seiner Verpflanzung nicht geblieben, was es in seinem Urlande gewesen war. Seine Anfänge der Kultur entwickelten sich im Westen von Asien, das seinen Einwohnern größere Anstrengungen zumuthete, schnell zu neuen Anwendungen, und kehrten von da bey einer Rückwanderung in ihr Urland wieder reicher und vollkommener zurück. ${ }^{208}$
\end{abstract}

\footnotetext{
${ }^{205}$ Konkret beruft sich Forster darauf, dass es den Hindus streng verboten sei, den Fluss Attock zu überqueren. Eine Reise über das Meer sei ihnen entweder ebenfalls verboten oder aber durch ihre ihnen vorgeschriebenen speziellen Diäten, welche sie außerhalb ihres Landes kaum einhalten könnten, sehr erschwert (vgl.Forster: Reise aus Bengalen nach England. Erster Theil, S. 84f.). Der These, dass die Inder ihr Land weder über den verbotenen Fluss noch über das Meer hätten verlassen können, widerspricht Meiners (vgl. Meiners, Christoph: Untersuchungen über die Verschiedenheiten der Menschennaturen in Asien und den Südländern, in den Ostindischen und Südseeinseln, nebst einer historischen Vergleichung der vormahligen und gegenwärtigen Bewohner dieser Continente und Eylande. Erster Theil. Tübingen 1811, S. 271).

${ }^{206}$ Vgl. Claudius: Eine asiatische Vorlesung, S. 21

207 „Die Indier konnten nicht von Mose nehmen, weil ihre Schriften so alt als Mose [...]; und Mose hat nicht von den Indiern genommen, weil er viel kürzer und aus der ersten Hand dazu konnte. [...] Die Altväter nach Noah und ihre Traditionen waren aber älter als die Indier, und daher konnten sie freylich ihre Nachrichten haben. [...] Übrigens brauchts deß Alles nicht, denn Mose hatte eine ErkenntnißQuelle, die ihm alle andre unnöthig und überflüssig machte." (Claudius: Eine asiatische Vorlesung, S. 21). Claudius schließt hier, dass die biblische Tradition durch die indische beeinflusst worden sein könnte. Umgekehrt lässt er eine Beeinflussung der indischen Texte durch - allerdings nur die älteste jüdische Tradition offen. Sie sei in ihren frühesten Texten älter und - was das wichtigste ist - Moses habe einen direkten Zugang zur Erkenntnis, die das Studium anderer Texte unnötig mache: die Offenbarung Gottes.

${ }^{208}$ Epochen der Kultur von Indien. In: Morgenblatt für gebildete Stände 2 (1808; Nr. 76 März). S. 301 302, hier S. 301
} 
Wissenschaft und Religion seien laut dem Autor also zunächst aus Indien gekommen, aber sie hätten sich in Westasien aufgrund härterer Lebensbedingungen positiv weiterentwickelt und seien in diesem vollkommeneren Zustand wieder nach Indien zurückgekehrt. Im folgenden Absatz führt er dazu aus, dass im Zuge der Eroberung Indiens durch kriegerische Stämme Priester nach Indien gekommen seien und dort die weiterentwickelte alte Weisheit wieder verbreitet hätten. Aus ihnen habe sich dann die Kaste der heutigen Brahmanen entwickelt. Das Urwissen sei also indischen Ursprungs, habe seine höchste Weisheit aber erst durch die Vervollkommnung im Westen erhalten.

Wird in dem eben zitierten Artikel von einer Vervollkommnung der indischen Kultur im Westen und deren „Reimport“ ausgegangen, so bestreitet Hegel, dass die indische Kultur für die modernen Kulturen überhaupt eine größere Bedeutung gehabt habe:

Indien ist ferner der Ausgangspunkt für die ganze westliche Welt, aber diese äußere welthistorische Beziehung ist mehr nur ein natürliches Ausbreiten der Völker von hier aus. Wenn auch in Indien die Elemente künftiger Entwicklungen zu finden wären, und wenn wir auch Spuren hätten, daß sie nach Westen herübergekommen sind, so ist diese Übersiedelung doch so abstrakt, daß das, was für uns bei späteren Völkern Interesse haben kann, nicht mehr das ist, was sie von Indien übernahmen, sondern vielmehr ein Konkretes, das sie sich selbst gebildet haben, und wobei sie am Besten thaten, die indischen Elemente zu vergessen. Das sich Verbreiten des Indischen ist vorgeschichtlich, denn Geschichte ist nur das, was in der Entwicklung des Geistes eine wesentliche Epoche ausmacht. Nun ist aber Indien nie vorgeschritten, sondern selber nur seiner Größe und seines Reichthums wegen gesucht worden. Und sowie stummer Weise Nordindien ein Ausgangspunkt natürlicher Verbreitung ist, so ist Indien überhaupt als gesuchtes Land ein wesentliches Moment der ganzen Geschichte. ${ }^{209}$

Hegel betrachtet die indische Kultur und Geschichte nur vor dem Hintergrund seiner persönlichen Philosophie ${ }^{210}$ und interpretiert sie entsprechend: Indien gehöre - da

\footnotetext{
${ }^{209}$ Hegel, Georg Wilhelm Friedrich: Vorlesungen über die Philosophie der Geschichte. Herausgegeben von D. Eduard Gans. Berlin 1837 (Georg Wilhelm Friedrich Hegel's Werke. Vollständige Ausgabe durch einen Verein von Freunden des Verewigten; 9), S. 146; die Vorlesungen wurden mehrfach zwischen 1822 und 1831 gehalten und anhand von Mitschriften posthum herausgegeben.

${ }^{210}$ Hegel, der sich zwar mit einigen zeitgenössischen Werken über Indien beschäftigte und sich dadurch auch Wissen über die indische Kultur aneignete, ging nicht nur in der Auswahl seiner Quellen, sondern auch in der Art und Weise seiner Interpretation stets von seiner eigenen Philosophie als Grundlage aus, in die dann das über Indien Gelesene eingepasst wurde. Für ihn ist Geschichte die Geschichte des Geistes, der ein Bewusstsein von seiner Freiheit entwickelt. Diese Entwicklung des Geistes zeige sich auch in der Stufenfolge der verschiedenen Völker. Diese hätten jeweils einen spezifischen, der Entwicklung entsprechenden Volksgeist, der sich in der Kultur des jeweiligen Volkes zeige. Die Geschichtswissenschaft solle sich mit diesem Volksgeist und somit mit der Entwicklung des Geistes beschäftigen und nicht mit einzelnen Individuen. Als notwendige und vernünftige Entwicklung des Geistes sei die Weltgeschichte nicht vom Zufall bestimmt. Dabei geht Hegel davon aus, dass sich der Lauf der Geschichte vom Anfang im Osten bis zu seiner Vollendung im Westen vollziehe. Alle Völker mit ihrer Kultur haben so einen ihnen eigenen notwendigen Platz in der Geschichte, sind aber
} 
Geschichte allein als Geschichte der Entwicklung des Geistes von Interesse sei - zu einer vorgeschichtlichen Zeit. Es sei zwar Ausgangspunkt verschiedener Völker, aber falls diese bei ihrer Wanderung indische Elemente mitgenommen haben sollten, so hätten sie diese so verändert und umgebildet, dass sie als ein selbst Gebildetes gelten könnten. Indien sei Ausgangspunkt einer „natürlichen Verbreitung“, keiner geistigen. Hegel wertet den fehlenden Einfluss indischer Kultur auf die nachfolgenden Völker als positiv: Sie hätten gut daran getan, ,die indischen Elemente zu vergessen“. Indien habe daher keine aktive Rolle in der Geschichte spielen können. Es habe aber eine gewisse passive Bedeutung, da es ein Sehnsuchtsland des in der Geschichte bedeutenden Westens sei. Als gesuchtes Land sei es ein „wesentliches Moment der ganzen Geschichte“. Indien spiele also nur als Objekt westlicher Vorstellungen eine Rolle, nicht als eigenständige Kultur. Es wird für Hegel so als Vorgeschichtliches zum Gegenstück der Geschichte. Und als solches soll es der Bestätigung von Hegels eigenen Vorstellungen dienen. ${ }^{211}$

Während z.B. Müller die Frage nach der Ursprünglichkeit der indischen Kultur aus dem romantisch geprägten Diskurs über Suche nach einem Urmythos betrachtet und Hegel Indien in sein Konzept der Entwicklung des Weltgeistes einpasst, ist ein anderer wichtiger Diskurs, der zur Auseinandersetzung mit der These von Indien als Wiege der Menschheit führt, die bereits genannte Frage nach der Entstehung der Menschheit und der verschiedenen Völker. Während der Ansatz eines Urstaats mit zwei Brennpunkten

durch fortschreitende Höherentwicklung hierarchisch gegliedert. Europa gilt Hegel als das Ende der Geschichte (vgl. z.B. Glasenapp: Das Indienbild deutscher Denker, S. 39-41, 59; Halbfass: Indien und Europa, S. 107-109; Menze: Das indische Altertum in der Sicht Wilhelm von Humboldts und Hegels, S: 287-290; Schnädelbach, Herbert: „Zweite Abteilung: Der objektive Geist. In: Drüe, Hermann u.a.: Hegels „Enzyklopädie der philosophischen Wissenschaften“ (1830). Ein Kommentar zum Systemgrundriß. Frankfurt a. M. 2000 (Hegels Philosophie. Kommentare zu den Hauptwerken herausgegeben von Herbert Schnädelbach; 3), S. 289-316, hier 314-316; Fulda, Hans Friedrich: G. W. F. Hegel. München 2003, S. 236-241; Rajan, Balachandra: Under Western Eyes. India from Milton to Macauly. Durham u. London 1999, S. 100-117)

${ }^{211}$ Vgl. Menze: Das indische Altertum in der Sicht Wilhelm von Humboldts und Hegels, S. 287f.; Glasenapp: Das Indienbild deutscher Denker, S. 39-45; Halbfass: Indien und Europa, S. 107-109; Halbfass, Wilhelm: Hegel, Schelling, Schopenhauer und Indien. In: Zeitschrift für Kulturaustausch 37. Jg. 3. Vj. (Utopie - Projektion - Gegenbild. Indien in Deutschland) (1987), S. 424-433, hier S. 425; Koch: Deutschlands literarisches Indienbild. In: German studies in India 12 (1988), S. 7; Maráthe: Spiegelungen Indiens in der deutschen Literatur des XIX. Jahrhunderts, S. 156 
von Görres ${ }^{212}$ fast wie ein neuer Mythos klingt, ${ }^{213}$ geht es vielen anderen Autoren eben nicht direkt um Indien, sondern um die Frage nach der Verwandtschaft und möglichen Hierarchisierung der Völker.

Im deutschsprachigen Raum sind es vor allem die Thesen Blumenbachs ${ }^{214}$, die Anerkennung und Zustimmung erfuhren. Blumenbach schrieb seine Abhandlung „De generis humanis varietate nativa“ zwar bereits 1775 und damit vor dem

212 Johann Joseph von Görres (1776-1848) setzte sich zunächst für die Ideen der französischen Revolution ein. Nach einer ernüchternden Reise nach Paris wandte er sich 1800 von der aktiven Politik ab und beschäftigte sich vermehrt mit Literatur und Philosophie. In seiner Heidelberger Zeit (18061808) hatte er enge Kontakte zu den Heidelberger Romantikern und setzte sich mit Schellings Naturphilosophie auseinander. Das Konzept des Organischen wurde prägend für sein Denken. Aber auch die katholische Religion gewann im Zuge seiner Auseinandersetzung mit dem Mittelalter an Bedeutung. Vor dem Hintergrund des Gedankens, dass alle Kulturen allein unvollkommen seien und nur zusammen als ein Organismus der Menschheit ihre ganze Bedeutung entfalteten, widmete sich Görres der Mythengeschichte. Doch auch die Politik ließ ihn nicht los. Der von ihm gegründete „Rheinische Merkur“ setzte sich gegen Willkürherrschaft und für eine Verfassung ein (vgl. Roegele, Otto, "Görres, Joseph von" in: Neue Deutsche Biographie 6 (1964), S. 532-536 [Online-Version]; URL: https://www.deutsche-biographie.de/pnd11854019X.html\#ndbcontent).

${ }^{213}$ Er beschreibt einen semitischen Urstaat, von dem aus sich die Semiten ellipsenförmig ausgebreitet hätten. Ein Brennpunkt habe sich am Kaukasus befunden, wo die vorderasiatischen Semiten, die Sonnenkinder, die Wurzel der europäischen Bevölkerung, gesiedelt hätten. Der zweite Brennpunkt habe sich in Indien befunden, wo die hinterasiatischen Semiten, die Mondkinder, beheimatet gewesen seien. Die Semiten hätten den anderen Völkern Bildung und Kultur gebracht und seien dabei in dem Charakter der Völker, zu denen sie gekommen waren, aufgegangen. Die verlorene Ursprache habe sich im Osten zu Sanskrit mit ihren Tochtersprachen entwickelt, im Westen zum ur-chaldäischen, assyrischen Pehlvi. Von den vier Endpunkten der beiden Achsen der Ellipse seien dann die übrigen Völker der Welt ausgegangen. Interessant ist, dass Görres anscheinend von einem Urvolk mit einer Ursprache ausgeht, das semitisch sei und sich in zwei Gruppen geteilt habe. Lediglich über die beiden Gruppen lasse sich anscheinend etwas Konkretes aussagen, die Ursprache sei dagegen verloren. Görres hält mit der These eines semitischen Urvolks an der zuvor so verbreiteten Vorstellung von dem hebräischen Volk als dem Urvolk und der hebräischen Kultur als der ursprünglichsten einerseits fest, verlegt diese Ursprünge aber andererseits in den Kaukasus und nach Indien. Trotz dieser Zweiteilung bekommt Indien bei Görres aber insofern einen Sonderstatus, als er die Veden als am altertümlichsten und den Natursinn am treuesten bewahrend ansieht. (vgl. Görres, Joseph: Mythengeschichte der asiatischen Welt. Erster Band. Hinterasiatische Mythen. Heidelberg 1810, S. XI, XXXIVf.). Eine ähnliche Aufspaltung des Ursprungs in ein semitisches und ein indisches Menschengeschlecht findet sich bereits bei Jones, der Indien mit den Hamiten, den Nachfahren eines der Söhne von Noah, von Sems Bruder Ham, identifizierte (vgl. Ilany, Ofri: „Alle unsere Wanderungen im Orient“. Die deutsche Sehnsucht nach dem Orient - Theologie, Wissenschaft, Rasse. In: Salaymeh, Lena u.a. (Hg.): Der Orient. Imagination in deutscher Sprache. Göttingen 2017 (Tel Aviver Jahrbuch für deutsche Geschichte; 45), S. 41-68, hier S. 55f.; 59f.).

${ }^{214}$ Johann Friedrich Blumenbach (1752-1840) war Professor der Medizin in Göttingen und spielte in der Entstehung der modernen Naturwissenschaft (vor allem der Zoologie und Anthropologie) eine bedeutende Rolle. Er setzte sich mit Hilfe anatomischer Studien mit der Frage auseinander, inwiefern es menschliche Rassen gebe und wich von der verbreiteten Vorstellung ab, dass alle biologischen Formen bereits von Beginn an vorgegeben seien. Vielmehr sei durchaus von Weiterbildungen und Veränderungen im Laufe der Zeit auszugehen (vgl. Kleinschmidt, Adolf, "Blumenbach, Johann Friedrich" in: Neue Deutsche Biographie 2 (1955), S. 329-330 [Online-Version]; URL: https://www.deutsche-biographie.de/pnd116208503.html\#ndbcontent; Lauer, Gerhard: Über Menschen, Schweine und andere Rassen. Die Varietäten der Menschen und ihre zoologischen Kritik in der gelehrten Literatur des 18. Jahrhunderts. In: Gantet, C. und Schock, F. (Hgg.): Zeitschriften, Journalismus und gelehrte Kommunikation im 18. Jahrhundert. Festschrift für Thomas Habel. Bremen 2014, S. 221-232, hier S. 223, 227) 
Untersuchungszeitraum dieser Arbeit. 1798 erscheint aber eine deutsche Übersetzung der dritten Ausgabe, die zeigt, dass Blumenbach auch in dieser Zeit noch rezipiert wird. Blumenbach begründet als Arzt und Physiologe die Einheit aller Menschen naturhistorisch und nicht anhand von kulturellen Merkmalen. Er lehnt die Vorstellung von verschiedenen Menschengattungen ab. Die Menschheit lasse sich zwar in verschiedene Varietäten einteilen, die sich hinsichtlich körperlicher Merkmale voneinander unterschieden, aber die genaue Grenzziehung zwischen den einzelnen Varietäten sei willkürlich, da die Übergänge fließend seien. Er selbst teilt die Menschen in fünf Varietäten ein, wobei er die Europäer, Inder, Westasiaten und Nordafrikaner der kaukasischen Varietät zurechnet. Diese stelle die ursprünglichste Menschenform dar, weil sie in ihren physiologischen Merkmalen genau die Mitte zwischen den Extremen der mongolischen und der äthiopischen Varietät einnehme. Als Physiologe macht er den Ursprungsort der Menschheit nicht an geistigen Merkmalen wie einer besonders alten Kultur und hohen Weisheit oder aber einer vermeintlichen Primitivität fest, sondern allein anhand von körperlichen Merkmalen, indem er davon ausgeht, dass die Unterschiede durch Entwicklungen von einer Mitte zu extremeren Formen hin entstanden. Die Menschheit ist also nach Blumenbach nicht in Indien, sondern am Kaukasus entstanden, auch wenn die Inder durch ihre Zugehörigkeit $\mathrm{zu}$ der kaukasischen Varietät ebenfalls zu der ursprünglichen Menschenvarietät gehörten. Das aber kann man nur erschließen, da Blumenbach die Inder in dieser Schrift in keiner Weise hervorhebt. Er beschreibt vielmehr alle Völker als gleichwertig. Allein die Georgier hebt er aufgrund ihrer Schönheit hervor. ${ }^{215}$

Eine sehr extreme und bereits zu seiner Zeit umstrittene Position vertritt Christoph Meiners. ${ }^{216}$ Er teilte bereits 1785 die Menschheit in zwei Urstämme ein: den

\footnotetext{
${ }^{215}$ Vgl. Blumenbach, Johann Friedrich: Über die natürlichen Verschiedenheiten im Menschengeschlechte. Nach der dritten Ausgabe und den Erinnerungen des Verfassers übersetzt, und mit einigen Zusätzen und erläuternden Anmerkungen herausgegeben von Johann Gottfried Gruber. Leipzig 1798, S. 203-206, 213f., 224

${ }^{216}$ Christoph Meiners (1747-1810) war Philosoph und Ethnograph. 1775 wurde er ordentlicher Professor an der Universität Göttingen. Er war der Ansicht, dass Philosophie auf Psychologie gründen müsse und wandte sich somit gegen Kant. Während er zunächst als nicht unumstrittener Vielschreiber bekannt war, zog er durch seine erstmals 1785 veröffentlichte These, dass die Menschheit in zwei Stämme eingeteilt werden könne, bereits unter Zeitgenossen viel Kritik auf sich. Insbesondere Georg Forster wandte sich gegen Meiners Vorstellung, dass sich die von ihm beschriebenen Stämme nicht nur durch physische, sondern auch intellektuelle und sittliche Voraussetzung unterschieden und dementsprechend unterschiedlich beurteilt und gewichtet werden könnten. Daraus folgte für Meiners auch die Verteidigung der Sklaverei und der Aristokratie. Die seit den 1790er Jahren diskutierte Emanzipation der Juden lehnte er ab (vgl. Prantl, Carl von, "Meiners, Christoph" in: Allgemeine
} 
mongolischen und den kaukasischen. Das geschah bei ihm nicht in dem Sinne, dass er wie z.B. Görres von eher mythischen Urstämmen ausgeht, die im Dunkel der Geschichte versunken sind und von denen die heutigen Völker abstammen, sondern dass er die Menschen in verschiedene Rassen einteilte, die sich hinsichtlich bestimmter körperlicher und geistiger Merkmale unterschieden. Dabei seien die kaukasischen Völker laut Meiners durchgehend stärker, größer, klüger, schöner. Bei den Indern unterschied Meiners zwischen den höheren Kasten, die kaukasisch-slawisch seien, und den niederen Kasten, die mongolisch seien. Insgesamt spielte Indien in seiner Konzeption der menschlichen Völker aber keine große Rolle. Er sah Indien auch nicht als Wiege der Menschheit. ${ }^{217}$ Diese Einteilung der Menschen in verschiedene Rassen behält Meiners auch in seinem zwischen 1811 und 1813 erschienenen Werk „Untersuchungen über die Verschiedenheiten der Menschen-naturen...“ bei. Allerdings beschreibt er die Inder nun nicht mehr als mit den übrigen asiatischen Menschen verwandt, sondern als eine eigenständige Rasse, die wiederum aus zwei unterschiedlichen Menschenklassen bestehe. ${ }^{218}$ In Asien fänden sich zwar die ältesten Kulturdenkmäler, allerdings nicht in Indien. Diese seien vielmehr erst nach den Eroberungen Alexanders geschaffen worden und wie auch die übrigen Künste und Wissenschaften allesamt griechisch geprägt. ${ }^{219}$ Meiners wendet sich hier also völlig von dem Bild Indiens als der Wiege der Menschheit und Kultur ab. Diese aus heutiger Sicht als rassistisch zu bezeichnende Verbindung von körperlichen Merkmalen mit geistigen und moralischen Möglichkeiten wurde von den Zeitgenossen Meiners bereits heftig kritisiert, so dass man hier nur von einer extremen Randposition sprechen kann. $^{220}$

Deutsche Biographie 21 (1885), S. 224-226 [Online-Version]; URL: https://www.deutschebiographie.de/pnd116863498.html\#adbcontent; Lauer: Über Menschen, Schweine und andere Rassen, S. 228; Hoorn: Dem Leibe abgelesen, S. 189-191; Lotter, Friedrich: Christoph Meiners und die Lehre von der unterschiedlichen Wertigkeit der Menschenrassen. In: Boockmann, Hartmut u. Wellenreuther, Hermann (Hgg.): Geschichtswissenschaft in Göttingen. Eine Vorlesungsreihe. Göttingen 1987 (Göttinger Universitätsschriften. Serie A: Schriften; 2)S. 30 - 75, hier S. 36, 46-56, 60-64).

${ }^{217}$ Vgl. Meiners, Christoph: Grundriß der Geschichte der Menschheit. Lemgo 1785; zur Abstammung der Inder S. 26f., 31f.

${ }^{218}$ Vgl. Meiners, Christoph: Untersuchungen über die Verschiedenheiten der Menschennaturen (die verschiedenen Menschenarten) in Asien und den Südländern, in den Ostindischen und Südseeinseln, nebst einer historischen Vergleichung der vormahligen und gegenwärtigen Bewohner dieser Continente und Eylande. Zweiter Theil. Tübingen 1813, S: 233f., 313

${ }^{219}$ Vgl. Meriners: Untersuchungen über die Verschiedenheiten der Menschennaturen. Zweiter Theil, S. $230 \mathrm{f}$.

${ }^{220}$ Vgl. Hoorn: Dem Leibe abgelesen, S: 187-191; zu Meiners Rassentheorie vgl. auch Lotter:

Christoph Meiners, S. 47-51 
Die Frage nach der Verwandtschaft und Abstammung der Völker spielt auch bei Friedrich Schlegel eine Rolle. Er hat zu Beginn seiner Sanskritstudien in Paris einen euphorischen Brief an Ludwig Tieck über seine Studien geschrieben: „Hier ist eigentlich die Quelle aller Sprachen, aller Gedanken und Geschichte des menschlichen Geistes; alles, alles stammt aus Indien ohne Ausnahme.“221 Diese romantische Suche des in Indien vermuteten Ursprungs der menschlichen Kultur ist Ausgangspunkt von Schlegels Studien. Durch seine Hinwendung zum Christentum verliert Indien allerdings mit der Zeit für ihn an Bedeutung. In seinem 1808 erschienenen Buch „Über die Sprache und Weisheit der Indier“‘222 ist diese Euphorie bereits gedämpft, aber Indien wird immer noch als bedeutender Ursprungsort dargestellt. Dabei unterscheidet er zwischen der Verwandtschaft der Völker, die sich in der Verwandtschaft ihrer Sprachen zeige, und der „Einheit des Ursprungs aller asiatischen Bildung“ ${ }^{223}$ und ihre

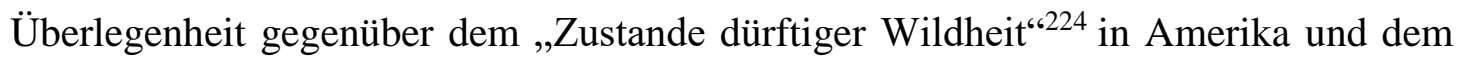
südlichen Afrika. Zur Begründung dieser Einheit der asiatischen Bildung nutzt Schlegel die oben bereits angesprochene These von indischen Kolonien:

\begin{abstract}
Wenn wir hingegen bei den asiatischen Völkern selbst im frühsten Alterthum etwas höheres als Wanderungen ohne einen andern Zweck, als den Drang des Bedürfnisses, wenn wir Einheit und Ähnlichkeit einer tief begründeten Verfassung und Denkart bei ihnen wahrnehmen, so müssen wir uns an die Riesengröße und Festigkeit der Bauart in ägyptischen und indischen Denkmälern, im Gegensatz der gebrechlichen Kleinheit moderner Gebäude, erinnern, um den Gedanken, daß die größten Reiche und vornehmsten Nationen von einem Stamme ausgegangen, daß sie Kolonien eines Volkes, wo nicht unmittelbar, doch mittelbar indische Kolonien seien, nicht zu ungeheuer zu finden. [...] Freilich braucht die Verbindung nicht immer unmittelbar gewesen zu sein; durch wie viele jetzt verlohrne Zwischenglieder mag die Lehre von der Seelenwanderung gegangen sein, ehe sie von Indien aus bis zu den Druiden des alten Galliens gelangte ${ }^{225}$
\end{abstract}

\footnotetext{
${ }^{221}$ Briefe an Ludwig Tieck. Ausgewählt und herausgegeben von Karl von Holtei. Dritter Band. Breslau 1864, S. 329

${ }^{222}$ Dieses Buch, in dem er die Ergebnisse seiner ab 1803 betriebenen Sanskritstudien zusammengefasst hat, ist bei seiner Erscheinung viel beachtet und oft sehr kritisch diskutiert worden. Denn es ist zu einer Zeit erschienen, in der Schlegel vor allem auch durch seine Konversion zum Katholizismus Schlagzeilen gemacht hat; deutliche Hinweise auf seine neue Religiosität sind auch in dem Buch zu finden, was vielen Lesern missfiel. Bedeutend war das Buch aber nicht nur durch die Kontroverse, die es ausgelöst hat, sondern es war eine wissenschaftliche Abhandlung über die alte indische Sprache und ihre Verwandtschaft mit anderen Sprachen von dem ersten deutschsprachigen Autoren, der außerhalb Indiens Sanskrit studiert hatte und damit einen direkteren Zugang zur indischen Literatur bekommen konnte. Damit förderte es das (wissenschaftliche) Interesse an der indischen Sprache und Kultur..

${ }^{223}$ Schlegel, Friedrich: Über die Sprache und Weisheit der Indier. Ein Beitrag zur Begründung der Alterthumskunde. Nebst metrischen Übersetzungen indischer Gedichte. Heidelberg 1808, S. 174

${ }^{224}$ Schlegel, F.: Über die Sprache und Weisheit der Indier, S. 174

${ }^{225}$ Schlegel, F.: Über die Sprache und Weisheit der Indier, S. $174 f$.
} 
Schlegel sieht also nicht nur Ägypten, sondern auch andere alte Hochkulturen durch Kolonien miteinander verbunden. Dabei bedeutet Kolonie für ihn nicht unbedingt, dass große Teile des indischen Volkes ausgewandert sind, sondern auch durch die Auswanderung einzelner Personengruppen könne großer Einfluss entstanden sein. So sei Persien durch eingewanderte Krieger und Adlige geprägt, während in Ägypten der Einfluss eingewanderter Priester besonders hoch gewesen sei. Von der durch Kolonisation entstandenen kulturellen Ähnlichkeit könne man aber nicht direkt auf genetische Verwandtschaft schließen, sondern müsse vor allem die sprachliche Ähnlichkeit berücksichtigen. So seien die Ägypter wiewohl kulturell ähnlich eben nicht mit den Indern verwandt. ${ }^{226}$ Schlegel geht nicht von einer einzigen Ursprache aus, sondern von mehreren, die er aufgrund von Unterschieden in der Entstehung hierarchisiert. Diese zunächst nur anhand der Sprachen erarbeitete Einteilung überträgt Schlegel später auf die entsprechenden Völker. ${ }^{227}$ Die meisten europäischen Sprachen seien aber mit dem Sanskrit verwandt und daher auch die meisten europäischen Völker mit den Indern.

Innerhalb der indogermanischen Völker differenziert Schlegel erneut: Während er die Griechen und Römer auf verwilderte, barbarisch gewordene und einem sinnlichen Naturdienst ergebene indische Kriegerstämme zurückführt, ${ }^{228}$ hätten die Vorfahren der Germanen das klimatisch günstige Indien zugunsten des kalten Nordens verlassen, um den im Norden gelegenen heiligen Berg Meru zu suchen. ${ }^{229}$ Tzoref-Ashkenazi interpretiert diese unterschiedlichen Darstellungen der Auswanderungen europäischer Völker (einmal als Verwilderung und einmal als Suche nach etwas Heiligem) als Versuch Schlegels zu zeigen, dass die Germanen keinesfalls die Barbaren gewesen seien, als die sie oft beschrieben wurden, sondern dass ihre Kultur auf mindestens ebenso hoher Stufe gestanden habe wie die der Griechen und Römer - ja dass ihre

\footnotetext{
${ }^{226}$ Vgl. Schlegel, F.: Über die Sprache und Weisheit der Indier, S. 179f.

${ }^{227}$ Schlegel ist der Ansicht, dass man willkürliche Antworten auf die Frage nach einem gemeinschaftlichen Ursprung zunächst zur Seite legen solle. Vielmehr solle man die Völker ohne vorgefasste Meinung untersuchen und anhand von Kennzeichen für ihr Alters einteilen. Diese Kennzeichen betreffen die Sprache, die Verwendung von Metallen und die Zähmung der Tiere. Insgesamt solle man vorsichtig sein, einzelne Befunde vorschnell als Beweis für verschiedene Menschengattungen anzusehen. Völker können sich verändern, durch das Vermischen von verschiedenen Völkern können neue entstehen und alte Völker können untergehen. (Vgl. Schlegel: Über die Sprache und Weisheit der Indier, S. 166f., 169-172)

${ }^{228}$ Vgl. Schlegel, F.: Über die Sprache und Weisheit der Indier, S. 184f, 187

${ }^{229}$ Vgl. Schlegel, F: Über die Sprache und Weisheit der Indier, S. 193-195
} 
Abkunft vielleicht sogar edler war als die der Mittelmeervölker. ${ }^{230}$ Auch Murti und Pollack sehen in der deutschen Indologie einen Versuch, die eigene Identität in Abgrenzung nicht mehr nur zur klassischen Antike, sondern auch zur christlichen Kultur und den damit verbundenen Semiten zu konstruieren, und ziehen einen Bogen zu Rassismus und Nationalsozialismus. ${ }^{231}$ Tzoref-Ashkenazi betont dagegen, dass der romantische Mythos von Indien zwar national, aber nicht rassistisch oder antisemitisch sei. Statt auf dem späteren Dualismus zwischen Ariern und Semiten basiere er auf einem Dualismus zwischen Indien und Griechenland, wobei dieser Gegensatz eigentlich auf eine Abgrenzung gegenüber Frankreich zielte. ${ }^{232}$ Auch Dusche argumentiert dahingehend, dass Schlegel Indien nutze, um die deutsche Kultur mithilfe einer engen, über sprachliche Verwandtschaft erreichten Anknüpfung an die alte indische Hochkultur von dem französischen Einfluss und damit dem Sinnbild der Moderne zu lösen. ${ }^{233}$ Tzoref-Ashkenazi beobachtet richtig, dass Schlegel in seinem Buch die verschiedenen Sprachen und mit ihnen die Völker hinsichtlich ihrer frühesten Vollkommenheit bzw. Tierähnlichkeit unterscheidet und es ihm um die Fragen nach der Verwandtschaft und Wanderungen der Völker, auch seines eigenen, geht. Dabei verbindet er diese Frage mit politischen Aspekten wie der Ursprünglichkeit der Monarchie oder der Ständegesellschaft (Kastenwesen) und siedelt sein eigenes Volk durch die direkte Abkunft von den Indern sowohl auf sprachlicher als auch auf politischer und religiöser Ebene sehr hoch an. Diese Vorstellungen werden allerdings nicht plakativ in den Mittelpunkt gestellt, sondern eher innerhalb einer weiter gefassten Beschreibung hier und da erwähnt. Die angenommene kulturell höhere Abkunft der Germanen wird der eher barbarischen der Griechen und Römer nicht direkt gegenübergestellt, sondern sie werden an verschiedenen Stellen des Textes in unterschiedlichem Zusammenhang entwickelt. Schlegel geht es nicht um eine

\footnotetext{
${ }^{230}$ Vgl. Tzoref-Ashkenazi, Chen: The Nationalist Aspects of Friedrich Schlegel's On the Language and the Wisdom of the Indians. In: Douglas T. McGetchin u.a. (Hg.): Sanskrit and 'Orientalism'. Indology and Comparative Linguistics in Germany, 1750-1958. New Delhi 2004, S. 107-130, hierS. 110, 119

${ }^{231}$ Vgl. Murti: India. The Seductive and Seduced "Other" of German Orientalism, S. 11, 13, 15, 20; Pollock, Sheldon: Indology, Power, and the Case of Germany. In: Macfie, A. L. (Hg.): Orientalism. A Reader. Edinburgh 2000, S. 302-323

${ }^{232}$ Vgl. Tzoref-Ashkenazi, Chen: Der romantische Mythos vom Ursprung der Deutschen. Friedrich Schlegels Suche nach der indogermanischen Verbindung. Göttingen 2009 (Schriftenreihe des Minerva Instituts für deutsche Geschichte der Universität Tel Aviv; 29), S. 16f.

${ }^{233}$ Indem Schlegel die deutsche Sprache auf eine Stufe mit alten Sprachen wie Latein und Griechisch stelle, Französisch aber nur als Ableitung des Lateinischen wahrnehme, wolle er Deutschland als wahres orientalisches Selbst Europas von Westeuropa abgrenzen, vgl. Dusche, Michael: Friedrich Schlegel's Writings on India. Reimagining Germany as Europe's True Oriental Self. In: Hodkinson, James u.a. (Hg.): Deploying Orientalism in Culture and History. From Germany to Central and Eastern Europe. Rochester N.Y. 2013, S. 31-54.
} 
(rassistisch motivierte) Hierarchisierung der Völker und wohl auch nicht in erster Linie um eine Erhöhung der germanischen Stämme, sondern wohl eher um eine Emanzipation von Frankreich sowie um eine Legitimation der besonders im germanischen Mittelalter noch erkennbaren alten Gesellschaftsformen wie der Monarchie und Ständeordnung sowie vor allem des Christentums.

1808 ist Schlegels ursprüngliche Euphorie bereits gedämpft. In den 1828 in Wien gehaltenen Vorlesungen „Philosophie der Geschichte“ stellt Indien dann nur noch ein Land unter vielen dar, sowohl hinsichtlich seiner Ursprünglichkeit als auch seiner Bedeutung. Schlegel folgt nun den Ausführungen des Alten Testaments und anderer alter Schriften und siedelt den Ursprungsort der Menschheit im mittleren, westlichen Asien zwischen Euphrat und Tigris an. Der Mensch sei ursprünglich ein von dem Wort Gottes erfülltes Wesen, das aber unter der Gewalt der Natur (statt unter der Macht Gottes) Veränderungen ausgeliefert sei bis hin zur Verwilderung einzelner auf diese Art entstehender Rassen. Obwohl Schlegel diese Rassen hierarchisiert, ist es ihm doch von entscheidender Bedeutung, die gemeinsame Abstammung aller Rassen von einem Urvater und die Einheit der Menschengattung zu betonen. Interessant ist, dass er hier das Wort Rasse durchaus negativ betrachtet: Dieses sei immer auch abstoßend. ${ }^{234}$ Schlegel sucht in den verschiedensten alten Überlieferungen nach Hinweisen darauf, dass die Menschheit sich zunächst in zwei Stämme geteilt habe: die kriegerischen, kunstliebenden, unfriedlichen Nachfahren Kains, der nach dem Brudermord nach Ostasien geflohen sei, und den friedlichen, gottesfürchtigen Patriarchen, die die Nachkommen Seths seien. ${ }^{235}$ Auch in den indischen Sagen macht er Hinweise auf den frühen Kampf dieser beiden alten Menschengruppen aus und zwar in den Kämpfen des Brahmanengeschlechts gegen verwilderte Kriegerstämme. Dabei betont er jedoch explizit, dass er keine Rangordnung der Völker aufstelle und keine Entscheidung darüber treffe, welche das höhere Alter habe. ${ }^{236}$ Auch hier geht es ihm also weniger um die Herausstellung einzelner Völker als vielmehr um die Darstellung einer alten göttlichen Weltordnung, die zerfallen sei und sich in Spuren in verschiedenen Kulturen erhalten habe.

\footnotetext{
${ }^{234}$ Vgl. Schlegel, Friedrich: Philosophie der Geschichte. In achtzehn Vorlesungen gehalten zu Wien im Jahre 1828. Erster Band. Wien 1828, S. 28-46

${ }^{235}$ Dabei handele es sich allerdings mehr um einen Gegensatz der Gesinnungen als der Abstammung (vgl. Schlegel: Philosophie der Geschichte, S. 48-55)

${ }^{236}$ Vgl. Schlegel: Philosophie der Geschichte, S. 57, 69f.
} 
Auch Friedrichs Bruder August Wilhelm Schlegel, der sich über seine Sanskritstudien vor allem wissenschaftlich profilieren möchte, setzt sich mit der Abstammung und der Verschiedenheit der Menschen auseinander. Er macht verschiedene Rassen an physiologischen Unterschieden fest, widerspricht aber der von anderen Autoren diskutierten These verschiedener Menschenarten entschieden. Er sieht es allerdings als wahrscheinlich an, dass es Völker gebe, die klüger, und andere, die wilder seien. Letztere würdigt er aber nicht in dem Maße herab, wie einige andere Autoren es zum Teil tun. Die Inder ordnet er der kaukasischen Rasse zu. Sie seien nicht, wie es ihre eigenen Mythen erzählen, in Indien entstanden, sondern aus dem westlichen Asien eingewandert und in Indien auf die dortige wildere Urbevölkerung getroffen. ${ }^{237}$ Indien gilt also auch hier nicht als Wiege der Menschheit. Die Inder bleiben aber wichtig durch ihre Verwandtschaft mit den übrigen indoeuropäischen Völkern und dem hohen Alter ihrer Überlieferungen.

Julius Klaproth ${ }^{238}$, der in seiner Abhandlung „Asia polyglotta“ den Begriff des indogermanischen Sprachstammes einführt und damit besonders die Verwandtschaft der indischen und germanischen Sprachen hervorhebt, betont aber auch klar, dass es richtig sei ,zu sagen, die deutsche Sprache stammt von denselben Wurzeln ab als das Sanskrit, aber unsinnig darum das Deutsche Volk von den Hindu abzuleiten.“239 Klaproth ist zwar die Verwandtschaft der Sprachen wichtig, aber Sanskrit und mit ihm Indien seien nicht Quelle und Ursprung der übrigen Sprachen und Völker, sondern diese leiteten sich von einem gemeinsamen Vorfahren ab.

\footnotetext{
${ }^{237}$ Vgl. Schlegel, August Wilhelm: De l'origine des Hindous. In: Oeuvres. Écrites en Francais et publiées par Eduard Böcking. Hildesheim u. New York 1972, S. 24-94, hier S. 30f. 39f., 49, 51,53

${ }^{238}$ Heinrich Julius Klaproth (1783-1835) interessierte sich bereits seit seiner Jugend für asiatische Sprachen und erlernte sowohl inner- als auch ostasiatische Sprachen. 1804 ging er nach Petersburg und nahm in den nächsten Jahren an zwei russischen Expeditionen zunächst nach Innerasien und anschließend in den Kaukasus und Georgien teil. Diese Reisen nutzte er dazu, umfangreiche Materialsammlungen zu dortigen Sprachen anzulegen. 1815 ging er nach Paris, wo er aufgrund einer durch W. v. Humboldt vermittelten Professur in Berlin verbunden mit der Erlaubnis, trotzdem in Paris $\mathrm{zu}$ leben und zu forschen, sich ohne Geldsorgen seiner wissenschaftlichen Arbeit widmen konnte. Besonders seine großen Materialsammlungen erfuhren viel Anerkennung. Sein Ansatz, ähnlich lautende, bedeutungsgleiche Wörter unterschiedlicher Sprachen ohne kritische Nachforschungen als verwandt anzusehen, stieß allerdings bereits bei einigen Zeitgenossen auf Kritik (vgl. Naundorf, Gert, "Klaproth, Heinrich Julius" in: Neue Deutsche Biographie 11 (1977), S. 706 f. [Online-Version]; URL: https://www.deutsche-biographie.de/pnd10082451X.html\#ndbcontent; Heinrich Julius Klaproth. In: Brockhaus Enzyklopädie Online. Versionsdatum: 2021-07-10, https://brockhaus.de/ecs/permalink/4ED75CE3B5A8F2A2CA110D1FB8BAE90B.pdf)

${ }^{239}$ Klaproth, Julius: Asia polyglotta. Paris 1823, S. 43
} 
Insgesamt lässt sich sagen, dass die Frage, ob und inwieweit Indien als Ursprungsland der Menschheit und der menschlichen Kultur gelten kann, um 1800 keinesfalls so eindeutig beantwortet wird, wie der vielzitierte Topos manchmal den Anschein hat. Auch wenn dem Topos so deutlich entgegenstehende Ansichten wie die von Meiners wohl eher die Ausnahme sind, so gibt es auch andere kritische Stimmen, die davor warnen, den Ursprung von allem vorschnell in Indien zu verorten. ${ }^{240}$ Wie wir gesehen haben, unterscheiden sich aber auch diejenigen, die von Indien als dem Ursprungsort überzeugt sind, sehr in ihrer Beurteilung dieser Annahme. In jedem Fall ist das Andere (und damit auch Indien) innerhalb dieses Diskurses in erster Linie nicht als solches von Interesse, sondern dient entweder der Suche nach den Ursprüngen (und damit verbunden der Identifizierung und Abgrenzung) des Eigenen oder aber der Begründung bzw. Ablehnung der Hierarchisierung der Völker und somit der Bestätigung bzw. Ablehnung bestimmter weltanschaulicher Vorstellungen. Der Diskurs über Indien als Wiege der Menschheit ist also geprägt von anderen Diskursen, die ihn zum einen überhaupt erst anregen und zum anderen auch die inhaltliche Ausrichtung beeinflussen.

Es stellt sich die Frage, ob es diese Thesen betreffend eine zeitliche Entwicklung gibt und wie diese gegebenenfalls ausgesehen hat. Ein Hinweis auf eine solche Entwicklung kann die Aussage in einer Rezension von Müllers „Glauben, Wissen und Kunst der alten Hindus“ in der Jenaischen Allgemeinen Literatur-Zeitung sein:

Der Vf. stellt mit einer Glaubensfreudigkeit, die Bewunderung erregt, [...] die eben jetzt zum Theil so lebhaft bestrittenen Ansichten und Behauptungen auf: ,Das alte Hindostan sey die Wiege der historisch zu erreichenden Menschheit; die ersten Menschen seyen die vollkommensten gewesen, strahlend im Lichte göttlicher Schönheit, Wahrheit und Offenbarung $[\ldots]$ '..241

Der Rezensent macht zwar nicht deutlich, welche der beiden Annahmen - Indien sei die Wiege der Menschheit oder die ersten Menschen seien die vollkommensten - umstritten sei, aber es fällt schon auf, dass einige der untersuchten späteren Texte eine eher

\footnotetext{
${ }^{240}$ So schreibt z.B. Windischmann, dass vor schnellen Folgerungen, dass aus Indien alles wie aus einem „Urborn“ hervorgegangen sei, gewarnt werden müsse (Bopp, Franz: Über das Conjugationssystem des Sanskritsprache in Vergleichung mit jenem der griechischen, lateinischen, persischen und germanischen Sprache. Nebst Episoden des Ramajan und Mahabharat in genauen metrischen Uebersetzungen aus dem Originaltexte und einigen Abschnitten aus den Veda's.

Herausgegeben und mit Vorerinnerungen begleitet von Dr. K. J. Windischmann. Frankfurt a.M. 1816, S. XVII).

${ }^{241}$ Ergänzungsblätter zur Jenaischen Allgemeinen Literatur-Zeitung 84 (1823), Sp. 281
} 
kritische Haltung in zumindest einer der beiden Annahmen einnehmen (sei es wie bei Hegel durch eine teleologische Ausrichtung der Geschichtsphilosophie, die keine frühe Vollkommenheit kennt, sei es durch mahnende Kritik an voreiligen Schlüssen oder die Annahme einer Polygenese der Völker). Nimmt man die Aussage Majers ${ }^{242}$ aus dem Jahr 1798 hinzu, dass man ,besonders in unsern Tagen manche scharfsinnige Hypothese aufgestellt [hat], deren Absicht es war uns zur Entdeckung desjenigen Landes zu führen, dessen Bewohner als Volk im Besitz der Anfänge der Künste und Erfindungen und aller höhern Kultur gewesen sind $[\ldots]^{« 243}$ - gemeint ist Indien im Gegensatz zu Ägypten -, so zeichnet sich die grobe Tendenz ab, dass Ende des 18. Jahrhunderts Indien beginnt, als Ursprungsort populär zu werden, und dass diese Popularität in der ersten Hälfte des 19. Jahrhunderts wieder abnimmt. Eine Erklärung dafür wäre, dass das Motiv häufig mit der Idealisierung Indiens als Ursprungsort nicht nur der Menschheit und ihrer Kultur, sondern auch der Wissenschaften, Künste und der Religion sowie einer ursprünglichen Weisheit verbunden ist. Und je mehr dieser romantische Diskurs über die Suche nach der verlorenen Einheit von Wissenschaft und Kunst, von Religion und Poesie an Anziehungskraft verliert und in der Spätromantik das Christentum und die eigene Geschichte und Kultur wichtiger werden, desto leichter kann Indien - auch im Zuge der Institutionalisierung der Indienstudien als Wissenschaft - als einem Land unter vielen sein Platz in der Geschichte der Menschheit zugewiesen werden.

\section{Kolonialismus und Kastenwesen - das gegenwärtige Indien}

\subsection{Der indische Subkontinent - Geographie, Flora und Fauna}

Geographische Angaben spielen vor allem in den Reiseberichten und natürlich in den Lexikonartikeln eine wichtige Rolle. Sie finden sich auch in allgemeinen Abhandlungen über Indien. Außerdem gibt es eine Reihe von Landkarten Indiens, die im Rahmen dieser Arbeit aber nicht weiter untersucht werden sollen. In den übrigen

\footnotetext{
${ }^{242}$ Georg Gottlob Friedrich Majer (1772-1818) war Kulturhistoriker und Orientalist. Er hatte zunächst Jurisprudenz und Staatswissenschaften in Jena studiert und war an der dortigen Bibliothek tätig. 1804 wurde er Gouverneur des Erbprinzen von Reuß-Schleiz. Sein Interesse galt der Kulturgeschichte und Mythologie. Außerdem wurde durch ihn Schopenhauers Faszination für Indien geweckt (vgl. Schillers Werke. Nationalausgabe. 36. Band, Teil II. Briefwechsel. Briefe an Schiller. 1.11.1795-31.3.1797. Anmerkungen. Herausgegeben von Norbert Oellers. Weimar 1976, S. 223; Halbfass: Indien und Europa, S. 122).

${ }^{243}$ Majer, Friedrich: Zur Kulturgeschichte der Völker. Historische Untersuchungen. Zweiter Band. Leipzig 1798, S. 12
} 
Texten zu Indien spielt die Geographie nur insofern eine Rolle, als immer wieder das besondere Klima für verschiedene Argumentationen herangezogen wird.

Die hier untersuchten Lexikonartikel und auch einige Abhandlungen beginnen ihre Beschreibung mit Angaben zur Größe, geographischen Lage und Untergliederung Indiens. Diese Beschreibungen ähneln einander, sind relativ sachlich und scheinen (auch wenn sie sich in Details unterscheiden) im Großen nicht weiter umstritten zu sein. ${ }^{244}$ Reisende und Missionare gehen dagegen weniger auf Indien als Ganzes ein, sondern konzentrieren sich vielmehr auf lokale Begebenheiten. Die indische Flora und Fauna wird ebenfalls vor allem in den Reiseberichten geschildert, es finden sich aber auch einzelne Artikel sowohl in den populären Journalen als auch in den wissenschaftlichen Zeitschriften. Insgesamt spielt dieser Aspekt Indiens in den Zeitschriftenartikeln aber eine deutlich untergeordnete Rolle und soll auch in dieser Arbeit nur relativ kurz angeschaut werden. Dabei sind es vor allem drei Themen, die immer wieder ins Auge fallen und zwar vor allem durch ihre Lust am Exotischen: der große Reichtum der Natur, das extreme Klima sowie die faszinierende Tierwelt.

Beide Lexikonartikel betonen den Reichtum der indischen Natur. So heißt es in der Auflage von 1809: „Kein Stück der alten Welt ist reicher als dieses an innern Schätzen und für die handelnden Europäer ergiebiger; Edelsteine, besonders Diamanten, und edlere Metalle, Gewürze und edle Früchte aller Art [...] finden sich in ungeheuerm Überfluß in diesem herrlichen Lande [... $]^{\text {“ }}$. ${ }^{245}$ In der Auflage von 1815 wird Indien aus europäischer Sicht aufgrund seines Reichtums sogar als „Wunderland“246 bezeichnet. Auch Ehrmann betont die reiche Fülle der indischen Natur:

Indien [...] ist ein ungemein schönes, reizendes, unter dem glücklichen Himmelsstriche liegendes, fruchtbares und sehr reiches Land, das nicht mit Unrecht von Vielen für das sogenannte Paradies, für die Wiege des Menschengeschlechts gehalten wird. Die Natur hat dieses Land besonders verschwenderisch ausgestattet und reichlich mit seinen schönsten Geschenken gesegnet, so daß schon in den frühesten Zeiten die Nachbarn es seines Reichtums wegen beneideten. ${ }^{247}$

\footnotetext{
${ }^{244}$ Vgl. Conversations-Lexikon. 1809, S. 326-332; Conversations-Lexikon. 1815, S. 715; Ehrmann

(Hg.): Neueste Kunde von Asien. Zweiter Band, S. 8 u. 19

${ }^{245}$ Conversations-Lexikon 1809, S. 327

${ }^{246}$ Conversations-Lexikon 1815, S. 709

${ }^{247}$ Ehrmann: Neueste Kunde von Asien. Zweiter Band, S. 19f.
} 
Während der Lexikonartikel von 1815 diesen Reichtum unter dem Begriff des Wunders zu fassen sucht - Indien galt wie oben gesehen bereits in der Antike als das Land der Wunder -, so greift Ehrmann hier einen Topos auf, der im Zusammenhang mit Indien ebenfalls weit verbreitet war, nämlich den bereits im Mittelalter verwendeten des (irdischen) Paradieses. Lag im Mittelalter - wie oben gesehen - der Schwerpunkt noch auf der Übereinstimmung der Informationen zu Indien mit den Schilderungen der Bibel (vgl. die Flüsse des Paradieses), so verbindet Ehrmann das Paradies mit dem oben beschriebenen, von Herder populär gemachten Topos Indiens als Wiege der Menschheit. Die Paradiesvorstellung wird also in gewisser Weise säkularisiert, indem Indien weniger als biblisches Ursprungsland fungiert, sondern vielmehr als Ursprungsland der Menschheit und der menschlichen Zivilisation Bedeutung erlangt. Das Land sei zwar gesegnet, allerdings nicht direkt von Gott, sondern von der Natur. In einem „Die Hindus“ überschriebenen Zeitschriftenartikel von 1791 heißt es:

Dieses Land ist ohnstreitig eines der fruchtbarsten in der bekannten Welt.
[...] Die Elephanten der Indianer waren die besten von der Welt, die Wälder
dieses Landes bevölkert von Thieren mancherley Art und die Berge
reichhaltig an Silber, Gold und edlen Steinen; - kurz hier schien Mutter
Natur [...] sich in ihrer größten Vollkommenheit zeigen zu wollen; hier hatte
sie reichlich ihre Gaben gespendet; hier floß aus ihrer milden Hand
Überfluß in allen ihren Reichen; hier schien sie ihre Kinder ohne Arbeit
nähren zu wollen; hier war es, wo sie jenen biblischen Spruch: Im Schweiß
deines Angesichts solt du dein Brod essen, förmlich zu widersprechen
schien.

Auch Perrin verweist auf die ungeheure Fruchtbarkeit des Landes, aber nicht ohne im gleichen Satz darauf hinzuweisen, dass viele Ressourcen aufgrund der Versäumnisse der Herrscher oftmals ungenutzt blieben. ${ }^{249}$ Anders als im Lexikonartikel und bei Ehrmann, wo eher ein Staunen und Bewundern von Ferne zum Ausdruck kommen, hat der Missionar Perrin, der selbst lange Zeit in Indien verbracht hat, viel deutlicher ein selbst erlebtes Bild eines konkreten zeitgenössischen Landes vor Augen, dessen praktische Probleme ihm nicht entgehen. ${ }^{250}$

\footnotetext{
${ }^{248}$ Klaußner: Die Hindus, S. 510f.

${ }^{249}$ Vgl. Hell, Theodor: M. Perrin's Reise durch Hindostan und Schilderung der Sitten, Einwohner, Natur-Producte und Gebräuche dieses Landes nach einem sechszehnjährigen Aufenthalte dasselbst. Nach dem Französischen bearbeitet von Theodor Hell. Wien 1811, S. 16

${ }^{250}$ Auch in einem Brief des Soldaten Peter Joseph du Plat, der 1783 mit einem hannoverschen Regiment nach Madras kommt (vgl. Tzoref-Ashkenazi, Chen: The Outsinder's Perspective on Colonial Conflict: A Hanoverian Officer's Narrative of the Second Anglo-Mysore War, 1783-1784. In: Ahuja, Ravi u. Christof-Füchsle, Martin (Hgg.): A Great War in South India. German Accounts of the AngloMysore Wars, 1766-1799. Berlin/Boston 2020, S. 319-343, hier S. 319) wird die Diskrepanz zwischen bestimmten tradierten Vorstellungen und der vor Ort erfahrenen Realität deutlich: „Es ist also in allen Betracht nicht daß paradisische Land, das wir in unsern Lande träumeten, nicht sind die Geld und
} 
Durch die Betonung des ungeheuren Reichtum Indiens wird das Land dem Eigenen kontrastierend entgegengesetzt. Bei der damit verbundenen Idealisierung geht es aber weniger darum, gezielt Indien zu erhöhen oder das Eigene zu kritisieren, sondern das Hauptmotiv scheint die Faszination für das Exotische und Wunderbare zu sein, die sich anhand dieses bereits seit der Antike populären Motivs ausdrückt und - zumindest bei den Reiseberichten und populären Zeitschriften - dem Unterhaltungswert Rechnung trägt. Auch bei der Beschreibung des indischen Klimas richtet sich das Interesse fast ausschließlich auf für die Europäer ungewohnte und mit dem Reiz des Fremden verbundene Extreme: die Hitze und der Monsun auf der einen Seite, sowie gemäßigte Schönheit zu den übrigen Jahreszeiten und bei Nacht. So beschreibt Perrin ausführlich die Regenzeit und verschiedene Winde. Besonders der Westwind sei „der lästigste und verderblichste“. 251

\begin{abstract}
Er weht ziemlich leise, aber er weht Gluth, eine verzehrende Gluth, welche die Kraft des stärksten Mannes lähmt, und, ohne Schweiß zu erregen, den Körper austrocknet. [...] Die Wirkungen dieses mörderischen Windes sind eben so schnell als verderblich. Einer meiner Missions-Brüder, der noch jung war, wurde während der Mahlzeit davon ergriffen, fiel augenblicklich bewußtlos hin, und starb einige Minuten darauf. ${ }^{252}$
\end{abstract}

Für das Klima, das „im größten Theile Hindostans ziemlich unangenehm ist“ werde man aber „durch den Genuß der herrlichen Nächte fast entschädigt [...]. Nichts gleicht

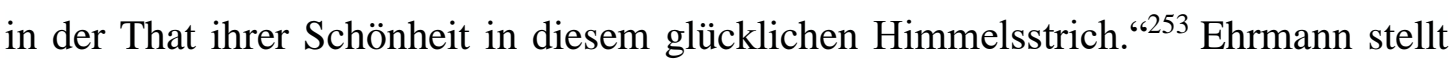
das schöne und gemäßigte Klima Nord- und Mittelindiens der extremen Hitze des Südens gegenüber, die er noch ausführlicher als Perrin aber ebenso anschaulich in ihrer Unerträglichkeit schildert. ${ }^{254}$ Sowohl bei Perrin als auch bei Ehrmann verbinden sich hinsichtlich des Klimas also Idealisierung und Darstellung des Anderen als monströses Fremdes. ${ }^{255}$ Neben der Faszination für Wetterextreme spielt das Klima eine wichtige

Diamanten Mienen, so offen, wie die Sage verbreitet hatte, nichts ist auch hier ohne Mühe und Arbeit, doch haben von der andern Seite so viele unrecht, die dem Land hier alles Gute absprechen [...].“ (Plat, Peter Josef du: Brief vom 29. März 1784. In: Ahuja, Ravi u. Christof-Füchsle, Martin (Hgg.): A Great War in South India. German Accounts of the Anglo-Mysore Wars, 1766-1799. Berlin/Boston 2020, S. 345-355, hier S. 254).

${ }^{251}$ Hell: M. Perrin's Reise durch Hindostan, S. 14

${ }^{252}$ Hell: M. Perrin's Reise durch Hindostan, S. 14

${ }^{253}$ Hell: M. Perrin's Reise durch Hindostan, S. 15

${ }^{254}$ Vgl. Ehrmann: Neuste Kunde von Asien. Zweiter Band, S. 20-23

${ }^{255}$ Die Betonung der großen Hitze vor allem in Berichten von Indienfahrern hat aber auch ganz praktische Gründe: Die Europäer waren dieses Klima nicht gewohnt und litten daher sehr darunter. Auch viele Todesfälle wurden auf die große Hitze zurückgeführt (vgl. z.B. Plat: Brief vom 29.Mürz 
Rolle als Argument, das im Rahmen der Klimatheorie zur Erklärung vieler der beobachteten Phänomene herangezogen wird.

Eine ähnliche Verbindung von Idealisierung und Darstellung als monströsem Fremden lässt sich auch bei der Darstellung der Tier- und Pflanzenwelt beobachten. Diese wird ob ihres Reichtums und ihrer Pracht in gewisser Weise idealisiert, durch das häufige Herausstellen der Gefährlichkeit und Größe einiger Tiere aber auch mit einem gewissen Reiz des Monströsen versehen. Auch wenn die meistens Autoren auch verschiedene andere „normale“ und harmlose Tierarten aufzählen, liegt der Fokus der Beschreibungen sehr häufig auf großen und gefährlichen Tieren wie z.B. Elefanten, Tigern und vor allem Schlangen. Dabei können die Tiere einfach als exotische Wesen beschrieben oder im Kontext des Alltags der Menschen thematisiert werden. So werden z.B. verschiedene Möglichkeiten, Schlangenbisse zu behandeln, diskutiert ${ }^{256}$, der Angriff eines Tigers geschildert ${ }^{257}$ oder wilde Jagden beschrieben. ${ }^{258}$

Während in den Reise- und Missionsberichten, den eher populären Artikeln und interessanterweise auch in den Lexikon-Artikeln eine gewisse Sensationslust die Auswahl und Aufbereitung der Themen motiviert, ähneln sich in der wissenschaftlichen Literatur zwar die vordergründigen Themen, aber die damit

1784, S. 355 „Das hiesige Clima ist der Kirchhoff der Europäer, da die Hitze den Körper ausmargelt, ihn matt und elend macht. Die vorzüglichsten Krankheiten sind hier der Sonnenstich [...] die Leberkrankheit, Ruhr und Krampfe, jeder Sonnenstich tödtet den Europäer in einen Augenblick, er fällt hin, und ist gleich todt.")

${ }^{256}$ Vgl. Des Fra Paolino da San Bartolomeo Reise nach Ostindien, S. 212-230, 245-253;

Conversations-Lexikon 1815, S. 709f.; Schulze (Hg.): Neuere Geschichte der Evangelischen MissionsAnstalten zu Bekehrung der Heiden in Ostindien. Vierter Band, 43. Stück, S. 648-656; Briefe eines italienischen Reisenden, S. 31-34; Ehrmann: Neueste Kunde von Asien. Zweiter Band, S. 31-39 (Ehrmann hebt allerdings die großen und giftigen Tiere deutlich weniger stark hervor als so manche anderen Autoren)

${ }^{257}$ Vgl. Seltsames Gefecht zwischen einem Tyger und mehreren englischen Soldaten. In: Verbesserter und Alter Voll-kommener Staats-Kalender, Genannt der Hinkende Bott. Lahr 1801, S. 67 2v; Susanne Greilich, die Orientbilder in Volksalmanachen des 18. und 19. Jahrhunderts untersucht hat, stellt ebenfalls fest, dass besonders wilde Tiere im allgemeinen sowie die Jagd auf sie die Leser im 19. Jahrhundert fasziniert haben (vgl. Greilich, Susanne: Orientbilder in französisch- und deutschsprachigen Volksalmanachen des achtzehnten und neunzehnten Jahrhunderts. In: Jahrbuch der Rückert-Gesellschaft e.V. 15 (2003), S. 60-78, hier S. 70)

${ }^{258}$ Vgl. z.B. Beschreibung einer Indischen Jagd (Auszug aus dem Briefe eines Engländers). In: Asiatisches Magazin 1 (1802). 2. Stück, S. 169-174; Merkwürdige Thierhetze zu Seringapatnam. Aus dem Essai sur l'Indoustan par Mr. Legoux de Flaix. In: Morgenblatt für gebildete Stände 2 (1808; Nr. 209; August), S. 835; Die Jagdpartien der Engländer in Indien. Nach der in den Asiatic Researches enthaltenen Erzählung des Obristen Ironside. In: Morgenblatt für gebildete Stände 6 (1812; Nr. 147+148; Juni), S. 585-587, hier 589-591; Die Tigerjagden in Indien. In: Morgenblatt für gebildete Stände 7 (1813; Nr. 284; November), S. $1134 f$. 
verbundene Zielrichtung ist eine andere. So gibt es im ersten Band der Indischen Bibliothek einen Artikel zur Geschichte des Elefanten, also eins großen, exotischen Tieres. Aber schon ein Blick in die Einleitung des Artikels verrät, dass diese Beschreibung sich inhaltlich deutlich von den bisher betrachteten unterscheidet:

\begin{abstract}
Wenn ich es unternehme, einen Beytrag zur Geschichte des Elephanten zu liefern, so fasse ich den Begriff der Geschichte in dem allgemeinsten Sinne. Denn es giebt nicht bloß eine natürliche Geschichte des Elephanten [...]; sondern das merkwürdige Thiere hat auch seine politische und militärische, ja vermöge des Eindrucks, den es auf den menschlichen Geist gemacht, seine mythologische, artistische und litterarische Geschichte. ${ }^{259}$
\end{abstract}

Der Elefant wird nicht nur als ein Tier wahrgenommen, dass man mit Methoden der Zoologie beschreiben kann, sondern es erlangt vor allem in seiner Beziehung zum Menschen seine Bedeutung und zwar nicht wie z.B. bei Paulinus a Sancto Bartholomaeo als eine direkte Bedrohung, sondern in seinem Wirken auf die menschliche Geschichte und Vorstellungswelt. Der Elefant wird also in einen deutlich weiteren Rahmen gestellt. Verschiedene Artikel zur Zoologie und Botanik im selben Band widmen sich dem Beobachteten zwar wieder rein aus biologischer Sicht, aber auch sie unterscheiden sich insofern von den bereits betrachteten Beschreibungen, als sie nicht die bekanntesten und als typisch indisch geltenden Tiere und Pflanzen beschreiben, sondern Wert darauf legen, neu entdeckte Arten vorzustellen. ${ }^{260}$ Den wissenschaftlichen Artikeln geht es also deutlich weniger um den Unterhaltungswert des Beschriebenen und dessen Darstellung als etwas Fremdes und Exotisches.

\title{
3.2 Die Inder
}

Die Schilderungen des Aussehens, des Charakters und der Sitten der Inder (gemeint sind hierbei fast ausschließlich die Hindus, die Muslime gelten zumeist als Eroberer und damit Einwanderer ${ }^{261}$ ) ähneln sich in den verschiedenen Textsorten und über die

\footnotetext{
${ }^{259}$ Zur Geschichte des Elephanten. In: Indische Bibliothek. Eine Zeitschrift von August Wilhelm von Schlegel. Erster Band. Bonn 1823, S. 129-231, hier S. 129

${ }^{260}$ Vgl. Botanik. In: Indische Bibliothek. Erster Band. Bonn 1823, S. 390-393 und Zoologie. In:

Indische Bibliothek. Erster Band. Bonn 1823, S. 393-399

${ }^{261}$ Eine Beschreibung der muslimischen Einwohner Kalkutta findet sich in einem Artikel aus dem Morgenblatt für gebildete Stände: „Die Mahomedaner sind hier (in Kalkutta) verhältnißmäßig ungefähr so zahlreich, wie die Protestanten in Irland. Sie bilden einen schöneren Schlag Menschen als die Hindus, haben auch im Allgemeinen mehr Erziehung und scheinen mir im Ganzen ein besseres Volk, in soweit auch ihre Religion besser ist. Sie sind hochmüthig und zornig, feindselig gegen die Engländer gesinnt, als gegen ein Volk, das ihnen die Herrschaft über das Land entrissen, auffallend geizig und hart gegen ihre abgöttischen Landsleute, wo sie nur immer Einfluß haben. Sie sind redlicher oder gelten doch dafür, und gegen ihres Gleichen auch wohlthätig; doch sind sie, wie mir scheint, bey
} 
Zeit hinweg sehr. Grob gesagt kann man die Beschreibungen in zwei Kategorien einteilen: Zum einen gibt es Texte, die die Inder sehr positiv beschreiben und als Vorbild von Europäern oder auch muslimischen Bewohnern Indiens abgrenzen. Sie enthalten zwar auch einige negative Aspekte, die die Grundtendenz aber nicht ändern. Zum anderen gibt es Texte, in denen die Inder mit sehr negativen Eigenschaften versehen werden. Die wenigen positiven Attribute werden oft heruntergespielt oder ins Negative verkehrt. Die unterschiedlichen Beurteilungen der Inder hängen zumeist mit der Rolle, die Indien in dem Weltbild des jeweiligen Autors einnimmt, und dem jeweiligen diskursiven Rahmen zusammen. Dementsprechend suchen sich viele Autoren passende Zitate aus der Literatur über Indien oder beobachten die Inder vor dem Hintergrund bestimmter Erwartungen oder in bestimmten Kontexten. Dieser Zusammenhang ist wenig verwunderlich und war zu erwarten. Interessant dabei ist jedoch, dass bei der Beschreibung der Inder immer wieder - und zwar von beiden Seiten - auf einige wenige, z.T. bereits seit der Antike tradierte Stereotype zurückgegriffen wird, die dann in die jeweils eine oder andere Richtung gedeutet und weiterentwickelt werden. $\mathrm{Zu}$ diesen Stereotypen gehört vor allem die Vorstellung, dass die Inder ruhig und zurückhaltend seien (was sie als sanft, duldsam und tolerant oder aber als träge, phlegmatisch und weiblich erscheinen lassen kann). Auch ihre Leidenschaftslosigkeit wird immer wieder betont (gedeutet entweder als positive Errungenschaft gegenüber negativen Gefühlen und Temperamenten sowie als Gelassenheit und Furchtlosigkeit bei Schicksalsschlägen oder aber negativ als Kaltherzigkeit und fehlendes Mitleid). ${ }^{262}$ Auch die vermuteten Ursachen für das So-Sein der Inder sind immer wieder die gleichen, oft bereits in antiken Texten: das Klima, die Religion, Mäßigkeit sowie der Verzicht auf Alkohol und Fleisch. Viele der den Indern zugeschriebenen Attribute ähneln denjenigen, die Said als Merkmale des Orientalismus ausgemacht hat und die im entsprechenden Kapitel oben beschrieben worden sind. Dazu gehört vor allem die Darstellung der Inder als weichlich oder auch weiblich. Einige Autoren entwerfen tatsächlich statische, essentialistische Bilder der Inder. Sie schreiben von „dem“ Inder, ohne zwischen verschiedenen Individuen zu unterscheiden. Das trifft im Übrigen auch auf die positiven, idealisierenden Indienbilder zu: Hier ist „der“ Inder nicht weichlich, sondern sanftmütig und tugendhaft. Individuelle Charakterzüge und Unterschiede

weitem nicht so nahe daran, das Christenthum anzunehmen als die Hindus, wenn gleich Manche unter ihnen unsere heilige Schrift lesen und häufig von den Christen sprechen, als wäre zwischen ihrer Religion und dem Islam ein geringer Unterschied.“" (Skizzen aus Ostindien. In: Morgenblatt für die gebildeten Stände 22 (1828, Nr. 71, März), S. 281)

262 Vgl. auch Amman: Östliche Spiegel, S. 39f. 
spielen aber auch hier kaum eine Rolle. So stehen sich in einem Großteil der Texte zwei stereotypische Bilder der Inder oder einzelne Aspekte davon gegenüber. Dabei zielen die entworfenen Bilder häufig auf die europäischen Leser und dienen als positives oder negatives Gegenbild zur europäischen Gesellschaft.

Schauen wir uns zunächst die überwiegend wohlwollenden Beschreibungen der Inder an. Bekannt und für die späteren Texte einflussreich waren auch hier die Ausführungen Herders in seinen „Ideen“. Er beschrieb die Inder als sanftmütig, zart, anmutig und schön. Ihre Seele habe eine stille Tiefe und sie seien höflich, tolerant und duldsam. Außerdem seien sie sehr reinlich und gebildet, sogar die niedrigsten Stämme könnten lesen und schreiben. Immer wieder betonte Herder die Tugend der Mäßigkeit bei den Indern: Mäßigkeit im Genuss, Verzicht auf Fleisch und Alkohol. Diese Mäßigung sei „ohne Zweifel eine kräftigere Methode zur Philosophie der Humanität als tausend gelernte künstliche Abstraktionen“263. Sie sei neben dem milden Klima sowie dem positiven Einfluss der Brahmanen die Ursache für die beschriebenen Charaktereigenschaften. ${ }^{264}$ Dabei entwirft Herder anhand der (ihm oft vorgeworfenen) Idealisierung der Inder ein Gegenbild zu der von ihm in einigen Aspekten kritisierten modernen europäischen Kultur und hat daher bei seiner Auswahl der indischen Charakterzüge immer auch die Europäer im Blick. Es geht ihm also weniger darum, die Inder als besonders positiv darzustellen, sondern sie den Europäern als Vorbild entgegenzusetzen und so seine Vorstellungen von Humanität zu verdeutlichen. Dabei wählt er gezielt die Tugenden der Inder aus, die dem modernen Europa seiner Ansicht nach fehlten. ${ }^{265}$ Bereits in der antiken und mittelalterlichen Tradition der Alexanderromane kam Indien eine ähnliche Funktion als Kontrastfolie für Missstände innerhalb der eigenen Gesellschaft und als positives Vorbild zu. In diesem Fall wurden die Brahmanen und Gymnosophisten dem stolzen Alexander als weise Asketen gegenübergestellt und verkündeten Ansichten der Kyniker und Stoiker bzw. galten zwar als Heiden, die aber dennoch durch ihr Verständnis des Gesetzes der Natur christliche Tugenden lebten. ${ }^{266}$

\footnotetext{
${ }^{263}$ Herder: Ideen zur Philosophie der Geschichte der Menschheit, S. 199

${ }^{264}$ Vgl. Herder: Ideen zur Philosophie der Geschichte der Menschheit, S. 160-163, 199f. 293

265 Vgl. auch Frank: Sanftes Gefühl und stille Tiefe der Seele, S. 16f., 145f.

${ }^{266}$ Vgl. Kragl: Die Weisheit des Fremden, S: 203-206, 245, 313f.; auch Marco Polo beschreibt die

Brahmanen als weise und enthaltsam (keusch, Vegetarier) sowie als naturverbunden, aber er stellt sie nicht direkt den Europäern entgegen (vgl. Kragl: Die Weisheit des Fremden, S. 281f)
} 
Wie verbreitet diese Stereotypen zur Beschreibung der Inder waren, zeigt ein Blick in Textausschnitte verschiedener Autoren. Der Missionar Paulinus a Sancto Bartholomaeo beschreibt die Inder als gewandt, behende und schwach, dabei aber höflich und gefällig. Sie handelten aus Überlegung heraus und führten einen gemäßigten, ehrbaren Lebenswandel. Außerdem hielten die Inder an ihren alten Traditionen fest, seien gelehrsam und hätten eine reine Moral. ${ }^{267}$ Der Maler Hogdes schreibt: „Ihre Sitten entsprechen diesem zarten Gliederbau. Sie sind mild, ruhig und außerordentlich aufmerksam.“ ${ }^{268}$ Außerdem betont er ihre Reinlichkeit und ihre Gastfreundschaft. ${ }^{269}$ Klaußner beschreibt 1791 die Inder als ,sanft und heiter, wie ihr Clima“270. Crawfurd, von dessen Werk ein Ausschnitt in dem Journal für Luxus und Moden erschienen ist, wo er eine große Leserschaft auch nicht speziell Indieninteressierter erreichen kann, bezeichnet die Inder als das sanfteste Volk der Erde. Sie seien ,geduldig und unterwürfig im Mißgeschick; aber unter dem Einflusse der Religion und Ehre wissen sie dem Tode Trotz zu bieten und ihn sogar geflissentlich aufzusuchen [...].“271 Außerdem seien sie fröhlich, anständig und reinlich und hätten bereits in der Kindheit ausgeprägte Geistesfähigkeiten. ${ }^{272}$ Auch Majer spricht von der Sanftmut der Hindus, die ,der sanftmüthigste Menschenstamm, die harmlosesten unter allen Sterblichen“ 273 seien. „Weichheit, Zartheit und Harmonie“ zeige sich ,in ihrer ganzen Gestalt“274 und sie seien ,,anmuthig und reizend““. ${ }^{275}$ Und auch im LexikonArtikel von 1809 heißt es, die Inder zeichneten sich aufgrund ihrer Religion durch Mäßigkeit und Sanftmut aus und hätten eine reine und musterhafte Moral. ${ }^{276}$ Ehrmann lobt ebenfalls den guten Charakter der Inder:

Sie sind sehr gutartige, menschenfreundliche, redliche, biedere Leute, ohne
heftige Leidenschaften [...]; sie sind dabei nüchtern, mäßig, sparsam, mit
sehr Wenigem vergnügt, gastfrei, ungemein dienstfertig, große Liebhaber
der Ruhe, und daher in allen ihren Arbeiten sehr langsam, doch nicht

\footnotetext{
${ }^{267}$ Vgl. Des Fra Paolino da San Bartolomeo Reise nach Ostindien, S. 18, 155-162, 284; vgl. auch Darstellung der Brahmanisch-Indischen Götterlehre, Religionsgebräuche und bürgerliche Verfassung. Nach dem lateinischen Werke des Vaters Paullinus a St. Barthholomaeo bearbeitet. Gotha 1797, S. 234

${ }^{268}$ Hodges: Reisen durch Ostindien, S. 10

${ }^{269}$ Vgl. Hodges: Reisen durch Ostindien, S. 44f.

${ }^{270}$ Klaußner: Die Hindus, S. 511

${ }^{271}$ Völker- und Sittenschilderung. Die Sitten der Hindus. In: Journal für Literatur, Kunst, Luxus und Mode 33 (Februar 1818), S. 73-90, hier S. 73

${ }^{272}$ Vgl. Völker- und Sittenschilderung, S. 79, 81

${ }^{273}$ Majer: Zur Kulturgeschichte der Völker, S. 56

${ }^{274}$ Majer: Zur Kulturgeschichte der Völker, S. 56

${ }^{275}$ Majer: Zur Kulturgeschichte der Völker, S. 58

${ }^{276}$ Vgl. Conversations-Lexikon. 1809, S. 336
} 
Dabei stellt auch Ehrmann die Inder den Europäern gegenüber, indem er sich auf das Urteil eines Reisenden bezieht: Während der Europäer höflich sei, weil ihm das Ehre bringe und ihn beliebt mache, sei der Inder höflich, weil er Höflichkeit für eine Pflicht halte und er den Anderen ehre; der Europäer ehre hingegen nur sich selbst. ${ }^{278}$

Viele der Autoren, die sich so positiv und in gewisser Weise auch idealisierend über die Inder äußern, setzten sich auch mit den Ursachen für die Unterschiede in den Charakterzügen auseinander. Dabei kommen einige zu sehr ähnlichen Schlüssen wie bereits Herder: Mäßigung, Verzicht auf Fleisch und Alkohol, ein positives Klima und ein guter Einfluss der Religion. So schreibt Crawfurd:

Die Abneigung gegen Blutvergießen, welche Religion ihnen einschärft, Erziehung und Gewohnheit befestigt; das Klima, welches die Zahl der Bedürfnisse vermindert; die Mäßigkeit im Genusse thierischer Nahrung, selbst unter denen, welchen sie nicht verboten ist, nebst der Enthaltung geistiger Getränke; all diese Ursachen tragen dazu bei, die Hindus vielleicht zum sanftesten Volke des Erdbodens zu machen. ${ }^{279}$

Auch Ehrmann sieht in dem Verzicht auf Fleisch einen möglichen Grund für den ruhigen, ausgeglichenen Charakter der Inder. ${ }^{280}$ Majer erwähnt ebenfalls die „einfachsten und unschuldigsten Speisen“, aber anstatt wie Crawfurd und Ehrmann diesen Umstand einfach als indische Tradition zu beschreiben, verbindet er sie mit der Vorstellung von einem ,zarte(n) Keim der natürlichen Einfalt, [...] Reinheit und Unschuld“. ${ }^{281}$ Diese natürliche Unschuld und Sanftmut wird aber keineswegs mit unwissender Naivität gleichgesetzt: Die Seele der Inder sei von einer „stille(n), duldende(n) Tiefe“. ${ }^{282}$ Inspiriert wurde dieses Indienbild Majers sicherlich auch durch die oben beschriebene Vorstellung von Indien als der Wiege und der (in romantischer Sicht noch nicht aus der allumfassenden Einheit herausgetretenen) Kindheit der Menschheit.

Einen in mancher Hinsicht ähnlichen, in anderer Hinsicht aber auch ganz anderen, sehr interessanten Ansatz diskutiert der Autor (wohl ein englischer Offizier in Indien) eines

\footnotetext{
${ }^{277}$ Ehrmann: Neueste Kunde von Asien. Zweiter Band, S. 50

${ }^{278}$ Vgl. Ehrmann: Neueste Kunde von Asien. Zweiter Band, S. 54

279 Völker- und Sittenschilderung, S. 73

${ }^{280}$ Vgl. Ehrmann: Neuste Kunde von Asien. Zweiter Band, S. 50

${ }^{281}$ Majer: Zur Kulturgeschichte der Völker. Zweiter Band, S. 56f.

${ }^{282}$ Majer: Zur Kulturgeschichte der Völker. Zweiter Band, S. 58
} 
Artikels aus dem Journal für Luxus und Mode. Er setzt sich nicht nur mit möglichen Ursachen für das So-Sein der Inder auseinander, sondern wirft auch die Frage auf, inwieweit es sich bei den Darstellungen der europäischen Autoren um Bilder handelt, die nicht nur auf Beobachtungen, sondern auch anderen Einflüssen beruhen:

\begin{abstract}
Wenn wir unsrer Phantasie folgen, und den Charakter der alten Hindus nach diesen Gattungen ihrer Volkspoesie schildern wollen, wie liebenswürdig würden sie erscheinen! Bescheiden, einfach in ihren Sitten, von starken Eindrücken lebhaft ergriffen, empfänglich für zarte Liebe; ja, wenn wir über den Unterschied, der zwischen poetischer Schilderung und der schwächern Zeichnung des wirklichen Lebens Statt findet, hinwegsehen, so wüßte ich nicht, ob nicht die Farben des entworfenen Gemäldes auch nicht heute für die Abkömmlinge der Hindus im Allgemeine gelten könnten, insbesondere da, wo sie von der Einmischung fremder Sitten frei blieben. Noch jetzt reden sie die Sprache der Dichtkunst und Liebe, obgleich in einem durchaus ländlichen Dialect. Wem ist dieß zuzuschreiben? Wohl nicht dem eigenthümlichen Bau der Sprache selbst [...]. Eben so wenig kann es von Verfeinerung durch Erziehung und Gesellschaft herrühren, denn ich habe im Allgemeinen bemerkt, daß die Hindus, selbst wenn sie auf Dörfern geboren waren, und von großen Städten, wie von den Besuchen der Europäer und Muselmänner entfernt lebten, sich auf eine feine, bildliche Weise ausdrückten. ${ }^{283}$
\end{abstract}

Wenn also weder dem Bau ihrer Sprache, noch einer verfeinernden Erziehung, jene Zartheit der Gedanken und Worte beigelegt werden kann, sollten wir denn nicht annehmen, daß die natürliche Wärme des Klima's, die üppige Fruchtbarkeit des ganzen Landes, ein Zartgefühl, eine Empfänglichkeit in den Sinnwerkzeugen hervorbringe, und die Nerven lebendiger erschüttere, als in unserm strengern und rauhern Klima? Ich bin überzeugt, daß diese Ansichten über die Hindus bei meinen Landsleuten in Indien im Allgemeinen wenig Glauben finden werden; sie werden geneigt seyn, dieselben für nichts anders, als eine schwärmerische Geburt des Vorurtheils und der Erdichtung zu halten. Unter ihnen herrschen zwei, durchaus verschiedene Meinungen über diesen Gegenstand. Die eine Parthei betrachtet Indiens Bewohner, Sitten, Erzeugnisse u.s.w., im Vergleich mit Europa, der Erwähnung unwerth, während ihre Gegner, obschon geringer an Zahl, doch nicht schwächer in ihren Beweisgründen, jedem Dinge im Orient einen entschiedenen und vermuthlich ungerechten Vorzug geben. [...] Ich bewundere das höhere Genie Europens, das sich in Gesetzen, im Handel, in Literatur, in alle den Künsten und Wissenschaften zeigt, die zur Verfeinerung des Lebens gehören, eben so, wie ihren stärkeren Nervenbau, ihren stolzern Muth, den sie in vielen herrlichen und glorreichen Kämpfen bewiesen: doch fühle ich mich versucht zu glauben, daß die Folgen dieser Superiorität, die zahllos vermehrten Bedürfnisse, die wachsende Schwelgerei, Lüsternheit befördernde Trachten, politische Verdorbenheit, religiöser Skepticismus u.s.w., wohl nicht den mäßigen Glücks-Zustand eines Volks gänzlich aufwiegen, das in allen Künsten der Verfeinerung bedeutende Fortschritte gemacht hat, und diejenigen, die ihm noch zu seiner Vollkommenheit fehlen, hoffentlich erreichen kann; eines Volks, das sich im Besitze eines minder glänzenden und ruhmvollen, aber zugleich bei weitem ruhigern und ausgebreitetern Glücks befindet, das überdies minder leicht umzustoßen ist. ${ }^{284}$

283 Über den Charakter der Hindus. Aus dem Englischen. In: Journal für Literatur, Kunst, Luxus und Mode 32 (1817, November), S. 715-721, hier S. 717f.

284 Über den Charakter der Hindus, S. 719-721 
Interessant ist, dass der Autor eine Parallele zwischen zeitgenössischen Vorstellungen von den Indern und den Schilderungen in indischen poetischen Texten zieht. Er stellt fest, dass man sich leicht von den liebenswürdigen literarischen Beschreibungen dazu verleiten lassen kann, auch die heutigen Inder auf dieselbe Art und Weise zu betrachten. Wenn man bedenkt, wie überschwänglich gerade die Frauengestalten der indischen Literatur in ihrer Zartheit und Anmut gelobt werden, so stellt sich tatsächlich die Frage, inwieweit die Lektüre dieser Werke die Wahrnehmung der realen Inder zumindest in den späteren Abhandlungen beeinflusst haben kann. Der Autor geht trotz seines Bewusstseins für eine mögliche Beeinflussung von der Annahme aus, dass viele der literarisch beschriebenen Charakterzüge auch auf die realen zeitgenössischen Inder zutreffen. Als Beleg führt er konkrete eigene Beobachtungen an. Vor allem in der Sprache und Ausdrucksweise der Inder sieht er einen bedeutenden Hinweis auf deren Charakter. Warum aber weisen die Inder solche feinen Züge in ihrer Sprache auf? Die Eigentümlichkeiten des Sprachbaus schließt der Autor rasch als Ursache aus. Auch den Einfluss der Erziehung, sei es durch gelehrte andere Hindus, sei es durch Europäer oder Moslems, verwirft er. Das ist insofern interessant, als in England immer wieder über Fragen der Erziehung und Bildung der Inder durch Europäer und nach europäischem Vorbild diskutiert worden ist. Der Autor macht in seinem Text deutlich, dass die Inder einer solchen Erziehung und Bildung nicht bedürften, jedenfalls nicht um anständig und glücklich zu sein. Denn die Europäer hätten zwar ihre Vorzüge und seien den Indern in einigen Bereichen überlegen (Künste, Wissenschaften, Mut), aber ihre Stärken führten nicht unbedingt zu einem glücklichen Leben, sondern zu immer weiteren Bedürfnissen, zu Skeptizismus und Verdorbenheit. In dieser Einschätzung ähnelt er den Ausführungen Herders. Die Europäer seien zwar in vielen Bereichen weiter entwickelt als die Inder und dafür bewundere er sie auch, sie verfehlten dabei aber das Ziel der Humanität bzw. eines ruhigen, anhaltenden Glückes. Der Autor idealisiert also nicht einfach die Hindus gegenüber den Europäern, sondern versucht in gewisser Weise, beiden gerecht zu werden, ihre Unterschiede aufzuzeigen und jedem die Überlegenheit in einem Bereich zuzugestehen. Ihm ist dabei bewusst, dass viele seiner Landsleute diese Auffassung nicht teilen werden, da sie einem der zwei Extremen zuneigen, die Hindus und ihre Kultur im Vergleich zu den Europäern für nicht beachtenswert zu erachten oder aber sie in einem solchen Maße zu idealisieren, dass sie allem Indischen den Vorzug gäben. In seiner Suche nach den Gründen für den Charakter der Hindus macht der Autor schließlich wie viele andere Autoren das milde Klima als Ursache aus. Da er zugleich den Einfluss der Bildung und Erziehung wie beschrieben zurückweist, 
impliziert das ähnlich wie bei Majer eine Natürlichkeit des indischen Charakters, die dem sich von der Natur entfernenden Europäer gegenübersteht. Dieses Bild setzt in gewisser Weise die Unterscheidungen des Mittelalters zwischen den Heiden, die ihre Weisheit aus dem (göttlichen) Buch der Natur gewonnen hätten, und den durch die göttliche Offenbarung in der Bibel gebildeten Christen fort. Hier die naturverbundenen, mit natürlichen Gaben versehenen Inder, dort die durch abstraktes Wissen gebildeten Europäer. Dieses Motiv der natürlichen Bildung ist im 18. Jahrhundert weit verbreitet (vgl. z.B. Rousseau Ansatz einer natürlichen Erziehung). Trotz dieser natürlichen Bildung und Einfachheit der Inder fallen sie dennoch nicht in die Kategorie des Edlen Wilden, da sie auch als eine hohe Zivilisation mit einer wissenschaftlichen und philosophischen Tradition angesehen werden. ${ }^{285}$

Obwohl sich die Tendenz zur Polarisierung zwischen Idealisierung und vernichtender Kritik, die der Autor des soeben zitierten Artikels in England ausmacht, auch im deutschsprachigen Raum erkennen lässt und einige Autoren kaum etwas Lobenswertes an den Inder erkennen wollen, gibt es doch nur wenige Autoren, die trotz aller Bewunderung die Inder uneingeschränkt positiv darstellen. Allerdings fällt auf, dass sie häufig bemüht sind, die beobachteten negativen Charakterzüge der Inder durch den Einfluss äußerer Umstände zu erklären und die Inder damit in gewisser Weise zu entschuldigen oder aber sie als nur auf wenige Inder zutreffend abzutun. So schreibt Crawfurd:

\begin{abstract}
Man muß wirklich erstaunen, daß die Anlage zu sanften Tugenden, die man bei den Hindus bemerkt, sie nicht vor einem Verbrechen bewahrt, welches sie verwerfen. Man sieht unter ihnen einige Spuren von Kindermord; aber diese verhaßte Gewohnheit beschränkt sich auf wenige Familien, die zu gewissen kriegerischen und unruhigen Casten gehören. ${ }^{286}$
\end{abstract}

Obwohl dieser Brauch nur auf wenige Familien zutreffe, beschreibt er mit einer gewissen Faszination für das Grausame ausführlich Kindsmord und Witwenverbrennung, bevor er dann nahezu nahtlos wieder dazu übergeht, die Anständigkeit der Inder zu betonen. Hier werden mehrere mit Indien verbundene Stereotype nebeneinandergestellt, ohne dass ein großes Bemühen um eine Verbindung dieser Stereotype zu erkennen wäre. Und so werden die durchaus die Sensationslust befriedigenden Schilderungen von Kindsmord und Witwenverbrennung, die in

\footnotetext{
${ }^{285}$ Vgl. auch Polaschegg: Athen am Nil oder Jerusalem am Ganges?, S. 48

${ }^{286}$ Völker- und Sittenschilderung, S. 74
} 
populären Beschreibungen Indiens nicht fehlen dürfen und auf die später noch eingegangen werden wird, ohne großen Kommentar von den ebenso beliebten Beschreibungen der Inder als sanft und anständig eingerahmt.

Auch Ehrmann zählt negative Eigenschaften der Hindus auf, wobei er jedoch versucht, für alle diese Eigenschaften äußere Ursachen zu finden:

\begin{abstract}
Nicht mit Unrecht wirft man den Hinduern schmuzzigen Geiz vor; aber bringt sie nicht ihre gepreßte Lage und die Habsucht der sie aussaugenden Europäer dazu? [...] Sie sind überhaupt große Liebhaber vom Zaudern und Zögern und schieben gar gern die Erfüllung ihres gegebenen Versprechens auf: auch suchen sie sich sehr oft durch Lügen zu helfen, wozu sie jedoch nicht selten die Noth treibt. Im Ganzen genommen sind die Hinduer ein sehr gutartiges, menschenfreundliches, sanftes Volk, das jedoch durch mancherlei widrige Schicksale, und besonders durch den Despotendruck der früheren Eroberer ihres Landes, und dann auch der hier angesiedelten Europäer sehr verdorben worden ist, und wenn es so fortdauert, immer mehr verdorben und herabgewürdigt wird. ${ }^{287}$
\end{abstract}

Ehrmann versucht, sein positives Bild von den Indern trotz aller negativen Dinge, die er gehört hat, aufrechtzuerhalten und sie auch gegenüber Kritikern in Schutz zu nehmen. Nicht die Inder seien schlecht, sondern die Taten der Eroberer, die ursächlich für die zunehmende Verdorbenheit der Sitten verantwortlich seien.

Andere Autoren stellen positive und negative Eigenschaften der Inder nebeneinander, ohne zu einer eindeutigen Beurteilung zu kommen. Das trifft z.B. auf die Darstellungen in den Lexikonartikeln zu, wobei in dem früheren Artikel die positiven, in dem späteren die negativen Aspekte überwiegen. Die Inder hätten einerseits eine reine und musterhafte bzw. strenge Moral, seien geduldig und sanft, aber andererseits seien sie auch weichlich, indolent und wiesen keinerlei Entwicklung auf. ${ }^{288}$

Als indolent bezeichnet auch der Missionar Dubois die Hindus: Sie seien träge, apathisch und indolent, zeichneten sich aber auch durch Mäßigung, Nüchternheit, Selbstbeherrschung, Geduld und Nachsicht aus. Dubois sieht also im Hinblick auf das für Europäer ungewohnt zurückhaltende Verhalten der Hindus sowohl negative als auch positive Interpretationsmöglichkeiten. Außerdem hält er fest, dass Apathie, Trägheit und Indolenz das Los aller Völker sei, die in dieser Klimazone geboren seien,

\footnotetext{
${ }^{287}$ Ehrmann: Neueste Kunde von Asien. Zweiter Band, S. 50f.

${ }^{288}$ Vgl. Vgl. Conversations-Lexikon. 1809, S. 336f.; Conversations-Lexicon. 1815, S. 717
} 
und bringt somit wieder die Klimatheorie als Ursache mit ins Spiel. ${ }^{289}$ Die Briefe Dubois' sind insofern interessant, als sie sehr deutlich zeigen, wie sehr Dubois in seiner Bewertung der Hindus zwischen den bereits vertrauten positiven und negativen Bildern schwankt. Die ersten Briefe sind überwiegend von seinem Ärger darüber, dass es unmöglich sei, die Hindus zu missionieren, geprägt. In diesem Zusammenhang äußert er sich sehr kritisch vor allem über die Brahmanen, die er als machtbesessene Lügner und Verführer beschreibt. Sie herrschten als „Betrüger“ über ein Volk von „Narren“. 290 In den späteren Briefen reagiert Dubois dann auf europäische Stimmen, die die Hindus in jeglicher Hinsicht als verdorben und schlecht darstellen. In diesen Briefen übernimmt Dubois nun die Rolle des Verteidigers der Hindus, die zwar auch Laster hätten, aber eben auch Tugenden. Unter diese Tugenden rechnet Dubois die bereits bekannten Merkmale der Friedlichkeit und Unterwürfigkeit, des guten Benehmens, der Mäßigung, des Verzichts auf Alkohol, der Gastfreundschaft. Sie hätten den Grad von Zivilisation erreicht, der dem Klima, ihren Bedürfnissen und ihrer natürlichen Anlagen angemessen sei und überträfen in einigen Bereichen sogar die Europäer. Dabei weist Dubois darauf hin, dass man immer nur Menschen von gleichem Stand miteinander vergleichen dürfe, also einen indischen Landwirt nur mit einem europäischen Landwirt, nicht aber mit dem europäischen aufgeklärten Bürgertum. Die Neigung der Hindus zu Unredlichkeit und Diebstahl, die er wie andere bei ihnen dennoch ausmacht, seien zu einem großen Teil Folge der Armut. Seine frühere Kritik hätte nur den Brahmanen und ihrem Missbrauch der Religion gegolten, nicht aber der großen Bevölkerungsmehrheit. ${ }^{291}$

Scharnhorst, der als Soldat nach Indien gekommen ist, scheint zwischen Stereotypen und eigenen Beobachtungen zu schwanken. So beschreibt er die Inder zwar als „ausserordentlich träge und faul“, aber dennoch seien sie in der Lage, „schwere Arbeit (zu) verrichten, grosse Lasten (zu) tragen, und ermüdende Tagesreisen aus(zu)halten

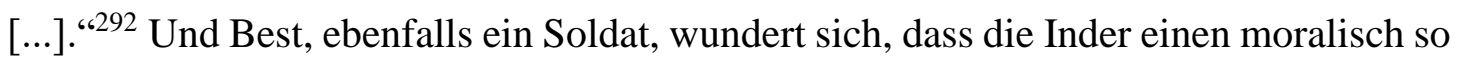
guten Charakter hätten, obwohl sie zu weichlich seien, sich gegen Eroberer zu wehren und von der Aufklärung nichts wissen wollten, sondern weiterhin ihrem Aberglauben

\footnotetext{
${ }^{289}$ Vgl. Dubois: Briefe über den Zustand des Christentums, S. 70-73

${ }^{290}$ Dubois: Briefe über den Zustand des Christentums, S. 82

${ }^{291}$ Vgl. Dubois: Briefe über den Zustand des Christentums, S. 137-158

292 Briefe auf einer Reise von Stade nach Madras, S. 104
} 
anhingen. Zudem ist er voll des Lobes für die Gewandtheit der indischen Soldaten (Sepoys) in europäischem Dienst. ${ }^{293}$

Während dieses Schwanken zwischen verschiedenen Bewertungen der Inder und ihrer Kultur für viele Autoren der Zeit typisch ist, gibt es auch Autoren, die überwiegend negative Bilder von den Indern liefern. Die immer wieder betonte Sanftmut der Inder kann - wie sich in den Lexikonartikeln schon andeutet - in den negativen Indienbildern in Weichheit, diese in Weichlichkeit oder auch Weiblichkeit umschlagen. Nicht selten wird das dann verbunden mit der Vorstellung, dass die Inder feige und schwach seien. Das war schon bei Sonnerat ${ }^{294}$ der Fall, der in seinem 1784 auf Deutsch erschienen Reisebericht die Inder als ,weichlich, feig und weibisch“ ${ }^{295}$ beschrieb. Die Bewohner Malabars seien aus Schwachheit sanft. ${ }^{296}$

Meiners und Hegel, die ebenfalls ein deutlich negatives Bild der Inder entwerfen, ergänzen die Attribute der Schwäche und Feigheit mit denen einer schlechten Moral und Hartherzigkeit. Meiners bezichtigt die Hindus der Habsucht und wirft ihnen eine doppelte Moral vor, indem sie die Tiere liebten und nicht verletzen dürften, gegenüber

\footnotetext{
${ }^{293}$ Vgl. Best: Briefe über Ost-Indien, S. 18, 122f. Das Lob der indischen Regimenter der britischen Armee (der Sepoys) findet sich auch bei anderen Autoren. So schreibt der aus Celle gebürtige, von französischen Hugenotten abstammende Leutnant Georg Carl de Roques, der mit einem hannoverschen Regiment 1781 nach Indien kommt, in seinem Tagebuch: „Es werden die schönsten und stärksten Indianer zu Sepoys genommen [...]. Sie sind wohlgebauet und haben dieselben Gesichtszüge, wie die Europäer. [...] Sie marschiren, richten sich und exerciren beßer als irgend eines der Englischen Regimenter in Indien [...] alle ihre guten Eigenschaften ins Kleinere, als Reinlichkeit, gute Wirtschaft, Munterkeit zu Tag- und Nachtzeiten etc habe ich nicht hinlänglich zergliedern können, da ich schon mehr ins Weitläufige gegangen, als ich es mir vornahm. Schließlich kann ich nicht unbemerkt laßen, das diese Truppen, in den Augen des Menschenkenners, vorzüglich wenn er dabey Soldat ist, als die verehrungswürdigsten der Welt scheinen müßen [...].“ (Roques, Carl de: Ein Tagebuch aus Südindien: Februar 1782 - Juni 1784. In: Ahuja, Ravi u. Christof-Füchsle, Martin (Hgg.): A Great War in South India. German Accounts of the Anglo-Mysore Wars, 1766-1799. Berlin/Boston 2020, S. 253-317, hier S. 269, 271; vgl. auch Christof-Füchsle, Martin: Two Hanoverian Lieutenants in the Tamil Plains: The Letters of Ferdinand Breymann and the Diary of Carl de Roques. In: Ahuja, Ravi u. Christof-Füchsle, Martin (Hgg.): A Great War in South India. German Accounts of the Anglo-Mysore Wars, 1766-1799. Berlin/Boston 2020, S. 201-221, hier S. 202, 209

${ }^{294}$ Pierre Sonnerat (1745-1814) wurde in Lyon geboren. 1768 kam er mit seinem Verwandten, dem Botaniker Pierre Poivre, auf die Isle de France (Mauritius). 1771 nahm er an einer Expedition zu den Seychellen, den Philippinen, den Molukken und Papua teil. 1774 brach er zu einer mehrjährigen Reise nach Indien und China auf. Er bereiste Malabar bis hinauf nach Surat. Später kam er aber auch an die Ostküste, wo er 1778 die Zeit des britisch-französischen Krieges in Pondicherry verbringen musste. Über beide Reisen veröffentlichte er ausführliche Beschreibungen (vgl. Oliver, S. P.: Pierre Sonnerat. In: The Gardeners' Chronicle. A Weekly Illustrated Journal of Horticulture and Allied Subjects. JulyDecember 1892. London 1892, S. 338)

${ }^{295}$ Herrn Sonnerat, Kommussärs beym Seewesen (...) Reise nach Ostindien und Ssina (...). Aus dem französischen Original in einen freien Auszug gebracht. Frankfurt u. Leipzig 1784, S. 7

${ }^{296}$ Vgl. Sonnerat: Reise nach Ostindien, S. 12
} 
ihren Mitmenschen aber kalt und hartherzig seien, keine echte Freundschaft kennten und undankbar, treulos und verräterisch seien. ${ }^{297}$ Das Motiv der doppelten Moral, dass sich auch bei Dubois andeutungsweise findet, ${ }^{298}$ führt auch Hegel an, der den sittlichen Zustand der Inder als den verworfensten bezeichnet, worin alle Engländer übereinstimmten. Für Hegel ist dieser Zustand der indischen Moral eine Folge des indischen Abstrahierens von allem Tun, das dazu führe, dass alles Tun nur durch vorgeschriebene äußere Gesetze bestimmt werde und nicht aus innerer Freiheit heraus geschehe.

\begin{abstract}
Man kann sich in seinem Urtheile über die Moralität der Inder leicht durch die Beschreibung der Milde, der Zartheit, der schönen und empfindungsvollen Phantasie bestechen lassen, doch müssen wir bedenken, daß es in ganz verdorbenen Nationen Seiten giebt, die man zart und edel nennen dürfte. [...] Dasselbe begegnet uns in vielen indischen Poesien, aber Sittlichkeit, Moralität, Freiheit des Geistes, Bewußtsein des eigenen Rechts sind ganz davon getrennt. Es giebt hier nur Pflichten der Kasten, nicht Pflichten der Menschen; die Vernichtung der geistigen und physischen Existenz hat nichts Konkretes in sich, und das Versenken in die abstrakte Allgemeinheit hat keinen Zusammenhang mit dem Wirklichen. List und Verschlagenheit ist der Grundcharakter des Inders; Betrügen, Stehlen, Rauben, Morden liegt in seinen Sitten; demüthig kriechend und niederträchtig zeigt er sich dem Sieger und Herrn; vollkommen rücksichtslos und grausam dem Überwundenen und Untergebenen. Die Menschlichkeit des Inders charakterisirend ist es, daß er kein Thier tödtet, reiche Hospitäler für Thiere, besonders für alte Kühe und Affen stiftet und unterhält, daß aber im ganzen Lande keine einzige Anstalt für kranke und altersschwache Menschen zu finden ist. Auf Ameisen treten die Inder nicht, aber arme Wanderer lassen sie gleichgültig verschmachten. ${ }^{299}$
\end{abstract}

Auch Hegel führt wie Meiners die Liebe für die Tiere bei gleichzeitiger Gleichgültigkeit gegenüber dem Leiden von Mitmenschen an, ${ }^{300}$ um zu zeigen, wie schlecht es um die Moral der Inder bestellt sei. Hegel entwirft das Bild eines machthungrigen, nur auf den eigenen Vorteil bedachten Menschen, dem moralische Vorgaben egal sind und der Gewalt einsetzt, sobald er sich dem Gegenüber überlegen fühlt und er sich einen Vorteil davon verspricht, der aber an sich nicht mutig, sondern

\footnotetext{
${ }^{297}$ Vgl. Meiners: Untersuchungen über die Verschiedenheiten der Menschennaturen. Band 2, S. 298, $306 f$.

${ }^{298}$ Vgl. Dubois: Briefe über den Zustand des Christentums, S. 106f.; sogar der sonst eher zur Idealisierung der Inder neigende Majer deutet an, dass die Menschenliebe der Hindus eher passiver Natur sei: Enthaltung von Beleidigungen des Nächsten. Aktive Hilfe und Wohltaten aber schienen nicht verbreitet zu sein (vgl. Majer: Zur Kulturgeschichte der Völker. Zweiter Band, S. 56)

${ }^{299}$ Hegel: Vorlesungen über die Philosophie der Geschichte, S. 166f.

${ }^{300}$ Diese Liebe zu den Tieren und die Sorge, ihnen kein Leid zu tun, sowie auch das Tierlazarett beschreibt ein Reisender in Ehrmanns „Neueste Beiträge zur Kunde von Indien“ sehr ausführlich. Auch die Verwunderung über das Fehlen ähnlicher Einrichtungen für Menschen findet sich dort (vgl. Ehrmann (Hg): Neueste Beiträge zur Kunde von Indien, S. 294-299).
} 
feige ist und gleich starken Anderen nur mit Unterwerfung, List und Verschlagenheit begegnet. Helmut von Glasenapp sieht eine Ursache für dieses negative Indienbild Hegels darin, dass dieser englische Berichte, die im Zuge der kolonialen Eroberung Indiens entstanden seien und z.T. auch der Propaganda dienten, kritiklos übernommen habe. ${ }^{301}$ Doch wie das Zitat zeigt, sind Hegel die verbreiteten positiven Ansichten über die Inder durchaus bewusst. Er verweist sie allerdings in das Reich der Poesie, ist aber anders als der oben genannte Autor des Artikels aus dem Journal für Luxus und Mode nicht der Ansicht, dass irgendeine Verbindung zur realen Sittlichkeit und Moralität bestehe. Als Ursache für die sittliche Verrohung macht Hegel eine Besonderheit der indischen Religion und Philosophie aus, die ihm auch an anderer Stelle immer wieder aufstößt, nämlich die Bedeutung der meditativen Versenkung in den göttlichen Urgrund, der für Hegel nichts Erfülltes ist, sondern leere abstrakte Allgemeinheit. Wie sehr Hegel diese Konzentration auf etwas für ihn Abstraktes und nicht auf die eigene Individualität beschäftigt und wie sehr er sie ablehnt und den Indern darin die Freiheit des Individuums aberkennt, werden wir noch später in seiner Auseinandersetzung über die Bhagavadgītā sehen. Hier ist nur erst einmal festzuhalten, dass nach Hegel die Inder aufgrund fehlender individueller Freiheit nur von außen angeordneten Pflichten folgten, nicht aber einem aus einem im eignen Innern entstandenen Pflichtgefühl. Zudem seien die von außen kommenden Pflichten nur Pflichten einzelner Kasten, nicht aber allgemein aller Menschen, was sie in ihrer Verbindlichkeit deutlich schwäche. Es sind also gerade Aspekte der indischen spirituellen Tradition, die viele andere Autoren an Indien bewundern und in denen sie den Grund für die sittliche Überlegenheit der Inder sehen, die Hegel hier als Hauptursache der moralischen Verworfenheit der Inder ausmacht und ablehnt.

Interessant ist, dass in den Darstellungen des Charakters sowohl in den positiv als auch in den negativ ausgerichteten Passagen die Inder als deutlich von den Europäern unterschieden beschrieben werden: Entweder wird ihre moralische Überlegenheit betont oder aber ihre Unterlegenheit, auf jeden Fall aber ihre Andersartigkeit. ${ }^{302}$ Ganz

\footnotetext{
${ }^{301}$ Vgl. Glasenapp: Das Indienbild deutscher Denker, S. 57

${ }^{302}$ Eine interessante Ausnahme stellt der oben bereits in einer Fußnote kurz erwähnte Leutnant de Roques dar. Er schreibt in seinem Tagebuch: „Das Herz, und die Gesinnungen der Indianer kennen zu lernen, ist in kurzer Zeit eine ganz ohnmögliche Sache; kan sich wohl einer schmeicheln, das Herz seiner eigenen Landsleute und deren Gesinnungen recht zu kennen? Zwischen welchen er gewöhnlich die Zeit seines Lebens zubringt, um so weniger mag er sagen, das er die Eigenschaften einer Nation, deren Sitten und Gebräuche so auserordentlich von den unsrigen abweicht, kenne. Ich werde mich also
} 
anders sieht es bei der Beschreibung des Aussehens der Inder aus. Zumindest die höheren Kasten gelten im Allgemeinen als schön ${ }^{303}$ und den Europäern auffallend ähnlich. Die unteren Kasten werden allerdings fast ausschließlich als das Andere der Europäer beschrieben, was insofern nicht verwundert, als sie auch als das Andere der Mitglieder der höheren Kasten der Inder gelten. ${ }^{304}$ Im Zusammenhang mit den höheren Kasten finden sich dagegen bei verschiedenen Autoren immer wieder Stellen, in denen die ähnlichen Gesichtszüge und auch eine ähnliche Hautfarbe der Inder und Europäer beschrieben werden. Besonders deutlich wird das bei Perrin:

\begin{abstract}
Die Nationen Indiens gleichen in Gesicht, Haltung, Bewegung und Gang den Franzosen fast durchgehend. Man thut keinen Schritt, ohne sich zu täuschen, und glaubt überall Freunde aus Frankreich unter der Menge zu entdecken. Je genauer man untersucht, je mehr wird man getäuscht, und wenn man eine bestimmte und charakteristische Beschreibung eines Indianers von mir verlangte, würde ich sagen, es sey diejenige Menschengattung, die den Franzosen am meisten, selbst oft bis auf die Farbe gleiche. ${ }^{305}$
\end{abstract}

nicht unterstehen, much weitläufig hierüber auszulaßen, sondern bloß anmerken, das so wie ihre Gestalt, auch ihre Herze, den Europäern sehr ähnlich ist, und ein Gemisch von Gut, und Bösen, von Stolz und Kriechenden, von Haß und Liebe, so wie es die Rücksicht auf seiner eigenen Wohlfahrth mit sich bringt, und mit dem Unterschiede, das in Ansehung der Ausschweiffungen, so dem Wohl des Körpers zuwieder sind, er mäßiger als der Europäer ist, da man selten unter ihnen einen [...] finden wird [...], welche ihre Gesundheit durch Ausschweiffung, im Trunk oder andere Naturtrieben, so sehr aufopfern als wir.“ (Roques: Ein Tagebuch aus Südindien, S. 272f.). Carl de Roques greift zwar das verbreitete Stereotyp der Mäßigung auf, aber er weigert sich, die Inder in ihrer Gesamtheit zu beurteilen und mit bestimmten Etiketten zu versehen. Vielmehr sieht er in ihnen Individuen, die sich untereinander genauso wie die Europäer unterscheiden.

303 „Die Gestalt der Hindu sagt Mack-Intosch in seiner Reisebeschreibung ist gerade, schlank und schön, ihre Glieder sind nach einem richtigen Ebenmaas fein und gleichförmig gebildet, ihre Finger sind lang und zarttastend, das Gesicht ist offen und gefällig, die Züge desselben sind bei dem weiblichen Geschlecht die zartesten Linien der Schönheit, bei dem männlichen, einer männlich sanften Seele. Ihr Gang, das ganze Tragen und die Haltung ihres Körpers ist im höchsten Grad anmuthig und reizend.“ (Majer: Zur Culturgeschichte der Völker. Zweiter Band, S. 57f.); es gibt aber auch Gegenstimmen: So war z.B. Sonnerat der Ansicht, dass die Inderinnen „fast durchgehends klein, häßlich, unreinlich und eckelhaft" seien (Sonnerat: Reise nach Ostindien, S. 8)

${ }^{304}$ So schreibt z.B. Meiners, die Natur habe die Hindus der höheren Kasten sowohl hinsichtlich der Seele als auch der körperlichen Eigenschaften deutlich besser ausgestattet als die der niederen Kasten. Die Hindus der unteren Kasten seien schwarzer, kleiner und hässlicher und hätten einen beschränkteren Geist. Er verbindet also körperliche Unterschiede mit geistigen und charakterlichen und sieht beide als naturgegeben an. (Vgl. Meiners: Untersuchungen über die Verschiedenheiten der Menschennaturen. Band 2, S. 241)

${ }^{305}$ Hell: M. Perrin's Reise durch Hindostan und Schilderung der Sitten, Einwohner, Natur-Producte und Gebräuche dieses Landes nach einem sechzehnjährigen Aufenthalte daselbst. Nach dem Französischen bearbeitet von Theodor Hell. Wien 1811, S.148f.; auch Ehrmann weist auf die Ähnlichkeit der höheren Kasten mit den Europäern hin, wobei er vor allem die fast weiße Hautfarbe betont und von der bei ihm negativ konnotierten dunklen Hautfarbe der unteren Schichten abgrenzt. Den Indern selbst sei ihre Schönheit allerdings nicht wichtig (vgl. Vgl. Ehrmann: Neueste Kunde von Asien. Zweiter Band, S. 48-50); Perrin weist ebenfalls darauf hin, dass die Inder ihre Schönheit nicht für wichtig hielten; und auch er beschreibt die verschiedenen Kasten hinsichtlich der Hautfarbe ähnlich wie Ehrmann von relativ hell bis zu schmutzig schwarz (vgl. Hell, Theodor: M. Perrin's Reise durch Hindostan, S. 149) 
Es ist eben nicht so, wie man es vielleicht zunächst erwarten würde, dass es Stimmen gibt, die sagen, die Inder sehen vielleicht nicht so aus wie wir, aber sie sind von ihren Geistesgaben und ihren moralischen Sitten wie wir, sondern die Inder können zwar aussehen wie wir, sind aber in ihrem Charakter ganz anders. Interessant ist das vor allem auch deshalb, weil in der oben angeführten Frage nach der Abstammung und Verwandtschaft der einzelnen Völker vor allem körperliche Merkmale wie zunächst die Hautfarbe, später anatomische Besonderheiten für eine Einteilung der Menschen nach Varietäten oder Rassen angeführt werden. Wenn nun zumindest die oberen Kasten der Inder den Europäern in dem Maße wie beschrieben ähneln, dann folgt daraus die Annahme einer Verwandtschaft beider Völker. Diese wird in der Tat immer wieder konstatiert und vor allem mit der Verwandtschaft der Sprachen begründet. Die großen Unterschiede in Charakter und Verhalten lassen sich dann auf zwei verschiedene Arten erklären: Entweder sind die Inder auf einem niedrigeren Entwicklungsstand stehengeblieben oder aber die Europäer haben sich von ursprünglichen Tugenden entfernt. Mal können die Europäer den Indern ein Vorbild sein, mal ist es umgekehrt. Beiden Erklärungsmustern liegt ein unterschiedliches Menschen- und Weltbild zu Grunde und beide finden sich in den Texten.

Die Textgattung scheint bei der Frage, wie die Inder beurteilt werden, keine große Rolle zu spielen. Negative und positive Bilder finden sich in allen Textsorten und stehen wie wir gesehen haben - sogar in ein und demselben Text nebeneinander. Eine weitaus größere Rolle spielen das Weltverständnis sowie philosophische und anthropologische Vorannahmen der Autoren. Eine Aussage Dubois' scheint allerdings darauf hinzudeuten, dass es möglicherweise zeitlich bedingte Unterschiede gibt. Er schreibt:

\footnotetext{
Wir sind bis auf die neuesten Zeiten fast einstimmig sowohl von alten als neuern Geschichtsschreibern, welche über Indien und seine Einwohner geschrieben haben, angewiesen worden, die Hindus als ein sanftes, mäßiges, industriöses, nachsichtiges, geduldiges und unterwürfiges Volk zu betrachten, das zwar ein völlig eigenthümliches System politischer Verwaltung besitzt, und mit keiner andern Nation der Erde eine Parallele zuläßt, aber dessen ungeachtet eine bedeutende Höhe der Civilisation erreicht hat [...]. Die Untersuchungen vieler aufgeklärter und scharfsinniger Schriftsteller aus verschiedenen Nationen, welche in neuern Zeiten das Land besuchten und den Charakter, die Sitten und Gewohnheiten dieses Volkes eben sowohl, als das unter ihnen herrschende System der Civiliation aufmerksam studirten, haben im Allgemeinen dazu gedient, die bereits über sie gehegte vortheilhafte Meinung zu bestärken [...]. Es war einigen Enthusiasten, welche in den letzten Jahren in dem Lande unter dem Titel von Reformatoren erschienen, vorbehalten, dieses gefällige Gemälde dadurch zu zerstören, daß sie uns darüber die anstößigsten Berichte ertheilten, und die sanften und harmlosen Hindus uns als ein von Bosheit jeder Art völlig beflecktes Volk, als ein Barbarengeschlecht, welches in den tiefsten Abgrund von Unwissenheit und Immoralität hinabgesunken, als ein
} 
Volk darstellten, das weit unter den wildesten Nationen, und durch seine thierischen Gewohnheiten und unnatürlichen Laster dem Thiere näher steht, als dem Menschen. ${ }^{306}$

Das Bild einer zwar eigentümlichen, aber dennoch hohen Zivilisation sei bisher ziemlich unumstritten gewesen und durch neuere Untersuchungen aufgeklärter, also mit den Mitteln der Vernunft arbeitender Beobachter bestätigt worden. In neuerer Zeit aber habe es eine durch „Reformatoren“ ausgelöste Abkehr von diesem Indienbild gegeben. Auch August Wilhelm Schlegel erwähnt eine Gruppe von Autoren, die „es sich zum eigentlichen Geschäfte macht, nicht nur den heutigen ziemlich entarteten Götterdienst der Indier, sondern auch die alte Grundlage, worauf er ruhet, mit den gehäßigsten und schwärzesten Farben zu schildern. “307 Diese Autoren seien in erster Linie Missionare, die in ihren Missionierungsbestrebungen nicht sonderlich erfolgreich gewesen seien und nun „den weltlichen Arm zu Hülfe rufen“308. Auch Dubois” Bezeichnung der Reformatoren als „Enthusiasten“ zielt auf den religiösen Enthusiasmus der sogenannten „Evangelicals“, einer christlichen Erweckungsbewegung, die Anfang des 19. Jahrhunderts politisch immer mehr an Einfluss gewinnen und so ihre Arbeit in Indien auch gegen den Willen der East India Company ausweiten kann. Aber auch die sogenannten „Anglizisten“, die den Einfluss der „Orientalisten“ (z.B. Jones und Wilkins) auf die Politik der East India Company mindern wollen, wollen Reformen. Hat die East India Company zunächst die Strategie gehabt, Indien auf der Grundlage der indischen Gesetze zu regieren und sich möglichst wenig in die indische Kultur einzumischen, fordern die „Anglizisten“ nun die Einführung westlicher Bildung auf der Grundlage der englischen Sprache in Indien und setzen sich damit in den 1820er Jahren schließlich auch durch. ${ }^{309}$ Diese Neuausrichtungen führen $\mathrm{zu}$ einer deutlichen Abwertung sowohl der indischen Religion als auch Kultur: Indien verliert in der Wahrnehmung vieler europäischer Beobachter den Status einer Hochkultur. Diese Veränderung vollzieht sich zwar vor

\footnotetext{
${ }^{306}$ Dubois: Briefe über den Zustand des Christentums, S. 168-170

${ }^{307}$ Indische Dichtungen. In: Indische Bibliothek 1 (1823), S. 28-96, hier S. 34

${ }^{308}$ Indische Dichtungen, S. 34

${ }^{309}$ Vgl. Schröder, Ulrike: Religion, Kaste und Ritual. Christliche Mission und tamilischer Hinduismus in Südindien im 19. Jahrhunder. Halle 2009 (Neue Hallesche Berichte. Quellen und Studien zur Geschichte und Gegenwart Südindiens. Im Auftrag der Franckeschen Stiftungen zu Halle. Herausgegeben von Michael Bergunder und Helmut Obst; 8), S. 47-53; Halbfass: S. Indien und Europa, S. 84f.; Inden: Orientalist Constructions of India, S. $280 \mathrm{f}$.
} 
allem in England, wird aber auch in anderen europäischen Ländern wahrgenommen, auch wenn sie dort nicht den gleichen Einfluss entwickeln kann wie in England. ${ }^{310}$

\subsection{Despotismus und Kastenwesen - die indische Regierungs- und}

\section{Gesellschaftsform}

Werden die indische Regierungs- und Gesellschaftsform beschrieben, so fallen immer wieder zwei Stichworte: Despotismus und Kastenwesen, das auch heute noch für viele als besonders typisch für Indien angesehen wird. Diese Herrschafts- und Gesellschaftsformen Indiens ziehen die Aufmerksamkeit vor allem aus dem Grund auf sich, dass sich innerhalb der Aufklärung im 18. Jahrhundert ein Diskurs über gesellschaftliche Gleichheit und Ungleichheit herausbildet. Die Entstehung von Ungleichheit wird in vielen gesellschaftlichen Bereichen diskutiert. In den indischen Erscheinungsformen des Despotismus und des Kastenwesens zeigen sich den Europäern als übersteigert wahrgenommene Formen des vertrauten Absolutismus und des Ständewesens, die anhand der anderen Kultur offener einer kritischen Analyse unterzogen werden können. Insbesondere die Gelehrten, die in der als Gelehrtenrepublik bezeichneten neuen Offenheit der wissenschaftlichen Diskussionen, in der über alle Standesunterschiede hinweg allein das Wissen als Partizipationskriterium gilt, die Vorteile einer solchen Emanzipation von ständischen Vorgaben erfahren haben, sehen in der strikt reglementierten indischen Gesellschaftsordnung ein großes Hindernis für den Fortschritt der indischen Kultur. Dementsprechend ablehnend fallen die meisten Äußerungen aus. Es gibt aber auch vereinzelte Stimmen, die in den zeitgenössischen Auswüchsen ehemals sinnvolle und gute Absichten erkennen wollen.

\subsubsection{Das Kastenwesen und seine Entstehung}

Berichte über das Kastenwesen sind schon sehr alt. Während es jedoch zunächst aufgrund von Ähnlichkeiten mit der Ständegesellschaft als Variante einer an sich vertrauten Gesellschaftsordnung aufgefasst wurde, führte die Lockerung der

\footnotetext{
${ }^{310}$ Auch Susanne Greillich hält die Beobachtung fest, dass die Orientalen allgemein in den Volksalmanachen zunächst überwiegend als positives Vorbild geschildert wurden. Dies habe sich aber ab den 20er Jahren des neunzehnten Jahrhunderts geändert: Nun unterstrichen die Almanache immer mehr die Grausamkeit, die Unwissenheit, den Aberglauben und die Leichtgläubigkeit der Orientalen, die nur durch die Christen gerettet werden könnten (vgl. Greillich: Orientbilder in französisch- und deutschsprachigen Volksalmanachen, S. 76-78).
} 
Sozialstruktur in Europa im Laufe des 18. Jahrhunderts dazu, dass das vergleichsweise starre Kastenwesen zunehmend als fremd empfunden wurde und vor allem im 19. Jahrhundert vermehrt auf Ablehnung stieß. ${ }^{311}$ Andererseits führte gerade die Kolonialisierung Indiens durch Großbritannien dazu, dass das Kastenwesen systematisch festgeschrieben und dadurch als prägende Gesellschaftsordnung gestärkt wurde. $^{312}$

In der frühen Neuzeit bezeichneten zunächst die Portugiesen die soziale Ordnung Indiens mit dem Begriff der Kaste, allerdings beschrieben die Autoren der frühesten Berichte dieser Tradition weit weniger als systematisch und feststehend als spätere Autoren. Sie maßen dem Kastenwesen auch eine weit geringere Bedeutung zu. ${ }^{313}$ Rogerius und Dapper beschrieben 1663 bzw. 1681 die vier Stämme der Inder: die Priester, die Adligen, die Kaufleute und die Handwerker, die wiederum in einzelne Unterstämme unterteilt seien. Sie führten auch die Sage an, wonach die Brahmanen aus dem Haupte Brahmās entsprossen seien, die Edlen und Krieger aus den Armen bzw. Schultern, die Kaufleute aus den Lenden bzw. dem Bauch und die Handwerker aus den Füßen. Zudem gebe es die „Perreas“, die verachtet seien, nicht zu den vier Stämmen gehörten und keinen Kontakt zu den übrigen Indern haben dürften. Sie erwähnten auch, dass frühere Autoren von sieben Kasten berichtet hätten bzw. dass es zunächst sieben Kasten gegeben habe. ${ }^{314}$

Auch in den späteren Texten variieren immer mal wieder die genaue Anzahl und die Bezeichnung (wohl auch je nach Sprache des betreffenden indischen Landesteils) der einzelnen Kasten. Als einen recht verbreiteten Konsens kann man aber die vier Hauptkasten der Brahmanen, Krieger, Kaufleute und Handwerker mit diversen Unterkasten sowie die kastenlosen und rechtlosen Paria ansehen. Diese Einteilung findet sich immer wieder in leicht variierenden Ausformungen und wird auch im Lexikonartikel von 1815 in dieser Form aufgeführt. ${ }^{315}$ Diese Systematisierung und

\footnotetext{
${ }^{311}$ Vgl. Osterhammel: Die Entzauberung Asiens, S. 331

${ }^{312}$ Vgl. Dirks, Nicholas B.: Castes of Mind. Colonialism and the Making of Modern India. Princeton 2001, S. 5, 13

${ }^{313}$ Vgl. Dirks: Castes of Mind, S. $19 \mathrm{f}$.

${ }^{314}$ Vgl. Dapper: Asia, S. 12-15; Rogerius: Offne Thür zu dem verborgenen Heydenthum, S. 3-28; auch der Bericht bei Sonnerat ähnelt den beiden erstgenannten (vgl. Sonnerat: Reise nach Ostindien, S. 1626)

${ }^{315} \mathrm{Vgl}$. Conversations-Lexikon. 1815, S. 716
} 
Zusammenstellung der Kasten beruht in erster Linie darauf, dass Beschreibungen in brahmanischen Texten durch britische Autoren und Übersetzer verallgemeinert wurden (vor allem „The Laws of Manu“ in der Übersetzung von William Jones ist hier zu nennen). Die Darstellung alter brahmanischer Überlieferungen wird auf die gesamte zeitgenössische Gesellschaft übertragen und auf diese Weise festgeschrieben. ${ }^{316}$ Dirks beschreibt diesen Einfluss des Kolonialismus folgendermaßen: „Under colonialism, caste was thus made out to be far more - far more pervasive, far more totalizing, and far more uniform - than it had ever been before, at the same time that it was defined as a fundamentally religious social order.“317 Während die Kasten der Krieger, Kaufleute und Handwerker zumeist nur kurz und relativ neutral beschrieben werden, scheiden sich an den Brahmanen die Geister. Entweder gelten sie als weise, gelehrte Priester, die sich von der abergläubischen Unterschicht abgrenzen, oder aber sie werden als besonders schändlich, machtgierig und habsüchtig verteufelt. Auch die Parias ziehen die Aufmerksamkeit auf sich. Sie werden (eher selten) als niedere Menschenart abgewertet oder aber (und das ist der häufigere Fall) neutral beschrieben, wobei der Umgang mit ihnen kritisiert wird.

Eine Frage, die einige Autoren beschäftigt, ist die nach der Entstehung der Kasten. Natürlich wird auch die oben mitgeteilte Sage der Entstehung aus Brahmā immer wieder angeführt, allerdings nicht als tatsächliche Herkunft, sondern als eine Begründung der Brahmanen für ihre Vormachtstellung gegenüber den übrigen Kasten. Das Kastenwesen ist in europäischen Augen ein Herrschaftssystem der Brahmanen und so wird vor allem der Frage nachgegangen, wie die Brahmanen an ihre Macht kommen konnten. Bereits Sonnerat hat die Theorie aufgestellt, dass das Kastenwesen aus einer Trennung der Armen von den Reichen zur Unterdrückung jener entstanden sei. ${ }^{318}$ Während Herder der Ansicht war, dass es nicht wahrscheinlich sei, dass die Brahmanen ihre führende Rolle mit Hilfe von gewalttätiger Unterdrückung erlangt hätten, ${ }^{319}$ geht Friedrich Schlegel davon aus, dass es bei der Trennung der seiner Ansicht nach ursprünglich verbundenen Priester- und Kriegerkaste zu gewaltsamen Auseinandersetzungen gekommen sein müsse. ${ }^{320}$

\footnotetext{
${ }^{316}$ Vgl. Dirks: Castes of Mind, S. 34f.

${ }^{317}$ Dirks: Castes of Mind, S. 13

${ }^{318}$ Vgl. Majer: Zur Culturgeschichte der Vöker. Band 2, S. 330

${ }^{319}$ Vgl. Herder: Ideen zur Philosophie der Geschichte der Menschheit, S. 291

${ }^{320}$ Vgl. Schlegel, Friedrich: Über Sprache und Weisheit der Indier, S. 184
} 
Meiners verbindet eine menschengemachte, künstliche Trennung der Brahmanen von den Kriegern mit der Annahme einer naturgegebenen Ungleichheit der Menschen, die sich in den Kasten manifestiere:

\begin{abstract}
Die Absonderung der Casten der Priester und der edlen Krieger war allem Vermuthen nach das Werk irgend eines Gesetzgebers oder Religionsstifters, der den priesterlichen Geschlechtern [...] ihre erblichen Vorrechte ertheilte, um sie entweder zu gewinnen, oder um sie für einen großen geleisteten Dienst zu belohnen. Die Absonderung der höhern Casten hingegen von den unteren war ein Werk der Natur selbst, in dem sie die Hindus der unteren Casten an Seele und Leib ungleich kärglicher ausstattete, als die der höheren. Die Hindus der unteren Casten sind nicht nur viel schwärzer, kleiner und häßlicher von Körper; sondern auch viel mehr beschränkt von Geist, und übelartiger von Gemüth, als die der höheren: besonders unglaublich träge, muthlos und unzuverlässig. Bey einer solchen natürlichen Ungleichheit mußte nothwendig in Hindostan ein ähnliches Verhältniß entstehen, wie in den westindischen und ostindischen Besitzungen der Europäer, wo die Weissen sich unter schwarzen oder rothen und braunen Völkern niederließen. Die Europäer in den auswärtigen Colonien entsprechen den höheren Casten der Hindus [...]. ${ }^{321}$
\end{abstract}

\title{
Meiners nutzt die Darstellung des Kastenwesens zur Untermauerung seiner These von \\ der Existenz verschiedener, sich stark voneinander unterscheidenden Menschenrassen.
}

Eine ganz andere Theorie vertritt Majer:

Bei einer aufmerksamen Betrachtung der Indischen Kasten-Einrichtung kann man nach unserer Überzeugung, nicht lange der Bemerkung entgehen, daß dieselbe blos und allein Folge der ersten, von einer aufgeklärten Priesterkaste gemachten, politisch-bürgerlichen Einrichtung des Volkes, gewesen ist. Zwar ist man bis jetzt, aus Mangel an einer solchen Anzahl von indischen Originalschriften [...], noch nicht im Stande, sich eine vollständige und zusammenhängende Vorstellung von dem eigentlichen und unbezweifelten Ursprung und der allmähligen Ausbildung des Religionssystems der Brahminen zu machen; allein der ganze Karakter desselben zeigt, daß es die Hervorbringung einer Gesellschaft aufgeklärter Menschen gewesen ist, deren Absicht es war, die ursprünglichen religiösen Ideen des Volkes unter welchem es entstanden ist, nach und nach in ein künstliches Gewebe zu vereinigen, durch welches sie im Stande waren, das Volk in jeder Hinsicht zu bilden und zu erziehen, aber nur bis zu einem solchen Grad, welche diesen Stiftern und ihren Nachfolgern, eine vom Anfang an durch die Gewalt der Meinung begründete Übergewalt, für die ganze Zukunft erhalten und zusichern konnte. ${ }^{322}$

Majer entwirft das Bild einer aufgeklärten und gebildeten Priesterschicht, die das Kastenwesen eingeführt habe, um auf diese Art und Weise das alte Wissen zu bewahren und zu schützen, und um Teile davon an das Volk weiterzugeben und das Volk so zu

\footnotetext{
${ }^{321}$ Meiners: Untersuchungen über die Verschiedenheiten der Menschennaturen. 2. Band, S. 240f.

${ }^{322}$ Majer: Zur Kulturgeschichte der Völker, S. 334f.
} 
erziehen. Sie bräuchten das Kastensystem, um selbst als Lehrer und Erzieher des Volkes auftreten zu können. ${ }^{323}$

Auch hier lässt sich wieder beobachten, wie sehr die persönliche Weltanschauung und die damit verbundene Beurteilung und Einordnung Indiens sogar die Hypothesen zur Entstehung des Kastenwesens beeinflusst. Autoren wie z.B. Majer, die davon ausgehen, dass die Menschen sich immer mehr von einer ursprünglichen Weisheit entfernen, sehen im Kastenwesen eher ein altes System zur Bewahrung dieser Weisheit (das dann vielleicht für andere Zwecke missbraucht worden ist). Andere, deren Weltbild vom Gedanken der Überlegenheit einzelner Kulturen oder Völker geprägt ist, neigen eher dazu, im Kastenwesen eine fast natürliche Trennung nach Können, Reichtum oder eben Zugehörigkeit zu einer Menschengruppe bzw. -rasse zu sehen. So stehen sich verschiedene Thesen zur Entstehung der Ungleichheit gegenüber.

Auch die Entstehung der kastenlosen Gruppe der Paria sorgt für Interesse. Verbreitet war die Ansicht, dass es sich bei dieser Gesellschaftsgruppe um Menschen und deren Nachkommen handele, die aufgrund von Verbrechen oder anderen Regelverstößen oder auch wegen Krankheiten aus ihren Kasten ausgestoßen worden seien. Diese These wird z.B. im Lexikonartikel von 1815 vertreten $^{324}$ und auch Meiners und Majer erwähnen diese Annahme. ${ }^{325}$ Klaußner berichtet sogar ganz konkret davon, welches Gesetz (nämlich das Verbot, Kuhfleisch zu essen) die Vorfahren der Parias übertreten hätten. ${ }^{326}$ So konkret will sich der italienische Arzt Lazzaro Papi, der sich immer wieder auch mit den sozialen und ökonomischen Bedingungen der Inder auseinandersetzt, nicht festlegen:

Was wohl die Ursache seyn mag, wodurch die andern Kasten veranlaßt wurden, diese unglücklichen Menschen mit Schimpf und Schande zu überhäufen, und sie auf immerwährende Zeiten zu brandmarken? Vielleicht machten sie sich einst eines unverzeihlichen Verbrechens schuldig, um

\footnotetext{
${ }^{323}$ Ein ähnlicher Gedanke wird auch in einem Artikel im Morgenblatt für gebildete Stände vertreten. Dort wird die Entstehung der Brahmanen (wie die anderer Priesterkasten in anderen Kulturen) damit erklärt, dass Völker in ihrer Kindheit einer gelehrten Schicht bedürften, die quasi die Vormundschaft über das noch kindliche Volk übernähmen, um so das Wissen vor dem Untergang zu bewahren. Bei einigen Völkern bliebe diese Vormundschaft auch über die Kindheit hinaus bestehen und verfestige sich zu einem Kastensystem wie in Indien. (Vgl. Brahmanen. In: Morgenblatt für gebildete Stände 2 (1808; Nr. 237), S. 945f., hier S. 945)

${ }^{324}$ Vgl. Conversations-Lexikon. 1815, S. 716 f.

${ }^{325}$ Vgl. Meiners: Untersuchungen über die Verschiedenheiten der Menschennaturen. 2. Band, S. 240;

Majer: Zur Kulturgeschichte der Völker, S. 331

${ }^{326}$ Vgl. Klaußner: Die Hindus, S. 516
} 
dessentwillen sie aus der menschlichen Gesellschaft verbannt wurden. Vielleicht waren sie mit der Pest, mit dem Aussatze, oder irgend einer andern steckenden Krankheit behaftet, weswegen sie von andern Menschen verstoßen, und in die Noth-wendigkeit gesetzt wurden, sich von ihnen ganz abzusondern, indeß der Abscheu, welchen man gegen sie hegte, auch nach beseitigter Gefahr noch immer fortdauerte, und das ganze Geschlecht dieser Unglücklichen einer immerwährenden, eben so ungerechten als barbarischen Herabwürdigung preis gegeben wurde. ${ }^{327}$

Der Autor betont, dass die Ursachen für das ursprüngliche Verstoßen (Verbrechen oder ansteckende Krankheit) zwar nachvollziehbar seien, die Ausgrenzung dann aber nie aufgehoben und sogar auf die Nachkommen ausgeweitet wurde. Die Missbilligung dieses Geschehens und der fehlenden Möglichkeit der Parias, sich aus ihrem Los zu befreien, macht der Autor mehr als deutlich.

\subsubsection{Beurteilung des Kastensystems}

Das Kastenwesen ist (neben der Witwenverbrennung) derjenige Aspekt der indischen Kultur, dem die überwiegende Anzahl der Autoren ablehnend gegenübersteht. Das trifft auch auf die Autoren zu, die Indien ansonsten sehr positiv beurteilen oder es sogar idealisieren, wobei die Unterschiede im Weltbild bzw. diskursiven Zusammenhang auch hier Einfluss darauf haben, wie das Kastensystem als solches und die einzelnen Kasten beurteilt werden.

So teilen vor allem Autoren, die dem oben beschriebenen Entwicklungsdenken zuneigen und einen permanenten Fortschritt als Ziel der Menschheit ansehen, die verbreitete These, dass diese Einrichtung die indische Gesellschaft lähme und so Fortschritt z.B. in Kunst und Wissenschaften verhindere. Dahinter steht die Vorstellung, dass sich die menschlichen Gesellschaften und Kulturen von einem einfachen, tierähnlichen Anfang hin zu einer immer komplexeren Moderne entwickeln (sollten), was durch die Kasten verhindert werde. So schreibt Ehrmann:

\footnotetext{
Wie nachtheilig eine solche, schon seit Jahrtausenden bestehende, höchst unpolitische Einrichtung ist, fällt Jedem in die Augen. Denn wie kann es anders seyn, als daß bei einer solchen Zwangsbeschränkung die Unterthanen eines Staates in der Cultur zurückbleiben, und theils übermüthig, theils sklavisch gesinnt werden müssen, da den Einen alle Vorzüge begünstigen, und der Andere gleichsam in Sklavenfesseln seufzet, ja in Fesseln, die noch schwerer drücken, als andere, da sie den Geist gewaltsam beschränken? ${ }^{328}$
}

\footnotetext{
${ }^{327}$ Briefe eines italienischen Reisenden. In: Ehrmann, Theophil Friedrich (Hg.): Neueste Beiträge zur Kunde von Indien. Aus dem Englischen und Italienischen. 3. Band. Weimar 1806, S. 281

${ }^{328}$ Ehrmann: Neueste Kunde von Asien, S. 62
} 
Das Kastenwesen enge den Geist ein und zwinge die Menschen zu bestimmten Tätigkeiten ungeachtet ihrer eigentlichen Begabung. Es mindere auch die Motivation der Menschen, Neues zu erschaffen und ihre Fähigkeiten zu verbessern, da sie entweder sowieso schon alle Vorzüge genießen können oder aber trotz allen Bemühens und Könnens niemals aus ihrer Kaste und Gesellschaftsschicht werden aufsteigen können. Es fehle also jeglicher Anreiz. ${ }^{329}$

Ein anderes Argument gegen die Kasten, das auch in dem Lexikonartikel von 1809 anklingt, ${ }^{330}$ ist, dass die Kasten die Einheit der Gesellschaft zerstörten und kein Mitgefühl für Menschen anderer Kasten zuließen. Sehr deutlich äußert sich der Italiener Papi:

\begin{abstract}
Welcher bösartige Genius, welcher Feind der menschlichen Natur, mag wohl die verabscheuungswürdige Einsetzung der Kasten erfunden haben? Wer kam wohl zuerst auf den verruchten Gedanken, die Menschen, welche die Natur ursprünglich zum gesellschaftlichen Leben bestimmte, von einander zu trennen und abzusondern? Wer durfte sich erkühnen, den wohlthätigsten unter allen Trieben, welche sie dem Menschen ins Herz senkte, für strafbar zu erklären? Der Mensch lebt mit den Thieren in Gesellschaft, vor welchen er einen so entschiedenen Vorzug behauptet, und er erfrecht sich, den Stolz so weit zu treiben, daß seine Nebenmenschen sich ihm nicht nähern, ihn nicht anrühren, nicht einmal die Luft einathmen sollen, die er einathmet? ${ }^{331}$
\end{abstract}

Hier scheint das bereits oben bei der Charakterisierung der Inder angesprochene Motiv wieder auf, dass die Inder eine doppelte Moral hätten, wenn sie die Tiere ehrten, aber kein Mitgefühl gegenüber ihren Mitmenschen empfänden und auch nicht empfinden dürften. Der Autor beruft sich hier darauf, dass Mitgefühl und Nächstenliebe ganz natürliche und gute Triebe seien, die in Indien künstlich unterdrückt würden. Das Kastenwesen laufe also der Natur des Menschen zuwider. Der Autor setzt sich im Folgenden kurz mit anderen Autoren auseinander, die im Kastenwesen ein gutes System zur Aufrechterhaltung von Ruhe und Ordnung durch die Zügelung der Leidenschaften sehen, das durch frühe Gewöhnung an eine bestimmte Rolle den Menschen das Leben in diesen Rollen erleichtere und angenehmer mache und das dadurch auch die Künste und Wissenschaften fördere. Er spricht dem Kastenwesen

\footnotetext{
${ }^{329}$ Eine ganz ähnliche Auffassung wird auch in dem Lexikon-Artikel von 1809 vertreten (vgl. Conversations-Lexikon 1809, S. 336f.); auch Papi macht das Kastenwesen für die Erschlaffung der Geisteskräfte verantwortlich (vgl. Briefe eines italienischen Reisenden, S. 305)

${ }^{330}$ Conversations-Lexikon 1809, S. 336f.

${ }^{331}$ Briefe eines italienischen Reisenden, S. 302
} 
diese möglichen positiven Auswirkungen allerdings ab, da die natürliche Freiheit des Menschen eingeschränkt werde und eine solche Unterwürfigkeit in einem gut eingerichteten Staat nicht notwendig sei.

Missionare wie z.B. Dubois sehen im Kastenwesen immer wieder ein gewaltiges Hindernis bei ihren Bekehrungsversuchen. So beklagt Dubois, dass es kaum Bekehrungen unter Angehörigen höherer Kasten gebe, denn durch die Konversion zum Christentum „,verliert ein Hindu Alles. Verwandte, Angehörige, Freunde - alle verlassen ihn! Güter, Besitzungen, Erbschaft, alles verschwindet!“" ${ }^{332}$ Wie wir in Kapitel3.6 sehen werden, setzen sich daher gerade die Missionare immer wieder mit den Hürden des Kastenwesens auseinander. ${ }^{333}$

Auch Hegel kritisiert die „Knechtschaft des Geistes“334 und betrachtet sie aus Sicht seiner Philosophie des Weltgeistes. Im Vergleich zur unterschiedslosen Einheit der chinesischen Kultur, die keine Unterschiede der Individuen kenne, trete in Indien nun das Besondere hervor, aber die Unterschiede verfestigten sich und erstarrten in festen Ständen, die dem Einzelnen keine Möglichkeit der individuellen Freiheit mehr ließen. Aufgrund von natürlichen Unterschieden zwischen den Menschen sei eine gewisse Form von ständischer Untergliederung Hegels Ansicht nach normal. In Indien bestehe jedoch die Besonderheit, dass die Menschen ihrem Stand nur aufgrund des Geburtsprinzips angehörten und keine Möglichkeit hätten, sich aus dieser Fessel zu befreien. Im mittelalterlichen Feudalwesen habe immerhin die Möglichkeit bestanden, in den geistlichen Stand zu wechseln. ${ }^{335}$

Die Anbindung des fremden Kastensystems an das Bekannte geschieht auch bei anderen Autoren über den Vergleich mit der europäischen Ständeordnung. ${ }^{336}$ Daher kann Kritik am Kastenwesen oder auch dessen Lob immer auch auf die Ständegesellschaft zielen. ${ }^{337}$ So gibt es in der Forschung die Vermutung, dass die

\footnotetext{
${ }^{332}$ Dubois: Briefe über den Zustand des Christentums in Indien, S. 12

${ }^{333}$ Vgl. auch Dirks: Castes aof Mind, S. 26-28

${ }^{334}$ Hegel: Vorlesungen zur Philosophie der Geschichte, S. 149

${ }^{335}$ Vgl. Hegel: Vorlesungen über die Philosophie der Geschichte, S. 148-152

336 Vgl. z.B. Windischmann, der relativ neutral von der Besonderheit des „Lehr- Wehr- Nähr- und Dienststandes“, die Inder und Germanen teilten (Bopp: Über das Conjugationssystem, S. XI)

${ }^{337}$ Vgl. Frank: Sanftes Gefühl und stille Tiefe der Seele, S. 155
} 
Darstellung des Kastenwesens bzw. das Ständewesen bei Friedrich Schlegel ${ }^{338}$ und Görres $^{339}$ als natürliche und ursprüngliche Einrichtung nicht in erster Linie allein auf diese alten Gesellschaftsformen ziele, sondern im Umbruch der zeitgenössischen europäischen Gesellschaft die alten Formen verteidigen solle. Die Idealisierung des Anderen könnte in diesem Fall also der Durchsetzung bestimmter politischer Forderungen in der eigenen Gesellschaft dienen. Auf der anderen Seite können anhand des indischen Kastenwesens innerhalb des in der Aufklärung wichtigen Diskurses über Freiheit und Gleichheit der europäische Absolutismus und das Ständewesen kritisiert werden.

Bei Herder und Majer zielt der Vergleich weniger auf die europäische Ständegesellschaft als vielmehr auf „alte“ Völker allgemein. So stellt Herder fest, dass es Einteilungen in Stände auch bei anderen Völkern gegeben habe, z.B. bei den alten Ägyptern. Und es sei auch keine Besonderheit, dass die Priester als erster Stand gelten. ${ }^{340}$ Auch Majer schreibt, die

gesellschaftliche und politische Verfassung der Indier ist auf die auch bei andern alten Völkern gewöhnliche Kasteneinrichtung gegründet gewesen. Nach derselben ist das Volk seit den ältesten Zeiten her in mehrere Stämme oder Kasten getheilt, deren Glieder erblich zu dem Beruf und der Lebensart ihrer Väter verpflichtet sind. ${ }^{341}$

Beide betonen damit zum einen die Normalität dieser Einrichtung und zum anderen das hohe Alter derselben. Ihnen geht es hier nicht um eine Kritik an der zeitgenössischen europäischen Gesellschaftsordnung. Während die Betonung bei Herder wohl eher

\footnotetext{
${ }^{338}$ Tzoref-Ashkenazi sieht in den Feststellungen Schlegels, dass das Kastenwesen die ursprüngliche Gesellschaftsform der indogermanischen Völker gewesen sei (vgl. Schlegel: Über die Sprache und Weisheit der Indier, S. 190f.) und dass diese besonders bei den Germanen ausgeprägte

Verfassungsform die natürlichste und beste sei (vgl. Schlegel, Friedrich: Über die neuere Geschichte. Vorlesungen gehalten zu Wien im Jahre 1810. Wien 1846 (Fried. v. Schlegel's sämmtliche Werke. Zweite Original-Ausgabe. Eilfter Band), S. 44) das Bemühen, für die von Schlegel favorisierte Ständeordnung in Indien ehrenvolle Vorfahren zu finden.Während die ursprüngliche Gesellschaftsform bei anderen Nachkommen der Inder, wie z.B. bei den Griechen und Römern, schnell zu Republiken, Anarchie und Tyrannei verfallen sei, hätten die Germanen sie sogar noch verbessert (vgl. TzorefAshkenazi: The Nationalist Aspects of Friedrich Schlegel's On the Language and the Wisdom of the Indians, S. 120). Da sich die Aussagen Schlegels zu Indien bzw. zur Bevorzugung der Ständeordnung in zwei verschiedenen Texten befinden, kann man allerdings nur sagen, dass Schlegel das Kastenwesen indirekt lobe; direkt tut er dies nicht.

${ }^{339}$ Görres sieht das Kastenwesen und die Herrschaft der Priester als die natürliche Gesellschaftsform des „Urstaat(s)“ an (Görres: Mythengeschichte der asiatischen Welt, S. 16), was von Kramer als Verteidigung der alten Ständeordnung und des Einflusses der Priester auch im zeitgenössischen Europa gedeutet wird (vgl. Kramer: Verkehrte Welten. Zur imaginären Ethnographie des 19. Jahrhunderts. Frankfurt a.M. 1977, S. 19f.).

${ }^{340}$ Vgl. Herder: Ideen zur Philosophie der Geschichte der Menschheit, S. 291

${ }^{341}$ Majer: Zur Culturgeschichte der Völker, S. 252
} 
darauf liegt zu zeigen, wie ähnlich sich unterschiedliche Völker sein können, geht es Majer anscheinend vor allem darum, das hohe Alter (,seit den ältesten Zeiten“) zu unterstreichen, was bei seiner romantischen Auffassung einer verlorenen goldenen Zeit eine positive Wertung des Kastenwesens bedeutet. Und tatsächlich sieht Majer, wie oben beschrieben, die ursprüngliche Aufgabe des Kastenwesens in der Bewahrung des alten Wissens und der Erziehung der Menschen. Dies gehe nur durch Täuschung, wie die Geschichte auch anderer religiöser und politischer Verfassungen zeige. Im Prinzip sei das gut, aber es drohe Missbrauch:

\begin{abstract}
An sich war dieses Verfahren gut und lobenswürdig, denn es hatte die wohlthätige Absicht, rohe wenig gebildete, unwissende oder durch eine übermäßige Verfeinerung der Sinnlichkeit geschwächte und verdorbene Menschen, zu ihrem Beßten durch erlaubte Täuschungen zu hintergehen. Nur der Mißbrauch, welchen die Priester und die um des beiderseitigen Vortheils willen mit ihnen einverstandenen Herrscher, davon gemacht haben, hat verursacht daß diese künstliche Erziehung dem menschlichen Geschlecht in vieler Hinsicht schädlich und nachtheilig gewesen ist. Besonders habe die ersteren [...] fast bei allen durch künstliche Erziehung gebildeten Völkern [...] gewisse den übrigen Staatsbürgern nachtheilige Vorzüge und Vorrechte zu erreichen gesucht. ${ }^{342}$
\end{abstract}

Das System als solches sei also alt und gut, aber gerade die Priester seien zu oft auf ihren eigenen Vorteil bedacht und missbrauchten das Kastenwesen zu diesem Zwecke.

Auch andere Autoren sehen in dem Kastenwesen eine ursprünglich positive Einrichtung, allerdings nicht wie Majer zur Erziehung des Menschen, sondern zur Stabilisierung des Staates und zur Aufrechterhaltung von Ruhe und Ordnung. So verhindere die unnatürliche Einteilung in Kasten zumindest Ehrgeiz und Verbrechen. ${ }^{343}$ Daher seien zum Christentum bekehrte Inder nicht unbedingt die besseren Untertanen, da dann der Einfluss der Kasten fehle. ${ }^{344}$ Auch hier beeinflusst der diskursive

\footnotetext{
342 Majer: Zur Culturgeschichte der Völker, S. 339f.

${ }^{343}$ Vgl. Über den Charakter der Hindus, S. 721; auch der Missionar Dubois, dessen ausführliches Werk über die indischen Kasten in britischen Regierungs- und Verwaltungskreisen große Beachtung fand, ist der Ansicht, dass es das alleinige Verdienst der Kastenbindung sei, dass Indien nicht in Barbarei versunken sei wie so viele andere Kulturen, sondern Wissenschaften, Künste und Zivilisation bewahren konnte (Dubois, J.A.: Description of the Characters, Manners and Customs of the People of India; and of their Institution, religious and civil. London 1817, S. 14; vgl. auch Dirks: Castes of Mind, S. 24) ${ }^{344}$ Vgl. die Rezension zu „Georg Viscount Valentia's und Heinrich Salts Reise nach Indien, Ceylon, dem rothen Meere, Abyssinien und Ägypten“ in Jenaische Allgemeine Literatur-Zeitung 119 (Juni 1812), Sp. 425-432, hier Sp. 430; mit positiven Bewertungen den Kastenwesens als ein eigentlich gutes System zur Erziehung des Menschen sowie zur Aufrechterhaltung von Ruhe und Ordnung setzt sich auch Lazzaro Papi auseinander. Er spricht dem Kastenwesen diese positiven Seiten allerdings ab, da die natürliche Freiheit des Menschen eingeschränkt werde (Vgl. Briefe eines italienischen Reisenden, S. 303f.)
} 
Zusammenhang, in welchem das Kastenwesen betrachtet wird, dessen Deutung und Beurteilung. Majer, dem es um Bewahrung und Verlust des alten Wissens geht, betrachtet das Kastenwesen unter diesem Blickwinkel. Die Reisenden und Missionare, die mit dem Alltag in Indien konfrontiert sind, sehen eher die praktischen Auswirkungen des Kastenwesens auf die Gesellschaft.

\subsubsection{Die Brahmanen}

Während der Brahmane in der Antike und im Mittelalter häufig als Inbegriff des weisen, gewaltfreien Asketen galt, ${ }^{345}$ ist in der Zeit um 1800 die These, dass die Brahmanen auf ihren Vorteil bedacht seien, weit verbreitet. Es gibt zwar auch Stimmen, die in ihnen nur die weisen Priester und Gelehrten sehen, oft aber werden sie der Habsucht bezichtigt. Während die beiden unteren Kasten meist eher kurz und sachlich beschrieben werden, die Krieger in ihrer Funktion als Herrscher etwas mehr Aufmerksamkeit bekommen und die Parias als Ausgestoßene bewegen und Mitgefühl oder Abscheu auf sich ziehen, scheint von den Brahmanen eine große Faszination auszugehen, die sich in Bewunderung oder Ablehnung manifestiert. Die Brahmanen können auch deswegen die europäischen Beobachter in ihrer Beurteilung spalten, da sie (ähnlich wie bereits für die Gesellschaftsordnung beschrieben) als ein verzerrtes Bild des europäischen Klerus in der Feudalgesellschaft fungieren können. Je nach diskursivem Zusammenhang und eigenen philosophischen Vorstellungen können sie unterschiedlich gedeutet werden. Religions- und Kirchenkritikern gelten sie als ein negatives Beispiel für die Macht des Klerus, die auf eigens zu diesem Zweck verbreiteten abergläubischen Vorstellungen beruhe. Romantiker sehen sie dagegen als lebendes Beispiel für die in Europa im Zuge der Aufklärung verlorene Einheit von Gelehrtem und Geistlichem.

Bei ihrer Beschreibung werden neben ihrer Kleidung und einer ihren Stand kennzeichnenden Schnur vor allem ihre Vorrechte und ihre Pflichten hervorgehoben. Die Brahmanen seien die Einzigen, die die heiligen Schriften lesen dürften, sie

\footnotetext{
${ }^{345}$ Dabei wurde ihre Lebensweise freilich auf der Basis antiker (vor allem kynischer und stoischer) Philosophie wahrgenommen und interpretiert. Eine ähnliche Deutung vor dem Hintergrund eigener Vorstellungen lässt sich auch in den Schriften des frühen Christentums beobachten: Obwohl die Kritik am Heidentum im Vordergrund stand, wurde die Aufmerksamkeit immer wieder auf die Ähnlichkeit der brahmanischen zur christlichen Askese gelenkt, wobei die Inder die Christen in ihrer Enthaltsamkeit noch übertrafen. Das konnte entweder als Vervollkommnung des christlichen Ideals oder aber als gefährliche Übertreibung desselben gewertet werden (vgl. Kragl: Die Weisheit des Fremden, S. 203-206, 246, 251f., 313-316)
} 
vollzögen Opfer und Zeremonien, sie müssten von allen übrigen geehrt werden, und ein Verbrechen gegen einen Brahmanen könne schlimme Strafen nach sich ziehen. Dagegen könnten Brahmanen selbst niemals mit dem Tode bestraft werden, egal, welches Verbrechen sie begangen hätten; lediglich die Verbannung drohe ihnen. Sie hätten sehr viele komplizierte Regeln zu befolgen, und zwar nicht nur in Ausübung ihrer Religion, sondern vor allem auch im Alltag, beim Essen, beim Umgang mit anderen Menschen und sogar beim Gang zur Toilette. Besonders deutlich hebt Hegel die beiden Seiten von Recht und Pflicht hervor: Während die Brahmanen einerseits als ein Gott verehrt werden müssten, hätten sie andererseits viele Regeln zu beachten, die in Hegels langer Aufzählung so wirken, als sei ihre Einhaltung praktisch unmöglich. ${ }^{346}$ Diese Beschreibungen der Rechte und Pflichten der Brahmanen unterscheiden sich natürlich je nach Text in gewissen Details, aber sie sollen hier nicht in allen Einzelheiten untersucht werden. Vielmehr möchte ich einige Textstellen vorstellen, die deutlich machen, welche Bilder von den Brahmanen entworfen werden und wie sie beurteilt werden.

Interessanterweise finden sich in den untersuchten Texten trotz aller Idealisierungen Indiens nur wenige Stellen, in denen die Brahmanen positiv oder zumindest neutral (wie z.B. bei Heeren ${ }^{347}$ oder Paulinus a Sancto Bartholomaeo) beschrieben werden. Dafür können unter anderem folgende zwei Gründe angeführt werden: Erstens schreiben viele der Autoren, die Indien für seine alte Weisheit bewundern und bei denen man daher eher ein positives Bild der Brahmanen erwarten würde, nur sehr wenig zur zeitgenössischen indischen Gesellschaft und zweitens findet sich auch bei ihnen oft die Ansicht, dass die alte Weisheit Indiens in neuerer Zeit auch von den Brahmanen nicht mehr wirklich verstanden werde, weshalb viele Brahmanen - wenn auch ohne Absicht - Aberglauben verbreiteten. Auch in der ansonsten neutral bis positiv gehaltenen Beschreibung von Majer lässt sich diese These finden. Majers Darstellung zeichnet sich vor allem dadurch aus, dass bei der Aufzählung der vielen Pflichten der Brahmanen nicht wie so oft diejenigen überwiegen, die den Europäern absurd anmuten und deren

\footnotetext{
${ }^{346}$ Vgl. Hegel: Vorlesungen über die Philosophie der Geschichte, S. 157f.

${ }^{347}$ Arnold Herrmann Ludwig Heeren (1760-1842) studierte Theologie an der Universität Göttingen. Sein Interesse galt aber vor allem der Kirchengeschichte und der historisierenden Philologie. 1799 wurde er Professor für Geschichte in Göttingen, wo er der Frage nachging, wie ein Gleichgewicht zwischen den Staaten möglich sein kann (vgl. Crusius, Irene, "Heeren, Arnold" in: Neue Deutsche Biographie 8 (1969), S. 195 f. [Online-Version]; URL: https://www.deutschebiographie.de/pnd118773607.html\#ndbcontent).
} 
genaue Befolgung praktisch unmöglich erscheint. Es werden dagegen Pflichten genannt, die dem Brahmanen dazu dienen, seine Leidenschaften zu zügeln und so einen über alles erhabenen Zustand zu erreichen. Die Pflichten der Brahmanen dienen bei Majer also nicht der Selbstdarstellung nach außen, sondern der inneren Vervollkommnung. Dennoch bemerkt Majer, dass viele dieser Pflichten und Übungen missverstanden und durch körperliche Selbstpeinigungen ersetzt würden. ${ }^{348}$

Der Vorstellung, dass die Gewohnheiten und Gesetze der Brahmanen in Verfall geraten seien, widerspricht interessanterweise ausgerechnet der Missionar Paulinus a Sancto Bartholomaeo, der die Verrichtungen der Brahmanen durchaus positiv beschreibt. ${ }^{349}$ Das wiederum wird von dem italienischen Indienreisenden Papi kritisiert, der schreibt, dass die Brahmanen sich seit ihrem Treffen mit Paulinus a Sancto Bartholomaeo sehr verändert haben müssten, sollten dessen Berichte zutreffend sein. Er selbst habe dergleichen nämlich nicht vorgefunden. Stattdessen sei es vielmehr so, dass die Brahmanen ihre Gesetze nur dann streng einhielten, wenn sie sich einen Vorteil davon versprachen, dass man sie mit einer Summe Geld aber leicht davon abhalten könne. Auch hier wird den Brahmanen also Habsucht vorgeworfen. ${ }^{350}$ Außerdem ließen die Brahmanen die Menschen in voller Absicht in Unwissenheit und Aberglauben, um die Schranken zwischen den Kasten zu erhalten:

Seine [Brahmās] Priester suchten es [das Volk] in der tiefsten Unwissenheit zu erhalten, häuften Fabeln auf Fabeln, anstatt nützliche Kenntnisse und faßlich Wahrheiten zu verbreiten, erfanden eine Menge nichtiger Formalitäten in Betreff der Religion, und verblendeten die Gemüther durch den crassesten Aberglauben. Sie bestrebten sich demnächst auf alle erdenkliche Art, jene künstlichen imaginären Dämme zu befestigen, welche die verschiedenen Kasten von einander absondern, leisteten eben dadurch den Eroberern Indiens den thätigsten Beistand [...]. ${ }^{351}$

Die Braminen machen sich ein eigenes Geschäft daraus, von Zeit zu Zeit allerlei Prophezeihungen zu verbreiten, allerlei Wunder zu erdichten, welche sich bald da, bald dort ereignet haben sollen, und das Volk durch drohende Orakelsprüche, welche sie auf die eine oder die andere Art

\footnotetext{
${ }^{348}$ Vgl. Majer: Zur Culturgeschichte der Völker, S. 257-290, besonders 283-285; auch in einem Artikel aus Cottas Morgenblatt weist der Autor darauf hin, dass die Brahmanen das Volk nicht allein aus taktischen Gründen in Unwissenheit hielten, sondern dass sie die alten Überlieferungen selbst nicht mehr zu deuten wüssten und sich um keine neuen Erkenntnisse bemühten (vgl. Brahmanen, S. 945f) ${ }^{349}$ Vgl. Darstellung der brahmanisch-indischen Götterlehre, S. 75; die Beschreibung in der deutschen Bearbeitung des Textes ist eher neutral gehalten, lässt aber eine positive Einstellung durchscheinen; da der Bearbeiter seiner eigenen Angabe nach viele Passagen, die seiner Ansicht nach von der Sache abwichen oder zu deutlich die eigene Meinung vertraten, gestrichen hat, können im Original durchaus deutlichere Beurteilungen zu finden sein

${ }^{350} \mathrm{Vgl}$. Briefe eines italienischen Reisenden, S. 310

${ }^{351}$ Briefe eines italienischen Reisenden, S. 308
} 
vernommen haben wollten, in Schrecken zu setzen, damit es die erzürnten Götter durch Opfer und Gaben versöhne. Ich würde nicht fertig werden, wenn ich alle die abgeschmackten Mährchen anführen wollte, welche bald dieser bald jener in der Absicht erdichtet, nicht etwa nur das gemeine Volk, sondern sogar die angesehensten Leute, selbst die Rajahs nicht ausgenommen, und zwar immer mit dem glücklichen Erfolge, hinter das Licht zu führen. ${ }^{352}$

Die Brahmanen hielten also das künstliche System durch fehlende bzw. falsche Unterweisungen aufrecht, um davon selbst Vorteile zu erlangen. Und sie nutzten ihren großen Einfluss, um die Menschen mit erfundenen Geschichten zu Opfern und Gaben zu verleiten. Das funktioniere sogar bei den angesehenen Leuten und den Herrschern. Eine Ursache für dieses Verhalten sieht der Autor in der Erblichkeit des Priesterstandes. Es gebe zu viele Nachkommen der Priester, die ebenfalls Priester werden müssten, und für deren Versorgung die eigentlichen priesterlichen Aufgaben nicht ausreichten, so dass sie sich, ,um ihren Lebensunterhalt zu gewinnen, allerlei Ränke und Betrügereien erlaubten, und folglich dem ganzen Staatskörper auf die unerträglichste Weise zu Last fielen.“ ${ }^{353}$ Die von Ideen der Spätaufklärung geprägte antiklerikale Haltung Papis kommt in diesen Beschreibungen deutlich zum Ausdruck.

Der Vorwurf, die Brahmanen nutzten den Aberglauben des Volks zu ihrem eigenen Vorteil aus, ist um 1800 sehr verbreitet. Er findet sich als allgemeines Wissen auch in dem Lexikon-Artikel von 1809. ${ }^{354}$ Ehrmann äußert diesen Vorwurf zwar nicht direkt, aber seine Beschreibung der Brahmanen wirkt wie eine Karikatur, die sie ebenfalls als habgierige, auf Kosten des Volkes lebende Gruppe von Menschen erscheinen lässt. Das liegt manchmal an der Wortwahl (so bezeichnet Ehrmann die Zeremonien der Brahmanen häufig als „,Gaukelpossen“(355), oft aber auch an den ausgewählten Szenen, in denen die Brahmanen auftreten. Eine solche ist z.B. die Folgende:

\footnotetext{
Wenn ein sehr reicher, vornehmer Mann sich verheirathet, so laufen die hungrigen Braminen aus allen Ecken und Enden auf zwanzig Stunden im Umkreise herbei, um bei der Hochzeit zu schmarotzen; so daß man ihrer oft zu Tausenden zählt, die alle Tage, so lange die Hochzeitfeierlichkeiten dauern, welche oft 30 Tage wegnehmen, gefüttert und am Ende noch mit einem Pagne oder Leibtuche beschenkt seyn wollen: welches Alles zusammen nicht selten ungeheure Kosten verursacht. ${ }^{356}$
}

\footnotetext{
${ }^{352}$ Briefe eines italienischen Reisenden, S. 323f.

${ }^{353}$ Briefe eines italienischen Reisenden, S. 307

${ }^{354} \mathrm{Vgl}$. Conversations-Lexikon. 1809, S. 335

355 Z.B. Ehrmann: Neuste Kunde von Asien, S. 82

${ }^{356}$ Ehrmann: Neueste Kunde von Asien, S. 82
} 
Die Brahmanen erscheinen hier nicht als Individuen, sondern als eine gesichtslose Menge, die fast wie Insekten aus allen Richtungen kommend über das Essen herfalle. Nicht die Brautleute wollen hier - aus welchen Gründen auch immer - die Brahmanen beschenken und es wird auch nicht als ritueller Teil der Hochzeitszeremonie beschrieben, sondern die Brahmanen sind es, die durchgefüttert werden wollen, die als Schmarotzer bezeichnet werden und ihre hohe Stellung ausnutzen, um unrechtmäßig einen materiellen Vorteil zu genießen. Diese hohe Stellung erscheint bei dieser Beschreibung der Brahmanen nur eine auf alten Traditionen beruhende zu sein, die durch keinerlei Verdienst in der Gegenwart begründet werden kann. An anderer Stelle wird beschrieben, wie ein Astrologe den Willen der Götter hinsichtlich einer Hochzeit einholen soll. Und da er gut bezahlt werde, gebe es meistens einen günstigen Ausspruch. ${ }^{357}$ Auch bei der Schilderung einer Beerdigung kommen die Brahmanen nicht gut weg. Sie bekämen viel Geld, da sie besonders den Reichen mit der heißen Hölle drohten und diese nun Opfergaben gäben zu Rettung der Seele des Verstorbenen. „Die dadurch aufgemunterten Braminen nehmen nun noch mancherlei abergläubische Possen und Gaukeleien vor.“ ${ }^{358}$ Ehrmann lehnt hier nicht nur die Zeremonien der Hindus als Aberglaube ab, sondern er wirft den Brahmanen vor, diese nicht um der Religion willen auszuführen, sondern allein aus Habsucht. ${ }^{359}$

Auch der Missionar Dubois findet kaum etwas Gutes bei den Brahmanen. Er sieht in ihnen ebenfalls Betrüger, die ihre Stellung ausnutzten, um Macht über das absichtlich in Unwissenheit gelassene Volk auszuüben. Zur Herrschaftssicherung hätten sie zwischen den Hindus und allen anderen Völkern eine undurchdringliche Linie gezogen. ${ }^{360}$ Dubois stellt allerdings auch fest, dass das Kastenwesen nicht nur die unteren Schichten unterdrücke, sondern auch die Brahmanen dazu zwinge, sich anderen gegenüber schlecht zu verhalten:

\footnotetext{
${ }^{357}$ Vgl. Ehrmann: Neuste Kunde von Asien, S. 79

${ }^{358}$ Ehrmann: Neueste Kunde von Asien, S. 105

${ }^{359}$ Als habsüchtig und und religiöse Riten skrupellos ausnutzend werden die Brahmanen auch in einem Artikel im Morgenblatt für gebildete Stände beschrieben: Sie würden nur deswegen den grausamen Brauch einer bestimmten Gruppe von Indern, die Witwen lebendig zu begraben, nicht verbieten, weil sie selbst dabei nichts zu gewinnen oder zu verlieren hätten. Denn diese Witwen wären so arm, dass die Brahmanen sowieso von ihnen nichts erhalten würden. Bei reichen Witwen würden sie hingegen sehr darauf achten, dass diese sich verbrennen ließen, anstatt begraben zu werden, da dann die Brahmanen aus ihrer Asche die teuren Schmuckstücke herausholen könnten. (Vgl. Die Hindus von F. Balthasar Solvyns. In: Morgenblatt für gebildete Stände 4 (1810; Nr. 95), S. 377-380, hier S. 379)

${ }^{360}$ Vgl. Dubois: Briefe über den Zustand des Christentums, S. 96
} 
Ein Brahmine ist überdieß durch die Pflicht genöthigt, egoistisch, intolerant und hochmüthig, insolent und wiederwärtig $\mathrm{zu}$ seyn. Er ist in der unverlöschlichen Ansicht erzogen, daß er das einzige vollkommene Wesen der Erde ist, ein Wesen von einem weit höhern Schlage, als alle andere Sterbliche [...]..$^{361}$

Er erkennt zwar an, dass das einzelne Individuum auch selbst von der Pflicht seiner Kaste genötigt sein mag, sich so zu verhalten, die Kaste der Brahmanen selbst aber sei etwas „Widernatürliches“362. Dubois kann sich diese in seinen Augen unnatürliche und von allen anderen Menschen sich absondernde Einrichtung nur dadurch erklären, dass die Brahmanen wohl „dem göttlichen Zorne und Fluche unterworfen““363 seien. Dabei spricht Dubois ihnen nicht Gotteskenntnis ab: Die Brahmanen hätten durchaus einen reinen Begriff vom einzig wahren Gott, aber sie brächten ihm keine Huldigung dar und ließen das Volk an dem Wissen um den Einen Gott nicht teilhaben. ${ }^{364}$

Insgesamt kann man sagen, dass die Brahmanen erstaunlich häufig mit negativen Attributen bedacht werden. Neben dem oben beschriebenen Einfluss von Diskursen, die der dem Macherhalt dienenden Verbindung von (absolutistischem) Staat und Klerus ablehnend gegenüberstehen, liegt eine weitere Ursache dafür sicherlich auch in der hohen Bedeutung, die die Aufklärung der Bildung und der rationalen Wissenschaft zuweist. Die aus Sicht vieler europäischer Autoren abergläubischen Lehren der Brahmanen verwehrten den Indern die Entwicklung, die Europa in der Aufklärung erlebt habe und lasse sie so in Unmündigkeit. Die Kriterien, die innerhalb des europäischen Diskurses über die Priorität der Vernunft erarbeitet worden sind, werden als allgemeingültig angesehen und als Maßstab zur Beurteilung der indischen Gelehrten verwendet. Die Vorstellung einer anderen Art von Wissen, das diesen Kriterien nicht entspricht und dennoch als hochstehend angesehen werden kann, sowie von Bräuchen, deren Sinn die Europäer zwar nicht verstehen, die aber dennoch von Bedeutung sein können, scheint außerhalb der diskursiven Möglichkeitsbedingungen zu stehen. Innerhalb des romantischen Diskurses ist das zwar etwas anders, da hier durchaus von der Existenz eines alten, umfassenden Wissens ausgegangen wird, doch wird auch hier die Verfügbarkeit dieses Wissens den zeitgenössischen indischen Gelehrten größtenteils abgesprochen. Daher unterscheiden sich die Beurteilungen der Brahmanen

\footnotetext{
${ }^{361}$ Dubois: Briefe über den Zustand des Christentums, S. 99

362 Dubois: Briefe über den Zustand des Christentums, S. 99

${ }^{363}$ Dubois: Briefe über den Zustand des Christentums, S. 99

${ }^{364}$ Vgl. Dubois: Briefe über den Zustand des Christentums, S. $99 f$.
} 
vor allem darin, ob angenommen wird, dass sie mit böser Absicht und zu ihrem eigenen Vorteil die Menschen bewusst in Unwissenheit ließen oder dass auch sie selbst die alte überlieferte Wahrheit nicht mehr verstünden und daher kaum anders handeln könnten. Das Bild vom weisen, tugendvollen Brahmanen gehört - wie wir noch sehen werden eher in den Bereich der schönen Literatur.

\subsubsection{Die Ausgestoßenen}

Neben den Brahmanen richtet sich das Interesse vieler Autoren auf Menschen, die unterhalb der vier eigentlichen Kasten stehen und als dem Kastensystem nicht zugehörig angesehen werden. Die bekannteste und am häufigsten beschriebene Gruppe ist die der Paria. Einige Autoren beschreiben außerdem noch die Pulichi, die noch weiter unten in der Gesellschaft angesiedelt seien. Die meisten Texte legen ausführlich dar, welche Pflichten diese Gruppen haben und welche Rechte ihnen nicht zuerkannt werden. So dürften sie sich Mitgliedern der übrigen Kasten nicht oder nur auf eine bestimmte Art und Weise nähern, seien nicht zu den religiösen Riten zugelassen und müssten die niedrigsten Arbeiten ausführen. Da diese Beschreibungen sich allerdings alle sehr ähnlich sind und daher die Rolle dieser Ausgestoßenen nicht sehr umstritten war, sollen diese Beschreibungen hier nicht näher untersucht werden. Ich möchte vielmehr der Frage nachgehen, wie die Existenz einer solchen Randgruppe eingeordnet und bewertet wurde.

Die Parias werden oft als Elende oder Unglückliche bezeichnet, was ein gewisses Maß an Mitgefühl andeutet. Direkte Verurteilungen dieses Systems sind allerdings erstaunlicherweise selten zu finden. Stattdessen schwanken viele Autoren zwischen Mitgefühl und Unbehagen oder sogar Abscheu. So beschreibt der Lexikonartikel von 1815 die Parias folgendermaßen:

\footnotetext{
unrein und unehrlich, verrichten sie die schmutzigsten Arbeiten, essen unreine Speisen, selbst gefallenes Vieh, dürfen die obern Kasten nicht berühren, nicht in die Tempel und auf die Märkte kommen, nicht aus den gewöhnlichen Brunnen Wasser holen, und sobald sie frech genug wären, einen Vornehmen durch ihren Anhauch zu verunreinigen, dürfte dieser sie ungestraft tödten. ${ }^{365}$
}

Es wird in diesem Abschnitt nicht ganz klar, ob der Autor die Begriffe „unrein und unehrlich“ nur deswegen benutzt, weil sie von der indischen Gesellschaft so bezeichnet

\footnotetext{
${ }^{365}$ Conversations-Lexikon 1815, S. 716
} 
werden, oder ob sie auch seine Eistellung gegenüber den Parias wiedergeben. Sie werden jedenfalls ohne einen Kommentar des Bedauerns mit den Parias verbunden, und der Zusatz „gefallenes Vieh“ zu den lediglich aus hinduistischer Sicht unreinen Speisen, verstärkt diese Abwertung der Parias noch.

Auch Ehrmann schwankt in seiner Beurteilung zwischen Bedauern der Unglücklichen und der Ablehnung ihrer für sein Empfinden anscheinend unreinen Sitten. So bezeichnet er sie - den indischen Standpunkt aufführend - als unrein Geltende und nennt sie - seine eigene Meinung ausdrückend - Unglückliche und Elende. An anderer Stelle jedoch wird sein Unbehagen über deren ekelhafte Speisen und den Alkoholgenuss deutlich, wie das folgende Zitat zeigt:

Da sie keinen Religionsgesetzen unterworfen sind, so genießen sie alle Speisen, selbst die ekelhaftesten, die ihnen vorkommen, lieben alle hitzigen Getränke, und überlassen sich dem Trunke, wenn sie dazu kommen können. Diese Unmäßigkeit, die bei einem Volke in der geschilderten Lage gar nichts Außerordentliches ist, und dann ihre Unreinlichkeit und ihre Verrichtungen der schmutzigsten, ekelhaftesten Arbeiten muß natürlich den so sehr die Reinlichkeit liebenden Hinduern einen Abscheu gegen diese, ohnehin verworfene Classe, einflößen. ${ }^{366}$

Obwohl ihm die Sitten der Parias zuwider sind, hat Ehrmann dennoch Verständnis dafür, da sie ihre Ursache in der sozial ausgegrenzten Lage der Parias hätten. ${ }^{367}$

Wie sehr auch europäische Reisende bei allem Verständnis für die elende Lage der Parias dennoch ihnen gegenüber Abscheu empfinden können, zeigen die Beschreibungen Perrins:

Wie dem auch sey, hielten die Parias etwas auf Ehre, so würden sie außerordentlich zu beklagen seyn; [...]. Aber diese so verachteten Menschen benutzen noch selbst die Verachtung, mit der man sie bezeichnet; indem sie sich dadurch von allen Gesetzen des Anstandes, welche die Kastenleute beobachten, für befreyt erachten. Sie trinken berauschende Getränke, nehmen mit allen Händen und essen alles, was ihnen Vergnügen macht. [...] Eingestehen muß man, daß die Unreinlichkeit der Parias einer ihrer Hauptfehler ist, und unstreitig ist dieß zum Theil die Ursache des Abscheus, den sie einflößen. Ich bin manchmal, wenn sich mir Parias näherten, fast ohnmächtig geworden [...]. ${ }^{368}$

\footnotetext{
${ }^{366}$ Ehrmann: Neuste Kunde von Asien, S. 61

${ }^{367}$ Auch Papi, der die Parias deutlich negativer schildert als Ehrmann, sieht es als offensichtlich an, dass das verächtliche Verhalten der Parias aus dem ebenso unfreundlichen Verhalten der übrigen Gesellschaft ihnen gegenüber resultiere (vgl. Briefe eines italienischen Reisenden, S. 281).

${ }^{368}$ Hell: M. Perrin's Reise. Band 1, S: 181-183
} 
Interessant ist, dass Perrin ein Unbehagen gegenüber den Parias nicht nur nicht ganz unterdrücken kann, sondern dass er deutlich ausspricht, dass die Parias keine Ehre hätten. Daher seien sie nicht nur unempfindlicher gegen ihr Leid, sondern nutzen die sowieso bereits existierende Verachtung dazu aus, sich über alle Gesetze des Anstands hinwegzusetzen. Alkohol und unreines Essen erscheinen hier nicht wie bei Ehrmann als bedingt durch die schlechten Umstände und die fehlenden Alternativen, sondern als ein Genießen. Auch indem er eine Ursache für den Abscheu gegenüber Parias in deren Unreinheit sieht, kommt das einer Schuldzuweisung nahe. ${ }^{369}$

Eine ganz andere Einstellung zu den Parias hat dagegen der Soldat Best. Er hält fest: „Ob gleich diese Kaste so sehr verachtet ist, so ist sie doch gewiß eine der nützlichsten. ${ }^{\text {‘370 }} \mathrm{Er}$ legt den Maßstab des Nutzens für die Gesellschaft an und stellt eine große Diskrepanz zwischen eben diesem Nutzen und der gesellschaftlichen Anerkennung fest. Damit stellt er unter den hier untersuchten Autoren allerdings eine Ausnahme dar.

Die Parias faszinieren also einerseits und werden auch bedauert, andererseits aber empfinden auch viele Europäer (gerade wenn sie selbst als Reisende in Indien waren) eine tiefsitzende Abscheu ihnen gegenüber, vielleicht weil sie die erzwungene oder auch nur als solche empfundene Unreinheit oder auch Unzivilisiertheit (im Vergleich zu den anderen Indern und ihnen selbst) beunruhigt. Indem viele Europäer in ihren Beschreibungen der Parias bei aller Kritik und allem Mitleid in vielen Aspekten den indischen Standpunkt übernehmen, machen sie die Parias, die (als normativ Fremdes) das Andere der sich ansonsten nur graduell unterscheidenden übrigen indischen Kasten sind, auch zu ihrem eigenen Anderen. Gleichzeitig werden sie aber auch damit konfrontiert, dass die Inder selbst das ganz anders sehen. Sie ordnen die Europäer nicht ihrem eigenen Kreis zu, sondern den Parias, da sie ebenfalls die indischen Normen nicht einhielten und daher aus Sicht der Inder in vielen Aspekten unrein seien. Interessanterweise berichten die europäischen Autoren darüber relativ sachlich und enthalten sich weiterer Kommentare, obwohl sie hier die Erfahrung machen, dass ihr

\footnotetext{
${ }^{369}$ Perrin schildert zudem sehr anschaulich seine täglichen Schwierigkeiten im Umgang mit den Parias, die er zwar missionieren und in seine neue Gemeinde einbinden möchte, was aber aufgrund der Verachtung durch die indische Gesellschaft, die auch die Bekehrten kaum ablegen könnten, kaum möglich sei (vgl. Hell: M. Perrin's Reise. Band 2, S. 59-62).

370 Best: Briefe über Ost-Indien, S. 23
} 
eigenes Empfinden von den anderen nicht geteilt wird und auch sie selbst Objekt kritischer Beobachtung können. ${ }^{371}$

\subsubsection{Väterlicher Freund oder Despot - das indische Herrschaftssystem}

Despotismus ist um 1800 eine verbreitete Stereotype zur Beschreibung orientalischer Herrschaftssysteme, die bereits seit der Antike bekannt ist. ${ }^{372}$ Auch die indischen Herrscher werden häufig als Despoten beschrieben. Interessanterweise wurden in der Frühen Neuzeit nur wenige der asiatischen Fürsten als Despoten oder Tyrannen beschrieben ${ }^{373}$ und der Moghul und sein Hof sowie die indische Regierungsform konnten bei europäischen Reisenden durchaus Bewunderung hervorrufen. Prunkvolle Zeremonien wurden nicht als fremd empfunden, sondern mit den eigenen Abläufen an europäischen Fürstenhöfen verglichen. Dennoch entstand ein Diskurs über orientalische Despotie, innerhalb dessen diese Herrschaftsform als typisch für Asien angesehen wurde. Die großen Weiten Asiens und das warme Klima förderten - nach Montesquieu - diese Herrschaftsform. ${ }^{374}$ Auch die Verschiebung der Machtverhältnisse in Indien Ende des 18. Jahrhunderts sowie die wachsende Kritik an Prunk und Zeremonien als Teil des Hoflebens auch in Bezug auf die europäischen Herrscherhäuser tragen zu diesem Diskurs bei. ${ }^{375}$ Es gab jedoch auch Gegenstimmen wie z.B. Voltaire und Anquetil-Duperron, die zeigen wollten, dass der Despotismus keineswegs das typische Herrschaftsmodell Asiens ist. ${ }^{376}$ Darüber hinaus konnte mit Erstarken der E.I.C. der Vorwurf des Despotismus auch gegen die Herrschaft der Engländer gerichtet werden. ${ }^{377}$

\footnotetext{
371 „Da die Europäer auch das Fleisch aller genießbaren Thiere essen, welches den Hinduern ein Gräuel ist, und manche andere, den Gewohnheiten dieses so einfach sittlichen Volkes ganz entgegenlaufende Sitten haben, so werden auch jene von ihnen in die Klasse der Parejer versezt." (Ehrmann: Neuste Kunde von Asien, S. 61); „Eben der Abscheu gegen die Parias fällt auch auf die Europäer, weil sie Kuhfleisch essen, in den Häusern und Tempeln ausspucken, beym Trinken das Geschirr an die Lippen halten, den Mund mit den Fingern wischen, so daß sie der Speichel verunreinigt und s.f." (Sonnerat: Reise nach Ostindien, S. 24)

${ }^{372} \mathrm{Vgl}$. Tzoref-Ashkenazi: German Soldiers in India, S. 82

${ }^{373}$ Vgl. Osterhammel: Die Entzauberung Asiens, S. 272, 274

${ }^{374}$ Vgl. Osterhammel: Die Entzauberung Asiens, S. 276-278

${ }^{375}$ Vgl. Flüchter, Antje: Weighing the Mughal. German Perception of Governmental Structures and the Staging of Power in the Early Modern Indian Mughal Empire. In: Flüchter, Antje u. Richter, Susan (Hg.): Structures on the Move. Technologies of Governance in Transcultural Encounter. Heidelberg 2012, S. 147-166, hier S. 151, 155f., 157, 159-161

376 Vgl.Osterhammel: Die Entzauberung Asiens, S. 289-296

${ }^{377}$ Vgl. Osterhammel: Die Entzauberung Asiens, S. 297-299; ein Beispiel dafür bietet Klaußner, der zwar die herrschende Regierungsform in Indien als Despotismus beschreibt, dabei aber betont, dass die Europäer die größten Tyrannen Indiens seien (vgl. Klaußner: Die Hindus, S. 526f.)
} 
Bei den Darstellungen zum indischen Herrschaftssystem muss man unterscheiden, auf wen die jeweilige Beschreibung zielt: auf die muslimischen Eroberer, auf zeitgenössische indische Fürsten, auf die alte indische Verfassung oder auf europäische Kolonialherren. Aufgrund der hohen Stellung, die die Brahmanen in Indien einnehmen, wird der Begriff z.T. auch auf die Brahmanen bezogen und von einem „Priesterdespotismus“ ${ }^{378}$ gesprochen. Darauf soll hier allerdings nicht noch einmal näher eingegangen werden, da die Kritik an den Brahmanen bereits erörtert worden ist.

Majer und Heeren gehören zu den wenigen, die sich mit der alten indischen Verfassung zu „Zeiten seiner Selbständigkeit und Freiheit“‘379 auseinandersetzen. Dabei kommen sie allerdings zu ganz unterschiedlichen Ergebnissen. Majer beschreibt den alten indischen Herrscher anhand alter indischer Gesetzestexte als Vater des Landes und idealen König:

\begin{abstract}
Besonders anziehend ist die Vorstellung welche sich diese Gesetze von einem vollkommenen König oder Raja machen. Zwischen ihm und seinen Unterthanen ist kein anderes Verhältnis als das eines Vaters zu seinen Kindern, wie es in den Zeiten der Unschuld und Einfachheit der Patriarchen gewesen seyn mag, angenommen. Glaubwürdigen Nachrichten zu Folge soll sich dieses Verhältnis bis auf unsere Zeiten in den innern weniger bekannten Gegenden von Indien erhalten haben. ${ }^{380}$
\end{abstract}

Die höchste Pflicht eines Königs sei es, sein Volk zu beschützen, weshalb der König zunächst an sich selbst arbeiten und seine Laster besiegen sollte. ${ }^{381}$ Der König solle sich als idealer König also auch durch eine besonders gute Moral gegenüber seinen Untertanen auszeichnen. Interessant ist, wie Majer dieses alte Königstum mit der Zeit der „Unschuld und Einfachheit“ in Verbindung bringt. Auch hier scheint also wieder die Vorstellung einer unschuldigen, einfachen, aber dabei sehr weisen goldenen Zeit des Ursprungs auf. Der Hinweis, dass dieses System in Gegenden, die weniger dem äußeren Einfluss anderer Kulturen ausgesetzt gewesen seien, noch immer zu finden sei, impliziert, dass diese goldene Zeit ohne von außen kommende Veränderungen noch immer andauern könnte.

Heeren, der sich für historische Regierungsformen und ein mögliches Gleichgewicht zwischen den Staaten interessiert, betrachtet weniger ein Ideal wie Majer, sondern setzt

${ }^{378}$ Brahmanen, S. 945

${ }^{379}$ Majer: Zur Culturgeschichte der Völker, S. 291

${ }^{380}$ Majer: Zur Culturgeschichte der Völker, S. 291f.

${ }^{381}$ Vgl. Majer: Zur Culturgeschichte der Völker, S. 292-294 
sich vielmehr mit mit der Frage auseinander, welche politischen Elemente die alte indische Verfassung enthielt. Er schreibt, dass Indien früher ein Priesterstaat bzw. eine Theokratie gewesen sei. In den Gesetzen werde eine monarchische Regierungsform beschrieben, die durch eine Priesteraristokratie beschränkt werde. Denn die Gesetze der Priester beschränkten den König, indem sie ihm seine Lebensart und seine Tätigkeiten genau vorschrieben. Dieser Keim des Republikanismus habe sich allerdings nicht entwickeln können, da die Macht des Fürsten nur durch die Priesterkaste, nicht aber durch die Nation als solche beschränkt gewesen sei. Daher könne man trotz allem von einem Despotismus sprechen, der zwar abgemildert sei, aber trotz allem seine barbarische Seite aufweise - besonders wenn die Interessen der Brahmanen in Gefahr seien. $^{382}$

Ehrmann bezeichnet das alte Indien ebenfalls als „monarchisch-despotische(n) Staat“. Auch viele der heutigen indischen Staaten seien noch monarchisch und despotisch. ${ }^{383}$ Ganz ähnliche Ansichten äußert auch Lazzaro Papi, der sowohl die alten indischen Gesetzestexte als auch die zeitgenössischen Beispiele indischer Herrschaft als wenig vorteilhaft ansieht:

\begin{abstract}
Man hat sich daher wohl vorzusehen, daß man dem Vorgeben derer keinen Glauben beimesse, die uns einen indischen Fürsten als einen Vater schildern, der von der zahlreichen Schaar seiner Kinder umgeben sey, nicht aber als einen Souverän, dessen von Glanz umstrahlte Majestät rings um ihn her Furcht und Schrecken verbreitet. ${ }^{384}$
\end{abstract}

Damit wendet er sich direkt gegen Autoren wie Majer, die seiner Ansicht nach ein zu positives Bild verbreiten.

Sind die Herrschaftsformen des alten Indiens bzw. zeitgenössischer Gebiete, die noch nicht erobert worden sind, in ihrer Beurteilung also durchaus umstritten, so gelten die zeitgenössischen muslimischen Herrscher durchweg als Despoten. Die hier

\footnotetext{
382 „Wenn wir den Geist dieser ältesten Indischen Verfassung und Gesetze betachten, so zeigt sich auf der einen Seite darin zwar ein Keim von Republikanismus, der jedoch nicht zu allgemeiner politischer Freyheit reifte. Jener Keim lag in der Verfassung der Gemeinheiten; aber er konnte sich nicht weiter entwicklen, weil die Casteneinrichtung dieß nicht gestattete. Die Macht der Fürsten ward nur durch die Priestercaste, nicht aber durch die Nation als solche, beschränkt; und der, wenn auch dadurch gemilderte, Despotismus verräth sich doch dadurch, daß auch in Menu's Gesetzen auf das Strafrecht des Königs die ganze königliche Autorität gegründet wird [...]. Auch wird die, sonst so milde, Gesetzgebung barbarisch, bey der Bestimmung einzelner Strafen, besonders bey Vergehung gegen Braminen.“ (Heeren: Ideen über die Politik, den Verkehr und den Handel der vornehmsten Völker der alten Welt, S. 450).

${ }^{383}$ Vgl. Ehrmann: Neuste Kunde von Asien, S. 183

${ }^{384}$ Briefe eines italienischen Reisenden, S. $445 \mathrm{f}$
} 
untersuchten Autoren beschäftigen vor allem die Fragen nach den Ursachen und Folgen des Despotismus. Auch wenn sie es in den hier untersuchten Texten nicht direkt thematisieren, so sind die Aussagen gegen den Despotismus immer auch im Kontext des in der Aufklärung geführten Diskurses über die negativen Auswirkungen des Absolutismus zu sehen.

Herder sieht - der Klimatheorie folgend - eine Ursache für die Verbreitung des Despotismus in Asien in dem dortigen Klima. Der Despotismus setze immer eine Art von Schwäche voraus, weshalb die Natur in den meisten despotische Ländern so beschaffen sei, dass sie ihre Bewohner mühelos ernähren könne. ${ }^{385}$ Dem widerspricht Papi vehement:

\begin{abstract}
Die Behauptung einiger Schriftsteller, daß die allzugroße Hitze des Klima's den Bewohnern der südlichen Erdgegenden jene Energie raube, die dazu erforderlich ist, die Freiheit zu erringen und sich in deren Besitze zu erhalten, und daß selbige dazu beitrage, den Despotismus zu befestigen, hat ganz und gar keinen Grund für sich. Im Gegentheil lehrt die Erfahrung, daß der Despotismus eine Giftpflanze ist, die überall, sowohl in den kalten als wärmern Himmelsstrichen, Wurzel schlägt und um sich wuchert, und dem Hauche des Nordwindes eben sowohl widersteht, als den heissen von der Sonne entwickelten Dünsten unter der Mittagslinie. Es hat zwar seine Richtigkeit, daß die Völker der Erde unter seinem verderblichen Einflusse in eine Erschlaffung versinken, die es ihnen schlechterdings unmöglich macht, etwas Großes zu unternehmen, oder nur daran zu denken; aber weit entfernt, daß diese Indolenz und Erschlaffung wo nicht die einzige, doch wenigstens die vornehmste Veranlassung seyn sollte, hat man sie vielmehr als eine traurige Folge desselben zu betrachten, welche davon herrührt, daß er die Quelle der Industrie verstopft, oder, welches eben so viel sagen will, daß er die Menschen verhindert, die Früchte ihrer Arbeiten in Sicherheit zu genießen. ${ }^{386}$
\end{abstract}

Der Autor sieht in Herders Argumentation Ursache und Folge vertauscht. Despotismus gebe es überall. Er sei keine Folge irgendeiner Erschlaffung aufgrund von Hitze, sondern die Erschlaffung resultiere aus dem Despotismus. Der Missionar Perrin spricht vom „Loos der Indier [...] Opfer des ungerechten Despotismus zu werden““387. Damit stellt Perrin das Leid der Inder als eine Art Schicksal hin, gegen das man nicht ankommen könne.

Papi, der sich auf seinen Reisen immer wieder auch für soziale und gesellschaftliche Fragen interessiert, setzt sich auch mit weiteren Folgen des Despotismus auseinander:

\footnotetext{
${ }^{385}$ Vgl. Herder: Ideen zur Philosophie der Geschichte der Menschheit, S. 243

${ }^{386}$ Briefe eines italienischen Reisenden, S. 435f.

${ }^{387}$ Hell: M. Perrin's Reise. Band 1, S. 134
} 
Nichts sucht man sorgfältiger zu vermeiden, als das Mißfallen des Fürsten, nichts eifriger zu erringen, als dessen Huld und Gnade. Hierauf reducirt sich Alles, was der Unterthan thut oder läßt; seine Tugenden und seine Laster; seine Ehre sowohl, wie seine Unehre; seine Verdienste, wie seine Nichtswürdigkeit. Niemand kann sich darauf verlassen, daß seine Tugend ihn schützen werde, wenn er dem Despoten, oder dessen Günstlinge verhaßt ist; Niemand läßt sich aus Furcht vor der zu erwartenden Strafe von den lasterhaftesten Handlungen abschrecken, wenn er Lust hat dergleichen zu begehen. Der unverbürgte Besitz seines Vermögens, die ungewisse Dauer seiner Beschäftigungen, seiner Freiheit, sogar seines Lebens, und der damit verbundene Gedanke, daß die Handhabung der Gerechtigkeit lediglich von der veränderlichen Laune des Fürsten abhange, erfüllen das Gemüth eines jeden einzelnen Unterthanen mit Furcht und Schrecken, und verbreiten überall Neid, Argwohn, und gegenseitige Zurückhaltung. Jeder lebt bloß für sich, ist einzig und allein für sich selbst besorgt. ${ }^{388}$

Seiner Ansicht nach führe der Despotismus in Indien dazu, dass jeder nur an sich selbst und an den momentanen Vorteil denke. Dabei würden Tugend und Moral deutlich geschwächt, da sie sich in der verängstigten Gesellschaft und bei dem willkürlich agierenden Herrscher nicht auszeichneten. Anschließend setzt sich der Reisende mit den Unterschieden zwischen dem indischen und dem europäischen Despotismus auseinander. Er ist der Ansicht, dass der Despotismus in Asien schlimmer sei als in Europa, da dort aufgrund der Goldgier des Herrschers viele Einwohner so täten, als wären sie arm. Das vorhandene Geld könne so nicht genutzt werden, anders als in Europa, wo es zwar auch eine Willkürherrschaft gebe, jeder aber wenigstens sein Geld für sich nutzen könne. Perrin beschreibt als Folge, dass die Inder auswandern, wenn die Unterdrückungen $\mathrm{zu}$ hart werden, wodurch dem Herrscher die Einnahmen ausgingen. ${ }^{389}$

Die europäischen Autoren stellen auch die Frage, warum sich die Inder nicht gegen die Despoten auflehnen. Perrin geht davon aus, dass die Inder anders als Europäer überhaupt nicht auf die Idee der Auflehnung kämen. Für sie sei die Vormachtstellung des Fürsten vor den Bedürfnissen der Nation eine Selbstverständlichkeit, die sie nicht in Frage stellten - ja sogar gegen andere verteidigen würden. ${ }^{390}$ Papi schreibt dagegen,

\footnotetext{
${ }^{388}$ Briefe eines italienischen Reisenden, S. 436f.

${ }^{389}$ Vgl. Hell: M. Perrin's Reise. Band 1, S. 133f.

390 „Der allgemeine Grundsatz, nach dem überall verfahren wird, ist dieser: Der Fürst ist alles, die Nation nichts. Dieser Grundsatz ist auch so wenig bestritten, daß das Volk selbst ihn gegen den vertheidigen würde, der ihn bestreiten wollte.“ (Hell: M. Perrin's Reise. Band 1, S. 118) „Nein, nein, diese braven und eines bessern Schicksals so würdigen Menschen kennen die gesellschaftswidrige Maxime nicht, die so lange der Wahlspruch unserer Staatsumwälzer war! Sie glauben nicht, daß Aufstand gegen den Oberherrn die heiligste aller Pflichten sey.“(Hell: M. Perrin's Reise. Band 1, S. 133)
} 
dass die Inder die Unterdrückung viel besser als Europäer ertragen könnten, weil sie schon „durch vieljährige Erfahrung daran gewöhnt“ seien und daher

\begin{abstract}
das Harte und Drückende derselben weit weniger, als jene empfinden würden, die das Sanfte und Milde einer anderen Regierungsform aus Erfahrung kennen, dessen wohlthätige Folgen selbst mit angesehen haben, oder sich dieselben wenigsten als möglich denken. Die Unwissenheit trägt eben so viel dazu bei, ihre Leiden zu mildern, als die Gewohnheit, sie ertragen zu müssen. ${ }^{391}$
\end{abstract}

Damit teilt der Autor die Menschen bei der Beurteilung des Despotismus quasi in zwei Klassen ein: die um eine bessere Regierungsform Wissenden und die Unwissenden. Das aber impliziert die These, dass der Despotismus in Indien zwar schlimm sei, die Inder aber dennoch nicht allzu sehr darunter litten und daher - möglicherweise - auch nicht sofort Handlungsbedarf bestehe. Das sieht Perrin anders: „Die Europäer in Indien könnten aus dieser falschen Politik der Fürsten jenes Landes sehr große Vortheile ziehen, wenn sie selbst gerechter und mäßiger wären. Die ganze Bevölkerung würde sich dann zu ihnen hinziehen.“" ${ }^{\text {“92 }}$ Aber auch sie machten die Inder zu einem „Opfer des ungerechten Despotismus ‘393.

\title{
3.4 Witwenverbrennung und Bajaderen - die Stellung der Frau
}

Das Thema Unterdrückung spielt nicht nur im Zusammenhang mit der gesellschaftlichen Ächtung der Paria und despotischen Herrschern eine Rolle, sondern kommt auch immer wieder bei der Auseinandersetzung mit der Rolle der indischen Frau zur Sprache. Dabei ist es aber keineswegs so, dass die Frage, inwieweit die indische Frau in der Gesellschaft unterdrückt wird, in demselben Ausmaß diskutiert wird, wie es in unserer Zeit der Fall ist. Das ist insofern nicht verwunderlich, als es in der Aufklärung zwar Diskurse über die Gleichberechtigung der Frau gibt und die alte Vorstellung, dass Frauen nicht über dieselben kognitiven Fähigkeiten verfügten wie Männer, weithin abgelehnt wird, von einer Emanzipation und Gleichberechtigung der Frau aber nicht die Rede sein kann. Selbst viele Frauen äußerten sich demgegenüber kritisch. Gerade im Zuge der Konzentration auf die Kleinfamilie wurde die Vorbereitung auf die Rolle als Hausfrau und Mutter ein wichtiges Erziehungsziel. ${ }^{394}$ Das macht sich auch bei der Beurteilung der indischen Frauen bemerkbar, die oft als

${ }^{391}$ Briefe eines italienischen Reisenden, S. 443

${ }^{392}$ Hell: M. Perrin's Reise. Band 1, S. 134

${ }^{393}$ Hell: M. Perrin's Reise. Band 1, S. 134

${ }^{394}$ Vgl. Meyer, Annette: Die Epoche der Aufklärung. Berlin 2010, S. 190 
gute Hausfrauen gelobt werden. Die untergeordnete Stellung der Frau wird bei Beschreibungen von Hochzeit, Ehe, Familie und Tod zur Sprache gebracht und manchmal sogar eher beiläufig erwähnt. Der Appell eines Missionars, der den europäischen Frauen die missliche Lage ihrer indischen Geschlechtsgenossinnen deutlich machen möchte und den wir später noch genauer ansehen werden, ist da eher die Ausnahme. Große Bedeutung und breite Aufmerksamkeit erhalten die indischen Frauen hingegen bei zwei Themen: der Besonderheit der indischen Tänzerinnen und vor allem dem Brauch der Witwenverbrennung. ${ }^{395}$ Besonders letzterer wird immer wieder ausführlich beschrieben und darf bei populären Darstellungen Indiens nicht fehlen. Daher möchte ich nach einem kurzen Einblick in die Beschreibungen der sonstigen Rechte und Pflichten der Frauen auf diese beiden Punkte ausführlicher eingehen.

\subsubsection{Ehefrauen und Mütter}

Frauen spielen - nicht nur im gesellschaftlichen Leben, sondern auch in den Beschreibungen - vor allem als Ehefrau und Mutter eine Rolle. Ausführlich werden immer wieder die Hochzeitszeremonien beschrieben. Gibt es im Detail vielleicht kleine Unterschiede, so sind sich die Autoren doch dahingehend einig, dass die Hochzeitszeremonien - wie im übrigen auch andere familiäre Feste wie Geburt und Tod - sehr aufwendig und prunkvoll sind. ${ }^{396}$ Die umfangreichen und genau festgelegten Abläufe werden z.T. bis ins Kleinste beschrieben. Ehe und Schwangerschaft beurteilen alle Autoren als die wichtigsten Ereignisse im Leben einer indischen Frau. Ehelosigkeit und Unfruchtbarkeit gelten als großes Unglück, ebenso eine frühe Witwenschaft. ${ }^{397}$ Die Textausschnitte zu diesen Themen ähneln einander inhaltlich sehr: Immer wieder wird betont, dass die Mädchen bereits als Kinder verheiratet würden (z.T. an alte Greise), ${ }^{398}$

\footnotetext{
${ }^{395}$ Vgl. auch Flüchter, Antje: Bajadere und Sati. Bilder der Inderin im deutschsprachigen Diskurs der Frühen Neuzeit. In: Ineichen, Martina u.a. (Hg.): Gender in Trans-it. Transkulturelle und transnationale Perspektiven. Beiträge der 12. Schweizerischen Tagung für Geschlechtergeschichte. Zürich 2009, S. 159-170, hier S. 159

${ }^{396}$ Vgl. z. B. Briefe eines italienischen Reisenden, S. 337; Ehrmann: Neueste Kunde von Asien, S. 82

${ }^{397}$ Vgl. z.B. Briefe eines italienischen Reisenden, S. 337, 344; Ehrmann: Neueste Kunde von Asien, S. 75f.; Heeren: Ideen über die Politik, S. 437; Hell: M. Perrin's Reise durch Hindostan, S. 5; vgl. auch bereits Sonnerat: Reisen nach Ostindien, S. 28; Best: Briefe über Ost-Indien, S. 75

${ }^{398}$ Vgl. z.B. Briefe eines italienischen Reisenden, S. 335; Ehrmann: Neueste Kunde von Asien, S. 76f.; Hell: M. Perrin's Reise durch Hindostan, S. 6; Unglückliche Lage des weiblichen Geschlechts in Indien. In: Morgenblatt für gebildete Stände 15 (1821; Oktober, Nr. 244), S. 975; vgl. auch bereits Herder: Ideen zur Philosophie der Geschichte der Menschheit, S. 214 und Sonnerat: Reise nach Ostindien, S. 28; Best: Briefe über Ost-Indien, S. 74
} 
dass auch enge Verwandte einander heiraten dürften, ${ }^{399}$ dass es selten Liebeshochzeiten gebe $^{400}$ und dass die indischen Frauen gute Hausfrauen und Mütter seien. ${ }^{401}$ Polygamie sei zwar erlaubt, aber sie sei sehr selten und komme vor allem bei den Reichen vor. ${ }^{402}$ Auch die fehlende Bildung(smöglichkeit) der Inderinnen wird immer wieder erwähnt. Dies wird zumeist damit begründet, dass die Aufgaben der Frauen im Haushalt seien und Bildung ihnen nicht zukomme bzw. sie ablenken würde. ${ }^{403}$

In der Beschreibung der einzelnen Themen gibt es also wenig unterschiedliche Ansichten. Zwar unterscheiden sich die Ausführungen in einigen Details, aber wirkliche Streitpunkte sind es nicht. Was sich je nach Autor unterscheidet, sind die Gewichtung und Beurteilung des Beschriebenen sowie die Art und Weise der Darstellung, weshalb durchaus unterschiedliche Bilder von der Rolle der Frau in der indischen Gesellschaft nebeneinanderstehen.

Die meisten Autoren bewerten in ihrer Darstellung einige Aspekte als positiv, andere als negativ. So schrieb bereits Herder, die Frauen würden von den Männern wie Kinder und Blumen behandelt. ${ }^{404}$ Dem widerspricht, dass Herder nur zwei Seiten später feststellte, dass die Männer der List der Frauen nicht gewachsen seien und sie daher unterdrückten. ${ }^{405}$ Zwei verbreitete Stereotype scheinen sich hier zu vermischen: auf der einen Seite das Bild des kindlich, naiven, naturverbundenen Inders und auf der anderen Seite das des asiatischen Despoten. Auch bei den Autoren des Untersuchungszeitraums ist das ähnlich. Zwar werden z.B. die arrangierten Ehen ${ }^{406}$ und eine gewisse

\footnotetext{
${ }^{399}$ Vgl. z.B. Des Fra Paolino da San Bartolomeo Reise nach Ostindien, S 274; Briefe eines italienischen Reisenden, S. 341

${ }^{400}$ Vgl. z.B. Ehrmann: Neueste Kunde aus Asien, S. 79; Unglückliche Lage des weiblichen Geschlechts in Indien, S. 975

${ }^{401}$ Vgl. z.B. Briefe eines italienischen Reisenden, S. 342f.; Ehrmann: Neueste Kunde aus Asien, S. 86; Schlegel, F.: Geschichte der alten und neuen Literatur, S. 136; anderer Ansicht ist Perrin, der die Frauen aufgrund ihrer Unterdrückung als zänkisch beschreibt, vgl. Hell: M. Perrin's Reise durch Hindostan, S. 9

402 Vgl. Des Fra Paolino da San Bartolomeo Reise nach Ostindien, S 274; Briefe eines italienischen Reisenden, S. 272f., 340f.; Ehrmann: Neueste Kunde von Asien. Zweiter Band, S. 83; Heeren: Ideen über die Politik, S. 438; Hegel sieht in der Polygamie einen Grund für die geringe Wertschätzung der Frau: So habe ein Inder, als sich seine Frau aus Trauer um ihr totes Kind selbst verbrennen wollte, gleichgültig darauf reagiert, da er zu Hause noch andere Frauen habe (vgl. Hegel: Vorlesungen über die Philosophie der Geschichte, S. 155)

${ }^{403}$ Vgl. z.B. Die Sitten der Hindus, S. 83; Forster: Reise aus Bengalen, S. 90; Unglückliche Lage des weiblichen Geschlechts in Indien, S. 975

${ }^{404}$ Vgl. Herder: Ideen zur Philosophie der Geschichte der Menschheit, S. 214

405 Vgl. Herder: Ideen zur Philosophie der Geschichte der Menschheit, S. 216

406 Vgl. Ehrmann: Neueste Kunde von Asien. Zweiter Band, S. 86
} 
Abhängigkeit der Frauen von den Männern ${ }^{407}$ kritisiert. Aber indem die Frauen selbst häufig als gute Hausfrauen und Mütter gelobt werden, die bescheiden und noch nicht vom Luxus verdorben seien und treu an ihren Männern hingen, ${ }^{408}$ erhält die Beschreibung bei diesen Autoren durchaus eine positive Färbung. Auf einige Berichte trifft das ganz besonders zu. So ruft Paulinus a Sancto Bartholomaeo, nachdem er aufgezählt hat, unter welchen Umständen die Männer mit den Frauen keinen Geschlechtsverkehr haben dürfen, aus: „Wer hätte wohl bei solchen Heiden eine so lautere und reine Moral gesucht? ${ }^{409 "}$

Während ein Großteil der Autoren auf eine mögliche Unterdrückung der Frau entweder nicht näher eingeht oder ihr die hohe Moral und die vorbildlichen Charakterzüge der indischen Frauen gegenüberstellt, gibt es auch einige Autoren, die die Unterdrückung direkt relativieren. Friedrich Schlegel schreibt ausdrücklich, dass es die Unterdrückung der Frau nicht gebe oder zumindest nicht gegeben habe, denn das stimme nicht mit

jenem hohen Begriff überein von der den Frauen schuldigen Ehrerbietung,
wovon die alten indischen Gesetzbücher und Gedichte so voll sind. Auch
herrscht der Geist einer solchen Unterdrückung und Geringschätzung des
weiblichen Geschlechts durchaus nicht in der indischen Denkart; in neuern
Zeiten mag das Beispiel der Mohamedaner ihre Sitten in diesem Puncte
verschlimmert haben. ${ }^{10}$

Den Frauen komme in der alten indischen Tradition Ehrerbietung zu. Eine mögliche Tendenz in Richtung Unterdrückung schreibt er dem negativen Einfluss der muslimischen Kultur zu.

Auch der Missionar Dubois betont, dass die Frauen in Indien als heilig galten, sehr geachtet würden und nicht herablassend behandelt werden dürften. Die Härte, die man im Umgang der Männer mit ihren Frauen in Indien beobachten könne, sei eher eine Art Zeremonie, die sich auf die Öffentlichkeit beschränke. Im Haus seien die Frauen die Herrscherinnen, sowohl über Haushalt und Gesinde, als auch über Geld und Wertsachen. Dabei seien sie sehr gute Hausfrauen und verrieten „im Allgemeinen eine

\footnotetext{
${ }^{407}$ Vgl. Heeren: Ideen über die Politik, S. 439

${ }^{408}$ Die indischen Frauen seien ,anspruchslos und bescheiden, von tadelfreier Aufführung, gute Haushälterinnen, zärtliche Mütter und eben so treue als folgsame Gattinnen." (Vgl. Briefe eines italienische Reisenden, S. 342f., vgl. auch S. 344); vgl. Ehrmann: Neueste Kunde von Asien. Zweiter Band, S. 86; Heeren: Ideen über die Politik, S. 439

${ }^{409}$ Des Fra Paolino da San Bartolomeo Reise nach Ostindien, S. 284

${ }^{410}$ Schlegel, F.: Geschichte der alten und neuen Literatur, S. 135
} 
Scharfsichtigkeit, eine Sparsamkeit und Einsicht [...], welche den häuslichsten Frauen in Europa Ehre machen würden." ${ }^{411}$ Die indischen Frauen seien sehr selbständig und in jede Arbeit der Männer mit eingebunden, sei es auf dem Feld, im Handwerk oder im Laden. Einige Frauen führten auch allein kleine Geschäfte. ${ }^{412}$ Natürlich hätten sie auch Fehler: Sie liebten Schmuck und seien ,lüstern, hartnäckig, reizbar, rachsüchtig, eigensinnig, flatterhaft, ungemein geschwätzig, verleumderisch und in sehr vielen Fällen zanksüchtig“413. Aber das seien die typischen Fehler aller Frauen in allen Kulturen.

Mit seinem Text wendet sich Dubois direkt gegen die Thesen eines anderen Missionars, den Briten Ward. Dieser äußert sich sehr kritisch über die Rolle der Frau in der indischen Gesellschaft:

\begin{abstract}
In diesem Lande, in welches das Licht des Christenthums noch nicht gedrungen ist, ist auch der Zustand des weiblichen Geschlechts stets beklagenswerth gewesen. Die Hindu-Gesetzgeber verbieten den Frauen ausdrücklich, eine Kenntniß von irgend einer Wissenschaft zu erlangen, und es besteht ein Befehl, welcher ihnen aufs strengste untersagt, in die heilige Schrift zu blicken. Ein indisches Frauenzimmer ist verachtet, sobald sie geboren wird; während die Eltern und ihre Freunde, wegen fehlgeschlagener Hoffnung, daß es kein Knabe ist, finstere Gesichter machen, erblickt sie das Licht der Welt. Jede Mutter vom Stamme Naiputs tödtet ihre Tochter gleich nach der Geburt. [...] Die Mädchen von den übrigen Stämmen genießen in ihrer Jugend nicht die mindeste Erziehung, viel weniger können sie einige Bildung erlangen. Es gibt keine einzige Mädchenschule in ganz Indien. Noch in ihren Kinderjahren wird das junge Mädchen ohne ihr Wissen an einen Mann verheirathet, den sie nie gesehen hat, und wenn beyde zum Erstenmale zusammentreffen, so sind sie auf Lebenszeit an einander gebunden. ${ }^{414}$
\end{abstract}

Ward betont den geringen Wert, den die Frauen sogar in den Augen der eigenen Eltern hätten, ihre Machtlosigkeit und Chancenlosigkeit. Die Frau scheint nur einen Zweck zu haben: Ehefrau und Mutter $\mathrm{zu}$ werden. Um seine Aussagen $\mathrm{zu}$ unterstreichen, beschreibt er die Tötung neugeborener Mädchen. Diese wird auch von anderen Autoren erwähnt, aber meistens nicht allzu ausführlich dargestellt. Außerdem ist die Rede oft allgemein von Kindstötung und nicht von der Tötung speziell der Mädchen. ${ }^{415}$ Ward

\footnotetext{
${ }^{411}$ Dubois: Briefe über den Zustand des Christentums, S.173

${ }^{412}$ Vgl. Dubois: Briefe über den Zustand des Christentums, S. 171-178

${ }^{413}$ Dubois: Briefe über den Zustand des Christentums, S. 179

${ }^{414}$ Unglückliche Lage des weiblichen Geschlechts in Indien, S. 975

${ }^{415}$ Vgl. z.B. Die Sitten der Hindus, S. 74; Hegel: Vorlesungen über die Philosophie der Geschichte, S. 156; Meiners: Untersuchungen über die Verschiedenheiten der Menschennaturen, S. 305 (Sowohl bei Hegel als auch bei Meiners geht es in diesem Zusammenhang allerdings weniger um die Kindstötung als solche, sondern um die Charakterisierung der Inder als grausam bzw. nicht am Leben hängend, indem möglichst viele grausame Tötungspraktiken aufgezählt werden.)
} 
wird dagegen in seiner Beschreibung sehr drastisch. Dabei geht es ihm anscheinend aber weniger um Sensationslust, als vielmehr darum, deutlich zu machen, welche Folgen Aberglauben haben kann, denn er betont in dem folgenden Textausschnitt nicht nur die Grausamkeit der Handlung an sich, sondern auch die fanatische Freude der Mütter dabei, sowie den Aberglauben als Ursache:

\begin{abstract}
Millionen Mütter werfen die Früchte, die unter ihrem Herzen lagen, jubelnd in die See. Stets patroulliert eine Abtheilung Soldaten an den Ufern, um diejenigen Mütter abzuhalten, die ihre Kinder lebendig in den Rachen des Alligators werfen, und mit vergnügter Miene das Schauspiel genießen wollen, wie das gierige Thier des unschuldigen Kindes Knochen zermalmt, wie es dessen Fleisch zerreißt und sein Blut trinkt. Aberglaube verleitet viele Frauen, sich den Wellen der heiligen Flüsse in Indien zu opfern. ${ }^{416}$
\end{abstract}

Dubois spricht sich auch gegen Wards Darstellung der häufigen Tötungen neugeborener Mädchen aus. ${ }^{417}$ Und das tut er so vehement und erfolgreich, dass Ward sich genötigt sieht, hinsichtlich seiner Formulierung (im obigen Zitat) einen Fehler einzuräumen: statt „Millionen“ (Mütter), die ihre Kinder töteten, müsse es einfach „Mütter“ heißen; es handele sich um ein Versehen des Setzers. ${ }^{418}$ So sehr das Schicksal der Frauen und Mädchen Ward vielleicht auch persönlich am Herzen liegen mag, er nutzt es hier gezielt, um die Dringlichkeit der Missionierung der Inder deutlich zu machen. Daher wendet er sich in einer Anrede auch direkt an die englischen Frauen, um diese für sein Anliegen zu sensibilisieren.

Auch der Missionar Perrin entwirft ein sehr düsteres Bild des Schicksals indischer Frauen. Die Mädchen - und zwar sowohl die Heiden als auch die Christen - würden bei ihrer Hochzeit gegen ein Brautgeld wie eine Ware verkauft. ${ }^{419}$

Die Ehe ist in Indien also ein Contract, wodurch ein Mann für sein Geld das Recht bekommt, eine Frau zu schlagen, während zugleich die Frau zum Besten des Verkäufers ihm alle ihre Neigungen, ihre Ruhe und Freyheit abtritt und überläßt, so lange sie in ehelicher Verbindung mit ihm steht, und wenn sie Kinder hat, die den Mann überleben, selbst für ihre ganze Lebenszeit. Denn sie ist die Sclavinn ihres Mannes und ihrer eigenen Kinder. Gegen den ersten steht sie in solcher Abhängigkeit, daß sie sich nie untersteht, ihn ihren Gatten zu nennen. Dieser Nahme wäre zu süß für sie, er würde sie zu angenehm täuschen. Sie spricht von ihm nur als von einem unbeschränkten Gebiether, von einem Herrn, dessen unterthänigste Dienerinn sie ist [...]. Auch ist dieser Titel nur zu gegründet. Die Frau bedient ihren Mann und selbst ihre Kinder wie eine elende Magd. Hat sie

\footnotetext{
${ }^{416}$ Unglückliche Lage des weiblichen Geschlechts in Indien, S. 975

${ }^{417}$ Vgl. Dubois: Briefe über den Zustand des Christentums, S. 190f.

${ }^{418}$ Vgl. Blicke auf Indien. In: Literatur-Blatt 14/15 (1824), S. 53-55, 57-58, hier S.58

${ }^{419}$ Vgl. Hell: M. Perrin's Reise durch Hindostan. Band 2, S. 7
} 
ihnen zu essen gegeben, so verzehrt sie in einem Winkel die Überbleibsel, die man ihr läßt. Und was das Empörendste ist, selbst ihre Lage als Mutter mehrerer Kinder vermehrt nur ihre Erniedrigung; denn diese mißhandeln sie nach dem Beyspiele des Vaters ungestraft [...]. ${ }^{420}$

Wie bei den anderen Autoren auch ist die Frau auf ihre Rolle als Ehefrau und Mutter beschränkt. Nur ist diese Rolle hier nichts Ehrenvolles. Die Frau kann sich nicht über ihre Zärtlichkeit und Liebe zu Mann und Kindern definieren, die auf Nähe und Gegenseitigkeit beruht, sondern ist in die distanzierte Rolle der Magd gedrängt, als gehöre sie selbst gar nicht zur Familie. Rechte irgendeiner Art scheint sie nicht zu haben. Die Gewalt, der die Frauen ausgesetzt seien, beschreibt Perrin auch in einer anderen Szene sehr drastisch. Eine Gruppe von Menschen sei bereit gewesen, sich zum Christentum bekehren zu lassen, habe dann aber doch die Taufe verweigert, als ihnen zur Bedingung gemacht wurde, ihren Brauch, der Braut bei der Hochzeit zwei Finger abzuschneiden, aufzugeben. ${ }^{421}$ Anders als Ward, der hervorhebt, dass das Licht des Christentums die beschriebenen Gegenden Indiens noch nicht erleuchtet habe, verweist Perrin immer wieder darauf, dass auch die zum Christentum bekehrten Inder im Umgang mit den Frauen nicht besser seien als die Hindus. Auch Dubois sieht im Christentum nicht unbedingt ein Heilmittel. Denn auch bei den christlichen Völkern des Orients herrsche Geschlechtertrennung. Und auch die Verbesserungen, die es in dieser Hinsicht vor noch nicht allzu langer Zeit in Europa gegeben habe, hätten ursächlich nicht viel mit dem Christentum zu tun. ${ }^{422}$

\subsubsection{Witwenverbrennung}

Das Thema, was im Zusammenhang mit den indischen Frauen mit Abstand am meisten fasziniert und immer wieder aufgegriffen wird, ist die Tradition der Witwenverbrennung. ${ }^{423}$ Dieses Motiv gehört seit den ersten Indienberichten der Antike zum Standardrepertoire der Indienliteratur. ${ }^{424}$ Bei dieser Tradition handelt es sich um etwas für die Europäer nicht nur kognitiv, sondern vor allem auch normativ Fremdes. Auch Sensationslust und Faszination des Exotischen und Grausamen spielen sicherlich

\footnotetext{
${ }^{420}$ Hell: M. Perrin's Reise durch Hindostan. Band 2, S. 7f.

${ }^{421}$ Vgl. Hell: M. Perrin's Reise durch Hindostan. Band 2, S. 9

422 Vgl. Dubois: Briefe über den Zustand des Christentums, S. 171f.

${ }^{423}$ Schon aus der Antike und frühen Neuzeit sind Berichte über Witwenverbrennungen bekannt. In der frühen Neuzeit wurden dabei die Witwen zunächst analog zu Märtyrern idealisiert, dann aber setzte sich die Auffassung immer mehr durch, dass die Selbstopferung nicht freiwillig stattfinde, sondern aufgrund von sozialem Druck, was entsprechend verurteilt wurde. Aber auch eine Erzählung als Kuriosität war möglich (Vgl. Dharampal-Frick: Indien im Spiegel deutscher Quellen der Frühen Neuzeit, S. 132f.)

${ }^{424}$ Vgl. Osterhammel: Die Entzauberung Asiens, S. 368
} 
eine große Rolle. Denn es fällt auf, dass zwar die Frage nach dem Ursprung dieser Tradition und den Motiven der Frauen angesprochen wird, es ansonsten aber so gut wie keine theoretische Auseinandersetzung mit den Hintergründen gibt. Stattdessen finden sich immer wieder Augenzeugenberichte, die den Ablauf einer Witwenverbrennung bis ins Detail beschreiben. Inhaltlich sind diese Beschreibungen einander sehr ähnlich, über die Abläufe scheint es kaum Uneinigkeit zu geben. Ähnlich wie bei der Rolle der Frau als Ehefrau und Mutter gehen aber die Beurteilungen und die durch die Art der Darstellung erzeugten Bilder deutlich auseinander. Die wichtigste Frage dabei ist, ob die Witwe sich freiwillig und aus Liebe $\mathrm{zu}$ ihrem Mann verbrennt und die Witwenverbrennung somit als eine aus europäischer Sicht zwar unverständliche und grausame, aber dennoch in gewisser Weise auch bewunderungswürdige Heldentat erscheint, oder ob die Witwe direkt mit Gewalt oder indirekt durch Drängen, Androhungen und Lockungen $\mathrm{zu}$ dieser Tat gezwungen wird und die Witwenverbrennung dadurch als ein weiterer Aspekt der Unterdrückung der Frau oder der Grausamkeit der Inder gedeutet wird. Entsprechend variieren auch die Begründungen für diese Tradition.

Die Gründe, die in den untersuchten Texten deutlich am häufigsten zur Erklärung des für die Europäer fremden Brauches genannt werden, sind folgende Thesen: Die Witwe verbrenne sich aus tiefer Liebe zu ihrem Mann und tiefer Verzweiflung wegen seines Todes, aus dem Tod aus Liebe sei eine Tradition erwachsen, die Witwenverbrennung sei wegen der Angst der Männer vor Giftanschlägen ihrer Frauen eingeführt worden, die Frauen zögen den Tod der schlechten gesellschaftlichen Stellung einer Witwe vor, die Tradition beruhe auf Eitelkeit und Ruhmsucht oder die Lehre von der Seelenwanderung habe sie gefördert.

Diese Thesen sind nicht neu. In der frühen Neuzeit dominierte die These von der Witwenverbrennung als Vorkehrung gegen Giftmischerinnen. Später traten andere Aspekte in den Vordergrund. ${ }^{425}$ Herder führte an, dass das Leben der Frauen an das Leben der Männer geknüpft worden sei, weil diese sich vor der List der Frauen schützen wollten. Zudem fördere die Seelenwanderungslehre falsches Mitleiden, unterdrücke aber wahres Mitgefühl. ${ }^{426}$ Auch Sonnerat deutete einen Einfluss der

\footnotetext{
${ }^{425}$ Flüchter: Bajadere und Sati, S. 164f.

${ }^{426}$ Vgl. Herder: Ideen zur Philosophie der Geschichte der Menschheit, S. 216, 294
} 
Seelenwanderungslehre an, die für die niedere Stellung der Witwe in der Gesellschaft verantwortlich sei. ${ }^{427}$ Für die Entstehung der Witwenverbrennung war für ihn dann aber doch die Liebe der Frau ausschlaggebend, wobei mit der Zeit aus einzelnen Fällen ein allgemeiner Brauch entstanden sei:

\begin{abstract}
Wahrscheinlich war die unbegränzte Liebe einiger Weiber für ihre Männer und die Verzweiflung über ihren Verlust die erste Triebfeder dieses unnatürlichen Opfers, das der öftere Gebrauch zuerst billigte, und dann allgemein machte. ${ }^{428}$
\end{abstract}

Wenn man den Ausführungen des Karmelitermönchs Paulinus a Sancto Bartholomaeo folgt, so stammen einige dieser Vermutungen bereits aus der Antike. So habe Diodor von Sizilien angenommen, dass es eine Zeit gegeben habe, in der die Inderinnen häufig ihre Männer vergiftet hätten, und dass dem mit der Einführung der Witwenverbrennung ein Ende gemacht werden sollte. Und Plutarch sei der Ansicht gewesen, dass die Witwen zum Beweis ihrer ehelichen Treue diesen Schritt wählten. ${ }^{429}$

Die verschiedenen Thesen zur Ursache dieses Brauchs werden von vielen Autoren aufgeführt und häufig zunächst gleichgewichtig nebeneinandergestellt. Interessanterweise neigen viele dann doch zu der Ansicht, dass der eigentliche Grund in äußeren Zwängen wie der Eifersucht der Männer und ihrer Sorge um ihre Ehre und ihre Sicherheit zu suchen sei und weniger in der Liebe der Frau. Daher lockten sie die Frauen mit religiösen Versprechungen. Außerdem sei der gesellschaftliche Stand der Witwen so schlecht, dass viele den Tod vorzögen.

Sehr ausführlich beschreibt Klaußner die These, dass die Witwenverbrennung als Reaktion auf Giftmorde durch die Frauen an ihren Ehemännern eingeführt worden sei. Allerdings seien die Frauen im Zuge der Einführung der Ehe als Institution von ehemals Geliebten zu Sklavinnen ihrer Männer geworden, was ihre Taten erkläre. ${ }^{430}$

\footnotetext{
427 „Man sieht den Wittwenstand als das größte Unglück an, weil man glaubt, ein Weib habe dieses Schicksal in einem vorhergehenden Leben verschuldet; wer also eine Wittwe heyrathen wollte, würde dem Laufe der göttlichen Gerechtigkeit widerstreben. Die Eltern der Wittwe stellen Wallfahrten an, thun Bußwerke und geben Allmosen, damit ihre Tochter wenigstens bey der bevorstehenden Seelenwanderung glücklicher seyn möge." (Sonnerat: Reise nach Ostindien, S. 28f.)

${ }^{428}$ Sonnerat: Reise nach Ostindien, S. 48

${ }^{429}$ Vgl. Des Fra Paolino da San Bartolomeo Reise nach Ostindien, S. 95

${ }^{430}$ Vgl. Klaußner: Die Hindus, S. $519 f$.
} 
Sowohl Crawfurd als auch Ehrmann und Paulinus a Sancto Bartholomaeo sehen die Hauptursache in der Eifersucht der Männer und ihrer Sorge um ihre Sicherheit. ${ }^{431}$ Sie verbinden diesen Grund allerdings mit verschiedenen weiteren. Crawfurd führt aus:

Das Gesetz empfiehlt jedoch diese Aufopferungen mehr, als daß es sie geböt. Es drückt sich darüber folgendermaßen aus: „Das Weib, welches sich mit ihrem Ehemanne verbrennt, reinigt die Familie ihrer Mutter, ihres Vaters, und ihres Gatten. Es giebt keine höhere Tugend, als die eines tugendhaften Weibes, das sich mit ihrem Gatten verbrennt. Ein tugendhaftes Weib kennt bei ihres Gatten Tode keine andere Pflicht, als sich, wie ihn, in dasselbe Feuer zu stürzen. So lange ein Weib in ihren allmählichen Seelenwanderungen anstehen wird, sich als treue Gattin auf dem Scheiterhaufen ihres Gemahls zu verbrennen, wird sie es nicht vermeiden, in irgend einem Thierkörper zum Leben zurückzukehren. (...). ${ }^{، 432}$

Die Witwe reinige durch ihre Verbrennung ihre Familie (nicht sich selbst) und verhindere für sich selbst eine Wiedergeburt als Tier. Die Frau hat für sich selbst also keinen positiven Anreiz (Reinigung), sondern nur den der Verhinderung von etwas Negativem. Außerdem wird immer wieder betont, dass es Sache der Tugend sei, sich zu verbrennen. Andernfalls - so muss man schließen - würde die Frau als untugendhaft gelten. Eine religiöse Vorstellung wie die Seelenwanderung (die auch in anderen Zusammenhängen als Ursache negativer Bräuche angeführt wird) diene also dazu, ein eigentlich weltliches Problem (Sicherheit und Ansehen der Männer) zu lösen.

Ehrmann und Paulinus a Sancto Bartholonaeo führen als weiteren konkreten Grund für die Frau, sich für den Tod zu entscheiden, an, dass ein Leben als Witwe noch schrecklicher sei:

\footnotetext{
Überdies ist der Zustand der Wittwen sehr traurig nach dem Tode ihrer Männer; sie verlieren alle ihre Rechte, haben keine Ansprüche auf ihres Gatten Verlassenschaft, und müssen sich der Gnade und Barmherzigkeit des nächsten Erben überlassen, der sie gewöhnlich zu sich nimmt, aber sie wie Sklavinnen behandelt. ${ }^{433}$
}

\footnotetext{
431 „Der Zweck dieser barbarischen Gewohnheit ist nicht zweifelhaft; im ganzen Morgenlande scheinen sich die Gesetzgeber mit den Mitteln beschäftigt zu haben, das Ansehen und die Sicherheit der Männer aufrecht zu erhalten.“ (Die Sitten der Hindus, S. 75); ihren Ursprung habe der Brauch in „Fanatismus und der Eifersucht der Männer“ (Ehrmann: Neuste Kunde von Asien. Zweiter Band, S. 107); auch Paulinus a Sancto Bartholomaeo stellt fest, dass „der Ursprung dieses sonderbaren Gebrauches in Staats- und Religions- Gründen zu suchen ist. Wenn eine Frau mit Gewißheit vorhersieht, daß der Tod ihres Mannes zugleich auch den ihrigen nach sich ziehen muß, so wird sie um so mehr für dessen Erhaltung besorgt seyn.“ (Des Fra Paolino da San Bartolomeo Reise nach Ostindien, S. 95)

${ }^{432}$ Die Sitten der Hindus, S. $75 f$.

${ }^{433}$ Ehrmann: Neuste Kunde von Asien. Zweiter Band, S. 107f.
} 
Die Witwe gelte in Indien als gesellschaftlich unnütz, zumindest wenn sie keine Kinder zu versorgen habe. Daher sei den Witwen eine gesellschaftlich anerkannte Rolle verwehrt. Sie würden als ehrlos angesehen, wenn sie sich nicht verbrannten, und müssten ihren Lebensunterhalt als Hure verdienen. ${ }^{434}$ Auch George Forster hält die gesellschaftliche Stellung der Witwe für ausschlaggebend. ${ }^{435}$

Best stellt diesen Aspekt ebenfalls in den Mittelpunkt. Während er zwar auch die bekannten Gründe Angst vor Mord durch die schlecht behandelte Ehefrau, „religiöse Schwärmerey und überspannte Begriffe von ehelicher Treue“" anführt, überwiegt in seiner Darstellung die Furcht davor, „nach dem Tode des Mannes ein elendes verworfenes Geschöpf zu werden!“4336. Das unterstreicht er durch die Erzählung über eine Witwe. Diese beschreibt er - wie viele andere Autoren auch - als jung und schön und hebt dadurch den zu frühen Tod einer Frau, die noch viele Lebensjahre vor sich haben sollte, hervor. Der Witwe wird vom Kommandanten der Stadt untersagt, sich mit ihrem verstorbenen Mann verbrennen zu lassen. Diese Entscheidung stürzt die Frau in Verzweiflung. Als Best sie daraufhin nach ihren Beweggründen fragt, erhält er

$$
\begin{aligned}
& \text { von ihr eine sonderbare Antwort. Sie sagte, daß sie nun ein verworfenes } \\
& \text { und unglückliches Geschöpf in den Augen ihrer Verwandten und der Welt } \\
& \text { sey, und ihre besten Jahre in Kummer und Unmuth hinbringen müsse; } \\
& \text { daher habe sie sich den Tod gewünscht; sollte sich jedoch ein Europäer } \\
& \text { finden, der sie als Maitresse anzunehmen gesonnen sey, so wolle sie gern } \\
& \text { von ihrem Vorsatze abstehn, auch den Schimpf, aus ihrer Kaste gestoßen } \\
& \text { zu werden, nicht achten. }{ }^{437}
\end{aligned}
$$

Die Witwe wünscht sich also keineswegs den Tod, sondern wählt ihn nur als letzten Ausweg aus einem in ihren Augen noch größeren Übel.

Während die genannten Autoren die Ursache in den von Männern bestimmten gesellschaftlichen Strukturen ausmachen, werden sowohl im Lexikonartikel von 1815 als auch in dem Bericht des Malers Hodges ein ganz anderes Motiv in den Mittelpunkt gerückt: die Eitelkeit und Ruhmsucht. Im Lexikon-Eintrag wird - der gebotenen Kürze

\footnotetext{
${ }^{434}$ Vgl. Des Fra Paolino da San Bartolomeo Reise nach Ostindien, S. 95, 279

${ }^{435}$ In den Kasten, in denen die Ehre eine größere Rolle spiele, ,,machen noch von Zeit zu Zeit Witwen mit einem rasenden Muth, welchem sie die Benennung einer warmen ehelichen Liebe geben, ihrem elenden Leben ein Ende, weil sie eine Erniedrigung nicht ertragen können, wodurch die weibliche Reize ausgelöscht und der Stolz ihres Geschlechts gedemüthigt wird.“ (Forster: Reise aus Bengalen, S. 88)

${ }^{436}$ Best: Briefe über Ost-Indien, S. 52

${ }^{437}$ Best: Briefe über Ost-Indien, S. 51
} 
der Textart angemessen - lediglich nüchtern festgehalten: „Es war von jeher religiöse Schwärmerei, kein Gebot; Eitelkeit, Ruhmsucht, selbst Liebe trieb oft die Weiber dazu. “438 Interessant ist, dass die Rolle der Männer und der Gesellschaft und jeglicher Druck von außen hier überhaupt nicht angesprochen werden. Es entsteht das Bild, als sei es lediglich der freie Wille der Frauen, sich zu verbrennen, wobei die religiösen Erwartungen als Schwärmerei entkräftet werden und der Liebe eher mit Verwunderung begegnet wird. Die wahren Gründe sieht der Autor in der Eitelkeit und Ruhmsucht der Frauen. Hogdes sieht in der Witwenverbrennung eine Tradition, die einst aus Liebe entstanden sei, religiös aufgeladen und so allgemeine Sitte geworden sei. Aufrechterhalten werde sie durch eine Mischung aus Aberglaube und Eitelkeit. Das macht er vor allem an dem ,theatralische(n) Gepränge ${ }^{\text {،439 }}$ fest, das die Verbrennungen begleite.

Anders als viele andere Autoren interessieren sich Hegel und Meiners eher weniger für die Entstehung dieser Tradition. Ihnen dient die Witwenverbrennung in erster Linie der Charakterisierung der Inder bzw. ihrer Philosophie. Sie stellen die Witwenverbrennung bewusst in eine Reihe mit anderen grausamen Handlungen der Inder wie z.B. Kindstötungen und der fehlenden Sorge für Kranke, die gezielt getötet würden, oder auch der Selbstopferungen am Tempel in Jagannatha. Bei Meiners erscheinen die Inder dadurch als grausam; sie schreckten nicht vor Taten zurück, die selbst „Mohren nie ohne das innigste Mitleiden mit den unglücklichen Schlachtopfern, und ohne den heftigsten Unwillen gegen die grausamen Opferpriester ansehen konnten. “440 Für Hegel ist der Brauch dagegen ein weiterer Beweis für die religiös-philosophische Vorstellung der Inder, dass es das Höchste sei, sich zum „Brahm“, zur abstrakten Einheit, zu erheben. Dazu gehöre, dass sie ,sich der Abstraktion widmen und von allen andern Lebensverhältnissen ausscheiden. Die Verachtung des Lebens und des lebendigen Menschen, das ist der Grundzug dieser Existenz. “441 Er führt weiter aus:

\footnotetext{
Also nur durch solche Negation seiner Existenz kommt man zur Macht eines Brahmanen; diese besteht aber in dem dumpfen Bewußtseyn, es zu einer vollkommenen Regungslosigkeit, zur Vernichtung aller Empfindung und alles Wollens gebracht zu haben [...]. So feige und schwächlich die Inder sonst sind, so wenig kostet es sie, sich dem Höchsten, der Vernichtung
}

\footnotetext{
${ }^{438}$ Conversations-Lexikon. 1815 , S. 717

${ }^{439}$ Hogdes: Reisen durch Ostindien, S. 95

${ }^{440}$ Meiners: Untersuchungen über die Verschiedenheiten der Menschennaturen, S. 304

${ }^{441}$ Hegel: Vorlesungen über die Philosophie der Geschichte, S. 154
} 
Es folgen Berichte über die oben erwähnten anderen Grausamkeiten. Dann fasst Hegel zusammen: „Das Moralische, das in der Achtung eines Menschenlebens liegt, ist bei den Indiern nicht vorhanden. Solcher Lebensweisen, die auf die Vernichtung hingehen, giebt es nun noch unendliche Modifikationen. ${ }^{6443}$ Es geht Hegel nicht in erster Linie um die angeführten indischen Bräuche als solche, also auch nicht um die Witwenverbrennung. Vielmehr setzt er sich mit der indischen Philosophie kritisch auseinander und nutzt die Witwenverbrennung als ein Argument zur Stützung seiner These von der lebensverachtenden Haltung der indischen Religion und Philosophie. Denn um diese geht es ihm eigentlich. ${ }^{444}$

Während Hegel und Meiners die Witwenverbrennung zur Charakterisierung der indischen Kultur nutzen und sie so eng an diese binden, versucht Friedrich Schlegel, sie aus diesem engen Rahmen zu lösen und als ein auch in anderen Kulturen verbreitetes Ritual zu interpretieren. Schlegel geht es nicht um mögliche soziale oder politische Ursachen; er lehnt die These, die Witwenverbrennung sei Teil der Unterdrückung der Frauen, klar ab. ${ }^{445}$ Vielmehr solle man sie im Vergleich mit den bei wilderen und kriegerischen Völkern üblichen Totenopfern interpretieren. Dort seien berühmten Herrschern und Helden neben seinen Waffen und anderen Geräten z.T. auch Sklaven mit ins Grab gegeben worden. Und es sei geschehen, dass sich

in der Wuth des Schmerzes, der Freund oder die Geliebte des Helden oft ihm nach in die Flammen oder in den Grabesschlund stürzte, als sollte mit dem großen Verstorbenen alles, was ihm lieb und theuer war, mit in seinen Untergang hinein gerissen werden. Auch in Indien fand diese scheinbar freiwillige, oft aber durch Überredung und Betäubung erkünstelte Opferung der Frauen ursprünglich nur in der Kriegerkaste Statt. Allgemein konnte sie nie sein, sie war in den ältern Zeiten vermuthlich sehr selten, obwohl sie als Heroismus bewundert oder empfohlen ward. Die vollkommene Gewißheit von einer unmittelbar Statt findenden, persöhnlichen Wiedervereinigung in

\footnotetext{
${ }^{442}$ Hegel: Vorlesungen über die Philosophie der Geschichte, S. 155f.

${ }^{443}$ Hegel: Vorlesungen über die Philosophie der Geschichte, S. 156

444 Ähnlich argumentiert auch der Autor eines Artikels in der Zeitschrift „Minerva“: „Mit dem allgemeinen Systeme der Bramareligion stimmt nichts mehr überein, als solche grausame Opfer. Eine Lehre, die das gegenwärtige Leben für nichts rechnet, spielt ungestraft mit dem Leben der Menschen. Jagranauts Wagen zermalmt die Schwärmer, die sich in Schaaren unter seine Räder werfen; der Scheiterhaufen des Gatten verzehrt auch die am Leben bleibende Gattin; die Mutter opfert ihre Tochter. Es giebt keine Thorheit und keine Grausamkeit, die nicht unter den Braminen Anhänger und Verbreiter findet." (Über den Kindermord bei den Hindus. In: Minerva. Ein Journal historischen und politischen Inhalts 84 (1812), S.460-463, hier S. 460f.).

${ }^{445}$ Vgl. Schlegel, F.: Geschichte der alten und neuen Literatur, S. 135
} 
Schlegel stellt mit dieser Einordnung in die Kategorie der bei Kriegern verbreiteten Totenopfer die Witwenverbrennung in einen größeren Rahmen: Sie ist jetzt nicht mehr ein auf Indien beschränktes, grausames und unverständliches Geschehen, sondern eine indische Variante eines auch bei anderen Völkern bekannten Rituals. Dennoch bleibt sie trotz dieser theoretischen Erklärung für Europäer unverständlich. Auch Schlegel spricht von einer „tadelswerthen Duldung“ 447 durch die Engländer. Anders als Ehrmann und Papi erklärt Schlegel diese jedoch nicht mit der Käuflichkeit der englischen Beamten, sondern mit dem Grundsatz der Engländer, die Inder auf Basis ihrer eigenen Gesetze und Kultur zu beherrschen, und mit der Notwendigkeit, auch fremde Gebräuche zu schonen, um als Befreier von den Verfolgungen muslimischer Herrscher zu gelten. ${ }^{448}$

Bereits bei den Beschreibungen verschiedener Ursachen für die Witwenverbrennung scheint die Beurteilung durch den jeweiligen Autor z.T. deutlich durch. Oft wird diese auch direkt ausgesprochen. Wie der Autor zu dieser Tradition steht, wird aber auch in seiner Art der Darstellung der Geschehnisse deutlich. Wichtig ist dabei die Frage nach der Freiwilligkeit des Geschehens: Sind die Frauen eher als Opfer oder als Heldinnen $\mathrm{zu}$ sehen? Und kann man wirklich von Freiwilligkeit sprechen, wenn ein möglicherweise eigener Wunsch der Frauen auf Aberglaube und religiösem Fanatismus beruht? $?^{449}$ Diese Frage ist durchaus umstritten. Bereits Dapper schrieb Ende des 17. Jahrhunderts, dass die Witwen der Brahmanen nicht gezwungen werden dürften, dass es sich aber für sie gehöre, wenn sie keine Kinder zu versorgen hätten, da es ansonsten Sünde wäre; bei den Kriegern würden sie aber durchaus gezwungen. ${ }^{450}$ Zwang oder nicht Zwang sind hier zwar scheinbar auf verschiedene Kasten verteilt, aber die Feststellung, dass es Sünde sei, sich nicht freiwillig zu verbrennen, impliziert auch bei den Brahmanen einen indirekten Zwang. Die in den untersuchten Texten direkt oder indirekt ausgedrückten Beurteilungen reichen von deutlicher Ablehnung und Verurteilung über eine gewisse Unsicherheit bis hin zu Versuchen, den fremden Brauch zu verstehen. Allerdings überwiegen die ablehnenden Urteile.

\footnotetext{
${ }^{446}$ Schlegel, F.: Geschichte der alten und neuen Literatur, S. 135

${ }^{447}$ Schlegel, F.: Geschichte der alten und neuen Literatur, S. 134

${ }^{448}$ Vgl. Schlegel, F.: Geschichte der alten und neuen Literatur, S. 134

${ }^{449}$ Vgl. Osterhammel: Die Entzauberung Asiens, S. 369

${ }^{450}$ Vgl. Dapper: Asia, S. 35f.
} 
George Forster ist einer der wenigen Autoren, die vor einer vorschnellen Verurteilung dieses Brauchs warnen. Zum einen sei diese Sitte nicht mehr so stark verbreitet und zum anderen könne sie für einen guten Zweck geschaffen worden sein:

Ungeachtet der Erfolg solcher Vorstellungen die fühlenden Herzen der europäischen Völker sehr peinlich afficiren muß; so darf man doch den alten Brauch der Hindus nicht voreilig verdammen, oder aus Grausamkeit und Ungerechtigkeit ableiten, da er vielmehr aus der Absicht entsprungen zu seyn scheint, das häusliche Leben angenehmer und sicherer zu machen. ${ }^{451}$

So schrecklich der Brauch für das „fühlende“ Herz der Europäer auch sein mag, könne er doch durch den Zweck, den er erfüllen soll, möglicherweise entschuldigt werden.

Paulinus a Sancto Bartholomaeo bezeichnet das Ereignis zwar als schrecklich, aber er inszeniert die Witwe nicht als Opfer. Die Witwe sei von Opium betäubt und stürze sich freiwillig ins Feuer. Auch die Beschreibung der weißgekleideten Witwe, die in einer Art Prozession zum Scheiterhaufen kommt, dort zunächst dem Feuer opfert und anschließend ihren Schmuck unter ihren Verwandten und Freundinnen verteilt, ähnelt eher der einer Heiligen als eines Opfers eines grausamen Verbrechens. ${ }^{452}$ Andere Autoren beschreiben die Abläufe der Witwenverbrennung relativ sachlich-nüchtern und deuten nur in der Wahl bestimmter Ausdrücke und Formulierungen Kritik an. ${ }^{453}$

Friedrich Schlegel schwankt in seiner Beschreibung zunächst zwischen Verständnis und Ablehnung:

Fremder für unser Gefühl, obwohl auch mit zarten, gefühlvollen Zügen durchwebt, sind jene Schilderungen von der furchtbaren Abtödtung indischer Büßer, oder von der in den indischen Darstellungen häufig erwähnten Todesweise der verwittweten Frauen. ${ }^{454}$

${ }^{451}$ Forster: Reise aus Bengalen, S. 89

${ }^{452}$ Vgl. Des Fra Paolino da San Bartolomeo Reise nach Ostindien, S. 93f.

${ }^{453}$ So beschreibt Crawfurd, wie die Witwe zwar auf dem Scheiterhaufen festgebunden wird, aber allem Anschein nach aus freiem Willen verbrannt werden möchte, und auch die Angehörigen und Brahmanen drängen sie nicht. Sie ist gefasst, wird aber auch nicht als Heldin beschrieben. Ihr Sohn zündet den Scheiterhaufen an, wendet aber die Augen ab. Einzig die Bezeichnung dieser Tradition als barbarisch und die Vermutung, einige Zuschauer kämen allein aus Neugierde, zeigen eine ablehnende Haltung des Autors dem Geschehen gegenüber (vgl. Die Sitten der Hindus, S. 76-78). Auch Hodges beschreibt die äußere Gleichgültigkeit der Zuschauer und die Ruhe und Gefasstheit der Witwe. Dennoch habe er Schwermut empfunden und fast wie in einem Aufschrei endet er, Vernunft und Natur empörten sich wider diese Tat, die er kaum glauben könne (vgl. Hodges: Reisen durch Ostindien, S. 95-100).

${ }^{454}$ Schlegel, F.: Geschichte der alten und neuen Literatur, S. 134 
Die Berichte über die Selbsttötungen seien fremd (hier vor allem in dem Sinn von unverständlich und daher auch beunruhigend), aber auch „mit zarten, gefühlvollen Zügen durchwebt“". Schlegel führt diesen Gedanken nicht weiter aus, zielt aber wohl darauf, dass bei aller Fremde auch die Europäer das Bild einer Liebenden, die aus Trauer um den verstorbenen Mann verzweifelt, oder auch das eines Büßers, der aus Liebe und Treue zu seiner Religion in gewisser Weise ebenfalls sich selbst opfert, mit Mitgefühl betrachten und nachempfinden können. Das Gefühl der Trauer und des Verlustes kennen sie ebenso, ziehen daraus aber keine solchen radikalen Konsequenzen. Erfolge die Verbrennung freiwillig, handele es sich dabei aber um einen Selbstmord, was aus christlicher Sicht impliziert, dass es Sünde ist. Die Betonung der Freiwilligkeit, mit der einige Autoren die Tat weniger grausam erscheinen lassen wollen, wird als Argument also in Frage gestellt. Geschehe die Verbrennung dagegen durch den „Zwang der Überredung“, sei sie nicht einfach eine Gewalttat, sondern ein „Menschenopfer“. 455

Ehrmann, der als hauptsächliche Ursache gesellschaftliche Umstände ausmacht, räumt am Ende seiner Ausführungen ein, dass einige Frauen sich vielleicht auch aus Leidenschaft für ihren Mann verbrennen lassen würden. Aber durch die Wortwahl „sich einem Vorutheile aufopfern “456 und durch die Anmerkung, dass die Brahmanen alles tun würden, um die Witwen ,zu diesem freiwilligen Opfer aufzumuntern““457, wird auch der Tod aus Liebe und Leidenschaft in ein schlechtes Licht gerückt.

Der den Idealen der Spätaufklärung verpflichtete Papi macht in seiner Wortwahl dagegen sehr deutlich, wie sehr er diesen Brauch ablehnt. Er spricht von einer

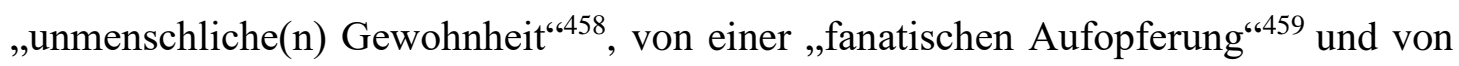
einem „fürchterliche(n) Brandopfer“460. Die Witwen bezeichnet er als „schwache Gemüther ${ }^{\star 461}$, als „Schlachtopfer“4462, aber auch als „Heldinnen““463. Auffällig ist bei diesem Text vor allem aber die negative Rolle, die den Brahmanen zukommt. Während sie in den übrigen Texten meistens die Witwe mit Gebeten begleiten oder die

\footnotetext{
${ }^{455}$ Schlegel, F.: Geschichte der alten und neuen Literatur, S. 134

${ }^{456}$ Ehrmann: Neuste Kunde von Asien. Zweiter Band, S. 108

${ }^{457}$ Ehrmann: Neuste Kunde von Asien. Zweiter Band, S. 108

${ }^{458}$ Briefe eines italienischen Reisenden, S. 349

${ }^{459}$ Briefe eines italienischen Reisenden, S. 349

${ }^{460}$ Briefe eines italienischen Reisenden, S. 352

${ }^{461}$ Briefe eines italienischen Reisenden, S. 349

${ }^{462}$ Briefe eines italienischen Reisenden, S. 351

${ }^{463}$ Briefe eines italienischen Reisenden, S. 353
} 
Zeremonie leiten, mal die Frau zu dem Tod drängen, mal sie aber auch davon abhalten wollen, schildert Papi die Brahmanen durchweg als Anstifter zur Verbrennung. Zwar beschreibt auch er die Versuche der Brahmanen, der Witwe ihr Vorhaben auszureden (was anscheinend Teil der Zeremonie war, da es sich bei vielen Augenzeugenberichten findet), aber er fährt fort:

Ich für meine Person zweifle sehr, daß es die Braminen mit diesem Abrathen ernstlich meinen, desto wahrscheinlicher kömmt es mir aber vor, daß sie bloß damit prahlen, um über das Schlachtopfer desto mehr Glanz zu verbreiten, und daß sie bloß deswegen von seiner Standhaftigkeit so viel Wesens machen, um es in seinem Vorhaben zu bestärken; denn auf der andern Seite machen sie ihm weiß, wenn es sich aus reiner wahrer Liebe verbrennen lasse, so werde es in den Flammen wenig oder gar keinen Schmerz empfinden, und sich überdies das Verdienst erwerben, den verstorbenen Gatten, falls er hienieden keinen guten Wandel geführt habe, in jenem Leben von der verdienten Strafe zu befreien. Der Tag, an welchem dieses fürchterliche Brandopfer veranstaltet wird, ist sowohl für die Familie der Wittwe, welche den Scheiterhaufen besteigt, als auch für die Angehörigen ihres verstorbenen Mannes, insonderheit aber für die Braminen, welchen diese Feierlichkeit viel Geld einbringt, ein Tag der Ehre und des Ruhms. ${ }^{464}$

Die Brahmanen seien für Ruhm und Ehre darauf Bedacht, dem Ganzen den Anschein von Freiwilligkeit zu verleihen. Eigentlich gehe es ihnen aber nicht um die Witwe oder den Toten, sondern um ihren eigenen Ruhm und anscheinend auch um eigene finanzielle Gewinne. Doch nicht nur durch Überredungskünste drängten die Brahmanen zum Opfer:

Die meisten dieser Wittwen gehen dem Tode als wahre Heldinnen entgegen,
lassen in ihren Gesichtszügen nicht die mindeste Spur von Zaghaftigkeit
blicken, und benehmen sich dabei mit aller erforderlichen Würde. Indessen
ereignet sich doch nicht selten der Fall, daß eine oder die andere, besonders
wenn die betäubenden Getränke, die ihr von den Braminen dargereicht
werden, nicht wirksam genug sind, bei Erblickung des Scheiterhaufens, der
sie in Asche verwandeln soll, zu zagen beginnt, und ihren Entschluß
bereuet. Wenn sie aber bei dieser Gelegenheit zu entrinnen sucht, so wird
sie von ihren eigenen Anverwandten, aus Rache wegen der ihnen
zugefügten Schmach, ums Leben gebracht, oder man verstößt sie zu einer
der verächtlichsten Kasten [...], wo sie, während ihrer ganzen noch übrigen
Lebenszeit, des Umgangs mit ihren Angehörigen und Freunden, so wie der
ehrenvollen Behandlung, die ihr in ihrem vorigen Stande widerfuhr, auf
immer beraubt ist. Die umstehenden Braminen aber, welche äußerst dafür
besorgt sind, die Personen, welche sich aufopfern, insonderheit aber sich
selbst die Ehren zu erhalten, machen gemeiniglich nicht viele Umstände,
sondern nehmen, während der Zeit, daß die dabei befindlichen Weiber und
Kinder heulen und schreien, eine Menge musikalischer Instrumente wild
durch einander tönen, und die versammelten Zuschauer einen fürchterlichen
Lärm machen, ihr Tempo wahr, wo sie die Unglückliche unversehens
fortschleppen, um sie mit Gewalt in den Scheiterhaufen zu stürzen, auf

${ }^{464}$ Briefe eines italienischen Reisenden, S. 351f. 
welchem sie, nebst dem Leichnam ihres schon dort befindlichen Gatten, verbrannt werden soll. ${ }^{465}$

Der Autor hält zwar in gewisser Weise am Bild der heldenhaften, mutigen und entschlossenen Witwe fest, aber dieses wird von der Gewalt der Angehörigen und der Brahmanen gegenüber der Witwe, sollte diese doch zaudern, deutlich an die Seite gedrängt. Aber auch die muslimischen Herrscher und die englischen Beamten werden kritisiert, da sie käuflich seien und gegen Geld die benötigte Erlaubnis für eine Verbrennung erteilten. ${ }^{466}$ Ähnliche Kritik äußern auch andere Autoren. ${ }^{467}$

Wie sehr dieses Thema die Menschen fasziniert, lässt sich auch anhand der Beiträge im Morgenblatt für gebildete Stände zeigen. Dort finden sich in den Jahren 1807, 1809, 1816, 1819, 1824 und 1827 jeweils ein Artikel, der sich der Beschreibung einer Witwenverbrennung widmet. Im Jahr 1821 sind es sogar zwei Artikel. Innerhalb von nur 21 Jahren werden so Leser, die gar nicht unbedingt die Intention haben, sich intensiv mit Indien zu beschäftigen, in 8 Artikeln allein im Morgenblatt mit der Witwenverbrennung konfrontiert. ${ }^{468}$ Diese Artikel sind fast alle ausführliche Beschreibungen eines Augenzeugen. Um der Frage nachzugehen, inwieweit sich der Diskurs über die Witwenverbrennung im Laufe der Zeit verändert, möchte ich diese Berichte im Folgenden genauer ansehen. Sie zeigen auch noch einmal sehr deutlich, wie typische Beschreibungen von Witwenverbrennungen von Augenzeugen aussehen.

Die ersten drei Beschreibungen sowie der Artikel von $1824^{469}$ ähneln sich darin, dass sie alle die Verbrennung als einen freiwilligen Entschluss der Witwe aus großer Liebe

\footnotetext{
${ }^{465}$ Briefe eines italienischen Reisenden, S. 353f.

${ }^{466} \mathrm{Vgl}$. Briefe eines italienischen Reisenden, S. 351

${ }^{467}$ So schreibt Ehrmann, dass der Brauch von den herrschenden Muslimen eigentlich nicht mehr geduldet werde und dass man in den englisch beherrschten Gebieten die Einwilligung des Gouverneurs brauche. Diese aber sei gegen eine ,ansehnliche Summe zu erkaufen“ (Ehrmann: Neuste Kunde von Asien. Zweiter Band, S. 108). Auch Schlegel spricht von einer ,tadelswerthen Duldung“ durch die Engländer. Anders als Ehrmann und Papi erklärt Schlegel diese jedoch nicht mit der Käuflichkeit der englischen Beamten, sondern mit dem Grundsatz der Engländer, die Inder auf Basis ihrer eigenen Gesetze und Kultur zu beherrschen, und mit der Notwendigkeit, auch fremde Gebräuche zu schonen, um als Befreier von den Verfolgungen muslimischer Herrscher zu gelten (vgl. Schlegel, F.: Geschichte der alten und neuen Literatur, S. 134).

${ }^{468}$ Auch in verschiedenen Volksalmanachen wird dieses Thema immer wieder aufgegriffen (vgl. Greilich: Orientbilder in französisch- und deutschsprachigen Volksalmanachen des achtzehnten und neunzehnten Jahrhunderts, S. 69)

${ }^{469}$ Vgl. Scenen aus Indien. Erste. In: Morgenblatt für gebildete Stände 1 (1807; Mai Nr. 109), S. 435f.; Erinnerungen aus Ostindien. In: Morgenblatt für gebildete Stände 3 (1809; April Br. 90), S. 357-359; Proben aus Ostindischen Zeitungen. Das Fest zu Jaggernauth, im Jahr 1814. In: Morgenblatt für
} 
zu ihrem Mann darstellen. Diese Freiwilligkeit wird unterstrichen durch ausführliche Schilderungen, wie die Witwe trotz aller Versuche der Umstehenden, ihr das Vorhaben auszureden, bei ihrem Entschluss bleibt. Die ausführlichste Beschreibung findet sich in dem Bericht von 1809. Dort erzählt der Autor, wie er einen Fußmarsch von anderthalb Stunden auf sich nimmt, um Augenzeuge einer Witwenverbrennung zu werden („Ich glaubte, diese Feyerlichkeit nicht versäumen zu müssen...“( $\left.{ }^{(470}\right)$. Die Witwe, wie so oft in den Berichten eine junge Frau, sei sehr gefasst gewesen. Der Autor empfindet Mitleid mit ihr und nennt sie das ,unglückliche Opfer der ehelichen Zärtlichkeit“. ${ }^{471}$ Die Musikanten spielten „die fröhlichsten Lieder“. ${ }^{472}$ Die Witwe sei mutig an die Grube herangetreten und sah ihren toten Mann mit „den zärtlichsten Blicken an, schlug sich vor die Brust, und brach in laute Thränen aus““ ${ }^{473}$ Nachdem sie in „,völliger Ruhe“‘474 Abschied von den Verwandten genommen habe, sei sie „unverzagt ${ }^{\text {“475 }}$ in die brennende Grube gesprungen, woraufhin die anwesenden Frauen ein „gräßliches Freudengeschrey“476 erhoben hätten. Dieser Textausschnitt stilisiert die Witwe zu einer treuen Liebenden und mutigen Heldin. Durch die Beschreibungen der Musik und des Freudengeschreis meint man fast, eine Art Rausch zu spüren, der auch den Autor nicht unberührt gelassen hat. Er beschreibt das Ereignis tatsächlich wie eine „Feyerlichkeit“. Allein durch die Erwähnung von Mitleid und einem schmerzenden Eindruck deutet er etwas Kritik an.

Auch der Bericht von 1821 spricht von einer Feierlichkeit, allerdings wird hier dieser Ausdruck mit dem Attribut „schrecklichen“477 versehen. Auch bei dieser Beschreibung geht es vor allem um Sensationslust und die Mitteilung von etwas Unerhörtem. Aber im Vergleich zu der ersten Darstellung wird der empfundene Schrecken deutlicher, auch wenn das Grausame des Geschehens wohl auch zur Erregung des Lesepublikums so detailliert geschildert wird. Auch hier bittet die Witwe aus eigenem Entschluss die Obrigkeit um die Erlaubnis zur Selbstverbrennung. Sie ist aber zwischendurch so

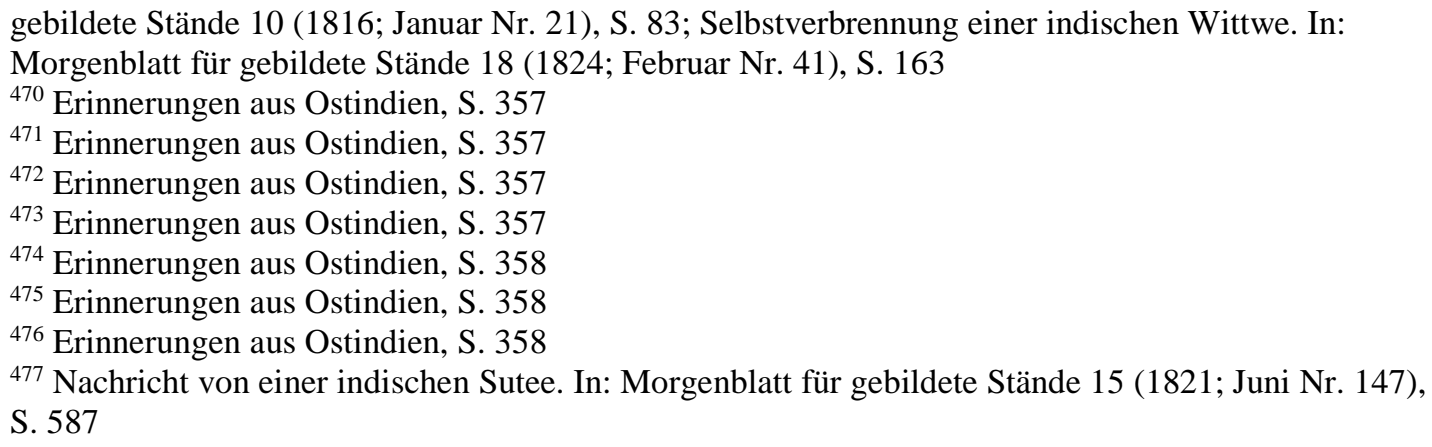


schwach, dass sie getragen werden muss. Wie in vielen Beschreibungen wird das Kind der Frau erwähnt. Es hat hier aber eine etwas andere Funktion als in vielen der anderen Texte. Wird es sonst von Anwesenden genutzt, um der Witwe ihren Entschluss auszureden, oder vom Autor erwähnt, um die Unnatürlichkeit und Grausamkeit dieser Tradition zu unterstreichen, so erfüllt hier der Sohn eine feste Rolle im Ablauf der Verbrennung, indem er der Tradition gemäß den Scheiterhaufen entzündet. Auch das dient dem Autor natürlich dazu, den Schrecken beim Publikum zu erhöhen, sei es, um Aufmerksamkeit $\mathrm{zu}$ erlangen oder diese Tradition $\mathrm{zu}$ kritisieren. ${ }^{478}$ Auch die Beschreibung ihres Todes ist deutlich ausführlicher als in vielen anderen Texten und spart nicht an grausamen Details:

\begin{abstract}
Als er sie niedergestellt, riß sie ein Stück von ihrem Kleide ab, und wickelte es um ihren ältesten Sohn, ein ungefähr achtjähriges Kind. Hierauf fielen ihr viele Männer und Weiber zu Füßen, und küssten diese. Das Schlachtopfer ermunterte die Weiber, im ähnlichen Falle ihrem Beyspiele zu folgen. Der Knabe warf nun eine angezündete Fackel in das Loch, aus welcher die Flamme prasselnd aufschlug. Die Wittwe gieng dreymal um dasselbe her [...], dann sprang sie schnell in dasselbe hinein und sezte sich neben die Leiche. Zu einem Augenblick umgaben sie die Flammen [...], und sie fuhr fort, mit den Händen zu klatschen, bis die Haut beynahe von ihrem Körper weggebrannt war. Endlich fielen ihre Hände und sie war bald todt; der Körper aber blieb in seiner aufrechten Stellung und hatte das Ansehen einer Bildsäule von Ebenholz mitten in den prasselnden Flammen. Das Volk jauchzte in einem fort, und sagte, eine solche entschlossene Sutee sey noch nie gesehen worden. [...] Ich stand nur drey Schritte vom Feuer. Die Unglückliche hatte das Gesicht gegen mich gewandt. Nie werde ich des gräßlichen Anblicks vergessen. Als ich sie zuerst sah, war etwas Wildes in ihrem Gesicht; nachher ward sie ruhig und gelassen; zulezt schwach, erschöpft und bewegt, als sie aber um den Scheiterhaufen herumging, war sie wieder zur vollkommensten Ruhe und Gelassenheit gelangt. ${ }^{479}$
\end{abstract}

In den meisten anderen Texten endet die Beschreibung der Verbrennung mit dem Sprung der Witwe in die Flammen. Hier aber wird ausgerechnet das eigentliche Verbrennen in aller Ausführlichkeit geschildert. Dennoch kritisiert der Text nicht direkt diese Tradition. Der Autor ist abgeschreckt, aber auch bei ihm ist eine Art Rausch zu spüren.

\footnotetext{
478 Ähnlich wie dieser Text stellt auch die kurze Notiz über das Begraben einer lebendigen Witwe von 1819 die Mitwirkung des eigenen Sohnes in den Mittelpunkt. Wohl auch aufgrund der Kürze fehlt hier der Darstellung selbst das Rauschhafte; sie beschreibt aber - deutlich ablehnend - den Rausch der Teilnehmer: „Der älteste neunzehnjährige Sohn dieser Frau warf die Erde handvollweis in das Grab. Als sie sich bis zur Höhe des Kopfes des unglücklichen Schlachtopfers anhäufte, stieß der fanatische Haufen, der diesem Schauspiel kaltblütig zusah, ein rasendes Freudengeschrey aus." (Lebendig begrabne Frau eines Hindu. In: Morgenblatt für gebildete Stände 13 (1819; Mai Nr. 121), S. 483)

${ }^{479}$ Nachricht von einer indischen Sutee, S. 587f.
} 
Auch in dem bereits erwähnten Artikel „Unglückliche Lage des weiblichen Geschlechts in Indien“ aus dem Morgenblatt von 1821 wird eine Witwenverbrennung geschildert und auch hier wird die Rolle des Sohnes bei der Verbrennung zur Steigerung der Kritik genau beschrieben. Anders als in dem eben besprochenen Beispiel fehlen hier der Witwe alle Merkmale der entschlossenen, mutigen Heldin, die selbst in das Feuer springt:

\begin{abstract}
Des Mittags, und unter dem Zulauf einer schaulustigen Menge, wird die Wittwe nach dem Todespfeiler gezogen; dort bindet man sie an den Leichnam ihres Lebensgefährten. Sie wird sodann auf den Scheiterhaufengehoben, und durch Reisbündel sogleich niedergedrückt; diese werden dann angezündet, und sowohl Musik als ein anhaltendes Freudengeschrey ertönt, so daß ihr letztes Todesgewimmer nicht gehört werden kann. Unter den Zuschauern befindet sich ihr Sohn, ihr Erstgeborener, der den Scheiterhaufen in Feuer setzt, und die Fortschritte der Flammen bewacht, die seine lebende Mutter in Asche verwandeln sollen. ${ }^{480}$
\end{abstract}

Der Sohn erscheint als kaltblütig, auch wenn er nicht direkt so bezeichnet wird. Es wird auch nicht direkt gesagt, dass die Frau gezwungen wird. Die Wortwahl („gezogen“, „Todesgewimmer“) weist aber deutlich darauf hin.

Noch drastischer in seiner Kritik ist der Artikel von 1827 über die in der Ostindischen Kompanie diskutierte Frage, ob die Witwenverbrennungen verboten werden sollten. Zunächst werden die genauen Opferzahlen und hinterlassenen Waisenkinder aufgezählt. Allein diese Zahlen von über 5000 Frauen und Kindern zwischen 1815 und 1823 sind abschreckend und sollen zeigen, dass es sich bei den Verbrennungen keineswegs um Einzelfälle handelt und dass sich nicht nur - wie vor allem in den frühen Texten oft behauptet - kinderlose Frauen verbrennen. Noch deutlicher wird die Verurteilung der Tradition als ein grausames Verbrechen, das abgeschafft werden müsse, durch die nun folgenden, sehr detailreichen Beschreibungen von Frauen und jungen Mädchen, die verzweifelt dem Scheiterhaufen zu entkommen suchen und von ihren Verwandten immer wieder mit Gewalt zurück in die Flammen geworfen werden. Diese Szenen, die beinahe an einen Horrorfilm erinnern, haben nichts mehr gemein mit den berauschenden Feierlichkeiten der erstgenannten Augenzeugenberichte. Auch sie sollen natürlich das Lesepublikum aufwühlen, aber sie dienen dabei wohl nicht in erster Linie der Unterhaltung, sondern sollen den dringenden Handlungsbedarf deutlich machen. Die Kritik richtet sich vor allem an die englische Regierung, die zu wenig

\footnotetext{
${ }^{480}$ Unglückliche Lage des weiblichen Geschlechts in Indien, S. 975f.
} 
unternehme. Die Strafen für Verwandte, die Witwen in den Tod zwingen, seien viel zu gering. Und das Argument, dass den europäischen Kaufleuten vielleicht Nachteile durch ein hartes Durchgreifen entstehen könnten, könne man nicht gelten lassen, da in anderen, weniger wichtigen Dingen durchaus eingegriffen worden sei. ${ }^{481}$ Interessanterweise widerspricht der Missionar Dubois dieser Forderung, da die Anzahl der Witwenverbrennungen gerade durch die Kritik an dieser Tradition und den Versuchen, sie zu unterbinden, gestiegen sei. ${ }^{482}$

Bei den Texten aus Cottas Morgenblatt ist auffällig, dass die späteren Texte das Thema Witwenverbrennung tendenziell kritischer beurteilen und darstellen als die früheren Texte. Um daraus eine allgemeine Tendenz abzuleiten, ist die Datenmenge zu klein. Eine Tendenz, die Witwenverbrennung gerade in den 1820er Jahren immer mehr zu verurteilen, würde allerdings zu der oben genannten Beobachtung passen, dass im Zuge der Neuausrichtung der Indienpolitik Englands die Beschreibungen der Inder sich in vielen Texten deutlich ins Negative gewandelt haben. ${ }^{483}$ Auch bezüglich der Frage, inwieweit gegen indische Traditionen vorgegangen werden sollte, die den Moralvorstellungen der Europäer widersprechen, ändert sich zu Beginn des 19. Jahrhunderts die Einstellung. Ist Ende des 18. Jahrhunderts die Politik der East India Company noch hauptsächlich auf Handelsgewinne und weniger auf Herrschaft ausgerichtet (der Generalgouverneur Wellesley (1798-1805) ist von Traditionalisten sogar an einem Verbot der Witwenverbrennung gehindert worden), so hat sich die öffentliche Meinung knapp 30 Jahre später so gewandelt, dass der nun amtierende Generalgouverneur Bentick ein Verbot 1829 durchsetzen kann. ${ }^{484}$

\subsubsection{Bajaderen}

Neben ihrer Rolle als Hausfrauen und Mütter sowie als Witwen finden indische Frauen vor allem als Tempeltänzerinnen - mit dem portugiesischen Begriff als Bajaderen

\footnotetext{
${ }^{481}$ Vgl. Verbrennung indischer Frauen. Aus dem englischen Missionsjournal. In: Morgenblatt für die gebildeten Stände 21 (1827; Oktober Nr. 243), S. 970-972

${ }^{482}$ Vgl. Dubois: Briefe über den Zustand des Christentums, S. 166

${ }^{483}$ Auch Antje Flüchter beschreibt einen Wandel im Bild der Witwenverbrennungen: Während in den frühneuzeitlichen Texten die Witwe in aller Regel als selbstständig handelndes Subjekt aus eigenem Willen in den Tod gegangen sei, häuften sich im 19. Jahrhundert im Zuge von Verbotsdiskussionen Berichte, in denen junge Witwen als Opfer inszeniert und von Europäern gerettet würden. Aus der selbstbestimmten Frau sei ein nicht vernunftbegabtes und nur aus einer Laune des Gefühls heraus handelndes Objekt geworden (Flüchter: Bajadere und Sati, S. 166).

${ }^{484}$ Vgl. Reinhard: Die Unterwerfung der Welt, S. 778
} 
bezeichnet - in den analysierten Texten Erwähnung. Ähnlich wie bei der Witwenverbrennung liegen hier bei den europäischen Beobachtern Faszination und Ablehnung eng beieinander. Die Bajaderen werden zunächst häufig als eine Art Huren beschrieben, die aber - und darin liegt das für die Europäer Befremdliche - in einem Tempel einem Gott dienen. ${ }^{485}$ Dieser anscheinende Widerspruch lässt sich aus europäisch-christlicher Sicht kaum erklären, es sei denn, man spricht der indischen Religion alles wirklich Religiöse und Tugendhafte ab oder wertet den Stand der Bajadere von einer Hure zu einer Tempeldienerin auf.

Den Weg der Abwertung der indischen Religion schlug bereits 1681 Dapper ein: Er beschrieb eine Prozession mit einem Götterbild und fügte an, dass in den Tempeln „Huren“486 seien, deren Beruf es sei, zweimal am Tag vor dem Bild zu tanzen. Mit ihrem Tanz sollen sie sich den Himmel verdienen. Interessanterweise stellte Dapper dann einerseits fest, dass diese Tänzerinnen nicht mit Christen oder Fremdlingen „buhlen“487 dürften, andererseits bezeichnet er sie als „unzüchtige Dirnen“ “488 und wundert sich, dass die Brahmanen sie in ihren als heilig geltenden Tempeln für die Götter tanzen ließen. Er spricht es zwar nicht direkt aus, aber implizit schwingt mit, dass das für einen heiligen Ort nicht ziemend sei.

Neben diesem sehr frühen Beispiel der deutlichen Abwertung der Bajaderen und mit ihnen der indischen religiösen Praxis findet sich bei Hegel eine spätere Version, die der ersten - sieht man von der philosophischen Begründung Hegels ab - recht ähnlich ist. Hegel geht von der Beschaffenheit des indischen philosophisch-religiösen Denkens aus und stellt fest, dass sich in der indischen Religion sowohl abstrakte Einheit als auch abstrakte sinnliche Besonderheit fänden, der ein ,gedoppelter Kultus“4889 entspreche:

Die eine Seite dieses Kultus besteh in der Abstraktion des reinen sich Aufhebens, in dem Vernichten des realen Selbstbewusstseyns, welche Negativität also in der stumpfen Bewusstlosigkeit einer Seits, anderer Seits in dem Selbstmorde, und dem Vernichten der Lebendigkeit durch

\footnotetext{
${ }^{485}$ Zunächst kamen die Europäer in Indien vor allem mit den im Lande umherreisenden Tanzgruppen in Kontakt. Die Tänzerinnen wurden zwar für ihr Können gelobt, aber schon früh wurden ihr Tanz auch als unmoralisch und anzüglich kritisiert. Diese ,sexuelle Komponente wurde im Übergang zur Moderne vor allem ein entscheidendes Element der Beschreibung der Tempeltänzerinnen, die im 17. Jahrhundert noch eher selten erwähnt wurden“ (Flüchter: Bajadere und Sati, S. 162)

${ }^{486}$ Dapper: Asia, S. 113

${ }^{487}$ Dapper: Asia, S. 114

488 Dapper: Asia, S. 114

${ }^{489}$ Hegel: Vorlesungen über die Philosophie der Geschichte, S. 165
} 
selbstauferlegte Qualen zu Erscheinung kommt. Die andere Seite des Kultus besteht in dem wilden Taumel der Ausschweifung, in der Selbstlosigkeit des Bewußtseyns durch Versenkung in die Natürlichkeit, mit der das Selbst sich auf diese Weise identisch setzt, indem es das Bewußtseyn des sich Unterscheidens von der Natürlichkeit aufhebt. In allen Pagoden werden daher Buhlerinnen und Tänzerinnen gehalten, welche die Brahmanen aufs Sorgfältigste im Tanzen, in den schönen Stellungen und Gebehrden unterrichten, und die um einen bestimmten Preis sich jedem Wollenden ergeben müssen. Von einer Lehre, von Beziehung der Religion auf Sittlichkeit kann hier im Entferntesten nicht mehr die Rede seyn. ${ }^{490}$

Hegel beschreibt zwei sehr gegensätzliche Seiten des indischen „Kultus“, die aber beide aus der Besonderheit der indischen Weltanschauung erwüchsen: die oben beschriebene Neigung zur Selbstabtötung sowie wilde Ausschweifungen. Auf letztere führt er die Existenz der Bajaderen zurück. Wie Dapper beschreibt er sie als eine Mischung aus „Buhlerinnen“ und „Tänzerinnen“, die sich - etwas anders als bei Dapper - gegen Geld jedem hingeben müssten. Wie diese Verbindung von Religion und Sexualität bei Dapper gegen die Heiligkeit steht, steht sie bei Hegel gegen die Sittlichkeit, die er daher der indischen Religion in diesem Fall abspricht.

Zeitlich zwischen diesen beiden deutlich ablehnenden Positionen steht eine Reihe von Darstellungen, die die Bajaderen deutlich differenzierter betrachten. Sie stehen der Einrichtung der Tänzerinnen zwar fast immer ebenfalls kritisch gegenüber, gestehen den einzelnen Frauen oft aber dennoch Sitte und Anstand zu oder betonen das Ansehen, das sie in der indischen Gesellschaft genießen.

Bei Paulinus a Sancto Bartholomaeo fehlen den Bajaderen zwar noch jegliche positive Aspekte, aber er betrachtet sie insofern differenzierter, indem er verschiedene Gruppen unterscheidet: Die Tempeldienerinnen reinigten den Tempel und trieben Unzucht mit Pilgern, während die Tänzerinnen in den Prozessionen für die Priester die Pilger ausforschten, so dass jene diesen anschließend weismachen könnten, die Gottheit hätte ihnen so viel über die Pilger offenbart. ${ }^{491}$

Auch Lazzaro Papi beschreibt die Aufgaben der Tänzerinnen überwiegend negativ, aber er macht auch deutlich, dass zumindest die Tempeltänzerinnen, die er als Devadasi bezeichnet, bereits als kleine Kinder von ihren Eltern aus unterschiedlichen Gründen in den Tempel gegeben würden und somit sich ihr Los nicht selbst ausgesucht hätten.

\footnotetext{
${ }^{490}$ Hegel: Vorlesungen über die Philosophie der Geschichte, S. 165

${ }^{491}$ Vgl. Des Fra Paolino da San Bartolomeo Reise nach Ostindien, S. 390
} 
Außerdem stünden sie trotz ihrer hauptsächlichen Aufgabe, den Brahmanen als Beischläferinnen zu Diensten zu sein, in der Bevölkerung in sehr hohem Ansehen, sowohl während ihrer Zeit im Tempel als auch danach. Denn diese sehe in ihnen „gottgeheiligte Jungfrauen“ ${ }^{492}$. Es sind vielmehr die Brahmanen, die in diesem Textausschnitt verurteilt werden, da diese die Mädchen von ihren Eltern für eben diese Zwecke forderten und auch nichts dagegen hätten, wenn sich die Einkünfte des Tempels dadurch erhöhen ließen, dass die Mädchen sich gegen Bezahlung auch anderen Männern hingeben. Auffallend am Bericht des italienischen Arztes ist die Ausführlichkeit und Art und Weise, mit der er die anmutigen Bewegungen, den Augenaufschlag, das reizendes Aussehen und die „ganze Zaubergewalt“ 493 der Tänzerinnen beschreibt. Das könnte natürlich dazu dienen, die Verwerflichkeit ihrer Tätigkeiten zu unterstreichen. Es drängt sich aber auch der Verdacht auf, dass der Reisende diesem Zauber wohl trotz seiner Abneigung selbst auch nicht ganz entgehen kann. Von den Tänzerinnen im Tempel unterscheidet der Autor Tänzerinnen, die ebenfalls bei Prozessionen tanzten, aber nicht an einen Tempel gebunden seien, sowie Tänzerinnen, die nicht bei religiösen Ereignissen, sondern weltlichen Festen auftreten und von den Portugiesen den Namen Bajaderen bekommen hätten. Obwohl diese Tänzerinnen in Indien nicht den gleichen Rang hätten wie die ersten beiden Gruppen, scheint der Autor von ihnen besonders fasziniert zu sein. Er betont, dass bei ihrem ganzen Auftreten, sowohl ihrem Tanze als auch ihrer Kleidung, der Anstand nicht verletzt werde. ${ }^{494}$

Sehr ähnlich ist auch die Beschreibung Ehrmanns. Auch er berichtet von den drei Klassen der Tänzerinnen, die fälschlicherweise Bajaderen genannt würden. Sie seien zwar

\footnotetext{
Buhlerinnen, und zwar sehr verführerische, ausgelernte Buhlerinnen, aber selbst unter der niedrigsten Classe derselben findet man das unverschämte, zurückstoßende, bis zum Ekel freche Betragen in Reden, Gebärden und Mienen der europäischen Lustdirnen nicht. Im Äußerlichen und vor Zeugen betragen sie sich so sittsam, wie die ehrbarsten Frauen. Doch thun sie unter vier Augen Alles, was sie ihrem Liebhaber gefällig machen kann; sie wissen ihn mit so vieler Zärtlichkeit zu behandeln und durch Schmeicheleien so sehr zu fesseln, daß es ihm ungemein schwer wird, sich wieder aus ihren Netzen loszuwickeln. Sie suchen auch nicht, wie die europäischen Buhlschwestern, ihre Liebhaber zu betrügen, zu bestehlen, auszuplündern,
}

\footnotetext{
${ }^{492}$ Briefe eines italienischen Reisenden, S. 358

${ }^{493}$ Briefe eines italienischen Reisenden, S. 357

${ }^{494}$ Vgl. Briefe eines italienischen Reisenden, S. 258-363
} 
und sie dann zu verlassen, wenn sie nichts mehr haben, um sich dann an Andere zu hängen. - Im Gegentheile beweisen sie eine außerordentliche Anhänglichkeit für ihre Liebhaber, sind mit einer mäßigen Belohnung zufrieden, und von der Unverbrüchlichkeit ihrer Treue hat man mehrere sehr schöne Proben. Man hat auch Beispiele, daß solche Tänzerinnen sich freiwillig mit der Leiche ihres verstorbenen Liebhabers haben verbrennen lassen! ${ }^{495}$

Auch Ehrmann beschreibt die Tänzerinnen als sehr verführerisch, aber er betont anders als Papi vor allem ihre Treue. In seiner Schilderung wirken sie eher wie Geliebte oder Lebensgefährtinnen ohne Trauschein und nicht so sehr wie Dirnen. Auf das Motiv der sich selbst mit dem verstorbenen Liebhaber verbrennenden Tänzerin werden wir bei der Untersuchung von Goethes „Der Gott und die Bajadere“ wieder zurückkommen.

Dubois vergleicht ebenso wie Ehrmann die indischen Tänzerinnen mit Europäerinnen, allerdings nicht mit Dirnen, sondern mit Schauspielerinnen. Die indischen Tänzerinnen seien nicht weniger anständig als diese und ihre Tänze nicht unanständiger als ein Walzer (den Dubois anscheinend aber nicht gutheißt). ${ }^{496}$

Best beschreibt die Tänzerinnen zunächst - anscheinend aus eigener Anschauung - in ihrer Funktion als Tempeldienerinnen, die bereits seit frühester Jugend zu Ehren der Götter tanzen. In seiner Darstellung legt er weniger das Augenmerk auf den (verführerischen) Tanz (wie Ehrmann oder Papi), sondern vielmehr auf den üppigen und teuren Schmuck. Anscheinend ist er sich jedoch nicht sicher, wie er die Mädchen einordnen soll. Denn nach dieser lediglich auf Tanz und Gottesdienst ausgerichteten Beschreibung fügt er an:

Zwar nur zum Dienst der Götter bestimmt, sind die Devadasis
demohngeachtet keine Vestalinnen, und gehören eigentlich unter die Klasse
der Freudenmädchen, deren sich, wie man sagt, die frommen Braminen und
reichen Indianer zu ihrem Vergnügen bedienen. 497

Dem eigenen Erleben als Tempeldienerinnen und Tänzerinnen steht also das Hörensagen als Freudenmädchen gegenüber.

Crawfurd und Forster setzen sich weniger mit Moral und Anstand auseinander, sondern betonen den gesellschaftlichen und sozialen Stand der Tänzerinnen. Sie stellen fest,

\footnotetext{
${ }^{495}$ Ehrmann: Neuste Kunde von Asien. Zweiter Band, S. $92 \mathrm{f}$.

${ }^{496}$ Vgl. Dubois: Briefe über den Zustand des Christentums, S. 164

${ }^{497}$ Best: Briefe über Ost-Indien, S. 43
} 
dass die Tänzerinnen eine eigene Gesellschaftsklasse oder Kaste bildeten und dass sie unter dem Schutz der Regierung stünden. Forster fügt hinzu, dass die Tänzerinnen anders als die meisten anderen Frauen - ein gewisses Maß an Bildung erlangten (z.B. lesen könnten). ${ }^{498}$

\subsection{Kolonialismus}

In der hier zu betrachtenden Zeit sind die Länder des deutschen Sprachraums noch nicht an der europäischen Kolonialpolitik beteiligt. Einen „Rechtfertigungszwang“499 für koloniale Eroberungen hat es also nicht gegeben. Die Aktivitäten anderer Länder wie England oder Frankreich werden aber durchaus verfolgt. Zudem sind deutschsprachige Autoren auch durch den internationalen Charakter des Wissensaustauschs innerhalb Europas in die Diskurse über Kolonialismus und Mission mit eingebunden. Die Frage, inwieweit deutschen Autoren in der Beurteilung des Kolonialismus eine andere Rolle zukommt als z.B. englischen Autoren ist in der Forschung allerdings umstritten. So geht z.B. Murti in Anlehnung an Said davon aus, dass die Menschen im deutschsprachigen Raum ebenso koloniale Phantasien hegten wie die Engländer (nur eben im Wettlauf um die Kolonien zu spät kommen) und daher ebenfalls Beiträge zur Rechtfertigung der Kolonien lieferten. ${ }^{500}$ Etwas vorsichtiger formuliert Amman: Die Deutschen identifizierten sich im Hinblick auf die Kolonisation durchaus mit der „gesamteuropäischen Sache“501, so dass sich auch hier kolonialistische Haltungen entwickeln konnten. Dagegen vertritt z.B. Lütt die Position, dass der Unterschied zu England gar nicht größer sein könne: auf der einen Seite das deutsche Indieninteresse, das von romantischer Verklärung geprägt sei, und auf der anderen Seite der Druck auf das britische Indienbild, die Unterdrückung der Inder in irgendeiner Weise zu rechtfertigen. ${ }^{502}$ Deutlich wird auf jeden Fall, dass sich deutschsprachige Autoren auch ohne eine entsprechende Politik ihrer Fürsten mit der kolonialen Eroberung Indiens auseinandersetzen. Wie die Wahrnehmung und Beurteilung der kolonialen Bestrebungen europäischer Mächte im Einzelnen aussieht, soll im Folgenden untersucht werden. Zunächst aber möchte ich noch einen kleinen Blick auf die Einstellungen der Engländer und der East India Company zum Umgang mit ihren

\footnotetext{
${ }^{498}$ Vgl. Die Sitten der Hindus, S. 83f.; Forster: Reise aus Bengalen, S. 59f.

${ }^{499}$ Lütt: Einleitung, S. 392

${ }^{500}$ Vgl. Murti: India, S. 5-7

${ }^{501}$ Ammann: Östliche Spiegel, S. 43

${ }^{502}$ Vgl. Lütt: Einleitung, S. 392
} 
indischen Besitzungen sowie auf diesbezügliche Diskurse in England und Frankreich werfen.

Aufgrund der großen Ausdehnung ihres Herrschaftsgebiets ist es besonders die britische Indienpolitik, die die Wahrnehmung der europäischen Herrschaft in Indien beeinflusst. Nicht nur hinsichtlich der Eroberungspolitik, die nun offensiver betrieben wird, erfährt die Herrschaft der Engländer in Indien um 1800 tiefgreifende Veränderungen. Der erste Generalgouverneur, Warren Hastings (1773-1785), hat noch die Absicht verfolgt, Indien in Anknüpfung an Traditionen der Mogulherrscher und der einheimischen Rechtsgewohnheiten zu regieren. Obwohl auch das aufgrund des oft unzureichenden Zugangs zu Originaltexten und der Festsetzung bestimmter Varianten und Interpretationen als allgemein rechtsgültig nicht immer gelang, führte es doch dazu, dass sich zumindest die gebildeten Engländer intensiver als bislang mit der indischen Kultur auseinandersetzten, indische Sprachen lernten und respektvollen gesellschaftlichen Umgang mit der (Moslem-)Oberschicht pflegten und zum Teil sogar einzelne Aspekte der indischen Kultur übernahmen. Dies ändert sich jedoch unter Hastings Nachfolgern. Bereits Cornwallis (1786-1793) steht den Indern skeptisch gegenüber und schließt sie von höheren Ämtern aus. Und Wellesley (1798-1805) führt den Kurswechsel auch auf politisch-militärischer Ebene fort, indem er eine stärker expansiv ausgerichtete Politik forciert. Bis zum Jahr 1819 müssen alle indischen Fürsten Subsidienverträge unterschreiben, die sie in direkte Abhängigkeit der Briten stellen. Obwohl die Verträge den Fürsten weiterhin eine interne Souveränität garantieren, greifen die Briten immer wieder auch in interne Angelegenheiten der Fürstentümer ein. Doch nicht nur das immer stärker ausgeprägte Gefühl der eigenen Überlegenheit führt zu gesellschaftlicher Distanzierung, sondern auch die Tatsache, dass die Anzahl der sich in Indien befindlichen Europäer mittlerweile stark angewachsen ist und eine eigene geschlossene Gesellschaftsschicht bildet, der auch immer mehr Frauen und ganze Familien angehören. Nach der anfänglich zumindest in einigen Schichten verbreiteten Faszination für die alte indische Kultur erfährt alles Indische zu Beginn des 19. Jahrhunderts sowohl bei den europäischen Bewohnern Indiens als auch in England selbst eine immer größere Ablehnung und Verachtung. Dazu tragen entscheidend die erstarkende religiöse Erweckungsbewegung, die mit dem Christentum den Indern auch die europäische Kultur bringen will, sowie die englischen säkularen Utilitaristen bei. James Mills „History of British India“ von 1817, in der die Inder als unzivilisiert dargestellt werden, da sie nicht das utilitaristische Streben nach 
Nutzen teilten, wird zur Pflichtlektüre der britischen Indienbeamten. Politisch zeigt sich das neue Denken z.B. in der konsequent auf Verwestlichung der indischen Sitten zielenden Kulturpolitik des 1828 eingesetzten neuen Generalgouverneurs Bentick. ${ }^{503}$ In der Mitte des Jahrhunderts ist dann ,die britische Verachtung für alles Indische zur Institution geworden“"504.

Es gibt aber auch einen antikolonialistischen Diskurs, der zunächst stark von den Revolutionen in Amerika (1776) und Haiti (1804) geprägt ist. Diese Ereignisse wurden von den Zeitgenossen nicht nur in England als einschneidende Ereignisse wahrgenommen, denn die Kolonialisierten forderten eigene Rechte ein und sagten sich von ihren europäischen Herrschern los. Intensive und auch kontroverse Debatten in Europa waren die Folge. Während sich der Diskurs in England vor allem an ökonomischen Gesichtspunkten orientierte, spielten in Frankreich stärker auch politische und humanitäre Aspekte eine Rolle. International besonders einflussreich waren die Ansichten Raynals, die dieser 1770 in seiner Geschichte der kolonialen Expansion vertrat: Nur unbewohnte Länder sollten von Eroberern in Besitz genommen werden dürfen und der Handel mit anderen Völkern solle auf der Basis von Gleichheit und Freiheit stattfinden. Andere Autoren betonten die Gleichheit oder zumindest die gleiche Entwicklungsfähigkeit aller Menschen. Dieser antikolonialistische Diskurs löste jedoch auch Gegenbewegungen aus. Während einige Autoren lediglich eine Reform des Kolonialwesens forderten, um weitere Abspaltungen von Kolonien zu verhindern, verteidigten andere die Kolonialpolitik explizit als legitim oder sogar notwendig, wobei sie auf die oben beschriebenen Rassentheorien zurïckgriffen oder aber europäische Eroberungen als notwendige Entwicklungshilfe für stagnierende Kulturen ansahen. ${ }^{505}$ Schon Buffon hatte zwar Sklaverei abgelehnt, den Kolonialismus aber pädagogisch-humanitär begründet. ${ }^{506}$ Die Aufklärung hatte zwar das Postulat aufgestellt, dass alle Menschen von ihren Anlagen her als gleich und damit auch gleichberechtigt anzusehen seien. Allerdings nutzten die verschiedenen Völker diese ihnen gegebenen Fähigkeiten, sich zu entwickeln und Wohlstand zu erlangen, in

\footnotetext{
${ }^{503}$ Vgl. Reinhard: Die Unterwerfung der Welt, S. 273f., 284-286, 632, 769f., 777f.; Förster: Die mächtigen Diener der East India Company, S. 123,132, 155, 157, 371

${ }^{504}$ Reinhard: Die Unterwerfung der Welt, S. 286

${ }^{505}$ Vgl. Lüsebrink, Hans-Jürgen: Kolonialismus. In: Thoma, Heinz (Hg.): Handbuch Europäische Aufklärung. Begriffe - Konzepte - Wirkung. Stuttgart u. Weimar 2015, S. 289-299, hier S. 290-295 506 Vgl. Lüsebrink: Kolonialismus, S. 205
} 
unterschiedlichem Maße. Daher vertreten viele Denker der Aufklärung die Ansicht, dass in dem Fall, wenn ein Volk nicht selbst die Möglichkeiten zur Entwicklung und Vermehrung seines Wohlstandes nutze, diese Aufgabe von anderen übernommen werden könne. ${ }^{507}$ Die Europäer erscheinen in diesem Diskurs nicht als Eroberer, sondern werden als eine Art Helfer und Erzieher der weniger entwickelten Völker umgedeutet. Auch hier lässt sich analog zu den Veränderungen in der englischen Indienpolitik mit Beginn des 19. Jahrhunderts ein Wandel feststellen. Während in der Epoche der Aufklärung die Herrschaft der Europäer über andere Teile der Welt keineswegs als selbstverständlich angesehen wurde, wird dieser ,selbst- und

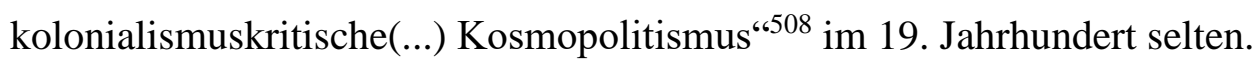

Auf die Kolonialpolitik - vor allem der Engländer - wird in verschiedenen Artikeln über Indien, in Reiseberichten sowie in Werken über die Geschichte der Handelskompanien eingegangen. Während ich in den übrigen Kapiteln nicht explizit zwischen Übersetzungen und Schriften deutschsprachiger Autoren unterschieden habe, da es mir um das im deutschen Sprachraum entstehende Gesamtbild von Indien geht, möchte ich hier beide Autorengruppen getrennt untersuchen, obwohl auch hier Übersetzungen von Werken z.B. englischer Reisender oder Militärs das deutsche Indienbild mitprägen. Das ist vor allem deshalb wichtig, da ansonsten kaum die oben aufgeworfene Frage nach einer möglichen Sonderrolle deutscher Beiträge zu dem Thema Kolonien untersucht werden könnte.

Auffällig ist, dass in den Texten, die sich konkret mit Indien beschäftigen, weder die englischen Autoren noch die aus anderen Ländern sich ausführlich mit der grundsätzlichen Frage beschäftigen, ob Kolonien und koloniale Eroberungen überhaupt moralisch vertretbar sind. Diese Frage mag in anderen thematischen oder zeitlichen Zusammenhängen durchaus diskutiert worden sein, in den hier untersuchten Texten aus der Zeit zwischen 1790 und 1830 ist es kaum der Fall. Vielmehr werden einzelne Unternehmungen der Europäer hinterfragt oder der Umgang der Eroberer mit den Indern beurteilt. Auch die deutschen Soldaten, die in englischem Auftrag in Indien

\footnotetext{
${ }^{507}$ Vgl. Meyer: Die Epoche der Aufklärung, S. 91

508 Osterhammel, Jürgen: Die Entzauberung Asiens. Europa und die asiatischen Reiche im 18. Jahrhundert. München 1998, S. 68
} 
stationiert sind, stellen die koloniale Situation nicht in Frage, sondern nehmen sie als gegeben hin. ${ }^{509}$

Zunächst möchte ich die in Form von Übersetzungen im deutschsprachigen Raum zugänglichen Texte englischer Autoren genauer ansehen. Wenig verwunderlich ist die Beobachtung, dass viele Autoren versuchen, das Vorgehen ihrer Landsleute positiv darzustellen oder zu rechtfertigen. Diese Rechtfertigungsversuche zeigen aber auch, dass es Kritik an der englischen Politik gegeben haben muss, auf die hier geantwortet wird.

Sehr deutlich zeigt sich dieser Rechtfertigungsdruck bei Major William Thorn ${ }^{510}$, der in einer Monographie den Krieg in Indien in den Jahren 1803 bis 1806 beschreibt. Immer wieder betont er, dass die Kritik an dem Vorgehen der Engländer ungerechtfertigt sei und den besonderen Bedingungen im Land nicht gerecht werde. So schreibt er z.B.:

\begin{abstract}
Es ist vieles über die angeblich in Hindoostan begangenen Ungerechtigkeiten gesagt, und die rednerische Erfindung ist nie geflissentlich mehr angestrengt worden, als in den Declamationen gegen die Eingriffe des europäischen Geizes und der Ehrsucht in diesem Lande. Allein der philanthropische Eifer ist zuweilen blind, und der parteiische immer ohne Mass; daher es dann kömmt, dass der Irrthum über die gute Absicht siegt und nicht allein ohne irgend eine vernünftige Ursache, sondern selbst gegen die offenbare Wahrheit und gegen das Interesse der Menschheit sein Geschrei erhebt. Von diesem Unrecht, das aus Vorurtheil entspringt, geben die brittischen Niederlassungen in Osten ein klägliches Beispiel, worüber man um so mehr erstaunen muss, da es der Mittel zu einer richtigen Belehrung sehr viele giebt, und die wohlthätigen, in ganz Indien geschehenen Veränderungen als eine Folge jener Verbindung allgemein eingestanden werden. Allein es scheint von denjenigen, welche geneigt sind, besondere Massregeln in abstracto zu verdammen, anstatt sie auf der allgemeinen Wagschale der Politik zu prüfen, entweder aus Unwissenheit, oder mit Vorsatz übersehen zu seyn, dass dieses Land nie unabhängig gewesen, wenigstens so weit, als die geschichtlichen Nachforschungen reichen. ${ }^{511}$
\end{abstract}

\footnotetext{
${ }^{509}$ Vgl. Tzoref-Ashkenazi: German Soldiers in India, S. 89

${ }^{510}$ William (zunächst Wilhelm) Thorn (1780-1843) wurde in der Nähe von Koblenz geboren, wo er auch seine Kindheit verbrachte. 1796 begann er durch Verbindungen zu Major George Gordon seine englische Militärlaufbahn, die ihn mit seinem Regiment nach Indien führte. Dort nahm er als Leutnant am zweiten Krieg gegen die Marathen (1803-1806) teil. Zwischen 1807 und 1810 war er Brigademajor in Mysore, bevor er anschließend zunächst nach Mauritius und dann nach Java ging. 1814 kehrte er nach Europa zurück und ließ sich in seinem Geburtsort nieder. Dort war er in der örtlichen Kirche aktiv. Außerdem veröffentlichte er mehrere Berichte über seine Zeit in Asien (vgl. Vetch, R.H.: Thorn, William [formerly Wilhelm]. In: Oxford Dictionary of National Biography [Online-Version]. URL: https://www.oxforddnb.com/search?q=thorn\%2C+william\&searchBtn=Search\&isQuickSearch=true). 511 Thorn, William: Der Krieg in Indien in den Jahren 1803 bis 1806, geführt von dem General Lord Lake, Oberfeldherrn, und dem General-Major Sir Arthur Wellesley, Herzog von Wellington. Gotha 1819, S.3f.
} 
Die Ungerechtigkeiten, über die so viel berichtet wird, seien nur ,angeblich“ geschehen. Der blinde Eifer der Menschenliebe verführe die Kritiker zu „rednerische(r) Erfindung“ und Irrtümern. Sie unterstellten den englischen Eroberern Geiz und Ehrsucht und übersähen, dass die Eingriffe der Engländer für Indien wohltätige Folgen gehabt hätten. Damit stellten sich die Kritiker gegen das „Interesse der Menschheit““. Hinzu komme, dass Indien nie unabhängig gewesen sei. Thorn argumentiert also in zwei Richtungen: Zum einen sei die Politik der Engländer für die Inder von Vorteil. Damit greift er auf den oben angesprochenen Diskurs über Chancengleichheit zurück, der die Eroberung als Hilfe für die unterentwickelten Völker zu legitimieren versucht. Zum anderen wären die Inder auch ohne das englische Eingreifen unfrei. Etwas später führt er noch ein drittes Argument an: Die Engländer handelten schlicht aus Not. In einem von Aufruhr und Umstürzen geprägten Land seien sie gezwungen, zur Verteidigung ihrer Handelsinteressen militärisch vorzugehen:

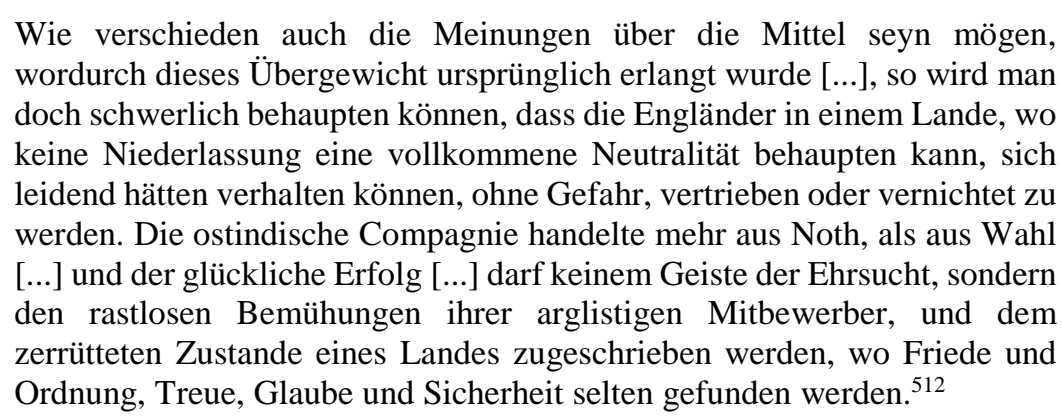

Neutralität sei für die englische Handelskompanie einfach keine Option. Dieser einseitig gefärbte Bericht über die Kriege in Indien wird im deutschsprachigen Gebiet allerdings nicht immer unreflektiert rezipiert. So schrieb ein Rezensent in der Jenaischen Allgemeinen Literatur-Zeitung:

Dass der Engländer in dem Vf. häufig ein wenig zu stark hervortritt, dass also manche Ereignisse gegen die Pflicht des Historiographen nur von einer Seite betrachtet sind - ist freylich mitunter für den Deutschen Leser, dem billigerweise keine andere Vorliebe beseelt, als die für's Recht, störend; indess bleibt immer noch des Schätzbaren so viel in diesem Werke, dass es die wärmste Anempfehlung verdient. ${ }^{513}$

\footnotetext{
512 Thorn: Der Krieg in Indien, S. 13; ähnlich äußert er sich z.B. auch auf S.15

${ }^{513}$ Rezension zu: Der Krieg in Indien. In: Jenaische Allgemeine Literatur-Zeitung 18 (1819), Band 1, Nr. 29, Sp. 226-229, hier Sp. 226
} 
Anders als der englische Verfasser ergriffen die deutschen Leser keinerlei Partei in den kriegerischen Auseinandersetzungen, sondern seien sich der geforderten Neutralität des Historikers bewusst und interessierten sich allein für das Recht.

Auch der Rezensent der englischen Ausgabe begegnet der Begeisterung Thorns für die englischen Heldentaten am Ende mit fast spöttischer Kritik, nachdem er zuvor dessen Ansicht dargestellt hat:

[Die Siege der Engländer] verbreiteten in allen friedlichen Staaten Indostans Freude und gaben der brittischen Herrschaft eine sichere Grundlage. (So der Vf.. Indessen kann diese Freude nicht gar gross gewesen seyn, denn, und das war ja so klar, dass es Jedermann begreifen konnte, die ganze glückliche und grosse Veränderung bestand ja nur im Wechsel des Unterdrückers!). ${ }^{514}$

Die Annahme der Engländer, ihre Verdrängung indischer Herrscher werde von den Indern mit Freude begrüßt, sei falsch, da auch die Engländer nur weitere Unterdrücker seien.

Das Argument, die Engländer handelten aus Notwehr ${ }^{515}$ und befreiten die Inder von den muslimischen Despoten findet sich in vielen Texten. Auch der Maler Hodges sieht die Schuld der Konflikte bei indischen Fürsten wie Hyder Ali, den er als schrecklichen Feind bezeichnet, vor dem sich auch die übrigen Inder fürchteten. Die Engländer erscheinen so als die Retter der von Despoten bedrohten Inder. ${ }^{516}$ Die englische Regierung betrage sich dabei „menschenliebend und großmüthig wie immer“517.

Es gibt aber auch in englischen Texten über die Politik der englischen Eroberer Kritik. Dem Angestellten der East India Company, George Forster, geht es in seinem Bericht weniger um die Frage, wie und mit welchem Recht die Engländer Herrscher weiter Teile Indiens geworden sind, sondern um ihr jetziges und zukünftiges Verhalten in ihrem Herrschaftsgebiet:

Die Engländer sollten sich nicht länger als Fremdlinge in einem Lande ansehen, worin sie im Grunde die Herren sind. Sie sollten also nicht sowohl schnelle und große Vortheile zu erlangen, als vielmehr die dauernde Wohlfahrt des Landes, und den Fleiß und Wohlstand der Unterthanen zu befördern suchen, ohne welche jene nicht bestehen kann. ${ }^{518}$

\footnotetext{
${ }^{514}$ Rezension von: Memoir of the War in India. In: Allgemeine Literatur Zeitung (1818), Band 3, Nr. 235, Sp. 182-184, hier Sp. 183f.

$515 \mathrm{Vgl}$. auch die in Kapitel II 7.1 beschriebene Inszenierung der Kriege als Verteidigungskriege, u.a. aufgrund des Verbots von Angriffskriegen.

${ }^{516}$ Vgl. Hodges: Reisen durch Ostindien, S. 11-15

${ }^{517}$ Hodges: Reisen durch Ostindien, S. 12f.

${ }^{518}$ Forster: Reise aus Bengalen, S. 30f.
} 
Er fordert nicht nur ein, sich wie ein Herrscher zu verhalten, der für das langfristige Wohlergehen der Untertanen zu sorgen hat, was impliziert, dass er dieses Verhalten nicht überall gewährleistet sieht, sondern äußert auch Kritik an einzelnen Unternehmungen der Engländer. So sei das „Betragen“ gegenüber den Marathen „eben so ungerecht, als unweise“ ${ }^{\text {5519 }}$ gewesen.

Im Gegensatz zu den eben betrachteten englischen Darstellungen äußern der französische Missionar Dubois und der Italiener Papi scharfe Kritik an den Europäern in Indien, wobei auch sie den europäischen Einfluss in Indien nicht grundsätzlich ablehnen. Dubois, dem es in erster Linie um den Zustand der Mission und des Christentums geht, macht die fehlenden Erfolge der Mission auch von dem unsittlichen Verhalten der Europäer abhängig:

Es ist, glaube ich, allgemein angenommen, daß die Invasionen und Eroberungen, welche die Europäer, getrieben vom Geize und einem unersättlichen Durste nach Herrschaft, in der alten und neuen Welt während der letzten drei oder vier Jahrhunderte zu machen nicht aufhörten, in den meisten Fällen sich mehr als ein Fluch, als wie ein Segen bewiesen und im Ganzen mehr Übel als Gutes hervorgebracht haben. Ohne von den Strömen Blutes zu reden, wodurch diese Eroberungen bewerkstelligt und die europäischen Besitzungen gegründet wurden, haben die Eindringenden unter vielen andern Übeln den Wilden berauschende, verderbliche Getränke zugeführt. ${ }^{520}$

In der langen Periode, während welcher ich in Indien lebte, habe ich Ortschaften besucht, welche von Europäern aus verschiedenen Nationen, von Engländern, Franzosen, Holländern, Dänen und Portugiesen bewohnt wurden. In keiner dieser Ortschaften habe ich irgend eine Veredelung oder Verbesserung in der Moral und der Religion der Eingebornen bemerken können. Einige Veränderungen, welche ich in dieser Hinsicht bemerkt habe, waren vielmehr Verschlechterungen. Wenn ihr Verkehr mit den Europäern eine Verwandlung bewirkte, so bestand diese darin, daß sie angereizt wurden, Alles das, was in ihren Gebräuchen gut war und sich rechtfertigen ließ, zu beseitigen und zu vernachlässigen, während sie alles Schlechte und Tadelhafte beibehielten. Niemand kann leugnen, daß die Hindus bis heute von den Europäern Nichts angenommen haben, außer ihre Laster und ihre Thorheiten. Sie sind zu allen Zeiten nur zu sehr geneigt gewesen, ihr schlechtes Beispiel nachzuahmen, während auf der andern Seite ihre Tugenden, der Geist der Liebe, der Liberalität, des Mitleidens und des Wohlwollens, welcher meisten Theils die Europäer charakterisirt, im Allgemeinen von den Hindus nicht eben bemerkt wurden. ${ }^{521}$

Dubois wirft den Europäern vor, den Indern nur „Laster und Thorheiten“ gebracht zu haben. Das, was in Indien zuvor gut war, sei abgeschafft worden, es sei aber nichts

\footnotetext{
${ }^{519}$ Forster: Reise aus Bengalen, S. 242

${ }^{520}$ Dubois: Briefe über den Zustand des Christentums, S. 109

${ }^{521}$ Dubois: Briefe über den Zustand des Christentums, S. 112f.
} 
Besseres an dessen Stelle getreten. Die Europäer seien aus Geiz und Herrschsucht nach Indien gekommen, nicht aus der - aus Dubois' Sicht anscheinend vertretbaren Motivation heraus, zur Besserung der Inder beizutragen. Doch obwohl Dubois die Laster der Europäer betont und - zwar nur im Nebensatz, dafür aber in drastischen Bildern - die von ihnen ausgeübte Gewalt erwähnt, so zeigt der letzte Satz, dass er doch die Europäer im Prinzip als sehr tugendvoll ansieht und den Hindus an ihrer Lage zumindest eine Mitschuld zuweist, da sie sich weigerten, die guten Charakterzüge der Europäer zu übernehmen. Dubois sieht die Europäer also durchaus als mögliche Lehrer der Inder, sieht aber in den aus falscher Motivation heraus begonnenen Invasionen das falsche Mittel dazu.

Auch Papi betont, obwohl er an Seite der Engländer gegen Tipu Saib kämpfte, die wenig vorbildhaften Eigenschaften und Handlungen der Europäer in Indien: Die Nachkommen der portugiesischen „Helden“ sind tief von ihrer „ehemaligen Höhe“ gesunken und „nähren sich größtentheils vom Rauben und Stehlen. Überhaupt ist hier ein Zusammenfluß von allerlei lüderlichem Gesindel, von Leuten, die des Landes verwiesen sind, von Spitzbuben, Mördern und Verbrechern jeder Art. " ${ }^{522}$ Auch die Holländer und Franzosen befänden sich aufgrund ihrer „Schlechtigkeiten“ und ihrer „lüderlichen Lebensart“ in den „erbärmlichsten Umständen“; denn „weder sie, noch die Indier haben Gelegenheit, etwas durch den Handel zu verdienen: die Industrie nützt zu Nichts; die Engländer monopolisiren Alles, ziehen Alles an sich, und wer kein Engländer ist, muß bei den gegenwärtigen Zeitläufen unvermeidlich zu Grunde gehen." ${ }^{\text {523 }}$ Während also die Engländer durch ihr Monopol alle Handelseinkünfte an sich rissen und den übrigen derartige Möglichkeiten versagten, überließen sich die übrigen Europäern ihren Lastern. Die Engländer erhielten viel Geld aus Indien und spielten mit den indischen Fürsten, denen sie einen Hauch von Macht vorgaukelten. ${ }^{524}$ Sie bezahlten die Fürsten, damit diese ,sich auf die schändlichste Weise dazu gebrauchen [lassen], die Bewohner derjenigen Districte, die ihrer Aufsicht anvertraut sind, auf die unbarmherzigste Weise zu peinigen, der Raubgier behülflich zu seyn, und

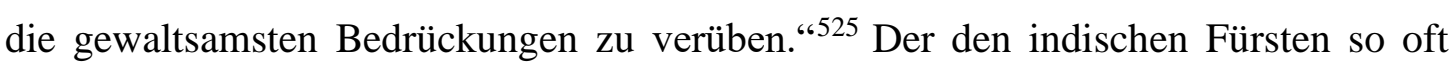
vorgeworfene Despotismus sei also auch ein Werk der Engländer, die ihre eigene

\footnotetext{
522 Briefe eines italienischen Reisenden, S. 518f.

${ }^{523}$ Briefe eines italienischen Reisenden, S. 520

${ }^{524} \mathrm{Vgl}$. Briefe eines italienischen Reisenden, S. 522-525

${ }^{525}$ Briefe eines italienischen Reisenden, S. 529
} 
Habsucht und Herrschsucht hinter den Bedrückungen der indischen Fürsten verbargen. Dabei frönten sie selbst ebenfalls wie die übrigen Europäern Lastern wie Trunksucht oder Völlerei. Das Geld, das die Engländer aufgrund ihrer Macht aus Indien erhielten, werde aus dem indischen Wirtschaftskreislauf abgezogen und käme so Indien nicht wieder zu Gute. Denn ihre Luxusgüter, die sie von diesem Geld kauften, würden aus England eingeführt und stärkten daher die englische Wirtschaft. ${ }^{526}$ Auch hier werden also nicht in erster Linie die kolonialen Eroberungen als solche kritisiert (die Portugiesen der Anfangszeit werden als Helden bezeichnet), sondern das konkrete Verhalten der Europäer. Das betrifft sowohl die einzelnen Individuen (Laster) als auch die Herrschaft der Engländer (Ausbeutung und Unterdrückung).

Unter den Texten der deutschsprachigen Autoren gibt es, wie die oben genannten Rezensionen bereits andeuten, viele kritische Beurteilungen. Doch auch diese richten sich oftmals weniger gegen das System des Kolonialismus als solches, sondern vor allem gegen das konkrete Verhalten der Engländer vor Ort. ${ }^{527}$ Schon 1783 und 1788 hatte Georg Forster in Rezensionen die Rücksichtslosigkeit und Habsucht der Bediensteten der East India Company kritisiert und der englischen Regierung vorgeworfen, in Indien nicht die Werte der Humanität aufrecht zu erhalten. Damit verhielten sich die Briten in Indien wie barbarische Despoten. Die durch äußere Umstände momentane Überlegenheit der Europäer verpflichte zu hoher Moral und dürfe nicht als Rechtfertigung für koloniale Eroberungen dienen. ${ }^{528}$ Auch Herder hatte sich gegen die Ausbeutung Indiens und die gewaltsame Unterdrückung der Inder ausgesprochen. ${ }^{529}$

Die allgemeine Verbreitung und Anerkennung kritischer Positionen gegenüber der englischen Politik zeigt sich auch in den Lexikonartikeln. Auffallend ist allerdings, dass sich die Sorge der Verfasser hier weniger auf die Freiheit der Inder und moralische

\footnotetext{
${ }^{526}$ Briefe eines italienischen Reisenden, S. 537-539, 542f.

${ }^{527}$ Einer, der sich kritisch gegen Unterdrückung allgemein äußert, ist Klaußner. Er schreibt: ,[...] diese sonst so edlen Britten, die in England so enthusiastisch für Volksfreyheit fechten, scheinen in Indien es ganz vergessen zu haben, daß auch seine Eingebohrnen von Gott und Rechtswegen frey seyn sollten, daß kein Land durch Sclaven blühen wird.“ (Klaußner: Die Hindus, S. 526)

${ }^{528}$ Vgl. Dharampal-Frick: Castigating Company Raj. Georg Forster and Matthias Sprengel on British colonialism (1781-1802). In: Beck, Thomas: Barrieren und Zugänge. Die Geschichte der europäischen Expansion. Festschrift für Eberhard Schmitt zum 65. Geburtstag. Wiesbaden 2004, S. 195-207, hier S. 198-202

${ }^{529}$ Vgl. Frank: Sanftes Gefühl und stille Tiefe der Seele, S. 144; Otto: Bekehrung der Indier, S. 450
} 
Fragen bezieht, wie bei Forster und Herder, sondern (wie in dem englischen Diskurs verbreitet) eher ökonomischer Natur ist. In dem Artikel von 1809 wird in einer Fußnote davor gewarnt, die

\begin{abstract}
Englische-Ostindische Compagnie bloß nach ihrer glänzenden Außenseite zu beurtheilen; denn ihre Administratoren brachten sie von Zeit zu Zeit, besonders seit der zweiten Hälfte dieses Jahrhunderts, durch schlechte Finanzplane, ungeheure Verschwendung, Bedrückung, Kriege, verursachte Theuerungen u.s.w. sehr herunter: sie saugten die schönsten Provinzen aus, überhäuften die Compagnie mit einer bisweilen das Capital übersteigenden Schuldenlast. ${ }^{530}$
\end{abstract}

Während es in dem Lexikonartikel von 1809 vor allem um die durch Verschwendung und Kriege verursachten Schulden der East India Company geht, steht 1815 die finanzielle Ausblutung Indiens im Mittelpunkt:

\begin{abstract}
Inzwischen haben Hungersnoth [...], Bedrückungen von Seiten der Compagniebedienten, stete Kriege und schreckliche Revolutionen im Innern des Landes, die Bevölkerung und die Masse des baaren Vermögens der Einwohner beträchtlich verringert. Souverains und Indische Privatpersonen haben große Summen verscharrt, die Engländer vielleicht noch größere nach China und Europa geschleppt. Das Erpressungs- und Betrugssystem der Englischen Compagniebedienten würde allen Glauben übersteigen, wenn es nicht durch unläugbare Thatsachen erhärtet wäre. Es sind alljährlich etwa 60 Engländer, die eine Masse von 50 Millionen Franken aus dem Lande schleppen, um daheim an der Themse gleich Indischen Nabobs zu schwelgen. ${ }^{531}$
\end{abstract}

Die Engländer hätten ein System von Bedrückungen, Erpressung und Betrug eingerichtet, das es ermögliche, dass nur wenige Menschen riesige Summen Geldes außer Landes brachten.

Auch Büsching ${ }^{532}$ betont in seiner Erdbeschreibung von Ostindien die Habsucht der Engländer. Was seine Beschreibung von vielen anderen unterscheidet ist sein Versuch, eine wirkliche Geschichte Indiens $\mathrm{zu}$ schreiben und nicht eine Geschichte der europäischen Eroberungen Indiens. Dennoch geht auch er natürlich auf die Herrschaft der Engländer ein. In seinen Beschreibungen der Ränke, Verschwörungen und Kriege

\footnotetext{
${ }^{530}$ Conversations-Lexikon. 1809, S. 328 (Fußnote)

${ }^{531}$ Conversations-Lexicon. 1815, S. 720

532 Der Theologe Anton Friedrich Büsching (1724-1793) reiste als Begleiter eines dänischen Gesandten nach Petersburg. Diese Reise veranlasste ihn dazu, nach seiner Rückkehr eine Erdbeschreibung zu verfassen, die später von Sprengel, Wahl und Hartmann fortgesetzt wurde (vgl. Michel, Wilhelm, "Büsching, Anton Friedrich" in: Neue Deutsche Biographie 3 (1957), S. 3 f. [Online-Version]; URL: https://www.deutsche-biographie.de/pnd1 19003554.html\#ndbcontent)
} 
werden die Handlungen der englischen Kompanie und der indischen Fürsten sehr ähnlich beschrieben. Sie nehmen sich nicht viel in ihren Versuchen, ihre Macht zu vergrößern. Er beschreibt Grausamkeiten indischer Fürsten, spricht aber auch von „übermüthig gewordenen“533 Engländern. Die Engländer beteiligten sich indirekt an den Grausamkeiten der indischen Herrscher, indem sie an deren Kämpfen teilnehmen. ${ }^{534}$ Ein wichtiger Antrieb der Engländer sei die Gier nach Reichtümern:

Die Londoner Directoren, welche sich von den bengalischen Siegen und den erlangten Reichthümern goldne Berge versprachen, [...] verlangten von ihren Beamten in Calcutta nicht nur das von Frankreich bedrängte Madras mit Baarschaften zu versehen, sondern auch die vergrößerten Einkünfte in Retourwaren anzulegen. Aber die großen Summen, womit Mir Jassier die Nabobswürde erkauft hatte, waren zu den bengalischen Kriegen verwandt, oder ihren Civil- und Militairbeamten zugefallen. Da diese damals mit reichen Schätzen nach Europa zurückgekehrt waren, und die Forderungen der Directoren nicht erfüllt werden konnten, so glaubten ihre Beamten, in Calcutta durch eine Revolution oder abermaligen Verkauf der Nabobswürde an den Meistbietenden sowohl die Einkünfte der Gesellschaft als ihre eigenen verbessern zu müssen. ${ }^{535}$

Die ostindische Gesellschaft war durch die Habsucht ihrer Beamten in kostbare, oft ganz unnöthige Kriege verwickelt worden, die ihr in der Ferne freilich Vortheile zeigten, die sie aber erst in künftigen Zeiten erwarten konnte, wenn die dabei bezielten Entwürfe glücklich ausgeführt wurden. ${ }^{536}$

Die Mitarbeiter der Kompanie ergriffen sehr fragwürdige Maßnahmen wie den Verkauf der Nabobswürde sowie Kriege, um sich zu bereichern. Das Interesse gilt hier allerdings nicht den ausgebeuteten Indern. Büsching beklagt vielmehr, dass sich die Mitarbeiter der Kompanie bereicherten, während die Aktionäre aufgrund der Schulden der Handelsgesellschaft nicht mehr, sondern weniger Dividende erhielten. ${ }^{537}$ Auch er stellt also vor allem ökonomische Aspekte in den Vordergrund.

Es gibt aber auch Stimmen, die ihr Augenmerk auf das Elend der Inder richten. So betont Remer ${ }^{538}$, dass Kriege und Habsucht der Engländer Indien zu Grunde richteten:

\footnotetext{
${ }^{533}$ Büsching, D. Anton Friedrich: Erdbeschreibung. Fünften Theils. Zweite Abtheilung, Asien, nemlich Hindostan und Dekan. Ausgearbeitet von Matthias Christian Sprengel. Hamburg 1802, S. 409

${ }^{534}$ Vgl. Büsching: Erdbeschreibung, S. 440

${ }^{535}$ Büsching: Erdbeschreibung, S. $415 f$.

${ }^{536}$ Büsching: Erdbeschreibung, S. 431

${ }^{537}$ Vgl. Büsching: Erdbeschreibung, S. 431f.

538 Julius August Remer (1738-1803) lehrte ab 1763 zunächst am Collegium Carolinum in Braunschweig und später in Helmstedt Geschichte (vgl. Zimmermann, Paul, "Remer, Julius August" in: Allgemeine Deutsche Biographie 28 (1889), S. 198 [Online-Version]; URL: https://www.deutschebiographie.de/pnd116436123.html\#adbcontent).
} 
Diese innern Kriege, weit mehr aber die keine Gränzen kennende, und mit der empörendsten Gewaltthätigkeit und Grausamkeit verbundene Habsucht der Beamten der Kompagnie, die bei den lauten Klagen darüber stets unbestraft blieb, sogen das Land so aus, daß seine Einwohner vor Druck und Elend hinstarben ${ }^{539}$

Wie viele andere auch macht Remer vor allem die Beamten der Kompanie für die Missstände verantwortlich, nicht die englische Regierung.

Ähnlich äußert sich auch Ehrmann. Der britische Kaufmannsstaat sei eine aristokratische Despotie, die nach ,ächt orientalisch-despotischen Grundsätzen von der Englisch-Ostindischen Handelsgesellschaft durch ihre habsüchtigen und stolzen Ober-

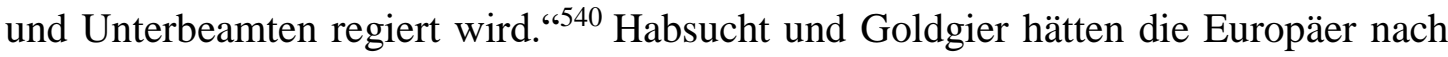
Indien getrieben. Sie überschwemmten Indien wie „ein Schwarm von Heuschrecken“ und brachten „Elend, Tod und Verderben“. 541

Die Europäer ließen sich bald auch auf den Küsten Indiens nieder, wo sie sich zum Nachtheile der Hinduer einnisteten und vermittelst der festen Plätze, die sie erbauten, die Dauer ihrer Niederlassungen wenigstens gegen die Eingebornen immer mehr sicherten. - Von da aus fraßen sie wie der Krebs immer weiter um sich, mischten sich in die Angelegenheiten der Landesfürsten, benutzten ihre Schwäche und Zwietracht, oder hetzten sie auch wohl gegen einander auf, brachten auf diese Weise außerordentliches Unglück über das schöne Land, und fischten dabei im Trüben, so daß sie ein Land nach dem andern an sich zogen [...]. ${ }^{542}$

Mit Begriffen wie Heuschrecken und Krebs wählt Ehrmann eine deutliche Bildsprache. Die Europäer fielen in ihrer Gier über die Inder her und brächten Unglück in das Land.

Beschreibt Ehrmann die Europäer in drastischen Bildern, so unterstreicht ein Artikel im Morgenblatt für gebildete Stände das tragische Schicksal der Inder:

Thränenvoll wendet sich das Auge des Betrachtenden auf die neuste Geschichte des unglücklichen Volks. Frömmigkeit, Fleiß, Sitte sind noch einheimisch bey ihm, und würden das Herz zu guter Hoffnung ermuntern, wenn nicht der unselige Handelsgeist der Britten und die übermüthige Schwelgerey der Gouverneurs, deren Willkühr sie das Land überlassen, jeden erwachenden Pulsschlag neuer Lebensregung erstickten, und alles mit eisernem Zepter zu Boden drückten! ${ }^{543}$

\footnotetext{
${ }^{539}$ Remer, Julius August: Handbuch der neuern Geschichte von der Kirchenverbesserung bis auf den Aachener Kongreß im Jahre 1818. Zweiter Band. Fünfte verbesserte und vermehrte Auflage vom Professor Saalfeld in Göttingen. Braunchschweig 1824, S. 220

${ }^{540}$ Ehrmann: Neuste Kunde von Asien. Erster Band, S. 34

${ }^{541}$ Ehrmann: Neueste Kunde von Asien. Zweiter Band, S. 11

${ }^{542}$ Ehrmann: Neuste Kunde von Asien. Zweiter Band, S. 11

${ }^{543}$ Das alte Indien. In: Morgenblatt für gebildete Stände. 1 (1807; Dezember, Nr. 305), S. 1217f., hier

S. 1218
} 
Den habsüchtigen Engländern werden hier die frommen und fleißigen Inder gegenübergestellt, die durch die Willkürherrschaft jener aber keine Möglichkeit zur Entfaltung eigener Tätigkeiten mehr bekämen.

Auch Paulinus a Sancto Bartholomaeo stellt in seinem Reisebericht die moralisch hochstehenden Hindus den lasterhaften Europäern gegenüber, die bei einem Angriff ein Kloster der Kapuziner getroffen hatten: „Diese Herren Engländer mochten wohl noch nicht in den Grundsätzen der heidnischen Indier unterrichtet seyn, die es für eine der unverzeihbarsten Sünden halten, die Tempel und Gotteshäuser zu verheeren. “544 Die Inder könnten über die Engländer und ihr Verhalten, mit dem sie ihre Kolonie zu Grunde richteten, nur staunen:

Geiz, Übermuth, Treuelosigkeit, Unglaube und Ungerechtigkeit richten allerdings ganze Reiche und Städte zu Grunde. Dieser Erfahrung zufolge, möchten einige andere Kolonieen in Indien wohl ebenfalls nicht lange in den Händen der Europäer bleiben. Schon haben dort der Alleinhandel, die Zwietracht, und die Veruntreuung fremder Gelder gar sehr überhand genommen, und die Indier können über die Schlechtigkeiten, welche sie täglich von den Europäern sehen, nicht genug erstaunen. ${ }^{545}$

Auch Paulinus a Sancto Bartholomaeo wendet sich nicht aus Prinzip gegen den Kolonialismus als solchen, sondern kritisiert Geiz und Habsucht der Engländer. Wie er $\mathrm{zu}$ Kolonialherren stehen würde, die eine höhere Moral aufwiesen und sich wie verantwortungsvolle Landesväter um Land und Bevölkerung kümmerten, wird nicht deutlich.

Auch Heeren, der ansonsten eher sachlich und wenig urteilend berichtet, erlaubt sich Kritik an der englischen Politik in Indien. Und auch er richtet sich gegen das konkrete Verhalten vor Ort. Die Engländer hätten in Indien ein schlechtes und nicht auf die Bedürfnisse und Besonderheiten des Landes eingehendes Herrschaftssystem errichtet, das Indien Leid bringe: „So kam in dem unglücklichen Bengalen Alles zusammen, was ein Volk zu Grunde richten kann: eine eben so verkehrte als tyrannische Administration, und die drückendsten Monopole. “546 Heeren prangert vor allem die

\footnotetext{
${ }^{544}$ Fra Paolino: Reise nach Ostindien, S. 8

${ }^{545}$ Fra Paolino: Reise nach Ostindien, S. 135

${ }^{546}$ Heeren, Arnold H. L.: Geschichte des Europäischen Staatensystems und seiner Kolonien. Göttingen 1809, S. 478
} 
Veränderungen der Regeln für die in Indien wichtige Erbpacht, die schlechte Justiz, die Anwendung britischer Gesetze, das Monopol der Regierung auf einige Handelsgüter sowie eine schlechte Geldwirtschaft an. ${ }^{547}$ Eine solche gewaltsam durchgesetzte Herrschaft könne „keinen andern als stets schwankenden Zustand zur Folge haben.“548 Auch die Neuorganisation der englischen Herrschaft brachte „für die Abhängigkeit von dem Mutterlande etwas, für Indien wenig, mehr für die Compagnie““.549 Heeren stellt fest:

\begin{abstract}
Aber dauernder Friede konnte in Indien nicht werden; und daher nie ein sicherer Etat. Es war der gewöhnliche Kreislauf der Eroberer. Die Bedrückungen erzeugten Widerstand, dieser Kriege, die Kriege Kosten, die Kosten neue Bedrückungen. [...] Um zu bestehen, ward endlich das Erobern Bedürfniß.550
\end{abstract}

Er gibt zwar der in England oft vertretenen Ansicht damit insofern Recht, als das weitere Eroberungen ab einem gewissen Zeitpunkt eine Art Selbstschutz gewesen seien. Aber er weist auch deutlich darauf hin, dass es allein der rücksichtslose Umgang der Engländer mit ihren neuen Untertanen gewesen sei, der sie in diese Situation gebracht habe.

Der Autor eines Artikels in der Zeitschrift „Minerva“ zitiert aus Flassons Werk „Histoire générale et raissonée de la diplomatie française“:

\begin{abstract}
Indien macht für sich allein ein abgesondertes festes Land aus, das vermöge seiner Größe und der verschiedenen Mächte, die es enthält, ein vollständiges politisches und Handelssystem haben und eines Tages für sich eine sehr wichtige Rolle spielen kann. Allein es muß, durch die Lehern (sic) und die Künste seiner Sieger gestärkt, so glücklich seyn, sie aus seiner Mitte zu verjagen. [...] Länder, die Männer wie Aurengzeb, Sevagi, Hyder-Ali und Tippu-Saib hervorbringen, sind von der Natur nicht bestimmt, auf immer Ketten zu tragen. Früh oder spät werden sie andere eben so kraftvolle Männer hervorbringen, die sich der Befreiung ihres Vaterlandes weihen werden.
\end{abstract}

Der Autor kritisiert zudem, dass die Europäer der Meinung seien, „Ostindien müsse nicht nach den nämlichen Grundsätzen behandelt werden, wie die europäischen

\footnotetext{
${ }^{547}$ Vgl. Heeren: Geschichte des Europäischen Staatensystems, S. 478

${ }^{548}$ Heeren: Geschichte des Europäischen Staatensystems, S. 479

${ }^{549}$ Heeren: Geschichte des Europäischen Staatensystems, S. 480

${ }^{550}$ Heeren: Geschichte des Europäischen Staatensystems, S. 481

${ }^{551}$ Frankreichs ehemalige Macht in Ostindien. In: Minerva. Ein Journal historischen und politischen Inhalts 87 (1813), S. 297-311, hier S. 310f.
} 
Staaten“ und sie daher ,,an die Stelle des Völkerrechts“ „eine gehäßige Willkühr gegen die indischen Fürsten“552 setzten.

Auch Danz ${ }^{553}$ kritisiert die Engländer:

Die Engländer, die sich in Kalkutta aufhalten, sind meistens Parvenus, die fast alle die Rohheit, die stupide Ernsthaftigkeit und den unverschämten Stolz besitzen, die allen dergleichen Leuten bei allen Völkern eigenthümlich sind. Jeder dieser Menschen hält die Compagnie für die Gebieterin des ganzen Erdbodens, und sich selbst für die Compagnie. ${ }^{554}$

Die Kritik richtet sich nicht gegen alle Engländer, sondern gegen diejenigen, die sich in Indien aufhalten und sich als Herrscher der Welt betrachteten. Anders als die bisher betrachteten Autoren geht es Danz nicht um eine möglichst neutrale Darstellung, sondern er ergreift in dem auch in Indien ausgetragenen Konflikt zwischen England und Frankreich ${ }^{555}$ Partei für letzteres. Die Kritik an England ist also nicht durch Mitgefühl mit den Indern motiviert, sondern soll das Anliegen der Franzosen stützen. Die Inder hält er für sanft und geduldig, aber für zu schwach und gleichgültig, um sich den Eroberern eigenmächtig zu widersetzen. ${ }^{556}$ Die Franzosen sollten sich mit einigen indischen Fürsten verbünden, die aus Ehrgeiz und Habsucht sowie dem Wunsch, die Engländer aus Indien zu vertreiben, darauf eingehen würden. Anschließend müssten die Franzosen allerdings aufpassen, dass sich ihre Verbündeten nicht gegen sie wendeten, da deren Ziel die Vertreibung aller europäischen Mächte aus Asien sei. ${ }^{557}$ Danz ist sich also im Klaren darüber, dass die Inder die Europäer in Indien nicht willkommen heißen, egal aus welchem europäischen Land sie kommen. Das aber scheint ihn nicht zu stören, er betrachtet das Geschehen aus europäisch-französischem Blickwinkel.

\footnotetext{
${ }^{552}$ Frankreichs ehemalige Macht in Ostindien, S.310

553 Johann Traugott Leberecht Danz (1769-1851) war zunächst Gymnasiallehrer in Weimar, später dann Professor der Theologie (vgl. Frank, G., "Danz, Johann Traugott Leberecht" in: Allgemeine Deutsche Biographie 4 (1876), S. 752 [Online-Version]; URL: https://www.deutschebiographie.de/pnd116025913.html\#adbcontent).

${ }^{554}$ Danz, Johann Traugott Leberecht: Der Marsch der Franzosen nach Indien. Notizen zu Beurtheilung der neuprojectirten Landexpedition. Jena 1808, S. 36f.

555 Versuche, in dem aus dem Österreichischen Erbfolgekrieg (1740-1748) entstandenen Konflikt zwischen Frankreich und Großbritannien ,in Indien Neutralität zu bewahren, scheiterte im Jahre 1744 und damit begann ein jahrzehntelanger Kampf zwischen beiden Seiten auf dem Subkontinent“ (Förster: Die mächtigen Diener der East India Company, S. 55).

556 Vgl. Danz: Der Marsch der Franzosen nach Indien, S. 15

${ }^{557}$ Vgl. Danz: Der Marsch der Franzosen nach Indien, S. 68f.
} 
Doch nicht alle deutschsprachigen Autoren lehnen die englischen Eroberungen ab oder kritisieren sie zumindest in einigen Bereichen. So zeigen die Brüder Schlegel größtenteils Verständnis für die englische Position. Friedrich Schlegel vertritt in seinen 1812 gehaltenen Vorlesungen zur Geschichte der alten und neuen Literatur eine sehr ähnliche Auffassung wie Hastings und viele Angestellte der East India Company zur Zeit Hastings: ${ }^{558}$

Die Herrschaft der Engländer in Indien beruht allein darauf, daß sie die Indier ganz nach ihren Gebräuchen, Sitten, und einheimischen Gesetzen beherrschen. Dadurch sind sie, was auch Einzelne für Bedrückungen sich erlaubt haben mögen, im Ganze die Wohlthäter der Indier geworden, indem sie dieselben von den Verfolgungen der unduldsamen Mohamedaner befreiten. ${ }^{559}$

Schlegel sieht zwar durchaus, dass die Herrschaft der Engländer „Bedrückungen“ mit sich bringt, aber das betreffe Einzelne. Für Schlegel ist hier aber das „Ganze“ von größerer Bedeutung. Und da beurteilt er die Briten als „Wohlthäter der Indier“, da die Unterdrückung durch die vormaligen Herrscher schlimmer gewesen sei. Wichtig für Schlegel ist, dass die Engländer in Indien nach indischen Gebräuchen und Gesetzen herrschten.

Auch sein Bruder August Wilhelm Schlegel begrüßt die Rücksichtnahme der Briten auf die indischen Traditionen und Gebräuche:

\begin{abstract}
Dieses mit der Weltherrschaft der Römer wetteifernde Reich streben sie nun fester zu gründen durch voraussehende und vorbeugende Staatsklugheit; durch eine geordnete, der Willkühr möglichst entzogene Verwaltung; besonders aber durch Schonung der Denkart ihrer Unterthanen, und durch Entscheidung der Rechtshändel nach den einheimischen Gesetzen, welche jedem der untergebenen Völker vermöge seiner Religionsbegriffe für heilig gelten. Sie stellen daher nur solche Beamten an, welche die Indischen Sitten und geselligen Verfassungen kennen. 560
\end{abstract}

Nichts könne die fremde Herrschaft mehr gefährden als Intoleranz. Gerade weil die Inder gemerkt hätten, dass Männer wie Jones ihre alten Schriften aus aufrichtigem Interesse studieren wollten und nicht, um sie zu verhöhnen, hätte sie sich ihnen geöffnet. ${ }^{561}$ Schlegel betont zudem, dass es nicht die Absicht der East India Company

\footnotetext{
${ }^{558}$ Vgl. Zoysa, Asoka de: „Blutrünstige Braminen am heiligen Strome“. Indienbilder in der deutschen Unterhaltungsliteratur zwischen Aufklärung und Restauration. Frankfurt a.M. (u.A.) 1997 (Europäische Hochschulschriften. Reihe 1. Deutsche Sprache und Literatur; 1597), S. 46

559 Schlegel, F.: Geschichte der alten und neuen Literatur, S. 134

${ }^{560}$ Schlegel, A. W.: Über den gegenwärtigen Zustand der Indischen Philologie, S. 226

${ }^{561}$ Vgl. Schlegel, A. W.: Über die Zunahme und den gegenwärtigen Stand unserer Kenntnisse von Indien. In: Berliner Taschenbuch auf das Gemein Jahr 1831, S. 1-160, hier S. 127f., 135f.
} 
gewesen sei, ein großes Herrschaftsgebiet zu errichten. Auch darin schließt er sich der

Ansicht englischer Autoren an:

\begin{abstract}
Eroberungssucht kann man den Directoren nicht vorwerfen: Vielmehr sind sie oft über die schon gewonnenen Siege bestürzt gewesen, und haben sich alle neuen Königreiche auf das dringenste verbeten. [...] Dieser edel gesinnte Mann [John Malcolm], der das Zutrauen und die Liebe der Indischen Völker besitzt, erhaben nicht nur über nationale sondern auch über Europäische Vorurtheile, hat einleuchtend dargethan, daß eine unüberwindliche Nothwendigkeit, eine nicht von menschliche Vorsätzen abhängige Verkettung der Begebenheiten, nach den ersten Schritten die Engländer zur Alleinherrschaft hingetrieben habe; daß eine schüchterne und neutrale Politik niemals befolgt worden sey, ohne alles bisher erworbene zu gefährden, und daß man sich in Indien entschließen müßte, entweder Ambos oder Hammer zu seyn. ${ }^{562}$
\end{abstract}

Äußere Umstände und die Unmöglichkeit, Neutralität zu wahren, hätten die Company gezwungen, ihre Herrschaft durch Eroberungen zu sichern. In zwei Punkten rückt aber auch Schlegel von der englischen Sicht ab: Zum einen kritisiert er deutlich Mills Diskreditierung der Inder, da das nur den Zweck verfolge, Gewalttätigkeiten gegenüber den Indern zu legitimieren. Zum anderen traut er den Engländer keinen immer angemessenen Umgang mit den geistigen Schätzen Indiens zu. Man müsse ihnen für das Zusammentragen der alten Texte dankbar sein, auch wenn sie sie nicht richtig würdigten. Ihr Umgang mit der indischen Kultur verfolge immer auch politische Zwecke. ${ }^{563}$ Diese

Zwecke und Antriebe liegen außer dem Bereich der Deutschen; dagegen werden die weltgeschichtlichen, philologischen und philosophischen Gesichtspunkte, die sich sogleich bey der Betrachtung der Indischen Denkmale darbieten, sie um so lebendiger ansprechen. Denn die Forschungen, welche das Auge für dergleichen Aussichten in die unbekannte Vorwelt schärfen, sind in Deutschland vorzugsweise einheimisch, und auswärtige Gelehrte ahnden manche Begriffe noch nicht, womit der Deutsche schon vertraut geworden ist. ${ }^{564}$

Gerade weil die deutschen Forscher keine politischen Zwecke verfolgten, seien sie in der Lage, tiefer in die indische Kultur einzudringen als andere. Ähnlich äußert sich auch Georg Forster, der ebenfalls der Ansicht ist, dass deutsche Autoren besser in der Lage seien, sich in andere Kulturen hineinzuversetzen, auch wenn sie keine direkte

\footnotetext{
${ }^{562}$ Schlegel, A. W.: Über die Zunahme und den gegenwärtigen Stand unserer Kenntnisse von Indien, S. $123 \mathrm{f}$.

${ }^{563}$ Vgl. Schlegel, August Wilhelm: Über den gegenwärtigen Zustand der Indischen Philologie. In: Jahrbuch der preußischen Rhein-Universität 1 (1819/21) Heft 2/3, S. 224-250., hier S. 224-226

${ }^{564}$ Schlegel, A. W.: Über den gegenwärtigen Zustand der indischen Philologie, S. 227
} 
Verbindung zu diesen Ländern hätten. ${ }^{565}$ Schlegel zeigt also durchaus ein „gewisses Unbehagen an Kolonialismus und Christianisierung“ 566 , aber er lehnt den Kolonialismus nicht grundlegend ab. Bhatti bemerkt, dass Schlegel im Prinzip auch nichts gegen kulturelle Kolonisation habe, sofern eine Kultur der anderen überlegen sei. Dies sei aber bei Indien und England nicht der Fall, da sie kulturell auf gleicher Ebene stünden. ${ }^{567}$

Das sehen andere Autoren wie Hegel oder vor allem auch Meiners völlig anders. Hegel vertritt die Ansicht, die „Engländer, oder vielmehr die ostindische Kompagnie sind Herren des Landes, denn es ist das nothwendige Schicksal der asiatischen Reiche, den Europäern unterworfen zu seyn [...].“ 568 In Hegels festgelegtem und daher notwendigem Lauf der Geschichte ist die europäische Expansion ein fester Bestandteil.

Meiners geht von einer natürlichen Ungleichheit der Völker aus, die sich auch in ungleichen Machtpositionen manifestiere:

Bey einer solchen natürlichen Ungleichheit [der verschiedenen indischen Schichten] mußte nothwendig in Hindostan ein ähnliches Verhältniß entstehen, wie in den westindischen und ostindischen Besitzungen der Europäer, wo die Weissen sich unter schwarzen oder rothen und braunen Völkern niederließen. Die Europäer in den auswärtigen Colonieen entsprechen den höheren Casten der Hindus [....$^{569}$

Aufgrund der ungleichen geistigen und körperlichen Fähigkeiten der verschiedenen Völker seien diese für unterschiedliche Arbeiten und Ämter geeignet:

Die Weissen erniedrigen sich weder in Westindien, noch in Ostindien zu knechtischen Arbeiten. Die Mulatten und farbigen Menschen werden zwar auf der einen Seite nie zu den schweren Arbeiten der Neger gebraucht; allein auf der andern Seite sind sie von manchen Ämtern und Verrichtungen

\footnotetext{
565 Vgl. Forster, Georg: Sakontala oder der entscheidende Ring ein indisches Schauspiel von Kalidas. Aus den Ursprachen Sanskrit und Prakrit ins Englische und aus diesem ins Deutsche übersezt mit Erläuterungen. Mainz und Leipzig 1791, S. XXVIII-XXX; vgl. auch Chakkalakal: Deutsch-indische Figurationen, S. 253f.. Chakkalakal stellt allerdings auch fest, das ,,bedeutet aber nicht im Umkehrschluss, dass sie außerhalb des kolonialen Feldes standen. Auch wenn deutsche Staaten zu diesem Zeitpunkt noch nicht als Kolonialmacht wahrgenommen wurden, bewegten sie sich durch ökonomische Beziehungen, durch transnationale wissenschaftliche Auseinandersetzungen, durch die Aushandlungen der eigenen nationalen Identität in Relation zu anderen europäischen Kolonialmächten auf einem kolonialen Feld.“ (Chakkalakal: Deutsch-indische Figurationen, S. 260).

${ }^{566}$ Bhatti, Anil: August Wilhelm Schlegels Indienrezeption und der Kolonialismus. In: Lehmann, Jürgen u.a. (Hg.): Konflikt Grenze Dialog. Kulturkontrastive und interdisziplinäre Textzugänge. Festschrift für Horst Turk zum 60. Geburtstag. Frankfurt a.M. 1997, S. 185-205, hier S.187

567 Vgl. Bhatti: August Wilhelm Schlegels Indienrezeption und der Kolonialismus, S. 198

${ }^{568}$ Hegel: Vorlesungen über die Philosophie der Geschichte, S. 147

${ }^{569}$ Meiners: Untersuchungen über die Verschiedenheiten der Menschennaturen. 2. Teil, S. 241
} 
ausgeschlossen, welche man den Weissen vorbehält. Was in den auswärtigen Colonien der Europäer erst seit einigen Jahrhunderten geschah, das geschah in Hindostan aus denselbigen Ursachen schon seit Jahrtausenden. ${ }^{570}$

Die Unterschiede zwischen den Völkern macht Meiners in sehr drastischen Bildern deutlich. Es sei viel, wenn ein Matrose nicht ganz vergesse, dass „die Hindus auch Menschen seyen. Er schwingt aus Scherz seinen Stock, und augenblicklich entfliehen fünfzig Hindus vor Entsetzen. ${ }^{\text {" }}{ }^{\text {711 }}$ Meiners rechtfertig den Kolonialismus also nicht nur, sondern sieht ihn als eine natürliche Gegebenheit und Notwendigkeit an. Die Hindus werden dabei in die Nähe von Tieren gerückt, die weder den Mut haben, sich zu verteidigen, noch den Unterschied zwischen einem wirklichen Angriff und einem Scherz verstehen.

Die oben aufgeworfene Frage, inwieweit die deutschsprachigen Autoren Teil haben an dem Diskurs der Kolonialmächte bzw. ob sie ebenfalls die Kolonialpolitik zu rechtfertigen suchen, kann insofern nicht eindeutig beantwortet werden, als sich eben sehr unterschiedliche Autoren mit diesem Thema auseinandersetzen und zu sehr unterschiedlichen Ergebnissen kommen. Diese reichen von einer deutlichen Kritik an den englischen Eroberungen bis hin zur Annahme, dass diese eine natürliche Gegebenheit seien. Auffällig ist aber, dass zumindest in den hier untersuchten Texten beide Extrempositionen, also auf der einen Seite eine explizite Verurteilung des Kolonialismus sowie auf der anderen Seite eine uneingeschränkte Verteidigung desselben relativ selten sind. Die überwiegende Anzahl der Autoren dieser Texte äußert sich nicht allgemein über den Kolonialismus, sondern kritisiert das konkrete Verhalten der Engländer in Indien in mehr oder weniger starker Ausprägung. Auch darf nicht vergessen werden, dass sich viele Autoren gar nicht oder kaum mit diesem Thema auseinandersetzen oder einfach nur möglichst sachlich und ohne Bewertungen über die Geschehnisse in Indien berichten. Dadurch, dass im deutschsprachigen Raum das Interesse vieler Autoren auf die klassische indische Kultur gerichtet ist, erfährt das zeitgenössische Indien oft nur eine geringe Aufmerksamkeit. Allgemein von einem romantisch verklärten Indienbild zu sprechen, das dem politischen Blick Englands entgegenstehe, ist aber auch zu kurz gegriffen. Denn in den Reise- und Missionsberichten sowie in geographischen oder historischen Abhandlungen zu Indien

\footnotetext{
${ }^{570}$ Meiners: Untersuchungen über die Verschiedenheiten der Menschennaturen. 2. Teil, S. 242

${ }^{571}$ Meiners: Untersuchungen über die Verschiedenheiten der Menschennaturen. 2. Teil, S. 266
} 
wird natürlich vor allem auch das zeitgenössische Indien behandelt, und somit ähnelt die Art der Betrachtung und Darstellung hier oftmals mehr dem englischen als dem romantischen Indienbild. Aber auch hier gibt es - wie gezeigt - Unterschiede zwischen den einzelnen Autoren. „Den“ deutschen Indienforscher hat es eben nie gegeben, sondern eine Vielzahl von Menschen, die sich aus den unterschiedlichsten Gründen mit dem Thema Indien beschäftigen.

\subsection{Mission}

Die ersten, die ausführlichere Informationen über die indische Kultur sammelten und in Europa bekannt machten, waren Missionare. Auch wenn diese Leistung - auch oder vielleicht sogar gerade von ihren Kritikern - dankbar und lobend anerkannt wurde ${ }^{572}$, so waren doch ihre Tätigkeit an sich sowie die Art und Weise ihres Vorgehens nicht unumstritten. In den hier untersuchten Texten wird zwar erstaunlich wenig auf das Thema Mission eingegangen, auch im Morgenblatt für die gebildeten Stände gibt es kaum Artikel dazu, aber gerade bei den Missionaren selbst spielt es natürlich eine wichtige Rolle und soll daher im Folgenden näher angeschaut werden.

Auch im Zusammenhang mit der Mission lässt sich ein Umbruch in den 1780er Jahren feststellen. Vermutlich angeregt durch die Arbeiten von Jones und anderen beginnen auch einige Missionare, sich intensiver mit der indischen Kultur (Sprache, Religion, Literatur) auseinander zu setzen. Vertrat Francke noch die Ansicht, man solle die Heiden bekehren und nicht deren Aberglauben in Europa verbreiten (weshalb er - wie oben beschrieben - auch einige Texte von Missionaren nicht veröffentlichte), setzt sich nun die Auffassung immer mehr durch, dass man zunächst die Inder besser verstehe müsse, um sie dann unterrichten und schließlich bekehren zu können. ${ }^{573}$ Einen weiteren Einschnitt gibt es in den ersten Jahrzehnten des 19. Jahrhunderts: Im Zuge der oben beschriebenen sich wandelnden Indienpolitik (mehr Kontrolle durch Europa und Forderungen nach Verbreitung der europäischen Kultur) ändert sich auch die Einstellung gegenüber den Missionsbestrebungen. Die englischen Besitzungen in Indien werden bis zu Beginn des 19. Jahrhunderts auf der Grundlage indischer Traditionen und nach dem Prinzip der Nichteinmischung regiert. Indien gilt vielen als „empire of opinion“, denn die britische Herrschaft beruht nicht auf einer überlegenen

\footnotetext{
572 Vgl. z.B. Briefe eines italienischen Reisenden, S. 463; Herder, Johann Gottfried: Adrastea und das 18. Jahrhundert. Neu herausgegeben von Johann von Müller. Stuttgart und Tübingen 1829, S. $145 f$.

${ }^{573}$ Vgl. Jürgens: German Indology avant la lettre, S. 49f., 57-60
} 
Militärmacht, sondern ist auf den Glauben der Inder, die Engländer seien unbesiegbar und ihre Herrschaft unumgänglich und vielleicht sogar nützlich, sowie ganz konkret auf die Hilfe indischer Truppen, der Sepoys, angewiesen. In den Bekehrungsversuchen der Missionare sehen die Beamten der East India Company eine Bedrohung dieser Herrschaftsform und damit ihrer Besitzungen und ihrer Handelsmöglichkeiten. Würden die Inder sich zu sehr zu dem neuen Glauben gedrängt fühlen, so könnten sie sich - so die Befürchtungen - gegen die Briten auflehnen. ${ }^{574}$ Verstärkt wird diese Angst 1806 durch einen Aufstand der Sepoys, der auch auf die Angst vor erzwungener Konversion zurückgeführt wird. Daher versagen die Beamten nicht nur den Missionaren und Konvertiten die Unterstützung, sondern verweigern ihnen die Einreise, erteilen Predigtverbote und bieten Konvertiten keine Stellen in der Company oder bei den Sepoys an. ${ }^{575}$ Das ändert sich zu Beginn des 19. Jahrhunderts, als die indische Kultur bei vielen Engländern deutlich an Ansehen verliert und die Vorstellung aufkommt, dass es besser sei, Indien nicht nach indischen Traditionen, sondern mit Hilfe westlicher Institutionen und Kultur $\mathrm{zu}$ regieren. ${ }^{576} \mathrm{Zu}$ dieser größeren Offenheit für eine Europäisierung der Inder kommt, dass Ende des 18. Jahrhunderts in England die Erweckungsbewegung erstarkt und sich vehement für eine Ausweitung und

\footnotetext{
${ }^{574}$ Die indischen Sepoys waren den englischen Truppen bereits während des Siebenjährigen Krieges zahlenmäßig weit überlegen. Bis in die 1780er Jahre wuchs ihre Zahl auf etwa 100.000 Mann an, die in europäischer Kampfführung geschult worden waren (vgl. Füssel, Marian: Panduren, Kosaken und Sepoys. Ethnische Gewaltakteure im 18. Jahrhundert zwischen Sicherheit und Stigma. In: Rogger, Philippe u. Hitz, Benjamin (Hg.): Söldnerlandschaften. Frühneuzeitliche Gewaltmärkte im Vergleich. Berlin 2014 (Zeitschrift für historische Forschung; Beiheft 49), S. 181-199, hier S. 196

${ }^{575}$ Auch die Missionare in Tranquebar stießen zunächst auf Widerstand der dänischen Ostindienkompanie und ,einer ausschließlich kommerziell ausgerichteten Kolonialobrigkeit (...), die alles zu vermeiden suchte, was Konflikte mit der indischen Bevölkerung hervorrufen und dem Handel abträglich sein konnte“ (Trepp, Anne-Charlott: „Daher entsteht so viel naturhistorisches Unheil“. Wissens- und Kulturtransfer zwischen Indien und Europa: Die Halleschen Missionsberichte. In: Beck, Andreas u. Kaminski, Nicola (Hg.): Literatur der Frühen Neuzeit und ihre kulturellen Kontexte. Bochumer Ringvorlesung im Sommersemester 2011. Frankfurt a. M. 2012, S. 229-255, hier S. 237) ${ }^{576}$ Auch die Missionare lassen sich (wie in Kapitel 3.2 für die Indienpolitik allgemein beschrieben) in „Orientalisten“ und „Anglisten“ unterteilen. Erste wollen alle Schichten des Volks erreichen und betonen daher die Bedeutung der indischen Mundarten für den Erfolg der Mission und übersetzen biblische Texte in indische Sprachen. Dagegen sehen die „Anglisten“ die indischen Sprachen als zu wenig entwickelt an, um so komplexe Inhalte wie Theologie und Wissenschaften zu vermitteln. Sie fordern daher eine konsequent englische Erziehung und Bildung der zu bekehrenden Inder. Ihre Zielgruppe besteht in erster Linie aus der brahmanischen Elite (vgl. Hemron, Anand Sebeyan: Transmission of knowledge by christian missionarie among the indigenous people of central-eastern India in the 19th century. In: Heyden, Ulrich van der u. Feldtkeller, Andreas (Hg.): Missionsgeschichte als Geschichte der Globalisierung von Wissen. Transkulturelle Wissensaneignung und -vermittlung durch christliche Missionare in Afrika und Asien im 17., 18. und 19. Jahrhundert. Stuttgart 2012, S. 155-171, S.161).
} 
Unterstützung der Mission einsetzt und damit auch in Teilen erfolgreich ist. ${ }^{577}$

Diese Auseinandersetzungen spiegeln sich auch in den hier untersuchten Texten wieder. So erwähnen sowohl ein Artikel über Bildungsanstalten in Indien, der $1819 \mathrm{im}$ Morgenblatt für gebildete Stände erschienen ist, als auch die Missionsberichte der Halleschen Missionare den wachsenden Missionseifer in England. ${ }^{578}$ Und auch die Sorge der East India Company, dass es aus Angst vor einer zu drängenden Missionspolitik zu Schwierigkeiten kommen könnte, wird in einigen Texten angesprochen. ${ }^{579}$

Interessant ist, dass es in den hier untersuchten Texten erstaunlich wenig um die generelle Frage geht, ob Mission sinnvoll und moralisch vertretbar ist. Vielmehr gehen die meisten Autoren davon aus, dass es an sich eine gute Sache sei, möglichst viele Menschen zum Christentum zu bekehren, kritisieren aber häufig das Vorgehen der Missionare vor Ort.

Einige Autoren stimmen der Ansicht zu, dass Mission ein gutes und notwendiges Unterfangen sei. Windischmann ist der Ansicht, dass an diesem „Werk der Liebe“ das „Heil und der Friede vieler Millionen“580 hänge. Man solle nicht, wie es einige der romantischen Autoren fordern, den alten ursprünglichen Glauben der Inder wieder erneuern, sondern die Seelen der Inder retten, indem man „das Licht des Evangeliums“ unter ihnen verbreite, so dass „der Geist der Wahrheit und des Verstandes“ ${ }^{\text {(581 }}$ sie durchdringe. Auch der Missionar Schwarz spricht sich erwartungsgemäß deutlich für die Mission aus. Er beruft sich auf den Befehl Gottes, allen Völkern das Evangelium zu predigen, da es kein anderes Mittel gebe, die Menschen auf den rechten Weg zu führen. Interessanterweise führt Schwarz nicht das Seelenheil der Menschen, sondern

\footnotetext{
${ }^{577}$ zu dem Verhältnis von Mission und Handel/Politik vgl. Reinhard: Die Unterwerfung der Welt, S. 285f., 632; Carson, Penelope: The East India Company and Religion, 1698 - 1858. Woodbridge 2012, S. 21f., 70-72, 91, 152, 164f., 169, 183

${ }^{578} \mathrm{Vgl}$. Bildungsanstalten für die Jugend in Hindostan. In: Morgenblatt für die gebildeten Stände 13 (1819, Januar, Nr. 17), S. 66-67, hier S. 67; Knapp, Georg Christian (Hg.): Neuere Geschichte der Evangelischen Missions-Anstalten zu Bekehrung der Heiden in Ostindien. 5. Band. Vorrede. Halle 1804, S. IX

${ }^{579}$ Vgl. Skizzen aus Ostindien, S. 281; Salt, Henry: Georg Viscount Valentia's und Heinrich Salts Reise nach Indien, Ceylon, dem rothen Meere, Abyssinien und Ägypten 1802,1803, 1804, 1805, 1806.

Weimar 1811, S. 253

${ }^{580}$ Vorerinnerungen von Windischmann, in: Bopp: Über das Conjugationssystem, S. XXXVI

${ }^{581}$ Vorerinnerungen von Windischmann, in: Bopp: Über das Conjugationssystem, S. XXXV
} 
einen eher säkularen Grund für die Notwendigkeit der Bekehrung an:

Es ist eine bloße Chimäre, wenn man sich einbildet, daß je die Heiden ohne die Erkenntniß von GOtt einen rechtschaffenen Wandel führen werden. Die Lobsprüche, die viele unserer Geschichtschreiber den Heiden dieses Landes ertheilt haben, werden durch eine genaue, ja selbst durch die flüchtigste Untersuchung ihres Lebenswandels widerlegt. ${ }^{582}$

Die Menschen würden erst in der Kenntnis des wahren Glaubens in der Lage sein, ein rechtschaffenes Leben zu führen. Ein Grund für diese eher politisch-gesellschaftliche Begründung könnten die oben geschilderten Vorwürfe sein, dass die Mission den politisch-wirtschaftlichen Interessen Englands schade. Denn auch in den Absätzen zuvor argumentiert Schwarz immer wieder damit, wie nützlich die Missionare der Regierung sein könnten. Etwas zurückhaltender als Windischmann und Schwarz, aber dennoch prinzipiell zustimmend formuliert ein Rezensent der Halleschen Missionsberichte in der Allgemeinen Literatur-Zeitung:

\begin{abstract}
Dem Fortgange und Gedeihen dieser Anstalten wird jeder Menschenfreund noch immer mit theilnehmender Freude zusehen. Geschähe auch, aus begreiflichen Ursachen weniger, als man wünschen mögte, so ist es doch immer ein grosses, edles und gewiss nicht fruchtloses, Unternehmen, sich zur Geistesbildung verlassener Menschen in entlegenen Weltgegenden berufen halten, und sich darinn thätig beweisen. ${ }^{583}$
\end{abstract}

Auch dieser Rezensent spricht nicht vom Seelenheil, sondern von der Geistesbildung, was sowohl religiös als auch weltlich gedeutet werden kann. Er hat in seiner Darstellung weniger die Inder im Blick, die für ihn verlassene Menschen in entlegenen Weltgegenden sind (also nicht Angehörige eines kulturell hochstehenden Volkes), sondern die Missionare. Egal ob sie erfolgreich seien oder nicht, so sei es doch eine edle Tat, sich um diese verlassenen Menschen zu kümmern. Sie kommt also - etwas überspitzt gesagt - eher dem Seelenheil oder dem Ansehen des Missionars zugute, als dem der Inder.

Dagegen bezieht Herder, der sich für eine Gleichwertigkeit und Gleichberechtigung der Kulturen einsetzt, ganz klar Position gegen die Bekehrungsversuche. In einem fiktiven

\footnotetext{
${ }^{582}$ Knapp (Hg.): Neuere Geschichte der Evangelischen Missions-Anstalten zu Bekehrung der Heiden in Ostindien. Fünfter Band. 51. Stück, S. 283

${ }^{583}$ Rezension zu: Neuere Geschichte der Evangelischen Missionsanstalten zu Bekehrung der Heiden in Ostindien 1791. In: Allgemeine Literatur-Zeitung (1792) Band 3, Nr. 224, Sp. 422
} 
Gespräch $^{584}$ lässt er einen Asiaten einem Europäer Einblick in die Empfindungen der Inder gewähren und ihn die Widersprüche der europäischen Mission aufzeigen. Der Asiate fragt, wie es den Europäern gehen würde, wenn sie in einer vergleichbaren Situation wären, wenn Plünderer und Unterdrücker versuchen würden, sie zu bekehren: „Käme Jemand in Euer Land, erklärte Euer Heiligstes, Gesetze, Religion, Weisheit, Staatseinrichtung u.f. auf eine freche Art für das Abgeschmackteste, wie würdet Ihr ihm begegnen?“"585 Der Europäer erwidert, dass der Fall hier anders liege, da die Europäer Macht und Kultur hätten. Der Asiate möchte ihm verdeutlichen, dass auch die Inder eine eigene Kultur haben und von dem, was sie von der europäischen Kultur mitbekämen, angewidert zurückschauderten. „Mit Menschen, die in allen Lastern leben, [...] wollen sie in keinen gemeinschaftlichen Himmel." ${ }^{\text {586 }}$ Wie bereits in seinen „Ideen“ stellt Herder auch hier den lasterhaften Europäern die „Barmherzigkeit, Sanftmuth und gute Werke“ ${ }^{587}$ der Inder gegenüber. Die Kultur der Inder sei der europäischen ebenbürtig. So wie die unteren Schichten der Europäer wie die indischen an Götzenbildern und Gebräuchen hingen, so glaubten die Brahmanen ebenfalls an den einen Gott. Verstünden die europäischen Missionare die indischen Göttergeschichten wortwörtlich und nicht wie die Inder als das, was sie sind, nämlich Märchen, so stünden sie noch unter dem indischen Volk. Zudem hätten die Europäer die Inder in keiner Weise glücklicher oder freier gemacht. ${ }^{588}$ Das aber falle auf die Europäer zurück, die

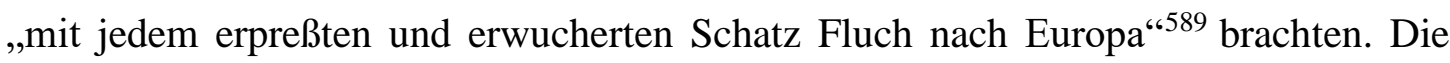
Mission sieht Herder im Zusammenhang mit wirtschaftlichen Interessen Europas, um eine wirkliche Rettung der Inder oder eine Verbesserung der dortigen Verhältnisse geht es - so Herders Wahrnehmung - nicht. ${ }^{590}$ Eine Ausnahme macht er nur für die dänische Mission in Tranquebar. ${ }^{591}$ In seinen „Ideen“ hat Herder bereits ein weiteres Argument

\footnotetext{
${ }^{584}$ Dieses Gespräch ist zwar fiktiv und daher möglicherweise den literarischen Texten zuzuordnen, aufgrund der klaren sachlichen Zielrichtung und Darstellung lässt er sich inhaltlich eher der Gruppe der Sachtexte zuordnen.

${ }^{585}$ Herder: Adrastea und das 18. Jahrhundert, S. 179

${ }^{586}$ Herder: Adrastea, S. 180

${ }^{587}$ Herder: Adrastea, S. 180

${ }^{588}$ Vgl. Herder: Adrastea, S. 180-187

${ }^{589}$ Herder: Adrastea, S. 191

${ }^{590} \mathrm{Zu}$ Herder vgl. auch Otto: Bekehrung der Indier durch unsre Europäische Christen: Herder protestiere gegen Einmischung unter Gewalt, zur Unterdrückung und zur Bereicherung. Dabei kritisiere er die Instrumentalisierung der Religion zu diesen Zwecken. Den Europäern gehe es um ihre Bereicherung, nicht um das Seelenheil der Inder (S. 450, 452)

${ }^{591}$ Herder: Adrastea, S. 187
} 
geäußert: Die Inder selbst seien - anders als die Europäer - tolerant und ließen jedem seine Religion und Lebensart. Warum solle man ihnen nicht die ihre lassen ${ }^{592}$

Die deutliche Kritik Herders an der Mission als solcher ist in den untersuchten Texten die Ausnahme. ${ }^{593}$ Die Art und Weise jedoch, wie missioniert wird, wird in vielen Texten mehr oder weniger stark kritisiert. Dabei geht es vor allem um folgende Fragen: Wie sollen die zu Bekehrenden angesprochen werden, inwieweit sollen kirchliche Strukturen in Indien aufgebaut werden, darf man die christlich-europäische Kultur indischen Traditionen in einem gewissen Grad anpassen, hat die Mission überhaupt Aussicht auf Erfolg und wenn nein, warum nicht?

In der Frage, wie die Inder zu bekehren seien, wird größtenteils einvernehmlich die Antwort gegeben: durch Gespräche und Unterricht. So gibt es immer wieder Berichte der Missionare, wie sie Inder ansprechen und ihnen vom Licht des Evangeliums berichten. Die Missionsberichte sind voll von solchen Gesprächen, die sich in ihrem Ablauf sehr ähneln. Auffallend ist, dass die Missionare immer wieder an die Vernunft der Inder appellieren, die doch einsehen müsse, dass die Missionare die Wahrheit verkündeten und die theologische Auffassung der Inder unlogisch sei. Auch Windischmann verbindet in dem obigen Zitat die Wahrheit des Christentums mit dem Verstand. Die von Said beobachtete Charakterisierung vieler orientalischer Kulturen als irrational lässt sich an dem Beispiel der Religion hier sehr gut zeigen: die indische wird als irrational, die christliche als vernünftig beschrieben. Viele Missionare beschreiben die für sie unverständliche Situation, dass die Inder sich zunächst zustimmend oder zumindest nicht ablehnend verhalten, sich dann aber doch nicht bekehren lassen. Entweder gehen sich einfach nicht weiter auf den Missionar ein oder sie stimmen ihm zwar zu, wollen aber an der Religion ihrer Väter festhalten. Vor allem

\footnotetext{
${ }^{592}$ Vgl. Herder: Ideen zur Philosophie der Geschichte der Menschheit, S. 293; auch andere Autoren betonen die große Toleranz der Hindus in religiösen Dingen (vgl. z.B. Über Verfassung, Religion, Gebräuche und Sitten der Maratten. In: Minvera. Ein Journal historischen und politischen Inhalts 38 (1801), S. 311-341, hier S. 232f.), aber sie ziehen daraus in der Regel nicht dieselben Konsequenzen wie Herder.

${ }^{593}$ Einen interessanten Gedanken gegen die Bekehrung der Inder äußert Salt, der die Behauptung aufstellt, die bekehrten Inder wären keineswegs, wie es so oft die Hoffnung ist, bessere Untertanen. Wäre die Bindung an die Kasten aufgehoben, so ,werden die Leidenschaften erwachen und das Talent wird sich geltend zu machen suchen." (Salt: Georg Viscount Valentia's und Heinrich Salts Reise nach Indien, S. 252). Die Wahrscheinlichkeit sei dann gering, dass sich die zahlenmäßig deutlich überlegenen Inder nicht gegen die Europäer erheben.
} 
in den ausführlichen Berichten der Halleschen Mission finden sich viele Beispiele, die diesem hier ähneln:

Er [ein Inder] sagte: Ihr habt freylich Licht und Wahrheit, wir aber tappen im Finstern: ihr haltet euch nur ein einen, wir an viele. Ich erwiederte: Eure Worte sind Wahrheit; warum bedenkt ihr aber nicht, daß ihr von allen euren Worten, Werken und Gängen Gott werdet Rechenschaft geben müssen. Der Tod kann euch leicht übereilen. - Er: Das ist Wahrheit. Dabey blieb es. ${ }^{594}$

Deutlich spricht auch der Missionar Perrin über dieses Verhalten:

Die Geistesart und die Vorutheile der Indier bilden auch Schwierigkeiten, welche diesem Lande eigenthümlich sind. Denn wenn man endlich dahin gelangt ist, ihnen das Licht sehen zu lassen, und von ihnen erlangt hat, daß sie eingestehen müssen, was man ihnen sage, sey vernünftig und erwiesen, so ziehen sie daraus doch nicht die nothwendige Folge, daß sie nun auch ihre Meinung und Betragen ändern müßten. Ein auffallendes Beyspiel davon ist folgendes: Nach meiner Ankunft in Pondichery, als ich die Sprache genug verstand, um die Indier unterrichten zu können, glaubte ich, ich brauche bloß zu sprechen, um die Götzentempel leer stehen zu sehen, und begriff gar nicht, wie es noch Götzendiener geben könne. Als ich bemerkte, daß selbst des Bischofs Bediente nicht Christen seyen, bezeugte ich diesem meine Verwunderung darüber, und war sogar so verwegen, ihm zu sagen, er solle mich nur bevollmächtigen, sie zu unterrichten, so sollten sie bald bekehrt seyn. [...] Zuerst beschäftigte ich mich nun damit, ihnen durch Vernunftgründe zu beweisen, daß ihre religiösen Ideen abgeschmackt wären, daß ihr Gottesdienst Gottes unwürdig sey, und ihre eigne Vernunft beschimpfe. Das gestanden sie ein. Stolz über diesen ersten Erfolg philosophirte ich nun mit meinen neuen Schülern weiter. „Ihr gebt zu, daß eure Religion die Gottheit nicht ehrt, doch muß der Mensch aber eine Religion haben. Nur die christliche entwickelt uns die Natur Gottes, und lehrt uns, was wir von ihm zu hoffen und zu fürchten haben. [...] Diese Religion müßt ihr also annehmen, damit Gott jenen finstern Gottesdienst, vergesse, durch den ihr ihn bis jetzt entehrt habt u.s.w. Was sagt ihr dazu?““ Nun fragte ich einen nach dem andern, und erhielt bloß folgende Antwort: „Ihre Religion ist heiliger als die unsere; aber doch wollen wir diese nicht verlassen; denn es ist die Religion unserer Familie, unserer Verwandten, unseres Landes. Unsere Vorväter haben in demselben Glauben gelebt und sind darin gestorben, und wir wollen auch sterben wie sie. “595

Dieser Ausschnitt zeigt sehr anschaulich das Vertrauen des Missionars auf die Vernunft (die Gnade und Kraft Gottes werden dagegen nicht erwähnt) und das Erstaunen darüber, dass die Inder sich trotz aller Einsichten nicht bekehren lassen.

Ein wichtiges Mittel der Bekehrung sind also direkte Gespräche und Unterricht. Darüber, wie diese Gespräche ablaufen sollen, gibt es allerdings unterschiedliche Ansichten. Während viele Missionare die Religion der Hindus diesen gegenüber als

\footnotetext{
${ }^{594}$ Schulze (Hg.): Neuere Geschichte der Evangelischen Missions-Anstalten zu Bekehrung der Heiden in Ostindien. Vierter Band. 37. Stück, S. 1

595 Hell: M. Perrin's Reise. Band 2, S. 55-57
} 
falsch, unvernünftig und gotteslästerlich kritisieren, ist es genau diese direkte Kritik am anderen, die der Missionar Dubois, der sich in seinen Briefen intensiv mit den Gründen für die geringen Erfolge der Mission auseinandersetzt, ablehnt:

\begin{abstract}
Inzwischen, wenn ich genöthigt werde, religilöse Disputationen mit Heiden zu halten, ahme ich keineswegs das abschreckende und erbitternde Verfahren mancher unhöflichen und intoleranten Personen meines Standes nach, welche von einem warmen, aber falschen und zuweilen gefährlichen Eifer angespornt, vom ersten Anfange an, wenn sie über Religion mit den Heiden disputieren, ihre Argumente mit den schmähenden und beleidigenden Phrasen eröffnen: „Alle Eure Götter sind nichts Anderes, als Dämonen, Ihr alle werdet in die Hölle kommen, um in ewigen Flammen das Verbrechen Eurer Abgötterei zu büßen;“ und ähnlicher tadelnder Rede. Ein solcher Ausdruck des Tadels und der Beleidigung dient, wie man leicht denken kann, bloß dazu, eine Erwiederung von Blasphemieen gegen die christliche Religion und ihren göttlichen Stifter zu veranlassen, und das Christentum selbst, seine Lehrer und seine Bekenner den Eingebornen mehr und mehr verhaßt zu machen. In meine religiösen Controversen vergesse ich niemals den Anstand, die Ruhe, die Nachsicht und die gegenseitige Achtung, welche immer bei solchen Umständen beobachtet werden sollten und vermeide sorgfältig Alles das, was ohne guten Erfolg das Gefühl und die Vorurtheile meiner Gegner verletzen könnte [...]. ${ }^{596}$
\end{abstract}

Dubois sieht auch die verbreitete Praxis, Bibeln oder Ausschnitte daraus ohne weitere Unterweisung zu verteilen, sehr kritisch. Er argumentiert, dass die Bibel „fast auf jeder Seite Erzählungen enthält, welche ihr [der Inder] Gefühl tief verwunden müssen, weil sie Vorurtheile, welche für die heiligsten gelten, “verletzen. ${ }^{597}$ Die Inder bedürfen laut Dubois zunächst der Vorbereitung. Sie müssen langsam und behutsam an die Lehren der Bibel herangeführt werden, ähnlich wie man Kindern zunächst Milch und dann erst feste Speise gibt. ${ }^{598}$

Auch andere Missionare setzen in ihrer Arbeit auf Unterricht, statt auf sofortige Bekehrung. Ein gern beschrittener Weg ist die Gründung von Missionsschulen. In den Anfangsjahren wurde dabei Religion selten direkt in der Schule unterrichtet, um die indischen Eltern nicht zu verschrecken. Nach und nach wurden dann auch moralische Geschichten und christliche Ethik mit in den Unterricht einbezogen. Der oben beschriebenen Wandel der Einstellung gegenüber der Mission in den 1820er Jahren zeigt sich aber auch an den Schulen. So werden ab den 1820er Jahren verstärkt auch Bibeltexte als Unterrichtsmaterial eingesetzt und nach 1823 ist christliche Religion

\footnotetext{
${ }^{596}$ Dubois: Briefe über den Zustand des Christentums, S. $15 f$.

${ }^{597}$ Dubois: Briefe über den Zustand des Christentums, S. 26

${ }^{598}$ Vgl. Dubois: Briefe über den Zustand des Christentums, S. 31f.
} 
Unterrichtsfach in fast allen Missionsschulen. ${ }^{599}$ Sehr anschaulich beschreibt der Feldprediger Friedrich Langstedt ${ }^{600}$, wie die indischen Kinder nach und nach in der Schule an das Christentum herangeführt werden:

\begin{abstract}
Alles dieses Angeführte [christliche Gebete und Sprüche aufsagen] thun sie [die indischen Schüler] ganz ungeheissen, und man läßt sie es als eine besondere Wohlthat ansehen, daß man ihnen erlaubt, an allem mit Theil zu nehmen. Anstatt mit dem Christenthum unmittelbar in sie zu dringen, welches sie sogleich zu Hause ihren Eltern erzählen und Aufsehen machen würden, läßt man sie nur zuhören, wenn man sowohl bei dem gewöhnlichen Unterricht, als auch bei dem Ausgehen und andern besondern Gelegenheiten, den Jünglingen die Würde des Christenthums, das weiße, gottselige, sich vor andern auszeichnende Verhalten nebst der Glückseeligkeit und frohen Hofnung eines wahren Christen vorhält, und wie ein unwissender und lasterhafter Christ weit verabscheuungswürdiger und strafbarer sey, als ein solcher, der in den vortreflichen Lehren des Christenthums noch nicht unterrichtet ist. ${ }^{601}$
\end{abstract}

Auch in einem Artikel des Morgenblatts für gebildete Stände wird betont, dass die Schulen zumindest nach außen hin nicht in erster Linie der Mission, sondern der Bildung der Inder dienen sollen:

Um dabey allen Argwohn zu vermeiden, als wäre es mir darum zu thun, ihren Kindern die christliche Religion aufzudringen, erklärte ich den Schullehrern sowol, als den Eltern, die nächste Absicht dieser Schulen gehe blos dahin, die Kinder auf leichterm und kürzerm Wege Lesen und Schreiben zu lehren, um sie dadurch verständiger, arbeitsamer und fähiger zu machen ihr ehrliches Brod einst zu erwerben, ihre armen Eltern zu unterstützen, Gott fürchten und die Obrigkeit ehren zu lernen, wir erklärten ihnen offen, unsre Religion sey ein zu köstlicher Schatz, als daß wir denselben aufzudringen gedächten, noch viel weniger sey es uns darum zu thun, ihre Kinder durch allerley Mittel anzulocken, sich taufen zu lassen.. Unter meinen heidnischen Zöglingen sind manche rechtschaffener, eingezogener und fleißiger, und entwickeln einen bessern Charakter, als manche Namen-Christen. ${ }^{602}$

Der Autor möchte keine bloßen „Namen-Christen“, ${ }^{603}$ sondern zunächst die Kinder bilden und erziehen, und erst wenn sie durch diese Erziehung bereit sind, ihnen direkt

\footnotetext{
${ }^{599}$ Vgl. Carson: The East India Company and Religion, S. 159-162

${ }^{600}$ Friedrich Ludwig Langstedt (1750-1804) kam als Feldprediger des kurhannöverschen 15.

Infanterieregiments nach Indien (vgl. Anemüller, Ernst, "Langstedt, Friedrich Ludwig" in: Allgemeine Deutsche Biographie 17 (1883), S. 692 [Online-Version]; URL: https://www.deutschebiographie.de/pnd10030074X.html\#adbcontent).

${ }^{601}$ Langstedt, Friedrich Ludwig: Hindostanische Denkwürdigkeiten. Ein Lesebuch zur Beherzigung für jeden Kosmopoliten. Nürnberg 1799, S. $294 \mathrm{f}$.

${ }^{602}$ Bildungsanstalten für die Jugend in Hindostan, S. 67

${ }^{603}$ Den Anspruch, keine bloßen „Namen-Christen“ zu erhalten, erheben auch die Missionare der Halleschen Mission „Die Missionarien bleiben übrigens dem von Anfang an befolgten und jederzeit als bewährt erfundenen Grundsatze noch immer treu, daß sie nehmlich auf wahre und lebendige Gemeinen Jesu unter den Heiden antragen, und nicht auf zahlreiche Haufen bloßer Namenchristen." (Knapp (Hg.): Neuere Geschichte der Evangelischen Missions-Anstalten. Fünfter Band. Vorrede, S. VI)
} 
das Christentum nahe bringen. Es geht ihm also anscheinend nicht um eine möglichst große Anzahl an Konvertiten, sondern um eine wirkliche Bekehrung zum christlichen Glauben. Daneben spielt auch die praktische Seite der Schule eine Rolle: Sie bilde die

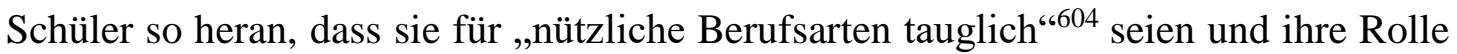
als Untertanen gut erfüllten, was die Schulen also auch für die Kolonialpolitik interessant machen soll.

Einen anderen Weg geht der Missionar Perrin. Das von ihm beschriebene Werk könne man „freylich nicht die Gründung einer kirchlichen Gemeinde nennen“605. Die Rede ist von der Taufe Todkranker und Sterbender. Während den Erwachsenen vor der Taufe noch gut zugeredet wird, um ihr Einverständnis zu erhalten, werden die Kinder oft heimlich und ohne Wissen der Eltern getauft:

\begin{abstract}
Einer der hauptsächlichsten Vortheile des Apostolats von Hindostan ist die Taufe der heidnischen Kinder. Dieser Nutzen ist um so viel schätzbarer, weil man sie nur in Todesgefahr und alsdann tauft, wenn man die gegründetste Hoffnung hat, daß sie die Gnade, die man ihnen dadurch verschafft, nicht wieder verlieren werden. Da Indien außerordentlich bevölkert ist, die Geißel des Krieges immer auf einigen Provinzen ruht, und die gewöhnliche Folge dieser halbwilden Kriege eine örtliche, stets sehr mörderische Hungersnoth ist, so ist die Ernte der Täuflinge unter den Kindern sehr reich. [...] Bey diesen Gelegenheiten vorzüglich gewähren die Katechisten einen Nutzen, der nicht zu berechnen ist. Sie führen sich in die Häuser ein, ohne daß man ihre Absicht vermuthet, unterhalten sich traulich mit der Familie, sehen ohne Schwierigkeit die kranken Kinder, und taufen sie, indem sie sich stellen, als ob sie ihnen eine Arzeney eingäben. Selten stirbt in Gegenden, wo es eifrige Katechisten gibt, ein heidnisches Kind ohne Taufe. ${ }^{606}$
\end{abstract}

Dieser Textausschnitt klingt etwas zynisch. Auch wenn er es vielleicht nicht direkt so meint, so erweckt Perrin doch den Eindruck, als seien die vielen Todesopfer unter den Kindern für diese ein Segen, da sie so durch die Taufe gerettet würden, auch wenn es ihnen selbst nicht bewusst sei. Perrin geht es also nicht darum, die Menschen zu bilden und $\mathrm{zu}$ besseren Untertanen zu erziehen, sondern ihm geht es um die Rettung der Seelen, aber es scheint ihm relativ egal zu sein, wie das erreicht wird. Bei den Erwachsenen geht Perrin davon aus, dass diejenigen, die reinen Herzens sind und auch ohne Kenntnisse des Christentums ein gottgefälliges Leben gelebt hatten, vor ihrem Tode offen für die Taufe seien und sich taufen lassen würden. Ebenso habe er die

\footnotetext{
${ }^{604}$ Bildungsanstalten für die Jugend in Hindostan, S. 66

${ }^{605}$ Hell: M. Perrin's Reise durch Hindostan. Band 2, S. 126

${ }^{606}$ Hell: M. Perrin's Reise durch Hindostan. Band 2, S. $123 \mathrm{f}$.
} 
Erfahrung gemacht, dass diejenigen, die auch im Angesicht des Nahen Todes eine Taufe ablehnten, ein lasterhaftes Leben geführt hätten: Fast alle, die

\begin{abstract}
die Taufe durch außerordentliche Mittel oder Umstände empfingen, während ihres Unglaubens rechtlich gelebt hatten, und daß wenn es Heiden gibt, die durch ihre Verblendung und Hartnäckigkeit den apostolischen Eifer betrüben, sie die Erleuchtung des Lichtes der Natur gemißbraucht, und sich, unerachtet der Vorwürfe und Erinnerungen ihres Gewissens, groben Lastern oder tadelnswürdigen Leidenschaften überlassen hatten. ${ }^{607}$
\end{abstract}

Perrin berichtet auch von großen Wundern, die er nach Taufen erlebt habe und die andere Inder dazu bringen, die Wahrheit des Christentums anzuerkennen.

Unter den Missionaren wird auch diskutiert, in wieweit sie sich in der konkreten Ausgestaltung der christlichen Bräuche den indischen Traditionen anpassen sollten. Einen solchen Weg waren im 17. und 18. Jahrhundert die Jesuiten gegangen. Roberto de Nobili hatte die von Metteo Ricci in China erprobte Methode der Akkomodation auf Indien übertragen, obwohl diese bei anderen Orden sehr kritisch gesehen wurde. Ziel der Akkomodation war es, bei der Mission die gesellschaftlichen und kulturellen Gegebenheiten des Anderen zu berücksichtigen und das Christentum „in einer für Einheimische kulturell akzeptablen Form“ zu präsentieren. Dabei ging es nicht um eine „inhaltliche Beeinflussung des Christentums durch asiatische Wert- und Kulturvorstellungen“, sondern um eine Trennung der „christliche(n) Glaubensinhalte von europäischen Riten“. ${ }^{608}$ Dubois berichtet davon, wie der Papst dieses Vorgehen der Jesuiten verdammt habe und wie daraufhin viele neue Christen sich wieder vom Christentum abwandten und begannen, die christliche Religion wegen ihrer Intoleranz zu verabscheuen. ${ }^{609}$ In der Tat war 1703 auf Geheiß des Papstes Charles Thomas de Tournon nach Asien gekommen und hatte den indischen Christen die einheimischen Bräuche verboten. Er wollte die konvertierten Inder auch zu solchen, in der christlichen Liturgie vergleichsweise unwichtigen Handlungen zwingen, die ihnen von Grund auf zuwider waren, z.B. das Berühren mit Speichel bei der Taufe. Andere Missionare verbanden das Christentum so eng mit der europäischen Kultur, dass sie von den neuen

\footnotetext{
${ }^{607}$ Hell: M. Perrin's Reise durch Hindostan. Band 2, S. 132

${ }^{608}$ Lederle: Mission und Ökonomie der Jesuiten in Indien, S. 139

${ }^{609}$ Dubois: Briefe über den Zustand des Christentums, S. 4-10; auch Papi beschreibt, wie die Jesuiten sich in indischer Art und Weise kleideten und sich zum Teil sogar an die Regeln des Kastensystems hielten (Briefe eines italienischen Reisenden, S. 463f.)
} 
Christen z.B. verlangten, Rindfleisch zu essen. Mit einer Bulle des Papstes 1744 und der Auflösung des Jesuitenordens einige Jahre später wurde der Ritenstreit beendet. ${ }^{610}$

Das Kastensystem ist eines der beiden Hauptbereiche, anhand derer die Frage der Anpassung auch nach dem gescheiterten Versuch der Jesuiten immer wieder diskutiert wird. Der andere Bereich betrifft die sinnliche Ausgestaltung der Zeremonien. Das Kastenwesen stellt die Missionare vor große Herausforderungen. Denn einerseits gebietet das Christentum Nächstenliebe gegenüber allen Geschöpfen Gottes, andererseits ist es aber oft unmöglich, Inder höherer Kasten zum Christentum zu bekehren, wenn das für sie bedeutet, dass sie in ein und derselben Kirche mit Parias beten sollen. Schon ein Besuch des Missionars bei Parias kann, sofern er denn bekannt wird, einigen Aufruhr auslösen. Auch wenn viele vielleicht mit der Vorstellung nach Indien gekommen sind, die starren Regeln des Kastensystems zu durchbrechen, werden doch die meisten irgendwann mit diesem Problem konfrontiert. Perrin berichtet, dass die Jesuiten eine zeitlang versuchten, dem Kastenwesen dadurch zu begegnen, dass sie Missionare nur für die höheren Kasten und andere nur für die Parias einführten. Das

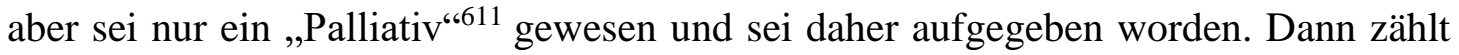
Perrin die Grundsätze auf, nach denen er selbst gehandelt habe: „1) Alle Gläubiger ohne Unterschied in den Kirchen sitzen zu lassen, 2) allen und an demselben Orte die Sacramente zu administriren, und 3) sie bey Krankheitsfällen in ihren Häusern zu besuchen. “612 Um das zur Zufriedenheit aller zu gestalten, habe er

neben der Gegend des Altes noch einen kleine Flügel anbauen [lassen], auf welchen das Dach des Hauptgebäudes mittelst einer Verlängerung herab ging. Dort saßen die Parias, hatten die Aussicht auf den Altar und das Heiligthum, waren aber durch eine kleine Mauer davon getrennt, die sich nicht zu übersteigen wagten. Wo das Locale mit dieß nicht erlaubte, verbarg ich die Parias so gut, daß die Götzendiener sie nicht gewahr werden konnten [...] Doch mußte ich einige Mahle mein Amt ganz einstellen, wenn ich es nicht üben konnte, ohne entweder die Ruhe der Christen oder mein Gewissen zu verletzen. Bey andern Gelegenheiten verrichtete ich es mitten in der Nacht, und in geheim gegen die Heiden; denn diese hatte ich allein zu fürchten. $\mathrm{Zu}$ diesem letzern Mittel mußte ich auch meine Zuflucht nehmen, um die dritte Pflicht zu erfüllen; denn wenn man mich zu einem Parias hätte gehen sehen, so wäre alles verloren gewesen; Vertrauen und Credit gingen dann hinweg. ${ }^{613}$

\footnotetext{
${ }^{610}$ Vgl. Reinhard: Die Unterwerfung der Welt, S. 632f., 643f.; Lederle: Mission und Ökonomie der Jesuiten in Indien, S. 140 - 143

${ }^{611}$ Hell (Hg.): M. Perrin's Reise durch Hindostan. Band 2, S. 60

${ }^{612}$ Hell (Hg.): M. Perrin's Reise durch Hindostan. Band 2, S. 61

${ }^{613}$ Hell (Hg.): M. Perrin's Reise durch Hindostan. Band 2, S. $61 \mathrm{f}$
} 
Perrin versucht also, einen Kompromiss zwischen seinem Gewissen, das von ihm eine Gleichberechtigung aller Menschen verlangt, und den örtlichen Gegebenheiten zu finden.

Auch für Dubois und Salt stellt das Kastenwesen ein schwerwiegendes Problem dar. Dubois bemängelt, dass es dem Gebot der Liebe zu allen Menschen entgegenstehe ${ }^{614}$ und Salt betont, dass für die Inder nichts empörender sei als eben diese Gleichheit aller Menschen und dass man den Schwierigkeiten mit den Parias auch aus dem Grund nicht entgehen könne, da es gerade diese Gruppe von Menschen sei, die am ehesten bereit sei, sich dem Christentum zu öffnen. ${ }^{615}$

Der zweite Bereich, in dem über eine Anpassung an indische Gewohnheiten diskutiert wird, betrifft die sinnliche Ausgestaltung des Gottesdienstes und anderer kirchlicher Handlungen. Dubois äußert sich folgendermaßen:

\begin{abstract}
Da sie außerdem von allen Seiten von einer Religion umgeben sind, welche auf die Sinne wirkt, welche ihre Jünger durch alle Arten sinnlicher Belohnungen in diesem und dem künftigen Leben anlockt, so ist ihr Gemüth zu ungebildet, eine Religion zu verstehen, welche bloß auf den Geist wirkt, ihnen nur unerforschliche Geheimnisse darbietet und ihnen hauptsächlich geistige Freunde verheißt. Die Hindus sind vermöge ihrer Erziehung und ihrer Sitten von solcher Beschaffenheit, daß sie für Alles das völlig unempfindlich sind, was nicht einen gewaltigen Eindruck auf die Sinne macht. [...] In der That, wenn Sie sich mit den Hindus über die christliche Religion unterhalten, werden Ihnen Ihre Zuhörer in Allem, was Sie sagen, bereitwillig beistimmen; aber sie werden Nichts empfinden. [...] Da die ersten dortigen Missionarien die Macht der Sinne über dieses Volk bemerkten, und daß sich seine Einbildungskraft bloß durch starkwirkende Dinge wecken ließ, meinten sie, es werde der Sache der Religion einigen Nutzen bringen, wenn sie sich so viel als irgend möglich an die Neigungen desselben anschlössen. Dieser Ansicht zufolge hielten sie den gewöhnlichen Pomp und Prunk, welcher dem katholischen Cultus verbunden, von den protestantischen Gemeinden aber gemeiniglich getadelt wird, nicht für ergreifend genug für sie, um auf den groben Sinn der Hindus hinreichenden Eindruck zu machen. Sie beschwerten demnach den katholischen Cultus mit einer Zugabe erhöheten äußern Glanzes, welcher in Europa unbekannt ist, in vielen Stücken von dem unter den Heiden gewöhnlichen nicht eben sehr abweicht und durchaus ungeeignet ist, manchem guten und aufrichtigen römischen Katholiken eine Art von Erbauung zu verschaffen. ${ }^{616}$
\end{abstract}

Dubois schließt sich zwar der These an, dass die Inder nur für etwas empfänglich seien, was direkt auf die Sinne wirke, und dass das ein Problem bei der Missionierung sei,

\footnotetext{
${ }^{614}$ Vgl. Dubois: Briefe über den Zustand des Christentums, S. 59

${ }^{615}$ Vgl. Salt: Georg Viscount Valentia's und Heinrich Salts Reise nach Indien, S. 250

${ }^{616}$ Dubois: Briefe über den Zustand des Christentums, S. 63-65
} 
aber er lehnt Versuche, den kirchlichen Ritus dem indischen Prunk anzupassen ab. Sie dienten nicht der Erbauung. Und indisch-christliche Prozessionen, die er beschreibt, hätten ihn immer beschämt. Dubois scheint also der Ansicht zu sein, dass ein solches Christentum eher dem Heidentum ähnele und seinen Charakter aufgebe.

Auch der Soldat Best geht davon aus, dass sinnliche Elemente nützlich bei der Bekehrung der Inder seien und nutzt diese Feststellung für einen Seitenhieb gegen den Katholizismus, der indischen Formen des Gottesdienstes nahekomme:

Die Katholiken haben jedoch stärkeren Zulauf als die Protestanten, und ich vermuthe, daß die Ursache davon in den äußerlichen Ceremonien des Gottesdienstes liegt, den die katholischen Priester ganz dem Geschmacke der Indier einzurichten wissen. Bey den heiligen Processionen der Katholiken werden die Mutter Gottes und andere Heilige wie indische Götzen auf Tragsesseln umher geführt, und Feuerwerke dabey abgebrannt. Kurz, es fehlt dabey nichts, als die Tanzmädchen der Indier. ${ }^{617}$

Ebenso hält Salt fehlenden Prunk für ein Hindernis bei der Missionierung. Anders als Dubois und Best ist er einer gewissen Form der Anpassung aber nicht abgeneigt:

Der bischöflichen Würde muß der höchste Grad des Glanzes, den unsere Kirche verstattet, gegeben werden. Die Eingebornen Indiens sind an ceremoniösen Pomp gewöhnt und werden sehr durch äußern Schein beherrscht; bei unsrer Vernachlässigung der Religion fehlt es ihnen leider an aller Achtung für dieselbe, und natürlich mußten in den Gemüthern der Hindu's Zweifel über unsern eignen Glauben an die Lehre entstehen, die wir ihnen mit so vielem Eifer aufzudringen suchen. Die eingebornen Bewohner von Kalkutta können freilich durch den Anblick einer einzigen Kirche auf den Gedanken kommen, daß wir eine Nationalreligion haben, aber ich weiß nichts, was unsere übrigen ostindischen Unterthanen davon benachrichtigen könnte. Während die muhammedanischen Eroberer Indiens in jeder Stadt ihres Gebiets Moscheen errichtet haben, sucht der Reisende, nachdem er Kalkutta verlassen hat, vergebens einen ähnlichen Beweis der Religion ihrer Nachfolger. ${ }^{618}$

Salt plädiert dafür, die äußere Präsenz des Christentums zu stärken, um die sinnlich geprägten Inder zu erreichen. Allerdings soll das nur in dem Rahmen stattfinden, den „unsere Kirche verstattet“.

Perrin stellt ebenfalls fest, dass das Christentum im Vergleich z.B. mit den heidnischen Pagoden nicht auffallend genug sei. ${ }^{619}$ Dennoch hält er die christlichen Zeremonien für

\footnotetext{
${ }^{617}$ Best: Briefe über Ost-Indien, S. 22

${ }^{618}$ Salt: Georg Viscount Valentia's und Heinrich Salts Reise nach Indien, S. $249 f$.

${ }^{619}$ Vgl. Hell (Hg.): M. Perrin's Reise durch Hindostan. Band 2, S. 57f.
} 
ein sehr wichtiges Mittel der Bekehrung, allerdings in einem etwas anderen Sinne als Salt und Dubois:

Eines der gewöhnlichsten Mittel, welches der Herr anwendet, um sie zu seiner Religion zu führen, ist der Eindruck unserer Ceremonien, und der Geist des Christenthums, den sie mit ungewohntem Scharfblick durch die Übungen des Gottesdienstes hindurch erblicken. Sie schließen aus dem Ernste in der Verwaltung des geistlichen Amtes, daß wir vollkommen von den Wahrheiten, die wir predigen, überzeugt, und als aufgeklärte Menschen unfähig sind, betrogen zu werden oder uns in unsern Ansichten zu irren. ${ }^{620}$

Perrin sieht die Inder durchaus dazu in der Lage, in den äußeren Zeremonien die innere Ernsthaftigkeit zu erkennen und daraus auf die tiefe Überzeugung der Gläubigen zu schließen. Auch Paulinus a Sancto Bartholomaeo macht einen Vorschlag, der zwar in gewisser Weise auf die Sinnlichkeit der Inder eingeht, aber dennoch an deren Geist gerichtet ist: Man solle - so seine Idee - die Inder am besten mit religiösen Schriften in Versform bekehren, da diese Poesie liebten. ${ }^{621}$ Ähnlich äußert sich auch Dubois. ${ }^{622}$

Neben der Frage, auf welche Art und Weise die Inder bekehrt werden sollen, wird als zweiter großer Hauptpunkt immer wieder erörtert, warum die Missionsbemühungen so selten von Erfolg gekrönt sind. Neben dem oben bereits angesprochenen Punkt, dass die Inder an dem Althergebrachten hingen ${ }^{623}$ und den von Perrin aufgeführten Gründen Klima und Armut ${ }^{624}$ machen die meisten Autoren vor allem die lasterhafte Lebensart der Europäer sowie die schlechte Qualifizierung der Missionare für die Misserfolge verantwortlich.

Sowohl Dubois als auch Perrin stellen fest, dass das unsittliche Betragen vieler Europäer auf das Ansehen der christlichen Religion abfärbe. ${ }^{625}$ Perrin macht das besonders deutlich:

\footnotetext{
${ }^{620}$ Hell (Hg.): M. Perrin's Reise durch Hindostan. Band 2, S.126f.

${ }^{621}$ Vgl. Fra Paolino: Reise nach Ostindien, S. 205

${ }^{622}$ Die Übersetzung der Bibel solle der indischen Poesie ähneln (vgl. Dubois: Briefe über den Zustand des Christentums, S. 40).

${ }^{623}$ Vgl. dazu auch Dubois: Briefe über den Zustand des Christentums, S. 62.

${ }^{624}$ Perrin vertritt die These, dass das Klima einer Religion, die Müßiggang strikt ablehne, nicht zuträglich sei (spielt dabei auf die verbreite Annahme an, dass das warme Klima Indiens eben diesen Müßiggang fördere). Die Armut der Bevölkerung sei insofern ein Problem, als das Christentum vor allem mit „Versprechungen und Drohungen“ arbeite, für die elende Menschen kaum empfänglich seien (Hell (Hg.): M. Perrin's Reise durch Hindostan, S. 55).

${ }^{625}$ Vgl. Dubois: Briefe über den Zustand des Christentums, S. 15; Hell (Hg.) M. Perrin's Reise durch Hindostan. Band 2, S. 62f.; auch der Leutnant de Roques macht unter anderem das ausschweifende und lasterhafte Verhalten vieler Europäer für die Misserfolge bei der Missionierung verantwortlich, da die
} 
Und gewiß ist es, wenn die jetzigen Europäer sich mit Anstand benähmen, wenn die Indier in ihrer Aufführung Beweise ihres Glaubens sähen, so würden sie leicht das Vergangene vergessen, sich nur mit dem Gegenwärtigen beschäftigen, die Religion schätzen, weil sie die Weißen dieselbe schätzen sähen, und sie annehmen, wenn die Weißen tugendhafter wären, als sie selbst es sind. Aber die verdorbenen Sitten fast aller dortigen Europäer bewirken, daß die Indier eine Religion verachten, von der sie glauben, daß sie mit Ungerechtigkeit, Unmenschlichkeit, Geitz; Wildheit, Gottlosigkeit und den schändlichen Ausschweifungen sich vertrage. ${ }^{626}$

Er äußert sogar die Hoffnung, dass Indien in dreißig Jahren christlich sein könne, sofern die Europäer nicht durch ihren Lebenswandel dieses verhinderten. ${ }^{627}$

Doch nicht nur die europäischen Einwohner werden kritisch betrachtet, sondern auch die Missionare selbst. Perrin stellt fest, dass nicht alle Missionare Heilige seien. Einige Prediger widersprachen den heiligen Wahrheiten „durch Sitten, die selbst Heiden erröthen ließen, und diese dahin brachten zu schwören, sie würden nie eine Religion annehmen, bey welcher man solche entartete Diener derselben finde. “628 Noch deutlicher wird Lazzaro Papi, der seine antiklerikale Haltung anhand der katholischen Priester verdeutlicht:

Die katholischen Priester, welche von Mestizen abstammen, sind rohe unwissende Menschen, die ein schändliches Leben führen, der Völlerei und andern Lastern ergeben sind, und dem Müssiggange fröhnen. Die Ceremonieen und Gebräuche der römisch-katholischen Kirche, werden in ihren Händen dergestalt verunstaltet, daß man sich unmöglich des Lachens enthalten kann. ${ }^{629}$

Diese Pfaffen leben, im eigentlichen Wortverstande, vom Dienste des Altars, und machen sich auf die schändlichste Weise der Simonie schuldig. Die Bußübungen, welche sie sich auflegen, sind eben so lächerlich als unanständig. ${ }^{630}$

Kamen sie [die Missionare] wirklich in der Absicht nach Indien für das Seelenheil dieser Unglaubigen (sic) zu sorgen, so würden die meisten dieser Herren weit besser gethan haben, wenn sie in Europa geblieben wären. Eigentlich war es ihnen aber bloß darum zu thun, sich auf eine oder die andere Art in Freiheit zu setzen, weil sie des Klosterlebens überdrüssig

Inder nicht verstehen würden, dass dieses Verhalten den Gesetzen des Christentums zuwiderlaufe, sondern es den Gesetzen selbst zuschreiben würden (vgl. Roques: Ein Tagebuch aus Südindien, S. 276).

${ }^{626}$ Hell (Hg.) M. Perrin's Reise durch Hindostan. Band 2, S. 63

${ }^{627}$ Vgl. Hell (Hg.) M. Perrin's Reise durch Hindostan. Band 2, S. 133

${ }^{628}$ Hell (Hg.) M. Perrin's Reise durch Hindostan. Band 2, S. 87

${ }^{629}$ Briefe eines italienischen Reisenden, S. 460

${ }^{630}$ Briefe eines italienischen Reisenden, S. 461; die hier erwähnten Bußübungen beschreibt Perrin recht ausführlich und wohlwollend; das ist insofern interessant, als die Hindus immer wieder vor allem auch wegen ihrer strengen Bußübungen z.T. bewundert, in den meisten Fällen aber kritisiert werden; eine Ähnlichkeit zwischen den Bußübungen der Hindus und der Missionare scheint Perrin aber nicht zu sehen (vgl. Hell (Hg.) M. Perrin’s Reise durch Hindostan. Band 2, S. 90-94). 
waren. [...] Die Intriguen, wodurch sie nicht nur einzelne Familien entzweien, sondern sogar die Ruhe kleiner Staaten beeinträchtigen, in welchen sie über die Gemüther schwacher und einfältiger Menschen herrschen; die Unwissenheit, welche sie mit aus ihren Klöstern nach Indien bringen, die dummen und einfältigen Streiche, welche sie machen, weil sie mit den Sitten und Gebräuchen der Einwohner, in deren Ländern sie sich aufhalten, gar nicht bekannt sind; der Stolz, welcher sie antreibt, dieselben sogleich verbessern zu wollen; das pedantische Ansehen, welches sie sich in Beiseyn solcher Personen geben, die weit mehr Verstand besitzen, wie sie selbst; die kleinen elenden Kunstgriffe, welche sie erdenken müssen, um sich ihren nothdürftigen Lebensunterhalt zu verschaffen; dies Alles macht sie nicht nur bei den Fürsten und Rajahs, sondern bei allen Indiern überhaupt, nur den niedrigsten Pöbel ausgenommen, entweder lächerlich, oder noch überdies verhaßt und verächtlich. ${ }^{631}$

Salt schlägt zur Lösung des Problems die Einsetzung eines Bischofs für Indien vor, der durch strenge Aufsicht die Geistlichen zu einem gesitteteren Lebenswandel anhalten solle. ${ }^{632}$

All dies führe dazu, dass fast ausschließlich aus ihrer Kaste Verstoßene, Parias und von der Armut Getriebene Christen würden. Auch die Heirat mit einem Christen/einer Christin oder ein Konflikt mit Beamten könnten $\mathrm{zu}$ einer Konversion führen. Angesehene und wohlhabende Inder würden diesen Schritt aber äußerst selten gehen. Denn wer Christ werde, der müsse damit rechnen, dass er von allen anderen geächtet und verlassen würde und sein Leben in der bisherigen Form aufgeben müsse. ${ }^{633}$ Dem widerspricht der Missionar Schwarz allerdings vehement: Man habe nicht nur Parias bekehrt, sondern auch viele Angehörige höherer Kasten. ${ }^{634}$

Insgesamt lässt sich also sagen, dass es in den Texten über Indien nur sehr selten um die Frage geht, inwieweit Mission an sich moralisch vertretbar ist. Vielmehr geht es um Fragen des Vorgehens der Missionare vor Ort und um mögliche Erfolgsaussichten. Dem entspricht, dass es fast ausschließlich Missionare sind, die sich zu diesem Thema äußern. Sie sehen sich in ihrer Arbeit direkt mit den für sie fremden Umständen konfrontiert und werden dabei vor die Frage gestellt, welche Aspekte ihrer eigenen christlichen Kultur so eng mit dem Christentum verbunden sind, dass sie für dieses

\footnotetext{
${ }^{631}$ Briefe eines italienischen Reisenden, S. 462f.

${ }^{632}$ Vgl. Salt: Georg Viscount Valentia's und Heinrich Salts Reise nach Indien, S. 247, 253

${ }^{633}$ Vgl. Dubois: Briefe über den Zustand des Christentums, S. 12; Briefe eines italienischen Reisenden, S. 462; Fra Paolino: Reise durch Ostindien, S. 306; Hindernisse, die den Missionen in Indien entgegenstehen. Aus dem Englischen. In: Minerva. Ein Journal historischen und politischen Inhalts 94 (1815), S. 161-168, hier S. 162-164; Briefe auf einer Reise von Stade nach Madras, S. 118f.; Roques: Ein Tagebuch aus Südindien, S. 276

${ }^{634}$ Vgl. Knapp (Hg.): Neuere Geschichte der Evangelischen Missions-Anstalten. Fünfter Band. 51. Stück, S. 276-278
} 
unverzichtbar sind, und welche europäisch, aber nicht direkt christlich sind. Welche eigenen Traditionen können bei der Mission in Indien durch indische Gewohnheiten ersetzt werden? Außerdem wird die Mission häufig vor dem Hintergrund der allgemeinen Indienpolitik diskutiert und die Frage erörtert, ob sie der Politik der Engländer schade oder nutze.

\section{Mythologie, Religion und Philosophie}

Einer der wichtigsten Bereiche innerhalb des Indiendiskurses ist die Auseinandersetzung mit indischen Mythologien, Religionen und Philosophien. Diese Themen beschäftigten bereits die Missionare der frühen Neuzeit, die - wie oben gezeigt - sich zur Bekehrung der „Heiden“ mit deren religiösen Vorstellungen und Begriffen auseinandersetzten. Auch später erfreuen sich diese Themen großen Interesses, auch wenn sich die Motivation verändert hat. Da dieses Themengebiet sehr umfangreich ist und sich auch viele Autoren damit beschäftigen, möchte ich im Folgenden lediglich auf die Aspekte näher eingehen, die besonders häufig oder intensiv diskutiert werden.

\subsection{Verschiedene Religionsgruppen}

Obwohl den Autoren bewusst ist, dass es in Indien verschiedene Religionsgruppen gibt, gilt die Aufmerksamkeit fast ausschließlich den Hindus. Muslime, Juden und die sogenannten Thomaschristen werden in den hier analysierten Texten nur am Rande erwähnt. Der Buddhismus erlangt erst etwas später größere Bekanntschaft und spielt daher in den Texten ebenfalls nur eine Nebenrolle. Und auch die Sikhs werden nur von wenigen Autoren beschrieben. So erwähnt zwar der Lexikoneintrag von 1809 Muslime, Sikhs und Hindus, geht aber nur auf letztere ausführlicher ein. ${ }^{635}$ Perrin erwähnt die Muslime kurz, attestiert ihnen aber lediglich einen gering ausgeprägten Glauben, ohne auf Lehren oder Bräuche einzugehen. ${ }^{636}$ Der englische Indienreisende Forster, der aufgrund seiner Reise von Kalkutta über Kaschmir und weiter nach Europa große Teile Nordindiens aus eigener Anschauung kennt, beschreibt als einer der wenigen die Gruppe der Sikhs. Sie verehrten einen Gott und beteten keine Bilder oder sonstigen Mittler an. Obwohl sie eine eigene Religionsgemeinschaft seien, folgten sie dennoch

\footnotetext{
${ }^{635}$ Vgl. Conversations-Lexikon 1809, S. 335

${ }^{636}$ Vgl. Hell: M. Perrin's Reise durch Hindostan, S. 16
} 
manchmal alten Bräuchen der Hindus. ${ }^{637}$ Ausführlicher werden sie hingegen von Matthias Sprengel in einem Aufsatz von 1802 dargestellt. ${ }^{638}$

Über den Buddhismus äußern sich zwar etwas mehr Autoren, aber es wird immer wieder deutlich, wie groß die Unwissenheit und Unsicherheit diesbezüglich lange sind, auch weil es zunächst keinen Zugang zu buddhistischen Schriften gibt. Das zeigt sich z.B. im folgenden Zitat Lazzaro Papis:

Buddha, Merkur, Odin und Foe, sollen ein und derselbe Gott gewesen seyn [...]. Sonnerat ist der Meinung, Buddha und Rama wären einerlei. Andere halten ihn für den Noah, andere für den Moses und noch andere für den Siphoa, den fünf und dreißigsten König Ägyptens. [...] Herr Jones meint, der Buddha der Hinduer sey zuverlässig derselbe Gott, der von den Chinesen Fo, oder Foe, genannt werde [...]. Was hiernächst die Meinung betrifft, als wenn Buddha der Merkur sey, so versichert mich mein Pandit, daß Buddha, als eine Avatara oder Verwandlung des Wischnu, durchaus nicht mit jenem Buda verwechselt werden dürfe, welchen die Indier für den Gott oder Genius des Planeten Merkur halten [...]. ${ }^{639}$

Man sieht deutlich, dass nicht nur verschiedene Deutungen zu Buddha diskutiert werden, sondern mit diesem Namen auch verschiedene Götter bzw. Personen bezeichnet werden, nämlich zum einen der Begründer des Buddhismus (chinesisch Fo) und zum anderen die neunte Inkarnation Viṣnus, die nicht von allen Autoren unterschieden werden. Auch Papi, der sich ausführlicher mit dem Buddhismus auseinandersetzt, ist sich hinsichtlich einer möglichen Identität beider nicht sicher. Buddha selbst beschreibt er als einen Reformator, denn es sei

\begin{abstract}
wahr, daß Buddha die Lehrsätze der Braminen in vielen Stücken reformirt hat. Die Braminen gestehen dies selbst ein, wiewohl sich übrigens noch immer nicht ausmitteln läßt, ob der Buddha, welchen die Einwohner von Barma verehren, das Nämliche geglaubt hat, was jener Buddha glaubte, welcher in der neunten Avatara des Wischnu auf Erden erschien, oder ob er als Gaudama [...] mit dem Resci Gautama einige Ähnlichkeit hat, dessen Frau vom Indra verführt wurde. ${ }^{640}$
\end{abstract}

Auch Creuzer ${ }^{641}$ und Humboldt sehen im Buddhismus eine Reform der brahmanischen Lehren, auch wenn Humboldt noch 1823 schreibt, dass ihm der Unterschied zwischen

\footnotetext{
${ }^{637}$ Vgl. Forster: Reise aus Bengalen, S. 255f.

${ }^{638}$ Vgl. Sprengel, Matthias: Über die Sieks in Hindostan. In: Asiatisches Magazin 1,3 (1802) S, 181200

${ }^{639}$ Briefe eines italienischen Reisenden, S. 153-155; auch Jones zieht in Betracht, dass Buddha mit Odin gleichzusetzen sei (vgl. Sedlar: India in the Mind of Germany, S. 38f.)

${ }^{640}$ Briefe eines italienischen Reisenden, S. 159f.

${ }^{641}$ Vgl. Creuzer: Symbolik und Mythologie der alten Völker. 2. Auflage. Band 1, S. 577
} 
Brahmanen und Buddhisten nie ganz klar gewesen sei. ${ }^{642}$ Die Kenntnisse über den Buddhismus und das Interesse an ihm wachsen mit der Zeit allerdings an. Von einem Studium des Buddhismus kann man aber erst ab 1826 reden, da in diesem Jahr eine wichtige Arbeit über Pali erscheint. ${ }^{643}$ Dass diese Forschung auf Interesse stößt, zeigt sich z.B. an einem Artikel im Morgenblatt für gebildete Stände aus dem Jahr 1826, in dem die Lehren der Brahmanen und Buddhisten vergleichend gegenübergestellt werden und sowohl auf Ähnlichkeiten als auch Unterschiede hingewiesen wird. ${ }^{644}$

Da der Großteil der Texte, die sich mit Religion in Indien beschäftigen, sich fast ausschließlich auf die hinduistischen Traditionen beziehen, werde ich mich in den folgenden Darstellungen ebenfalls darauf beschränken. Der später sogenannte Hinduismus wird von den meisten Autoren um 1800 als eine einheitliche Religion aufgefasst. Dennoch sind sie sich bewusst, dass es innerhalb dieser Religion sehr verschiedene Strömungen und Ansichten gibt, die sie zumeist als „Sekten“ bezeichnen. Berichte über unterschiedliche Gruppen innerhalb der hinduistischen Religion finden sich bereits im 17. Jahrhundert bei Dapper. ${ }^{645}$ Trotz möglicher Unterschiede im Detail werden von den meisten Autoren zwei „Sekten“ angenommen: die Anhänger Viṣnus und Śivas. ${ }^{646}$ Diese „Sekten“ beschäftigen die Autoren immer wieder, und es wird versucht, sie zu ordnen - vor allem chronologisch in ihrer Entstehung, aber auch inhaltlich. Ein sehr verbreitetes Erzählmuster ist, dass die Sekte der Anhänger Brahmās von den Anhängern Viṣnus und Śivas in einem großen Krieg vernichtet worden sei und mit ihnen auch ihre Tempel. Diese vernichtete Sekte Brahmās gilt dabei vielen Autoren als die ursprünglichste und reinste indische Lehre. So schreibt z.B. Creuzer:

\begin{abstract}
Die älteste Religion, die in das Dunkel der Vorwelt zurücktritt, ist diejenige, welche durch Brahma, den Schöpfer der Welt, offenbart wurde, Brahmaismus. Diesem Brahma (dem höchste Wesen, welches in der Indischen Lehre von der Dreifaltigkeit Gottes die erste Person ist, Gott der Vater), dem ersten Gott und Lehrer im Fleisch, haben vor vielen Jahrtausenden die Menschen auf fromme Weise, mit ihren Herzen in heiliger Unschuld, einfach, Schlicht und rein gedienet mit unblutigen Opfern, mit den Erstlingen der Früchte, mit der Milch der zahmen Thiere u.s.w. Aber diese Religion konnte auf der bösen Erde nicht fortbestehen, sie
\end{abstract}

\footnotetext{
${ }^{642}$ Vgl. Leitzmann, Albert (Hg.): Briefwechsel zwischen Wilhelm von Humboldt und August Wilhelm Schlegel. Herausgegeben von Albert Leitzmann. Mit einer Einleitung von B. Delbrück. Halle 1908, S. 149 (Mai 1823)

${ }^{643}$ Vgl. Sedlar: India in the Mind of Germany, S. 39

${ }^{644} \mathrm{Vgl}$. Hauptunterschied in den Lehren der Buddhisten und der Braminen. In Morgenblatt für die gebildeten Stände 20 (1826; Nr. 270 November), S. 1079

645 Vgl. Dapper: Asia, S. 17-19

${ }^{646}$ Vgl. Conversations-Lexikon. 1809, S: 336; Forster: Reise aus Bengalen, S. 38
} 
musste weichen und wurde so gänzlich ausgerottet, dass auch keine Spur mehr übrig ist von jenen alten Tempeln, in denen Brahma verehrt wurde. ${ }^{647}$

Nachdem diese erste Lehre etwa tausend Jahre gegolten, folgen nun Religionskriege. Es kommt Schiwa, die zweite Incarnation, und bringt den Lingam, als Bild des Todes und Lebens. Die alte, stille, einfache Feier musste dem neuen Orgiasmus Platz machen. In wilden Festen berauscht sich die religiöse Phantasie, und blutige Opfer fallen an den Altären der schrecklichen Cali. ${ }^{648}$

Es folgt Wischnnu, die dritte Incarnation, welcher das wilde Feuer des Schiwaismus sänftigt. Wischnu milderte den Lingamdienst, trieb aus den groben Stoff, vergeistigte und stumpfte ab die herbe Schärfe. ${ }^{649}$

Die erste reine und unschuldige Religion sei verdrängt worden vom blutigen „Orgiasmus“, der später etwas abgemildert worden sei. Diese Vorstellung von einem Verfall der ehemals hochstehenden indischen Religion ist um 1800 sehr verbreitet und wird uns im Folgenden noch weiter begegnen.

Auch Friedrich Majer beschäftigt ein Jahr zuvor die These der Vernichtung der Religion Brahmās, die er ähnlich wie Creuzer als rein und unverfälscht bezeichnet:

Die älteste ausgebildete, aber in ihrer ursprünglichen Gestalt schon seit Jahrtausenden nicht mehr vorhandene Religion der Indier war diejenige, welche in den frühesten Zeiten des Menschengeschlechts durch Brahma, den Schöpfer und Herrn aller Dinge, offenbart wurde. Das Gemeinsame in der Denkart der drei andern einheimischen religiösen Hauptsekten Indiens ist unmittelbar, oder mittelbar aus derselben hervorgegangen. ${ }^{650}$

Das gänzliche Aufhören des eigentlichen Brahmaismus, der Verfall des auf die reine und unverfälschte Lehre und Religion des Brahmaveda gegründeten Kultus, ist in ein geheimnißvolles Dunkel gehüllt. Nur so viel ist gewiß, daß seitdem auch die darin vorgeschriebene Verehrung des Brahma im Allgmeinen abgekommen ist. ${ }^{651}$

Um zu erklären, warum gegenwärtig keine Tempel, keine Verehrung und keine Verehrer des Brahma mehr gefunden werden, erzählen die heutigen Indier: die Anhänger des Siwa und Wischnu hätten sich in längst verflossenen Zeiten miteinander verbunden, die Sekte des Brahma vertilgt, und ihre Tempel zerstört, damit seine Verehrung auf immer in Vergessenheit kommen möchte. Andere sagen: Brahma werde in den Brahmanen, und diese würden statt seiner verehrt, weil sie von seinem Geschlecht wären, weil er in ihnen wohne $\left[\ldots . .6{ }^{652}\right.$

Majer macht nicht mit letzter Sicherheit Religionskriege für das seltsame Fehlen von

Tempeln für Brahmā verantwortlich. Berichte indischer Zeitgenossen legten das nahe,

\footnotetext{
${ }^{647}$ Creuzer: Symbolik und Mythologie der alten Völker. 2. Auflage, Band 1, S. 569f.

${ }^{648}$ Creuzer: Symbolik und Mythologie der alten Völker. 2. Auflage, Band 1, S. 575

${ }^{649}$ Creuzer: Symbolik und Mythologie der alten Völker. 2. Auflage, Band 1, S. 576

${ }^{650}$ Majer, Friedrich: Brahma oder die Religion der Indier als Brahmanismus. Leipzig 1818, S. 3

${ }^{651}$ Majer: Brahma, S. 21

${ }^{652}$ Majer: Brahma, S. 22
} 
aber es sei auch möglich, dass die Verehrung der Brahmanen an die Stelle der Verehrung des Gottes Brahmā getreten sei. Da Majer anschließend viele Beispiele für Kämpfe und Streit zwischen den Göttern aufzählt, tendiert sein Beitrag in eine ähnliche Richtung wie derjenige Creuzers.

Bereits bei Sonnerat finden sich Hinweise auf das Auslöschen der Sekte Brahmās. Dabei stehen für Sonnerat interessanterweise weniger die Unterschiede dieser Religionsgruppen als vielmehr ihre Gemeinsamkeiten im Mittelpunkt. Sie unterschieden sich zwar durch ihre Zeremonien und Gebete, aber ihre übrigen Feste und Gebräuche und auch ihre wichtigsten Lehren stimmten überein. ${ }^{653}$

Es gibt aber auch Autoren, die unterschiedliche Religionsgruppen nicht an den drei Göttern Brahmā, Viṣṇu und Śiva festmachen, sondern an unterschiedlichen Lehren. ${ }^{654}$ Perrin stellt lediglich fest, jeder Inder habe seinen Lieblingsgott, und weist darauf hin, dass seiner Beobachtung nach die Inder zwar nicht alle Götter gleich stark verehrten, aber dennoch aus Furcht vor den übrigen Göttern sich davor hüteten, diese zu verachten. ${ }^{655} \mathrm{Zu}$ Berichten über die alten, traditionellen Sekten der Hindus kommen noch vereinzelte Hinweise auf neu entstehende reformatorische Sekten. Diese seien wie viele europäische Autoren davon ausgegangen, dass die ursprüngliche Religion der Hindus verfallen sei, und wollten durch eine Art Reformation zurück zu diesen reinen Lehren. ${ }^{656}$ Wichtig sei vor allem der gelehrte Brahmane Ram-Mohun-Roy, der auch europäische Wissenschaften sowie die christliche und muslimische Religion kenne. Er behaupte,

daß die Hindus von ihrer Religion, so wie sie in den Wedas und in der Wedanta enthalten ist, ganz abgewichen sind, und an die Stelle des reinen Glaubens an einen Gott, der darin gelehrt werde, eine abscheuliche Vielgötterey und einen sehr verächtlichen Aberglauben eingeführt haben,

\footnotetext{
${ }^{653}$ Vgl. Sonnerat: Reise nach Ostindien, S. 101

${ }^{654}$ Briefe eines italienischen Reisenden, S. 225; Religionsparteyen der Indier. In Morgenblatt für die gebildeten Stände 3 (1809; Nr. 150 Juni), S. 597-598

${ }^{655}$ Vgl. Hell: M. Perrin's Reise durch Hindostan, S. 15

656 „Es sind seit einiger Zeit von mehrern Hindus Sekten errichtet worden, welche den gemeinen Götzendienst und Aberglauben eifrig bestreiten, reinere Begriffe von Gott und Religion hegen, und sich eines moralisch-bessern Lebenswandels befleißigen, als der große Haufe ihrer Landsleute. Einige dieser Sekten haben auch den Kastenunterschied aufgehoben, welcher eine der Hauptfestungen Satans in Indien ist (!). Dieses ist ein sehr wichtiges Ereigniß. Denn man hat Ursache zu hoffen, da, wenn diese Festung erst von dem Fürsten des Friedens erobert worden ist, das ganze Land sich bald seinem segensreichen Scepter unterwerfen wird.“ (Über Reformatoren unter den Hindus. In: Morgenblatt für gebildete Stände 15 (1821; Nr. 249 Oktober), S. 994f. hier S. 994)
} 
und daß sie daher ihre jetzigen religiösen Meinungen und Gebräuche auf keine Weise zu vertheidigen im Stande sind. ${ }^{657}$

Indem betont wird, dass der Reformator von westlichen Einflüssen und Ansichten geprägt sei, kann man in ihm ein Beispiel für das im Zusammenhang mit der Theorie des Orientalismus diskutierten Phänomens sehen, dass einige der von den Europäern beschriebenen Menschen diese Zuschreibungen aufgreifen, übernehmen und zu einem Teil der eigenen Identität machen. In diesem Fall übernimmt der indische Gelehrte die europäische Ablehnung des zeitgenössischen indischen Götterglaubens sowie die Vorstellung, dass dieser nur eine Verfallserscheinung des eigentlich guten ursprünglichen Glaubens sei. Der Autor des hier zitierten Artikels sieht das allerdings anders und merkt an, dass er an den Reformator geschrieben habe, dass die Veden nicht Monotheismus, sondern eher einen Pantheismus lehrten. Er ist also der Ansicht, die alten indischen Texte besser $\mathrm{zu}$ verstehen als die Inder selbst. Dieses Überlegenheitsgefühl der eigenen Gelehrsamkeit ist unter den europäischen Autoren weit verbreitet und zwar nicht nur bei denjenigen, die der indischen Kultur allgemein eher kritisch gegenüberstehen, sondern oft auch bei denjenigen, die die alten indischen Schriften bewundern. Auch hier spielt das Motiv des Verfalls der ehemals hohen Kultur Indiens eine Rolle.

Nicht nur aufgrund der zunächst nur spärlichen Informationen, sondern vor allem auch wegen der vielen unterschiedlichen religiösen Texte mit sich scheinbar oder tatsächlich widersprechenden Lehren erscheint die Religion der zunächst sogenannten „heidnischen“ Inder vielen Europäern als eine „sehr merkwürdige und sonderbare Lehre“, als „außerordentlich dunkel“ ${ }^{658}$. Sie sei so kompliziert, dass selbst die gelehrtesten Inder sie nicht verständlich erklären könnten ${ }^{659}$ bzw. sie selbst nicht mehr verstünden. ${ }^{660}$ Erklärt werden diese Widersprüchlichkeiten z.B. durch Geheimhaltung und Täuschung seitens der Brahmanen oder durch den bereits erwähnten angenommenen Verfall der Religion. ${ }^{661}$ Für viele Europäer scheint das Unsystematische der indischen Lehren nur schwer zu ertragen sein, was zur Folge hat, dass es immer wieder Versuche gibt, die Lehren zu systematisieren. King spricht sogar davon, dass der Hinduismus eine westliche Konstruktion sei, die der Diversität des

\footnotetext{
${ }^{657}$ Über Reformatoren unter den Hindus, S. 994

${ }^{658}$ Conversations-Lexikon. 1809, S. 335

${ }^{659} \mathrm{Vgl}$. Forster: Reise aus Bengalen, S. 30

${ }^{660} \mathrm{Vgl}$. Conversations-Lexikon. 1809, S. 335

${ }^{661}$ Vgl. z.B. Conversations-Lexikon. 1809, S. 335
} 
indischen Glaubens lange Zeit nicht gerecht geworden sei. Den Europäern sei es aufgrund ihrer eigenen Erfahrungen nicht möglich sich vorzustellen, dass verschiedene Lehren nebeneinander ohne Konflikte bestehen könnten. Dieser Gedanke scheint außerhalb der Möglichkeiten dessen, was in Diskursen über Religionen bzw. Konfessionen gedacht und gesagt werden kann, zu stehen. King führt aus, dass sie daher dazu neigten, die unterschiedlichen Lehren als Teile einer übergeordneten Einheit zu interpretieren, was dazu führe, dass diese konstruierte Religion des Hinduismus verworren und ungeordnet erscheine. Die Annahmen der westlichen Gelehrten und ihre Konzentration auf die schriftliche Tradition der Brahmanen unter Abwertung der zeitgenössischen religiösen Praxis beeinflusse aber ihrerseits die indische Selbstwahrnehmung, da einige Inder zur Festigung der nationalen Identität auf sie zurückgriffen. ${ }^{662}$ Auch Inden sieht in dem vom Westen beschrieben Hinduismus ein Konstrukt, das der Sicherung der Herrschaft diene. ${ }^{663}$ Hier ist nicht der Ort, die Beschreibungen der europäischen Gelehrten mit den neuesten Forschungen der Indologie $\mathrm{zu}$ vergleichen. Aber die beschriebenen Tendenzen, die religiösen Strömungen zu systematisieren und $\mathrm{zu}$ vereinheitlichen und alles Abweichende als Degeneration anzusehen, werden aus den untersuchten Texten deutlich. ${ }^{664}$

\subsection{Die Suche nach mythologischen Gemeinsamkeiten}

Mit Herders Sammlungen von Volksliedern, in denen er den ursprünglichen Charakter der Poesie und des jeweiligen Volkes ausgedrückt sieht, ${ }^{665}$ richtet sich das Interesse auch auf Literaturen aus bislang eher unbeachteten Kulturen. Zudem stehen bei der Suche nach der ursprünglichen Poesie nicht mehr nur ein Kanon von hoher Literatur im Mittelpunkt, sondern verstärkt auch Texte, die wie viele Volkslieder nicht direkt auf einen Autor zurückgeführt werden können und daher weniger künstlich zu sein scheinen: Märchen und Mythen. Sie gelten vielen Vertretern der Romantik als

\footnotetext{
${ }^{662} \mathrm{Vgl}$. King: Orientalism and Religion, S. 98-105

${ }^{663} \mathrm{Vgl}$. Inden: Imagining India, S. 85f.

${ }^{664}$ Wie sehr diese Auffassung ,des“ Hinduismus als einer einheitlichen und daher verwirrend widersprüchlichen Religion die Wahrnehmung indischer Religiosität durch den Westen bestimmt hat und häufig noch immer bestimmt, macht Antje Linkenbach exemplarisch an Darstellungen in Schulbücher aus den 1970er bis 1990er Jahren deutlich (vgl. Linkenbach, Anje: Weltreligion Hinduismus: Zur Konstruktion des Indienbildes in deutschen Schulbüchern. In: Bultmann, Christoph u. Linkenbach, Antje (Hgg.): Religionen übersetzen. Klischees und Vorurteile im Religionsdiksurs. Münster 2015 (Vorlesungen des Interdisziplinären Forums Religion der Universität Erfurt; 11), S. 2343, hier S. 33-43

${ }^{665}$ Vgl. Buschmeier, Matthias u. Kauffmann, Kai: Einführung in die Literatur des Sturm und Drang und der Weimarer Klassik. Darnstadt 2010 (Einführungen Germanistik), S. 57
} 
Ausdruck des kollektiven Unbewussten und somit als Offenbarung der göttlichen Natur. ${ }^{666}$ Sie spielen aber auch eine wichtige Rolle bei dem Versuch einer Erneuerung der europäischen Literatur. Schon in der „Rede über die Mythologie“ hat Friedrich Schlegel beklagt, dass es der deutschen Literatur an einer Mythologie, die der Literatur als Mittelpunkt dienen könne, fehle. Ähnlich wie im „Ältesten Systemprogramm“ des deutschen Idealismus schlägt auch Schlegel vor, selbst eine neue Mythologie zu erschaffen. ${ }^{667}$ Dieses zunächst stark ästhetische Interesse der Romantik an der Mythologie wird später oftmals abgelöst oder ergänzt durch eine Hinwendung zu religiösen Fragen, die z.B. auch Ausdruck in der Konversion Schlegels zum Katholizismus findet. Dies verändert freilich die Sichtweise auf die Mythologie, schmälert aber kaum deren Bedeutung als ein wichtiges Thema, mit dem man sich auseinandersetzen sollte.

Eine Möglichkeit, sich den zunächst fremden religiösen Vorstellungen und Riten anzunähern und sie an Bekanntes anzuknüpfen, liegt in dem Vergleich der indischen Mythen mit den vertrauten griechischen, römischen sowie den schon früher bekannt gewordenen ägyptischen Mythen. Ein solcher Vergleich ist nicht neu. Bereits die Griechen und Römer hatten die für sie fremden orientalischen Götter (z.B. aus der ägyptischen Mythologie) in das klassische Pantheon aufgenommen. ${ }^{668}$ Als im 18. Jahrhundert vergleichende Religionsstudien immer populärer werden, wächst auch die Beliebtheit neuerer Vergleiche von indischen, ägyptischen und klassisch-antiken Göttern. So setzte bereits 1724 La Croze nicht nur Osiris und Bacchus gleich (wie das bereits Herodot getan hatte), sondern sah auch im indischen Gott Śiva eine weitere Variante dieser Gottheit. Diese Gleichsetzungen und Einordnungen in das vertraute Pantheon der klassischen Antike ermöglichen es, sich der fremden indischen Götterwelt in einem bekannten Rahmen und mit Hilfe vertrauter Vorstellungen anzunähern. ${ }^{669}$ Eng damit verbunden ist auch ein in dieser Zeit beginnender Umbruch in der Interpretation der griechischen Kultur. Indem sich das Interesse vieler Autoren nun weniger auf die Unterschiede zu anderen Kulturen, sondern vor allem die Gemeinsamkeiten richtet,

\footnotetext{
${ }^{666}$ Vgl. Hoffmeister, Gerhart: Deutsche und europäische Romantik. Zweite Auflage. Stuttgart 1990 (Sammlung Metzler; 170), S. 146

${ }^{667}$ Vgl. Pikulik, Lothar: Frühromantik. Epoche - Werke - Wirkung. Zweite Auflage. München 2000, S. 157-160

${ }^{668}$ Vgl. Mitter: Much maligned monsters, S. 82

${ }^{669}$ Vgl. Mitter: Much maligned monsters, S. 79, 83
} 
rücken auch Aspekte der griechischen Kultur ins Blickfeld, die zuvor kaum berücksichtigt worden sind (z.B. die Bedeutung von Phallussymbolen, die sich eben nicht nur in den orientalischen, sondern auch in der griechischen Mythologie finden, was entsprechende Funde in Herculaneum bestätigen). Die später von Nietzsche bekannt gemachte These des Dionysischen in der griechischen Kultur beginnt sich herauszubilden. ${ }^{670}$

Während für die Frühromantik die Bedeutung des Mythos eine ästhetische ist und es in der Auseinandersetzung mit den alten Mythologien nicht um deren Erforschung geht, sondern eine neue Mythologie als Bezugspunkt für die Dichtung geschaffen werden soll, sind die späteren romantischen Mythologen wie Creuzer oder Görres deutlich weniger auf die Zukunft ausgerichtet. Sie versuchen durch den Vergleich der möglichst ältesten mythologischen Dichtungen verschiedener Kulturen die eine ursprüngliche, allen alten Völkern gemeinsame (Natur-)Offenbarung zu rekonstruieren. Dieser Wandel zeigt sich exemplarisch bei Friedrich Majer: Hat er zunächst versucht, mit Hilfe der Mythologie die sich aus ihr entwickelte Dichtung zu verstehen, so sieht er später in ihr eine Quelle für Informationen über die Vorzeit und das Wesen aller Religionen. ${ }^{671}$

Die synkretistischen Zusammenstellungen von verschiedenen Göttern aus unterschiedlichen Mythologien sind in den ersten zwei Jahrzehnten des 19. Jahrhunderts in einigen Kreisen sehr beliebt. Sie unterschieden sich jedoch voneinander hinsichtlich der Motivation sowie darin, ob die Götter in eins gesetzt, gleichen Prinzipien zugeordnet oder einfach verglichen werden. Natürlich gibt es auch bei der Zuordnung und Zusammenfassung der verschiedenen Götter und anderer mythologischer Gestalten Unterschiede zwischen den einzelnen Autoren, ${ }^{672}$ aber auf diese möchte ich hier nicht näher eingehen. Eine genaue Untersuchung, welcher Autor

\footnotetext{
${ }^{670}$ Vgl. Mitter: Much maligned monsters, S. 80; Safranksi, Rüdiger: Romantik. Eine deutsche Affäre. München 2007, S. 161f.; Becker-Cantarino: Mythos und Symbolik bei Karoline von Günderode und Friedrich Creuzer.. In: Strack, Friedrich (Hg.): 200 Jahre Heidelberger Romantik. Heidelberg 2008 (Heidelberger Jahrbücher; 51), S. 281-298, hier S. 291

${ }^{671}$ Vgl. Tzoref-Ashkenazi: Der romantische Mythos vom Ursprung der Deutschen, S. 85-88; Kramer: Verkehrte Welten, S. 21, 24; Safranski: Romantik, S. 156-159; Willson: A mythical image, S. 105-107 ${ }^{672}$ Das wird z.B. bei der Auseinandersetzung Dalbergs mit dem indischen Kṛṣna deutlich: „Krshna und die ganze indische Mythe von ihm, ist sehr verschieden gedeutet. Einige finden in ihm den Apollo Nomios der Griechen, oder die Dichtung dieses Volks, von dem Hirtenleben Apollo's. Andere finden wieder die Pandionen der Griechen darinn, und noch andre endlich glauben, dass Krshna der verdorbene Name Christi sey, dessen Geschichte in apocryphischen Evangelien nach Indien herübergebracht worden.“ (Dalberg, F. H. von: Gita-govinda oder die Gesänge Jajadeva's eines altindischen Dichters. Aus dem Sanskrit ins Englische, aus diesem ins Deutsche übersetzt mit Erläuterungen. Erfurt 1802, S. 97f.)
} 
welche indischen Götter mit welchen griechischen, römischen, ägyptischen etc. Göttern vergleicht bzw. gleichsetzt, würde nicht nur zu umfangreich werden, sondern auch wenig zielführend sein. Im Folgenden möchte ich daher mein Augenmerk vor allem darauf richten, was die Motivation für den Mythenvergleich ist und ob die Mythen gleichgesetzt oder nur vergleichend analysiert werden.

Bereits Jones hat die zunächst fremden indischen Götter vor dem Hintergrund des antiken Pantheons interpretiert und somit in den Bereich des Vertrauten überführt:

\begin{abstract}
Wir begnügen uns hier mit der Behauptung dessen, was wir außer allem Streit darthun könnten: nehmlich, daß wir hier (in Indien) unter den Anbetern eben der Gottheiten leben, die in dem alten Griechenland und Italien unter verschiedenen Nahmen göttlich verehrt wurden; daß wir die Anhänger jener philosophischen Grundsätze um uns haben, welche die Ionischen und Attischen Schriftsteller mit allen den Schönheiten ihrer melodischen Sprache erläuterten. [...] Auch die Scythischen und Hyperboreischen Lehren und Mythologieen können in diesen östlichen Gegenden aufgefunden werden. Es ist ebenfalls keinem Zweifel unterworfen, daß Wod oder Oden, dessen Religion, dem Berichte der nordischen Schriftsteller zufolge, ein fremder Stamm in Scandinavien einführte, der Buddha der Indier gewesen ist. ${ }^{673}$
\end{abstract}

Jones geht davon aus, dass die Götter Indiens dieselben seien wie die anderer antiker Völker, die in den verschiedenen Kulturkreisen lediglich unter verschiedenen Namen verehrt würden. Auch bei den philosophischen Lehren der verschiedenen Völker gebe es Entsprechungen. Damit hebt er die indischen Götter bis auf die exotischen Namen völlig in den vertrauten Rahmen der griechischen Mythologie. Die indische Mythologie verliert damit in gewisser Weise ihre Eigenständigkeit und wird zu einer bloßen weiteren Variante des bereits Bekannten. Interessant ist, dass Jones schreibt, er lege hier nur dar, was „außer allem Streite“ sei, ganz so als sei die Gleichsetzung der verschiedenen mythischen Gestalten ein unumstrittener Fakt. Dass dem jedoch nicht so ist, werden wir später noch sehen. Die Ähnlichkeit zwischen den verschiedenen Mythologien führt Jones darauf zurück, dass „,schon vor undenklichen Zeiten eine Verbindung statt gefunden habe“ ${ }^{674}$. Könne man die Ähnlichkeit zwischen den Religionen der Inder, Griechen und Römer sowie einiger anderer wie der Ägypter, Chinesen, Perser, Phönizier und anderer „hinlänglich beweisen, so können wir auch

\footnotetext{
${ }^{673}$ Jones, William: Über die Hindus. In: Kleuker, J.F. (Hg.): Abhandlungen über die Geschichte und Altertümer, die Künste, Wissenschaften und Literatur Asiens. 1. Band Riga 1795, S. 1-24, hier S. 13-15 ${ }^{674}$ Jones, William: Über die Gottheiten Griechenlands, Italiens und Indiens. In: Kleuker, J.F. (Hg.): Abhandlungen über die Geschichte und Altertümer, die Künste, Wissenschaften und Literatur Asiens. 1. Band Riga 1795, S.161-249, hier S. 162
} 
annehmen, daß die vorzüglichsten Einwohner der ersten Welt, zu der Zeit allgemein verbunden oder verwandt waren, als sie von der vernunftmäßigen Anbetung des einzigen wahren Gottes (und dies geschah nur zubald) abweichen. ${ }^{6675}$ Für Jones beruht die Ähnlichkeit der Mythen also nicht darauf, dass sie eine alte, geheime Weisheit enthalten, sondern darauf, dass die Aufspaltung in verschiedene Kulturen frühestens zur Zeit des Abfalls von dem ursprünglichen Monotheismus stattgefunden habe bzw. dass es zu dieser Zeit noch enge Verbindungen zwischen ihnen gegeben haben müsse.

Bekannt für ihre mythologischen Vergleiche sind im deutschsprachigen Raum vor allem Creuzer, Görres und Kanne. Sie alle fertigen in den Jahren 1810/11 vergleichende Untersuchungen verschiedener Mythologien an, haben dabei aber ganz unterschiedliche Intentionen und Schwerpunkte.

Kanne, dessen Denken sich in dem Spannungsfeld von pietistisch geprägter Religiosität und Wissenschaft positioniert, geht von einer ursprünglichen Gotterkenntnis aus, die den frühesten Menschen in einem höheren Schauen gegeben wäre. ${ }^{676}$ Das ursprüngliche unmittelbare Wissen von Gott hätten die Menschen im Laufe der Zeit verloren, aber das bedeutet für Kanne nicht, dass es deshalb keine Gotteserkenntnis mehr geben könne. In den Verheißungen des Christentums, aber auch durch den Weg der Wissenschaft und einzelner Erleuchteter sieht er eine Möglichkeit, „die Erkenntnis Gottes dahin zurückzuführen, wo sie ausgegangen ist““ ${ }^{677}$ Das Werk habe „erst wieder begonnen, und nun erst sind wir von neuem berufen“":678

\footnotetext{
Wer möchte dann in der Geschichte glauben vollenden zu können, was nur die Zeit vollenden kann? Nur in den Vorsaal der ersten Weisheit ist es zu treten erlaubt, hier die Zeichen der alten Menschensprache zu lernen und aus ihnen soviel der ursrpünglichen Lehre zu schöpfen, als überzeugen kann, daß das Leben des ersten Menschengeschlechts mit reinem Schauen in das Reich der Geister begonnen habe und nicht der Sieg der Vernunft über die Thierheit der Verlust paradiesischer Unschuld gewesen sei. Früher war ein höheres Schauen durch ein höheres Seyn. Weil Gott im Menschen und der Mensch in Gott lebte, so ist nur eine lebendige Erkenntnis gewesen. Was wir dann aber in der Urkunde eigentliche Forschung nennen müssen, war nur späteres Zurückstreben des sich selbst überlassenen, vom lebendigen Seyn in Gott verlassenen Geistes, aber eine Fortsezung des ursprünglichen Zustandes, die nur einen solchen Anfang voraussezt. Auf dieser Stufe erkennen wir größtentheils die Indische Lehre. Sie, die am
}

\footnotetext{
675 Jones: Über die Gottheiten Griechenlands, Italiens und Indiens, S. 162

${ }^{676}$ Vgl. Kanne: Pantheum der ältesten Naturphilosophie, S. 2, 4f.

${ }^{677}$ Kanne: Pantheum der ältesten Naturphilosophie, S. 5

${ }^{678}$ Kanne: Pantheum der ältesten Naturphilosophie, S. 5
} 
reinsten die alte Wahrheit gerettet hat, kann, wie sie ist, doch selbst nur abgeleitet sein von der Weisheit des ersten Stammvolks. ${ }^{679}$

Die Menschen sollen sich auf den Weg machen, die ursprüngliche Wahrheit zu suchen, denn auch in den indischen Schriften sei der Geist schon von Gott getrennt gewesen und habe zu der ursprünglichen Einheit zurückgestrebt. Kanne stellt sich die Frage, wie man eine ursprüngliche Einheit des Wissens und der Überlieferungen beweisen könne. Würden alle Völker in ihrem Glauben an den Einen ewigen Gott übereinstimmen, so wäre das kein Beweis, denn „die menschliche Vernunft, da sie auf Einheit und Ideale ausgehe, habe überall und zu allen Zeiten diesen Glauben hervorbringen müssen.“680

\begin{abstract}
Allein eben jene äußern Gestaltungen des göttlichen Ideals, die Erzählungen von den Erscheinungen Gottes in der Natur, sind es, die uns den Ursprung eines allgemeinen Glaubens von einer Urnazion noch beweisen können. Ihnen allein nach ist die Übereinstimmung der Völkersagen weder als nothwendig noch als zufällig gedenkbar; aus Einer Tradition müssen alle Traditionen geflossen sein, z.B. wenn die Sagen der Amerikaner in Hispaniola, der Skandinaven, Inder, Perser [...] übereinstimmend mit der Sprache der Hebräer, erzählen, der erste Mensch sei aus Brod und Speichel geschaffen worden. ${ }^{681}$
\end{abstract}

Die reine Erkenntnis Gottes, die den Menschen aufgrund ihrer Gottebenbildlichkeit und ihrer Vernunft gegeben war und daher keine ursprüngliche Einheit der Menschheit beweisen könne, sei verloren gegangen, da die Menschen schon sehr früh begonnen hätten, den unsichtbaren Gott in seinen sichtbaren Erscheinungen zu verehren. Diesen so entstandenen Polytheismus, den Kanne abschätzig als „verunstaltet“ und „Aberglauben“ bezeichnet, habe sich auch in Indien verbreitet, auch wenn dort die reine Lehre nie ganz in Vergessenheit geriet. ${ }^{682}$ Doch so sehr Kanne diese Entwicklung zu bedauern scheint, sieht er in ihr doch die einzige Möglichkeit, durch das Aufzeigen von Übereinstimmungen zwischen den Göttererzählungen der verschiedenen Völker den Beweis für die oben aufgeworfene Frage nach dem gemeinsamen Ursprung dieser verschiedenen Traditionen zu erbringen. Und vor diesem Hintergrund und mit eben dieser Intention macht sich Kanne daran, in den verschiedenen Mythen (nicht nur Europas und Asiens, sondern wie das obige Zitat zeigt, soweit möglich auch anderer

\footnotetext{
${ }^{679}$ Kanne: Pantheum der ältesten Naturphilosophie, S. 5

${ }^{680}$ Kanne: Pantheum der ältesten Naturphilosophie, S. 6

${ }^{681}$ Kanne: Pantheum der ältesten Naturphilosophie, S. 8

682 „So sehen wir nun die ursprüngliche Gottheitslehre in Abgötterrei und Vielgötterei verunstaltet und zerrissen, und der alte Glaube liegt unter den Trümmern des Aberglaubens vergraben. Zwar hat Indien in den Schulen der Priester und ihren heiligen Schriften die reine Idee immer festgehalten, aber in Ständen, Sekten und Ländern hat dennoch auch hier der gröbste Kultus den Gott in der Natur von Gott dem Geiste geschieden." (Kanne: Pantheum der ältesten Naturphilosophie, S. 7)
} 
Regionen) nach Übereinstimmungen $\mathrm{zu}$ suchen und so eine Art Urmythos $\mathrm{zu}$ rekonstruieren. Dabei geht er oft von seiner Vorstellung, wie dieser Urmythos ausgesehen haben müsse, aus, um anschließend aus den verschiedenen Mythologien passende Erzählungen zusammenzutragen. Dabei zeigt er nicht nur Ähnlichkeiten oder funktionale Übereinstimmungen verschiedener mythologischer Gestalten auf, sondern setzt sie gleich (teilweise indem er sie einfach zu einem Doppelnamen verbindet wie z.B. ,Joseph-Apollon“683). Die Identität dieser mythologischen Figuren macht er nicht nur an ähnlichen Taten und Erlebnissen fest, sondern nutzt auch (vermeintliche) etymologische Verwandtschaft ihrer Namen oder Beinamen. Immer wieder finden sich ganze Reihen etymologischer Gleichsetzungen von Begriffen aus verschiedensten Sprachen. Wie sehr dieses Vorgehen oft wirkt, als werde mit Hilfe von phantasievollen Assoziationen versucht, alles miteinander $\mathrm{zu}$ verbinden, mag dieser beispielhaft herausgegriffene Textausschnitt zeigen:

\begin{abstract}
Was dort Berg, Baum, Zweig hieß, das Wort ram, rim - bedeutet in andern Sprachen singen, dichten, german. reimen, franz. rimer; le ramage Vogelgesang, und weil Wort Zahl ist, lapp. römur, der Kalender. Der Indische Rama ferner ist der Berg- und Baumgeborne Romus und Remus eine Menschwerdnung Wischnus, woher romi indisch-zigeun. noch Mensch und Mann [...] bedeutet. Daher war seine Gattin Sidha eine Roman und Granatapfels-Göttinn (von [...] malum runivum, vom Riesen, da er sie geraubt, wie die Vanen Iduna mit den Apfeln, in den Paradiesgarten unter den Se-sembaum [...] gesezt [...]. Diese Namen dann - Se-Sem und Rama in einen vereinigt, ist Parvadi im Semibaume, so verwandelt Semi-Rama genannt, nachdem sie vorher der Taube Gestalt gehabt hatte. So ist in einem Mythus alles wieder zusammengeflossen, und Semirama, als assyrische Semiramis aus dem Taubenei geboren, bringt uns zu jenen Sagen von der Zwillingsgeburt aus dem Weltei zurück; die römischen Kureten waren dann Rhomus und Remus als Rama. ${ }^{684}$
\end{abstract}

Laut Kanne lassen sich Spuren der alten Weisheit in allen Mythen finden. Dennoch haben die indischen Mythen für ihn eine besondere Bedeutung, da sie die alte Lehre am reinsten bewahrt hätten. Neben den auch von anderen Autoren häufig mit den indischen Texten verglichenen griechischen, römischen und ägyptischen Mythen zieht Kanne auffällig häufig auch Erzählungen aus dem Alten Testament hinzu. Auch ein JesusWort kann für ihn zur Stützung seiner Argumentation dienen. ${ }^{685}$ Denn obwohl die indischen Texte aufgrund ihres hohen Alters für die Rekonstruktion des alten Wissens eine wichtige Rolle spielten, komme der jüdisch-christlichen Überlieferung eine ganz besondere Bedeutung zu:

\footnotetext{
${ }^{683}$ Kanne: Pantheum der ältesten Naturphilosophie, S. 83

${ }^{684}$ Kanne: Pantheum der ältesten Naturphilsophie, S. 316

${ }^{685}$ Vgl. z.B. Kanne: Pantheum der ältesten Naturphilosophie, S. 19
} 
[...] aber ist die hebräische Sagengeschichte in ihrem ganzen Umgang erklärt, so erkennen wir hier dennoch mehr als bloßes Schiksal, nemlich daß dies merkwürdige Volk von Anfang her dazu berufen gewesen, nicht, wie Indien und Persien, der Welt den alten Glauben zu erhalten, sondern im wiedergeretteten alle göttlichen Verheißungen zu erfüllen und mit dem lange erwarteten Messias eine neue Zeit zu beginnen. ${ }^{686}$

Auch Görres führt alle Mythen auf eine Urmythe zurïck. Dabei geht auch er von einer ursprünglichen Einheit der Menschheit aus: „Ein Dienst und eine Mythe war in uralter Zeit, es war eine Kirche und auch ein Staat und eine Sprache. “687 Der Mensch dieser Frühzeit sei „somnabül“6688, er wandele

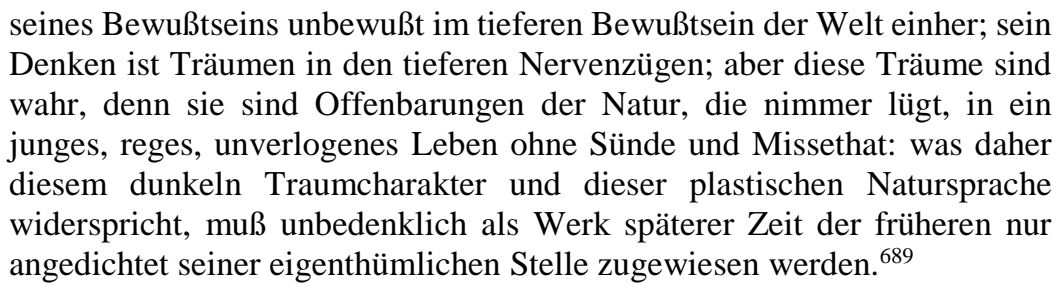

In einem traumähnlichen Zustand hätten die ersten Menschen Zugang zum tieferen Bewusstsein der Welt gehabt und dort die Wahrheit der Naturoffenbarung erfahren. Denn die Gottheit habe sich zuerst in dem sichtbaren Universum offenbart und diese „Mysterien der Natur wurden in der Menschheit offenbar [...].“ ${ }^{690}$ An dieser Vorstellung hält Görres fest; er macht sie sogar zu seinem Kriterium, anhand dessen er die Echtheit und das Alter seiner Quellen bestimmt: Alles, was dem Traumcharakter widerspreche, könne nicht aus dieser ersten Zeit stammen. Das ist nicht nur ein fragwürdiger Umgang mit These und Belegen, sondern auch eine Form von „othering“. Die alten Überlieferungen müssen sich nach Görres' Ansicht durch ihre Andersartigkeit auszeichnen. Ist diese nicht ausgeprägt genug, überdenkt Görres nicht seine These, sondern zweifelt an der Echtheit der Quellen. Görres ist der festen Überzeugung, dass die reine Idee der Gottheit nie einem Volk gefehlt habe und dass die Religion in ihrer inneren Wesenheit keine Geschichte, also keinerlei Veränderungen durchlaufen habe. Lediglich in ihrer äußerlichen Erscheinung sei die Religion Veränderungen unterworfen, denn jede Zeit habe ihre eigenen Propheten und ihre eigene Sprache. Und

\footnotetext{
${ }^{686}$ Kanne: Pantheum der ältesten Naturphilosophie, S. 8

${ }^{687}$ Görres: Mythengeschichte der asiatischen Welt, S. 11

${ }^{688}$ Görres: Mythengeschichte der asiatischen Welt, S. X

${ }^{689}$ Görres: Mythengeschichte der asiatischen Welt, S. Xf.

${ }^{690}$ Görres: Mythengeschichte der asiatischen Welt, S. 1
} 
die Gottheit offenbare sich immer auf eine solche Art und Weise, wie die Menschen der jeweiligen Zeit in ihrem Stand der Entwicklung des Reflexionsvermögens es zu fassen vermögen. ${ }^{691}$ Görres entwirft in Analogie zur Geburt und den Lebensaltern des Menschen eine Abfolge verschiedener Religionsformen. Diese Urmythen der Menschheit möchte er anhand der Überlieferungen der verschiedenen Völker rekonstruieren. Denn so wie sich das Urvolk in verschiedene Völker teilte, die die Urheimat verließen, so hätten sich laut Görres auch aus den gemeinsamen Urmythen verschiedene Varianten entwickelt. ${ }^{692}$ Diese rekonstruierten Urmythen erzählt Görres zunächst, wobei Ausschnitte aus verschiedenen Mythen lediglich der Untermalung dienen. Anschließend beschreibt er - anders als Kanne - die Mythologien und Lehren der einzelnen Völker von Ost nach West, von den Chinesen und den - deutlich ausführlicher beschriebenen - Indern über die Perser, Babylonier, Ägypter und Geschichten des Alten Testaments bis hin zu den Nordeuropäern. Das kommt für Görres einer Bewegung von den ältesten Überlieferungen zu den jüngeren gleich. Denn je näher eine Überlieferung

\begin{abstract}
dem Hauptstrome [sei], der von Indien aus über den Caucasus nach Westen dringt, um so näher auch dem Mittelpunkt der Lebenswärme, um so näher den alten heiligen Traditionen, um so mehr durchquollen von dem Herzblute des religiösen Gefühls, um so reicher daher die Formen, um so größer und lebendiger und umfassender die Anschauung. ${ }^{693}$
\end{abstract}

Indien, als nahe am Ursprung dieses Stroms gelegen, kommt dadurch natürlich eine besondere Bedeutung zu, aber auch andere dem Strome nahe Kulturen sind für Görres wichtig. Trotz dieser Ost-West-Bewegung verbindet Görres die verschiedenen Mythologien miteinander, indem er immer wieder Erzählungen und Lehren der Chinesen und Inder vergleichend anführt oder aber die antike griechische oder römische Mythologie heranzieht. Dieses Vorgehen hebt die scheinbare Ordnung des Erzählens wieder auf und verquickt die verschiedenen Mythologien miteinander - eine Erzählform, die wegen ihrer Verworrenheit sowohl damals ${ }^{694}$ als auch heute immer wieder auf Kritik stößt. Michelsen spricht sogar von einem „Strome eines in

\footnotetext{
${ }^{691}$ Vgl. Görres: Mythengeschichte der asiatischen Welt, S. 3-6

${ }^{692}$ Vgl. Görres: Mythengeschichte der asiatischen Welt, S. 54

693 Görres: Mythengeschichte der asiatischen Welt, S. 54; vgl. zu dem geographischen Vorgehen Michelsen: Der Sog der Mythe, S. 452-454

${ }^{694}$ Vgl. z.B. die Kritik an der Form der Mythengeschichte in der Rezension zu Rhode, J.G.: Über Alter und Werth einiger morgenländischen Urkunden. In: Allgemeine Literatur-Zeitung (1817), Band 2, Nr. 168, Sp. 505-510, hier Sp. 507
} 
ungeheuren Sprachergüssen und -niederschlängen sich ergehenden, alle Unebenheiten unter seinen Fluten verschwinden lassenden Überschwemmungsvorgangs “695. Diese vielen vergleichenden Verweise auf Mythen aus anderen Kulturkreisen führen nicht unbedingt zu einer Erweiterung oder Vertiefung des Themas, sondern ähneln eher einer Anhäufung von Material, das immer wieder auf das allen Gemeinsame verweisen soll. ${ }^{696}$

Während Kanne und Görres zwar die Mythen verschiedenster Kulturen ansehen, der indischen Kultur aber dennoch eine besondere Rolle zugestehen, geht es Creuzer in seiner Arbeit in erster Linie um die Ursprünge der griechischen Antike. Er möchte zeigen, dass vor Homer in Thrakien ein „ehrwürdiger Priesterstand“ in „symbolischer und mythischer Form“ Lehren einer „Orphischen Religion“697 verbreitet habe, die als reine Lehre nur den Weisen zugänglich gewesen sei, während sie für die anderen in „das Dunkel der Samothrakischen, Attischen und anderer Mysterien, so wie in die Schranken esoterischer Philosophie“ ${ }^{698}$ zurücktrat. ${ }^{699}$ Doch die Vorherrschaft der Homerischen Mythologie habe die alte Bedeutung verdrängt. ${ }^{700}$ Erst die „Meister der Alt-Jonischen Philosohie“ (gemeint sind Pherekydes von Syros und Pythagoras) hätten „das verdrängte Symbol in seine alten Rechte“ wieder eingesetzt und die Griechen ,aus der Zerstreuung durch das Viele, zur Betrachtung des Einen und Ganzen“701 hingeführt. Denn schon die alten Mysterien hätten „,den grossen Satz von Einem Gotte“ gelehrt. $^{702}$ Creuzer weist auf „eine [...] Verwandtschaft mit Sätzen der morgenländischen

\footnotetext{
${ }^{695}$ Michelsen: Der Sog der Mythe, S. 447

${ }^{696}$ Michelsen spricht in diesem Zusammenhang von Kumulation als Stilmittel, vgl. Michelsen: Der Sog der Mythe, S. 455

${ }^{697}$ Creuzer: Symbolik und Mythologie der alten Völker. Erster Band, S. 210

${ }^{698}$ Creuzer: Symbolik und Mythologie der alten Völker. Erster Band, S. 211

${ }^{699}$ Vgl. auch Jamme, Christoph: „Göttersymbole“. Friedrich Creuzer als Mythologe und seine philosophische Wirkung. In: Heidelberger Jahrbücher 51 (2007), S. 487-498, hier S. 488

700 ,,(Was) Vorderasien in halb verhüllter Bedeutsamkeit Heiliges gelehrt und geübt hatte, ward von dem Griechen, bei der vollen Klarheit seines Olympos, vergessen. Es tönten fort die orgiastischen Lieder auf den phrygischen und thrakischen Bergen, aber ihren wunderbaren Inhalt verstand der Hellene nicht mehr; in griechischen Städten übte man den heiligen Dienst Syriens und Phöniziens, aber kaum ahndete man noch seine Bedeutung.“ (Creuzer: Symbolik und Mythologie der alten Völker. Erster Band, S. 206); „Statt der alten Ruhe und asiatischen Beschaulichkeit war jetzt die That, menschlich empfunden und gedacht, Mittelpunkt der Religion geworden, und die Sage bemächtigte sich der äusserlich gewordenen Andacht. Die Ungenügsamkeit ältester Göttersymbolik wird gefügt unter griechisches Maass. Schöne Sinnlichkeit und plastische Ründung verdrängen mit der Missgestalt zugleich den gewichtigen Inhalt älterer Bedeutung.“ (Creuzer: Symbolik und Mythologie der alten Völker. Erster Band, S. 207)

${ }^{701}$ Creuzer: Symbolik und Mythologie der alten Völker. Erster Band, S. 209

${ }^{702}$ Creuzer: Symbolik und Mythologie der alten Völker. Vierter Theil. Zweite völlig umgearbeitete Ausgabe, S. 10
} 
Lehre“ ${ }^{703}$ hin und hält auch einen direkten Einfluss im Zuge der Eroberungen Alexanders für möglich. ${ }^{704}$ Dabei denkt er allerdings in erster Linie an Ägypten sowie Phönizien und Kleinasien. ${ }^{705}$ Folgerichtig spielt die indische Mythologie in der ersten Ausgabe der „Symbolik“ keine große Rolle. Erst in der zweiten Auflage von 1819 ist ihr ein eigenes Kapitel gewidmet. Creuzer stellt nun zwar fest, dass „sich die Übereinstimmung dieser Vorderasiatischen Systeme mit den Oberasiatischen Religionen, und, was die wesentlichsten Punkte betrifft, die Einheit der mythischen Anschauungen der alten Indier, Perser, Ägyptier, Phönicier und anderer Völker bewähret“ 706 , die mythischen Ansichten dieser Völker also im Wesentlichen übereinstimmen, aber er zieht bei den Untersuchungen der griechischen Mythologie auch in der zweiten Auflage die indische Mythologie kaum zum Vergleich heran, sondern beruft sich vor allem auf Ägypten. Eine bedeutende Ausnahme ist das Kapitel über Dionysos. Wie andere Autoren auch verbindet Creuzer Dionysos mit dem indischen Śiva. ${ }^{707}$ Insgesamt beruft sich Creuzer aber deutlich weniger auf Indien als andere Autoren. ${ }^{708}$

Kanne, Görres und Creuzer widmen sich in ganzen Monographien dem Mythenvergleich. Aber auch andere Autoren erwähnen ähnliche Vergleiche, wenn auch oft nur am Rande. Claudius stellt ohne weitere Ausführungen fest, dass auch die Inder ihren Apoll und die neun Musen hätten ${ }^{709}$. Ob er dabei von der Identität der Götter ausgeht oder ihnen nur funktionelle Ähnlichkeit zuschreibt, wird nicht klar. Diese rein funktionale Verwandtschaft sieht Forster bei Kasyapa und Uranos als gegeben an. $\mathrm{Ob}$ der Name Śiva tatsächlich mit dem ägyptischen Isis und Osiris (etymologisch)

\footnotetext{
${ }^{703}$ Creuzer: Symbolik und Mythologie der alten Völker. Erster Band, S. 210

${ }^{704}$ Vgl. Creuzer: Symbolik und Mythologie der alten Völker. Erster Band, S. 214

705 Vgl. Creuzer: Symbolik und Mythologie der alten Völker. Erster Band, S. 271

706 Vgl. Creuzer: Symbolik und Mythologie der alten Völker besonders der Griechen. Zweiter Theil. Zweite völlig umgearbeitete Ausgabe. Leipzig und Darmstadt 1820, S. 18

${ }^{707}$ Aufgrund der griechischen Sage, dass Dionysos nach Indien gezogen sei, ist er derjenige der griechischen Götter, der besonders häufig mit der indischen Mythologie in Verbindung gebracht wird (vgl. z.B. Cowan, Robert: The Indo-German Identification. Reconciling South Asian Origins and European Destinies, 1765-1885. Rochester 2010, S. 12-14). Anders als die griechischen Mythologen dreht Creuzer aber die Bewegung des Mythos um: Nicht Dionysos sei nach Griechenland gezogen, sondern der Dionysos-Mythos sei aus Indien über Ägypten und Kleinasien nach Griechenland gekommen und dort heimisch geworden. Der indische Dionysos sei „Schiwa-Dewaincha mit dem Phallus" gewesen (Creuzer: Symbolik und Mythologie der alten Völker. Dritter Theil, S. 134). Auch Görres und Kanne verknüpfen Śiva mit Dionysos (vgl. Görres: Mythengeschichte der asiatischen Welt, S. 46f.; Kanne: Pantheum der ältesten Naturphilosophie, S. 98).

${ }^{708}$ Vgl. auch Kocziszky: Das Konzept und die Rolle des Orients in Creuzers Werk im Vergleich zu Görres, S. 310

${ }^{709}$ Vgl. Claudius: Eine asiatische Vorlesung, S. 44f.
} 
verwandt sei, möchte er aber nicht entscheiden. Auch die von Jones aufgestellte Behauptung, dass die mit Hirten in Verbindung stehenden Götter Apoll und Kṛ̣ṇa einander entsprächen, lässt er unkommentiert. ${ }^{710}$ Sein englischer Namensvetter George Forster geht ebenfalls auf die Ähnlichkeiten zwischen den verschiedenen Mythologien ein. Anders als z.B. Görres führt er die Ähnlichkeiten zwischen den indischen, griechischen und ägyptischen Göttern aber nicht auf einen gemeinsamen Urmythos bzw. Uroffenbarung zurück, sondern sieht sie als Folge der Handelskontakte dieser Völker. ${ }^{711}$

Eine andere Art der Gleichsetzung von Indischem und Europäischen -in diesem Fall durch die Inder selbst - spricht Paulinus a Sancto Bartholomaeo an: Er beklagt, dass die Inder häufig Christliches mit Heidnischem verwechselten, indem sie z.B. sagten, ihre „Göttin Lakshmi sey unsere liebe Frau; Brahma, Vishnu und Shiva stellten unsere Dreieinigkeit vor““ ${ }^{712}$ Aufgrund dieser Gleichsetzungen hielten sie es nicht für nötig, sich zum Christentum zu bekennen. Nur einige Seiten später zeigt Paulinus a Sancto Bartholomaeo dann freilich seinerseits Ähnlichkeiten zwischen der ägyptischen und indischen Mythologie und religiösen Praxis auf. ${ }^{713}$

Die Vergleiche und Gleichsetzungen unterschiedlicher Mythologien sind allerdings nicht nur in ihrer genauen Ausgestaltung, sondern auch als solche umstritten. Das wird unter anderem an dem Briefwechsel Georg Forsters deutlich. So schreibt ihm Herder im Dezember 1791, dass Jones Abhandlung über die indische Mythologie merkwürdige Zusammenstellungen enthalte. Heyne ist bereits im August 1790 noch deutlicher geworden: Jones könnte so vieles aufklären, wenn er nicht so viele ungereimte Hypothesen aufstellen und überall Ähnlichkeiten Indiens mit Italien und Griechenland

\footnotetext{
${ }^{710}$ Vgl. Forster, Georg: Sakontala, S. 294, 298, 305

711 „Wenn man den Götterdienst der Hindus mit den Religionen der alten Völker vergleicht, so stößt man auf eine unverkennbare Ähnlichkeit von mehrern Gottheiten; und könnte man eine genaue Beschreibung von den Beschäftigungen und Eigenschaften der untergeordneten indischen Gottheiten erhalten, so würde man vermuthlich finden, daß das Pantheon des Abendlandes aus dem Götterrathe des Brimha bevölkert worden. Die Ägyptier und Griechen haben von ihrer Gemeinschaft mit Hindostan vermöge des Handels über das rothe Meer mehrere Spuren nachgelassen." (Forster: Reise aus Bengalen, S. 76f.)

712 Des Fra Paolino da San Bartolomeo Reise nach Ostindien, S. 18

${ }^{713}$ Vgl. Des Fra Paolino da San Bartolomeo Reise nach Ostindien, S. 24f.
} 
sehen würde. Für Heyne sei das Schwärmerei. ${ }^{714}$ Dem stimmt Forster in seinem Antwortschreiben zu. Auch er sei es leid, dass Jones nur sein System vortrage ohne konkrete Quellenangaben, die seine Hypothesen überprüfbar machen würden. Aber solche synkretistischen Ideen herrschten jetzt mehr denn je. Man müsse untersuchen, was davon wahr und was eine Täuschung der Phantasie sei. Dazu müsse man klären, was die verschiedenen Völker selbst erfanden und was sie von einem möglichen gemeinsamen Ursprung mitbrachten. Außerdem sei $\mathrm{zu}$ berücksichtigen, dass Ähnlichkeiten auch durch Analogien im Denken entstanden sein könnten. ${ }^{715}$ Forster folgt mit seiner Forderung nach überprüfbaren Quellenangaben ganz dem epistemologischen Ideal der Aufklärung, nichts zu glauben (auch keinen Autoritäten), sondern alles (überlieferte) Wissen kritisch zu überprüfen.

Einem zu großen Einfluss der Phantasie schreibt auch Papi die synkretistischen Zusammenstellungen zu:

\begin{abstract}
Ungeachtet der großen und mannichfaltigen Verschiedenheiten, die zwischen den Göttern der Indier und jenen der Griechen und Römer statt finden, giebt es gleichwohl noch immer Leute, welche steif und fest glauben, daß die Mythologie dieser Völker eine und dieselbe und bloß aus einem Lande in das andere versetzt worden sey. Herr Wilford, unter andern, der, eben so wie Herr Maurice und Pater Paolino, mit einer sehr ausgebreiteten Gelehrsamkeit eine lebhafte Phantasie vereint, läßt dieser letzteren dergestalt den Zügel schießen, daß er jeden, der sich seiner Leitung überließe, weit über die Gränzen der Vernunft und einer gesunden Beurtheilungskraft hinaus führen, und ihn in das Gebiet der Träume und Schimären versetzen würde. $\mathrm{Er}$ hat verschiedene Abhandlungen herausgegeben, worin er die sämmtlichen Götter der Indier so leicht wie man eine Hand umdreht, nach Ägypten, Syrien, Griechenland und Italien versetzt. ${ }^{716}$
\end{abstract}

Er führt beispielhaft verschiedene etymologische Ableitungen griechischer Götternamen von indischen auf und fragt, ob man, nur weil die Peruaner wie die Perser die Sonne anbeteten, sagen könne, dass jene von diesen abstammten. Auch andere könnten ähnliche Ideen wie die Inder haben; es müsse also nicht zwangsläufig alles aus Indien stammen. ${ }^{717}$

\footnotetext{
${ }^{714}$ Vgl. Briefe an Forster. Bearbeitet von Brigitte Leuschner u.a. Berlin 1982 (Georg Forsters Werke. Sämtliche Schriften, Tagebücher, Briefe. Herausgegeben von der Akademie der Wissenschaften der DDR; 18), S. 417 (Brief von Heyne August 1790)

${ }^{715}$ Vgl. Georg Forster's sämmtliche Schriften. Herausgegeben von dessen Tochter und begleitet mit einer Charakteristik von G.G. Gervinus. In neun Bänden. Achter Band. Briefwechsel. Leipzig 1843, S. 128

${ }^{716}$ Briefe eines italienischen Reisenden, S. 182f.

${ }^{717}$ Vgl. Briefe eines italienischen Reisenden, S. 183-189, 199, 202
} 
Auch Heeren kritisiert die Vergleiche mit anderen Mythologien. Dabei warnt er allerdings nicht vor Schwärmerei wie Heyne, sondern vor Verfälschungen der Interpretation: Da

\begin{abstract}
sowohl die Britten als auch der Pater Paullino gleich darauf ausgiengen, Ähnlichkeiten mit der griechischen und Ägyptischen Götterlehre aufzufinden [...] und Vergleichungen anzustellen. Sie fanden was sie suchten; diese Meinungen wurden nun in Umlauf gesetzt, und trugen, nicht wenig dazu bey, die ganze Ansicht des Indischen Alterthums zu trüben und zu verwirren. ${ }^{718}$
\end{abstract}

Beginne man die Untersuchung der indischen Quellen mit zu konkreten Vorstellungen, so finde man nur das, was man von vornherein erwartet habe.

Ganz anders argumentiert Majer: Man solle die indischen Dichtungen nicht mit denen der Ägypter oder Griechen vergleichen, da jene „Blumen“ „zu zart“ seien, um, „ohne klimatisirt zu werden, an den Gestaden des Mittelmeers zu blühen“. ${ }^{719}$ Die Ähnlichkeiten solle man sich dadurch erklären, dass man annehmen solle, dass die indischen Dichtungen älter seien und die griechischen beeinflusst hätten. Majer geht es also nicht wie Forster, Heyne und Papi um fehlende Beweise und mangelnde Quellenangaben, sondern er befürchtet, dass die fremden Texte bei direkten Vergleichen mit den vertrauten antiken Werken nicht angemessen beurteilt werden könnten.

Auch hier zeigen sich deutliche Unterschiede zwischen romantischen Autoren und denen der Aufklärung: Während jene die Mythologien in einem philosophischreligiösen Sinn als Überreste einer Uroffenbarung deuten, die ggf. auch für zeitgenössische Suchende von unmittelbarer Bedeutung sein können, geht es diesen um eine genaue wissenschaftliche Prüfung möglicher Ursachen der beobachteten Ähnlichkeiten und um die Frage, in wie weit diese in konkreten historischen Untersuchungen eine Rolle spielen können. Die Mythen haben hier also lediglich einen historischen Wert.

\footnotetext{
${ }^{718}$ Heeren: Ideen über die Politik, den Verkehr und den Handel der vornehmsten Völker der alten Welt, S. 362

${ }^{719}$ Majer, Friedrich: Über die mythologischen Dichtungen der Indier. In: Poetisches Journal. Erster Jahrgang erstes Stück. Von Ludwig Tieck 1 (1800), S. 165-216, hier S. 169
} 


\subsection{Götter und Seelenwanderung - die Grundzüge indischer Religion}

Neben der vergleichenden Betrachtung verschiedener Mythologien und dem Versuch, eine Art Urmythologie zu rekonstruieren erfahren indische Gottesvorstellungen sowie die Lehren der Seelenwanderung große Aufmerksamkeit.

\subsubsection{Monotheismus, Polytheismus oder Pantheismus}

Im Folgenden möchte ich zunächst die Auseinandersetzung mit den indischen Gottesvorstellungen ausführlicher darstellen, allerdings ohne auf Unterschiede in der Beschreibung einzelner Götter oder anderer Details einzugehen. Vielmehr möchte ich die Fragestellungen herausgreifen, die in den Texten immer wieder im Mittelpunkt stehen oder den Hintergrund für Beschreibungen bilden: Ist die indische Religion in ihren Grundzügen monotheistisch, polytheistisch oder pantheistisch? Und wie ist die Vielzahl an Göttern zu deuten, insbesondere die drei Götter der Trimūrti?

Ein wichtiger Aspekt bei der Einordnung und Beurteilung der indischen Religion(en) besteht für die europäischen Gelehrten und Reisenden in der Frage, ob es sich hierbei um im Kern monotheistische, polytheistische oder pantheistische Lehren handelt. Obwohl die Vielzahl der indischen Götter oft kritisiert wird, so geht ein Großteil der hier untersuchten Autoren interessanterweise davon aus, dass die Religion der Inder ursprünglich den Glauben an nur einen Gott gelehrt habe. Während das einfache Volk den Glauben an den einen Gott größtenteils vergessen habe, hielten viele Brahmanen jedoch noch immer daran fest. Inwieweit dieser eine Gott als monotheistisch oder pantheistisch anzusehen sei, ist unter den europäischen Autoren allerdings hoch umstritten. Eine weitere Frage, die viele beschäftigt, ist, wie das Nebeneinander von einem Gott und einer Vielzahl weiterer Götter zu erklären ist.

Bereits im 17. Jahrhundert betonte Dapper, dass die Vielzahl an Göttern keine Götter im eigentlichen Sinne seien:

Ferner dienet auch dieses zu wissen / daß eben derselbige Bramma etliche andere unter sich habe / denen er die Sorge über etliche absonderliche Sachen befihlt. Diese sind eigentlich für keine Götter zu halten / sondern allein vor Dewetaes / oder Engel und Diener GOttes. ${ }^{720}$

Ferner so erkennen die Heyden oder Indianer [...] nicht nur allein einen Gott / sondern auch / daß ein oberster GOtt sey /welcher einig ist / und daß

\footnotetext{
${ }^{720}$ Dapper: Asia, S. 17
} 
ihme sonst keiner gleich sey; wiewohl sie nach ihren unterschiedlichen Secten demselben nicht einen / sondern unterschiedliche Namen geben und zueignen. $^{721}$

Dapper macht zunächst deutlich, dass die Inder einen einzigen höchsten Gott annehmen. Zu den übrigen Göttern finden sich hier zwei Erklärungsmuster: Zum einen beschreibt er die Götter als den Engeln ähnliche Diener Gottes, zum anderen können verschiedene Namen bei unterschiedlichen Sekten auch ein und denselben Gott meinen. Kurz darauf aber schreibt er dieser Aussage widersprechend, dass die Inder auch andere Götter anbeteten und ihnen menschliche Eigenschaften und Verhaltensformen andichteten. Selbst alte Helden würden als Götter angebetet. ${ }^{722}$ „Sie dienen [...] dem höchsten GOtt / den geringern Göttern / und dem Teufel.“7723 Die oben beschriebene Schwierigkeit, die widersprüchlich erscheinenden indischen Lehren angemessen zu beurteilen, wird hier sehr deutlich. Dapper findet in der fremden Religion die Spuren von zwei unterschiedlichen, ihm vertrauten Konzepten: dem Monotheismus und dem Polytheismus. Diese kann er aber weder sinnvoll miteinander verbinden, noch ist es ihm möglich vor dem Hintergrund dieser Vorannahmen die indische Religion als etwas drittes, ganz anderes zu interpretieren.

Ähnlich wie Dapper beschreiben auch andere Autoren ein höchstes Wesen und interpretieren die übrigen Götter als Genien und Dschinnen ${ }^{724}$ oder wie Papi als den Engeln oder Heiligen ähnliche, dienende Wesen:

$\mathrm{Da}$ die Indier nur ein einziges allerhöchstes Wesen anerkennen, und folglich nichts weniger als Götzendiener sind, [...] dies hat seine vollkommene Richtigkeit. Sie verehren die Bilder ihrer Gottheiten genau so und nicht anders, wie die Katholiken die der heiligen Jungfrau, der Engel und Heiligen; wiewohl übrigens der dumme und unwissende Pöbel in Indien, eben so wie anderwärts, nicht weiß was er denkt, was er thut, was er glaubt. [...] Die verschiedenen Götter und Göttinnen der Indier sind eigentlich nichts anderes, als Diener und Günstlinge des Allerhöchsten, oder Erscheinungen, Emanationen und Theile seines Wesens, die unter mancherlei Gestalten und Formen die Bösen vernichten und strafen, oder sie wieder auf den Weg der Tugend zurückführen, die Guten aber aufmuntern, belohnen und schützen. Diese Strahlen und Ausflüsse des allerhöchsten unendlich weisen, unendlich guten, und unendlich mächtigen Wesens, entfernen sich aber oftmals von ihrem Urquell, nehmen eine ganz

\footnotetext{
${ }^{721}$ Dapper: Asia, S. 104

${ }^{722}$ Vgl. Dapper: Asia, S. 104, 108

${ }^{723}$ Dapper: Asia, S. 110

${ }^{724}$ Vgl. Forster: Sakontala, S. 283
} 
andere Natur an, und verunreinigen sich durch die Beimischung von allerlei menschlichen Lastern und Schwachheiten. ${ }^{725}$

Diese „Ausflüsse“ des Höchsten würden aber von dem einfachen Volk oft falsch interpretiert und entfernten sich so von ihrem eigentlichen Wesen. ${ }^{726}$ Interessanterweise sieht der Autor in den Fehldeutungen des einfachen Volkes kein typisch indisches Phänomen.

Ähnlich sieht es auch Paulinus a Sancto Bartholomaeo, der zwar feststellt, dass es in Indien Dumme gebe, die nicht wie die übrigen Inder den einzigen wahren Gott, sondern Gott in allem verehrten, dann aber sofort hinzufügt, Dumme gebe es eben überall. ${ }^{727}$ Eine Unterscheidung zwischen dem eher monotheistisch geprägten Glauben der Brahmanen und dem Volksglauben entwarf bereits Sonnerat: Das einfache Volk bete nur einen der drei Götter der Trimūrti an, einige Brahmanen jedoch alle drei zusammen in ihrer Einheit. ${ }^{728}$ Auch viele andere Autoren lösen die für sie widersprüchlichen Beobachtungen von monotheistischen und polytheistischen Aspekten innerhalb der indischen Religion dadurch auf, dass sie zwischen einer monotheistischen höheren Lehre und einem polytheistischen Volksglauben unterscheiden. So schreibt Ehrmann, dass die Religion der Brahmanen zur „Eingötterei oder Anerkennung und Verehrung eines einzigen höchsten Wesens“" gehöre:

Der Grundbegriff dieser Religion ist der Glaube an eine einzige höchste, vollkommene Gottheit, welche die Regierung des Weltalls durch Untergötter führen läßt, welche menschliche Leidenschaften und Fehler habe, und von dem Pöbel angebetet werde; aber die Vornehmeren, Aufgeklärten und Gelehrten sind reine Deisten. Daher man dieses Volk zu Unrecht zu den Heiden gerechnet hat. ${ }^{729}$

Ehrmann unterscheidet also zwischen dem „Pöbel“ und den „Aufgeklärten“. Interessant ist, dass er in Indien eine in Europa verbreitete Strömung (Deisten) sowie eine Aufklärung zu erkennen glaubt und auf etwaige Unterschiede hier nicht weiter eingeht. Kanne verbindet die Unterscheidung nach sozialer Stellung mit der ebenfalls

\footnotetext{
${ }^{725}$ Briefe eines italienischen Reisenden, S. 68f.

726 Ähnlich beschreibt es später auch der Herausgeber der Briefe des Reisenden, Ehrmann (Vgl. Ehrmann: Neueste Kunde von Asien. Zweiter Band, S. 141f.

${ }^{727}$ Vgl. Des Fra Paolino da San Bartolomeo Reise nach Ostindien, S. $326 f$.

${ }^{728}$ Vgl. Sonnerat: Reise nach Ostindien, S. 84

${ }^{729}$ Ehrmann: Neueste Kunde von Asien. Erster Band, S. 37
} 
verbreiteten These, dass der alte reine Glaube größtenteils zerstört und nur bei einigen Priestern noch lebendig sei:

\begin{abstract}
So sehen wir nun die ursprüngliche Gottheitslehre in Abgötterrei und Vielgötterei verunstaltet und zerrissen, und der alte Glaube liegt unter den Trümmern des Aberglaubens vergraben. Zwar hat Indien in den Schulen der Priester und ihren heiligen Schriften die reine Idee immer festgehalten, aber in Ständen, Sekten und Ländern hat dennoch auch hier der gröbste Kultus den Gott in der Natur von Gott dem Geiste geschieden. ${ }^{730}$
\end{abstract}

Sogar Best, der als Soldat nach Indien gekommen ist, betont in seinem kurzen Abriss der indischen Religion, dass die Inder von einer höchsten Gottheit ausgingen, deren Ausfluss die Seelen aller lebendigen Wesen seien. Die Götter der indischen Mythologie, die sich gut mit der griechischen und römischen vergleichen lasse, bezeichneten Eigenschaften des göttlichen Wesens. ${ }^{731}$ Auch ein weiterer Soldat aus Hannover, der sich im entsprechenden Abschnitt seines Berichts über seine Zeit in Indien vor allem auf die dort gemachten Beobachtungen, die Götterbilder, Gebräuche und Feste konzentriert, betont zunächst, „die erste und wichtigste [Hauptlehre], die wenigstens unter den Weisen der Nation und dem denkenden Theile derselben Statt findet, ist diejenige, nach welcher sie ein Einziges, höchstes göttliches Wesen, den Schöpfer und Erhalter der Welt erkennen.“732

Häufig gehen die Autoren von drei oder vier verschiedenen Gruppen verehrter Wesen aus. Da sei zunächst der höchste, über allen stehende einige Gott, darunter die drei Götter der indischen Trimūrti (Brahmā, Viṣṇu und Śiva), auf die später noch eingegangen werden soll, und zuunterst niedere Gottheiten und Dämonen. Ein solches Schema findet sich z.B. in den ansonsten eher auf die Mission konzentrierten Halleschen Berichten. Der Versuch der Systematisierung trägt hier allerdings kaum zum besseren Verständnis bei. Es entsteht eher der Eindruck, als habe der Autor versucht, alle Geschichten und Informationen in einen einheitlichen Rahmen zu pressen. ${ }^{733}$ Dieses drei- oder vierteilige Schema findet sich in leicht unterschiedlichen

\footnotetext{
${ }^{730}$ Kanne: Pantheum der ältesten Naturphilosophie, S. 7

${ }^{731}$ Vgl. Best: Briefe über Ost-Indien, S. 26f.

732 Über Götterlehre, Feste und gottesdienstliche Gebräuche der Malabaren oder Tamuler. In: Neues Hannoversches Magazin 68 (1791), Sp. 1073-1120, hier Sp. 1075

${ }^{733}$ Vgl. Schulze, Johann Ludwig (Hg.): Neuere Geschichte der Evangelischen Missions-Anstalten zu Bekehrung der Heiden in Ostindien. Vierter Band. Halle 1796, 42. Stück, S. 560-568
} 
Varianten auch bei dem Engländer Forster ${ }^{734}$, bei Majer ${ }^{735}$, Ehrmann ${ }^{736}$ und im Lexikoneintrag von $1809^{737}$.

Von diesen Göttergruppen richtet sich das Hauptinteresse der meisten Autoren einerseits auf das höchste Wesen und andererseits auf die Trimūrti genannten drei Götter Brahmā, Vișṇu und Śiva, deren Rezeption wir uns zunächst ansehen werden. Für die Interpretation der Trimūrti gibt es im Prinzip drei Deutungen, die eng miteinander zusammenhängen, aber bei den einzelnen Autoren unterschiedlich stark gewichtet werden. Die drei Götter werden entweder als Schöpfungen oder Offenbarungen des höchsten Gottes angesehen, als Personifikationen der Attribute der höchsten Gottheit gedeutet oder aber als Versuche, den an sich unbegreiflichen einen Gott für die Menschen erfahrbar zu machen, interpretiert. Manchmal kommen auch mehrere dieser Deutungen zusammen.

Zu den Autoren, die in den drei Göttern Schöpfungen bzw. Offenbarungen der höchsten Gottheit sehen, gehört Kleuker ${ }^{738}$ :

Die Gottheiten dieses Systems theilen sich in das Eine Ewige Urwesen und in die erzeugten Götter mit ihren weiblichen Hälften. ${ }^{739}$

Nach dem Urwesen oder dem ewigen Einen, und dessen zwiefachen Urkraft, kommen die drey erstgezeugten Götter, Brahma, Wischnu und Schiwa, mit ihren weiblichen Hälften, in Betracht, deren Charakter, Eigenschaften und Wirkungen zusammengenommen die unendliche Gottheit als erkennbar, oder im Zustande ihrer Offenbarung und Wirksamkeit ausser sich, vorstellen sollen. Daher die äussere Verehrung der Gottheit durch Gebete, Opfer und religiöse Gebräuche sich zunächst an diese hält und sie fast allein zu Gegenständen hat. ${ }^{740}$

Kleuker weist den drei Götter die Funktion zu, in ihren einzelnen Eigenschaften die unendliche und als solche unbegreifliche Gottheit erkennbar $\mathrm{zu}$ machen. Dabei

\footnotetext{
${ }^{734}$ Vgl. Forster: Reise aus Bengalen, S.34f., 44

735 Vgl. Majer: Über die mythologischen Dichtungen der Indier, S. 172, $177 \mathrm{f}$.

${ }^{736}$ Vgl. Ehrmann: Neueste Kunde von Asien. Zweiter Band, S. 141-143

${ }^{737}$ Vgl. Conversation-Lexikon, S. 335f.

${ }^{738}$ Johann Friedrich Kleuker (1749-1827) studierte Philosophie, Theologie und Altertumskunde und vertrat Ansichten eines christlichen Supranaturalismus (vgl. Göbell, Walter, "Kleuker, Johann Friedrich" in: Neue Deutsche Biographie 12 (1980), S. 56 f. [Online-Version]; URL: https://www.deutsche-biographie.de/pnd119021498.html\#ndbcontent).

${ }^{739}$ Kleuker, Johann Friedrich: Das Brahmanische Religionssystem im Zusammenhange dargestellt und aus seinen Grundbegriffen erklärt: wie auch von den verschiedenen Ständen Indiens mit besonderer Rücksicht auf Fr. Paullini a S. Bartholomaeo Systema Brahmanicum etc. Nebst einem kurzen Auszuge aus eben desselben Sidharvbam oder Samskrdamischen Grammatik. Riga 1797, S. 33

${ }^{740}$ Kleuker: Das Brahmanische Religionssystem, S. 40
} 
interpretiert er die drei Götter aber nicht als bloße Attribute oder menschliche Erklärungsversuche, sondern als Schöpfungen der Gottheit bzw. als eben diese Gottheit im Zustand der Offenbarung.

Creuzer sieht in den drei Göttern Personifizierungen der „drei Grundideen der Gottheit: Schöpfung, Erhaltung und Zerstörung“. Doch habe „das an sich natürliche und unschuldige, anfangs auch blos allegorische Bestreben, jene Prädikate der Gottheit durch Attribute dem Auge darzustellen, die Religion allmählig gänzlich in Verfall [...] $]^{6741}$ gebracht. Auch der Lexikoneintrag von 1815 vertritt die These, dass die drei Götter zunächst Eigenschaften des einen Gottes darstellten, sich dann aber durch Personifizierung verselbständigten. ${ }^{742}$

Die beschriebene Vorstellung, dass die drei Götter der Trimūrti nur personifizierte Allegorien seien, ist - wie gesehen - sehr verbreitet. Sie erfährt aber auch Kritik. Besonders Papi äußert sich klar gegen diese These:

\begin{abstract}
In diesen und andern dergleichen Fabeln [...] haben gewisse Leute, außer dem klaren und buchstäblichen Sinne, auch noch einen mystischen und allegorischen zu finden geglaubt. Die drei Götter, Brama, Wischnu und Schiwa, sagt Bailly, sind eigentlich nichts anderes, als eben so viele Äußerungen des göttlichen Wirkungsvermögens, oder Eigenschaften des höchsten Wesens, welche man aus Unwissenheit einzeln dargestellt und personificirt hat. Ich für mein Theil zweifle sehr, daß dies wahr ist; so wie ich überhaupt von jeher auf die so gepriesene Weisheit der alten Indier, Ägypter, Chaldäer u.s.w. nicht viel gehalten habe. Wenn es wirklich, wie einige vorgeben, gegründet ist, daß die Erfinder jener Gottheiten im Stande waren, sich mit dergleichen abstrakten Begriffen zu beschäftigen; so sollte ich dann nicht auf eben die Art behaupten dürfen, daß Vulkan, Venus, Neptun, und andere, sowohl griechische als römische Gottheiten, eben auch weiter nichts als Attribute des höchstens Wesens seyen, und daß derjenige, welcher dieselben erfand, nur allein dies und sonst nichts dadurch habe ausdrücken wollen? ?43 $^{74}$
\end{abstract}

Gleichzeitig lehnt er auch die verbreitete Vorstellung ab, dass der indische Glaube zunächst monotheistische Züge gehabt habe, die später lediglich verdorben worden seien. Vielmehr sei die Religion bereits bei den rohen Menschen des Naturzustands entstanden und mit ihr auch die Gottheiten und eben auch Brahmā, Viṣnu und Śiva.

\footnotetext{
${ }^{741}$ Creuzer: Symbolik und Mythologie der alten Völker. Erster Theil. Zweite völlig umgearbeitete Ausgabe, S. 590

742 Vgl. Conversations-Lexikon 1815, S. 717

${ }^{743}$ Briefe eines italienischen Reisenden, S. 85
} 
Dieser „rohe Entwurf“ sei später von Priestern mit etwas mehr Vernunft versehen und verbessert worden. ${ }^{744}$

Die indische Trimūrti fasziniert nicht nur wie die übrigen Götter durch ihre Exotik, sondern auch, weil sie trotz allem erstaunliche Parallelen $\mathrm{zu}$ der christlichen Dreieinigkeit aufweist bzw. diese in ihr gesucht werden. Zwar zieht nur ein kleiner Teil der Autoren diesen Vergleich, er ist aber im damaligen Diskurs durchaus präsent. Während Papi nur knapp feststellt, dass die Trimūrti „,von einer ganz anderen Art" ${ }^{6745}$ sei als die Dreieinigkeit der Christen, und Kanne zwar Ähnlichkeiten feststellt, sich dann aber mehr auf den Gegensatz der weiblichen und männlichen Aspekte der Götter konzentriert $^{746}$, betonen sowohl Müller als auch Perrin die Ähnlichkeit und zum Teil auch Gleichwertigkeit der indischen Trimūrti mit der christlichen Dreieinigkeit. Perrin formuliert vergleichsweise vorsichtig:

Vorzüglich interessirt uns hier jene Indische Dreyeinigkeit, die mit der, welche die Christen anbethen, viel Analogie zu haben scheint. Denn so sagen die frommen Heiden, Wischnu ist Mensch geworden, hat mit den Riesen gekämpft und ist manchmahl verschwunden. Wer glaubt nicht in dieser Dichtung die Menschwerdung des Wortes $\mathrm{zu}$ sehen, die Versuchungen des Menschensohnes, seine Mühen, seine Verfolgungen und seinen Streit mit den höllischen Mächten? Das Wort ist die zweyte Person der göttlichen Dreyeinigkeit. Wischnu nimmt denselben Platz in der Indischen ein, und vielleicht ist er der Sohn des Brama, der die erste Person und folglich das Princip der Göttlichkeit ist. Und gibt es nicht einige Ähnlichkeit zwischen Wischnu und Kristschnu, welches den Christ bedeuten würde? ? $^{747}$

Müller dagegen scheint sich seiner Sache sehr sicher zu sein:

„Rein wie die heilige Dreifaltigkeitsmyste des Christenglaubens zeigt sich die Urantike der Trimurtilehre; nur ein Gott, und - hier - Dreifachheit in Kraftäusserung nach aussen; spater erst drei Symbolpersonen, und diese drei eins. Auch hier gilt: Tres sunt et hi tres unus sunt. Brahma Anherr der Welt, Gott Vater; Wischnu, auch Christna, der in Einfleischungen erscheinende Menschheit- und Weltretter; Heiland am Rande des Verderbens; der Gottgesandte Sohn des urheiligen Brahm, Mittler zwischen ihm und den Menschen. Schiwa - im Guten Sinne - Geisteslicht, Geisteswärme, Herzensglut, Lichtzünder, Gnadenspender, Reiniger, Erheller, Entwickler - der heilige Geist. Und diese drei, in verschiedener Wirkung sich wechselweis haltend und hebend, sich verzweigend und

\footnotetext{
${ }^{744}$ Vgl. Briefe eines italienischen Reisenden, S. 86f.

745 Briefe eines italienischen Reisenden, S. 71

${ }^{746}$ Vgl. Kanne: Pantheum der ältesten Naturphilosophie

${ }^{747}$ Hell: M. Perrin's Reise durch Hindostan, S. 30
} 
verwebend, die drei Farben eines Strahls, die drei Gnadenwipfel eines Stammes; diese drei eins [...]. ${ }^{748}$

„Das Resultat der nähern Sichtung dieser göttlichen Dreiheiten ist im Grunde kein anderes, als die christliche Trinitätsdogma [...]. “749

Perrin und Müller ordnen beide die drei indischen Götter den Personen der Trinitätslehre zu und interpretieren so etwas für sie zunächst Fremdes mit einem vertrauten Schema. Der Missionar Perrin legitimiert dieses Vorgehen mit der Annahme, die Ähnlichkeiten beruhten darauf, dass den Indern der wahre Glaube gelehrt worden sei, sie ihn aber vergessen hätten. ${ }^{750}$ Auch Friedrich Schlegel sieht in den drei indischen Göttern Ähnlichkeiten mit der Dreifaltigkeitslehre. Auch er sieht in Viṣṇu den Sohn und in Śiva den (hier: bösen) Geist. Brahmā ist für ihn jedoch nicht der Vater, sondern die Natur, das produktive Ich. ${ }^{751}$

Wie oben beschrieben sind sich die meisten Autoren einig, dass mit der indischen Religion kein reiner Polytheismus vorliegt - trotz der vielen Götter. ${ }^{752}$ Dementsprechend sind die meisten durchaus bereit, zumindest der vermuteten Urform dieser Religion Anerkennung zu zollen. Umso mehr fällt es auf, in welchem Maße Goethe die indische Götterlehre ablehnt. Zwar äußern sich auch andere Autoren abfällig über die vermenschlichten und lasterhaften Götter, ${ }^{753}$ aber sie halten sie nicht für den ursprünglichen Kern der indischen Lehre. Goethes Kritik setzt zudem an einem anderen Punkt an. Für ihn steht nicht mögliches lasterhaftes Verhalten der Götter im Mittelpunkt, sondern die schiere Anzahl der Götterfiguren:

Die indische Lehre taugt von Haus aus nichts, so wie denn gegenwärtig ihre vielen tausend Götter, und zwar nicht etwa untergeordnete, sondern alle gleich unbedingt mächtige Götter, die Zufälligkeiten des Lebens nur noch mehr verwirren, den Unsinn jeder Leidenschaft fördern und die

\footnotetext{
${ }^{748}$ Müller: Glauben, Wissen und Kunst der alten Hindus, S. 161-166

${ }^{749}$ Müller: Glauben, Wissen und Kunst der alten Hindus, S. 168

${ }^{750}$ Vgl. Hell: M. Perrin's Reise durch Hindostan, S. 31

${ }^{751}$ Vgl. Schlegel, Friedrich.: Vorlesungen und Fragmente zur Literatur. Erster Teil. Orientalia. Mit

Einleitung und Kommentar herausgegeben von Ursula Struc-Oppenberg. Paderborn u.a. 2002

(Kritische Friedrich-Schlegel-Ausgabe; 15), S. 47

${ }^{752}$ Besonders deutlich spricht das Majer aus: „Von einem Polytheismus im gewöhnlichen Sinne des

Wortes ist demnach im Brahmanismus durchaus nicht die Rede, und eben so wenig von

Göttergeschichten. Wenn die in ihm in schöner Einfalt und Klarheit ausgesprochene Karakteristik und Ordnung der Weltwesen, späterhin in der Religion des Siwa durch eine aus der materiellen Sphäre der Natur genommene Entwicklung und Fortbildung derselben zum eigentlichen Polytheismus geführt hat, so lag die Schuld ganz außer seinen Gränzen." (Majer: Brahma, S. 213).

${ }^{753}$ Vgl. z.B. Ehrmann: Neueste Kunde von Asien. Zweiter Band, S. 142f.
} 
Verrücktheit des Lasters, als die höchste Stufe der Heiligkeit und Seligkeit, begünstigen. ${ }^{754}$

Goethe, der anders als andere Autoren gar nicht erst versucht, die indischen Götter zu systematisieren und zu ordnen, stört vor allem die in seinen Augen fehlende Hierarchie der indischen Götter. Auf die Frage, warum ihn das so abschreckt, werden wir später noch im Zusammenhang mit seinen Xenien kurz zu sprechen kommen.

Die meisten Autoren sind sich einig, dass die Inder an einen höchsten Gott glauben oder zumindest glaubten. Dieser wird zumeist als der ewige Eine, als die Seele und der Schöpfer der Welt beschrieben. ${ }^{755}$ Diese Beschreibung ähnelt dem christlichen Gott, allerdings mit pantheistischen Zügen, und wird weithin positiv beurteilt und dargestellt. ${ }^{756}$ Einer der wenigen, die diese Ansicht nicht teilen, ist Hegel. Zwar erkennt auch er in der indischen Religion einen höchsten Gott an, allerdings sieht er große Unterschiede zu dem christlichen Gott:

Es ist schwer aufzufinden, was die Indier under Brahm verstehen. Wir bringen die Vorstellung des höchsten Gottes, des Einen, des Schöpfers des Himmels und der Erden, mit, und lassen diese Gedanken dem indischen Brahm zufließen. ${ }^{757}$

Andere Engländer [...] meinten, Brahm sey ein nichtssagendes Epitheton, das auf alle Götter angewendet werde [...]. Brahm sey so die einfache Substanz, welche sich wesentlich in das Wilde der Verschiedenheit auseinanderschlägt.. Denn diese Abstraktion, diese reine Einheit ist das Allem zu Grunde Liegende, die Wurzel aller Bestimmtheit. Beim Wissen dieser Einheit fällt alle Gegenständlichkeit weg, denn das rein Abstrakte ist eben das Wissen selbst in seiner äußersten Leerheit. ${ }^{758}$

\footnotetext{
${ }^{754}$ Goethe, Johann Wolfgang von: West-östlicher Divan. Teil 1. Herausgegeben von Hendrik Birus. Frankfurt a. M. 1994, S. 164 (Sämtliche Werke. Briefe, Tagebücher und Gespräche. Herausgegeben von Friedmar Apel u.a.I. Abteilung: Sämtliche Werke, Band 3/1)

${ }^{755}$ So schreibt z.B. Creuzer: „Dies ist also Brehm, der ewig Eine, welcher Eins ist mit dem All, der, äusserlich betrachtet, unendliche Gestalten haben würde, dessen Selbst aber keine Gestalt hat, sondern das Schauen ist, das Organ und das Object des Schauens zugleich, welcher kleiner ist als ein Atom, und grösser als die Welt, seinem Wesen nach unaussprechlich und undarstellbar. Er ist das ewige, allein wahrhaftig bestehende, in Seeligkeit und Freude sich offenbarende Wesen. Die Welt ist nur sein Name, sein Bild.“ (Creuzer: Symbolik und Mythologie der alten Völker. Erster Theil. Zweite völlig umgearbeitete Ausgabe, S. 588)

${ }^{756}$ Vgl. z.B. das obige Zitat von Creuzer; Majer: Über die mythologischen Dichtungen der Indier, S. 171f.; Majer: Brahma, S. 28-35; Humboldt, Wilhelm von: Über die unter dem Namen Bhagavad-Gita bekannte Episode des Mahabharata. Gelesen in der Akademie der Wissenschaften am 30. Juni 1825 und 15. Juni 1826. In: Abhandlungen der Königlichen Preußischen Akademie der Wissenschaften zu Berlin 1825. 1828, S. 1-64, hier S. 10-17; Ast, Friedrich von: Grundriss der Geschichte der Philosophie. Zweite, vermehrte und verbesserte, Auflage. Landshut 1825, S. 20

${ }^{757}$ Hegel: Vorlesungen über die Philosophie der Geschichte, S. 162

${ }^{758}$ Hegel: Vorlesungen über die Philosophie der Geschichte, S. 164
} 
Für Hegel ist der höchste Gott der Inder lediglich ein abstraktes Konzept, das nicht durch Fülle (wie die anderen Autoren sie beschreiben), sondern durch Leere geprägt sei. Und auf diese leere Abstraktheit richtet sich Hegels Kritik. ${ }^{759}$

Über die groben Züge der höchsten Gottheit herrscht also zunächst weitgehende Einigkeit. Hoch umstritten ist jedoch, ob in der indischen Vorstellung der monotheistische oder pantheistische Aspekt überwiegt. Für die früheren Autoren stand zunächst die für sie erstaunliche, da den gängigen Vorstellungen vom Heidentum widersprechende Feststellung monotheistischer Züge im Hinduismus im Mittelpunkt. Diese Feststellung konnte vielfach auch als Rechtfertigung bzw. Aufwertung des Hinduismus dienen. Auch Holwell und Dow beschrieben die indische Religion noch als im Kern monotheistisch. Dow wies allerdings bereits darauf hin, dass Gott in der indischen Lehre als eine alles belebende Seele angesehen werde und sich darin vom christlichen Gott unterscheide. Darin liege die Gefahr, dass sich im Laufe der Zeit diese Lehre in Pantheismus und Naturverehrung wandeln könnte. ${ }^{760}$ Im Zuge des Pantheismusstreits gewann diese Möglichkeit eine zusätzliche argumentative Funktion und damit auch an Gewicht. Ausgelöst durch Jacobis und Mendelssohns Auseinandersetzung darüber, ob Lessing als Spinozist und Pantheist zu bezeichnen sei, entbrannte in den 1780er Jahren eine Debatte über den Pantheismus als Folge der von den Deisten propagierten Vernunftreligion. Jacobi und andere setzten den Pantheismus in letzter Konsequenz mit Atheismus gleich und sprachen ihm aufgrund der Verneinung des freien menschlichen Willens die Möglichkeit einer Moral ab, die zwischen gut und böse unterscheiden könne. ${ }^{761}$

Diese Auseinandersetzung wird von Friedrich Schlegel in seiner 1808 erschienenen Schrift „Über Sprache und Weisheit der Indier“ wieder aufgegriffen. So gewinnt spätestens jetzt die Frage, inwieweit der Gott der Inder pantheistisch sei, große

\footnotetext{
${ }^{759}$ Die Kritik Hegels an indischem Denken ähnelt seiner Kritik an der deutschen Romantik, der er ebenfalls eine falsche Vorstellung vom Absoluten vorwirft. Hegels Indienkritik lässt sich daher immer auch als Abrechnung mit der Romantik lesen (vgl. Germana, Nicholas: India and Hegel's ,scientific“ method in the Phenomenology of Spirit. In: Cho, Joanne Miyang u.a. (Hg.): Transcultural Encounters between Germany and India. Kindred spirits in the nineteenth and twentieth centuries. London u. New York 2014, S. 25-36, hier S. 29, 34).

${ }^{760}$ Vgl. Herling: The German Gìtā, S. 62f., 66-69

${ }^{761}$ Vgl. Mittelstraß, Jürgen (Hg.): Enzyklopädie Philosophie und Wissenschaftstheorie. Band 6: O-Ra. 2., neubearbeitete und wesentlich ergänzte Auflage.Stuttgart 2016, S. 84; Herling: The German Gītā, S.89f.; Park, Peter K. J.: A Catholic Apologist in an Pantheistic World: New Approaches to Friedrich Schlegel. In: McGetchin, Douglas u.a. (Hg): Sanskrit and ,Orientalism‘. Indology and Comparative Linguistics in Germany, 1750-1958. New Delhi 2004, S. 84-86
} 
Bedeutung, da anhand dieser Frage auch der Pantheismus selbst bewertet und diskutiert wird. Schlegel entwirft in seiner Schrift eine zeitliche Abfolge von verschiedenen philosophischen Systemen in Indien: Zunächst habe es ein System der Emanation gegeben, in dem die Unterscheidung zwischen Gut und Böse nicht aufgehoben werde und eine Rückkehr der Seelen zu Gott nur möglich, aber nicht notwendig sei. Dieses System der Emanation begreift Schlegel als missverstandene Offenbarung. Aus der dann folgenden Lehre des Dualismus sei bei dem Versuch, die Vorstellung von der Einheit Gottes zu bewahren und das Böse nicht als externe Größe bestehen zu lassen, der Pantheismus entstanden, wie er sich z.B. in der Bhagavadgītā finde. Dieser hebe den Unterschied zwischen Gut und Böse auf (untergrabe somit die Moral) und habe einen negativen und abstrakten Begriff des Unendlichen, der leer und ohne Inhalt sei eine Vorstellung, die der Hegels nahekommt. Der Pantheismus beruhe nicht mehr auf einer Offenbarung, sondern sei ein reines Vernunftsystem und stehe daher den europäischen Philosophien sehr nahe. ${ }^{762}$ Schlegel schreibt: „Er schmeichelt dem Eigendünkel des Menschen eben so sehr als seiner Trägheit.“ “763 „Tiefer ist der menschliche Geist in der orientalischen Philosophie nicht herabgesunken, als bis zum Pantheismus, welcher der Moral eben so verderblich als der Materialismus, und zugleich auch für die Fantasie zerstörend ist. ${ }^{\text {“764 }}$ Schelling antwortet auf diese Kritik am indischen Pantheismus mit einer Schrift über die Freiheit des menschlichen Willens, was deutlich zeigt, dass den Zeitgenossen sehr wohl bewusst ist, wen Schlegel eigentlich meint: Seine Kritik am indischen Pantheismus zielt in erster Linie weniger auf Indien selbst als vielmehr auf pantheistische Ansätze innerhalb des deutschen Idealismus'. ${ }^{765}$

Creuzer und Hegel schwanken in ihrem Urteil zwischen Monotheismus und Pantheismus und versuchen, beides miteinander zu verbinden. So schreibt Creuzer:

Es ist hier eine Art von Monotheismus, freilich nicht so, wie ihn die speculative Vernunft vorstellt; allein es lässt sich doch nicht dabei verkennen, dass der Gott ein dem Ganzen einwohnender Gott ist, dass eine Seele in der Welt ist. Es ist offenbar eine pantheistische Ansicht [...]. ${ }^{766}$

\footnotetext{
${ }^{762}$ Vgl. Schlegel, F.: Über Sprache und Weisheit der Indier, S. 97-110, 125-127, 140-152

${ }^{763}$ Schlegel, F.: Über Sprache und Weisheit der Indier, S. 141f.

${ }^{764}$ Schlegel, F.: Über Sprache und Weisheit der Indier, S. 152

${ }^{765}$ Vgl. Herling: The German Gītā, S. 151; Behler: Das Indienbild der deutschen Romantik, S. 35f.

${ }^{766}$ Creuzer: Symbolik und Mythologie der alten Völker. Erster Theil. Zweite völlig umgearbeitete Ausgabe, S. 547
} 
Und Hegel stellt in seiner Rezension von Humboldts Abhandlung über die Gita fest:

Dieses reine Seyn, weil es nicht bis zur Bestimmung der unendlichen Subjectivität fortgeführt ist, gibt den Indischen Pantheismus, wie zugleich insofern den Monotheismus, weil das reine Seyn das Eine ist. ${ }^{767}$

Dieser Monotheismus ist aber eben so wesentlich Pantheismus, denn wenn das Eine auch als Wesen oder als die Abstraction des Allgemeinen bestimmt wird, ist es um dieser Abstraction selbst willen die Unmittelbarkeit, und darin allerdings als das Seyn der Dinge, immanent und identisch mit ihnen, das Geschöpf insofern nicht vom Schöpfer unterschieden [...]. ${ }^{768}$

Majer stimmt Schlegel dagegen zwar eindeutig zu, dass es sich um Pantheismus handle, aber dieser könne nicht direkt mit dem späteren europäischen verglichen werden, wie Schlegel es tue. Außerdem habe der Pantheismus schon das Wesen des ältesten Religionssystems bestimmt:

Zunächst zeigt es sich, obgleich achtbare Stimmen unter uns das Gegentheil versicherten, über jeden Zweifel erhaben, daß schon die Grundlage dieses ältesten Religionssystems wirklich ein Pantheismus war. Freilich aber ein indischer und nicht jener einseitige und abgezogene späterer Weltweisen, in welchem kein Gegensatz von Geist und Materie statt findet und welchem mit Recht der Vorwurf gemacht wird, daß der Unterschied zwischen Gut und Böse in ihm aufgehoben, und also keine Moral vorhanden sey. Ganz anders erscheint der aus dem kindlichen Gottesgefühl reiner und unverstimmter, zum ersten Nachdenken gekommener, Gemüther hervorgegangene indische des Brahmaismus. In allen Hervorbringungen und Hervorgehungen des Wesens der Wesen lassen Geist und Materie sich vereinigt und doch im Widerstreit bemerken. Man erkennt einen sich wechselseitig durchdringenden und belebenden Idealismus und Realismus, in welchem eben so, wie unter sich selbst, Emanation, Dualismus, die Lehre von der Seelenwanderung und Naturdienst im weitesten Sinne des Wortes, also fest verschlungen sind, das eins von dem anders gar nicht getrennt werden darf, wenn von einer richtigen Vorstellung und Würdigung dieses sehr vollkommenen und vollendeten Pantheismus, dieses erhabenen Naturalismus die Rede seyn soll. ${ }^{769}$

Im indischen Pantheismus seien Vorstellungen der Emanation und des Dualismus so miteinander verwoben, dass man sie nicht trennen könne. Für Majer ist diese Lehre daher vollkommen und erhaben. Das Zitat zeigt aber auch deutlich, dass diese

\footnotetext{
${ }^{767}$ Hegel, Georg Wilhelm: Über die unter dem Nahmen Bhagavad-Gita bekannte Episode des Mahabharata; von Wilhelm von Humboldt. Zweiter Artikel. In: Jahrbücher für wissenschaftliche Kritik. Herausgegeben von der Societät für wissenschaftliche Kritik. Jahrgang 1827. Stuttgart und Tübingen 1827, Sp. 1441-1492, Sp. 1480

${ }^{768}$ Hegel: Über die unter dem Nahmen Bhagavad-Gita bekannte Episode des Mahabharata; von Wilhelm von Humboldt. Zweiter Artikel, Sp. 1480

${ }^{769}$ Majer: Brahma, S. 207f.
} 
Einordnung der indischen Lehre als Pantheismus umstritten war, denn ,achtbare Stimmen“ behaupteten laut Majer das Gegenteil.

Einer derjenigen, die das Gegenteil behaupten, ist Niklas Müller. Er beklagt, dass nur wenige den Glauben an den Einen Gott in Indien sähen. Die Gebildetsten seien dort noch Monotheisten. ${ }^{770}$ Zwar stimmt er Schlegel darin zu, dass aus der Emanationslehre die „kläglichen Verirrungen des Pantheismus“ entstehen können, aber er hält daran fest, dass der ,in der Religion seiner Urahnen unterrichtete Hindu, welcher hinter den Bildformen des Ritus und Kultus überhaupt die ursprüngliche Bedeutsamkeit festzuhalten weiß, [...] wahrer Theist“771 bleibe. „Der fromme und weise Hindu kennt jenen leeren, inhaltslosen, sich in Nichts auflösenden Indifferentismus des in blos negativen Begriffen der Gottheit sich mittelbar selbst zernichtenden Pantheismus nicht. ${ }^{6772}$

Wie aufgeladen die Frage nach dem Pantheismus durch die Verbindung mit der zeitgenössischen europäischen Philosophie ist, zeigt auch der Briefwechsel zwischen Wilhelm von Humboldt und August Wilhelm Schlegel. Schlegel, der einen Text Humboldts über die Bhagavadgītā veröffentlichen möchte, bittet diesen, in dem Text das Wort pantheistisch weglassen zu dürfen. Es könne entbehrt werden, da nicht die ganze Lehre der Bhagavadgītā abgehandelt werde. Im weiteren Verlauf seines Schreibens wird deutlich, dass diese Frage in eine Auseinandersetzung zwischen den Brüdern Schlegel hineinspielt, da Friedrich die Lehre der Bhagavadgītā schon früh als pantheistisch bezeichnet habe, sein Bruder August Wilhelm diesem aber widersprochen habe. Er wirft die Frage auf, ob zum reinen Theismus wirklich die Lehre von der Extramundanität der Gottheit erforderlich sei und schlägt vor, die indische Lehre mit den theosophischen Mystikern zu vergleichen. Humboldt antwortet ihm daraufhin, dass das Wort zwar gern gestrichen werden könne und dass man die Lehren der Bhagavadgītā nicht mit dem gleichsetzen dürfe, was man gemeinhin mit dem Begriff Pantheismus bezeichne. Dennoch müsse man von einem Pantheismus sprechen, da ein wichtiges Kriterium für Theismus die Schöpfung aus dem Nichts sei, die es in der indischen Vorstellung aber nicht gebe. Das aber schließe Spiritualismus nicht aus. ${ }^{773}$

\footnotetext{
${ }^{770}$ Vgl. Müller: Glauben, Wissen und Kunst der alten Hindus, S. VI, XII

${ }^{771}$ Müller: Glauben, Wissen und Kunst der alten Hindus, S. 83

772 Müller: Glauben, Wissen und Kunst der alten Hindus, S. 84

${ }^{773}$ Vgl. Leitzmann (Hg.): Briefwechsel zwischen Wilhelm von Humboldt und August Wilhelm Schlegel, S. 185f., 200f. (Februar/März 1826)
} 


\subsubsection{Seelenwanderung und Erlösung}

Ein anderer wichtiger Aspekt, der in Texten über indische Religion kaum fehlen darf, ist die Lehre der Seelenwanderung. Diese ist eng verbunden mit der indischen Vorstellung, die sichtbare Welt sei nur ein Schein, und die Aufgaben der in diesem Schein gefangenen Seelen sei es, diese Täuschung zu erkennen und so den Kreislauf von Tod und Wiedergeburt zu durchbrechen. Schaut man sich diese Themen in den hier untersuchten Texten an, so lässt sich feststellen, dass in den älteren Texten die Lehre der Seelenwanderung zumeist ohne den beschriebenen philosophischen Kontext behandelt wird. Statt sie innerhalb der indischen Vorstellungswelt einzuordnen und zu beschreiben, wird sie vielmehr in die Nähe der christlichen Lehre von Sünde und und Strafe gerückt. Die Wiedergeburt z.B. als Tier wird als Strafe (nicht als Folge oder Entwicklungsmöglichkeit) aufgefasst, und auch ein indisches Konzept der Hölle wird in einigen Texten angedeutet. Die Bedeutung der Wiedergeburt als Folge der fehlenden Erkenntnis der im Schein gefangenen Seele scheint erst nach und nach bekannter geworden zu sein und wird erst ab ca. 1800 thematisiert. Die alten Deutungsmuster überwiegen aber auch dann noch. Indische Ansätze, wie die Täuschung der Seele überwunden werden könne, werden erst noch später (ab ca. 1820) intensiver diskutiert.

Wie sehr die Interpretation der Seelenwanderung in den frühen Texten von christlichen Vorstellungen geprägt war, zeigt sich sehr deutlich bei Dapper und Sonnerat. Dapper schrieb, dass die Inder glaubten, „daß es umb der Sünden willen geschehe / daß mancher Seelen /wann sie sterben / aus ihrem Leibe in einen andern fahren [...]". ${ }^{774}$ Einige kämen vor ihrer Wiedergeburt in die Hölle, andere blieben für immer dort. Die Wiedergeburt erfolge laut Dapper also nicht aufgrund der fehlenden Erkenntnis der Seele, sondern wegen ihrer Sünden. Sonnerat griff sogar auf die christliche Vorstellung eines richtenden Gottes zurück, wenn er schreibt, die „Seele eines ieden lebendigen Geschöpfes wird nach dem Tode vor den Richtstuhl des höchsten Wesens gebracht, gerichtet, und entweder belohnt, oder nach der Menge und Abscheulichkeit ihrer Laster in der Hölle gestraft." ${ }^{\text {775 }}$ Erst durch Bußübungen könnten sie die Würde erlangen, die es ihnen ermögliche, ,,in die Wohnung der Gottheit einzugehen“. 776

\footnotetext{
${ }^{774}$ Dapper: Asia, S. 129

775 Sonnerat: Reise nach Ostindien, S. 103

776 Sonnerat: Reise nach Ostindien, S. 103
} 
Auch Paulinus a Sancto Bartholomaeo beschreibt die Wanderung der Seelen (sowie eine Art Hölle) als Strafe für Sünden, aber darüber hinaus auch als Möglichkeit, durch eine Art Reinigung die ewige Seligkeit zu erlangen. Allerdings bindet er diese fremde Lehre weniger an christliche Vorstellungen als vielmehr an die antike Schule des Pythagoras an. ${ }^{777}$ Ähnlich interpretieren auch der Engländer Forster, der Soldat Best und der Arzt Papi die Geschehnisse nach dem Tod als Strafe und Reinigungsmöglichkeit. Allerdings betonen sie - anders als Dapper -, dass die Inder im Gegensatz zu den Christen nicht an eine ewige Strafe glaubten, denn eine ewige Höllenqual vertrage sich nicht mit der Güte Gottes. ${ }^{778}$

Ein etwas anderes, aber dennoch an christliche Vorstellungen angelehntes Konzept vertritt Kleuker. Er beschreibt, wie einige Wesen der Geisterwelt durch Neid und Habsucht aus dem Himmel verstoßen worden seien und fortan zur Strafe und Bewährung als Seelen auf der Erde leben müssten. Der Verführer der Geister sei immer noch der größte Feind der Seelen. ${ }^{779}$ Diese Darstellung lässt an Erzählungen vom Fall des Engels Luzifer denken und zeigt, wie sehr eigene Deutungsmuster das Verständnis fremder Erzählungen prägen können.

Die Interpretation der Seelenwanderung als Strafe und Buße für Sünden hält sich noch lange. Obwohl bereits 1800 bzw. 1802 Majer und Claudius das Konzept der Māyā, also der Welt als Schein, beschreiben, sprechen noch die Lexikon-Artikel von 1809 und 1815 von Strafe und Hölle. ${ }^{780}$ Ein Artikel aus dem Morgenblatt für gebildete Stände aus dem Jahr 1821 führt sogar einen ganzen Katalog von Sünden und ihren entsprechenden Folgen im nächsten Leben an. ${ }^{781}$

In den hier untersuchten Texten wird die indische Vorstellung, dass die sichtbare Welt nur Schein sei, in dem die Seelen gefangen seien, das erste Mal 1800 von Majer beschrieben. Auch die Vereinigung der Seelen mit dem Körper sei nur ein traumähnlicher Schein. Ebenso seien die Seelen dem Leiden nur scheinbar unterworfen.

\footnotetext{
${ }^{777}$ Vgl. Des Fra Paolino da San Bartolomeo Reise nach Ostindien, S. 339-341; Paolino: Darstellung der Brahmanisch-Indischen Götterlehre, S. 25

${ }^{778}$ Vgl. Briefe eines italienischen Reisenden, S.222; Forster: Reise aus Bengalen, S. 42f.; Best: Briefe über Ost-Indien, S. 30f.

${ }^{779}$ Vgl. Kleuker: Das Brahmanische Religionssystem, S. 108f.

${ }^{780}$ Vgl. Converstions-Lexikon. 1809, S: 336; Conversations-Lexikon 1815, S. 717

${ }^{781}$ Vgl. Ansicht der Braminen über ein diesem Leben vorhergegangnes Daseyn. In: Morgenblatt für gebildete Stände 15 (1821; Nr. 129 Mai), S. 515
} 
Der Weg, diese Täuschung zu überwinden, bestünde allein in der andächtigen Verehrung:

Diese Andacht giebt der Seele eine vollständige Zufriedenheit. Die Zufriedenheit hält sie an die Betrachtung. Die Betrachtung vernichtet den Stolz, der sich durch die eitlen und nichtigen Ideen Mein und Ich der Dinge anmaßet. Nicht eher als bis sie diesen Geist der Anmaßung in sich vernichtet hat, kann die Seele und also nur unter einer göttlichen Form, die Seligkeit erhalten, am Ende ihrer Laufbahn in die Substanz der Gottheit, aus welcher sie kam, wieder zurück. ${ }^{782}$

Die Seele könne durch Andacht die Vorstellungen von Mein und Ich aufgeben und sich ihrer göttlichen Form erinnern und so die Seligkeit erlangen. Das Verhältnis von Seele und Gottheit ist hier nicht das von Sünde und Strafe, sondern die Seele ist dem Leiden deshalb unterworfen, weil sie ihre göttliche Herkunft vergessen und mit dem Schein der materiellen Welt verwechselt habe.

Ähnlich beschreibt es auch Claudius:

Diese Vedanta-Philosophie [...] lehret: daß die materielle und sinnliche Welt kein reelles Wesen und keine reelle Existenz habe, sondern nur Schein und Täuschung sey, und nur in so weit existire, als sie empfunden wird. Nämlich: das selbstständige Wesen wollte dadurch, als durch ein großes mannichfaltiges und doch harmonisches Gemälde oder musikalisches Drama, in den sinnlich gewordenen Geistern eine Reihe von Bildern, Empfindungen und Ideen erregen und hervorbringen, ohne die sie nicht genesen und wieder zurecht gebracht werden konnten; und diese Art von Täuschung, zu der sich jenes Wesen aus Liebe herabließ, nennen die Vedanta-Philosophen Maya. Indeß war die Reihe von Bildern, Empfindungen und Ideen selbst, ihnen noch nicht die Genesung; denn sie lehrten, daß alle Bewegungen, alles Würken und Treiben in der menschlichen Seele Maya sey, d.i. Täuscherey, vergänglich und eitel; ausgenommen, was durch die erste Ursache in ihr gewürkt werde. [...] Gott kann nur aus Gott erkannt werden; nichts kann von ihm einen wahren Begriff geben, als er selbst. Alle Eindrücke, Ideen und Begriffe, die seine sichtbaren und sinnlichen Werke auf uns machen, sind nur Begriffe von endlichen und unvollkommenen Dingen; die können keine Erkenntniß des Unendlichen, Vollkommenen geben, aber den Anfang dazu machen können sie, und eine Gährung veranlassen, wie die Vedanti sagen, die damit endigt, daß die Seele sich ihres Ursprungs lebendig bewußt, und alles andre Bewußtseyn in ihr wie Nichts wird. ${ }^{783}$

Gott habe die Welt als Schein geschaffen, allerdings nicht, um die Seelen zu täuschen, sondern um ihnen einen Anstoß zu geben, sich ihres Ursprungs bewusst zu werden.

\footnotetext{
782 Majer: Über die mythologischen Dichtungen der Indier, S. 174

${ }^{783}$ Claudius: Eine asiatische Vorlesung, S. 45f.
} 
Die Vorstellung von Sünde spielt aber auch in dem nun bekannter werdenden Konzept von Māyā eine Rolle, da das Verhalten des Menschen auf der Erde die Wiedergeburten bestimme. Dabei geht es allerdings weniger um einzelne Verfehlungen, sondern es wird vielmehr betont, wie wichtig die Erkenntnis Gottes und die Vereinigung mit ihm sowie das Bemühen der Seele, diese zu erlangen, sind. ${ }^{784}$ Creuzer, der Māyā in Bezug auf die Welt als Sein, in Bezug auf Gott aber als Schein und Täuschung beschreibt, macht Stolz und Egoismus als Hinderungsgründe für die Vereinigung mit Gott aus:

Stolz ist der Grund des Falles seeliger Geister; Abtödtung seiner selbst die unerlassliche Forderung, die an jeden Menschen ergeht, und zwar eine Abtödtung sowohl dem Leibe als dem Geiste nach. In letzterem Betracht ist sie Vergessen aller Individualität, Verzichten auf alles Selbstische; und dies wird dann Indisch nationell zu der Lehre vom Tode, als dem Eingange zum wahren Leben, und von der höchsten Seeligkeit schon in diesem Leben, wenn die Contemplation das Bewusstseyn (Schauen) der Gottheit an die Stelle des Selbstbewusstseyns setzt. Diese Beschaulichkeit und Ekstase ist also nicht blos ein physischer Zustand, eine Art von Rausch aus Enthaltsamkeit, sondern eine ethische Vollendung und Selbstentäusserung, und, kühn zu sprechen [...], eine Deification, wenn man sie nicht nach den gewöhnlichen Erscheinungen der indischen Gaukler (Jongleurs), sondern nach dem Geiste der Indischen Lehre betrachtet. “785

Das Selbstbewusstsein und das Festhalten am Individuellen sollten ersetzt werden durch das Schauen der Gottheit in der Kontemplation. Dabei betont Creuzer, dass es sich dabei nicht bloß um Rausch und Ekstase handele, sondern er spricht von „Deification“, also Vergöttlichung, Gott-Werdung, auch wenn er es kaum zu wagen scheint, dieses Wort zu nutzen.

Müller spricht ganz ähnlich von einer „Unifikation mit der Gottheit“ ${ }^{786}$. Die menschlichen Seelen seien von gleichem Wesen wie die Gottheit:

Diese Emanazionstheile, in individuelle Formen verpflanzt, sind als ausgeschlossene Gottheitstheile bildlich in Banden gefallen, und daher, analog nach Menschennatur zu schließen, leidend. [...] Je stärker der Körper über den Geist herrscht [...]; desto mehr leidet, nach bildlichem Ausdrucke, die Gottheit in dem Menschen-Körper, desto stärker wird ihr Licht in demselben verdunkelt. ${ }^{787}$

\footnotetext{
${ }^{784}$ Vgl. Majer: Brahma, S. 55-63

${ }^{785}$ Creuzer: Symbolik und Mythologie der alten Völker. Erster Theil. Zweite völlig umgearbeitete Ausgabe, S. 636f.

${ }^{786}$ Müller: Glauben, Wissen und Kunst der alten Hindus, S. 192

${ }^{787}$ Müller: Glauben, Wissen und Kunst der alten Hindus, S. 208
} 
Müller beeilt sich aber zu betonen, dass die Unifikation nur möglich, nicht aber zwingend notwendig sei und daher keineswegs die Freiheit des Willens einschränke, wie es dem Pantheismus vorgeworfen wird. ${ }^{788}$ Auch die Bestrafung in einer Art Fegefeuer sei daher nicht ausgeschlossen. Allerdings sei die ewige Hölle eine „nur nach gemeinem Menschensinne, relative Ewigkeit“789.

Während es zunächst vor allem um die Feststellung geht, dass die Inder an eine unsterbliche Seele, an Seelenwanderung und ein System von Belohnung und Strafe glaubten, und sich dann das Interesse auf die dahinterliegende Theorie der Māyā und der Möglichkeit einer Wiedervereinigung mit der Gottheit richtet, stellen Wilhelm von Humboldt und in seinem Gefolge auch Hegel Ende der 1820er Jahre die Frage in den Mittelpunkt, wie eine solche Wiedervereinigung zu erreichen sei. Humboldt führt aus, dass „die Vollendung des Weisen [...] in die höchste Ruhe, die Vertiefung und den Übergang in die Gottheit gesetzt ${ }^{\text {‘790 }}$ werde. Diese Vertiefung (Humboldts Wort für $\mathrm{Yoga}^{791}$ ) bedeute aber nicht, dass der Übende sich völlig aus der Welt zurückziehe und auf jegliche Handlungen verzichte, sondern dass er das tue, was er tun müsse, aber ohne an den Früchten des Tuns festzuhalten und ohne sich den Fesseln der Leidenschaft zu unterwerfen. Humboldt ist diese Feststellung, dass Vertiefung nicht ein Leben in Müßiggang fördere, sehr wichtig. Auch die Freiheit des Menschen bleibe in dieser Lehre gewahrt, da der Mensch aus eigenem Willen diesen Weg der Vertiefung gehen müsse. $^{792}$

Während Humboldt die Bhagavadgītā als sehr wesentlich empfindet und für deren Lektüre dankbar ist, ${ }^{793}$ lehnt Hegel den hier gelehrten Weg deutlich ab. Zwar könne

\footnotetext{
788 „Die Rückkehr des einzelnen Menschen in Gottheiten ist nicht ein in Gottheitsfügung Vorangeordnetes, kein Muß der Bestimmung das die sittliche Freiheit zernichtet und Laster und Tugend zu leerer Gleichbedeutenheit und gleicher Unwirksamkeit hinabdrängt; sondern eine Möglichkeit über welche des Menschen Wille selbst bestimmt, ob sie sich in Wirklichkeit verwandle, oder in widerstrebende Unthunlichkeit auflöse." (Müller: Glauben, Wissen und Kunst der alten Hindus, S. 210)

${ }^{789}$ Müller: Glauben, Wissen und Kunst der alten Hindus, S. 211

${ }^{790}$ Humboldt: Über die unter dem Namen Bhagavad-Gitá bekannte Episode, S. 7

791 „Im philosophischen Sinne ist Yoga die beharrliche Richtung des Gemüths auf die Gottheit, die sich von allen andren Gegenständen, selbst von den inneren Gedanken zurückzieht, jede Bewegung und Körperverrichtung möglichst hemmt, sich allein und ausschliessend in das Wesen der Gottheit versenkt, und sich mit demselben zu verbinden strebt." (Humboldt: Über die unter dem Namen Bhagavad-Gitá bekannte Episode, S. 34)

792 Vgl. Humboldt: Über die unter dem Namen Bhagavad-Gitá bekannte Episode, S. 5-7, 37, 44

${ }^{793}$ Vgl. Leitzmann (Hg.): Briefwechsel zwischen Wilhelm von Humboldt und August Wilhelm Schlegel, S. 178f. (Juni 1823)
} 
man in der Forderung, auf die Früchte des Handelns zu verzichten, die „moralische Forderung, das Gute nur um seiner selbst, die Pflicht nur um der Pflicht willen zu thun, erkennen.“794 Doch habe er sich nicht durch den ,ersten guten Anschein täuschen“795 lassen und so finde er Dinge, vor denen er „weder religiöse noch moralische Achtung ${ }^{6796}$ habe. Denn die Pflichten, nach denen das Handeln ausgerichtet sein soll, ergäben sich in den Lehren der Bhagavadgītā nicht aus Sittlichkeit, sondern allein aus dem Gesetz der Kaste, deren Erhaltung sie dienten. ${ }^{797}$ Zudem sei Yoga „eine Vertiefung

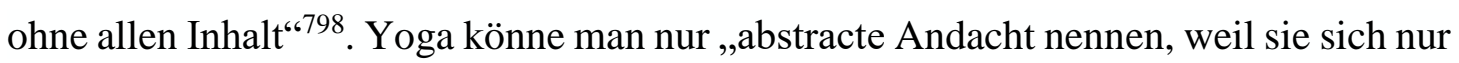
in die vollkommene Inhaltslosigkeit des Subjects und des Gegenstandes, und damit gegen die Bewusstlosigkeit hineinsteigert.“799 So sei das „Indische Vereinsamen der Seele in die Leerheit [...] eine Verstumpfung, die vielleicht selbst den Namen Mysticismus gar nicht verdient, und die auf keine Entdeckung von Wahrheiten führen kann, weil sie ohne Inhalt ist." ${ }^{800}$ Anders als Humboldt hebt Hegel die radikalen Unterschiede zwischen europäischen und indischen Vorstellungen hervor, weshalb es für Konzepte wie Yoga im Westen auch kein entsprechendes Wort gebe. ${ }^{801}$

Die großen Unterschiede in der Beurteilung der indischen Lehre, die bei Humboldt und Hegel deutlich hervortreten, finden sich auch bei anderen Autoren. Die indischen Lehren werden von einigen verehrt, von anderen strikt abgelehnt und wieder andere finden in ihnen sowohl Gutes als auch Schlechtes. Das gilt auch für die Lehre der Seelenwanderung. Während der Engländer Forster lobt, dass sie zu größerer Humanität

\footnotetext{
${ }^{794}$ Hegel, Georg Wilhelm: Über die unter dem Nahmen Bhagavad-Gita bekannte Episode des Mahabharata; von Wilhelm von Humboldt. Erster Artikel. In: Jahrbücher für wissenschaftliche Kritik. Herausgegeben von der Societät für wissenschaftliche Kritik. Jahrgang 1827. Stuttgart und Tübingen 1827, Sp. 51-63, Sp. 56

${ }^{795}$ Hegel: Über die unter dem Nahmen Bhagavad-Gita bekannte Episode des Mahabharata; von Wilhelm von Humboldt. Erster Artikel, Sp. 59

${ }^{796}$ Hegel: Über die unter dem Nahmen Bhagavad-Gita bekannte Episode des Mahabharata; von Wilhelm von Humboldt. Erster Artikel, Sp. 59

${ }^{797}$ Vgl. Hegel: Über die unter dem Nahmen Bhagavad-Gita bekannte Episode des Mahabharata; von Wilhelm von Humboldt. Zweiter Artikel, Sp.1449f.

${ }^{798}$ Hegel: Über die unter dem Nahmen Bhagavad-Gita bekannte Episode des Mahabharata; von Wilhelm von Humboldt. Zweiter Artikel, Sp. 1446

${ }^{799}$ Hegel: Über die unter dem Nahmen Bhagavad-Gita bekannte Episode des Mahabharata; von Wilhelm von Humboldt. Zweiter Artikel, Sp. 1446

${ }^{800}$ Hegel: Über die unter dem Nahmen Bhagavad-Gita bekannte Episode des Mahabharata; von Wilhelm von Humboldt. Zweiter Artikel, Sp.1455

${ }^{801}$ Zu der Auseinandersetzung zwischen Humboldt und Hegel vgl. Maillard: La „Bhagavad gita“, S. 131-143; Herling: The German Gita, S. 203-249; Bergunder, Michael: Die Bhagavadgita im 19.

Jahrhundert. Hinduismus, Esoterik und Kolonialismus. In: Bergunder, Michael (Hg.): Westliche Formen des Hinduismus in Deutschland. Eine Übersicht. Halle 2006 (Neue Hallesche Berichte. Quellen und Studien zur Geschichte und Gegenwart Südindiens; 6), S. 187-211, hier S. $190 f$.
} 
und Menschenliebe geführt habe, ${ }^{802}$ sieht Herder das eher kritisch, da die Gefahr bestünde, dass sie falsches Mitleiden fördere, wahres Mitgefühl aber verhindere. ${ }^{803}$

Papi schreibt:

Es verhält sich mit den Glaubenslehren und philosophischen Meinungen der Indier auf eben die Art, wie bei uns Europäern. Einige sind schön, wahr, und erhaben; andere sind aus der Luft gegriffen und unwahr, übrigens aber sinnreich und in Ansehung der Erfindung frappant; noch andere, und zwar die meisten, sind alltäglich, läppisch, abgeschmackt, und belachenswerth. ${ }^{804}$

Zu der zweiten Klasse gehöre auch Lehre der Seelenwanderung. ${ }^{805}$

Wie komplex das Thema ist (auch aufgrund der Existenz verschiedener philosophischer Schulen in Indien) und wie sehr die Kenntnisse der europäischen Gelehrten innerhalb des Untersuchungszeitraums anwachsen, zeigt ein Artikel über die „Transactions of the Royal Asiatic Society“ in der Allgemeinen Literatur-Zeitung aus dem Jahr 1828, der im Vergleich zu den früheren Texten deutlich ausführlicher und differenzierter ist in der Darstellung:

Die Inder zählen mehrere philosophische Schulen [...]. Ihr erstes und letztes Zeil ist Freyheit des Geistes (Moksha [...]; es sollen die Mittel gelehrt werden, wodurch man den Geist von den sinnlichen Objecten ablenken, von Leidenschaften befreyen, zur ewigen Glückseligkeit vorbereiten könne. In Bestimmung der Mittel welche hiezu geschickt machen, ist es nun zuvörderst, wodurch die Schulen von einander abgehen: bald gelangt man zu seinem Zwecke durch höheres Wissen (vidyâ [...]) oder Erforschung des Geistes (âtmâ) und dessen Verhältnisses zur Materie (prakriti); bald durch Meditation, Quietismus und eine Vertiefung oder Einigung (yoga) der Seele mit Gott; bald durch gute Werke und strenge Befolgung aller in den Veden vorgeschriebenen Pflichten, Opfer und Bussübungen. Eben so verschieden sind die Ansichten über das zu erzielende summum bonum [...] selbst: es besteht in der Unabhängigkeit von äussern Eindrücken [...] oder in Freyheit von Unruhe und Schmerz [...]; oder in der Befreyung von künftiger Seelenwanderung; oder in der Vereinigung mit der Gottheit wobey die Individualität entweder aufhören oder fortbestehen kann. ${ }^{806}$

Der Autor unterscheidet die Lehren verschiedener Schulen sowohl hinsichtlich des Weges als auch des Ziels. Auffällig ist auch die differenzierte Bezeichnung mit verschiedenen Ausdrücken der indischen Philosophie.

\footnotetext{
${ }^{802}$ Vgl. Forster: Reise aus Bengalen, S. 40

${ }^{803}$ Vgl. Herder: Ideen, S. 294

${ }^{804}$ Briefe eines italienischen Reisenden, S. 221

${ }^{805} \mathrm{Vgl}$. Briefe eines italienischen Reisenden, S. 221

${ }^{806}$ Orientalische Literatur. In: Allgemeine Literatur-Zeitung (1828), Band 2, Nr. 182, Sp. 601-608, hier Sp. 606
} 


\title{
4.4 Aberglaube und Buße
}

Während die religiösen und philosophischen Texte der Inder durchaus Anerkennung erfahren, wird die zeitgenössische religiöse Praxis in den allermeisten Fällen als abschreckendes Beispiel für Aberglauben beschrieben. Dabei geht es zum einen um einen eher als Zeichen der Unwissenheit belächelten Aberglauben (wie den Glauben an Zauberei und Wahrsagerei) und zum anderen um grausamen Bußübungen, die auf deutliche Ablehnung stoßen. Auch die Verehrung des Lingams findet oft Erwähnung.

Bereits 1782 nutzte Goethe in einem Brief an Charlotte von Stein Elemente der indischen Mythologie wie selbstverständlich als Beispiel für die Verbreitung von unwissenschaftlichen, abergläubischen Theorien:

\begin{abstract}
Er [Hans Caspar] kommt mir vor wie ein Mensch der mir weitläufigen erklärte die Erde sey keine akkurate Kugel, vielmehr an beyden Polen eingedruckt, bewiese das auf's bündigste, und überzeugte mich daß er die neusten ausführlichsten richtigsten Begriffe von Astronomie und Weltbau habe; was würden wir nun sagen wenn solch ein Mann endigte: schlieslich muß ich noch der Hauptsache erwähnen, nämlich daß diese Welt deren Gestalt wir aufs genauste dargethan, auf dem Rücken einer Schildkröte ruht sonst sie in Abgrund versincken würde. ${ }^{807}$
\end{abstract}

Die Vorstellung, dass die Welt auf dem Rücken einer Schildkröte ruhe, war Goethe und vielen anderen z.B. aus den Berichten Dappers ${ }^{808}$ oder Sonnerats ${ }^{809}$ vertraut und konnte daher ohne Verständnisschwierigkeiten in dieser Funktion verwendet werden. Indien konnte also bereits vor 1790 als allgemein verständliches Bild für irrationale Vorstellungen dienen.

Die Hindus werden von vielen Autoren als abergläubisch beschrieben. Laut Ehrmann glaubten sie an „Wahrsagerei, Einfluß der Gestirne, Zauberei, Hexerei, Gespenster, böse Geister, Talismane und andere Zaubermittel, an Bessenheit, Geisterbannerei u.s.w. “810. Ehrmann führt das auf zwei Gründe zurück: Zum einen seien die Hindus „noch so wenig aufgeklärt und so unwissend“ ${ }^{811}$ und zum anderen förderten die

\footnotetext{
${ }^{807}$ Goethe, Johann Wolfgang: Das erste Weimarer Jahrzehnt. Briefe, Tagebücher und Gespräche vom 7. November 1775 bis 2. September 1786. Herausgegeben von Hartmut Reinhart. Frankfurt a.M.1997 (Sämtliche Werke. Briefe, Tagebücher und Gespräche. II. Abteilung: Briefe, Tagebücher und Gespräche. Herausgegeben von Karl Eibel u.a., Band 2 (29), S. 411

${ }^{808}$ Vgl. Dapper: Asia, S. 63

${ }^{809}$ Vgl. Sonnerat: Reise nach Ostindien, S. 89

${ }^{810}$ Ehrmann: Neueste Kunde von Asien, S. 136

${ }^{811}$ Ehrmann: Neueste Kunde von Asien, S. 135
} 
Brahmanen diesen Aberglauben. ${ }^{812}$ Diese von Ehrmann benutzte Argumentation, dass die Brahmanen keinerlei Interesse an einer Aufklärung des Volkes hätten, sondern vielmehr aus der eigennützigen Motivation des Machterhalts heraus den allgemeinen Aberglauben förderten, ist um 1800 weit verbreitet. Sie findet sich auch bei dem Engländer Forster ${ }^{813}$, bei Kleuker ${ }^{814}$ und in dem Lexikon-Artikel von $1815^{815}$. Auch Perrin schließt sich dieser These an. Die Brahmanen sowie auch viele Fürsten teilten den (Aber-)Glauben des einfachen Volkes selbst nicht, schürten aber absichtlich diese Irrtümer. ${ }^{816}$ Als weitere Gründe für den Aberglauben macht Perrin Gewohnheit und Faulheit sowie eine angeborene Gottesehrfurcht aus:

\begin{abstract}
Die Bewohner Hindostans sind von Natur gottesfürchtig, und man kann selbst hinzu setzen, was der große heilige Leo vom heidnischen Rom sagte: Sie würden sich ein Gewissen daraus machen, wenn irgend eine Gegend der Welt sich schmeicheln könnte, irgend einen Götzen zu besitzen, den sie nicht auch anbetheten. Sie sind mit den Ideen übernatürlicher Dinge und Wesen so verschwistert, daß alles, was die Gottheit betrifft, ihnen leicht zu glauben wird. ${ }^{817}$

Ihr Heidenthum ist sogar sehr blind. Alles, was man ihnen von der Natur der Götter sagt, so übertrieben es auch seyn möge, nehmen sie buchstäblich an. So werden sie heute, nach der Entscheidung eines Bramen, den Stein anbethen, auf den sie gestern ihre Wäsche legten, um sie zu trocknen. Wenigstens thun sie so, als ob sie alles dieses glaubten. Sie sind durch Gewohnheit, Faulheit, Mangel an Forschungseifer, und vorzüglich durch den Wunsch, das zu seyn, was ihre Vorältern waren, an ihren Aberglauben gefesselt $\left[\ldots . .{ }^{818}\right.$
\end{abstract}

Perrin schildert das einfache Volk als sehr leichtgläubig und naiv. Was auch immer die Brahmanen sie zu verehren hießen, würden sie ohne weitere Fragen oder Zweifel verehren.

\footnotetext{
812 Vgl. Ehrmann: Neuste Kunde von Asien, S. 136

${ }^{813}$ Vgl. Forster: Reise aus Bengalen, S. 41f.

814 „Die Religionslehren des Brahmanischen Systems [...] mögen gehalten werden, wofür sie wollen, so sind sie bey weitem nicht so schlecht, daß sie nicht einen bessern und heilsamern Gebrauch erlaubten, als die Brahmanen - im Ganzen genommen - davon zu gestatten gut finden. Diese eben so stolze, als abergläubische, dabey verschmitzte und eigennützige Priesterkaste [...] hat von jeher dafür gesorgt, daß einem Indier nichts schwerer, ja nichts unmöglicher wird, als seinen Gott in Einfalt und Unschuld des Herzens zu verehren. Sie, die Brahmanen, sind sehr früh auf einen unendlichen Apparat von Götzenund Bilderdienst, Cärimonien, Opfern, Reinigungen, Büßungen und Wallfahrten bedacht gewesen, der auf ihren Eigennutz und auf die Erhaltung der Fesseln des Aberglaubens oder des Seelen- und Gewissenszwangs, so sehr berechnet ist.“ Die Brahmanen lassen das Volk ,in einem desto bedauernswürdigern Aberglauben, je weniger es selbst im Stande ist, den ursprünglichern Sinn jener allegorischen Dichtungen zu verstehen, oder auch nur zu ahnen. Hievon hat der unwissendere Theil der Brahmanen - das ist bey weiten der größte - selbst keine Idee, indem er alles ganz buchstäblich

glaubt."(Vgl. Kleuker: Das Brahmanische Religionssystem, S. 119-121)

${ }^{815} \mathrm{Vgl}$. Conversations-Lexikon. 1815, S. 717

${ }^{816}$ Vgl. Hell: M. Perrin's Reise durch Hindostan. 2. Theil, S. 4, 22 f.

${ }^{817}$ Hell: M. Perrin's Reise durch Hindostan. 2. Theil, S. 4

${ }^{818}$ Hell: M. Perrin's Reise durch Hindostan. 2. Theil, S. 21f.
} 
Bei dieser Art des Aberglaubens werden die einfachen Hindus zumeist als Opfer der Brahmanen oder einer zu naiven Gottesfurcht dargestellt und eher belächelt als verurteilt. Der indische Aberglaube wird als das Andere stilisiert, um sich dadurch der eigenen aufgeklärten Rationalität zu versichern. Die Kritik richtet sich gegen die Herrschsucht der Brahmanen. Diese Argumentation greift z.T. auf die oben bereits vorgestellte These zurück, dass die Lehren der Hindus in ihrer alten, unverfälschten Form durchaus Wahres enthielten, aber im Laufe der Zeit immer mehr verfälscht worden seien. Das einfache Volk habe den ursprünglichen Kern ihres Glaubens vergessen und auch einigen Brahmanen sei er nicht mehr bewusst. Die übrigen verschwiegen ihn zur Festigung ihrer Macht. Interessant ist, dass bei der konkreten Auseinandersetzung mit dem Aspekt der indischen Religionspraxis, der besonders große Aufmerksamkeit der europäischen Beobachter auf sich zieht, diese Trennung zwischen dem naiven Volk und den machtbewussten Brahmanen bzw. zwischen der alten Lehre und ihrer Verfälschung eine deutlich geringere Rolle spielt: die viel beschriebenen Bußübungen, die einerseits Entsetzen hervorrufen, andererseits aber auch eine Neugierde auf Exotisches und eine gewisse Lust am Grausamen befriedigen.

Die Bußübungen erlangten schon früh große Bekanntheit. Bereits Dapper beschrieb grausame und blutige Rituale und Bußen, die einige Inder durchführten, um ins Paradies zu kommen. ${ }^{819}$ Um 1800 sind die Büßenden mit dem verbreiteten Bild von Indien eng verbunden, was die Feststellung in den Anmerkungen zur ŚakuntalāÜbersetzung von Forster, die indischen Büßenden seien zu bekannt, als dass man ausführlicher darauf eingehen müsse ${ }^{820}$, deutlich zeigt. Im übertragenen Sinn können die Büßenden sogar als Bild für einen streng zurückgezogen lebenden Einsiedler Verwendung finden. So schreibt Goethe 1816 augenzwinkernd an von Fritsch, dass er diesen Winter meistens zu Hause geblieben sei und schon beinahe als indischer Büßender hätte gelten gönnen. ${ }^{821}$

\footnotetext{
${ }^{819}$ Vgl. Dapper: Asia, S. 120-122

${ }^{820}$ Vgl. Forster: Sakontala, S. 292

${ }^{821}$ Vgl. Goethe, Johann Wolfgang: Napoleonische Zeit. Briefe, Tagebücher und Gespräche vom 10.Mai 1805 bis 6. Juni 1816. Teil II: Von 1812 bis zu Christianes Tod. Herausgegeben von Rose Unterberger. Frankfurt a.M. 1994 (Sämtliche Werke. Briefe, Tagebücher und Gespräche. II. Abteilung: Briefe, Tagebücher und Gespräche. Herausgegeben von Karl Eibl u.a., Band 7/34), S. 573
} 
Bei den Darstellungen der Bußpraxis und Opferhandlungen kann man zwei Gruppen von Autoren unterscheiden: Während eine Mehrheit der Autoren die Grausamkeit vieler Bußübungen ausführlich schildert, betont eine Minderheit, dass diese Praktiken zwar früher vielleicht verbreitet waren, jetzt aber kaum noch vorkämen und insgesamt im Vergleich mit anderen Kulturen deutlich weniger blutig seien. Zu dieser Minderheit gehören z.B. Sonnerat, Müller und etwas zögerlicher auch Perrin. Letzterer beschreibt zwar auch verwundert die Bereitschaft der Inder, sich selbst zu quälen, ${ }^{822}$ aber es gebe auch viele Betrüger, die ihre strengen Bußübungen nur zum Schein vollzögen, um damit die Menschen zu beeindrucken. ${ }^{823}$ Perrin hält fest: „Die Altäre der Indier triefen nicht von Blut, wie die der meisten andern heidnischen Nationen. Ihre Götter gaben sich zu der Sanftmuth der Landessitten her [...]. ${ }^{\text {“824 }}$ Auf die höhere Friedfertigkeit im Vergleich zu den Nachbarn verweisen auch Müller und Sonnerat. Sie argumentieren, dass die Inder zwar sehr selten auch Menschenopfer kannten, aber anders als bei den Nachbarvölkern vor allem Pflanzen oder Tiere opferten. Während aber Müller davon ausgeht, dass der ursprünglich reine Gottesdienst in späterer Zeit durch groben Naturdienst verdorben worden sei, ${ }^{825}$ sieht Sonnerat die zeitlichen Abläufe genau andersherum: Die Opferungen habe es nur in den ältesten Zeiten gegeben; sie seien aber durch die Lehre von der Seelenwanderung abgeschafft worden. ${ }^{826}$ Auch die berühmten Selbstopferungen bei dem Fest von Jagannātha würden höchstens noch von einigen wenigen Fanatikern begangen. ${ }^{827}$

\footnotetext{
822 „Die Indier glauben tugendhaft zu seyn, wenn sie viel bethen, streng fasten, die Sorge für ihren Körper vernachlässigen, sich oft baden, die Livree der Götter, die sie anbethen, tragen, ihre Feste mit Pracht begehen, und keinen der Gebräuche ihrer Kaste übersehen, auch Almosen geben, und sich außerordentliche Büßungen auferlegen. [...] Ein gewisser Instinct überredet die unglücklichen Indier, daß nichts die Gottheit mehr ehre als Büßungen, oder freywillige Entziehung von Vergnügungen. Sie sie einmahl vom Dämon der Penitenzen besessen, so wüßte ich nicht, was für Tollheiten sie nicht verüben, welchen Qualen sie sich nicht unterwerfen könnten“ (Hell: M. Perrin’s Reise durch Hindostan. 2. Theil, S. 25)

${ }^{823}$ Vgl. Hell: M. Perrin's Reise durch Hindostan. 2. Theil, S. $26 f$.

${ }^{824}$ Hell: M. Perrin's Reise durch Hindostan. 2. Theil, S. 47

${ }^{825}$ Vgl. Müller: Glauben, Wissen und Kunst der alten Hindus, S. 289f.

${ }^{826}$ „Der Gottesdienst eines unverdorbenen gutmüthigen Volkes wird niemahls wild seyn, weil es sich nur wohlthätige Gottheiten wählet. Es wird zwar viele Priester, aber keine Opferpfaffen haben, und wenn es auch seine Abhängigkeit von Gott zu bezeugen Opfer für nöthig findet, so wird es selbige nur aus dem Pflanzenreiche nehmen. So ist wirklich der ietzige Gottesdienst der Indier beschaffen. In den ältern Zeiten opferten sie zwar Thiere und sogar Menschen, dennoch aber hatten sie einen Abscheu an Blut, und statt ihre Opfer abzuschlachten, begnügte sich der Hohepriester damit, sie zu ersticken. Der durch Wischenu eingeführte Lehrsatz von der Seelenwanderung schaffte alle blutigen Opfer ab [...].“ ( Sonnerat: Reise nach Ostindien, S. 107); diese Abfolge vertritt auch Papi, der ansonsten aber wenig Interesse daran zeigt, die Bußübungen in seiner Darstellung abzumildern (vgl. Briefe eines italienischen Reisenden, S. 248)

${ }^{827}$ Vgl. Sonnerat: Reise nach Ostindien, S. 119
} 
Dieses Fest steht gewissermaßen stellvertretend für die grausamsten Auswüchse des indischen Büßer- und Opferwesens. Eine ausführliche Beschreibung findet sich im Morgenblatt für gebildete Stände. ${ }^{828}$ Der Soldat Scharnhorst erwähnt ebenfalls ein solches Fest, wenn auch ohne genauere Benennung, und bezeichnet es als lächerlich und abscheulich. ${ }^{829}$ Auch Hegel verweist auf dieses Fest:

\begin{abstract}
Beim Gottesdienst in dem berühmten Tempel des Jagannâtha [...] wird das Bild des Gottes Wischnu auf einem Wagen herumgefahren; gegen fünfhundert Menschen setzen denselben in Bewegung, und Viele schmeißen sich vor die Räder desselben hin und lassen sich zerquetschen. Der ganze Strand des Meeres ist schon mit Gebeinen von Geopferten bedeckt. ${ }^{830}$
\end{abstract}

Weitere Artikel im Morgenblatt beschreiben auch andere Formen von Selbstopferungen. ${ }^{831}$ Am häufigsten jedoch sind Beschreibungen von Selbstpeinigungen wie z.B. das Aufhängen von Menschen an Metallhaken, das Leben in Käfigen, Verharren in unbequemen Stellungen und andere. ${ }^{832}$ Es gibt aber auch sehr viele Texte über indische Religion, in denen weder Aberglaube noch Bußübungen thematisiert werden. Die Texte, in denen sie vorkommen, sind vor allem Reiseberichte und Artikel im Morgenblatt für gebildete Stände. Dort erfüllen sie häufig eine ähnliche Funktion wie Beschreibungen von Witwenverbrennungen und sind sowohl Ausdruck einer gewissen Erregung über exotische, abstoßende Geschehnisse als auch Beispiele, die die Kritik an bestimmten Aspekten der indischen Kultur untermalen sollen.

Einige Autoren setzen sich damit auseinander, warum solch strenge Bußübungen ausgeübt werden. Ein wichtiger Grund sei der Versuch, sich für das nächste Leben gute Bedingungen zu verdienen. Die Erzählung von den strengen Bußen des König Wiswamitra regt Windischmann zu der Interpretation an, die Bußübungen dienten auch dazu, die Götter direkt dazu zu nötigen, Hilfe zu leisten oder Wünsche zu erfüllen. Anders als im Christentum würde das Geschehen nicht der göttlichen Fügung anheim

\footnotetext{
${ }^{828}$ Vgl. Das Fest zu Jaggernauth, im Jahr 1814. In: Morgenblatt für gebildete Stände 10 (1816; Nr. 21 Januar), S. 83

${ }^{829}$ Briefe auf einer Reise von Stade nach Madras, S. $116 f$.

${ }^{830}$ Hegel: Vorlesungen über die Philosophie der Geschichte, S. 156

${ }^{831} \mathrm{Vgl}$. Skizzen aus Ostindien, S. 281f.; Indischer Aberglaube. In: Morgenblatt für gebildete Stände 18 (1824; Nr. 57 März), S. 226f.

${ }^{832}$ Vgl. z.B. Briefe eines italienischen Reisenden, S. 211f.; Ehrmann: Neueste Kunde von Asien. Zweiter Band, S. 162f.; Hell: M. Perrin's Reise durch Hindostan, S. 26-28; Best: Briefe über OstIndien, S. 32f.
} 
gestellt, sondern solle durch Selbstvernichtung erzwungen werden. ${ }^{833}$ Hegel beschreibt, dass darüber hinaus die Bußübungen für die Kriegerkaste die einzige Möglichkeit seien, das zu erreichen, was die Brahmanen bereits allein durch die Geburt als Brahmane erlangten: „Brahm“ zu sein. ${ }^{834}$ Papi fügt den Bußübungen neben dem eben beschriebenen Bestreben, für ein gutes nächstes Leben zu sorgen bzw. das Göttliche bereits in diesem Leben zu erreichen, eine weitere Funktion hinzu:

\begin{abstract}
Sie werden von selbst einsehen, lieber Freund, daß das ganze Bestreben dieser Phantasten bloß darauf abzweckt, eine gewisse eingebildete Vollkommenheit zu erreichen; daß es Menschen sind, denen ihre glühende trübsinnige Phantasie den Kopf verrückt. Einige thun auf die Schätze, die Ehrenstellen, und die Freuden dieses Lebens, bloß deswegen Verzicht, weil sie dereinst in jenem Leben desto reichlicher dafür entschädigt zu werden hoffen; von andern hingegen geschieht solches bloß in er Absicht, noch hienieden recht viele Reichthümer zusammen zu scharren, und sich zu hohen Ehrenämtern emporzuschwingen. Hinter ihrer affectirten Demuth und Erniedrigung, ist ein gränzenloser Stolz versteckt. ${ }^{835}$
\end{abstract}

Einige Inder verzichteten nicht auf Reichtümer und Ehren, um im nächsten Leben davon zu profitieren, sondern nutzten Bußübungen, um eben diese Reichtümer und Ehren bereits in diesem Leben zu erlangen. Die Vollkommenheit, die die Inder zu erreichen hofften, nennt der Reisende eine „eingebildete Vollkommenheit“", denn hinter der zur Schau getragenen Demut verstecke sich grenzenloser Stolz. Er relativiert diese Kritik allerdings dahingehend, dass es von diesen Büßenden nur sehr wenige gebe. ${ }^{836}$

Während viele Autoren den Bußübungen innerhalb der indischen Religionspraktik einen festen Platz einräumen, weisen andere Autoren darauf hin, dass die Bußübungen trotz ihrer Verbreitung sich nicht durch die indischen religiösen Schriften legitimieren lassen. So wird bereits in den Anmerkungen zur Śakuntalā-Übersetzung von Forster darauf hingewiesen, dass die Bhagavadgìtā deutlich mache, dass auf die strengen Bußübungen nicht allzu viel Wert gelegt werden sollte. Sie seien vermutlich aus missverstandenen Stellen heiliger Bücher entstanden, in denen allein von geistigen Bußübungen und geistiger Enthaltsamkeit die Rede sei ${ }^{837}$ Auch Majer relativert über zwanzig Jahre später den Wert der Bußübungen: Sie seien nur dann wirklich hilfreich, wenn man wirkliche Reue verspüre. Zudem habe Andacht einen größeren Wert als alle

\footnotetext{
${ }^{833}$ Vgl. Bopp: Über das Conjugationssystem, S. XXV-XXIX

${ }^{834}$ Vgl. Hegel: Vorlesungen über die Philosophie der Geschichte, S. 307-309

${ }^{835}$ Briefe eines italienischen Reisenden, S. 213

${ }^{836} \mathrm{Vgl}$. Briefe eines italienischen Reisenden, S. 213

${ }^{837}$ Vgl. Forster: Sakontala, S. 292
} 
anderen Pflichten und Übungen, denn nur wahre Andacht vernichte die Sünden und führe zu Gott. ${ }^{838}$

\section{Literatur, Kunst und Wissenschaften}

Die Übersetzung des indischen Dramas Śakuntalā durch Georg Forster 1791 bedeutet für die Rezeption der indischen Kultur im deutschsprachigen Raum einen tiefen Einschnitt. Sie lenkt die Aufmerksamkeit eines größeren Publikums nicht nur auf Indien als solches, sondern speziell auf die alte indische Kultur. Das Bild Indiens in der Öffentlichkeit ist nun nicht mehr nur von dem geprägt, was die alten Griechen Wunderbares darüber zu erzählen wussten oder was Indienreisende über das zeitgenössische Leben in Indien berichten, sondern wird um das Wissen erweitert, dass auch Indien - ähnlich wie Griechenland und Ägypten - eine alte Hochkultur war. Die Śakuntalā selbst wird von vielen in den Kanon klassischer Literatur aufgenommen. Das Bild, das dieses Werk von der indischen Kultur vermittelt, beeinflusst die Vorstellungen, die die Leser sich von eben dieser Kultur und von den Indern selbst machen. Das gilt insbesondere dann, wenn es dieses Drama ist, dass ihre Aufmerksamkeit erstmals auf Indien lenkt. Doch nicht nur die Indienwahrnehmung um 1800 wird zumindest bei denjenigen Autoren, für die Indien eine neue Entdeckung ist, durch die Śakuntalā entscheidend mitgeprägt, sondern auch für die Interpretation und Darstellung dieser Indienwahrnehmung durch die Wissenschaft ist sie von großer Bedeutung. Gerade vor diesem Hintergrund ist es wichtig $\mathrm{zu}$ betonen, dass die Übersetzung durch Forster zwar ein sehr einschneidendes Ereignis ist, dass aber die Śakuntalā keineswegs das Indienbild um 1800 in dem Maße bestimmt, wie es in der Forschung manchmal den Anschein hat. Das wird allein aus den oben ausführlich beschriebenen anderen Aspekten und Themen deutlich, die ebenso sehr $\mathrm{zu}$ den Vorstellungen gehören, die mit dem Begriff Indien verbunden sind.

Obwohl Indien aufgrund seiner Literatur von einigen Autoren in den Kreis der alten Hochkulturen aufgenommen wird, wird, anders als es bei der klassischen griechischen Kultur der Fall war, der indischen Kunst und Wissenschaft kaum Aufmerksamkeit geschenkt. Die Beobachtungen in diesen Bereichen der indischen Kultur können die Vorstellungen, die sich die Autoren von einer alten Hochkultur machen, nicht in ausreichendem Maße erfüllen und stören so das Bild, das sie sich von dem alten Indien

\footnotetext{
${ }^{838}$ Vgl. Majer: Brahma, S. 191f.
} 
machen (wollen). Die überraschende Kluft zwischen der hohen Literatur und der in den Augen der europäischen Beobachter wenig entwickelten Kunst und Wissenschaft wird zumeist mit einem negativen Einfluss religiöser Vorgaben erklärt.

\subsection{Indische Literatur}

Das Bild, welches sich die Rezipienten um 1800 von den literarischen Werken Indiens machen, ist deutlich von dem Drama Śakuntalā geprägt. Es ist nicht nur das erste indische Drama, das ins Deutsche übersetzt worden ist, sondern es erlangt auch eine besonders große Bekanntheit. Es gibt kaum einen Text über indische Literatur, in dem es nicht zumindest erwähnt wird. Wie selbstverständlich die Kenntnis der Śakuntalā ist, zeigen sowohl Creuzer als auch Klaproth sehr deutlich durch ihre rhetorische Frage: „Wer kennt nicht die Sakontala[...]?“839 Und Heeren führt aus, dieses Drama, „den Lesern zu bekannt, als daß es nöthig wäre, ihren Inhalt ausführlich ihnen ins Gedächtniß zurück zu rufen, hat auch in Europa nicht geringe Aufmerksamkeit erregt." ${ }^{840}$ Die Śakuntalā ist jedoch nicht nur sehr bekannt, sie erfreut sich auch großer Beliebtheit. In den untersuchten Texten finden sich keine deutlich kritischen oder abwertenden Äußerungen über dieses Drama. Stattdessen schwingt in vielen der Äußerungen Begeisterung mit. Grenzmann stellt dazu fest: „Die Publikation der “Sakontala“ trifft ins Zentrum der im Laufe des 18. Jahrhunderts entstandenen Vorstellungen vom indischen Kontinent. “841 Sie scheint viele Vorstellungen von Indien zu bestätigen und weckt gleichzeitig das Bedürfnis, die bestehenden Kenntnisse zu erweitern.

Forster selbst, der das Werk in der englischen Übersetzung von Jones kennengelernt hatte, äußert sich während und kurz nach der seiner Übertragung ins Deutsche zwar sehr wohlwollend und angetan, allerdings fehlt bei ihm noch die überschwängliche Begeisterung, mit der andere Autoren sich kurz darauf über das Drama äußern. Er sieht dieses Drama als ein Beispiel dafür, wie die menschlichen Geisteskräfte an verschiedenen Orten und unter unterschiedlichen Rahmenbedingungen auch

\footnotetext{
${ }^{839}$ Creuzer: Symbolik und Mythologie der alten Völker. Erster Band. Zweite völlig umgearbeitete Ausgabe, S. 559; vgl. Klaproth, Julius: Einleitung. In: Asiatisches Magazin 1 (1802), erstes Stück, S. 3 8, hier S. 6

${ }^{840}$ Heeren: Ideen über die Politik, S. 378

${ }^{841}$ Grenzmann, Ludger: Zur frühen deutschsprachigen Rezeption von Georg Forsters SakontalaÜbertragung von 1791. In: Hellfaier, Detlev u.a. (Hgg.): Der wissenschaftliche Bibliothekar. Festschrift für Werner Arnold. Wiesbaden 2009, S. 231-256, hier S. 234
} 
unterschiedliche Ergebnisse hervorbringen. Forsters Interesse an der Śakuntalā ist also eher die eines Anthropologen und Philologen als eines Literaturliebhabers. ${ }^{842}$

Ganz anders klingt die erste Reaktion Herders. Er bedankt sich in einem Brief bei Forster für die Übersetzung: Angenehmer und dabei so unerwartet sei ihm so leicht kein anderes Werk gewesen. So etwas gebe es nur alle 2000 Jahre einmal. Hier ist die Begeisterung deutlich spürbar, wobei nicht ganz deutlich wird, ob sie nur der Śakuntalā als solcher gilt oder ob es gerade das Unerwartete ist, die Freude, ein solches Werk in Indien (und nicht z.B. in Griechenland) zu finden, das Herder so bewegt. Durch die Lektüre wird Herder dazu angeregt, weitere indische Texte zu lesen. Auch wirbt er aktiv bei Bekannten für das Drama. ${ }^{843}$ In seinen Briefen „Über ein morgenländisches Drama“ liefert er dann ein Jahr später Interpretationsansätze und Gedanken über die Śakuntalā, die die folgende Rezeption nicht nur dieses Dramas, sondern der indischen Literatur allgemein nachhaltig prägen. Bevor wir uns diese Gedanken näher ansehen, möchte ich zunächst noch die Beliebtheit der Śakuntalā anhand einiger Zitate untermalen und einen kurzen Blick auf weitere bekannte indische Texte werfen.

Das - auch um 1800 - bekannteste Lob der Śakuntalā sind vermutlich die Verse Goethes, die dieser 1791 an Jacobi schickt und die Herder seinen Briefen über die Śakuntalā voranstellt:

\section{Willst du die Blüthe des frühen, die Früchte des späteren Jahres, Willst du, was reitzt und entzückt, willst du, was sättigt und nährt, Willst du den Himmel, die Erde mit Einem Nahmen begreifen - Nenn' ich Sakontala Dich, und so ist alles gesagt. ${ }^{844}$}

Für Goethe liegt der Reiz dieses Dramas in seinem umfassenden Wesen: Himmel und Erde, Kindheit und Alter (Blüte und Frucht) erscheinen hier in eins. Noch 1830 spricht er von großem Enthusiasmus, den die erste Lektüre bei ihm erregt habe, und einem „höchst schätzbaren Werke“ ${ }^{845}$, in dem der natürlichste Zustand mit ernstester

\footnotetext{
${ }^{842}$ Vgl. Forster, Georg: Briefe 1790 bis 1791. Bearbeitet von Brigitte Leuschner und Siegfried Scheibe. Berlin 1980 (Georg Forsters Werke. Sämtliche Schriften, Tagebücher, Briefe. Herausgegeben von der Akademie der Wissenschaften der DDR; 16), 221 (an Heyne Januar 1791), 289f. (an Heyne Mai 1791) ${ }^{843} \mathrm{Vgl}$. Briefe an Forster, S. 467 (November 1791 von Herder)

${ }^{844}$ Herder Johann Gottfried: Über ein morgenländisches Drama. Einige Briefe. In: Johann Gottfried von Herder's Blumenlese aus morgenländischen Dichtern. Herausgegeben von Johann von Müller. Wien 1813, S. 259-298, hier S. 260

${ }^{845}$ Goethe: Die letzten Jahre, S. 319
} 
Gottesbetrachtung verbunden sei. ${ }^{846}$ Aber auch andere Autoren drücken ihre Verwunderung, Freude und Ergriffenheit aus. Ähnlich wie Herder, der davon spricht, dass eine Entdeckung wie die Śakuntalā unerwartet gewesen sei, betont auch Creuzer, dass sie die „Europäische Welt mit Recht in Erstaunen gesetzt hat.“847 Majer spricht von „Achtung und Liebe“ ${ }^{848}$, die die Śakuntalā entlocke, und bezeichnet sie als „liebliche Hervorbringung des indischen Genius“" mit einem „feenhaften Zauber“849. Und ein Rezensent in der Jenaischen Allgemeinen Literatur Zeitung schreibt:

Dass Hr. G. sich ergriffen und hingerissen fühlte, als er zum erstenmale die Sakontala [...] las, glauben wir gern; man muss prosaischer als prosaisch seyn, um nicht den Reiz eines Gedichtes zu fühlen, das von Goethe in dem bekannten Distichon [...] so gerecht und treffend gewürdigt ist $[\ldots] .{ }^{850}$

Diese herausgegriffenen Zitate zeigen deutlich die Beliebtheit dieses Stückes indischer Kultur. ${ }^{851}$

Andere Werke der indischen Literatur, die in den untersuchten Texten angesprochen und als literarische Werke diskutiert werden (also nicht nur als Quelle für die Mythologie von Interesse sind), sind vor allem das Gìtagovinda und das Gedicht Meghadūta sowie (erstaunlicherweise in weitaus geringerem Umfang) auch das Rāmāyaṇa und das Mahābhārata. Die Art und Weise, wie vor allem das Gītagovinda beschrieben wird, ähnelt den Kommentaren zur Śakuntalā sehr. Beide zusammen prägen entscheidend das Bild, das sich die meisten der Autoren von der indischen Literatur machten. Das ist insofern nicht verwunderlich, da - wie viele Autoren betonen - zunächst kaum mehr von den literarischen Werken Indiens bekannt geworden ist. So schreibt Creuzer noch 1819: „Allein von dem Reichthume dieser Literatur ist leider bis jetzt noch Wenig bekannt [...].“" ${ }^{652}$ Ähnlich äußert sich Heeren ein Jahr zuvor. Er

\footnotetext{
${ }^{846}$ Vgl. Goethe: Die letzten Jahre, S. 319

${ }^{847}$ Creuzer: Symbolik und Mythologie der alten Völker. Erster Theil. Zweite völlig umgearbeitete Ausgabe, S. 559

${ }^{848}$ Majer: Zur Kulturgeschichte der Völker, S. 163

${ }^{849}$ Majer: Über die mythologischen Dichtungen der Indier, S. 165

${ }^{850}$ Rezension zu: Sakontala, oder: der verhängnißvolle Ring: indisches Drama des Kalidas in sechs Aufzügen / Kalidasa. Metrisch für die Bühne bearbeitet von Wilhelm Gerhard. In: Jenaische Allgemeine Literaturzeitung 18 (1821; Nr. 53 März); Sp. 420-422, hier Sp.421

${ }^{851}$ Eine Zusammenfassung der Faszination, die dieses Drama auslöste, findet sich z.B. auch bei Steiner, Gerhard: Kalidasas Sakontala oder die deutsche Entdeckung Indiens. In: Rasmussen, Detlef (Hg.): Der Weltumsegler und seine Freunde - Georg Forster als gesellschaftlicher Schriftsteller der Goethezeit. Tübingen 1988, S. 59-69; Leifer: Indien und die Deutschen, S. 98-112

${ }^{852}$ Creuzer: Symbolik und Mythologie der alten Völker. Erster Theil. Zweite völlig umgearbeitete Ausgabe, S. 559
} 
wundert sich, warum gerade die literarischen Werke Indiens, die den Europäern doch am meisten zusagen sollten, so vernachlässigt worden seien. ${ }^{853}$ Entsprechend fordern verschiedene Autoren, noch weitere literarische „Schätze“ ${ }^{854}$ Indiens zu Tage zu fördern und mehr Texte zu übersetzen. ${ }^{855}$

Welches Bild aber bietet sich den Lesern um 1800 von der indischen Literatur? Welche Gedanken und Themen werden angesprochen? Ein Großteil der Äußerungen der untersuchten Texte lassen sich drei großen Themenfeldern zuordnen: erstens die Beschreibung der indischen Literatur als Ausdruck einer kindlichen Naivität und Naturverbundenheit, zweitens die Frage, inwieweit die indische Literatur europäischen Regeln und Kriterien entspricht bzw. entsprechen sollte, und drittens die Diskussion über den besten Umgang mit den neu entdeckten Werken in Übersetzungen, kritischen Ausgaben und Adaptionen.

Der erste der drei genannten Punkte sticht sofort ins Auge. Bereits Forster verbindet 1791 in dem Bild, welches er von dem Drama Śakuntalā zeichnet, den Hinweis auf die Naturverbundenheit der Inder und ihren kindlichen Geist, der sich in ihren literarischen Werken zeige, mit einer Naturmetaphorik: Er spiele „mit diesen Blumen Indiens“, um die „Dichtungen ihrer Kindheit“ zu studieren. Der „kindliche Geist, der in diesen Blumen weht“, werde sein Fürsprecher sein. ${ }^{856}$ In diesen Werken sollen die Europäer, die - durch ,wissenschaftliche Verfeinerung in Kenntnissen und Sitten zu einer künstlich abgemessenen, raisonnirten Lebensweise gestimmt“ - „leicht des einfachen Naturgefühls entwohnen“ ${ }^{657}$, eben dieses Naturgefühl wieder entdecken. Denn in dem Werk sei „Feinheit, Gefühl, Dichterschwung darin bey einer kindischen Einfalt in der noch ungebildeten Dramatisirungskunst“ “ 858

\footnotetext{
${ }^{853}$ Vgl. Heeren: Ideen über die Politik, S. 374

${ }^{854}$ Goethe, Johann Wolfgang: Goethes Gespräche. Zweiter Teil. Zürich1950 (Goethe, Johann Wolfgang: Gedenkausgabe der Werke, Briefe und Gespräche. Herausgegeben von Ernst Beutler), S. 36 (Juli 1818 mit Wilhelm Gerhard)

${ }^{855}$ Vgl. z.B. Majer: Zur Kulturgeschichte der Völker, S. 161; Briefe an Forster, S. 467 (November 1791 von Herder)

${ }^{856}$ Forster: Sakontala, S. V

${ }^{857}$ Forster: Sakontala, S. XXXII

${ }^{858}$ Forster: Briefe 1790 bis 1791, S. 164 (Juli 1790 an Spener)
} 
Herder greift die Naturmetaphorik auf und bezeichnet das Drama ebenfalls als „Blume“ ${ }^{\text {"859 }}$. Auch den Gedankengang, die Europäer mögen durch die indische Literatur „immer vertrauter mit dem Geiste der Natur werden“ ${ }^{860}$, übernimmt Herder. Die Sprachbilder aus dem Bereich der Pflanzen ziehen sich weiter durch Herders Kommentar: Die Szenen seien mit „Blumenketten“ ${ }^{\text {681 }}$ gebunden, jede „,entspringt aus der Sache selbst, wie ein schönes Gewächs, natürlich. ${ }^{6862}$ Die Natur spielt also eine dreifache Rolle: Erstens seien die kindlichen Inder im Gegensatz zu den Europäern noch vertraut mit dem ursprünglichen Geist der Natur und voller „Naturliebe“6863. Das führe zweitens dazu, dass auch ihre Literatur durch diesen Geist geprägt sei und ganz natïrlich erwachse und nicht künstlich erdacht werde. Und drittens nutzen sowohl Herder als auch Forster sprachliche Bilder aus dem Bereich der Natur, um diese naive, kindliche Natürlichkeit besonders herauszustreichen. Diese unverdorbene Natürlichkeit und Naturverbundenheit werde vor allem durch die Figur der Śakuntalā repräsentiert. Sie sei „das Kind der Natur, aufgeblüht im reinsten Äther, einem Schutz- und Erziehungsorte der Frauen. Wald und Blumen, die geheiligt Einsamkeit sind das umzäunte Paradies, worin diese unbekannte Hochgeborne, als eine Blume, verborgen und ungestört sich entfaltete [...]. ${ }^{6864}$ Auch Forster schreibt, die Hauptperson Sakontala „interessirt blos durch diese einfache, kindliche Naivität, durch die Zartheit ihres schwärmerischen Gefühls [...]. “665

Diese Art der Interpretation und Beschreibung (Natürlichkeit, kindliche Naivität, Zartheit) wird von vielen Autoren übernommen. Creuzer schreibt, man bemerke an dem Drama „zuvörderst die Innigkeit und das sinnige Wesen, das tiefe und zarte Naturgefühl und die gleichsam idealisirte Ansicht der Pflanzenwelt [...]. “866 Schiller attestiert dem Drama als Haupteigenschaft Zartheit und Mangel an Bewegung ${ }^{867}$ und nennt es als ein

\footnotetext{
${ }^{859}$ Herder, Johann Gottfried: Blumenlese aus morgenländischen Dichtern. Herausgegeben durch Johann von Müller. Wien 1807 (Johann Gottfried Herder's sämmtliche Werke. Zur schönen Literatur und Kunst. Neunter Theil), S. 209

${ }^{860}$ Herder: Blumenlese, S. 210

${ }^{861}$ Herder: Blumenlese, S. 210

${ }^{862}$ Herder: Blumenlese, S. 211

${ }^{863}$ Herder: Blumenlese, S. 211

${ }^{864}$ Herder: Blumenlese, S. 212

865 Forster: Sakontala, S. 328

${ }^{866}$ Creuzer: Symbolik und Mythologie der alten Völker. Erster Theil. Zweite völlig umgearbeitete Ausgabe., S. 560

${ }^{867}$ Vgl. Goethe, Johann Wolfgang: Ästhetische Schriften 1824-1832. Über Kunst und Altertum V-VI. Herausgegeben von Anne Bohnenkamp. Frankfurt A.M.1999 (Sämtliche Werke. Briefe, Tagebücher
} 
Beispiel für naive Dichtung (im Gegensatz zur sentimentalischen) ${ }^{868}$. Majer bittet darum, die „Sakontala, die unter ihren Schwestern zuerst auf europäischen Boden verpflanzt wurde, freundlich und sorgsam [zu] pflegen, wie es ihr zarter Bau verlangt [...].“ ${ }^{869}$ Sie werde ,als eine der schönsten Blumen einer zarten nur in diesen Verhältnissen herumschweifenden Phantasie erscheinen [...]. “870 Auch er stellt fest, dass sich Śakuntalā sowie alle weiblichen Charaktere „durch eine große Einfalt und Unschuld, durch ein liebliches Kolorit von Reinheit und Natürlichkeit aus[zeichnen], am meisten aber sie, durch ihre einfache kindliche Naivität, ihr anspruchsloses, ungezwungenes und ungekünsteltes Betragen, ihr zartes schwärmerisches Gefühl und die feine natürliche Äußerung der ihrer Seele eigenthümlichen Empfindungen. “ ${ }^{* 871}$ Der Rezensent zu Gerhards Schauspielbearbeitung schreibt von dem „zarten Duft dieser Indischen Blüthe“‘.872

Auch auf andere indische literarische Texte wird dieses Konzept der Naturverbundenheit übertragen. So erklärt Dalberg ${ }^{873}$, dass wir auch im Gītagovinda „in einer Blüthen- und Blumenwelt wandeln, dergleichen nur die Kindheit eines so zart organisirten Volks, als das Indische, dichten konnte. ${ }^{\text {“874 }}$ Die Werke des Orients seien „Schilderungen aus der lebendigen Schöpfung; um so stärker und wahrer, als der Orientale mehr in der Natur lebt, ihren Erscheinungen näher ist, sie also besser kennt, tiefer fühlt, und lebendiger malt.“ ${ }^{875}$ Ein Kommentar zum erst einige Jahre später bekannt gewordenen und von Goethe sehr gelobten Meghadūta verzichtet zwar auf den Verweis auf Blumen und Pflanzen, spricht aber auch von einer „reizende(n) Einfalt“ und einer „Zauberwelt, wo die Phantasie weich auf goldigen Flügeln, von lächelnden

\footnotetext{
und Gespräche. Herausgegeben von Friedmar Apel u.a. I. Abteilung: Sämtliche Werke; 22), S. 36 (Februar 1802)

${ }^{868}$ Schiller, Friedrich: Über naive und sentimentalische Dichtung. Herausgegeben von Klaus L. Berghahn. Stuttgart 2005, S. 80 (Fußnote)

${ }^{869}$ Majer: Zur Kulturgeschichte der Völker, S. 161

${ }^{870}$ Majer: Zur Kulturgeschichte der Völker, S. 163

${ }^{871}$ Majer: Zur Kulturgeschichte der Völker, S. 215 f.

${ }^{872}$ Rezension zu: Sakontala, Sp. 421

${ }^{873}$ Der Jurist Friedrich Hugo von Dalberg (1760-1812) war Geheimrat in Kurtrier. Sein Interesse galt aber vor allem der Musik und den Wissenschaften. In seiner Musiktheorie stand er romantischen Anschauungen nahe (vgl. Komma, Karl Michael, "Dalberg, Friedrich Hugo Freiherr von" in: Neue Deutsche Biographie 3 (1957), S. 488 f. [Online-Version]; URL: https://www.deutschebiographie.de/pnd116028203.html\#ndbcontent).

${ }^{874}$ Dalberg.: Gita-govinda, S. XIIIf.

875 Dalberg: Gita-govinda, S. XXIV (Anmerkung D)
} 
Träumen umspielt, sich wiegt [...].“876 Das Werk beinhalte sowohl „Zauberei und Wollust“ als auch den „Ausdruck der zärtesten unschuldigsten Gefühle“ ${ }^{\text {"877 }}$. Die bei der Śakuntalā zu dem Komplex aus Naturverbundenheit und ursprünglicher unverdorbener Natürlichkeit gehörende Zartheit und kindliche Naivität werden also auch dem Meghadūta zugeschrieben.

Ergänzt werden diese Attribute mit einer weiteren Gruppe zusammenhängender Eigenschaften, die bei der Darstellung einiger literarischer Werke immer mal wieder genannt werden: üppige Fülle, Phantasie, Zauber- und Traumwelt. Diese Zuschreibungen spielen allerdings gegenüber den bisher genannten nur eine untergeordnete Rolle und betreffen vor allem das Gītagovinda. Hinsichtlich dieses Werks wird vor allem die Frage diskutiert, inwieweit die Sinnlichkeit der dargestellten Liebe wollüstig und anstößig sei. Ein großer Verteidiger dieser Sinnlichkeit ist Goethe, der sich darüber beklagt, dass nicht nur Jones, sondern auch Dalberg in ihren Übersetzungen die in ihren Augen anstößigen Stellen gestrichen hätten. Gerade dadurch erhalte das Stück einen lüsternen Charakter, den es im Original nicht gehabt habe ${ }^{878}$ Auch Majer appelliert, wenn auch nicht so deutlich wie Goethe, an die Leser, die sinnlichen Stellen dieser ,vor uns handelnden lieblichen Einfalt der frühesten Zeiten“ ${ }^{\circ 879}$ nicht vorschnell zu verurteilen:

Über die poetischen Schönheiten dieser Lieder noch besonders zu sprechen, masse ich mir nicht an. Niemand aber, der sich Rechenschaft davon geben möchte, vergesse das Vaterland dieser zauberischen Töne und glühenden Farben, deren Glanz und Lebhaftigkeit hie und da zu mildern, ich nicht wagen durfte. Selig sind, die reines Herzens sind, und solchen wird diese harmonische Verschlingung geistiger und sinnlicher Liebe nicht anstössig seyn. Nur heuchelnde Ziererey oder blinde Unkenntniss der menschlichen Natur, kann diese von jener, und nur thierische Rohheit jene von dieser trennen wollen. ${ }^{880}$

\footnotetext{
${ }^{876}$ Mégha Doûta oder die verkündigende Wolke. Ein samskritanischs Gedicht von Kalidasa. In: Journal für Literatur, Kunst, Luxus und Mode (1817, März), S. 213-222, hier S. 215

${ }^{877}$ Mégha Doûta, S. 217

${ }^{878}$ Goethe, Johann Wolfgang: Mit Schiller. Briefe, Tagebücher und Gespräche vom 24. Juni 1794 bis zum 9. Mai 1805. Teil II. Vom 1. Januar 1800 bis zum 9. Mai 1805. Herausgegeben von Volker C. Dörr und Norbert Oellers. Frankfurt am Main 1999 (Sämtliche Werke. Briefe, Tagebücher und Gespräche. II. Abteilung: Briefe Tagebücher und Gespräche. Herausgegeben von Karl Eibl u.a., Band 5, 32), S. 227

${ }^{879}$ Majer, Friedrich: Gita-Govinda. ein indisches Singspiel. Von Jajadeva. aus der Ursprache ins Engl. von W Jones, und aus diesem ins Dt. übers., und mit einigen Erl. begleitet von Friedrich Majer. In: Asiatisches Magazin 2 (1802), 4. Stück, S. 294-375, hier S. 374

${ }^{880}$ Majer: Gita-Govinda, S. 374
} 
Heeren berichtet relativ neutral von dem „Geist der erotisch lyrischen Poesie“. Das Ziel der Liebe sei „sinnlicher Genuß, sie selber mehr Begierde als Leidenschaft ${ }^{\star}{ }^{\star 881}$. Die von Goethe beanstandeten Kürzungen seien daher nicht verwunderlich. Man werde aber dennoch vom Gītagovinda gefesselt, den „Reichthum der Phantasie, die Stärke und Lebendigkeit der Gefühle“ sowie „zarte(...) Empfänglichkeit für die Schönheiten der Natur ${ }^{6882}$ auszeichnen.

Wir haben bereits gesehen, dass die indische Kultur vielen Autoren insgesamt als Repräsentant einer alten Vorzeit und als Wiege der Menschheit galt. Dementsprechend wird auch der indischen Literatur immer wieder das Attribut eines hohen Alters zugeordnet. Viele Autoren räumen zwar ein, dass die schriftlichen Aufzeichnungen nicht so alt sind, wie ursprünglich oft angenommen, aber sie weisen darauf hin, dass diesen Texten eine reiche Kultur mündlicher Überlieferung oder verlorener ähnlicher Texte vorangegangen sein muss. ${ }^{883}$

Die Interpretation der indischen Literatur als einerseits sehr sinnlich und andererseits kindlich-naiv zeigt, dass sie trotz ihrer Aufnahme in den Kanon wichtiger Texte nicht auf dergleichen Ebene wie die europäische Literatur eingeordnet wird. Sie ist bei aller betonten Ebenbürtigkeit dennoch ein Anderes der (modernen) europäischen Literatur. In ihrem sinnlichen Aspekt entspricht sie einem - auch von Said angeführten - als typisch empfundenen Charakterzug des Orientalischen und steht der kühleren Rationalität der Europäer gegenüber. In ihrem kindlich-naiven Aspekt unterliegt sie einer Idealisierung als eine vom modernen Europa nicht mehr erreichbare, natürliche Ursprünglichkeit und Naturverbundenheit. Als solche wird sie der europäischen Literatur zwar einerseits als überlegen angesehen, andererseits aber schauen viele europäische Rezipienten auch aus einer Art überlegener Distanz auf die idealisierte Vorwelt herab, da sie diese z.B. in Form der alten indischen Texte nicht wie die Inder

\footnotetext{
${ }^{881}$ Heeren: Ideen über die Politik, S. 372

${ }^{882}$ Heeren: Ideen über die Politik, S. 373

883 „Die indische dramatische Dichtkunst hat in Indien ein sehr hohes über alle historische Denkmäler hinausgehendes Alterthum.“ (Majer: Zur Kulturgeschichte der Völker, S. 158); „In wie späten Zeiten auch beide indische Heldengedichte, der Ramayan und Mahabharat mögen überarbeitet und in ihre jetzige Gestalt gebracht worden sein, das Wesentliche der Dichtung ist alt [...].“ (Schlegel, Friedrich: Geschichte der alten und neuen Literatur, S. 123); „Die dramatische Dichtungsart muß im indischen Reiche ein Alterthum haben, welches über alle historische Denkmäler hinausgeht.“ (Forster: Sakontala, S. XII; Vorbericht des englischen Übersetzers); „Wenn wir sie eine sehr alte Litteratur nennen, so verstehen wir darunter, daß mehrere ihrer Hauptwerke ihrem Inhalte und ihren wesentlichen Bestandtheilen nach sehr alt sind; womit aber keineswegs behauptet wird, daß sie in ihrer jetztigen Form schon in den ältesten Zeiten vorhanden gewesen.“ (Heeren: Ideen über die Politik, S. 387)
} 
nur naiv-unmittelbar erleben könnten, sondern durch ihre Erfahrung der Moderne von einer höheren Ebene der Reflexion herab.

In dem obigen Kapitel über die Darstellung der Inder haben wir gesehen, dass der Autor des Artikels „Über den Charakter der Hindus“ die Vermutung anstellt, dass die auffälligen Ähnlichkeiten zwischen den Beschreibungen der Charaktere der indischen Literatur und dem Volk der Inder als solches darauf zurückzuführen seien, dass die Autoren sich von den literarischen Charakteren in ihrer Wahrnehmung der Inder zu sehr hätten beeinflussen lassen. Die von dem Autor angesprochenen Ähnlichkeiten sind in der Tat deutlich zu erkennen. Sowohl die literarischen Figuren als auch die realen Inder werden als zart, sanft, kindlich-naiv, naturverbunden beschrieben. Ob der Grund dafür tatsächlich die Voreingenommenheit der Autoren durch ihre Lektüre z.B. der Śakuntalā ist, lässt sich zwar nicht beweisen, ist allerdings sehr wahrscheinlich. So geht z.B. Majer davon aus, dass „die Werke der Dichter den Geist und Karakter der Völker am besten und lebendigsten darstellen.“ ${ }^{884}$ Die Śakuntalā sei „ein wahres und lebendiges Kompendium der Nazionalbegriffe und Sitten der Indier, ein treues Gemälde ihrer individuellen Empfindung-, Denkungs- und Handlungsweise.“ ${ }^{885}$ Dementsprechend versucht Majer anhand dieses Dramas unter anderem die Grundsätze des indischen philosophischen Systems, den Entwicklungsstand der indischen Malerei sowie Informationen zur indischen Gesellschaft zu konstruieren.

Die Entdeckung der eigenständigen indischen Literatur, die - wie viele Autoren betonen - frei von fremden Zusätzen sei, ${ }^{886}$ wirft als zweiten großen Themenkomplex die Frage nach der universalen Gültigkeit der aristotelischen Poetik auf. Die Frage, welche poetischen Regeln universal gültig sind und welche den zeitlichen und kulturellen Gegebenheiten zugeschrieben werden müssen, fasziniert vor allem Forster und Herder. Forster vertritt dabei die Ansicht, dass auch literarische Werke selbstverständlich dem Einfluss von äußeren Umständen unterliegen und dass daher ein indisches Drama sich von europäischen Vorstellungen unterscheiden müsse. ${ }^{887}$ Daher dürfe man auch nicht vorschnell vergleichen und europäische Maßstäbe an die indische Literatur anlegen:

\footnotetext{
${ }^{884}$ Majer: Zur Kulturgeschichte der Völker, S. 140

${ }^{885}$ Majer: Zur Kulturgeschichte der Völker, S. 150f.

${ }^{886}$ Gerade das Fremde und Unvertraute sei ein Beweis der Echtheit der Texte (vgl. Vgl. z.B. Heeren: Ideen über die Politik, S. 339, 373; Herder: Blumenlese, S. 222-224; Bopp: Über das Conjugationssystem, S. XVIII (Vorrede von Windischmann))

${ }^{887}$ Vgl. Forster: Briefe 1790 bis 1791, S. 221 (Januar 1791 an Heyne)
} 
Vielleicht wäre es sogar nöthig, vor einer zu raschen Vergleichung der Kunstprodukte eines so entfernten, so von europäischen Sitten abgeschiedenen Volks mit den unsrigen, und vor der Anwendung unserer Regeln auf etwas, das ohne einen Begrif von diesen Regeln entstand, recht ernstlich zu warnen. Die Billigkeit forderte wohl, daß man es deutlich auseinandersezte, wie die Verschiedenheit der indischen Mythologie, Geschichte und Sitten, von der griechischen zum Beispiel, den Kunstwerken jenes Landes eine uns ungewohnte Gestalt und Maschinerie verleihen müsse, wie aber das Interessante eines solchen Werks gar nicht darin bestehe, ob es fünf oder sieben Aufzüge habe, sondern daß die zartesten Empfindungen, deren das menschliche Herz fähig ist, sich so gut am Ganges und bei dunkelbraunen Menschen, wie am Rhein, am Tyber, am Ilissus bei unserem weissen Geschlechte äussern konnten. ${ }^{88}$

Es sei nicht wichtig, nach welchen Regeln ein Drama aufgebaut sei und dass die Kulturen sich darin unterscheiden. Entscheidend ist für Forster die Erkenntnis, dass die menschlichen Empfindungen universal sind und alle Völker verbinden.

Herder wagt dennoch den Vergleich mit Aristoteles. Dabei interessiert auch ihn, welche poetischen Regeln universale Gültigkeit haben und welche nicht. ${ }^{889}$ Herder überprüft bei dem Vergleich nicht jedes Detail der aristotelischen Vorgaben, sondern versucht, aus Aristoteles‘ Aussagen das Wesentliche herauszufiltern und dann zu schauen, ob diese wesentlichen Aspekte auch bei dem indischen Drama gegeben sind. Dazu rechnet Herder die Nachahmung einer Handlung, die Anfang, Mitte und Ende hat und eine gewisse ernsthafte Größe besitzt. Das alles finde sich auch bei der Śakuntalā. Denn es komme nicht auf die Länge des Stückes an, sondern darauf, dass das Stück ein Ganzes sei, bei dem kein Teil zu viel oder zu wenig sei. Die bei der Śakuntalā fehlende Einheit von Zeit und Ort sei für das griechische Drama nur deshalb erforderlich gewesen, weil das griechische Theater aus dem Chor entstanden sei und sich um diesen herum aufbaue. Daher gehörten diese Einheiten nur zu dem ,eigentliche(n) Local- und Zeitmäßige(n)“ und könnten daher „kein Gesetz für alle Orte und Zeiten der Welt‘ ${ }^{\star 890}$ sein. Auch die zweite Hauptforderung Aristoteles', dass das Drama durch Mitleiden und Furcht wirken solle, erfülle das indische Drama und zwar vor allem in der Figur der „Sakontala“. ${ }^{891}$ Herder entdeckt jedoch auch Unterschiede, die er durchaus für relevant erachtet. So sei es für Aristoteles wichtig, dass die Handlung sich ganz natürlich entwickle. Ganz anders gehe der indische Autor vor. Für ihn stehe nicht der

\footnotetext{
${ }^{888}$ Forster: Sakontala, S. XXXIIIf.

${ }^{889}$ Vgl. Herder: Blumenlese, S. 229

${ }^{890}$ Herder: Blumenlese, S. 241

${ }^{891}$ Vgl. Herder: Blumenlese, S. $230 f$.
} 
natürliche Gang der Handlung im Vordergrund, sondern die Begebenheiten seien als Zeichen einer „höheren Ordnung“ 892 , eines „heiligen, göttlichen, wunderbaren Zusammenhang(s) ${ }^{\text {“ } 893}$ zu deuten. Folglich sei für die Inder das aus unserer Sicht Unnatürlich-Wunderbare viel glaubhafter und natürlicher. ${ }^{894}$ Es sei nicht so, dass „das Wunderbare schlechthin die Belehrung aufhebe; es macht diese nur angenehmer, indem hinter seinem geheimnißreichen Schleier der Verstand gleichsam verstohlen und desto freiwilliger sich selbst belehrtet.“895 Das Wunderbare könne auch die „Wirkung des tragischen Schreckens und Mitleidens “ ${ }^{* 96}$ verstärken. Aufgrund dieser Unterschiede schlägt Herder vor, die Śakuntalā nicht einer der beiden Gattungen des Lust- oder Trauerspiels zuzuordnen, sondern sie als ein „episches Drama“6977 zu klassifizieren. Herders Argumentation ist insofern interessant, als sie die Zerrissenheit zwischen neuen Ansätzen und dem Anhaften an alten Denkmustern zeigt. Herder möchte sich einerseits insofern von Teilen der aristotelischen Poetik lösen, als er zeigen möchte, dass einige Aspekte dieser Poetik nicht universale Gültigkeit besitzen. Andererseits greift er auch dann immer wieder auf Aristoteles zur Stützung seiner Argumentation zurück, wenn er Unterschiede aufzeigt, indem er immer wieder darauf hinweist, dass Aristoteles es eigentlich auch gar nicht so viel anders sieht. Die griechische Poetik bleibt also der wichtigste Bezugspunkt und wird in ihrer allgemeinen Gültigkeit nicht infrage gestellt.

Ähnliche Gedanken wie Herder äußert auch Heeren. Auch er stellt fest, dass das indische Drama aufgrund der fehlenden Beschränkung von Raum und Zeit als einzige Einheit nur die der Handlung kenne, wobei auch die Handlung verglichen mit der griechischer Dramen sehr umfangreich sei. Aus diesem Grund stimmt Heeren der englischen Bezeichnung ${ }^{898}$ Kālidāsas als „Indischen Shakespear“899 ${ }^{‘ 8 u}$, dessen Dramen ebenfalls nicht in allen Punkten den klassischen Vorgaben entsprechen.

Das Liebliche und das Rührende steht ihm nicht minder zu Gebote als das Furchtbare und das Erhabene. Aber auch das Komische verschmäht er nicht ganz; wenn er gleich nur sparsam und mit Vorsicht es gebraucht. Ist der Ausdruck der Leidenschaft vielleicht nicht so heftig bey ihm als bey dem

\footnotetext{
${ }^{892}$ Herder: Blumenlese, S. 233

${ }^{893}$ Herder: Blumenlese, S. 234

${ }^{894}$ Vgl. Herder: Blumenlese, S. 236

${ }^{895}$ Herder: Blumelese, S. 238

${ }^{896}$ Herder: Blumenlese, S. 239

${ }^{897}$ Herder: Blumenlese, S. 240

${ }^{898}$ Vgl. Forster: Sakontala, S. 281 (Vorbericht des englischen Übersetzers)

${ }^{899}$ Heeren: Ideen über die Politik, S. 380
} 
Brittischen Dichter; so vergesse man nicht, daß Beherrschung der Leidenschaften die große Aufgabe für den Indischen Weisen ist. ${ }^{900}$

Mehr als die Unterschiede bei den drei Einheiten des Dramas beschäftigt Heeren allerdings etwas anderes, das auch bei Herder bereits angeklungen war: „Jenes Eigenthümliche der Indischen Poesie, daß ihr nicht das rein Menschliche genügt, daß sie das Göttliche mit dem Menschlichen verschmilzt, aber so daß jenes vorherrschend ist, zeigt sich in ihren Dramen wie in ihrem Epos. “901 Was Herder als das Walten einer höheren Ordnung und damit das Vorherrschen des Wunderbaren beschreibt, deutet Heeren als „Vernachlässigung des rein Menschlichen“902 und zwar sowohl im Drama als auch im Epos. Während in griechischen Epen Götter nur als Nebenfiguren aufträten, seien in den indischen Werken jene

\begin{abstract}
höheren Wesen [...] die Hauptpersonen, um deren Schicksal sich die Handlung dreht; und wenn ja bloße Menschen auftreten, so bleiben sie diesen doch weit untergeordnet. Soll aber dennoch einer von ihnen eine bedeutende Rolle spielen, so bedient sich der Dichter fast jedesmal der Mittel, die ihm zu Gebote stehen, ihn den Göttern näher zu bringen. Es ist eine Bemerkung, die sich leicht jedem von selbst aufdringt, daß das Indische Epos in dieser Rücksicht weit mehr Ähnlichkeit mit dem religiösen Epos der Deutschen und der Britten hat. Aber der Indische Dichter hat vor den Dichtern dieser Völker große Vortheile voraus. Eine viel reichere Welt steht ihm zu Gebote. Es ist nicht der Ewige und Unsichtbare, der als handelnde Person aufgeführt wird; es ist jene zahllose Menge der Devas und Devanis; nicht, wie die Engel, einförmig durch Geschlechtlosigkeit, durch vollkommene moralische Reinheit oder Verworfenheit. ${ }^{903}$
\end{abstract}

Interessant ist, dass Heeren durch den Vergleich mit Shakespeare und den religiösen Epen die indische Literatur weniger dem Bereich der klassischen als vielmehr der romantischen Literatur zuordnet, auch wenn er das nicht direkt ausspricht. In eine ähnliche Richtung geht im übrigen auch Dalbergs Bemerkung, dass die Gesänge des Dichters des Gītagovinda noch heute gleich den Liedern Ossians gesungen würden. ${ }^{904}$ Vielleicht liegt darin auch ein Grund für die Begeisterung gerade einiger Romantiker für die indische Kultur.

\footnotetext{
${ }^{900}$ Heeren: Ideen über die Politik, S. 381; auch Majer greift den Vergleich mit Shakespeare auf (vgl. Majer: Zur Kulturgeschichte der Völker, S. 159)

901 Heeren: Ideen über die Politik, S. 379

902 Heeren: Ideen über die Politik, S. 349

${ }^{903}$ Heeren: Ideen über die Politik, S. 350

${ }^{904}$ Vgl. Dalberg: Gita-govinda, S. VII
} 
Auch Majer thematisiert den Unterschied von natürlichem Gang der Handlung in den griechischen Dramen und dem „,heiligen, göttlichen, wunderbaren Zusammenhang“9005 der indischen Literatur und schließt sich Herders Bezeichnung als „dramatisches Epos $^{\text {“906 }}$ an. Während Herder und Majer und etwas distanzierter auch Heeren diesen Umstand relativ neutral beschreiben, äußert Humboldt direkte Kritik. Ihm fehle in der indischen Literatur die „freie, allgemeine Ansicht des Universums, die tiefe Menschlichkeit““ ${ }^{907}$ Ganz anders sieht es Goethe: Die Hauptpersonen der Śakuntalā seien zwar „Götter und Götterkinder“, aber sie führten „ein ganz gewöhnliches Naturschauspiel“ auf und zeigten „die allernatürlichsten Zustände“. ${ }^{908}$ Auch im Meghadūta gehe es um „rein menschliche Verhältnisse“. ${ }^{909}$ Damit grenzt er sich von der auch in dem Zitat von Majer aufscheinenden romantischen Begeisterung für uralte indische Weisheiten, die aus den indischen Texten herausgearbeitet werden sollten, ab. Goethe betont dagegen die Klassizität der alten indischen Dichtungen, die sich eben „aus dem Conflikt mit der abstrusesten Philosophie auf einer und mit der monstrosesten Religion auf der andern Seite im glücklichsten Naturell durchhelfen und von beiden nicht mehr annehmen, als ihnen zur inneren Tiefe und äußern Würde frommen mag.“910 Die Frage, inwieweit die indische Literatur das Menschliche thematisiere bzw. vernachlässige, ist insofern für viele Autoren von großer Wichtigkeit, als im Zuge der Aufklärung nicht mehr die göttliche Weltordnung, sondern der Mensch selbst in den Mittelpunkt des Interesses gestellt wird.

Die europäischen Autoren haben keine großen Schwierigkeiten damit, Unterschiede im Aufbau des indischen und des europäischen Dramas als lokale Besonderheiten, die nichts über den Wert des jeweiligen Werkes aussagen, anzuerkennen. Das wird auch durch Experimente mit verschiedenen Formen in der jüngeren europäischen Literatur (wie z.B. bei Shakespeare oder den Romantikern) erleichtert. Der inhaltliche Unterschied (Menschlichkeit, Natürlichkeit bzw. Götter, Wunder) lässt sich weniger

\footnotetext{
${ }^{905}$ Majer: Zur Kulturgeschichte der Völker, S. 164

${ }^{906}$ Majer: Zur Kulturgeschichte der Völker, S. 164

${ }^{907}$ Wilhelm von Humboldt's Briefe an F. G. Welcker, S. 47f. (Mai 1821 an Welcker)

${ }^{908}$ Goethe, Johann Wolfgang: Indische Dichtungen. In: Goethes Werke. Herausgegeben im Auftrage der Großherzogin Sophie von Sachsen. Band 42,2. Fotomechanischer Nachdruck d. Ausg. Weimar, Böhlau 1907. München 1987, S. 50-53, hier S. 50

${ }^{909}$ Goethe: Indische Dichtungen, S. 51

${ }^{910}$ Goethe: Indische Dichtungen, S.50; vgl. auch Lauer, Gerhard: Goethes indische Kuriositäten. In: Kunz, Edith Anna u.a. (Hgg.): Figurationen des Grotesken in Goethes Werken. Bielefeld 2012, S. 159179, hier S. 171-174
} 
leicht abtun, da er das auf die Vernunft gegründete Weltbild vieler Autoren betrifft. Herder und Goethe lösen das, indem sie hinter der äußeren Hülle der Götter und Wunder als Kern die Darstellung von Vernunft und Natürlichkeit vermuten. Heeren und Humboldt sehen das anders und bemängeln die fehlende Menschlichkeit. Aus den festgestellten Unterschieden ziehen die hier untersuchten Autoren sehr ähnliche Schlüsse, was die europäische Lektüre der indischen Werke betrifft. Man müsse die eigenen Formen beim Lesen vergessen ${ }^{911}$ und die europäischen Regeln nicht anwenden. ${ }^{912}$ Die indischen Werke müssten im indischen Geist gelesen ${ }^{913}$ und nur aus sich selbst heraus beurteilt werden. ${ }^{914}$

Das dritte Thema, das in den untersuchten Texten von Bedeutung ist, ist die Frage nach der richtigen Aufnahme, Übersetzung und Adaption der indischen Texte. Wie sollen sie übersetzt werden? Wie sollen sie für das Publikum aufbereitet werden? Kann man sie z.B. für Aufführungen dem europäischen Geschmack anpassen? Dieses Thema ist oben schon einmal kurz angesprochen worden, als es darum ging, ob es richtig war, dass die Übersetzer des Gītagovinda möglicherweise als anstößig empfundene Stellen gestrichen hatten.

Für Jones scheint es ganz normal zu sein, die indische Literatur an die europäischen Gewohnheiten anzupassen. So schlägt er vor, die Śakuntalā für eine mögliche Aufführung (in Indien, da nur da die nötigen Kenntnisse vorhanden seien) auf fünf Akte zu kürzen, da es Szenen gebe, die problemlos gestrichen werden könnten. ${ }^{915}$ Auch Gerhard, der das Stück für die deutsche Bühne bearbeiten möchte, ist der Ansicht, dass er dafür Kürzungen vornehmen und den Schluss abändern müsse. Goethe bestärkt ihn darin, denn auch wenn er dafür vielleicht von anderen kritisiert werden könne, so habe doch ein Dichter die Freiheit, das zu ändern, was nicht in die Zeit passe. ${ }^{916}$ Der Rezensent von Gerhards Bearbeitung ist dagegen der Ansicht, dass ein solches Unterfangen zum Scheitern verurteilt sei. Er fragt, ob Gerhard nicht eingefallen sei,

\footnotetext{
${ }^{911}$ Vgl. Forster: Briefe 1790 bis 1791, S. 221 (Januar 1791 an Heyne)

${ }^{912}$ Vgl. Majer, Friedrich: Der Bhaguat-Geeta oder Gespräche zwischen Kreeshna und Arjoon. In: Asiatisches Magazin 1 (1802), S. 406-453, hier S. 411 (Brief Hastings)

${ }^{913}$ Vgl. Herder: Blumenlese, S. 211

${ }^{914}$ Vgl. Majer: Zur Kulturgeschichte, S. 163; vgl. dazu auch Ewert, Michael: Interkulturelle Hermeneutik. Georg Forsters Rezeption altindischer Dichtung. In: Georg-Forster-Studien 9 (2004), S. 17-37

915 Vgl. Forster: Sakontala, S. XXIIIf.

916 Vgl. Goethe: Goethes Gespräche. Zweiter Teil, S. 35f. (7.7. 1818 mit Gerhard)
} 
dass „das, was auf unseren Bühnen erscheinen soll, Regeln und Bedingungen unterworfen ist, die unumstösslich sind, weil sie ihren Grund in der Nationalität, in dem Charakter und Sitten unseres Volkes haben? ${ }^{\text {‘917 }}$ Das Drama sei zu anders.

\begin{abstract}
Ein Drama nach unseren Begriffen, ist das Werk einmal nicht, denn ihm fehlt das, was in dieser Hinsicht gefodert wird und gefodert werden muss nach allem oben Angegebenen; ihm fehlt dramatische Einheit und Handlung auch dann noch, wenn man weit davon entfernt ist, Aristoteles enge Regeln, als Regeln, von denen kein Abweichen gilt, aufzustellen. ${ }^{918}$

Darum wird gewiss dieses Indische Drama, mit Beybehaltung seiner Wesentlichkeit, als recitirendes Schauspiel bearbeitet, bey keiner Nation Europas Aufnahme finden; und wollte der Bearbeiter diese Wesentlichkeit dem Zwecke, die Dichtung auf die fremde Bühne zu verpflanzen, opfern, was thät er dann anders, als eine zarte Blüthe muthwilig vernichten - um ein Krüppelgewächs zu erzielen!‘‘919
\end{abstract}

Derjenige, der die Śakuntalā für die deutsche Bühne bearbeiten möchte, stehe laut dem Rezensenten vor dem Dilemma, dass er entweder die indischen Besonderheiten beibehalten könne, damit aber riskiere, dass das Werk keine positive Aufnahme finde, oder dass er es den europäischen Erwartungen anpasse, dann aber das, was dieses indische Drama auszeichne, zerstöre. Wenn überhaupt hätte Gerhard es zu einer Oper verarbeiten sollen. ${ }^{920}$ Das haben Schubert und Neumann versucht. Dabei aber ist genau das geschehen, was der Rezensent von Gerhard befürchtet: Durch die Anpassung des Fremden an das Eigene sind dem Werk genau die Elemente verlorenen gegangen, deretwegen es in Europa überhaupt erst so beliebt gewesen ist. ${ }^{921}$

Es wird jedoch nicht nur über mögliche Bühnenbearbeitungen diskutiert, sondern auch darüber, wie eine möglichst gute Übersetzung aussehen sollte. Auch hier stellt sich für den Übersetzer die Frage, inwieweit die Übersetzung dem Original ähneln sollte, z.B. indem versucht wird, das indische Versmaß nachzubilden, oder versucht werden sollte, dem europäischen Geschmack z.B. durch die Verwendung von vertrauten Versmaßen entgegen zu kommen. Bekannt sind dazu Goethes Ausführungen über drei Arten von Übersetzungen: Möchte man sich mit einer anderen Literatur erstmalig bekannt machen, so seien zunächst einfache Prosaübersetzungen hilfreich. In einem zweiten

\footnotetext{
${ }^{917}$ Rezension zu Sakontala, Sp. 421

918 Rezension zu Sakontala, Sp. 422

${ }^{919}$ Rezension zu Sakontala, Sp. 422

${ }^{920}$ Vgl. Rezension zu Sakontala, Sp. 421

${ }^{921}$ Vgl. Schubert, F.: Sacontala. Vorgelegt von Manuela Jahrmärker (Notenteil) und Thomas Aigner (Libretto). Kassel u.a. 2008, S. XI; zu dem Entwurf von Schubert und Neumann vgl. auch Grenzmann: Zur frühen deutschsprachigen Rezeption von Georg Forsters Sakontala-Übertragung, S. 239-245
} 
Schritt werde dann versucht, sich den fremden Sinn anzueignen und darzustellen. Goethe nennt diese Zeit parodistisch. Gewinnt die andere Kultur so mehr und mehr an Vertrautheit, könne es passieren, dass man mit der Übersetzung möglichst nah an das Original herankommen möchte. Das könne zunächst auf Widerstand stoßen, da Besonderheiten der eigenen Kultur dafür aufgegeben werden müssten. Für das auf diese Weise entstehende Dritte müsse sich erst der Geschmack der Menschen entwickeln. ${ }^{922}$ Goethe selbst ist sehr an Übersetzungen interessiert, die dem Original möglichst nahekommen und lässt sich daher einige Stellen aus indischen Texten von Kosegarten direkt aus dem Original übersetzen. ${ }^{923}$

Herder und Majer lehnen Übersetzungen in Versform ab. Majer ist der Ansicht, dass von den indischen metrischen Gesetzen noch zu wenig bekannt sei. ${ }^{924}$ Genau das aber versucht Bopp ${ }^{925}$ mit seinen Nachbildungen des indischen Metrums, allerdings zu einer Zeit, als die indischen Schloken nicht mehr unbekannt sind. ${ }^{926}$

Die Kontroverse über die richtige Art der Übersetzung spiegelt sich auch sehr schön in dem Briefwechsel zwischen August Wilhelm Schlegel und Wilhelm von Humboldt wider. Humboldt, der bereits gegenüber Welcker geäußert hat, dass man die Eigentümlichkeiten der indischen Texte beibehalten und sie nicht z.B. durch die Verwendung des Hexameters zerstören solle, ${ }^{927}$ vertritt auch Schlegel gegenüber diese Ansicht: Die Übersetzungen sollten möglichst nicht im Originalversmaß geschehen, da dies den Übersetzer zu sehr einschränke, auch wenn das noch deutlich besser sei als die Verwendung von europäischen Versmaßen. Besser aber sei es, wenn möglichst wörtlich übersetzt werden würde. Schlegel dagegen lehnt eine wörtliche Übersetzung $\mathrm{ab}$, da die orientalische Wortfülle, die im Original für eine durchaus positive Mannigfaltigkeit sorge, in der Übersetzung in Wiederholungen ausarte. Wichtiger als die wörtliche Übersetzung sei es, in der Darstellung den echten Sinn zu vermitteln und

\footnotetext{
922 Goethe: West-östlicher Divan. Teil 1, S. 280f.

${ }^{923} \mathrm{Vgl}$ z.B. Goethe: Indische Dichtungen, S. 52

${ }^{924}$ Herder: Blumenlese, S. 214; Majer: Gita-govinda, S. 374

${ }^{925}$ Franz Bopp (1791-1867) lernte ab 1812 in Paris Sanskrit und gilt als einer der Begründer der vergleichenden Sprachwissenschaft. 1821 wurde er Professor in Berlin (vgl. Wüst, Walther, "Bopp, Franz" in: Neue Deutsche Biographie 2 (1955), S. 453-454 [Online-Version]; URL: https://www.deutsche-biographie.de/pnd118659332.html\#ndbcontent).

${ }^{926}$ Vgl. Bopp: Über das Conjugationssystem, S. XV (Vorrede von Windischmann)

${ }^{927}$ Vgl. Wilhelm von Humboldts Briefe an F.G. Welcker. Herausgegeben von R. Haym. Berlin 1859, S. 48 (Mai 1821)
} 
zwar in einer verständlichen Sprache. Daher möchte Schlegel auch alle indischen Begriffe übersetzen und nicht, wie z.B. Wilkins, feste Begriffe der indischen Philosophie und Kultur einfach im Sanskrit belassen. Humboldt mahnt allerdings an, dass es wichtig sei, dabei möglichst darauf zu achten, ein und denselben SanskritTerminus mit ein und demselben Wort aus der Zielsprache zu übersetzen, da es sich um feste philosophische Begriffe handle. ${ }^{928}$ Interessant ist auch, dass als Zielsprache für die Übersetzungen sowohl von Jones als auch Schlegel das Lateinische favorisiert wird, da dies zum einen die europäische Gelehrtensprache sei und zum anderen weil das Lateinische dem Sanskrit so ähnlich sei. ${ }^{929}$

Einen ganz anderen Ansatz verfolgt Rückert, der sich mit freieren Nachdichtungen indischer Texte einen Namen macht. Damit erreicht er ein deutlich größeres Publikum als Schlegel und Bopp mit ihren wissenschaftlichen Übersetzungen ins Lateinische. Bopp, der ebenfalls lateinische Übersetzungen anfertigt, zeigt sich von Rückerts Methode durchaus angetan. Da Rückert seine Übertragungen größtenteils erst nach dem gewählten Untersuchungszeitraum anfertigt, soll hier jedoch nicht näher darauf eingegangen werden. ${ }^{930}$

Die indische Literatur wird jedoch nicht nur gelesen, übersetzt und bearbeitet, sondern regt auch zu eigenen literarischen Experimenten an. Dabei sind nicht nur Texte gemeint, in denen Indien oder Inder direkt eine Rolle spielen, sondern bei denen Stil und Aufbau vor allem der Śakuntalā die Autoren inspirieren, auch wenn die Ideen nicht unbedingt immer ausgeführt werden. Das bekannteste Beispiel ist wohl das Vorspiel auf dem Theater in Goethes Faust, von dem Heinrich Heine sagt, dass Goethe dazu durch die Śakuntalā angeregt worden sei, bei der es ein ähnliches Vorspiel gebe. ${ }^{931}$ Novalis plant anscheinend für die Fortsetzung des Heinrich von Ofterdingen, ein „wunderbares Drama in Versen, wie die «Sakontala»““932 Und Creuzer rät Günderrode

\footnotetext{
928 Vgl. Leitzmann (Hg.): Briefwechsel zwischen Wilhelm von Humboldt und August Wilhelm Schlegel, S. 107, 205f.

${ }^{929}$ Vgl. Schlegel, August Wilhelm: Ramayana id est carmen epicum de Ramae rebus gestis [...]. In: Oeuvres. Écrites en Francais et publiées par Eduard Böcking. Hildesheim/New York 1972, S. 281-287, hier S. 283; Forster: Sakontala, S. XIf.

${ }^{930} \mathrm{Zu}$ der Kontroverse zwischen Rückert, Bopp und Schlegel vgl. Czapla: Annäherungen an das ferne Fremde, S. 131-141

${ }^{931}$ Vgl. Heine, Heinrich: Aphorismen und Fragmente. In: Heine, Heinricht: Werke und Briefe in zehn Bänden. Band 7. 2. Auflage. Berlin und Weimar 1972, S. 363-432, S. 364

${ }^{932}$ Novalis Werke. Herausgegeben und kommentiert von Gerhard Schulz. Vierte Auflage. München 2001, S. 283
} 
dazu, sie solle im Stile der Sakontala dichten. ${ }^{933}$ Und auch inhaltlich lassen sich Autoren von indischem Gedankengut anregen. So sind einige Gedichte Herders (wie z.B. die „Gedanken einiger Brahmanen“) keine Nachdichtungen im eigentlichen Sinne, aber sie nehmen Gedanken und Motive aus der indischen Geisteswelt mit auf. ${ }^{934}$

\subsection{Indische Kunst, Bildhauerei und Architektur}

Verglichen mit der indischen Literatur gibt es über die indische Kunst relativ wenig Äußerungen, die inhaltlich weitestgehend übereinstimmen. Die Kunst habe sich in Indien nicht frei entwickeln können, weil sie durch die strengen Vorgaben der Priester an feste Motive und Darstellungsformen gebunden sei. Daher können die wenigsten Autoren an der indischen Kunst Gefallen finden, auch wenn sie betonen, dass die Inder von ihren Anlagen her genauso fähig zur Kunst seien wie die Europäer. Der indischen Kunst gehe es nicht um Schönheit, sondern um Allegorien und Symbole, mit denen sie möglichst umfassend alle religiös-philosophischen Aussagen darstellen möchten. Das führe zu der in europäischen Augen grotesken Anhäufung verschiedener Elemente. Aber auch in den klimatischen Verhältnissen werden Ursachen für die Unterschiede in der Kunst gesucht.

Besonders ausführlich setzt sich Creuzer mit dem Unterschied zwischen indischer und griechischer Kunst auseinander. Dabei geht es ihm weniger um unterschiedliche Stilrichtungen oder Stufen des Könnens, sondern um die Grundidee und Grundmotivation in der Kunst:

Hier, im Gebiete der Kunst, sehen wir nun schon Indien auf einem ganz
andern Wege als Griechenland. In Indien ist der Charakter der Symbolik
das Bedeutsame, im Gegensatz gegen das Poetische, Plastische und Schöne,
und bei der ganzen Indischen heiligen Bildnerei (was auch vom Mythus gilt)
ist die, freilich von Wenigen gefasste Grundidee vorherrschend, dass die
heiligen Bilder (Symbole und Mythen) nur Erinnerungen sind an das Wesen
des Ewigen, dessen Bild viel besser im reinen Denken wohnt und im Herzen
der Frommen. Es zeigt sich demnach ein scharfer Gegensatz dieser
Innerlichkeit der Religion der Indier gegen die Äusserlichkeit (plastische
Gestalt) der Griechischen [...]; und da die Symbole nur Erinnerungen sind,
nicht Abbilder, wie die Griechischen Götterbilder, so wird nicht das Schöne
gesucht, sondern das möglichst Erschöpfende. Dies zeigt sich auch
zuvörderst in dem Überfluss und Reichthum ihrer Symbolik, besonders

\footnotetext{
${ }^{933}$ Creuzer, Friedrich: Die Liebe der Günderrode. Friedrich Creuzers Briefe an Caroline von Günderrode. Herausgegeben und eingeleitet von Karl Preisendanz. München 1912, S. 231 (Brief vom 20.Februar 1806)

${ }^{934} \mathrm{vgl}$. Maiilard, Christine: Entzauberungsphantasien. Indienrezeptionen und Seelenkunde in Johann Gottfried Herders Lyrik der 1790er Jahre. In: Eckel, Winfried u.a. (Hg.): Projektionen - Imaginationen - Erfahrungen. Indienbilder der europäischen Literatur. Remscheid 2008, S. 109-127
} 
ihrer Götterattribute. Unzählige Beiwerke hat jeder ihrer Götter, jedoch keines bedeutungslos [...], und die ganze Geschichte des Gottes liegt in Symbolen, so dass wir gewiss die Behauptung wagen können, es habe kein Volk der Erde seine Religion so ausführlich symbolisirt, wie das Indische. Andererseits zeigt sich dies auch an der Ungenügsamkeit der Indischen Symbolik, d.h. sie will Alles sagen, das Weltall soll in den Symbolen der grossen Götter ganz und in jeder Beziehung im Bilde dargestellt werden. Daher denn die vielköpfigen, vielarmigen, wunderbar grotesken Götterbilder [...]. ${ }^{935}$

Die indischen Künstler wollen nicht in ihrer Kunst das möglichst Schöne suchen, sondern das möglichst Umfassende. Creuzer scheint das eher interessiert zu beobachten als kritisch („wunderbar grotesk(...) $)^{\text {“) }}$. Er stellt aber auch fest: „,Maass aber ist das ewige Gesetz aller Schönheit; Unmaass bringt das Abentheuerliche, Seltsame und Ungeheure hervor. Da also das Symbol in Indien einzig dem Bedeutsamen dienstbar war, so erscheint es unschön, oft ungeheuer und furchtbar [...]. “936

Andere Autoren sehen die indische Kunst deutlich weniger interessiert, sondern eher kritisch. Das ist vor allem dann der Fall, wenn es ihnen in erster Linie um die Kunst selbst geht und weniger um die Philosophie dahinter. So schreibt z.B. der Maler Hodges:

Es thut mir leid, daß ich von der bildenden Kunst der Hindu's so vortheilhaft nicht reden kann, als gelehrte Schriftsteller zu thun pflegen, die über Brama's Religion geschrieben haben. Ich betrachte diese Werke nur mit Augen des Künstlers, und so kann ich sie bloß den rohen Versuchen der kunstliebenden Indianer vergleichen, die ich auf Otaheiti und andern Inseln der Südsee erblickte. ${ }^{937}$

Hodges macht wie Creuzer und die meisten anderen Autoren die Bindung der Kunst an die Religion und Mythologie für die fehlende Entwicklung der Kunst verantwortlich:

Die Gemälde der Hindu's, sind wie die Arbeiten ihres Meissels, größtentheils Gegenstände der Religion, und nicht so vollkommen wie die mohrischen Abbildungen nach dem Leben. Man weiß, beständiges Studium der einfachen Natur bringt zuweilen eine staunenswürdige Täuschung hervor, zu welcher der Mahler idealischer Gegenstände sich nicht empor arbeiten kann. “938

\footnotetext{
${ }^{935}$ Creuzer: Symbolik und Mythologie der alten Völker. Erster Theil. Zweite völlig umgearbeitete Ausgabe, S. 646f.

${ }^{936}$ Creuzer: Symbolik und Mythologie der alten Völker. Erster Theil. Zweite völlig umgearbeitete Ausgabe, S. 647f.

${ }^{937}$ Hodges: Reisen durch Ostindien, S. $35 f$.

${ }^{938}$ Hogdes: Reisen durch Ostindien, S. 174
} 
Die Anlehnung der Kunst an die Natur bewertet Hodges höher als den Versuch, „,idealische(...) Gegenstände“ darzustellen.

Auch Papi macht die fehlende Weiterentwicklung der indischen Kunst an der Gebundenheit der Künstler an Traditionen und religiöse Motive fest und beurteilt diese kritisch:

\begin{abstract}
Wenn die Behauptung gegründet ist, daß man Indien als die Wiege der Künste und Wissenschaften zu betrachten habe, so kann man zugleich nicht in Abrede stellen, daß sie nach Verlauf so vieler Jahrhunderte in dieser nämlichen Wiege noch immer in eben dem rohen und unförmlichen Zustande liege, wie ehedem. [...] Dieser ängstlichen Anhänglichkeit der Inder, an alles das, was ihnen von ihren Urvätern gelehrt und vorgeschrieben wurde, ist es hauptsächlich mit zuzuschreiben, daß sie in den Künsten und Wissenschaften noch immer so weit zurück sind, ob ihnen gleich die Natur, wie mich dünkt, eben so viel Talent und Geisteskräfte verliehen hat, als den Europäern..$^{939}$

Übrigens liegt die Schuld keineswegs an dem Künstler, wenn die Arbeit schlecht ausfällt. Der Maler, der Bildhauer, der Steinschneider darf seine Modelle nicht selbst wählen, sondern er muß seine Götter genau so darstellen, wie es ihm durch die Religion vorgeschrieben wird. Er sieht sich daher genöthigt, immer nach gewissen unabänderlich festgesetzten Normen zu arbeiten, immer dieselben Verhältnisse beizubehalten, die man in Betreff dieser oder jener Gliedmaßen eines Gottes ein für allemal angenommen hat. Wenn er nur im mindesten davon abwiche, oder sich einfallen ließe, eine Statue, oder ein Gemälde zu verfertigen, das die ältern an Schönheit überträfe, so würde er sich nicht nur den Vorwürfen, sondern sogar der Ahndung der Braminen aussetzen. ${ }^{940}$
\end{abstract}

Diese Argumentation teilen auch viele andere Autoren wie Paulinus a Sancto Bartholomaeo $^{941}$ und Majer, die darauf hinweisen, dass es den Indern keineswegs an guter Anlage zum Malen fehle, wie ihre Kopien europäischer Bilder beweisen ${ }^{942}$, sowie der Maler Müller ${ }^{943}$ und Claudius, wobei dieser das Fehlen jeglicher „NeuerungsSucht" in Indien anders als die meisten anderen begrüßt, denn

die Bilder und Alles an ihnen habe seine Bedeutung und müßte deßwegen nicht geändert und schöner oder vernünftiger gemacht werden, weil sonst mit der Sache auch das Zeichen, und, so an, Alles verlohren sey. Und diese Asiatischen Priester sind um dieser Denkart willen nicht genug zu bewundern und zu loben, und sie sollten eingentlich von den andern Welttheilen darüber komplimentirt werden. ${ }^{944}$

\footnotetext{
${ }^{939}$ Briefe eines italienischen Reisenden, S. 398

${ }^{940}$ Briefe eines italiensichen Reisenden, S. 418

${ }^{941}$ Vgl. Des Fra Paolino da San Bartolomeo Reise nach Ostindien, S. 391f.

${ }^{942}$ Vgl. Majer, Friedrich: Bemerkungen zu einem indischen Gemälde. In: Curiositäten der physischliterarisch- artistisch- historischen Vor- und Mitwelt 1(1812), S. 510-520, S. 515

${ }^{943}$ Vgl. Müller: Glauben, Wissen und Kunst der alten Hindus, S. 74f.

944 Claudius: Eine asiatische Vorlesung, S. 26
} 
Claudius stellt hier die künstlerische Sicht gegenüber der theologischen zurück.

Neben dem Hauptargument des großen Einflusses der Religion werden noch andere Argumente für den Rückstand der indischen Kunst angeführt. Bereits Sonnerat sah eine der Ursachen im heißen Klima. ${ }^{945}$ Jomard und Paulinus a Sancto Bartholomaeo führen diesen von Sonnerat nur angedeuteten Gedanken weiter aus: Da in Indien aufgrund der klimatischen Bedingungen ,die Noth, die Mutter aller Künste“9946 nicht so verbreitet gewesen sei, hätten zum einen die Menschen keinen Antrieb gehabt, sie für ihren Lebensunterhalt als Künstler zu verdingen, ${ }^{947}$ und zum anderen habe der ,natürliche Überfluß des Goldes, der Perlen und der Edelsteine [...] in ihre Künste einen fehlerhaften Geschmack der Nachahmung eingeführt (...). Sie haben für schön genommen, was nur gänzend und kostbar war [...] und sie haben dem Luxus, wie einer neuen Gottheit, geopfert. “948

Ein anderes Argument, das zeigt, wie sehr die Autoren in ihrer Beurteilung von der griechischen Kunst geprägt sind, ${ }^{949}$ führt das mangelnde Interesse der Inder, menschliche Körper abzubilden, darauf zurück, dass die Inder fast nackt gingen und daher die Phantasie keinen so großen Anreiz habe. Im Gegensatz dazu stellten sie ihre Figuren jedoch - anders als die Griechen - immer in Gewänder gehüllt dar, was nach Ansicht der genannten Autoren der Kunst nicht förderlich sei. Denn der Hauptgegenstand sei eben der Körper. ${ }^{950}$

Wie aber wird die indische Kunst charakterisiert? Was genau wird bemängelt? Das sind vor allem zwei Aspekte: Zum einen wird angemerkt, dass die Inder keinen Sinn für die perspektivische Darstellung und Proportionen hätten. Und zum anderen wird kritisiert,

\footnotetext{
945 Vgl. Sonnerat: Reise nach Ostindien, S. 49

946 Des Fra Paolino da San Bartolomeo Reise nach Ostindien, S. 392

${ }^{947}$ Vgl. Des Fra Paolino da San Bartolomeo Reise nach Ostindien, S. 392

948 Jomard: Parallele zwischen den Alterthümern von Indien und denen von Ägypten (Bruchstück eines Versuchs über die Kunst in Ägypten). In: Journal für Literatur, Kunst, Luxus und Mode 34 (1819, Dezember), S. 728- 744, S. 743

${ }^{949}$ Die griechische Kunst erhält ihre Bedeutung als Maßstab und Vergleichswert vor allem auch durch Winckelmann. Diese hatte 1755 Einfalt und Größe der griechischen Kunst als Vorbild zur Nachahmung empfohlen (vgl. z.B. Cowan: The Indo-German Identification, S. 44).

${ }^{950}$ Vgl. Majer: Bemerkungen zu einem indischen Gemälde, S. 517f.; Des Fra Paolino da San Bartolomeo Reise nach Ostindien, S. 392; Creuzer: Symbolik und Mythologie der alten Völker. Erster Theil. Zweite völlig umgearbeitete Ausgabe, S. 649
} 
dass sie in dem Versuch, möglichst umfassend alles symbolisch darzustellen, nicht auf Maß und Ordnung achteten.

Majer vergleicht die indische Kunst „wegen des gänzlichen Mangels an Haltung, Perspectiv und Helldunkel“ mit den „Gemälden des Mittelalters“951. Ähnlich wie es bei dem Vergleich der indischen Literatur mit Shakespeare der Fall ist, wird hier mit dem Mittelalter ebenfalls eine von Teilen der Romantik geschätzte Kultur herangezogen. Das trifft im Übrigen auch auf den von Papi gezogenen Vergleich der indischen Baukunst mit der gotischen zu. ${ }^{952}$ Auf die fehlende Perspektive bei den Indern weisen auch Sonnerat und Forster hin. ${ }^{953}$ Außerdem fehle es den Bildern an Lebendigkeit. ${ }^{954}$

Der andere Kritikpunkt, das Fehlen von Maß und Ordnung, trifft vor allem Bildhauerei und Architektur. Ausführlich findet sie sich in einem Artikel im Journal für Literatur, Kunst, Luxus und Mode:

\begin{abstract}
Es ist vergeblich, wenn man in den Indischen Gebäuden Einheit des Plans und der Bearbeitung, so wie Symmetrie in der Verzierung suchen wollte. Einheit und Mannichfaltigkeit, dieß ist das große Gesetz der Baukunst und aller schönen Künste; dieß scheinen die Indier nicht gekannt zu haben, und wie die Zierrathen, welche sie mit Verschwendung allenthalben ausgeschüttet haben, nicht mit Ordnung vertheilt sind, entsteht nicht sowohl Reichthum, als Verwirrung, ihre Künstler haben die Anwendung reiner und gleichmäßiger Umrisse und regelmäßiger Vergleichung verschmäht, sie haben durchaus den majestätischen Effect verkannt, welchen große Linien in der Architectur hervorbringen. ${ }^{955}$

Also, wenn die Ägypter den Geist der Ordnung und Aufeinanderfolge bis auf's äußerste trieben, so waren die Indier gleichsam durch den entgegengesetzten Geist auf die Unbeständigkeit der Formen hingeleitet. Sie suchten vermuthlich Verschiedenheit in der Wirkung, aber ohne Einheit brachte diese nichts als Unordnung, Verwirrung und Ermüdung für das Auge hervor ${ }^{956}$
\end{abstract}

Die Inder verteilten laut Jomard Verzierungen, ohne auf eine Einheit der Formen zu achten. Das erzeuge bei dem Betrachter Verwirrung. Diese Verwirrung wird vor allem von Goethe kritisiert: Die indische Kunst zerstreue und verwirre die

\footnotetext{
${ }^{951}$ Majer: Bemerkungen zu einem indischen Gemälde, S. 517f., Interessanterweise hat Majer einige Jahre zuvor aus dem Drama Śakuntalā abgeleitet, dass die indische Kunst sehr hoch entwickelt gewesen sein müsse und auch perspektivisches Zeichnen gekannt haben müsse (vgl. Majer: Zur Kulturgeschichte der Völker, S. 348)

952 Vgl. Briefe eines italienischen Reisenden, S. 425

${ }^{953}$ Vgl. Sonnerat: Reise nach Ostindien, S. 49; Forster: Reise aus Bengalen, S. 109

954 Vgl. Majer: Bemerkungen zu einem indischen Gemälde, S. 517; Paolino: Darstellung der

Brahmanisch-Indischen Götterlehre, S. 232; Briefe eines italienischen Reisenden, S. 419

955 Jomard: Parallele zwischen den Alterthümern, S. 731

956 Jomard: Parallele zwischen den Alterthümern, S. 739
} 
Einbildungskraft. ${ }^{957}$ Auch in den Berichten eines Missionars der Halleschen Mission heißt es, dass indische Gebäude „mehr Ungeheures als Schönes (zeigen); und ich fand wenig Geschmack und Symmetrie in ihrer Baukunst. Weder die menschlichen noch thierischen Figuren haben eine schickliche Proportion. “958 Und auch Papi schreibt:

\begin{abstract}
Jene Basreliefs und Verzierungen sind zwar allerdings sehr künstlich, mit vieler Geduld und einer in das kleinste Detail sich erstreckenden Genauigkeit gefertigt: allein man hat deren nicht nur zu viele an einer und derselben Stelle zusammengruppirt, sondern man vermißt auch an allen die edle Simplizität, Eleganz, Correcktheit und Reinigkeit, des griechischen und römischen Geschmacks. ${ }^{959}$
\end{abstract}

Das Zitat macht aber auch deutlich, dass die Baukunst trotz aller Kritik häufig positiver beurteilt wird als die Malerei. Denn die Baumeister seien nicht so eng an die Vorgaben der Mythologie und Religion gebunden und hätten dadurch mehr Freiheiten. ${ }^{960}$

\title{
5.3 Wissenschaften
}

Über den Stand der Wissenschaften bei den Indern wird relativ wenig berichtet. Die Aussagen, die es gibt, ähneln sich allerdings sehr. Insgesamt ist die Ansicht weit verbreitet, dass die Wissenschaften bei den Indern nicht sehr weit entwickelt seien. Hegel ist sogar der Ansicht, dass „bei genauerer Kenntniß des Werthes derselben [Kunst und Wissenschaft] das viele Gerede von indischer Weisheit um ein Bedeutendes ist verringert worden."961 Auch ein Lexikoneintrag von 1809 zeichnet ein negatives Bild von den indischen Wissenschaften:

\begin{abstract}
Kein Wunder also, daß die Hindus in der Geistescultur noch eben da stehen, wo sie vor vielen Jahrhunderten waren. Alle Wissenschaften sind in den Händen der Braminen: Medicin und Chirurgie werden ganz schlecht betrieben, Philosophie nicht viel besser, und eben so elend andre Wissenschaften; am weitesten ist man in der Naturlehre und Sternkunde gekommen. [...] Der gemeine Haufe lebt in größter Unwissenheit, kann sich nicht von dem Aberglauben und den Vorurtheilen seiner Urväter trennen, hat wenig Speculationsgeist $[\ldots] .{ }^{962}$
\end{abstract}

Lediglich einige wenige Wissenschaften werden als höher entwickelt angesehen. Das soll im Folgenden vor allem anhand von Zitaten des italienischen Arztes Papi, der vergleichsweise ausführlich auf dieses Thema eingeht, näher angesehen werden.

\footnotetext{
${ }^{957}$ Vgl. Goethe: Die letzten Jahre, S. 225f. (Dezember 1824 an August Wilhelm Schlegel)

${ }^{958}$ Schulze (Hg.): Neuere Geschichte der Evangelischen Missions-Anstalten zu Bekehrung der Heiden in Ostindien. Vierter Band, 83. Stück, S. 147

959 Briefe eines italienischen Reisenden, S. $418 f$.

${ }^{960}$ Vgl. Des Fra Paolino da San Bartolomeo Reise nach Ostindien, S.389

${ }^{961}$ Hegel: Vorlesungen über die Philosophie der Geschichte, S. 167

962 Conversations-Lexikon. 1809, S. 337
} 
Besonders die Astronomie gilt als sehr alt und gut entwickelt. Die Kenntnisse seien allerdings in jüngster Zeit nicht mehr weiterentwickelt und zum Teil sogar wieder vergessen worden:

\begin{abstract}
Eine jener Wissenschaft, womit sich die Indier seit undenklichen Zeiten beschäftigt, und worin sie ziemlich starke Fortschritte gemacht haben, ist die Astronomie. Einige ihrer ältern astronomischen Tafeln sind nach Europa gebracht, sehr genau untersucht, mit den unsrigen verglichen und durchgehends richtig befunden worden. ${ }^{963}$

Ich übergehe daher Alles hierher Gehörige mit Stillschweigen, und merke nur noch an, daß zwar diese Braminen die astronomischen Tafeln bei ihren Berechnungen zum Grunde legen, aber von den Angaben, worauf sie eigentlich beruhen, nichts mehr verstehen, und eben so wenig wissen, wer sie verfaßt hat. ${ }^{964}$
\end{abstract}

Über die Ähnlichkeit und mögliche Verwandtschaft des indischen Tierkreises mit denen anderer Kulturen wird in den 1830er Jahren ausführlich diskutiert. ${ }^{965} \mathrm{Da}$ sich diese Diskussion allerdings außerhalb des gewählten Untersuchungszeitraums befindet, werde ich nicht näher darauf eingehen. Auch die mathematischen Kenntnisse der Inder werden gelobt:

\begin{abstract}
Vorzüglich macht den Indiern die Erfindung jener zehn Zahlen viele Ehre, deren man sich heutzutage in Europa allgemein zu bedienen pflegt, und wodurch das Rechnen eben so sehr erleichtert wird [...]. Die Leichtigkeit, mit welcher die Indier rechnen, ist wirklich bewundernswerth. Sie lösen die schwersten arithmetischen Probleme durch Kopfrechnen auf, und sind längst damit fertig, wenn der Europäer noch immer die Feder in der Hand hat, um Zahlen auf das Papier zu rotieren (!). ${ }^{966}$
\end{abstract}

Selbst Hegel, der ansonsten mit Kritik an der indischen Kultur nicht spart, erkennt die indischen Kenntnisse in Geometrie, Astronomie und Algebra an. Die Geschichtswissenschaft sei dagegen in Indien überhaupt nicht ausgeprägt:

Wenn wir in der neueren Zeit mit den Schätzen der indischen Litteratur bekannt worden sind, wenn wir gefunden haben, daß die Inder großen Ruhm in der Geometrie, Astronomie und Algebra erlangten, daß sie es in der

\footnotetext{
963 Briefe eines italienischen Reisenden, S. 401f.

${ }^{964}$ Briefe eines italienischen Reisenden, S. 402; vgl. auch die Rezension Forsters über „Voyage dans les mers de l'Inde“"von Le Gentil (Forster, Georg: Rezensionen. Bearbeitet von Horst Fiedler. Berlin 1977 (Georg Forsters Werke. Sämtliche Schriften, Tagebücher, Briefe. Herausgegeben von der Akademie der Wissenschaften der DDR; 11), S. 26

965 Vgl. die Äußerungen Schlegels gegenüber Böckh (Briefe von und an August Wilhelm Schlegel. Gesammelt und erläutert durch Josef Körner. Erster Teil. Die Texte. Zürich u.a. 1930, S. 528f. (19. September 1837)

966 Briefe eines italienischen Reisenden, S. 402f.
} 
Philosophie weit brachten, und daß das grammatische Studium so angebaut worden ist, daß keine Sprache als ausgebildeter zu betrachten ist, als das Sanskrit, so finden wir die Seite der Geschichte ganz vernachlässigt, oder vielmehr gar nicht vorhanden. Die indische Empfindung und Phantasie ist unfähig ein bestimmtes Daseyn, das Daseyn in seiner Objektivität aufzufassen; sie verflüchtigt sich vielmehr in Dunst, Theils in Träume, Theils in Mythologie. Hierin zeigt sich eben der Gegensatz von den Chinesen, denn die Geschichte erfordert Verstand, die Kraft, den Gegenstand für sich freizulassen und ihn in seinem verständigen Zusammenhange aufzufassen. ${ }^{967}$

Die Inder seien daher nicht fähig zur Geschichtsschreibung. Diese sei aber wichtig für

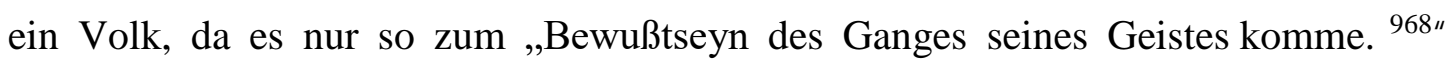
Deshalb ist gerade für Hegel das Fehlen einer Geschichtswissenschaft in Indien ein deutliches Zeichen für die fehlende Entwicklung des Landes. Auch Heeren weist darauf hin, dass noch keine indischen historischen Werke gefunden worden seien:

Critische Geschichte kann unmöglich unter einer Nation sich bilden, die keinen Sinn dafür hat, und keinen Werth darauf legt. Nicht um historische Wahrheit, sondern um dichterischen Schmuck ist es ihr zu thun. Die Erzählung soll nicht den Verstand, sie soll die Einbildungskraft beschäftigen. [...] Ich behaupte nicht zu viel, wenn ich sage, daß die Inder von dem was wir historischen Styl nennen, nicht einmal einen Begriff haben. ${ }^{969}$

Am ausführlichsten beschäftigen sich die Autoren der hier untersuchten Texte mit der indischen Arzneikunst:

Mit den Nebenzweigen der Naturwissenschaft, die Astronomie ausgenommen, sind die Inder noch zur Zeit wenig oder gar nicht bekannt. Noch nie kam es ihnen in den Sinn, einen Leichnam zu öffnen, um die Gestalt, den Nutzen, und die Verrichtungen der innern Theile des menschlichen Körpers kennen zu lernen. Daher ihre gänzliche Unerfahrenheit in der Physiologie und ihre wenige Bekanntschaft mit der Wundarzneikunst. ${ }^{970}$

Wiewohl nun die Indier äußerst leichtgläubig sind, und häufig von ihren Quacksalbern betrogen werden, so glaube ich dennoch, daß manche ihrer Arzneimittel zur Heilung gewisser Krankheiten sehr zweckmäßig angewendet werden könnten, wenn sie dieselben nur nicht, wie solches häufig $\mathrm{zu}$ geschehen pflegt, mit einander verwechselten, und keinen verkehrten Gebrauch davon machten. ${ }^{971}$

\footnotetext{
${ }^{967}$ Hegel: Vorlesungen über die Philosophie der Geschichte, S. 170

${ }^{968}$ Hegel: Vorlesungen über die Philosophie der Geschichte, S. 170

${ }^{969}$ Heeren: Ideen über die Politik, S. 320f.

${ }^{970}$ Briefe eines italienischen Reisenden, S. 403

${ }^{971}$ Briefe eines italienischen Reisenden, S. 406
} 
Die Thesen, dass die Inder zwar altes Wissen über durchaus wirksame Arzneimittel besitzen, allerdings über keinerlei Kenntnisse von Anatomie und Chirurgie verfügen, werden auch von anderen Autoren vertreten. So schreibt Paulinus a Sancto Bartholomaeo:

\begin{abstract}
Diese beiden Wissenschaften [Botanik und Arzneikunde] werden in Indien schon seit drei tausend Jahren getrieben, und beschäftigen noch heut zu Tage eine sehr große Anzahl Menschen. Wenn man nach einem Arzte schickt, so kommen ihrer gewiß fünf bis sechs. Man findet sogar Knaben, welche ausgebreitete Kenntnisse in der Botanik besitzen; und dies ist auch gar kein Wunder, da man sie schon in den frühesten Lebensjahren dazu anhält, die Kräuter und ihre Eigenschaften kennen zu lernen. Erlaubten es die Gesetze und die Religion der Indier, daß sie Thiere zergliedern und die Anatomie studieren dürften, so würden sie es unfehlbar in der Arzneikunst sehr weit bringen; da ihnen aber dies aufs strengste verboten ist, so versteht es sich von selbst, daß diese Wissenschaft keine großen Fortschritte machen kann. Indeß sah ich aber gleichwohl, daß Malabarische Ärzte mitunter Kranke wieder herstellen, auf deren Rettung Europäische gänzlich Verzicht gethan hatten. Überhaupt thun es die Malabaren an Kenntniß der einfachen Arzneimittel den meisten Europäern zuvor. ${ }^{972}$
\end{abstract}

Auch ein Artikel im Morgenblatt für gebildete Stände vertritt die Ansicht, dass die Inder bereits früh gute medizinische Kenntnisse gehabt haben müssen und dass ihre „geduldige Beobachtungsgabe und der natürliche Scharfsinn“ 973 sie für wissenschaftliche Forschungen qualifizieren. Allerdings hätten sie aufgrund von religiösen Vorurteilen keine anatomischen und chirurgischen Kenntnisse erwerben können.

Über das wissenschaftliche Forschen und Lehren allgemein stellt Heeren fest, dass die Inder nicht klar zwischen wissenschaftlicher und poetischer Literatur unterschieden. ${ }^{974}$ Und auch anderen Autoren fällt immer wieder die Besonderheit auf, dass die indische wissenschaftliche Literatur überwiegend in Versen abgefasst ist. Auch ein Zeitschriftenartikel über den Zustand indischer Universitäten weist darauf hin und sieht darin einen weiteren Hinweis auf die schlechte Didaktik in der indischen Lehre, bei der die Studenten die ersten fünf Jahre schweigend dem Lehrer zuhören müssten:

Und wer könnte die fünfjährige Zeit des Stillschweigens, die metrische Form der Lehrbücher, und das mechanische Auswendiglernen für gute Zeichen von der Methode des Unterrichts halten? Indessen könnte der

\footnotetext{
972 Des Fra Paolino da San Bartolomeo Reise nach Ostindien, S. 414f.

973 Über die medizinischen und chirurgischen Kenntnisse der Hindus im Allgemeinen. In: Morgenblatt für die gebildeten Stände 17 (1823; Nr. 292 u. 293), S. 1166f. u. 1171f., S. 1166

974 Vgl. Heeren: Ideen über die Politik, S. 328
} 
Umgang mit den Lehrern selbst das Mangelhafte dieser Methode ersetzen. $^{975}$

Nur schade, daß die Lehrer selbst ihrem Geiste keine vollkommene Ausbildung gegeben haben, und der Regel nach die Indolenz lieben. Wie ermunternd zur Thätigkeit kann ein Umgang mit Männern seyn, die ihren Stand blos der Bequemlichkeit und reicher Pfründen wegen gewählt haben? wie lehrreich der Aufenthalt bey Halbgelehrten? Und wo etwa ein Mann von Geist eine Ausnahme von dieser Regel machen sollte, welche Lernbegierde läßt sich von einem so langsamen und trägen Schlage Menschen erwarten, wie sich die Hindu in allen Verhältnissen zeigen? Kein Wetteifer belebt zur Arbeit, weil er Aufopferung der Gemächlichkeit fodern würde, auf welche der indolente Hindu nicht Verzicht thun mag; keine Hoffnung zu Belohnungen, wenn man sich auszeichnen würde, vermehrt den Fleiß, weil die Geburt schon alle Vorzüge ertheilt, die sich hoffen lassen. ${ }^{976}$

Der Autor beurteilt also nicht nur die indischen Lehrmethoden, sondern auch die fehlende Motivation aufgrund der durch das Kastenwesen vorgegebenen Lebensweise sowie die angeborene Trägheit der Inder als sehr hinderlich für eine gute Bildung.

Auch hinsichtlich der indischen Wissenschaft finden sich also die bereits bekannten stereotypen Erzählmuster: Es habe bereist sehr früh ein vergleichsweise tiefes Wissen gegeben, das aber mit der Zeit immer mehr verloren gegangen bzw. veraltet sei, da die Forschungen nicht fortgeführt worden seien. Auch neuere Entwicklungen, die die europäische Wissenschaft auszeichneten, habe Indien nicht mitgemacht. Verbunden wird das mit dem Bild von der großen Ruhe, Gleichgültigkeit und dem Traditionsbewusstsein der Inder, die dazu führten, dass die Inder zwar in einigen Wissenschaften durch frühes und eifriges Studium gute Kenntnisse erlangt hätten, dass es ihnen aber auch an jeglicher Motivation fehle, sich mit Interesse und Neugierde anderen Bereichen zuzuwenden und Neues zu entdecken. Die indischen Wissenschaften entsprächen eher dem vormodernen Wissenschaftsmodell, bei dem es darum gehe, das tradierte Wissen zu sichern. Die hier untersuchten Autoren vertreten dagegen die im Zuge der Aufklärung entwickelte Forderung nach einem systematischen Wissenszuwachs. 977

\footnotetext{
975 Indische Universitäten. In: Morgenblatt für die gebildeten Stände 3 (1809; Nr. 107 u. 108), S. 427

${ }^{976}$ Indische Universitäten, S. 427

977 Vgl. Baasner, Rainer: Einführung in die Literatur der Aufklärung. Darmstadt 2006, S. 12; Meyer:

Die Epoche der Aufklärung, S. 32
} 


\section{Sanskrit und die Entstehung der Indologie}

\subsection{Sanskrit und die vergleichende Sprachwissenschaft}

Die alte indische Sprache Sanskrit spielt in den Untersuchungen der Europäer erst relativ spät eine größere Rolle, prägt dann aber entscheidend die Entstehung der Indologie als Wissenschaft. Sanskrit galt lange als geheime Sprache der Brahmanen und übte dadurch eine gewisse Faszination aus. Da es aber lange Zeit für Europäer kaum möglich war, an nähere Informationen über diese Sprache zu kommen, war diese Faszination sehr vage. Die Kenntnisse der wenigen Europäer, denen es vor der zweiten Hälfte des 18. Jahrhunderts gelungen war, Sanskrit zu erlernen, wurden kaum bekannt bzw. gerieten schnell in Vergessenheit. ${ }^{978}$ Dadurch hatte Sanskrit lange Zeit, ähnlich wie die Hieroglyphen, eine Art Aura des Geheimnisvollen und Unverständlichen. Diese Vorstellung findet sich auch noch nach Beginn der wissenschaftlichen Erforschung und damit Entzauberung der alten indischen Sprache, wie ein Ausschnitt eines Briefes Goethes an den Großherzog aus dem Jahr 1820 zeigt: Etwas, das er nicht verstanden habe, sei ihm „eine Art Sanskrit geblieben“979. Als die ersten Engländer in den 1780er Jahren beginnen, Sanskrit zu erlernen und dieses Wissen an andere weiterzugeben, entwickelt sich schnell ein wissenschaftliches Interesse. Die Sanskrittexte werden nun nicht mehr nur aus dem Wunsch heraus gelesen, Wissen über die indische Kultur zu erlangen, sondern werden selbst zum Objekt der Literatur- und Sprachwissenschaft. Zuvor standen bei den Missionaren und anderen Indienreisenden die in verschiedenen Landesteilen gesprochenen indischen Sprachen wie Tamil im Mittelpunkt des Interesses, da sich leichter Inder finden ließen, die bereit waren, diese Sprachen zu lehren. Zudem war es für die Missionare wichtig, mit der Bevölkerung kommunizieren zu können. Ganz anders ist es bei den Sprachwissenschaftlern, die die Indologie als neue Wissenschaft einführen. Sie interessieren sich fast ausschließlich für Sanskrit und damit für das klassische Indien. Mit den zeitgenössischen Sprachen gerät auch die zeitgenössische indische Kultur aus dem Fokus der Aufmerksamkeit. Außerdem lösen die Philologen, die selbst nie in Indien gewesen sind, die Augenzeugen wie Reisende und Missionare als Autorität ab. ${ }^{980} \mathrm{Im}$ Folgenden möchte ich zunächst die Aussagen

\footnotetext{
978 Vgl. Cohn: Colonialsm, S. 25; Hanco: German Indology, S. 62; Sedlar: India, S. 6-9

${ }^{979}$ Briefwechsel des Herzogs-Großherzogs Carl August mit Goethe. Herausgegeben von Hans Wahl. II. Band 1807-1820. Mit einem Bildnis des Herzogs. Berlin 1916 (Carl August. Darstellungen und Briefe zur Geschichte des Weimarischen Fürstenhauses und Landes. Im Auftrag Seiner Königlichen Hoheit des Großherzogs Wilhelm Ernst von Sachsen zur Hundertjahrfeier des Großherzogtums. Herausgegeben von Erich Marcks. IV. Abteilung: Briefwechsel des Herzogs-Großherzogs Carl August mit Goethe), S. 311 (Oktober 1820)

${ }^{980}$ Vgl. Hanco: German Indology, S. 62, 67, 70f.
} 
zur Charakterisierung des Sanskrit sowie zur vermuteten Verwandtschaft der später so genannten indoeuropäischen Sprachen untersuchen. Anschließend soll ein Blick auf den von Friedrich Schlegel angestoßenen Streit über die Unterscheidung von mechanischen und organischen Sprachen geworfen werden. Abschließend möchte ich dann kurz auf die Entstehung der neuen Wissenschaft der Indologie eingehen.

Sanskrit wird von den verschiedenen Autoren sehr ähnlich charakterisiert. Es gibt nur wenige strittige Punkte. Die alte indische Sprache wird als wohlklingend beschrieben. Der Engländer Forster berichtet bereits Ende der 1790er Jahre, Sanskrit sei eine „sehr kraftvolle und wohlklingende, oder wenigstens in’s Ohr fallende Sprache.“" ${ }^{\text {“91 Ganz }}$ ähnlich äußert sich ungefähr zwei Jahrzehnte später Heeren:

Keine andere der alten Sprachen Asiens hat in unsern Tagen mehr die Aufmerksamkeit auf sich gezogen, als das Sanscrit. ${ }^{982}$

[...] und auch wenn die Lobpreisungen, die zuweilen von ihr gemacht sind, übertrieben seyn sollten; so kann man doch nicht anstehen sie für eine der wohlklingendsten, der reichsten und der gebildetsten Sprachen der Welt zu erklären. ${ }^{983}$

Der Wohlklang des Sanskrit wird zwar nicht allzu häufig thematisiert, aber es wird dem auch nicht widersprochen.

Wichtiger als der Wohlklang der Sprache ist einigen Autoren ein weiteres, häufig benanntes Charakteristikum des Sanskrit: die philosophische Ausdruckskraft. Bereits Claudius weist darauf hin, dass Sanskrit viele Wörter für philosophische Spekulationen kenne. ${ }^{984}$ Auch Heeren lobt den „hohen Grad der wissenschaftlichen Ausbildung“ und den ,„philosophische(n) Reichthum““985. Friedrich Schlegel schreibt:

Es ist wahr, beinah die ganze indische Sprache ist eine philosophische oder vielmehr religiöse Terminologie; und vielleicht ist keine Sprache, selbst die griechische nicht ausgenommen, so philosophisch klar und scharf bestimmt als die indische $[\ldots] .9^{986}$

\footnotetext{
${ }^{981}$ Forster: Reise aus Bengalen, S. 62f.

982 Heeren: Ideen, S. 281

${ }^{983}$ Heeren: Ideen, S. 282

${ }^{984}$ Vgl. Claudius: Eine asiatische Vorlesung, S. 37

985 Heeren: Ideen, S. 283

${ }^{986}$ Schlegel: Über Sprache und Weisheit der Indier, S. 68
} 
Schlegel sieht in dieser engen Verbindung zwischen Sprache und „Denkart“987 der Inder den Grund dafür, dass sich Sanskrit im Vergleich zu anderen Sprachen im Laufe der Zeit deutlich weniger verändert habe. Auch sein Bruder August Wilhelm Schlegel lobt den großen Einfluss, den der „speculative Geist“ auf Sanskrit gehabt habe: „Statt daß in andern Sprachen die Philosophie ihre Bezeichnung der Begriffe der Sinnlichkeit hat abborgen müssen, sind im Sanskrit ursprünglich philosophische Ausdrücke in das Leben und in die Poesie eingetreten [...].“ "988 Humboldt dagegen ist in seiner Beurteilung etwas skeptischer. Im Vertrauen schreibt er an Welcker:

\begin{abstract}
Aber zwischen dem Sanskrit und dem Griechischen scheint nun wieder eine Kluft zu liegen. Denn ich halte das Sanskrit nicht für den vollendeten Ideengebrauch fähig. Als das Zeichen und das Resultat von diesem sehe ich die ausgebildete Prosa an, und ich glaube nicht, dass man diese über die Griechen zurück hinaus aufsuchen darf. [...] Es [Sanskrit] ist in meiner Ansicht ein Centrum, von dem man zurück auf die minder ausgebildeten Sprachen, um den Mechanismus der Sprache zu beurtheilen, und vorwärts auf die höher ausgebildeten, um die Fähigkeit der Sprache zur Ideenentwicklung zu beurtheilen, gehen kann. Ich sage indess dies nur Ihnen, den Enthusiasten für die Indische Sprache würde ich mit so kühnen Behauptungen nicht entgegentreten mögen. ${ }^{989}$
\end{abstract}

Sanskrit ist für Humboldt durchaus eine gebildete Sprache, die allerdings die Möglichkeiten, Ideen auszudrücken, anders als das Griechische noch nicht vervollkommnet habe. Das Zitat ist aber auch in anderer Hinsicht sehr interessant. So zeigt es sehr gut, wie sehr Indien in dieser Zeit polarisieren kann. Es ist nur schwer möglich, sich zu diesem Themenbereich neutral zu verhalten. Entweder man begeistert sich für Indien (bzw. einige Aspekte seiner Kultur) oder aber man läuft Gefahr, von den „Enthusiasten“ zurückgewiesen zu werden.

Auch der grammatische Bau der Sanskritsprache kann Begeisterung hervorrufen. Bereits Jones schreibt:

„Die Sanscrit ist, es mag mit ihrem Alterthume seyn wie es will, von wunderbarer Bauart: sie ist vollkommener als das Griechische, reicher als das Lateinische, und viel feiner gebildet als beyde [...].“ 990 Die „bewunderungswürdige Bildung der

\footnotetext{
${ }^{987}$ Schlegel: Über Sprache und Weisheit der Indier, S. 68

${ }^{988}$ Humboldt, Wilhelm von: Über die Bhagavad-Gita. Mit Bezug auf die Beurtheilung der

Schlegelschen Ausgabe im Pariser Asiatischen Journal. In: Indische Bibliothek. 2. Band. Bonn 1827, S. 218-258, S. 230 (Anm. d. Hgs.)

${ }^{989}$ Humbolt: Briefe an Welcker, S. 54f.

${ }^{990}$ Jones, William: Über die Hindus. In: Abhandlungen über die Geschichte und Alterthümer, die Künste, Wissenschaften und Literatur Asiens von Sir William Jones und andern Mitgliedern der im
} 
Sanskritsprache“"991 gibt Anlass zu der These, dass diese Sprache möglicherweise nicht natürlichen Ursprungs sei. Wie Papi berichtet, vertrete Dow die Ansicht, dass „sie von einer Gesellschaft gelehrter Männer, welche die Regularität, die Harmonie, hauptsächlich aber eine bewunderungswürdige Simplizität und Energie des Ausdrucks, von grundaus studirt hatte, nach gewissen rationellen Regeln festgesetzt wurde. “992 Sie sollte den Brahmanen zur Geheimhaltung ihrer Religion vor dem gemeinen Volk dienen. Papi stimmt zwar zu, dass Sanskrit „eine der vortrefflichsten und ausgebildetsten Sprachen ist" ${ }^{993}$, schenkt der These Dows über die künstliche Erfindung allerdings keinen Glauben. Auch Majer und Heeren lehnen diese These ab. ${ }^{994}$ Klaproth vertritt dagegen die Meinung, dass Sanskrit für viel älter gehalten werde, als es tatsächlich sei, denn es weise ,alle Spuren der Neuheit“ auf und ist „gewiss eine ziemlich junge Schrift- und Büchersprache“‘995. Auch Meiners greift diesen Gedanken auf und nutzt ihn als Argument dafür, dass die indische Kultur keineswegs so alt sei, wie vielfach angenommen werde, sondern erst durch griechischen Einfluss und auf diesem aufbauend entstanden sei:

\begin{abstract}
Der ganze Bau der Sanscrit-Sprache ist so einfach und regelmäßig, daß man fast glauben muß: sie sey nicht allmählich gebildet, sondern in kurzer Zeit durch eine Gesellschaft von unterrichteten Männern zu einer gelehrten oder Büchersprache umgeschaffen worden. Eben diese Sprache enthält eine Menge von Griechischen, Lateinischen und alt-Persischen Wörtern, und zwar für Begriffe und Gegenstände, die längst hätten bezeichnet seyn müssen, wenn die Hindus vor ihrer Bekanntschaft mit den Griechen ein wissenschaftlich-gebildetes Volk gewesen wären. ${ }^{996}$

Keine Vermuthung ist daher gegründeter, als diese: daß die Hindus, und besonders die Priester der Hindus, nicht lange nach dem Alexander angefangen haben, sich die Künste und Kenntnisse der Griechen zuzueignen: daß die Schrift und Sprache der Brahminen in eben diesem Zeitraum gebildet, ihre ältesten heiligen Bücher geschrieben, und ihre ältesten Pagoden und in Felsen gehauenen Tempel errichtet worden [...]. ${ }^{997}$
\end{abstract}

Damit stellt sich Meiners gegen die Ansichten des Großteils der hier untersuchten Autoren und vertritt eine größtenteils nicht anerkannte Außenseiterposition.

\footnotetext{
Jahr 1784 zu Calcutta in Indien errichteten gelehrten Gesellschaft. Erster Band. Aus dem Englischen übersetzt von Johann Christian Fick, Lehrer am ill. Gymnasium zu Erlangen, durchgesehen, und mit Anmerkungen, ausführlichen Erläuterungen und Zusätzen bereichert von D. Johann Friedrich Kleuker. Riga 1795, S. 1-24, S. 11

${ }^{991}$ Briefe eines italienischen Reisenden, S. 57

992 Briefe eines italienischen Reisenden, S. 58

993 Briefe eines italienischen Reisenden, S. 59

${ }^{994}$ Vgl. Heeren: Ideen über die Politik, S. 284f.; Majer: Zur Kulturgeschichte der Völker, S. 132

${ }^{995}$ Klaproth, Julius: Asia polyglotta. Paris 1823, S. 45

${ }^{996}$ Meiners: Untersuchungen über die Verschiedenheiten der Menschennaturen, S. 231

${ }^{997}$ Meiners: Untersuchungen über die Verschiedenheiten der Menschennaturen, S. 232
} 
Ein Thema, das durch die Entdeckung des Sanskrit aktuell wird und dann im wissenschaftlichen Diskurs über die reine Erforschung der alten indischen Sprache hinausgeht, ist die Feststellung, dass Sanskrit eine solche Ähnlichkeit mit verschiedenen europäischen Sprachen aufweist, dass die meisten Autoren von einer Verwandtschaft ausgehen. Diesen Schluss zieht bereits Jones. Die Ähnlichkeiten zwischen den Sprachen können nicht auf einem Zufall beruhen. ${ }^{998}$ Auch der Missionar Paulinus a Sancto Bartholomaeo weist auf die verblüffende Ähnlichkeit zwischen Sanskrit und Latein hin. Er schließt daraus, dass

\begin{abstract}
die Samscredam-Sprache gewiß nicht vor der Sündfluth existirte [...]. Sie entstand vielmehr in Chaldäa, und zwar zur Zeit jener allgemeinen Sprachverwirrung, aus welcher man die Analogie mehrerer andern Wörter herleiten muß, deren sich damals so manche Völkerschaften, und folglich auch die Vorfahren der Brahmanen und Lateiner, bedienten. ${ }^{999}$
\end{abstract}

Paulinus a Sancto Bartholomaeo zieht also zur Erklärung der offensichtlichen Verwandtschaft der Sprachen biblische Erklärungsmodelle heran. Dabei geht er von einer gemeinsamen Quelle der betreffenden Sprachen aus und nicht von gegenseitiger Beeinflussung. Anders ist es bei einem anderen Missionar, bei Perrin. Er führt die beobachteten Ähnlichkeiten darauf zurück, dass bestimmte indische Wörter „offenbar aus dem Lateinischen kommen, wenn man nicht annehmen will, daß dieses sie aus dem Sanskrit geschöpft habe.“1000 Letztere Annahme scheint Perrin jedoch abwegig zu sein. Diese Äußerungen der Missionare stammen aus einer Zeit, in der die wissenschaftliche Beschäftigung mit Sanskrit gerade erst begonnen hat und noch nicht allzu bekannt geworden ist. Die Annahme, dass Sanskrit deshalb vielen europäischen Sprachen ähnele, weil es vieles von diesen übernommen hätte, wird von den späteren, hier untersuchten Autoren einhellig abgelehnt, sofern sie sich mit diesem Thema überhaupt auseinandersetzen. Eine Ausnahme stellt Meiners dar, der die Ähnlichkeiten dazu nutzt, seine These, dass die Inder ihre Kultur von den Griechen übernommen hätten, zu untermauern. Die anderen Autoren gehen dagegen von einer gemeinsamen Ursprache aus, aus der sich die verwandten Sprachen entwickelt hätten.

Im deutschsprachigen Raum wird diese These 1808 durch Friedrich Schlegel einem größeren Publikum bekannt gemacht und durch detailliertere Vergleiche untermauert:

\footnotetext{
998 Jones: Über die Hindus, S. 11

${ }^{999}$ Des Fra Paolino da San Bartolomeo Reise nach Ostindien, S. 319

${ }^{1000}$ Hell: M. Perrin's Reise durch Hindostan, S 32
} 
Das alte indische Sonskrito [...] hat die größte Verwandtschaft mit der römischen und griechischen so wie mit der germanischen und persischen Sprache. Die Ähnlichkeit liegt nicht bloß in einer großen Anzahl von Wurzeln, die sie mit ihnen gemein hat, sondern sie erstreckt sich bis auf die innerste Structur und Grammatik. Die Übereinstimmung ist also keine zufällige, die sich aus Einmischung erklären liesse; sondern eine wesentliche, die auf gemeinschaftliche Abstammung deutet. Bei der Vergleichung ergiebt sich ferner, daß die indische Sprache die ältere sei, die andern aber jünger und aus jener abgeleitet. ${ }^{1001}$

Schlegel betont bei seinen Sprachvergleichen immer wieder die große Bedeutung, die der vergleichenden Grammatik zukomme. Denn allein diese könne ausschließen, dass es sich bei den Ähnlichkeiten nicht um aus einer anderen Sprache übernommenen Wörter handele. Da die indischen Formen im Vergleich zu denen der anderen Sprachen zumeist länger sind und Schlegel davon ausgeht, dass sich längere Formen im Laufe der Zeit zwar „leicht abschleifen und verwischen, aber nicht umgekehrt“1002, steht für ihn fest, dass die ,indische Form die ältere sei““1003. Ein weitere Indiz für diese These sieht er in der Beobachtung, dass oft ,auch die an sich ziemlich entfernten Formen der abgeleiteten Sprachen in dem indischen Worte, wie in ihrer gemeinschaftlichen Wurzel zusammen[treffen]. “1004 Auch können einige Wörter der neueren Sprachen, die sich nicht aus sich selbst heraus in ihrer Zusammensetzung erklären lassen, im Vergleich mit den entsprechenden indischen Wurzeln verständlich werden. ${ }^{1005}$ Sanskrit nimmt für Schlegel innerhalb dieser verwandten Sprachen eine der gemeinsamen Quelle dieser Sprachen sehr nahe Position ein. Damit kommt sie der in dieser Zeit von vielen Autoren gesuchten Ursprache nahe, wenn auch unter zwei Einschränkungen: Erstens betont Schlegel, dass es nicht nur eine Ursprache gegeben haben, Sanskrit daher auch nicht mit allen Sprachen der Welt verwandt sei. Und zweitens geht Schlegel davon aus, dass Sanskrit ebenfalls von einer noch älteren Sprache abgeleitet sein könnte ${ }^{1006}$, nur dass es eben keine älteren Zeugnisse dieser Sprache gebe. Obwohl Sanskrit also nicht die eine Ursprache sei, benutzt Schlegel den Begriff Sanskrit bzw. indisch in einer ganz ähnlichen Funktion. Eine Sprache zeichne sich seiner Ansicht nach dann besonders aus, wenn sie möglichst viele ,indische(...) Wurzeln“"1007 habe.

\footnotetext{
${ }^{1001}$ Schlegel, Friedrich: Über die Sprache und Weisheit der Indier, S. 3

1002 Schlegel, Friedrich: Über die Sprache und Weisheit der Indier, S. 15

${ }^{1003}$ Schlegel, Friedrich: Über die Sprache und Weisheit der Indier, S. 15

${ }^{1004}$ Schlegel, Friedrich: Über die Sprache und Weisheit der Indier, S. 15

1005 Schlegel, Friedrich: Über die Sprache und Weisheit der Indier, S. 16

1006 Vgl. Schlegel, Friedrich: Über die Sprache und Weisheit der Indier, S. 41, 62

1007 Vgl. Schlegel, Friedrich: Über die Sprache und Weisheit der Indier, S. 11, 58f.
} 
Diese Verwendung von „indisch“ als eine Art Synonym für „ursprachlich“ findet sich auch bei Bopp, der im Gotischen ,manche ächt indische Worte“ ${ }^{\text {1008 }} \mathrm{zu}$ finden glaubt. Interessant ist, dass Bopp in seiner 1816 (also 8 Jahre nach Schlegels Text) erschienenen Abhandlung bereits die Verwandtschaft von Sanskrit und verschiedenen europäischen Sprachen als bekannt und allgemein anerkannt voraussetzt. So schreibt er einfach von „Sprachen, die mit der altindischen gemeinschaftlichen Ursprunges sind“ 1009 bzw. von „Sprachen, die von dem Sanskrit, oder mit ihm von einer gemeinschaftlichen Mutter abstammen“1010, ohne diese Verwandtschaft als solche gesondert einzuführen oder zu erläutern. Wie Schlegel sieht Bopp vor allem in den grammatischen Strukturen Beweise für die Verwandtschaft der Sprachen, wobei er bei den jüngeren Sprachen eine allmähliche Zerstörung der ehemals längeren Formen feststellt, was bei ihm allerdings keinen so negativen Beiklang hat wie bei Schlegel. ${ }^{1011}$ Auch Übereinstimmungen bei grammatischen Abweichungen und Unregelmäßigkeiten sieht er als deutlichen Hinweis für eine Verwandtschaft an. ${ }^{1012}$ Während er 1816 noch davon spricht, dass Sprachen wie Latein und Griechisch entweder von Sanskrit abstammen oder mit diesem von einer älteren Quelle, scheint er einige Jahre später der letzteren Variante den Vorzug zu geben. Denn er stellt fest, dass einige Formen des Griechischen und Lateinischen die Formen der „Urgestalt" ${ }^{\text {1013 }}$ noch besser bewahrten als das Sanskrit. Auch August Wilhelm Schlegel sieht grammatische Abweichungen und Anomalien, die sich in gleicher Weise bei verschiedenen Sprachen finden, als ein wichtiges Zeichen für deren Verwandtschaft an. ${ }^{1014}$

Friedrich Schlegel dienen seine Beobachtungen über die Verwandtschaft der Sprachen und die besondere Bauart des Sanskrit als Stütze seiner Philosophie. Indem er zwischen organischen und mechanischen Sprachen unterscheidet, ${ }^{1015}$ entwickelt er ein Kriterium, anhand dessen er Sprachen qualitativ beurteilen und bewerten kann. Denn die

\footnotetext{
1008 Bopp: Über das Conjugationssystem, S. X

1009 Bopp: Über das Conjugationssystem, S. 7

${ }^{1010}$ Bopp: Über das Conjugationssystem, S. 9

1011 Bopp: Über das Conjugationssystem, S. 11; vgl. auch Herling: The German Gita, S. 174

1012 Vgl. Bopp: Vergleichende Zergliederung des Sanskrits, S. 117

${ }^{1013}$ Bopp: Vergleichende Zergliederung des Sanskrits, S. 118

${ }^{1014}$ Vgl. Briefwechsel zwischen Wilhelm von Humboldt und August Wilhelm Schlegel, S. 68 (Brief vom 01. Dezember 1822)

${ }^{1015}$ Die organischen veränderten die Bedeutung und grammatische Funktion, indem sie durch Flexion ihre Wurzel bzw. Endung veränderten. Die mechanischen Sprachen müssten dagegen für jede neue Bedeutung ein neues Element an die Wurzel anhängen (vgl. Schlegel, Friedrich: Über die Sprache und Weisheit der Indier, S. 45-52)
} 
organischen Sprachen stehen für ihn deutlich über den mechanischen Sprachen. Die grammatische Struktur der organischen Sprachen empfindet Schlegel als ein lebendiges, natürliches Wachsen aus einer relativ kleinen Anzahl von ursprünglichen Wurzeln. ${ }^{1016}$ Diese Art der Sprachbildung setze allerdings etwas wichtiges voraus:

\begin{abstract}
ein sehr feines Gefühl nehmlich für den unterscheidend eigenthümlichen Ausdruck, für die ursprüngliche Naturbedeutung, wen ich so sagen darf, der Buchstaben, der Wurzellaute und Sylben; ein Gefühl, das wir uns jetzt, da das Gepräge der Worte durch langen Gebrauch verwischt, das Ohr durch die verworrne Menge allartiger Eindrücke abgestumpft worden ist, kaum mehr in seiner ganzen Regsamkeit und Lebendigkeit vorstellen können, was aber doch wohl vorhanden gewesen seyn muß, weil ohne dasselbe keine Sprache, wenigsten keine solche, hätte entstehen können. ${ }^{1017}$
\end{abstract}

Diese Sprachen seien nicht ,aus einem bloß physischen Geschrei und allerlei schallnachahmenden oder mit dem Schall spielenden Sprachversuchen entstanden, wo dann allmählig etwas Vernunft und Vernunftform angebildet worden wäre.“1018 Sie seien vielmehr der Beweis, dass ,der Zustand des Menschen nicht überall mit thierischer Dumpfheit angefangen“, sondern dass bei einigen Menschengruppen „,von Anfang die klarste und innigste Besonnenheit statt gefunden“ “1019. Diese ursprüngliche „,innigste Besonnenheit“ und das mittlerweile verlorene Gefühl für die „ursprüngliche Naturbedeutung“ bringt Schlegel in Verbindung mit der von ihm angenommenen, bereits beschriebenen Uroffenbarung. ${ }^{1020}$ Dadurch aber werden die organischen Sprachen und vor allem ihre ältesten Formen nicht nur zu einem Indiz für die postulierte Uroffenbarung, sondern auch zu einer Möglichkeit, sich dieser durch sprachgeschichtliche Forschungen anzunähern. Für die mechanischen Sprachen gelte dies allerdings nicht, da sie nicht diese ursprüngliche Lebendigkeit aufweisen und daher wohl doch eher durch Schallnachahmung entstanden seien. ${ }^{1021}$ Sanskrit, das Schlegel als eine sehr alte, wenig veränderte organische Sprache gilt, kommt somit eine bedeutende Rolle $\mathrm{zu}^{1022}$

\footnotetext{
${ }^{1016}$ Vgl. Schlegel, Friedrich: Über die Sprache und Weisheit der Indier, S. 50f.; Polaschegg beschreibt, dass Schlegel den Sprachstrukturen kulturelle Eigenschaften zuschreibt, wobei oft alte, diesen Kulturen zugeordnete Topoi wieder aufscheinen (vgl. Polaschegg: Der andere Orientalismus, S. 191)

1017 Schlegel, Friedrich: Über die Sprache und Weisheit der Indier, S. 42

1018 Schlegel, Friedrich: Über die Sprache und Weisheit der Indier, S. 62

1019 Schlegel, Friedrich: Über die Sprache und Weisheit der Indier, S. 62

1020 Vgl. Schlegel, Friedrich: Über die Sprache und Weisheit der Indier, S. 105f.

${ }^{1021}$ Vgl. Schlegel, Friedrich: Über die Sprache und Weisheit der Indier, S. 51f., $65 f$.

1022 Vgl. auch Rothermund: The German Intellectual Quest for India, S. 35f.
} 
Die von Schlegel getroffene Unterscheidung zwischen organischen und mechanischen Sprachen wird von anderen Autoren aufgegriffen und diskutiert. Creuzer übernimmt von Schlegel das Konzept der größeren Lebendigkeit der organischen Sprachen und stellt fest, dass „keine mit solchem Rechte eine organische genannt werden können, keine so lebendig seyn, als die Sanscritsprache“"1023. Ansonsten geht er aber nicht weiter darauf ein, da es für ihn keine allzu große Bedeutung zu haben scheint. Anders ist es bei Bopp, Humboldt und August Wilhelm Schlegel. Zwischen ihnen entsteht eine Diskussion darüber, ob die von Friedrich Schlegel getroffene Unterscheidung überhaupt zutrifft und ob Flexion aus Agglutination oder aus der von Schlegel beschriebenen Entfaltung des Wurzellautes entstanden sei. Bopp bezeichnet zwar Sanskrit als eine wahrhaft organische Sprache, versucht dann aber zu zeigen, dass die Flexion z.B. aus Pronomen entstanden sei. Und während August Wilhelm Schlegel eher der Ansicht seines Bruders zustimmt, dass die organische Bildungsart der Sprachen nur in der Urzeit der menschlichen Entwicklung existiert habe und Sanskrit von der gemeinsamen Ursprache am meisten bewahrt habe, stellt sich Humboldt entschieden gegen die These, dass man Sprachen anhand der Kriterien der Flexion bzw. Agglutination in Sprachgruppen einteilen könne, da beide Prinzipien auch bei ein und derselben Sprache zu finden seien und keine Sprache völlig ohne Agglutination auskomme. ${ }^{1024}$ Auch sei es nicht sicher, dass das flektierende System älter sei als das agglutinierende. Er warnt zudem vor „diesem etymologisirenden, rathenden und im Blinden tappenden Unfug“، ${ }^{1025}$ Diese Sorge teilt er mit Heeren, der den großen Missbrauch mit Etymologien kritisiert:

\begin{abstract}
Ohne von dem Sanscrit und dem Zend etwas weiter zu besitzen als ein paar dürftige Wortverzeichnisse, (Wörterbücher kann man sie nicht nennen), haben sie schon die Verwandtschaft der Sprachen ergründet; und ähnliche Laute reichen sofort hin Abstammungen zu beweisen, die man oft geneigt seyn möchte nur für Scherze zu halten! ${ }^{1026}$
\end{abstract}

Dabei hat Heeren aber in erster Linie die Mythologen im Sinn, die die Identität der unterschiedlichen Götter so manches Mal versuchen etymologisch zu beweisen

\footnotetext{
${ }^{1023}$ Creuzer: Symbolik und Mythologie der alten Völker. Erster Theil. Zweite völlig umgearbeitete Ausgabe, S. 548

1024 Vgl. Leitzmann (Hg.): Briefwechsel zwischen Wilhelm von Humboldt und August Wilhelm Schlegel, S. XIII, 32, 64, 72f., 167f. (Einleitung, Brief vom 01. November 1821 von Humboldt, Brief vom 29. Mai 1822 von Schlegel, Brief vom 24. Mai 1824 von Humboldt),; Bopp: Über das Conjugationssystem, S. 7

1025 Briefwechsel zwischen Wilhelm von Humboldt und August Wilhelm Schlegel, S. 113 (Brief vom 30. Dezember 1822)

${ }^{1026}$ Heeren: Ideen über die Politik, S. 394f.
} 
Der Diskurs über Ursprung und Verwandtschaft der Sprachen berührt deutlich Fragen nach der eigenen Identität. Mit dem Sanskrit wird eine Sprache aus einer anderen, weit entfernten Kultur entdeckt, die der eigenen Sprache so sehr ähnelt, dass von einer Verwandtschaft ausgegangen werden muss, die aber andererseits es erlaubt, die Kriterien für die Verwandtschaft von Sprachen genauer festzulegen und so zu der Feststellung beiträgt, dass es verschiedene Sprachfamilien geben muss. Damit rückt Indien als ein zunächst Anderes in den Bereich des Eigenen, indem es als ein Teil der eigenen Vergangenheit identifiziert wird. Das Eigene wird nicht mehr gegenüber dem Indischen abgegrenzt, sondern das Indische dient dazu, das Eigene von anderen, dritten Kulturen abzugrenzen. Da diese Verwandtschaft mit dem Indischen auf den ältesten Wurzeln beruht, entsteht allerdings eine neue Distanz: die der zeitlichen Entfernung. Sanskrit und mit ihm Indien steht für die nicht mehr näher zu definierende Vorzeit und verliert somit die Bedeutung als konkretes, greifbares Gegenüber. Wie wir im nächsten Kapitel sehen werden, braucht es für das Verstehen dieses historisch Anderen nun die Vermittlung von Experten. ${ }^{1027}$

\subsection{Anfänge der Indologie}

Die Diskussionen über Klassifizierung und Verwandtschaft der Sprachen entzünden sich an Fragen, die im Zusammenhang mit dem Sanskritstudium Bedeutung erlangen, gehen dann aber bald darüber hinaus und berühren grundlegendere Themen. Hier zeigt sich deutlich, dass in den 1820er Jahren die Indologie bereits im (sprach-) wissenschaftlichen Diskurs angekommen ist. Das vorherige Kapitel zeigt darüber hinaus deutlich, wie sehr dieses Themenfeld in relativ kurzer Zeit ein wissenschaftlicher Diskurs unter einigen wenigen Experten wird. Während sich zu anderen Aspekten der indischen Kultur Autoren mit unterschiedlichem Hintergrund und unterschiedlichen Interessen äußern, ist die Zahl der Sanskritkundigen relativ klein. Und aus diesem kleinen Kreis von Sprachwissenschaftlern entwickelt sich die neue Disziplin der Indologie.

Das systematische Studium der indischen Sprache und Kultur beginnt in Indien und zwar 1784 mit der Gründung der Asiatic Society of Bengal, die erstmals einen

\footnotetext{
1027 Vgl. auch Polaschegg: Der andere Orientalismus, S. 201f., $278 \mathrm{f}$.
} 
Austausch der Forscher ermöglicht und mit den Asiatic Researches eine Publikationsplattform bietet, die sehr zur Verbreitung der indologischen Kenntnisse in Europa beiträgt. ${ }^{1028}$ Mit dem Aufenthalt des britischen Offiziers Alexander Hamilton in Paris ergibt sich ab 1803 die Möglichkeit, auch außerhalb Indiens Sanskrit zu erlernen. Paris wird „the capital of nascent Indology“1029, wo auch 1815 der erste europäische Lehrstuhl für Indologie entsteht. ${ }^{1030}$ Der erste Deutsche, der diese Gelegenheit ergreift, ist - wie bereits dargestellt - Friedrich Schlegel, der aber nach seiner bekannten Abhandlung „Über die Sprache und Weisheit der Indier“ seine Indienstudien bald wieder einstellt. Anders ist es bei seinem Bruder August Wilhelm Schlegel, der nach seinem Sanskritstudium bei Chézy und Bopp 1818 den ersten Lehrstuhl für Indologie im deutschsprachigen Raum an der neugegründeten Universität in Bonn erhält. Ihm folgt Bopp mit dem zweiten Lehrstuhl 1821 in Berlin. In England entsteht der erste Lehrstuhl der Indologie dagegen erst 1833. Das große Interesse, das die Indienstudien im deutschsprachigen Raum hervorrufen, findet seinen Ausdruck auch darin, dass es hier im Vergleich zu anderen europäischen Ländern sehr schnell eine deutlich größere Anzahl an Indologen und indologischen Lehrstühlen gibt. Dennoch ist die Anzahl der Studenten sowohl in Bonn als auch in Berlin zunächst sehr begrenzt. ${ }^{1031}$

Anders als in England, wo die Erforschung der indischen Sprache und Kultur aus praktischen Erwägungen heraus entstanden und auch später noch eng mit der britischen Herrschaft in Indien verbunden ist und daher das zeitgenössische Indien nicht aus den Augen verliert, ist das Studium in Deutschland auf das klassische Indien ausgerichtet. Dabei wird die alte Schriftkultur der brahmanischen Elite als die ursprüngliche indische Kultur angesehen und andere Aspekte der indischen Kultur sowie neuere Entwicklungen entweder nicht beachtet oder aber als Degeneration abgetan. ${ }^{1032}$ August Wilhelm Schlegel schreibt in einem Brief an Altenstein explizit, dass man sich in

\footnotetext{
1028 Vgl. Sedlar: India, S. 17

${ }^{1029}$ Schwab: The Oriental Renaissance, S. 67

${ }^{1030}$ Vgl. Schwab: The Oriental Renaissance, S. 78

${ }^{1031}$ Vgl. Czapla: Annäherungen an das ferne Fremde, S. 136; Herling: The German Gita, S. 167;

Leifer: Indien, S. 150; Schwab: The Oriental Renaissance, S. 78f.; Goldmann: Indologies, S. 28;

Sengupta, Indra: Shishyas of Another Order. Students of Indology at the Universities of Bonn and

Berlin. In: Douglas T. McGetchin (Hg.): Sanskrit and 'Orientalism'. Indology and Comparative Linguistics in Germany, 1750-1958. Delhi 2004, S: 137-171, hier S. 140-143

1032 Vgl. Goldmann, Robert P.: Indologies. German and Other. In: McGetchin, Douglars (Hg.): Sanskrit and 'Orientalism'. Indology and Comparative Linguistics in Germany, 1750-1958. Delhi 2004, S. 27 40, hier S. 31-34
} 
Deutschland vor allem auf die ältesten Denkmäler konzentrieren würde. ${ }^{1033} \mathrm{Er}$ versucht, die Indologie als eine den klassischen Philologien gleichgestellte Wissenschaft zu etablieren, z.B. indem er fordert, die Prinzipien der klassischen Textkritik auch auf die Herausgabe indischer Originaltexte anzuwenden. Auch seine Übersetzungen in lateinischer Sprache dienen der Anbindung der Indologie an die klassischen Philologien, um sie als Altertumswissenschaft zu legitimieren. Damit aber entscheidet er sich dafür, die indischen Texte in erster Linie einem kleinen Kreis von Wissenschaftlern zugänglich zu machen, kaum jedoch einem weiteren Publikum. ${ }^{1034}$ Außerdem betont er, dass man nicht in allem den Darstellungen und Erklärungen der indischen Gelehrten folgen dürfe, da diese an den indischen Horizont gebunden seien und nicht wie die Europäer in historischer und philologischer Kritik geschult seien. ${ }^{1035}$ Damit aber gesteht Schlegel nur den Europäern die Fähigkeit zu, die indische Kultur nach wissenschaftlichen Maßstäben zu erforschen. ${ }^{1036}$

Der Versuch, die Sanskritstudien über eine Anbindung an die klassische Philologie zu legitimieren, und die damit verbundene Konzentration auf die Sprache und Schriften des indischen Altertums sowie die Beschränkung auf einen kleinen Expertenkreis trifft nicht bei allen Autoren auf Zustimmung. So ist es Humboldts erklärtes Ziel,

\begin{abstract}
dass das Gedicht auch unter denen bekannt werde, die nicht Sanskrit wissen. So trefflich die Schlegel'sche Übersetzung ist, so liest sie niemand, und wer sie liest, lernt doch das Gedicht nicht kennen. Man ermüdet über den Wiederholungen [...]. Dann ist auch das Lateinische gerade die Sprache, in die man so etwas nicht übersetzen darf. ${ }^{1037}$
\end{abstract}

Auch Heeren äußert sich gegenüber dem Vorwurf Schlegels, Heeren habe ohne Sprachkenntnisse, also ohne Experte zu sein, eine eine Einführung in die Sanskritliteratur geschrieben, kritisch:

Warum bekümmern sich die Sanskritisten selber so wenig um die Sachen, und bleiben nur bei der Sprache stehen? [...] Sprachkunde ist noch nicht Altertumskunde; es giebt aber ein großes Publikum, dem weit mehr an der

\footnotetext{
1033 Vgl. Briefe von und an August Wilhelm Schlegel, S. 337 (März 1820 an Altenstsein)

${ }^{1034}$ Vgl. Schlegel: Ramayana, S. 282f., Schlegel: Observations sur la critique du Bhagavad-Gita, S. 293; Marchignoli, Saverio: Canonizing an Indian Text? A.W. Schlegel, W. von Humboldt, Hegel, and the Bhagavadgítá. In: McGetchin, Douglas (Hg.): Sanskrit and 'Orientalism'. Indology and Comparative Linguistics in Germany, 1750-1958. Delhi 2004, S. 245-270, hier S. 251, 254; Poltermann: Den Orient übersetzen, S. 93 1035 Vgl. Schlegel: Observations, S. 293f.

1036 Vgl. auch Marchignoli: Canonizing an Indian Text, S. 253

${ }^{1037}$ Humboldt: Briefe an Welcker, S. 138 (Oktober 1826); vgl. auch Marchignoli: Canonizing an Indian Text, S. 254
} 
Schlegel versucht, den Zugang zu dem wissenschaftlichen indologischen Diskurs nicht nur durch seine Übersetzungen ins Lateinische zu begrenzen, sondern auch durch die Forderung, nur Sanskritkundige hätten die nötigen Voraussetzungen, sich qualifiziert zu äußern. Das ist insofern neu, als an den oben beschriebenen Diskursen über das zeitgenössische Indien und auch über die indische Religion alle teilnehmen können, die die behandelten Themen entweder aus eigener Anschauung oder aufgrund umfangreicher Bildung durch Lektüre kennen.

Auch ein deutscher Missionar, der in Indien tätig ist, kritisiert Schlegels Vorgehen und zwar konkret seine Reduzierung des weiten Feldes der indischen Studien auf das klassische Indien. Er schenke dem zeitgenössischen Indien zu wenig Beachtung. So habe er übersehen, dass das Tamulische eine eigenständige Sprache sei und nicht von dem Sanskrit abgeleitet. Außerdem verstehe der Missionar nicht, warum Schlegel statt der zeitgenössischen Form „Bramine“ das veraltete „Brachmane“ nutze. Man sage ja schließlich auch nicht „romanisch“ statt „römisch“, nur weil es im Lateinischen „,romanus“" heiße. ${ }^{1039}$

Auffallend ist, dass es in dem kleinen Kreis der Autoren, die sich dem wissenschaftlichen Studium der Indologie widmen, zu vielen Auseinandersetzungen kommt, die über reine Meinungsverschiedenheiten von Fachkollegen hinausreichen und schnell persönlich werden. Besonders August Wilhelm Schlegel befindet sich in mancherlei Streit und reagiert empfindlich auf Kritik. ${ }^{1040}$ Goethe und Heine führt das

\footnotetext{
${ }^{1038}$ Heeren, Arnold Hermann Ludwig: Etwas über Studien des alten Indiens. Antwort an Herrn Prof. A.W.v. Schlegel auf dessen an mich gerichtete drei ersten Briefe in seiner Indischen Bibliothek. Göttingen 1827, S. 26

${ }^{1039}$ Aus dem Briefe eines deutschen Missionars im südlichen Indien. In: Indische Bibliothek 2 (1827), S. 162-180, hier S. 165; vgl. auch Jürgens: German Indology, S. 68f., 71

${ }^{1040}$ Schlegel ärgert sich sehr über Anmerkungen von Langlois über seine Ausgabe der Bhagavadgītā, was unter anderem in seinen Kommentaren zu einem Brief Humboldts zu diesem Thema deutlich wird (z.B. „Hr. Langlois hat seindem mit seinen Kritiken fortgefahren, und zwar auf eine Weise, welche mich bewogen hat, seine Befugniß zum Richteramt etwas näher zu prüfen, und für so viele Bereitwilligkeit im Zurechtweisen ihm den Gegendienst einer gründlichen Zurechtweisung zu leisten." (Über die Bhagavad-Gita. Mit Bezug auf die Beurtheilung der Schlegelschen Ausgabe im Pariser Asiatischen Journal. Aus einem Briefe von Herrn Staatsminister von Humboldt. In: Indische Bibliothek 2 (1827), S. 218-258, hier S. 219); auch fragt er Humboldt, ob es ihn störe, wenn er sich ,in der Nachbarschaft Ihres so milden und ruhigen Aufsatzes (...) einigen Spott über Chézy und Langlois“" erlaube (Briefwechsel zwischen Wilhelm von Humboldt und August Wilhelm Schlegel, S. 190
} 
zu der Vermutung, dass Schlegel sich vor allem aus dem Grund mit Indien und Sanskrit beschäftige, dass man in dieser neuen Wissenschaft noch leichter Aufsehen erregen könne und die Konkurrenz noch kleiner sei. ${ }^{1041}$ Der indologische Diskurs hat für die Wissenschaftler im deutschsprachigen Raum also zwar nicht direkt mit (kolonialer) Macht (über die Inder) zu tun, aber er bietet Möglichkeiten sich zu profilieren und Deutungshoheit und somit die Macht über Aussagemöglichkeiten innerhalb des Diskurses zu erlangen. Der wissenschaftliche Diskurs über das alte Indien wird neben der Verknappung der Akteure durch Forderungen nach bestimmten Kenntnissen und Fähigkeiten auch rein praktisch dadurch eingeschränkt, dass gerade in den Anfängen der Indologie der Zugang zu den benötigten Materialien nur eingeschränkt möglich ist. Immer wieder beklagt Schlegel in seinen Briefen und Texten, wie schwer es sei, indische Texte zu erhalten, dass es kaum Hilfsmittel wie Lehrbücher, Wörterbücher und Textzusammenstellungen gebe und auch indische Texte könne man im deutschsprachigen Raum erst drucken, nachdem er selbst den Bau von indischen Typen veranlasst und eine Druckerei eingerichtet habe. ${ }^{1042}$

\section{Indien als lebendes Museum - eine Zwischenbilanz}

Wie wir gesehen haben, wird die Aufmerksamkeit in verschiedenen Diskursen auf Indien gelenkt. Die Autoren widmen sich dieser in ihren verschiedenen Aspekten neu entdeckten Kultur selten lediglich aus Neugierde auf das Andere, sondern sie weisen Indien innerhalb ihres Weltbildes bzw. verschiedener Diskurse eine bestimmte Funktion zu. Diese Diskurse lassen sich entweder dem Spektrum der Aufklärung zuordnen (wie z.B. die Frage nach der Einheit und Entwicklung der Menschheit, nach einer natürlichen Religion, nach der Entstehung und den Folgen von Herrschaft und Ungleichheit, nach der Überwindung von Aberglauben) oder aber sie gehören in den Bereich romantischer Überlegungen (wie z.B. die Suche nach der verlorenen ursprünglichen Weisheit und Einheit allen Wissens und Glaubens). Entsprechend

(Februar 1826 von Schlegel). Auch über Bopps Haltung zur Entstehung der Flexionsendungen aus z.B. Pronomen ist Schlegel sehr enttäuscht, wie z.B. der Briefwechsel zwischen Humboldt und Schlegel zu diesem Thema zeigt, vgl. z.B. Humboldts Einwand, wenn Schlegel weiter so über Bopp schreiben werde, so werde er dem Verdacht der Eifersucht nicht entgehen (Briefwechsel zwischen Wilhelm von Humboldt und August Wilhelm Schlegel, S. 232 (Juni 1829 von Humboldt). Und auch mit Heeren geriet Schlegel heftig aneinander (vgl. z.B. Heerens ausführliche Antwort auf Schlegel; Heeren: Etwas über meine Studien des alten Indiens).

${ }^{1041}$ Vgl. Fröschle, Hartmut: Goethes Verhältnis zur Romantik. Würzburg 2002, S. 181f.; Heine,

Heinrich: Die romantische Schule. Kritische Ausgabe. Herausgegeben von Helga Weidmann. Stuttgart 1997, S. 65

1042 Vgl. Schlegel: Zustand der Indologie, S. 7; Briefe von und an August Wilhelm Schlegel, S. 373-

377 (an Altenstein März 1820) 
unterschiedlich sind die Gewichtungen der Themen und ihre Interpretation und Bewertung. Tendenziell neigen dabei die romantischen Autoren eher dazu, Indien zu idealisieren, während sich bei den Reisenden und Missionaren eher kritischere Positionen finden. Verallgemeinern kann man diese Tendenz aber nicht. Denn diese Verteilung ergibt sich vor allem auch daraus, dass die romantischen Autoren sich vor allem für die klassische Kultur des alten Indiens interessieren, die aber auch von vielen anderen Autoren gelobt wird. Die eher der Aufklärung oder auch Mission verpflichteten Autoren setzten sich dagegen viel mehr mit der zeitgenössischen indischen Kultur auseinander, die auch von romantischen Autoren - sofern sie sie überhaupt beachten durchaus kritisch gesehen wird. Ein wesentlicher Unterschied liegt in der Deutung des von den meisten nicht in Frage gestellten Unterschieds zwischen altem und zeitgenössischem Indien. Während die Romantiker von einem Verfall einer ehemals hochstehenden Kultur, deren ursprüngliche Weisheit auch den modernen europäischen Kulturen verloren sei, ausgehen, sehen die anderen Autoren zwar das alte Indien als für seine Zeit durchaus hochstehend an, aber es habe seitdem - anders als Europa - keinerlei Entwicklung durchlebt. Osterhammel spricht von einem „Degenerationsdiskurs“ und einem „Stagnationsdiskurs“. ${ }^{1043}$ In beiden Fällen wird Indien als eine Kultur beschrieben, die nicht auf der gleichen (zeitlichen) Entwicklungsstufe steht wie die eigene europäischen Kultur der Beobachter. Für die einen hat Indien diese Entwicklung nicht durchlaufen, für die anderen ist die zeitgenössische indische Kultur nur insofern von Bedeutung, als sich in ihr vielleicht Spuren der eigentlich bedeutsamen alten Kultur finden lassen, auf die allein sich die Aufmerksamkeit richtet. Indien wird so, wie in der Einleitung bereits angedeutet, zu einem lebenden Museum, in dem die eigene Frühzeit entweder als überwundene Zeit des Aberglaubens oder aber eine verlorene goldene Zeit beobachtet werden kann. Einen Punkt, der in diesem Zusammenhang wichtig ist, führt Ludwig Amman an. Er betont den großen Einfluss, den der im Verhältnis ungeheuer schnelle Wandel der europäischen Kulturen zu Beginn der Moderne gehabt habe. Vieles, was die Europäer an den Indern und ihrer Kultur kritisierten, sei so ähnlich vor nicht allzu langer Zeit auch in Europa selbstverständlich gewesen (z.B. Ständewesen, Vormacht der Kirche, Berufung auf Autoritäten statt eigener Forschung). Eingefordert würden also relativ neue Errungenschaften der Moderne; und dass sie so vehement eingefordert würden, liege möglicherweise unter anderem auch daran, dass sie auch in Europa noch nicht überall und in allen Gesellschaftsschichten in dem Maße verbreitet

1043 Osterhammel: Die Entzauberung Asiens, S. 389f. 
seien, wie es von einigen Autoren gewünscht werde. Dieser Wandel werde allerdings nicht immer vorbehaltlos befürwortet, sondern bedeute auch den Verlust der alten, gewohnten Ordnung. Darin liege auch ein Motiv für die Sehnsucht nach der Natürlichkeit und Einfachheit Indiens. Amman betont, dass sich die neue, moderne Lebensweise der Europäer sehr von der anderer Kulturen unterscheide und dass daher europäische Reisende in traditionelleren Gesellschaften, die sich nicht so schnell veränderten, schnell den Eindruck gewinnen könnten, dass überhaupt kein Wandel stattfinde. Der Fortschrittsglaube und Drang zur Vervollkommnung vieler Europäer führe dazu, dass europäische Reisende sich z.B. die Unterwerfung der Inder unter das Schicksal häufig nicht anders erklären könnten, als dass sie zu träge oder gleichgültig seien, um etwas zu verändern. ${ }^{1044}$

Bei der Beurteilung einiger Aspekte der indischen Kultur lässt sich die Tendenz erkennen, dass ab den 1820er Jahren die Zahl der negativen Urteile ansteigt. ${ }^{1045}$ Dies kann zum einen mit der Ablösung des noch frühromantisch geprägten Ringens um das Absolute und der damit verbundenen Suche von Spuren alten Wissens durch die Zuwendung zum Mittelalter und zum Christentum sowie zum anderen mit den beschriebenen Reform- und Missionsbestrebungen in England erklärt werden. Aber auch diese Tendenz kann keinesfalls verallgemeinert werden. Durch die Institutionalisierung der Indologie als Wissenschaft erfährt die Indienkunde - ebenfalls beginnend in dieser Zeit - in gewissem Sinne eine Spaltung: Konnten zuvor fast alle Aspekte der indischen Kultur von allen, die durch eigene Anschauung oder aufgrund angelesenen Wissens ausreichend Kenntnisse hatte, behandelt werden, so spalten sich nun die wissenschaftlichen Indologen von den übrigen Autoren auf zweierlei Weise ab: Zum einen gewähren sie nur noch ausgewiesenen Sprachkundigen Zugang zu dem wissenschaftlichen indologischen Diskurs und zum zweiten beschränken sie diesen Diskurs zumindest im deutschsprachigen Raum auf die alte indische Schriftkultur.

Obwohl viele Themen umstritten sind und von verschiedenen Autoren sehr unterschiedlich gedeutet werden, lassen sich dennoch einige Merkmale und Begriffsfelder ausmachen, die Indien in fast allen Aspekten und von fast allen Autoren zugeschrieben werden (wenn auch manchmal in unterschiedlicher Deutung). Diese

\footnotetext{
1044 Vgl. Ammann: Östliche Spiegel, S. 28f.

1045 Ähnliches beobachtet Greilich auch für das Bild des Orientalen in den Volksalmanachen (vgl. Greilich: Orientbilder, S. 77)
} 
Merkmale sind: das hohe Alter, die Ursprünglichkeit, die Naturverbundenheit und natürliche Weisheit, die kindliche Naivität, eine gewisse Ruhe bzw. Trägheit, die fehlende Entwicklung, der Verfall der alten Sitten, Reichtum und Üppigkeit, das Monströse bzw. Unförmige, das Geheimnisvolle, das Abergläubische und Irrationale sowie das Strenge und Grausame. Die indische Kultur gilt als sehr alt, Sanskrit weise sehr alte Strukturen auf und gilt als der Ursprache sehr nahestehend, die Literatur sei unvorstellbar hohen Alters, die Wissenschaft in einigen Gebieten schon sehr früh sehr hoch entwickelt, die indische Gesellschaftsordnung müsse sehr alt sein, ebenso auch die indischen Mythen. Indien wird z.T. als Wiege der Menschheit angesehen, die Inder und auch Teile ihrer Literatur werden als kindlich-naiv beschrieben, da sie ja der Kindheit der Menschheit entstammten und sich nicht weiterentwickelt hätten. Sie seien naturverbunden, ihre Literatur zeige eine Blumensprache und ihre Religion bestehe im Kern aus einer natürlichen Offenbarung bzw. alten Weisheit. Ihre Sitten und Moral seien aufgrund eines natürlichen Gespürs gut. Die Inder selbst seien aber leichtgläubig, ihre Religion voll Aberglaube, ihre Ablehnung des Christentums und der neueren Wissenschaften irrational. Die Natur (sowohl Pflanzen und Tiere als auch die Berge und Bodenschätze) seien reich und üppig, aber auch die Götterbilder und -erzählungen seien üppig und ausgeschmückt. Dadurch seien sie in gewisser Weise monströs, ihre Bauwerke durch üppige, aber ungeordnete Verzierungen unförmig. Auch die Literatursprache zeichne sich durch üppige Redewendungen aus und die religiösen Riten seien prunkvoll. Sowohl die alten Mythen als auch Sanskrit gelten lange als geheimnisvoll. Und viele Riten gelten als grausam. Diese Aufzählung lässt sich sicher noch fortsetzen. Es werden zwar nicht immer die hier aufgeführten Begriffe genutzt, aber inhaltlich spielen diese Vorstellungen immer wieder eine wichtige Rolle. Neben dem Klima sind es diese Merkmale, auf die sich die verschiedenen Autoren in ihren Argumentationen berufen, weshalb ich sie in der Einleitung als Stützungsbegriffe bezeichnet habe. Immer wieder werden Besonderheiten der indischen Kultur auf das Festhalten an alten Traditionen, auf eine naive Kindlichkeit, auf die Weichheit und Trägheit, auf die üppige Natur usw. zurückgeführt. Die so entstehenden Argumentationsmuster hängen eng miteinander zusammen und bilden ein diskursives Netz, in dem die einzelnen Aspekte je nach Zusammenhang mal als These, mal als Argument fungieren können. Dabei werden die positiv besetzten Attribute des hohen Alters, der Ursprünglichkeit, Natürlichkeit und Weisheit vor allem dem alten Indien zugeschrieben. Die negativ besetzten wie Irrationalität, Verfall, fehlende Entwicklung dienen dagegen überwiegend der Charakterisierung des zeitgenössischen Indiens. Als 
Assoziativbegriffe, also Begriffe, die mit ihrer bloßen Nennung beim Leser bestimmte Teile verschiedener Indienbilder und der damit zusammenhängenden Diskurse assoziieren können, fungieren als typisch indisch geltende Begriffe wie Brahmane oder Paria. Diese werden, wie wir gesehen haben, auch außerhalb des indischen Diskurses in einem übertragenen Sinne verwendet.

Wie wir bereits gesehen haben, werden viele dieser Attribute bereits seit der Antike Indien zugeschrieben. So wurde schon im alten Griechenland darüber spekuliert, ob die Menschheit in Indien entstanden sei. Auch Weisheit, Reichtum, Monströses und Grausames wurden in Antike und Mittelalter mit Indien verbunden. Im Mittelalter findet sich auch die Vorstellungen einer natürlichen Tugend und intuitiven Weisheit (im Gegensatz zu der auf christlichen Werten und Schriften beruhenden Tugend und Weisheit). Diese Charakterisierungen werden später in unterschiedlichen Kontexten wieder aufgegriffen und zum Teil umgedeutet. So werden die Vorstellungen von der Ursprünglichkeit und dem hohen Alter der indischen Kultur sowohl in der Aufklärung als auch in der Romantik erneut von Bedeutung. In der Aufklärung spielen sie eine wichtige Rolle zum einen in dem deistischen Versuch zu beweisen, dass alle Religionen von einer ursprünglichen natürlichen Religion abstammen, und zum anderen in der Suche nach dem Ursprung und der Genese der Menschheit und der menschlichen Sprache. In der Romantik geht es dagegen vor allem darum, in der alten indischen Kultur Reste einer verlorenen goldenen Zeit zu finden. In diesem Zusammenhang werden auch die bereits im Mittelalter betonte Natürlichkeit der indischen Kultur sowie die kindliche Naivität, die schon von den Humanisten den Brahmanen zugeschrieben wurde, wichtig, da sie als Zeichen der Nähe zu den goldenen Anfängen der Menschheit gedeutet werden können. Auch die Aspekte des Geheimnisvollen und Paradiesischen werden in der Romantik wieder aufgegriffen und in den eigenen Kontext eingepasst.

Während viele der Attribute also schon sehr früh mit Indien verbunden sind, entstehen andere erst im Kontext der Aufklärung. So wird das Fehlen von kultureller Entwicklung zwar bereits bei den Humanisten angedeutet, seine volle Bedeutung erlangt das Konzept aber erst im Fortschrittsdenken der Aufklärung. Auch die Vorstellung vom Verfall der alten indischen Kultur spielt erst in der Neuzeit eine Rolle, und zwar zunächst im Kontext des Deismus als Abfall des Hinduismus von der ursprünglichen natürlichen Religion und später im Zusammenhang mit der romantischen Vorstellung eines verlorenen goldenen Zeitalters. Auch die Betonung von Aberglauben und 
Irrationalität ist Teil der Aufklärung. Zwar galten die Inder bereits im Mittelalter und in der beginnenden Neuzeit als Heiden (im Gegensatz zu den Christen), aber in der Aufklärung wird diese Dichotomie verschoben hin zu dem Gegensatz von Aberglaube und Irrationalität der Inder versus rationalem Denken der Aufklärung. Zudem wird Aberglaube im Diskurs der Aufklärung über Ungleichheit als Mittel der Unterdrückung gebrandmarkt. Auch die Attribute der Ruhe und Duldsamkeit der Inder erhalten in diesem Kontext eine neue negative Bewertung, da in ihnen ebenfalls eine Ursache der Unterdrückung gesehen wird.

Interessant ist es, wenn diese festen Stereotypen, die in den Vorstellungen vieler Autoren und Leser fest mit Indien verbunden sind, auf konkrete Erlebnisse in Indien stoßen. Das lässt sich bei einigen Darstellungen von Reisenden, im deutschsprachigen Raum z.B. der Soldaten feststellen. Diese stehen dann vor der Schwierigkeit, die Widersprüche zwischen den erlernten Erwartungen und den Wahrnehmungen vor Ort für sich zu lösen (z.B. die oben erwähnte Feststellung von Scharnhorst, dass die „faulen“ Inder hart arbeiten oder die von Best als Tempeldienerinnen beschriebenen Bajaderen, die - wie man sagt - Freudenmädchen sein sollen). ${ }^{1046}$ 


\section{Indien in der deutschen Literatur}

Nicht nur in Sachtexten wie Reiseberichten und wissenschaftlichen Abhandlungen ist Indien um 1800 ein beliebtes Thema. Auch in der schönen Literatur, vor allem in Schauspielen und Opern sowie in Gedichten, dient Indien als exotische Kulisse, ermöglicht Kritik oder wird als Sehnsuchtsort verklärt. Auch hier werden also spezifische Indienbilder entworfen, die im Folgenden anhand einer Auswahl von Schauspielen, Opern, Gedichten, Romanen und Erzählungen untersucht werden sollen. ${ }^{1047}$ Dabei möchte ich zunächst häufig wiederkehrende Handlungsschemata und

\footnotetext{
${ }^{1047}$ Untersucht wurden: Beer, Michael: Der Paria. Trauerspiel in einem Aufzuge. Stuttgart und Tübingen 1829; Bernardin de Saint-Pierre, J. H.: Die indische Hütte. In: Paul und Virginie und die Indische Hütte. Von J. H. Bernardin de Saint-Pierre. Neue Übertragung durch G. Fink. Pforzheim 1840, S. 311-412; Brentano, Clemens: Einer Jungfrau bei dem Geschenk der Sakontala. In: Brentano, Clemens: Gesammelte Gedichte. Berlin 2017, S. 345f.; Bremer, Johann Gottlieb: Tippo-Saib und Laura oder Strafe und Rettung in den Folgen des jugendlichen Leichtsinns zweyer Militairpersonen. Eine authentische Geschichte. Berlin 1791; Gehe: Eduard Heinrich: Jessonda. Große Oper in 3 Aufzügen. München 1836; Goethe, Johann Wolfgang von: Howards Ehrengedächtnis. In: Goethe, Johann Wolfgang: Gedichte 1800-1832. Herausgegeben von Karl Eibl. Frankfurt a. M. 1988 (Sämtliche Werke. Briefe, Tagebücher und Gespräche. Herausgegeben von Hendrik Birus u.a. I. Abteilung: Sämtliche Werke; 2), S. 503f; Goethe, Johann Wolfgang von: Der Gott und die Bajadere. Indische Legende. In: Goethe, Johann Wolfgang: Gedichte 1800-1832. Herausgegeben von Karl Eibl. Frankfurt a. M. 1988 (Sämtliche Werke. Briefe, Tagebücher und Gespräche. Herausgegeben von Hendrik Birus u.a. I. Abteilung: Sämtliche Werke; 2), S. 150-153; Goethe, Johann Wolfgang von: Zahme Xenien II. In: Goethe, Johann Wolfgang: Gedichte 1800-1832. Herausgegeben von Karl Eibl. Frankfurt a. M. 1988 (Sämtliche Werke. Briefe, Tagebücher und Gespräche. Herausgegeben von Hendrik Birus u.a. I. Abteilung: Sämtliche Werke; 2), S. 630-640; Goethe, Johann Wolfgang: Paria. In: Goethe, Johann Wolfgang: Gedichte 1800-1832. Herausgegeben von Karl Eibl. Frankfurt a. M. 1988 (Sämtliche Werke. Briefe, Tagebücher und Gespräche. Herausgegeben von Hendrik Birus u.a. I. Abteilung: Sämtliche Werke; 2), S.450-456; Günderrode, Karoline von: Der Adept. In: Günderrode, Karoline von: Sämtliche Werke. Frankfurt a.M. und Basel 2006, S. 49-51; Günderrode, Karoline von: Die Malabarischen Witwen. In: Günderrode: Sämtliche Werke, S. 325; Günderrode, Karoline von: Briefe zweier Freunde. In: Günderrode: Sämtliche Werke, S. 350-362; Günderrode, Karoline von: Geschichte eines Braminen. In: Günderrode: Sämtliche Werke, S. 303-314; Günderrode, Karoline von: Udohla in zwei Acten. In: Günderode: Sämtliche Werke, S. 203-231; Heine, Heinrich: Den König Wiswamitra. In: Heine, Heinrich: Buch der Lieder. Bearbeitet von Pierre Grappin. Hamburg 1975 (Historischkritische Gesamtausgabe der Werke. Herausgegeben von Manfred Windfuhr. Band I/1), S. 258; Hensler, Karl Friedrich: Das Schlangenfest in Sangora. Eine heroisch komische Oper in zwey Aufzügen. Wien 1797; Hensler, Karl Friedrich: Das Sonnenfest der Braminen. Ein heroisch komisches Original-Singspiel in zwey Aufzügen. In: Sammlung einiger Singspiele, aufgeführt auf der k. k. privil. Marinellischen Schaubühne in der Leopoldstadt. Wien 1790; Herder, Johann Gottfried: Indien. In: Johann Gottfried von Herder's sämmtliche Werke. Zur schönen Literatur und Kunst. Sechszehnter Theil. Stuttgart und Tübingen 1817, S. 51.; Herklots: Die Bajaderen. Heroische Oper in drey Akten mit Ballet. München 1817; Heyden, Friedrich von: Magandola. In: Heyden, Friedrich von: Dramatische Novellen. Erster Theil. Königsberg 1819, S. 181-262; Jean Paul: Hesperus. In: Jean Paul: Sämtliche Werke. Abteilung I. Erster Band. Darmstadt 2000, S. 471-1236; Kanne, Friedrich August: Padmana. Trauerspiel in fünf Aufzügen. Wien 1818; Kotzebue, August von: Die Indianer in England. Frankfurt und Leipzig 1790; Lewald, August: Der Paria. Tragödie in fünf Acten nach C. Delavigne frei für die deutsche Bühnen bearbeitet. Nürnberg 1825; Mereau, Sophie: Serafine. Ein Gedicht in sechs Gesängen. Berlin 1802 (Gedichte von Sophie Mereau. Zweites Bändchen); Plümicke, Carl M.: Lanassa. Nach der Veuve du Malabar des le Mierre. Berlin 1782; Sondershausen, Karl: Der Hindu. In: Dramatische Gedichte. Zweites Bändchen. Altenburg 1823, S. 55-140; Tarnow, Fanny: Die Prophetin von Caschimir oder Glaubenskraft und Liebesglut. Nach Lady Morgan. Erster Theil. Leipzig 1826; Tarnow, Fanny: Die Prophetin von Caschimir oder Glaubenskraft und Liebesglut. Nach Lady Morgan. Erster Theil. Leipzig 1826; Vulpius, Christian August: Die Portugiesen in Indien. Ein historisch-
} 
Motive untersuchen und anschließend Figurentypen aufzeigen, die charakteristisch für auftretende Inder sind. Abschließend soll herausgearbeitet werden, auf welche Art und Weise Indien in den literarischen Texten als solches markiert und wie es dargestellt wird. Dabei möchte ich vor allem der Frage nachgehen, inwieweit sich die hier aufgegriffenen Themen, Beurteilungen und Stereotype von denen der Sachtexte unterscheiden bzw. ihnen ähneln. Da bei den literarischen Texten die Funktion, die Indien innerhalb eines Textes einnimmt, und damit auch eine Deutung des Indienbildes viel enger mit der Gesamtaussage des entsprechenden Textes zusammenhängt als bei den Sachtexten und sich daher auch weniger leicht einzelne Textausschnitte aus dem Gesamtzusammenhang herauslösen und analysieren lassen, werde ich mich bei der folgenden Untersuchung darauf beschränken, allgemeine Themen und Tendenzen herauszuarbeiten. Für weiterführende Deutungen wären genauere Interpretationen der Einzeltexte nötig, was im Rahmen dieser Arbeit zu weit führen würde.

\section{Handlungsmotive}

Obwohl die inhaltlichen Unterschiede zwischen verschiedenen literarischen Texten, die in irgendeiner Weise das Thema Indien aufgreifen, durchaus beträchtlich sein können, so lassen sich interessanterweise die meisten Geschehnisse, die berichtet werden, einer relativ kleinen Anzahl von Handlungsmotiven zuordnen. Diese Motive können handlungsbestimmend sein, können aber auch lediglich in einer Nebenhandlung eine Rolle spielen. Außerdem finden sich oft mehrere Motive in einem Text. Die unterschiedlichen Motive sollen im Folgenden kurz dargestellt werden, um einen Einblick in die Szenarien zu geben, die mit Indien verknüpft werden. Ausführlichere Analysen der Personen, der Darstellung Indiens sowie der aufgegriffenen Themen erfolgen in den entsprechenden Kapiteln.

\subsection{Rettung einer Witwe/eines Menschenopfers}

Eines der markantesten und häufigsten Motive, das sich vor allem in Schauspielen und Opern findet, ist das der Rettung eines Menschenopfers bzw. einer Witwe. De Zoysa, der die Darstellung Indiens in literarischen Texten ausführlich untersucht und auch viele der heute eher unbekannten Texte dokumentiert und den Inhalt kurz referiert, spricht in diesem Zusammenhang von Opfer- bzw. Witwenstücken. ${ }^{1048}$ Die Opfer sind 
gewöhnlich junge Frauen, die von europäischen Heeresführern gerettet werden. Die Witwenstücke stellen dabei eine Unterform der Opferstücke dar, die aufgrund der als typisch indisch geltenden Tradition der Witwenverbrennung an den indischen Kontext gebunden sind. Das Motiv des (religiös motivierten) Menschenopfers findet sich dagegen auch in Texten, die in Südamerika angesiedelt sind. ${ }^{1049}$ Ein Grund für die Häufung dieses Motivs gerade in den Schauspielen und Opern liegt sicherlich in seiner fesselnden und zugleich wenig komplexen Dramatik, die in erster Linie der Unterhaltung der Zuschauer dienen und eine leichte Identifikation mit den Hauptpersonen ermöglichen soll.

Das Motiv des Menschenopfers kommt in den hier untersuchten Texten in den beiden Stücken von Hensler ${ }^{1050}$, „Das Sonnenfest der Braminen“ und „Das Schlangenfest in Sagora“, sowie in Zumbachs „Die Pullichi auf Malabar“ vor. In allen drei Stücken aus den 1790er Jahren werden schiffbrüchige Europäer von einem Inder und seinen Kindern gerettet und geraten in Konflikte mit anderen Indern. ${ }^{1051}$ Während sowohl beim „Sonnenfest“ als auch bei den „Pullichi“ eine bzw. mehrere Töchter des Inders vom Opfertod bedroht sind und durch den Eingriff der Europäer gerettet werden, sind es beim „Schlangenfest“ zunächst die Schiffbrüchigen selbst, die geopfert werden sollen und von anderen Europäern gerettet werden müssen. In einer zweiten Handlung wird dann wiederum die Tochter des Inders, der die Schiffbrüchigen bei sich aufgenommen hatte, vor die Wahl gestellt, entweder den Samorin zu heiraten oder geopfert zu werden. Und auch ihr eilen die Europäer zur Hilfe, auch wenn es letztlich der Samorin selbst ist, der Güte walten lässt. Kontext und Grund des geforderten Menschenopfers unterscheiden sich jeweils. Einmal steht ein Sonnenfest an, bei dem traditionell ein Mädchen geopfert wird, einmal geht es um einen Brauch, bei der Hochzeit der Tochter des Souba zwei Pullichi-Mädchen zu opfern und einmal fordert

\footnotetext{
${ }^{1049}$ Vgl. De Zoysa: "Blutrünstige Braminen am heiligen Strome“, S. 82f.

${ }^{1050}$ Karl Friedrich Hensler (1759-1825) hatte eigentlich Theologie studiert. Nachdem 1784 ein von ihm geschriebenes aufklärerisches Stück aufgeführte worden war, wandte er sich jedoch dem Theater zu und wurde 1786 Hausdichter am Leopoldstädter Theater. Nachdem er mit dem 1790 uraufgeführten Singspiel „Das Sonnenfest der Braminen“ großen Erfolg hatte, versuchte er 1796 mit „Das Schlangenfest von Sangora“" erneut mit einem indischen Stoff, das Publikum zu begeistern. Er konnte allerdings nicht an den vorherigen Erfolg anknüpfen. Beide Stücken sind von humanitären Idealen der Aufklärung und des Freimaurertums beeinfluss (Hensler war seit 1785 Mitglied der Wiener Loge „Zur neugekrönten Hoffnung) (vgl. Pausch, Oskar, "Hensler, Karl Friedrich" in: Neue Deutsche Biographie 8 (1969), S. 564-565 [Online-Version]; URL: https://www.deutschebiographie.de/pnd1 19267659.html\#ndbcontent; Schmitt: Der Exotismus in der deutschen Oper zwischen Mozart und Spohr, S. 216-222).

${ }^{1051}$ Das Motiv der schiffbrüchigen Europäer ist dem Publikum um 1800 bereits aus einigen Türkenopern vertraut (vgl. De Zoysa: "Blutrünstige Braminen am heiligen Strome“, S. 79f.)
} 
ein Kult des „Jaka“ die Opfer. Die Rollenverteilung der auftretenden Personen ist aber sehr ähnlich. Auf der einen Seite befinden sich die Europäer, die dem Aberglauben der Inder Vernunft und christliche Milde entgegensetzen, sowie die indische Familie, die die Schiffbrüchigen gerettet hat und die in zwei Fällen als Pullichi bzw. Vertriebene außerhalb der indischen Gesellschaft steht und ebenfalls aus Mitgefühl und Nächstenliebe heraus handelt. Auf der anderen Seite sind vor allem die Opferpriester sowie Angehörige des indischen Fürstenhofs, die nicht nur aus religiösen Gründen, sondern auch aus machtpolitischen Erwägungen oder persönlichem Verlangen heraus die Opferhandlung mit aller Macht durchsetzen wollen. Obwohl die allermeisten Sachtexte das Vorkommen von Menschenopfern in Indien ausschließen und nur die Bedeutung von Selbstopferungen hervorheben, setzen die Autoren der genannten Stücke Indien vor allem aus dem Grund als Handlungsort ein, um durch die drohende Opferung eine Gefahrensituation zu schaffen, die nicht nur den Anstoß zu Handlung gibt, sondern auch eine klare Verteilung von gut und böse erlaubt. Indien wird in diesen Stücken als fremdes, exotisches Land inszeniert. Dabei werden Aspekte wie z.B. die Sprache, die ein Verständnis eigentlich erschweren sollten, völlig außer Acht gelassen. Das Fremde Indiens liegt allein in den religiösen Bräuchen, die die Europäer - dem Diskurs der Aufklärung folgend - als grausam und einer alten und unentwickelten Zeitstufe angehörig empfinden. Hier stehen also vor allem die bereits seit der Antike bekannten Attribute des Monströsen (hier bezogen auf die Götter) und des Grausamen sowie die in der Aufklärung an Bedeutung gewinnenden Attribute Aberglauben, Irrationalität und fehlende Entwicklung im Mittelpunkt.

Eine Sonderform der Opferstücke sind die Witwenstücke, die sich - ebenso wie die Berichte über Witwenverbrennungen in den Sachtexten - großer Beliebtheit erfreuen. ${ }^{1052} \mathrm{Im}$ Mittelpunkt dieser Stücke steht eine noch junge Witwe, die - ebenfalls auf Drängen der Priester - ihrem Mann auf den Scheiterhaufen folgen soll. In den beiden

\footnotetext{
${ }^{1052}$ Es gibt viele Bearbeitungen des Stoffes und einzelne Stücke werden lange Zeit in den Schauspielhäusern gespielt (vgl. De Zoysa: "Blutrünstige Braminen am heiligen Strome“, S. 246, 100).
} 
Stücken „Lanassa““1053 und „Jessonda“"1054, die beide auf dem Stoff von Lemierres „La Veuve du Malabar“ beruhen, steht die Rettung vor der Verbrennung im Mittelpunkt der gesamten Handlung. Sie erfolgt mit Hilfe eines abtrünnigen Brahmanen und eines europäischen Heerführers samt seinen Soldaten. Dabei werden dem hinterhältigen und grausamen Handeln der Brahmanen die Tugendhaftigkeit und Selbstlosigkeit der Europäer entgegengesetzt: Während sich der europäische Heerführer allein aus Mitgefühl zum Eingreifen entschließt, sich dann aber trotz der Dringlichkeit und seiner aufkeimenden Liebe zur Witwe an ein einmal gegebenes Wort gebunden fühlt und so erst nach Ablauf eines verabredeten Waffenstillstands zur Tat schreiten kann, agieren die Brahmanen listig und hinterhältig und fühlen sich selbst nicht an Regeln gebunden, deren Einhaltung sie von anderen einfordern.

In dem Schauspiel „Der Paria“ von Beer ${ }^{1055}$ ist die Witwenverbrennung Teil der Vorgeschichte: Der Paria hatte seine jetzige Frau, eine Brahmanentochter, vor dem Flammentod gerettet, ein Motiv, das sich in dieser Form bereits in „Die indische Hütte“ findet. Der Paria löst damit die Handlung des Stücks aus, da ihr Bruder diese Schmach nun Jahre später rächen will. Es steht also weniger die Rettung selbst im Mittelpunkt, als vielmehr die Folgen, die aus dieser Rettung resultieren. Ähnliches gilt auch für „Marie von Montalban““1056, wo der vermeintlich tote Ehemann der geretteten Witwe

\footnotetext{
${ }^{1053}$ Das Trauerspiel „Lanassa“ ist eine Adaption aus dem Jahre 1782 von Carl Martin Plümicke (17491833). Plümicke war Dramaturg bei der Schauspieltruppe des Prinzipals Carl Theophil Doebbelin. Er schrieb keine auf eigenen Konzepten beruhende Theaterstücke, sondern adaptierte zeitgenössische Erzählstoffe oder bearbeitete aktuelle Stücke anderer Autoren (vgl. Meier, Albert, "Plümike, Carl Martin" in: Neue Deutsche Biographie 20 (2001), S. 551 f. [Online-Version]; URL: https://www.deutsche-biographie.de/pnd116246871.html\#ndbcontent).

1054 „Jessonda“ ist eine Oper des den Freimaurern nahestehenden Violinisten und Komponisten Louis Spohr (1784-1859), die 1824 in Leipzig mit großem Erfolg uraufgeführt wurde. Das Libretto stammt von dem Juristen und Dichter Eduard Heinrich Gehe (1793-1850). „Jessonda“ fand Eingang in das Repertoire der meisten deutschen Opernhäuser und wurde bis zum ersten Weltkrieg immer wieder aufgeführt (vgl. Brown, Clive: Louis Spohr. A critical biography. Cambridge 1984, S. 157-163; Wulfhorst, Martin, "Spohr, Louis" in: Neue Deutsche Biographie 24 (2010), S. 733-735 [OnlineVersion]; URL: https://www.deutsche-biographie.de/pnd118616366.html\#ndbcontent; Schnorr von Carolsfeld, Franz, "Gehe, Eduard Heinrich" in: Allgemeine Deutsche Biographie 8 (1878), S. 497 [Online-Version]; URL: https://www.deutsche-biographie.de/pnd102522359.html\#adbcontent). ${ }^{1055}$ Michael Beer (1800-1833) wuchs in einem Elternhaus auf, in dem er schon früh Kontakt zu Künstlern und Schauspielern hatte. Er studierte Philosophie und Geschichte. In seinem Trauerspiel „Der Paria“ setzte er sich für die Gleichberechtigung der Juden ein. Für ein weiteres, auch von Goethe geschätztesTrauerspiel, ,Struensee“ erhielt er die Förderung des bayerischen Königs Ludwig I. (vgl. Maiworm, Heinrich, "Beer, Michael" in: Neue Deutsche Biographie 1 (1953), S. 737 [Online-Version]; URL: https://www.deutsche-biographie.de/pnd118657887.html\#ndbcontent).

1056 „Marie von Montalban“ ist eine Oper von Peter von Winter (1754-1825), die 1800 uraufgeführt wurde und neben „Das unterbrochene Opferfest“ zu seinen besten Werken zählt. Das Libretto stammt von Karl Reger, der Johann Nepomuk Komarecks Fortsetzung von „Lanassa“, „Marie von Montalban oder Lanassas zweiter Teil“" von 1792 adaptierte (vgl. Dietz, Max, "Winter, Peter Ritter von" in:
} 
Rache fordert, weil seine Frau sich nicht für ihn verbrannt, sondern einen Europäer geheiratet hat. In „Die Portugiesen in Indien“ von Vulpius ${ }^{1057}$ wird in einer Nebenhandlung eine Witwe durch Europäer gerettet, aber anders als die Witwen in den bereits angesprochenen Texten kann sich diese Witwe nicht auf ihr neues Leben einlassen. Sie bekommt Gewissensbisse, dass sie nicht der Tradition gefolgt ist, und ersticht sich. Neben den auch in „Der Paria“ und in „Marie von Montalban“ thematisierten Anfeindungen durch die Gesellschaft, setzt sich Vulpius in dieser kurzen Episode auch mit dem inneren Druck auseinander, der auf den geretteten Frauen lasten kann. Er zeigt, dass das (gut gemeinte) Eingreifen der Europäer nicht immer auch für die Betroffenen gut sein muss.

\subsection{Witwenverbrennung als Liebesbeweis}

Während die oben beschriebenen Witwenstücke die Tradition der Witwenverbrennung ähnlich negativ darstellen wie die meisten Sachtexte, gibt es auch eine andere Gruppe von literarischen Texten, in denen die Witwenverbrennung im Gegensatz dazu als höchster Beweis von Liebe und Treue interpretiert und entsprechend weniger abgewertet, zum Teil sogar idealisiert wird. Der bekannteste dieser Texte ist vermutlich Goethes „Der Gott und die Bajadere“, in dem eine Bajadere durch den Gott Mahadöh geprüft wird. Durch den Versuch, sich zusammen mit dem toten Geliebten zu verbrennen, stellt sie ihre Liebe und Treue unter Beweis und wird daraufhin von dem

\footnotetext{
Allgemeine Deutsche Biographie 43 (1898), S. 470-474 [Online-Version]; URL: https://www.deutsche-biographie.de/pnd119055716.html\#adbcontent; Brown: Louis Spohr, S. 157). ${ }^{1057}$ Christian August Vulpius (1762-1827) war der Bruder von Goethes Frau Christiane. Er studierte in Jena und Erlangen Rechtswissenschaften, interessierte sich daneben aber auch für Geschichte. Da er sich selbst und einige Geschwister schon früh mit eigenen literarischen Werken finanziell über Wasser halten musste, orientierte er sich in seinen Texten an den Vorlieben des Publikums und schrieb z.B. Ritter- und Abenteuerromane. Daneben verfasste er auch Opern sowie Trauer- und Lustspiele. Auf Vermittlung von Goethe kam er 1789 zum Verleger Göschen nach Leipzig. 1797 wurde er zum Registrator an der Bibliothek in Weimar ernannt, was ihm die Gelegenheit gab, seine kulturgeschichtlichen Studien wieder aufzunehmen. Sein bekanntestes Werk ist der Roman „Rinaldo Rinaldini“ (1798). Vulpius setzte sich aber auch mit den politischen Ereignissen seiner Zeit auseinander. So schrieb er z.B. einen Fortsetzungsroman über die französische Revolution, der er zunächst Sympathie entgegenbrachte. Schon bald schlug sie jedoch in Abneigung um. Vulpius selbst sah immer mehr in der mittelalterlichen Ständeordnung eine Gesellschaftsform, in der sich das Bürgertum in familiärer Verbundenheit mit den anderen Ständen entfalten könne (vgl. Dammann, Günther: Antirevolutionärer Roman und romantische Erzählung. Vorläufige konservative Motive bei Chr. A. Vulpius und E. T. A. Hoffmann. Kronberg /Ts 1975, S. 7-9; Mendheim, Max, "Vulpius, August" in: Allgemeine Deutsche Biographie 40 (1896), S. 379-381 [Online-Version]; URL: https://www.deutsche-biographie.de/pnd118770489.html\#adbcontent; eine ausführlichere Biographie findet sich z.B. in Meier, Andreas (H.): Christian August Vulpius. Eine Korrespondenz zur Kulturgeschichte der Goethezeit. Band 1: Brieftexte. Berlin / New York 2003 (Quellen und Forschungen zur Literatur- und Kulturgeschichte), S. XIII-XCIII)
} 
Gott aus den Flammen gerettet und erhöht. Auch in dem Trauerspiel „Padmana“1058 fungiert der Flammentod für die Witwe des Fürsten als Beweis ihrer Liebe und Treue und als letzter Ausweg. Sie wird von einem anderen Mann begehrt, der nun aus dem Verlangen heraus, sie zu besitzen, zu den Waffen greift und ihren Mann tötet. Die Frau flieht vor dem Begehren des Angreifers zu ihrem Mann auf den Scheiterhaufen und beweist ihm so ihre Treue. Ob sie sich auch ohne die akute Bedrohung für den Flammentod entschieden hätte, wie es die Bajadere tut, bleibt offen.

In der Oper „Die Bajaderen“1059 fungiert die Witwenverbrennung nicht in erster Linie als Prüfung der Treue, sondern sie ist ein Liebesbeweis, der in gewissem Sinne überhaupt erst die Hochzeit der zwei Liebenden ermöglicht. Diese wird bislang dadurch verhindert, dass die Erwählte des Rajahs eine Bajadere ist, die dem Tempeldienst verpflichtet ist und daher nicht heiraten darf. Nur um ihrer Liebe willen ist sie nicht dazu bereit, ihrer Pflicht zu entsagen. Erst als der Rajah verwundet wird und zu sterben droht, ändert sich das. Denn er darf nur dann auf Einlass in die Wohnung der seligen Geister hoffen, wenn er verheiratet ist, aber keine der Frauen, die ihn bisher begehrt hatten, ist zu diesem Opfer bereit. Erst jetzt entschließt sich die Bajadere, aus Liebe zu dem Rajah und um seiner Seele den Weg zu Brahmā zu ermöglichen, ihre Gelübde zu brechen und in die Ehe einzuwilligen, auch wenn das für sie als seine baldige Witwe unvermeidlich den Tod auf dem Scheiterhaufen zur Folge hat. Durch die unerwartete Genesung des Rajahs bleibt ihr dieses Opfer dann jedoch erspart.

Auch in dem Gedicht „Die Malabarischen Witwen“ von Karoline von Günderrode geht es nicht um eine Prüfung der Treue. Die Witwenverbrennung wird auch nicht wie in

\footnotetext{
${ }^{1058}$ Das Trauerspiel „Padmana“ stammt von dem Komponisten und Schriftsteller Friedrich August Kanne (1778-1833). Kanne studierte zunächst Theologie und Medizin und wandte sich dann der Musik zu. 1809 ging er nach Wien, wo er von Fürst Lobkowitz gefördert wurde. Dort schrieb er Musikkritiken, Schauspiele und Gelegenheitsdichtungen (vgl. Kanne, Friedrich August. In: Österreichisches biographisches Lexikon, S. 217 [Online-Version]. URL: https://www.biographien.ac.at/oebl_3/217.pdf)

1059 „Die Bajaderen“ ist eine Übersetzung der französischen Oper „Les Bayadères“ durch Karl Alexander Herklots (1759-1830). Herklots war Jurist am Kammergericht Berlin. Für das dortige Hoftheater übersetze er französische und italienische Singspiele und schrieb auch einige eigene Werke. Das Libretto zum französischen Original stammt von Victor-Joseph Ètienne de Jouy. Dieser kam als Angehöriger der Armee 1781 zunächst für drei Jahre in die französische Kolonie Guyana. Anschließend verbrachte er vier Jahre in Indien und Ceylon. Nachdem er 1795 aus der Armee entlassen worden war, begann er, als Schriftsteller tätig zu werden (vgl. Kürschner, Joseph, "Herklots, Karl Alexander" in: Allgemeine Deutsche Biographie 12 (1880), S. 115 [Online-Version]; URL: https://www.deutsche-biographie.de/pnd117519901.html\#adbcontent; Gerhard, Anselm: Die Verstädterung der Oper. Paris und das Musiktheater des 19.Jahrhunderts. Stuttgart 1992, S. 43).
} 
„Die Bajaderen“ in Kauf genommen, um die Seele des Mannes zu retten, sondern der freiwillige Tod wird als höchster Beweis und Sinn der Liebe, als ewige Vereinigung der Liebenden und als Lebensgipfel verherrlicht. ${ }^{1060}$

Das Motiv der Opferung aus Liebe ist gerade in den Gedichten von Goethe und Günderrode ungleich komplexer und vielschichtiger als die zuvor besprochene Rettung einer Witwe. Hier entfällt die Notwendigkeit, eine einfache Identifikation mit den Hauptpersonen sowie eine relativ eindeutige Einteilung in gut und böse zu ermöglichen. Vielmehr ist es gerade die Vielschichtigkeit und Uneindeutigkeit, die den Reiz der Gedichte ausmacht.

\subsection{Liebe zwischen Indern und Europäern}

Ein weiteres Motiv, das sich häufig auch in Verbindung mit der Rettung eines Opfers/einer Witwe findet, ist die Liebe zwischen Indern und Europäern. In den meisten Fällen ist die Frau indisch und der Mann europäisch, was zu den von Said beschriebenen Dichotomien zwischen Ost und West passt, nach denen der Westen sich selbst als männlich, stark und rational, den Osten aber als weiblich, schwach und irrational beschreibt. Entsprechend ist in diesen Liebesbeziehungen der Mann in der Regel der Starke, der die schwache Frau beschützt und rettet und der dem irrationalen Aberglauben, der zu der Bedrängnis der Frau geführt hat, entgegentritt. Nach diesem Prinzip funktionieren die bereits angesprochenen Werke „Lanassa“, „Marie von Montalban“, „Jessonda“, „Pullichi“, „Schlangenfest“ sowie in Einschränkungen auch der Roman „Die Prophetin von Caschimir“. ${ }^{1061}$ Letzterer ist hinsichtlich dieser

\footnotetext{
${ }^{1060}$ Für Günderrode ist der Liebestod nicht nur eine Möglichkeit, die Trennung der Liebenden zu überwinden und sie auf ewig zu vereinigen, sondern aufgrund ihrer Nähe zum Neuplatonismus bedeutet der Tod für sie nicht einfach das Ende des Lebens, sondern nur einen Übergang der Seele bei ihrer Heimkehr in die Weltseele (vgl. Becker-Cantarino, Barbara: Liebestod: Goethe „Der Gott und die Bajadere“ und Günderrode „Die Malabarischen Witwen“. In: Arnold, Antja u. Pape, Walter (Hgg.): Emotionen in der Romantik. Repräsentation, Ästhetik, Inszenierung. Salzburger Kolloquium der Internationalen Arnim-Gesellschaft. Berlin u.a. 2012, S. 21-31, hier S. 29).

1061 „Die Prophetin von Caschimir“ ist eine Übersetzung des 1811 erschienenen Romans „The Missionary“ von Lady Sidney Morgan (geb. Owenson). Lady Morgan (um 1780 - 1859) war die älteste Tochter eines irischen Schauspielers. Sie war sehr belesen und veröffentlichte mehrere Gedichtbände und Romane. Darin setzte sie sich unter anderem mit der Rolle Irlands, interreligiösen Konflikten sowie den Themen Freiheit und Frauenrechte auseinander (vgl. Dean, Dennis R.: Morgan [née Owenson], Sidney, Lady Morgan. In: Oxford Dictionary of National Biography [Online-Version] URL: https://www.oxforddnb.com/view/10.1093/ref:odnb/9780198614128.001.0001/odnb9780198614128-e-19234?rskey=3t1VuM\&result=2) Die Übersetzung stammt von Fanny Tarnow (1779-1862). Tarnow war zunächst als Erzieherin tätig und verdiente sich später durch verschiedene eigene Werke sowie Übersetzungen aus dem Englischen und Französischen ihren Lebensunterhalt (vgl. Mendheim, Max, "Tarnow, Fanny" in: Allgemeine Deutsche Biographie 37 (1894), S. 399-402 [Online-Version]; URL: https://www.deutsche-biographie.de/pnd118837052.html\#adbcontent).
} 
Zuschreibungen allerdings weniger eindeutig, auch wenn der Mann hier ebenfalls als stark und rational und die Frau als emotional beschrieben werden. Ähnliche wie die Gedichte, aber anders als die Schauspiele und Opern, erlaubt auch die Gattung des Romans Raum für Zwischen- und Grautöne, für Entwicklung und Ambivalenz. Der Missionar, der die Prophetin, eine hohe hinduistische Priesterin, zu retten versucht, ist zugleich dafür verantwortlich, dass sie überhaupt in Not gerät. Denn die Liebe zueinander ist beiden aufgrund ihres Priestertums verboten, weshalb die Priesterin verstoßen wird. Auf ihrer Flucht vor Verfolgern rettet der Missionar die Prophetin, wenn sie z.B. zu schwach ist. Am Ende aber ist sie es, die sich für ihn opfert und ihn so vor dem Tod bewahrt. In den zuerst genannten Texten sind die kulturellen Unterschiede zwar Auslöser für die Handlung, stehen aber dennoch nicht zwischen den Liebenden. Entweder spielen sie in dieser Hinsicht einfach keine Rolle oder aber sie werden dadurch gelöst, dass sich die Inderin der europäischen Kultur annähert. Lanassa tritt sogar zum christlichen Glauben über. Anders ist es in dem Roman „Die Prophetin“. Hier werden die unterschiedlichen kulturellen Bedingungen und deren Einfluss auf das Gelingen bzw. die Unmöglichkeit einer Liebesbeziehung immer wieder thematisiert. Dabei geht es vor allem um religiöse Unterschiede aber auch Gemeinsamkeiten. So ist beiden aufgrund ihres Status als Priester eine Ehe verboten. Immer wieder festigen sich beide in ihrem Entschluss, an diesem Verbot festzuhalten, und kommen dann doch wieder ins Zweifeln. Aber ihre Religionen stehen nicht nur aufgrund dieses Verbots zwischen den beiden. Während es für die Prophetin kein Problem ist, einen Christen zu lieben, da ihr Glaube anderen Religionen die Kenntnis der Wahrheit nicht abspricht, ist es für den Missionar die Bedingung für eine Beziehung, dass die Prophetin sich zum christlichen Gott bekennt. Denn nur dann könne ihre Seele gerettet werden und nur dann sei ein Wiedersehen nach dem Tod möglich. Darauf werde ich später noch zurückkommen.

Der einzige Fall innerhalb der hier untersuchten Texte, in denen sich ein indischer Mann in eine Europäerin verliebt, findet sich in dem Lustspiel „Die Indianer in England“" von Kotzebue. ${ }^{1062}$ Das liegt sicherlich auch daran, dass dieses Stück nicht wie

\footnotetext{
${ }^{1062}$ August Friedrich Ferdinand von Kotzebue (1761-1819) war Schriftsteller und Jurist und stand seit 1781 in den Diensten der Zarin Katharina II. Als Präsident des Gouvernements-Magistrats der Provinz Estland wurde er 1785 in den russischen Dienstadel erhoben. Nach einigen Abstechern z.B. nach Wien, Weimar und Berlin setzte sich Kotzebue in Estland publizistisch gegen Napoleon ein. Nach der Niederlage Napoleons kam Kotzebue im Auftrag des Zaren Alexander erneut nach Weimar, um von
} 
die meisten anderen in Indien spielt, sondern in England, wo das Zusammentreffen mit einer Europäerin durchaus wahrscheinlicher ist. Ein aus Indien vertriebener Vater ist mit seiner Tochter nach England gekommen. Er verliebt sich in die Tochter der Nachbarn, seine Tochter verliebt sich in deren Bruder. Als der verloren geglaubte Sohn des Inders unvermittelt auftaucht und sich ebenfalls in die Tochter des Nachbarn verliebt, verzichtet sein Vater auf seinen Anspruch. Auch hier scheint die unterschiedliche Herkunft zunächst zwischen dem Glück der Liebenden zu stehen. Anders als bei „Die Prophetin“ sind es jedoch weniger tatsächliche kulturelle Unterschiede, die problematisch sind, sondern Vorurteile, die in ihrer Überzeichnung für die dem Lustspiel eigene Komik sorgen. Vor allem die Mutter des Mädchens hat Einwände gegen eine Verbindung mit Indern. Im Laufe des Stücks stellt sich jedoch heraus, dass diese Einwände weniger auf die Tatsache zielen, dass es sich um Inder handelt, als vielmehr auf vermutete finanzielle und Standesunterschiede. Ein indischer Fürst mit dem nötigen Vermögen wird ohne Schwierigkeiten als gleichwertig anerkannt. ${ }^{1063}$ Das erinnert an die Darstellung der Inder in mittelalterlichen Texten, in denen auch die Standesunterschiede bedeutender waren als die der Herkunft. In „Die Indianer in England“" geht mit der anderen Herkunft der Geschlechter auch eine andere Rollenverteilung einher: Das oben beschriebene Schema des starken Mannes, der die schwache Frau rettet, entfällt, denn der junge Inder und in gewisser Weise auch sein Vater weisen einige sonst eher den Inderinnen zugeschriebene Merkmale auf. So sind sie z.B. eher zögerlich und gefühlsbetont.

\footnotetext{
dort aus den Zaren über alle neuen Entwicklungen in den deutschsprachigen Ländern und Frankreich zu unterrichten. Aufgrund seiner Parteinahme für die Monarchie wurde Kotzebue 1819 von dem Studenten Sand ermordet. Kotzebues Leben war geprägt durch die Spannung zwischen seiner bürgerlichen Herkunft mit den entsprechenden Ideen und Werten und dem Leben als russischer Adliger. So werden in seinen frühen Werken immer wieder die Gleichheit der Menschen, die Forderung nach bürgerlicher Freiheit sowie allgemeine Toleranz und Menschlichkeit thematisiert. Zum Beispiel setzte er sich in „Die Negersklaven“ gegen die Sklaverei ein. In anderen Schriften ergriff er dagegen Partei für eine uneingeschränkte Monarchie. Das erfolgreiche Lustspiel „Die Indianer in England“" schrieb Kotzebue bereits 1787. Die Uraufführung fand ein Jahr später in Reval statt. Veröffentlicht wurde es 1790. Seiner Auffassung folgend, dass das Theater moralisch bilden und erziehen solle, weist das Stück durchaus sozialkritische Elemente (gegen Vorurteile und Standesdünkel, für die Gleichheit der Menschen und allgemeine menschliche Werte) auf (vgl. S. Klingenberg, Karl-Heinz: Iffland und Kotzebue als Dramatiker. Weimar 1962 (Beiträge zur deutschen Klassik), S. 80-90, 122f.; Heizmann, Bertold: Im Schatten Goethes: Kotzebue. Röttenbach 2019, S. 3740; Lentz, Sarah: „Wer helfen kann, der helfe!“ Deutsche SklavereigegnerInnen und die atlantische Abolitionsbewegung, 1780 - 1860. Göttingen 2020 (Veröffentlichungen des Instituts für Europäische Geschichte Mainz; 261), S. 108- 113)

${ }^{1063}$ Vgl. De Zoysa: "Blutrünstige Braminen am heiligen Strome“, S. 374
} 


\subsection{Konflikte aus dem Begehren einer Frau}

Weniger markant als die Opfer- und Witwenstücke und auch nicht auf den indischen Kontext beschränkt ist ein weiteres Motiv, das in einigen der Texte von Bedeutung ist: Aus dem Begehren einer Frau, die dieses Ansinnen nicht erwidert, entsteht der handlungsbestimmende Konflikt. Besonders ausgeprägt ist dieses Schema in dem Trauerspiel „Padmana“. Der Großmogul begehrt die Ehefrau eines indischen Fürsten und beginnt ihretwegen einen Krieg gegen ebendiesen Fürsten. In „Der Hindu“1064 versucht ein Europäer, den indischen Freund der von ihm begehrten Inderin loszuwerden, indem er ihn entführen lässt. Und auch in Beers „Der Paria“ trägt das Begehren, das der Rajah für die Ehefrau des Parias empfindet, entscheidend zur Eskalation des Konflikts bei. In Sophie Mereaus „Serafine“ ${ }^{\text {1065 }}$ ist dieses Motiv zwar nur eines unter vielen, aber auch hier wird durch die Eifersucht eines zurückgewiesenen Mannes zunächst das Glück der Hauptpersonen verhindert. Da dieses Handlungsschema weder an Indien als Schauplatz noch an bestimmte indische Personengruppen als Handlungsträger gebunden ist und auch interkulturelle Konflikte keine Rolle spielen, ist es für die Fragestellung der vorliegenden Arbeit jedoch kaum relevant.

\subsection{Konflikte zwischen den Kasten}

Anders als bei dem eben beschriebenen Motiv sind Konflikte, die aus dem Zusammenstoß unterschiedlicher Kasten entstehen, an den indischen Kontext gebunden, auch wenn die in ihnen zum Teil geäußerte Kritik nicht immer auf das indische Gesellschaftssystem zielen muss, sondern sich auch auf ähnliche Strukturen in Europa richten kann. Ein typisches Motiv, das sich aus dem Kastenwesen ergibt, ist die

\footnotetext{
${ }^{1064}$ Das dramatische Gedicht „Der Hindu“ wurde 1823 von Philipp Karl Christian Sondershausen veröffentlicht. Sondershausen (1792-1882) studierte in Jena Theologie. Als Freiwilliger nahm er 1813 an den Kämpfen gegen Napoleon teil, wobei er schwer verwundet wurde. 1818 ging er nach Weimar, wo er zunächst als Prediger an der Hof-und Stadtkirche tätig war. Doch schon bald wechselte er als Hofmeister an das dortige Pageninstitut. Sondershausen veröffentlichte einige dramatische Dichtungen, die allerdings nur geringen Erfolg hatten (vgl. Brümmer, Franz, "Sondershausen, Karl" in: Allgemeine Deutsche Biographie 34 (1892), S. 621-622 [Online-Version]; URL: https://www.deutschebiographie.de/pnd117478830.html\#adbcontent).

1065 Sophie Mereau (1770-1806) war eine der ersten Frauen, die - nach der Scheidung von ihrem ersten Mann - von der Tätigkeit als Schriftstellerin leben konnten. Sie schrieb sowohl Romane und Erzählungen als auch Gedichte. Außerdem übersetzte sie literarische Texte aus verschiedenen europäischen Sprachen und arbeitete an verschiedenen Musenalmanachen und Taschenbüchern mit. 1803 heiratete sie den Romantiker Clemens Brentano. Sie stand im engen Austausch nicht nur mit dem Kreis der Romantiker, sondern auch mit Schiller (vgl. Feilchenfeldt, Konrad, "Mereau, Sophie" in: Neue Deutsche Biographie 17 (1994), S. 129 f. [Online-Version]; URL: https://www.deutschebiographie.de/pnd11858104X.html\#ndbcontent).
} 
Unterdrückung der Kastenlosen, der Paria oder Pullichi. In dem bereits angesprochenen Stück „Pullichi““ werden die Pullichi als aus der Gesellschaft ausgestoßene Gruppe beschrieben, die für obere Schichten unentgeltlich arbeiten müssen, nur zu essen haben, was sie im Meer oder im Wald finden, und aus deren Reihen die Opfer für eine Zeremonie ausgewählt werden. Sie werden von den anderen indischen Personen des Stücks herablassend und auf grausame Art und Weise behandelt. Handlungsbestimmend ist der Konflikt zwischen den Kasten in diesem Stück allerdings nicht, da im Mittelpunkt die Rettung der Opfer steht. Dementsprechend wenig komplex werden Stellung und Gefühle der Pullichi beschrieben. Anders ist das in den Trauerspielen „Der Paria“ von Beer und „Der Paria“ von Lewald (eine Nachdichtung des Stücks von Delavigne) ${ }^{1066}$. In beiden Stücken ist die Identität der Hauptperson als Paria der Auslöser für die tragische Handlung. In dem Stück von Beer tragen die bereits genannten Motive „Rettung einer Witwe“ und „Begehren einer fremden Frau“ zur Entstehung des Konflikts bei, aber allein aufgrund der Tatsache, dass die Hauptperson ein Paria ist, geht sein Gegenspieler so weit, dessen Frau mit Gewalt nehmen zu wollen. In dem Stück von Lewald geht es darum, dass ein Paria seine Herkunft verheimlicht. Das ermöglicht es ihm, allein aufgrund seiner Taten beurteilt zu werden und so innerhalb der Gesellschaft Anerkennung zu finden. Er ist ein erfolgreicher Feldherr und soll die von ihm geliebte Tochter des Oberpriesters heiraten. In dem Moment aber, in dem offenbar wird, dass er ein Paria ist, verliert er bis auf die Liebe seiner Verlobten alles und wird zum Tode verurteilt. Hier führt allein der Kastenunterschied dazu, dass ein hoch angesehener Mann getötet und die Tochter des Oberpriesters, da sie zu ihm hält, verbannt wird. Das Motiv einer Ehe zwischen einem Paria und einer Brahmanin findet sich auch in „Die indische Hütte“, allerdings steht es hier nicht im Mittelpunkt. Die in den genannten Stücken zum Ausdruck gebrachte Verurteilung der

\footnotetext{
${ }^{1066}$ Die Tragödie „Le Paria) von Casimir Delavigne (1793-1843) wurde 1821 mit Erfolg uraufgeführt. Delavigne gilt als einer der ersten französischen Anhänger Byrons. Dessen Merkmale des Weltschmerzes und der Rebellion finden sich auch in „Le Paria“. Das Stück wurde von dem Schauspieler, Regisseur und Schriftsteller August Lewald (1792-1871) ins Deutsche übersetzt. Lewalds frühen Erzählungen waren von den phantastischen Erzählungen E.T.A. Hoffmanns geprägt. Durch seine Bekanntschaft mit Heine wandte er sich in den 1830er Jahren dem jungen Deutschland zu. Da Lewald, der als junger Mann zum Christentum konvertierte, als Jude geboren worden war, liegt die Annahme nahe, dass auch beim ihm - ähnlich wie bei Beer - am Beispiel des Parias auf das Schicksal der Juden aufmerksam gemacht werden soll (vgl. Selbmann, Rolf, "Lewald, August" in: Neue Deutsche Biographie 14 (1985), S. 408 f. [Online-Version]; URL: https://www.deutschebiographie.de/pnd1 19164035.html\#ndbcontent; Casimir Delavigne. In: Illustrirte Zeitung. Zweiter Band. Leipzig 1844, S. 145f.; Evans, David O.: A source of Hernani: Le Paria, by Casimir Delavigne. In: Modern Language Notes 47 (1932), 8, S. 514-519, hier S. 514, 516)
} 
gesellschaftlichen Ausgrenzung bestimmter Gruppen zielt allerdings in erster Linie nicht auf die indische Gesellschaft, sondern ist eine verdeckte Kritik an der um 1820 erstarkenden Judenfeindlichkeit in Europa. ${ }^{1067}$ Hier dient also ein zunächst fremd anmutender Aspekt der anderen Kultur nicht nur zur Konstruktion eines handlungsbestimmenden Konflikts, sondern dient zudem als Bild für einen Teil der eigenen Kultur, in dessen verfremdenden Spiegel das Eigene zugespitzter dargestellt werden kann.

Ein ganz anderer Konflikt zwischen den Kasten wird in dem Stück „Magandola“1068 durchgespielt. Hier geht es nicht um die aus der Gesellschaft ausgestoßenen Paria, sondern um die Gewalttätigkeit der Kriegerkaste, die die Brahmanen vertrieben hat und sich auch untereinander bekämpft. Die Versöhnung der Kasten steht hier sinnbildlich für den Ausgleich von weisem, aber auch kaltem Kopf mit dem warmen, aber oft auch heißblütigen Herz. Auch hier geht es dem Autor also nicht um die beschriebene andere Kultur, sondern er veranschaulicht anhand des Brahmanen, der für eine weise, zurückhaltende, aber mitunter auch gefühlskalte Lebensform steht, und des Kriegers, der das warme und gefühlvolle, zuweilen aber auch wilde und stürmische Herz symbolisiert, seine These von dem erforderlichen Ausgleich dieser Kräfte.

\subsection{Militärische/politische Konflikte}

In vielen der Texte werden politische oder militärische Konflikte durchgespielt. Dabei stehen sich entweder Inder bzw. bestimmte indische Gruppen und Europäer gegenüber oder es geht um Auseinandersetzungen zwischen den muslimischen Herrschern und den Hindus oder aber die Marathen greifen an. Militärische Auseinandersetzungen zwischen Europäern und Indern finden sich vor allem in den genannten Opfer/Witwenstücken, wo europäische Truppen (mal sind es Engländer, mal Portugiesen) versuchen, das Opfer zu retten. In einigen Fällen wie z.B. bei „Jessonda“ und „Lanassa“ entsteht der Konflikt zwischen Europäern und Inder nicht erst durch die Dramenhandlung, sondern beide Gruppen befinden sich bereits zu Beginn der

\footnotetext{
${ }^{1067}$ Vgl. De Zoysa: "Blutrünstige Braminen am heiligen Strome“, S. 125-133

1068 „Magandola“ erschien 1819 in „Dramatische Novellen“ von Friedrich von Heyden (1789-1851). Heyden wurde nach einem Jura-Studium und dem Dienst in einem preußischen Jägerbataillon (1813) Referendar in Oppeln. 1826 ging er als Regierungsrat nach Breslau. Mit seinen literarischen Werken und seinen Bühnenstücken hatte er allerdings nur mäßigen Erfolg (vgl. Schulz, Eckhard, "Heyden, Friedrich von" in: Neue Deutsche Biographie 9 (1972), S. 67 f. [Online-Version]; URL: https://www.deutsche-biographie.de/pnd11678699X.html\#ndbcontent).
} 
Handlung im Krieg, der durch das geplante grausame Ritual verschärft wird. In den meisten Fällen werden die genauen historischen Umstände nicht weiter präzisiert. Die Kolonisation Indiens durch die Europäer bildet zwar oft den Rahmen für die eigentliche Handlung, wird aber selbst kaum thematisiert. Eine Ausnahme stellen „Das Schlangenfest“" von Hensler und „Die Portugiesen in Indien“ von Vulpius dar. Dort ist als historischer Hintergrund ein Ereignis zu erkennen, das bei „Das Schlangenfest“ nur sehr wenig detailliert angedeutet wird, bei Vulpius dagegen ausführlich geschildert wird: die ersten Versuche der Portugiesen, mit Hilfe von Gesandtschaften die Freundschaft der indischen Herrscher zu erlangen und Handelsbeziehungen zu etablieren. In beiden Texten wird beschrieben, wie die Portugiesen beim König zwar zunächst Gehör finden, sich dann aber Intrigen des Katuals und anderer einflussreicher Persönlichkeiten wie Priestern oder Kaufleuten ausgesetzt sehen. Am Ende jedoch gelingt es ihnen zumindest vorläufig, ein friedliches Einvernehmen mit dem König zu erreichen. Vulpius, der sich an portugiesischen Texten orientiert, spielt dieses Schema anhand verschiedener Gesandtschaften mehrfach durch. Dabei differenziert er zwischen verschiedenen indischen Reichen, in denen die Europäer mal mehr, mal weniger freundlich aufgenommen werden und die auch untereinander Streitigkeiten austragen ${ }^{1069}$ Beim „Schlangenfest“ sind die eigentlichen Gegenspieler der Portugiesen die Priester des Jaka, bei Vulpius sind es die muslimischen Kaufleute. ${ }^{1070}$ Beide Gruppen bedienen sich aber desselben Tricks, um den König von ihren Vorbehalten den Europäern gegenüber zu überzeugen: Sie lassen z.B. einen Propheten auftreten, der verkündet, dass von den Fremden Gefahr ausgehe. Außer bei Vulpius und Hensler gibt es auch im Lustspiel „Die Indianer in England“ eine Szene, in der der historische Kontext der Kolonialpolitik angesprochen wird. Dort wird - wenn auch nur am Rande - beschrieben, wie ein indischer Herrscher zwischen den Auseinandersetzungen der Engländer und der Franzosen, die ihren Krieg auch auf Indien ausweiten, zerrieben wird.

\footnotetext{
${ }^{1069}$ Vgl. auch De Zoysa: "Blutrünstige Braminen am heiligen Strome“, S.310-317; zu Vulpius’ Text vor dem Hintergrund der Aufklärung vgl. Opitz, Alfred: Die Portugiesen in Indien (1793) von Christian August Vulpius oder Schwierigkeiten der deutschen Aufklärung mit den portugiesischen Entdeckungsreisen. In: Siepmann, Helmut (Hg.): Portugal, Indien und Deutschland. Akten der V. Deutsch-Portugiesischen Arbeitsgespräche (Köln - 1998). Köln u. Lissabon 2000, S. 32-44 ${ }_{1070}$ Tatsächlich gab es Versuche muslimischer Kaufleute, den „Handel der Portugiesen mit dem Herrscher vor Calicut, dem Zamurin, zu unterbinden, da sich Araber und indische Muslime auf den Handel von der indischen Westküste zum Persischen Golf und zur arabischen Küste spezialisiert hatten. Geschickt nutzten die Portugiesen jedoch Konflikte kleiner lokaler Herrscher aus" (Lederle: Mission und Ökonomie der Jesuiten in Indien, S. 66)
} 
Bei den Auseinandersetzungen mit der muslimischen Bevölkerung Indiens sind die gegen die Europäer intrigierenden Kaufleute, wie sie sich bei Vulpius finden, die Ausnahme. Weitaus häufiger geht es um die Mogul-Herrschaft und die damit zusammenhängenden Konflikte mit der hinduistischen Bevölkerung. In dem bereits erwähnten Stück „Padmana“ ist es der muslimische Herrscher Akbar, der die Frau eines indischen Fürsten begehrt. Auch wenn der konkrete Krieg, der nun ausbricht, diese unerwiderte Liebe zur Ursache hat, wird am Ende des Personenverzeichnisses ausdrücklich betont, dass die Handlung zur Zeit „der gewaltsamen Einfälle der Musulmannen in Indien“"1071 spielt. Auch Günderrodes Stück „Udohla“ spielt vor dem Hintergrund der Mogulherrschaft. Der Vater Udohlas ist wegen Aufstands gegen den Mogul verhaftet und hingerichtet worden. Und auch Udohla selbst droht die Gefangennahme. In dem Stück „Der Paria“ von Lewald macht sich die Hauptfigur einen Namen damit, dass sie gegen die „Tartaren“ kämpft. Mit diesem Begriff wurden fälschlicherweise auch die Mongolen bezeichnet, weshalb aller Wahrscheinlichkeit nach auch hier die Moguln gemeint sind.

Eine dritte Gruppe, die in militärischen Auseinandersetzungen gezeigt wird, sind die Marathen ${ }^{1072}$. Sie bedrohen in „Der Hindu“ ein englisch beherrschtes Gebiet und werden von indischen Truppen zurückgetrieben. In „Die Bajaderen“ greifen die Marathen Benares an. Die Marathen werden in beiden Texten mit sehr negativen Attributen versehen: Sie seien „räuberische Schaaren“ und „Barbarben“, 1073 die Frauen und Kinder ermordeten und sie lebendig aufschlitzten. ${ }^{1074}$ Das ist insofern nicht verwunderlich, als in der Zeit um 1800 die Engländer in mehreren Kriegen gegen die Marathen kämpfen, was auch in Europa verfolgt wird. Die aktuellen Geschehnisse in Indien werden also durchaus in literarischen Verarbeitungen aufgegriffen, allerdings größtenteils nur durch Andeutungen. ${ }^{1075}$

\footnotetext{
${ }^{1071}$ Kanne: Padmana, S. 6

1072 Das Marathenreich im Dekhan dehnte sich im 18. Jahrhundert immer weiter aus. „Die Marathen beherrschten sechs Dekhan-Provinzen, von denen aus sie weitere Gebiete überfielen und Zwang auf die Bevölkerung ausübten [...].“ Dem Mogulherrscher „Aurangzeb gelang es nicht, die Marathenmacht einzudämmen. So erlangten die Provinzherren größere Selbständigkeit, während der Widerstand der Hindu-Bevölkerung wuchs“ (Lederle: Mission und Ökonmie der Jesuiten in Indien, S. 78).

${ }^{1073}$ Herklots: Die Bajaderen, S. 18

1074 Vgl. Sondershausen: Der Hindu, S. 101f.

1075 Vgl. De Zoysa: "Blutrünstige Braminen am heiligen Strome“, S. 189
} 
Johann Gottlieb Bremer wählt noch eine weitere Konfliktsituation als Hintergrund seiner Erzählung „Tippo-Saib und Laura“: den Krieg der Engländer gegen Mysore unter Tipu Sultan und die mit ihm verbündeten Franzosen Ende des 18. Jahrhunderts. ${ }^{1076}$ Ein deutscher Soldat, der mit einem Regiment aus Hannover für die Engländer kämpft, gerät in die Gefangenschaft von Tippo-Saib. In seiner Erzählung, die sich als eine Warnung an europäische Abenteurer versteht, die sich in Indien leichtes Glück versprechen, orientiert sich Bremer an Berichten deutscher und englischer Soldaten aus Indien. Auffällig ist allerdings, dass er die indischen Soldaten in sehr viel stärkerem Maße als Feiglinge abwertet und Tippo-Saib als grausamen Tyrannen darstellt, als es in seinen Vorlagen der Fall ist. ${ }^{1077}$

\subsection{Suche nach Weisheit}

Während die Tradition der Witwenverbrennung und die Abwertung der Paria Themen sind, die auch in den Sachtexten auf großes Interesse stoßen, und auch die aktuellen politischen Ereignisse, die in den einigen literarischen Texten angedeutet werden, in den Sachtexten ausführlich behandelt werden, so findet sich in einigen romantisch geprägten literarischen Texten ein Motiv, das zwar in der Antike und im Mittelalter noch verbreitet war, sich aber in den Sachtexten um 1800 ebenfalls lediglich bei den romantisch geprägten Autoren finden lässt: die Weisheit der Inder und die Suche nach ihr. Dieses Motiv eignet sich in seiner philosophisch-religiösen Ausrichtung nicht für Schauspiele oder Opern, da es weniger um eine äußere Handlung als vielmehr um innere Geschehnisse geht. Es findet sich daher vor allem in Gedichten und Erzählungen. Besonders Karoline von Günderrode spielt dieses Motiv mehrfach durch. In „Geschichte eines Brahminen“ kommt der Sohn eines zum Islam konvertierten Christen nach langer Suche nach Indien. Zuvor hat er bereits verschiedene andere Philosophien und Religionen ausprobiert, findet aber in keiner das, was er sucht. Von Sehnsucht getrieben kommt er nach Indien und wird dort der Schüler eines weisen Brahmanen. Dort bleibt er und lebt fortan in Frieden und Zurückgezogenheit wie ein Brahmane. Die

\footnotetext{
1076 zu Haider Ali und Tipu Sultan vgl. Kapitel I 7.1

1077 Vgl. Bremer: Tippo-Saib und Laura; vgl. auch Tzoref-Ashkenazi: German Soldiers in India, S. 142-145; Bremers Erzählung ähnelt in Aufbau und Struktur sehr dem Genre Reisebericht bzw. Soldatenbericht. Durch die vielen erklärenden Einschübe erinnert der Text über weite Teile eher an einen Sachtext als an eine literarische Erzählung. Dabei greift Bremer vor allem negative und abwertende Stereotype über Indien und die Inder auf und verstärkt diese oft noch: Die Inder seien feige, weichlich und zu Sklaven der Europäer bestimmt, dabei aber grausam, wenn es ihre Stärke erlaube; sie verehrten Tiere (die indische Religion wird fast ausschließlich als Tierverehrung dargestellt), kümmerten sich aber nicht um notleidende Menschen; Diebstähle und Betrügereien seien an der Tagesordnung; die Frauen seien wollüstig.
} 
Suche nach Weisheit findet hier also ihre Erfüllung in Indien. Etwas anders ist es in „Der Adept“. Auch hier kommt ein Suchender nach Indien und wird ein Schüler der Priester. Anders als der zuvor genannte Schüler des Brahmanen wird dieser bereits bei seiner Ankunft in Indien als ein Weiser bezeichnet. Er muss allerdings feststellen, dass sein bisheriges Wissen eitel war. Von den Priestern bekommt er eine geheimnisvolle Weihe und nähert sich im Folgenden immer mehr der Ewigkeit an, entfernt sich aber auch gleichzeitig von den Menschen. Am Ende findet er zwar die Ewigkeit, aber nicht sein Glück, denn der Mensch, so stellt er fest, sei nicht für die Ewigkeit geschaffen. In „Briefe zweier Freunde“ geht es nicht um eine wirkliche Reise nach Indien, sondern die Suche nach Weisheit beschränkt sich auf das Studium alter indischer Schriften. Diese legt Eusebio seinem Freund ans Herz, damit dieser den Zustand der Auflösung im Göttlichen verstehen lerne.

Das indische Wissen kann also durch einen persönlichen Lehrer, geheimnisvolle Weihen oder alte Schriften vermittelt werden. Der persönliche Lehrer spielt auch in Jean Pauls Roman „Hesperus“ eine Rolle und zwar in Person des Inders Dahore. Bei ihm scheint es allerdings weniger um greifbares Wissen zu gehen als vielmehr um seine Lebensweise und Weltsicht. Denn er wird von seinen Schülern zwar als wichtiger Lehrer und Vorbild beschrieben, allerdings sieht man ihn im Roman kaum in dieser Funktion. Er unterrichtet kaum direkt und beschäftigt sich mehr mit sich selbst als mit seinen Schülern. ${ }^{1078}$

In der Erzählung „Die indische Hütte“ ist das Motiv der Weisheitssuche handlungsbestimmend. Hier wird es allerdings - anders als in den anderen untersuchten Texten und anders als in den antiken und mittelalterlichen Berichten - nicht mit dem Brahmanen, sondern mit dem Paria als weisem Lehrer verbunden. Eine Gruppe englischer Gelehrter wird in alle Welt ausgesandt, um Antworten auf wichtige Fragen der Menschheit zu finden. Ein Gelehrter kommt auch nach Indien. Doch von der angeblichen Weisheit der Brahmanen wird er enttäuscht. Durch Zufall trifft er einen Paria, bei dem er Glück und Weisheit findet. Anders als die Brahmanen, die vor allem die Einhaltung aller Regeln überwachen und die Exklusivität des brahmanischen

\footnotetext{
${ }^{1078} \mathrm{Zu}$ der Person des Emanuel/Dahore vgl. z.B. Espagne, Geneviève: Orient-Bezüge in Jean Pauls „Hesperus“. In: Goer, Charis u. Hofmann, Michael (Hg.): Der Deutschen Morgenland. Bilder des Orients in der deutschen Literatur und Kultur von 1770 bis 1850. München 2008, S. 117-136, hier S. $121-130$
} 
Wissens betonen, lehrt der Paria, dass jeder die Wahrheit mit einfältigem Herzen in der Natur finden könne. In der Erzählung geht es also anders als bei einigen der oben genannten Texten nicht um ein spezifisch indisches Wissen, sondern um eine Kritik an der Oberflächlichkeit und Überheblichkeit des Klerus, der eine einfache, natürliche Weisheit gegenübergestellt wird.

Auch in Mereaus Gedicht „Serafine“ gibt es das Motiv, dass ein Europäer der Schüler eines Brahmanen wird und im Alter selbst wie ein indischer Asket lebt. Anders als bei den meisten zuvor genannten Personen treibt ihn jedoch nicht die Suche nach spiritueller Erfüllung nach Indien, sondern Indien ist ihm - wie auch den anderen Europäern, die es in diesem Text nach Indien verschlagen hat - ein Zufluchtsort, an dem er einen möglichst großen Abstand zu persönlichen Schicksalsschlägen in Europa bekommen möchte. Erst vor Ort findet er in der indischen Lehre einen Halt.

\subsection{Bezug auf die Śakuntalā}

Neben den bislang besprochenen Schauspielen, Opern, Romanen, Erzählungen und längeren Gedichten gibt es einige (kürzere) Gedichte, die keine eigentliche Handlung haben, aber dennoch auf das Thema Indien eingehen. Hinzu kommen Texte, in denen Indien im Prinzip keine Rolle spielt, die aber in einzelnen Szenen oder Sätzen auf Indien anspielen oder lediglich einen Begriff, der aus dem indischen Kontext stammt, in übertragenem Sinn für etwas Anderes benutzen. In diesen Fällen kann man also nicht von Handlungsschemata oder -motiven sprechen, eher von Themen.

Das markanteste davon ist der Bezug auf das Drama Śakuntalā. In dieser Gruppe von Texten wird gewöhnlich eine europäische Frau mit der indischen Śakuntalā verglichen. Dieser Vergleich stellt ein hohes Lob dar und dient der Verherrlichung der entsprechenden Frau. In „Godwi oder das steinerne Bild der Mutter“ von Brentano ist es nur ein kurzer Vergleich: die verehrte Frau habe „die andächtigste, zarteste Seele einer Sakontala“. ${ }^{1079}$ Das indische Drama spielt ansonsten keine Rolle und der Vergleich wird auch in keiner Weise kommentiert oder erklärt. Die Konnotationen, die mit der bloßen Nennung des Namens verbunden sind, müssen also um 1800 zum einen sehr bekannt und zum anderen auch relativ eindeutig sein. Ausführlicher greift Brentano in dem Gedicht „Einer Jungfrau bei dem Geschenk der Sakontala“ auf dieses

\footnotetext{
${ }^{1079}$ Brentano, Clemens: Godwi oder das steinerne Bild der Mutter. Stuttgart 1995, S. 236
} 
Thema zurück. Auch hier wird die europäische Frau mit der Hauptperson des indischen Dramas verglichen, um auf diese Weise vor allem ihren Charakter zu rühmen. Die Frauen werden als aus dem verlorenen Paradiese stammend beschrieben, als rein, klar, demütig und unschuldig. ${ }^{1080}$ Die Attribute ähneln den Beschreibungen, die die Sachtexte von der Hauptfigur des indischen Dramas machen, sehr. Die Begeisterung, die die Autoren der Sachtexte über die Śakuntalā äußern, wird hier in Gedichtform verarbeitet und auf andere Frauen übertragen. Auch in dem Briefroman „Phaethon“ spielt das indische Drama eine Rolle. Hier dient es allerdings nicht dem Lob einer Frau, sondern es wird beschrieben, in welch eine gerührte Stimmung die gemeinsame Lektüre des Dramas ein junges Paar versetzt. Ihm stockt beim Lesen die Stimme, ihr Auge ist voll Tränen und beide drücken sich in stillem Verständnis und gemeinsamem Erleben die Hand. ${ }^{1081}$ Steht bei den bisher genannten Beispielen vor allem die weibliche Hauptperson im Mittelpunkt der Sehnsucht und Verehrung, überträgt Herder in seinem Gedicht „Indien“ die Sehnsucht und Verehrung, die die weibliche Hauptfigur, Śakuntalā, bei vielen Menschen erfährt, auf Indien als ganzes, das sich als „heiliges““ und ,ätherische(s) “1082 Land unter anderem dadurch auszeichne, dass Śakuntalā dort lebe. Die Begeisterung, die Forsters Übersetzung des indischen Dramas auslöste, wird in der Literatur so verdichtet, dass allein der Name der Śakuntalā in der Lage ist, ein ganzes Bündel an Gefühlen und Sehnsüchten aufzurufen. Goethe beschreibt das sehr eindrücklich in seinem bekannten Gedicht: ,[...] Willt du den Himmel, die Erde mit Einem Namen begreifen - // Nenn ich Sakontala Dich, und so ist alles gesagt.“1083

\subsection{Indien als das Absurde/Abergläubische}

Ein anderes Motiv, das nicht Teil einer Handlung im eigentlichen Sinne ist, aber dennoch typisch für einige sich auf Indien beziehende Texte, ist die Darstellung Indiens bzw. bestimmter Aspekte der indischen Kultur als etwas Absurdes und als Beispiel für Aberglauben. Besonders markant sind in dieser Hinsicht einige „Zahme Xenien“ Goethes. In ihnen spricht sich Goethe vehement gegen indische Götterfiguren aus. Sie verkörpern für ihn das Absurde, das er besonders dann als unerträglich empfindet, wenn er es nicht nur in Worten ausgedrückt, sondern in Bildern und Figuren vor Augen

\footnotetext{
${ }^{1080}$ Vgl. Brentano, Clemens: Werke. Band 1. München 1963, S. 347f.

1081 Vgl. Waiblinger, Wilhelm: Phaeton. Teil 1 und 2. Dresden 1920, S. 88-91

${ }^{1082}$ Herder, Johann Gottfried: Werke. Erster Theil. Gedichte. Berlin 1879, S. $176 \mathrm{f}$.

${ }^{1083}$ Herder: Über ein morgenländisches Drama, S. 228
} 
gestellt sieht. ${ }^{1084}$ Auch Heinrich Heine stellt in einem seiner Gedichte Teile der indischen Mythologie als absurd dar. Anders als bei Goethe, dem es in seiner Kritik um ein für ihn existentielles Problem zu gehen scheint, macht Heine sich über die bekannte Erzählung von dem König Wiswamitra eher lustig, als dass er sie direkt kritisiert. ${ }^{1085}$ Auf diesen Aspekt der Wahrnehmung Indiens als Ort des Absurden und des Aberglaubens wird später noch ausführlicher eingegangen.

\section{Figurentypen}

Im Folgenden sollen typische Figuren des Inders und der Inderin, wie sie in den verschiedenen literarischen Texten auftreten, herausgearbeitet werden. Denn so unterschiedlich die einzelnen Personen auch sind, ähneln sie sich doch häufig in bestimmten Charaktereigenschaften oder in der Funktion, die sie in den verschiedenen Handlungen ausfüllen. Selbstverständlich gibt es auch indische Personen in den Texten, die sich keiner dieser Figurentypen zuordnen lassen. Dabei handelt es sich aber größtenteils um Nebenrollen. Das Bild des Inders wird in den literarischen Texten jedoch vor allem von den folgenden Figurentypen geprägt.

\subsection{Der Brahmane}

Eine Gruppe von Indern, die in literarischen Texten häufig eine wichtige Rolle spielt, stellen die Brahmanen dar. Sie werden auch in den Sachtexten überdurchschnittlich häufig erwähnt. Dort werden sie, wie wir gesehen haben, größtenteils als machtbewusste und gierige Menschen dargestellt, die den Aberglauben gezielt zu ihrem Vorteil fördern und ausnutzen. Auch in den literarischen Texten finden sich ganz ähnliche Darstellungen. Es gibt aber - anders als in den Sachtexten - auch das Gegenbild des weisen Brahmanen sowie zwischen den beiden Extremen den zweifelnden Brahmanen. Während letzterer zusammen mit dem machtbewussten Brahmanen auftritt, finden sich der machtbewusste und der weise Brahmane in der Regel nicht in ein und demselben Text. Ihnen entsprechen ganz unterschiedliche Vorstellungen und Konzepte von Indien.

\footnotetext{
${ }^{1084}$ Goethe, Johann Wolfgang: Zahme Xenien II. In: Goethe, Johann Wolfgang: Gedichte 1800-1832. Herausgegeben von Karl Eibl. Frankfurt a. M. 1988 (Sämtliche Werke. Briefe, Tagebücher und Gespräche. Herausgegeben von Hendrik Birus u.a. I. Abteilung: Sämtliche Werke. Band 2), S. 630-640 1085 Vgl. Heine, Heinrich: Den König Wiswamitra, S. 258
} 


\subsubsection{Der böse/machtbewusste Brahmane}

De Zoysa beschreibt zwei Versionen des bösen Brahmanen: den vermutlich aus dem „lasziven Orientalen“1086 der Türkenopern entstandenen „lasterhaften Braminen“1087 und den möglicherweise an die heidnischen südamerikanischen Opferpriester angelehnten „blutrünstigen Braminen“ 1088 . Letzterer darf in den Opfer- und Witwenstücken als böser Gegenspieler nicht fehlen. In allen hier untersuchten Opferstücken („Das Sonnenfest“, „Das Schlangenfest“, „Die Pullichi“) und Witwenstücken („Lanassa“, „Jessonda“, „Marie von Montalban“) sind es die Brahmanen bzw. der Oberbrahmane, die auf den Opfertod der Frauen bestehen und die Rettung mit allen Mitteln verhindern wollen. In den auf der „Veuve du Malabar“ beruhenden Stücken „Lanassa“ und „Jessonda“ dringt der Oberbrahmane darauf, dass die Portugiesen den vereinbarten Waffenstillstand einhalten und daher die Witwe nicht mit Waffengewalt gerettet werden dürfe. ${ }^{1089}$ Er selbst aber bricht den Waffenstillstand und lässt heimlich die Portugiesen angreifen, denn „Noth erkennt kein Gesetz“1090, wie er in „Lanassa“ argumentiert. Als das misslingt, will er die Witwe trotz der nahenden Rettung durch die Portugiesen noch schnell verbrennen lassen oder notfalls sogar selbst töten. ${ }^{1091}$ Er lässt sich von keinem Appell für mehr Menschlichkeit umstimmen, und auch als er selbst am Ende tödlich verwundet ist, weist er ein Versöhnungsangebot des portugiesischen Heerführers verächtlich zurück. ${ }^{1092}$ Auch in „Marie von Montalban“ wendet der Oberbrahmane eine List an, um die von den Portugiesen gerettete Witwe doch noch zu verbrennen. Ein Motiv der Figur des durchweg negativ gezeichneten Oberbrahmanen der drei genannten Stücke ist die Rache - sowohl an den Portugiesen, als auch an der Witwe. Dieses Motiv ist besonders in „Marie von Montalban“ beherrschend. ${ }^{1093}$ Der Oberbrahmane will jedoch nicht nur Rache für seine eigene Ehre, sondern auch für die Götter. Denn zumindest in „Jessonda“ wird deutlich, dass der Oberbrahmane nicht (nur) aufgrund persönlicher Interessen den Opfertod verlangt, sondern tatsächlich selbst an die Lehre zu glauben scheint, dass die Götter dieses Opfer verlangen. Als sein heimlicher Angriff auf die Portugiesen misslingt und ein Donner

\footnotetext{
${ }^{1086}$ De Zoysa: "Blutrünstige Braminen am heiligen Strome“, S. 154

${ }^{1087}$ De Zoysa: "Blutrünstige Braminen am heiligen Strome“, S. 154

${ }^{1088}$ De Zoysa: "Blutrünstige Braminen am heiligen Strome“, S. 155

${ }^{1089}$ Vgl. Gehe: Jessonda, S. 31

1090 Plümicke: Lanassa, S. 74

${ }^{1091}$ Vgl. Gehe: Jessonda, S. 42-44

1092 Vgl. Plümicke: Lanassa, S. 84

1093 Vgl. Plümicke: Lanassa, S. 83; Winter: Marie von Montalban, S. 9; Gehe: Jessonda, S. 38
} 
ertönt, deutet er das als Zorn der Götter über die abtrünnige Witwe. Durch ihren Tod will er die Götter besänftigen. ${ }^{1094}$

In dem Opferstück „Das Schlangenfest“ stehen sich zwei verschiedenen Schulen der Brahmanen gegenüber. Während die Priester des Sonnengottes in ihren Ansichten gar nicht so weit von denen der Europäer entfernt sind und die Menschenopfer zunächst eher aus Gewohnheit dulden, sie am Ende aber verbieten, bestehen die Priester des Jaka, des Opfergottes, auf dieser Tradition. Sie wollen die Europäer loswerden aus Angst, diese könnten ihnen die Opferungen verbieten. Dafür greifen sie auch auf Trug und List zurück und fühlen sich dabei im Recht, denn der „Zweck rechtfertiget die Mittel - der Himmel sieht auf das Innere, die Gottheit kennt unser Herz. “1095 In dem anderen Opferstück Henslers, „Das Sonnenfest“, ist es auch der Brahmane, der auf der Tradition des Menschenopfers besteht. Allerdings handelt er nicht nur aus uneigennützigen oder seiner ganzen Kaste Vorteile verschaffenden Motiven heraus. Für ihn erfüllt die bevorstehende Opferung einen anderen, ganz konkreten Zweck. Er begehrt das für das Opfer ausersehene Mädchen für sich als seine Frau. Dieses Ziel möchte er mit Hilfe der Tradition erreichen, dass ein Opfer durch den Hochzeitsantrag eines Brahmanen freigekauft werden kann. Während die anderen bislang beschriebenen Brahmanen tatsächlich überwiegend aus religiösen Motiven heraus handeln (denn auch ihre Rache soll vor allem die Götter rächen), ist es bei diesem Brahmanen ein persönlicher, weltlicher Gewinn, der ihn zum Handeln treibt.

Auch in „Die Pullichi“ handeln die Priester heimtïckisch. Ihnen geht es vor allem um ihre persönliche Macht und die Macht der Priesterkaste. Das spricht der Oberpriester auch ganz deutlich aus, als er dem zum Vezir aufgestiegenen europäischen Schiffbrüchigen einen Pakt zur Ermordung des Herrschers anbietet: „Unsere Gewalt und Gewinn verschlinge sich, wenn du willst, mit dem Deinigen in Eins. Die Natur gab uns diese Indier preis. Wir benutzen sie zu unserem Glück und Vergnügen. [...] Wir verlangen von dir Ungestörtheit, das Volk glauben zu machen, was wir wollen. “ ${ }^{1096}$ Als der Vezir dieses Ansinnen entrüstet ablehnt, richtet sich der Hass der Priester auf ihn. Ihn mit freundlichen Worten umschmeichelnd wollen sie ihn hinterrücks ermorden.

\footnotetext{
1094 Vgl. Gehe: Jessonda, S. 38f.

1095 Hensler: Das Schlangenfest, S. 58

${ }^{1096}$ Zumbach: Die Pullichi, S. 86
} 
Hier wird die in den Sachtexten häufige Kritik, die Brahmanen hielten das Volk absichtlich in Aberglauben, um es beherrschen zu können, auf die Bühne gebracht.

Neben den Opfer- und Witwenstücken sind es vor allem die Texte, in denen es um die Ausgrenzung der Paria geht, in denen die Figur des bösen/machtbewussten Brahmanen eine Rolle spielt. In Beers Stück „Der Paria“ ist das nur eine Nebenrolle, da die Brahmanen in keiner Hauptrolle auftreten. Aber sie werden von dem Paria als „listige Priester“1097 bezeichnet. Und der sich nahende Brahmane, der den Paria zum Opfer holen soll, wird als heranrückende Gefahr inszeniert, da er es sein wird, der das Opfer vollzieht. In dem Stück „Der Paria“ von Delavigne zweifelt der Brahmane zwar zuweilen an seinem Leben als Priester, aber das Todesurteil für einen Paria, der sich unerlaubt nähert, spricht er ohne zu zögern und lässt sich auch nicht durch die Bitte seiner eigenen Tochter um Gnade umstimmen. Ihn lenken wie die Oberbrahmanen in den Witwenstücken vor allem religiöse Überzeugungen und er fühlt sich als der Vollstrecker „,des Himmels Zorn“1098. Nicht grausam, aber dennoch sehr machtbewusst sind die Brahmanen in „Die indische Hütte“. Sie wollen in der konkreten Handlung niemanden opfern, aber sie sind überheblich und auf ihr eigenes Ansehen und ihren Abstand zum einfachen Volk bedacht und genießen ihre Macht.

Die Darstellung der Brahmanen in den genannten literarischen Texten ähnelt insofern derjenigen der Sachtexte, als auch in den Sachtexten die Brahmanen häufig als machtbewusst und gierig dargestellt werden. Auch sind sie in einigen Berichten über Witwenverbrennungen die treibende Kraft. Allerdings finden sich in den Sachtexten keine Beschreibungen eines „blutrünstigen Braminen“, der Menschenopfer zelebriert. Daher vermutet De Zoysa dessen Quelle nicht in Reiseberichten oder Lexikonartikeln, sondern in dem oben erwähnten literarischen Vorbild des heidnischen Opferpriesters. ${ }^{1099}$ In den machtbewussten/grausamen Brahmanen inszenieren viele Autoren den Klerus der anderen Kultur als fremd und rückständig. Neben der Faszination für das Exotische geht es dabei im Kontext der Aufklärung auch um Kritik, die sich nicht nur auf Indien bezieht, sondern auch Aspekte der eigenen Kultur im Sinn haben kann: die Kritik an Irrationalität und Aberglauben und die Kritik an dem Machtbewusstsein und der manipulativen Kraft des Klerus. Indem Aspekte der

\footnotetext{
1097 Beer: Der Paria, S. 40

${ }^{1098}$ Lewald: Der Paria, S. 66

1099 Vgl. De Zoysa: "Blutrünstige Braminen am heiligen Strome“, S. 153f.
} 
indischen Kultur als komplementär zur europäischen Aufklärung inszeniert werden, dienen sie als Beispiel für das zu überwindende vormoderne Denken.

\subsubsection{Der zweifelnde Brahmane}

Ein anderer Typus ist der zweifelnde Brahmane. Er tritt zusammen mit dem bösen Brahmanen auf, wenn auch deutlich seltener als dieser. Er findet sich vor allem in den an der „Veuve du Malabar“ orientierten Witwenstücken „Lanassa“ und „Jessonda“. Dort soll ein junger Brahmane die Witwenverbrennung vorbereiten, aber er bekommt Zweifel und entscheidet sich, der Witwe zu helfen. In „Jessonda“ betont der Brahmane, er sei nicht durch freie Wahl, sondern bereits in jungen Jahren in diese „Sekte“ gekommen, die ihm „schwere Pflichten“1100 auferlege. Er leidet darunter, dass es das Ziel der Brahmanen sei, dass der Leib sterbe, damit der Geist lebe. Der junge Brahmane aber sehnt sich nach dem Leben. ${ }^{1101}$ Bislang gehorchte er dem Oberbrahmanen, aber als er als Todesbote zur Witwe geschickt wird, ist es für ihn, als erwache er aus „dumpfer Nacht zum göttlichen Leben“1102 und er entscheidet sich gegen das asketische Dasein der Brahmanen und für das Leben und zwar sowohl für ihn selbst als auch für die Witwe.

Während sich der Brahmane in „Jessonda“ sofort in die Schwester der Witwe verliebt und sich schnell entscheidet, den Frauen zu helfen, ist der junge Brahmane in „Lanassa“ zunächst voller Zweifel. Er weiß nicht, ob sein Erschaudern bei Witwenverbrennungen „blos weichliches Gefühl ohne Menschenliebe“ oder „Schwärmerei“1103 ist und er bittet, von „dieser strafbaren Empfindlichkeit“1104 geheilt zu werden. Er fleht um Zeit, damit er die Wahrheit erkennen könne, da Tugend nur mit Überzeugung möglich sei, und er grübelt über Ursprung und Sinn der Witwenverbrennung. Er kritisiert den „blinden Eifer meiner Obern“1105, fühlt sich aber verpflichtet, ihrem Befehl zu gehorchen. Wie der Brahmane in „Jessonda“kam auch er bereits sehr früh zum Tempel. Dort wurde er zunächst von einem alten Brahmanen erzogen, der dem Typus des weisen Brahmanen entspricht und der ebenfalls unter den „rauhen Gesetzen“ 1106 der

\footnotetext{
${ }^{1100}$ Gehe: Jessonda, S. 5

${ }^{1101}$ Vgl. Gehe: Jessonda, S. $6 f$.

1102 Gehe: Jessonda, S. 14

${ }^{1103}$ Plümicke: Lanassa, S: 8f.

${ }^{1104}$ Plümicke: Lanassa, S. 9

1105 Plümicke: Lanassa, S. 24

1106 Plümicke: Lanassa, S. 26
} 
Brahmanen gelitten habe. Von ihm habe der junge Brahmane gelernt, die Menschen zu lieben. Bei den übrigen Priestern aber erblicke er nur „unlautre Absichten, Härte, Unmenschlichkeit“1107. Auch dieser Brahmane entscheidet sich schließlich dazu, sich gegen den Oberbrahmanen zu stellen und der Witwe $\mathrm{zu}$ helfen. Die Figur des zweifelnden Brahmanen dient in den Texten dazu, die Kritik an bestimmten indischen Traditionen zu vertiefen, da diese nun nicht mehr nur von außen aus dem Mund der europäischen Eroberer kommt, sondern von innen heraus entsteht.

Anders ist es bei dem Brahmanen in Lewalds „Der Paria“. Er wird nicht von moralischen oder religiösen Zweifeln geplagt, sondern fragt sich, ob sein Weg zur Macht für ihn selbst und sein eigenes Glück die richtige Entscheidung gewesen ist. Sein Ziel im Leben sei es gewesen, als oberster Priester höchste Verehrung und Macht zu erlangen. Dieses Ziel habe er auch erreicht, aber nun werde ihm bewusst, wie viel er dafür geopfert hat. Er musste sich selbst dem Leben und der Natur entziehen, durch Fasten, Schweigen und Opfern. Daher fühle er sich, „wie im heil'gen Grab gefangen“1108 und empfindet all sein Wissen als eitel. Andere beneidet er darum, sich auf den „Blumenpfaden“ ${ }^{1109}$ der Natur zu verirren und liebevolle Beziehungen zu pflegen. Anstatt aber sein eigenes Leben zu ändern, versucht der alte Brahmane, seine Macht und Ehre, die er schwinden sieht, mit allen Mitteln zu erhalten, auch wenn er dabei das Glück seiner Tochter zerstört. Denn er kann es nicht ertragen, diese Macht, für die er alles, was das Leben glücklich macht, geopfert hat, nun auch noch zu verlieren.

\subsubsection{Der weise Brahmane}

Der Typus des weisen Brahmanen wurde bereits in der Person des Lehrers des jungen Brahmanen in „Lanassa“ angedeutet. Dort tritt er allerdings nicht selbst in Erscheinung, sondern es wird nur von ihm berichtet. In einigen Texten mit dem Handlungsschema „Suche nach Weisheit“ sowie in dem Drama „Magandola“ spielt er jedoch eine wichtige Rolle. Der Brahmane in „Geschichte eines Braminen“ wird als „wahre(r) Priester, ein(...) Mittler zwischen Gott und den Menschen“"1110 beschrieben. Er führt die

\footnotetext{
1107 Plümicke: Lanassa, S. 27

${ }^{1108}$ Ewald: Der Paria, S. 21

1109 Lewald: Der Paria, S. 20

${ }^{1110}$ Günderrode: Geschichte eines Braminen, S. 312
} 
Hauptperson in die „Weisheit der Braminen“"1111 ein. Als er seinen Tod kommen spürt, möchte er „,in ungestörter Betrachtung des Todes sterben“1112. Diese hier angedeutete Bedeutung, die die Inder der richtigen Vorbereitung auf den Tod zuweisen, wird auch in einigen Sachtexten erwähnt. In „Geschichte eines Braminen“ wird dieser Tod noch dadurch in ein geheimnisvolles Licht gesetzt, dass kurz nach dem Tod ein befreundeter Brahmane ankommt, der bereits von dem Geschehenen weiß und genau aus diesem Grund die Reise angetreten hat.

Die Berichte der Sachtexte, dass die Inder dem Tod sehr gelassen entgegenblicken und es ihnen sehr wichtig ist, sich auf ihr eigenes Sterben gut vorzubereiten, scheint bei einigen Autoren der Romantik auf Resonanz gestoßen $\mathrm{zu}$ sein. Entsprechend bedeutungsvoll ist das Thema Tod auch für den Lehrer Dahore in Jean Pauls „Hesperus“. Fast den gesamten Roman hindurch wartet dieser auf den Tod, von dem er sich Erlösung verspricht. Er scheint ganz genau zu wissen, wann er sterben wird, und bereitet sich darauf vor. Auch er kann als eine Variante des weisen Brahmanen angesehen werden, auch wenn nie gesagt wird, ob er tatsächlich Brahmane ist. Er ist ein indischer Lehrer, der „wie ein Brahmin, von poetischen Blumen“ 1113 zurückgezogen in der Natur lebt. Sein Charakter zeichnet sich durch in gewissem Sinne kindlich-naive Züge aus. In der Abgeschiedenheit der Natur, in einem heiligen Hain, lebt auch der weise Brahmane in dem Schauspiel „Magandola“. Bei ihm spielt der Tod allerdings keine Rolle. Er ist vielmehr in Anlehnung an den Brahmanen Kanna in dem Drama Śakuntalā konzipiert: als weiser Pflegevater des Götterkindes Magandola.

Der Brahmane in dem Stück „Padmana“ ist in gewisser Weise auch ein weiser Brahmane, allerdings entspricht er nicht dem hier geschilderten Typus des weisen Lehrers, der in der Abgeschiedenheit der Natur lebt und seinem Studium und seinen Übungen nachgeht. Der Brahmane in „Padmana“ lebt vielmehr am Hof des Fürsten als dessen Berater. Er zeichnet sich auch nicht durch besondere Gelehrtheit oder Spiritualität aus wie die anderen, sondern ist aufmerksam und klug und erkennt so mögliche Gefahren, die weder der Fürst noch Padmana wahrhaben wollen. Er erfüllt auf diese Weise auch die Funktion eines Ratgebers/Lehrers, allerdings nicht im spirituellen, sondern im weltlichen Bereich, der für dieses Drama auch weitaus

\footnotetext{
${ }^{1111}$ Günderrode: Geschichte eines Braminen, S. 312

1112 Günderrode: Geschichte eines Braminen, S. 313

1113 Jean Paul: Hesperus, S. 681
} 
bedeutender ist, als für die Texte, die die typische Figur des weisen Brahmanen aufweisen.

In der Figur des weisen Brahmanen werden die bereits in der Antike und im Mittelalter beschriebenen Attribute der Ursprünglichkeit, Natürlichkeit, kindlichen Naivität und geheimnisvollen Weisheit, die in der Romantik wieder an Bedeutung gewinnen, idealisiert. Auf diese Art und Weise entsteht die Figur eines idealen Weisen und Lehrers, der seine Weisheit nicht neuen, auf logischem Denken und empirischen Versuchen beruhenden Erkenntnissen verdankt, sondern uralten Überlieferungen und natürlicher Intuition.

\subsection{Der Paria}

In den Sachtexten ist es neben dem Brahmanen, der die größte Aufmerksamkeit erfährt, vor allem der Paria, der die Autoren beschäftigt. Auch in den literarischen Texten spielt er eine Rolle, wenn auch eine deutliche kleinere als der Brahmane und die noch zu betrachtenden Figurentypen der jungen Frau und des jungen Kriegers. Zudem wird der Paria in den literarischen Texten - anders als in den Sachtexten - durchweg positiv dargestellt. Sein niedriger Stand und seine Verachtung durch die indische Gesellschaft werden zwar betont, aber sie weiten sich - anders als in einigen Sachtexten - nicht auf die Wertung durch den Autor und seine Helden aus. Der Paria tritt vor allem in zwei Varianten auf: der weise/hilfsbereite Paria und der sein Glück suchende Paria.

\subsubsection{Der weise/hilfsbereite Paria}

Der weise/hilfsbereite Paria wird zuerst 1791 in der Erzählung „Die indische Hütte“ von Bernardin de Saint-Pierre eingeführt. In der Rolle des „humanen Aufklärer(s)“(1114 wird ihm dort ein so „hohes Ansehen“ ${ }^{1115}$ zuteil, wie sonst kaum einer anderen indischen Figur. Dieser Paria kümmert sich liebevoll sowohl um einen englischen Reisenden als auch um dessen indische Begleiter, obwohl diese ihn als „Mensch, [...] der weder Glauben noch Gesetz hat ${ }^{\text {"1116 }}$ beschreiben und sich weigern, seine Hütte zu betreten. Diese Hütte und ihre Bewohner werden als Inbegriff von Frieden, Harmonie und Glück inszeniert. Sogar Hund und Katze liegen friedlich nebeneinander. In dem

\footnotetext{
${ }^{1114}$ De Zoysa: "Blutrünstige Braminen am heiligen Strome“, S. 116

1115 De Zoysa: "Blutrünstige Braminen am heiligen Strome“, S. 116

1116 Bernadin de Saint-Pierre: Die indische Hütte, S. 355
} 
Paria findet der Reisende auch endlich den langgesuchten Lehrer, der ihn in die wichtigsten Weisheiten der Menschheit einweihen kann. Der Paria schöpft dabei seine an Rousseau erinnernden Lehren direkt aus der Natur. Jeder Mensch sei verpflichtet, selbst die Wahrheit „mit einem einfältigen Herzen“"1117 in der Natur und in seinem Herzen zu suchen. Denn Sinne und Vernunft führten in die Irre. Von diesen Lehren ist der englische Gelehrte so begeistert, dass er am Ende ausspricht: „Ich habe die halbe Welt durchreist und überall nur Irrthum und Zwietracht getroffen; Wahrheit und Glück sind mir erst in Eurer Hütte entgegengekommen." ${ }^{1118}$

In den anderen beiden Texten, in denen die Figur des hilfsbereiten/weisen Parias auftritt, steht vor allem die Hilfsbereitschaft und Gutherzigkeit des Parias/Pullichis im Mittelpunkt. Der Paria in Beers gleichnamigem Stück nimmt einen Krieger bei sich auf und versorgt voll Mitleid seine Wunde, obwohl dieser ihn kurz zuvor als „Ungeheuer“1119 beschimpft und einen Dolch nach ihm geworfen hat. Obwohl der Paria Zweifel hat, ob ihm durch sein Handeln nicht großes Unglück entstehen könne, da er einem Feind helfe, so muss er doch „dem gewalt'gen Drang, dem lauten Schlag des tiefbewegten Herzens “ ${ }^{1120}$ folgen. Er handelt also nicht aus rationaler Überlegung heraus, weil er sich Vorteile verspricht, sondern ganz im Gegenteil: Er handelt gegen die rational begründete Furcht, weil sein Herz es ihm gebietet. Seine Frau verhält sich ganz ähnlich wie er: Auch sie hilft dem Krieger und hindert ihn daran, eine giftige Frucht zu essen, obwohl das bedeutet, dass sie durch ihre Stimme ihre Identität verrät und sich selbst dadurch in Gefahr begibt. Beide Eheleute stellen also die Stimme ihres Gewissens und Herzens über ihre eigene Unversehrtheit. So dramatisch ist es bei den Pullichi nicht. Ihnen droht durch die Rettung und Aufnahme der schiffbrüchigen Europäer keine direkte Gefahr. Hier geht es vielmehr darum, dass sie ihr weniges Essen, das noch nicht einmal für sie allein reicht, mit den Gästen teilen, ihnen sogar die größte Portion zukommen lassen und selbst hungern.

Wie oben bereits beschrieben zielt die Darstellung der indischen Kastenlosen in einigen Fällen nicht nur auf die indische Gesellschaftsordnung, die das Schicksal des Einzelnen so sehr an seine Geburt knüpft, sondern soll die Leser bzw. Zuschauer auch für das

\footnotetext{
${ }^{1117}$ Bernadin de Saint-Pierre: Die indische Hütte, S. 266

1118 Bernadin de Saint-Pierre: Die indische Hütte, S. 410f.

1119 Beer: Der Paria, S. 24

${ }^{1120}$ Beer: Der Paria, S. 26
} 
Schicksal der europäischen Juden sensibilisieren. Dafür ist eine positive Zeichnung der Paria unerlässlich. Gerade diejenigen, die am meisten Unmenschlichkeit erfahren und denen viele Menschenrechte abgesprochen werden, weisen in den hier vorgestellten Stücken ein besonderes $\mathrm{Ma}$ an Menschlichkeit auf. Durch die Übertragung der Problematik auf eine andere Kultur können die Leser mit einer größeren Distanz Probleme der eigenen Gesellschaft betrachten und hinterfragen. ${ }^{1121}$

\subsubsection{Der sein Glück suchende Paria}

Die Parias/Pullichi der eben besprochenen Stücke leiden selbstverständlich darunter, aus der Gesellschaft ausgestoßen zu sein und ohne Rechte und Sicherheit leben zu müssen. Doch sie finden Wege, mit diesem Unglück umzugehen. Der Pullichi in „Die Pullichi“ nimmt sein Schicksal sogar als gerecht hin, da er weiß, dass sein Vorfahr großes Unrecht begangen hat und dafür bestraft wurde. Der Paria in „Die Indische Hütte“ erläutert dagegen detailliert, dass er nur durch das Unglück seiner Abstammung zu den wichtigsten Erkenntnissen und zur Wahrheit gekommen sei, da dieses extreme Leiden ihn zum Nachdenken zwang. Die übrigen Menschen scheint er eher zu bedauern, da auch sie trotz des scheinbaren Glücks leiden, ohne jedoch zu Wahrheit und Frieden zu finden. Der Paria bei Beer hadert mehr mit der Bedrohung durch die Gesellschaft und macht aus seiner Angst heraus Brahmā zunächst Vorwürfe, warum dieser die Paria mit seinem Hass verfolge. Er vermutet, dass es vielleicht die Strafe dafür sein könne, dass ein Paria einst Brahmā die „Huld'gung“1122 verweigert habe. Dann aber besinnt er sich: Nicht Brahmā stoße die Paria von sich, denn er sei der Schöpfer der Natur, dessen „heiliges Gesetz [...] Lieb' und Duldung“ ${ }^{1123}$ heiße. Vielmehr seien es die Priester, die durch ihre Lügen die Paria erniedrigten. Dieser Glauben an die Güte Brahmās gibt dem Paria Stärke. Aber er spürt in sich auch die männliche Kraft, die sich nur ,am Licht der That“1124 , also innerhalb der Gesellschaft entfalten und beweisen könne. Doch er zügelt diese Wünsche und fügt sich seinem Schicksal. Keiner dieser Ausgestoßenen, die dem Typus des weisen/hilfsbereiten Paria entsprechen, versucht, gegen seine Situation aufzubegehren. Finden sie wie in „Die indische Hütte“ ihr Glück, so liegt es außerhalb des gesellschaftlichen Miteinanders.

\footnotetext{
${ }^{1121}$ Vgl. De Zoysa: "Blutrünstige Braminen am heiligen Strome“, S. 125-133

1122 Beer: Der Paria, S. 9

1123 Beer: Der Paria, S. 9

${ }^{1124}$ Beer: Der Paria, S. 10
} 
Anders ist es bei dem Typus Paria, der sein Schicksal in die Hand nimmt und versucht, sein Glück innerhalb der Gesellschaft zu finden. Ein markantes Beispiel dafür ist Idamor aus dem Stück von Delavigne. Er verlässt seine geschützten Wälder und seinen Vater und will sich als Krieger beweisen. Auch er sieht die Schuld an seinem Unglück bei den Priestern:

\begin{abstract}
Ich trüg' die Last, die die Geburt mir schon so riesig auf die Schultern wälzte, ruhig, nicht hätte mich's zur Raserey gebracht, wenn sie mein Stamm durch Frevel sich verdiente. - Nicht klag' ich dich drob an, erhabner Schöpfer! Doch jene Auserwählten Brama's zeih ich der Lüge und es des Hochmuths, deren Stimme sein Wort verkündet, seine Sprache deutet. ${ }^{1125}$
\end{abstract}

Er könnte wie der Pullichi das Unglück ertragen, wenn er es wie dieser als gerechte Strafe ansehen würde. Aber da er es den Lügen der Brahmanen anlastet, lehnt er sich dagegen auf - zunächst innerlich, dann auch durch Taten. Allerdings versucht er nicht, das Schicksal der Paria insgesamt zu verbessern, er kämpft nicht für seine Rechte als Paria, sondern er gibt sich als Krieger aus und sucht so das Glück nur für sich bzw. für eine von ihm geschaffene Kunstfigur. Dieses Glück aber ist trügerisch und muss scheitern. Er kann zwar in seiner Rolle als Krieger den Angriff eines feindlichen Heeres abwehren und dadurch große Anerkennung der Gesellschaft erlangen. Aber trotz dieses Beweises, dass ein Paria aufgrund seiner Anlagen den Angehörigen anderer Kasten ebenbürtig ist, verhindern die Lüge und die mit der Entdeckung verbundene Empörung der Menschen eine allgemeine Anerkennung des Parias Idamor als gleichwertiges Mitglied der Gesellschaft. Die traditionelle Verachtung der Paria wiegt für die Menschen höher als die tatsächlichen Taten Idamors.

Ein anderer Paria, der sich gegen sein Unglück auflehnt, ist der Paria in Goethes PariaTrilogie. Ihm geht es jedoch nicht darum, sich selbst unter den Menschen zu beweisen, sondern er wendet sich auch im Namen seiner Leidensgenossen direkt an Brahmā. Denn anders als die meisten anderen Paria duldet er die Verachtung der Menschen durchaus. Er folgt sogar deren Auffassung und sieht sich selbst und die Paria ebenfalls als unedel und schlecht an. Aber er möchte ein Zeichen, dass sie dennoch Brahmās Kinder sind.

${ }^{1125}$ Lewald: Der Paria, S. 5 
Daher bittet er Brahmā um einen eigenen Gott für die Paria, was Brahmā ihm auch erfüllt. Glücklich erkennt er Brahmā nun als „Schöpfer [...] der Welten““1126 an. ${ }^{1127}$

\subsection{Die junge Frau}

Eine Figur, die in kaum einem Schauspiel mit dem Thema Indien fehlen darf (in den Gedichten und Erzählungen ist sie weniger vertreten) ist die junge Inderin. Sie zeichnet sich durch ihre Schönheit aus, für die sie von den Männern gepriesen wird. Die meisten dieser jungen Frauen sind liebevoll und zart, können aber, wenn es darauf ankommt, auch sehr mutig sein. Man kann zwei Haupttypen unterscheiden: Die Frauen des ersten Typs werden als naturverbunden, unverdorben, naiv und kindlich geschildert, die des zweiten Typs gehören der Oberschicht an, sind z.B. Mitglieder des Hofes. Da zum Teil auch Hofdamen einige der Attribute des ersten Typs aufweisen, sind die Übergänge zwar fließend, die Haupttendenzen lassen sich aber dennoch gut erkennen. Zu diesen Haupttypen kommt noch die eher selten als Hauptperson auftretende Bajadere hinzu.

\subsubsection{Das Naturkind/Götterkind}

Während die Dame am Hof keine typisch indische Figur ist, sondern auch in anderen kulturellen Kontexten vorkommt und sich von den europäischen Damen kaum unterscheidet, weist das Naturkind/Götterkind viele der Eigenschaften auf, die in den Sachtexten als charakteristisch für Inder beschrieben werden: Sie ist hilfsbereit, voll Mitgefühl, kindlich-naiv, ungekünstelt, direkt, sanftmütig. Die einzelnen Personen dieses Typus verteilen sich zwischen den Polen des an der Śakuntalā orientierten naturverbundene Götterkindes und des naiv-fröhlichen Mädchens. Jenem entspricht am meisten Magandola aus dem gleichnamigen Schauspiel, diesem das Mädchen Gurli aus „Die Indianer in England“.

Magandola wächst - wie Śakuntalā - bei einem Brahmanen inmitten von Blumen und wilden Tieren in einem verborgenen Tal auf. Da dort anders als bei der Śakuntalā aber nicht noch weitere Einsiedler und Mädchen leben, kennt Magandola die Menschen

\footnotetext{
1126 Goethe: Paria, S. 455

${ }^{1127}$ Goethes Paria hat sowohl die zeitgenössischen Leser als auch die Forschung häufig etwas ratlos zurückgelassen. Warum inszeniert Goethe hier eine neugeschaffene Göttin als Erlösung und Hoffnung für die Paria, die ebenso monströs anmutet, wie es die von Goethe so scharf zurückgewiesenen indischen Götter tun? Auf diese Fragen näher einzugehen, würde hier zu weit führen, da ich hier lediglich die verwendeten Bilder und Themen vorstellen möchte. Für weiterführende Analysen vgl. z.B. Blumenthal, Lieselotte: Goethes „Paria“. In: Jahrbuch des Wiener Goethe-Vereins 81/83 (1977/79), S. 185-200; Mayer, Mathias: Paria. In: Otto, Regine und Bernd Witte (Hgg.): GoetheHandbuch. Band 1: Gedichte. Stuttgart u. Weimar 1996, S. 478-481
} 
nicht und ist in dem Umgang mit ihnen völlig unerfahren. Sie ist kindlich-naiv, gläubig und fromm, aber sie spürt auch eine unbekannte Sehnsucht, die sie zunächst nicht zu deuten vermag. Diese Sehnsucht zielt zum einen - wie bei den meisten Mädchen des Typs Naturkind - auf die erwachende Liebe zu einem Mann, zum anderen aber spürt sie in sich die Aufgabe, Frieden zu bringen. Denn wie sich herausstellt, ist Magandola die Tochter der Göttin Ganga, die ihr diese Aufgabe zugedacht hat. Auch darin erinnert sie an Śakuntalā, die die Tochter einer Nymphe des niederen Himmels ist. Als sie sich ihrer Aufgabe bewusst wird, ist sie mutig und stark und stellt sich den Gefahren.

Kein Götterkind, aber doch durch ihre hohe Stellung als Prophetin von Kaschmir ausgezeichnet, ist auch Tamajandri aus dem Roman „Die Prophetin von Caschimir“ in gewisser Weise ein durch ihre „kindliche Frömmigkeit“ 1128 charakterisiertes Naturkind. Zwar ist sie durchaus mit der Welt bekannt, aber die meiste Zeit lebt sie zusammen mit ihrem Reh - zurückgezogen in einer Hütte in der Natur, um ihren Übungen und Ritualen nachzugehen. Auch sie zeichnen eine „angeborne Güte ihres Herzens“"1129, das „eben so zart als tiefempfindend“"1130 ist, aus. Ihr „,tiefes, zärtliches Gefühl“ und ihre „ungefärbte(...) Einfalt“ sind nicht „durch die Außenseite der Convenienz verschleiert, oder unter Künsteleien versteckt“, wie es „in einem ausgebildeteren Zustande der geselligen Verhältnisse“ ${ }^{\text {(1131 }}$ geschieht. Sie weist damit wie die übrigen Personen dieses Typus einen Charakter auf, der nicht durch die Regeln und Gepflogenheiten der Gesellschaft verzerrt worden ist, sondern noch der Natur entspricht und an Rousseau denken lässt. Allerdings haben die kulturellen Vorstellungen sie schon so weit geprägt, dass ihr einige Vorurteile und Ansichten der brahmanischen Oberschicht als völlig natürlich erscheinen. Sie ist im Vergleich zu der männlichen Hauptperson zunächst eher die Schwache, am Ende aber ist sie es, die sich für ihn opfert und ohne zu zögern den eigenen Tod auf sich nimmt, um ihn zu retten.

Sowohl bei Mangandola als auch bei Tamajandri, die in gewisser Weise als das weibliche Pendant des weisen Brahmanen angesehen werden können, sind die Naturverbundenheit und Natürlichkeit eng mit ihrer Frömmigkeit verbunden. Dagegen beruhen sie bei den sich stark ähnelnden Mädchen Tita („Das Schlagenfest“), Bella

\footnotetext{
1128 Tarnow: Die Prophetin von Caschimir. Erster Theil, S. 128

1129 Tarnow: Die Prophetin von Caschimir. Erster Theil, S. 107

1130 Tarnow: Die Prophetin von Caschimir. Erster Theil, S. 112

1131 Tarnow: Die Prophetin von Caschimir. Erster Theil, S. 114
} 
(„Das Sonnenfest“), Odahy („Die Pullichi“) und Gurli („Die Indianer in England“) darauf, dass sie (aus verschiedenen Gründen) sehr zurückgezogen leben und dadurch wenig Kontakt zu gesellschaftlichen Gepflogenheiten haben. Alle vier leben allein mit ihrem Vater und z.T. mit einem Vertrauten des Vaters sowie Geschwistern ohne viel Kontakt zu anderen Menschen. Am ehesten ist Bella in die Gesellschaft eingebunden, aber auch sie wird vor allem im familiären Kontext geschildert. Während Odahy aufgrund ihrer Zugehörigkeit zu den Pullichi von der Gesellschaft ausgeschlossen ist, wurden die Väter von Tita und Gurli aus politischen Gründen vertrieben, weshalb ihre Töchter nicht am Hof, sondern abgeschieden von der höheren Gesellschaft aufwachsen. Tita, Bella und Odahy zeichnen sich durch ihr großes Herz, ihr Mitgefühl und ihre Hilfsbereitschaft aus. Sie sind mit ihrem einfachen Leben zufrieden und werden als kindlich-naiv, unschuldig, ungekünstelt, offen und direkt beschrieben. Sie besorgen sich ihre Nahrung selbst, indem sie z.B. Fischen gehen. Als sie sich in einen Mann verlieben, verstehen sie zunächst das ihnen unbekannte Gefühle der Liebe nicht. Sie sprechen aber sehr offen und direkt sowohl über ihre Gefühle als auch über ihre Wünsche und Abneigungen. Sie können aber auch mutig und entschlossen sein, wenn es darum geht, ihren Geliebten zu retten. Gurli unterscheidet sich von den drei eben beschriebenen Mädchen dadurch, dass sie in Europa unter weitaus besseren Bedingungen lebt und zumindest während der Dramenhandlung keine Nöte oder Gefahren kennt. Sie kommt dadurch auch kaum in eine Situation, in der ihre Hilfsbereitschaft gefordert wäre, die daher auch nicht thematisiert wird. Die übrigen genannten Eigenschaften treffen aber auch auf sie $\mathrm{zu}$ und werden in deutlich überzogener Weise dargestellt. Gurli ist noch deutlich direkter in ihren Äußerungen, versteht ihre Sehnsucht nach Liebe deutlich weniger und ist auch deutlich naiver und kindlicher. Während Tita hin und wieder in der dritten Person von sich selbst spricht, macht Gurli das durchgehend. Auch versteht sie von gesellschaftlichen Regeln und Konventionen noch weniger als die zuvor genannten Mädchen. Während Magandola der Śakuntalā in vielem nachempfunden wurde, repräsentiert die noch vor der Śakuntalā-Übersetzung Forsters geschaffene Gurli einen ganz anderen Typus des Menschen im Naturzustand. Bei ihr steht die Ungezwungenheit und das Ungekünstelte ihres Verhaltens im Vordergrund. ${ }^{1132}$ Magandola dagegen gehört in den Kontext der

\footnotetext{
${ }^{1132} \mathrm{Zu}$ der Figur Gurli in Bezug auf den „Edlen Wilden“ vgl. Zhang, Chunjie: German Indophilia, Feminity, and Transcultural Symbiosis around 1800. In: Fuechtner, Veronika u. Rhiel, Mary (Hg.): Imagining Germany Imagining Asia. Essays in Asian-German Studies. New York 2013, S. 204-219, hier S. 209-216
} 
romantischen Vorstellungen einer ursprünglichen Naturoffenbarung und eines intuitiven Wissens in der Kindheit der Menschheit.

Die Inszenierung einer Inderin als reines, unschuldiges und oft auch naives Naturkind erlaubt die Übertragung von Motiven des „Edlen Wilden“ (vgl. Kapitel 5.4) auf Indien, obwohl Indien aufgrund seiner alten Hochkultur ansonsten nicht in dieser Rolle fungiert. Dementsprechend ist es für eine solche Inszenierung notwendig, dass die Inderin bereits früh der Einflusssphäre der indischen Kultur entzogen ist: Sie wächst als Einsiedler im Wald auf oder wurde aus ihrer eigentlichen sozialen Stellung vertrieben. ${ }^{1133}$

Eine interessante Variante dieses Figurentyps ist auch Serafine in dem gleichnamigen Gedicht von Mereau. Auch sie wird zunächst wie ein Götterkind inszeniert. Eine Unbekannte setzt sie bei einem Einsiedler aus, bei dem sie in einem geheimen Tal aufwächst. Daher ist auch sie zunächst nicht mit anderen Menschen und ihrer Lebensweise vertraut. Immer wieder wird auch ihre besondere Schönheit, sowohl des Körpers als auch der Seele, betont und mehrfach fragen sich die Menschen, ob sie eine Nymphe oder ein anderes himmlisches Wesen sei. Darin gleicht sie also dem Figurentyp des Götter-/Naturkindes in der Art der Śakuntalā. Im Laufe des Gedichts stellt sich allerdings heraus, dass sie zwar aufgrund ihres abgeschiedenen Lebens die Naivität des Naturkindes aufweist, alle anderen Vermutungen, die man als Leser zunächst hat, jedoch nicht der Realität entsprechen: Sie ist kein Kind von Göttern oder Nymphen; sie ist noch nicht einmal Inderin. Vielmehr stammt sie - ohne es zu wissen ursprünglich aus Spanien und der Einsiedler ist ihr nichts davon ahnender Vater. Er entspricht auch nicht - wie man zunächst vermuten könnte - dem Typus des weisen Brahmanen, da er sich mit der Beschwörung von Geistern und Nymphen beschäftigt. Und sogar das paradiesische Tal, in dem die beiden leben, entpuppt sich als bloßes Trugbild und Zauberei. Mereau spielt hier mit den vor allem aus der Śakuntalā vertrauten Figurentypen, Landschaften und Handlungsmotiven und nutzt sie, um beim Leser bestimmte Erwartungen zu wecken, die jedoch nicht erfüllt werden. ${ }^{1134}$

\footnotetext{
${ }^{1133}$ Die Frauen bieten sich für diese Rolle auch deswegen an, weil im 1800 nicht nur den „Edlen Wilden“ eine natürliche Unschuld zugeschrieben wird, sondern häufig auch jungfräulichen Mädchen (vgl. Zhang: German Indophilia, Feminity, and Transcultural Symbiosis around 1800, S. 211). Die hier beschriebenen Inderinnen vereinigen in sich beide Aspekte.

${ }^{1134}$ Für einen detaillierteren Vergleich mit der Śakuntalā vgl. Grenzmann: Zur frühen deutschsprachigen Rezeption von Georg Forsters Sakontala-Übertragung von 1791, S. 246-256.
} 


\subsubsection{Die Dame am Hof und ihre Vertraute}

$\mathrm{Zu}$ dem Typus der Dame gehören die Witwe des Rajas, Jessonda, und die Witwe eines vornehmen Inders, Lanassa, aus den gleichnamigen Stücken. Hinzu kommen Padmana, die Ehefrau eines indischen Fürsten („Padmana“), Amra, die Adoptivtochter des Gouverneurs („Der Hindu“), Nerissa/Ewana, die angebliche Schwester des Sultans („Udohla“) und Neala, die Tochter des Oberbrahmanen („Der Paria“). Dieser Figurentypus zeichnet sich durch große Schönheit aus, die die Bewunderung der Männer auf sich zieht. Die Handlung entsteht aus verschiedenen Ansprüchen und Wünschen, die andere an sie richten, während die Damen selbst kaum aktiv zum Geschehen beitragen. Eine Ausnahme stellt in dieser Hinsicht Padmana dar, die durch List in die Handlung eingreift und am Ende sogar bereit ist zu kämpfen, auch wenn es nicht mehr dazu kommt. Ansonsten teilen die Damen deutlich weniger gemeinsame Charaktereigenschaften als die Naturkinder. Viele von ihnen könnten - mit anderem Namen und in einer anderen Handlung - auch an europäischen Höfen auftreten. Sie sind eher durch ihre Funktion innerhalb der Handlung gekennzeichnet als durch eine spezielle Charaktereigenschaft. Dennoch werden auch sie größtenteils als mitfühlend, sanft und auf das Wohl anderer bedacht beschrieben. De Zoysa weist darauf hin, dass diese Unschuld und Sanftmut dem Frauenideal der Zeit entspricht und daher möglicherweise auch eigene zeitgenössische Ideale auf die indische Welt projiziert werden. ${ }^{1135}$

Anders als die Dame selbst ist die Vertraute, die viele von ihnen begleitet, eher zum Handeln bereit. Amazili und Palmira ermuntern Jessonda bzw. Lanassa dazu, sich zu retten bzw. auf die Rettungsangebote anderer einzugehen. Jessonda und Lanassa sind dagegen zunächst zurückhaltend, da sie niemanden ihretwegen in Gefahr bringen möchten. Besonders tatkräftig aber ist Padmanas Vertraute Dewajani. Diese geht als Padmana verkleidet in das Lager der Feinde und versucht dort, als ihre List auffliegt, Padmanas Gegenspieler zu erdolchen und nimmt dafür sogar ihren eigenen Tod in Kauf. 


\subsubsection{Die Bajadere}

Bajaderen, die in den Sachtexten als eine Mischung aus Tempeldienerinnen, Tänzerinnen und Prostituierten dargestellt werden, treten auch in einigen literarischen Texten auf. Normalerweise handelt es sich um Nebenrollen. Die Bajaderen treten in einer Gruppe als ein Kollektiv oder eine Art Chor auf. So begleitet z.B. ein Chor von Bajaderen in „Jessonda“ die Brahmanen, um das anstehende Ritual der Witwenverbrennung anzukündigen und mitzugestalten. Sie erfüllen damit eine sehr ähnliche Funktion wie Chöre in anderen Dramen auch: Sie kündigen Ereignisse an, kommentieren das Geschehen und bringen in ihrer Rolle als Tempeldienerinnen in gewisser Weise die kollektiven Ansichten und Urteile zwar nicht des Volkes allgemein, aber doch der religiös-klerikalen Gemeinschaft zum Ausdruck. Auf der Bühne sorgen sie durch ihren Auftritt auch dafür, ein exotisches Ambiente zu schaffen. Auch in der Oper „Die Bajadere“ gibt es einen Chor von Bajaderen, der eng mit der Ausführung von religiösen Zeremonien verbunden ist. In „Das Sonnenfest“ erfüllen Tänzer und Tänzerinnen ebenfalls ihre Rolle bei einer religiösen Zeremonie (hier allerdings einem Opfer). Als ein Attribut Indiens, dass dieses Land eindeutig als solches ausweist, treten sie in „Die indische Hütte“ ganz kurz auf, indem sie singend und tanzend den englischen Reisenden in der Nähe des Tempels begrüßen. In diesen Texten dienen die Bajaderen zwar als Tänzerinnen der Unterhaltung des Theaterpublikums bzw. Lesers, innerhalb des Textes sind sie aber vor allem in der Funktion der Tempeldienerin zu sehen. Anders ist es in Vulpius” „Die Portugiesen in Indien“. Dort werden die Tänzerinnen nicht mit dem Dienst im Tempel, sondern allein mit Auftritten auf Feiern in Verbindung gebracht.

In den hier untersuchten Texten tritt eine Bajadere nur zweimal als Hauptperson auf: In Goethes „Der Gott und die Bajadere“ und in der Oper „Die Bajaderen“. In beiden Texten geht es darum, dass eine Bajadere beim (vermeintlichen) Tod ihres Geliebten ihre Treue und Bereitschaft, sich für den Geliebten zu opfern, beweist. Ansonsten aber unterscheidet sich die Darstellung der Bajadere in beiden Texten sehr. Bei Goethe ist die Bajadere eine Prostituierte im Haus der Liebe, die sich um den auf die Erde gekommenen Gott Mahadöh kümmert. Dieser erkennt aber ihr „menschliches Herz“ durch „tiefes Verderben“1136 und stellt sie auf die Probe. Sie verliebt sich in ihn und aus dem vormals künstlichen Verhalten wird „Natur“. ${ }^{1137}$ Diese Liebe und Treue geht

\footnotetext{
1136 Goethe: Der Gott und die Bajadere, S.151

${ }^{1137}$ Goethe: Der Gott und die Bajadere, S 151
} 
soweit, dass sie sich nach seinem Tod wie eine Witwe mit ihm verbrennen möchte. Goethe inszeniert hier die Läuterung einer Prostituierten, die zunächst Liebeshandlungen nur mechanisch und für einen bestimmten Zweck verrichtet, die dann aber durch den Gott lernt, was wahrhafte Liebe bedeutet und die ihre Berufung in der bedingungslosen Liebe findet. ${ }^{1138}$ In der Oper ist die Bajadere dagegen ein angesehenes Mitglied der Tempeldienerinnen. Sie weigert sich, dem Werben des Königs nachzugeben, obwohl auch sie ihn liebt. Aber sie fühlt sich an ihre Gelübde gebunden. Erst als der König schwer verwundet ist, ändert sich das. Er braucht nach den Vorstellungen der Brahmanen eine Ehefrau, um nach dem Tod von Brahmā aufgenommen zu werden. Als sich jedoch keine Frau zu einer Ehe breit erklärt, da sie als Witwe ebenfalls sterben müsste, fühlt die Bajadere sich nicht mehr durch ihr Gelübde gebunden und stimmt der Ehe mit dem König zu. In beiden Texten erfährt die Bajadere eine positive Darstellung. Dabei wird ihr gutes Herz ähnlich wie bei den Paria gerade durch den Kontrast zu ihrem zumindest zweifelhaften Stand um so mehr hervorgehoben.

\subsection{Der junge Krieger/junge Mann}

Als Gegenstück zur jungen Frau tritt in vielen Texten der junge Krieger bzw. der junge Mann auf. Er ist oder wird in den meisten Fällen der Geliebte der jungen Frau. In dieser Funktion ist seine Rolle nicht als typisch indisch zu bezeichnen. Dementsprechend kann sie in vielen Texten - vor allem in den Witwen- und Opferstücken - auch von europäischen Heerführern ausgefüllt werden. Die indischen Figuren dieses Typs lassen sich - ähnlich wie die jungen Frauen - danach unterscheiden, ob sie in erster Linie ein Kämpfer oder ebenfalls ein Kind der Natur sind. Anders als bei den jungen Frauen ist hier dieser Unterschied nicht an den sozialen Status geknüpft. Der Raja Rosami (,Der Hindu“) zeigt sehr deutliche Züge des Naturkinds, während der Paria Idamor („Der Paria“) sich zunächst als Krieger profiliert. Zu dem typischen Krieger, der mutig, tapfer und entschlossen ist und für andere kämpft, gehören Badur („,Das Schlangenfest“) und Behadur („Padmana“). Sie sehen in dem Kampf ihre Pflicht, um ihr Land und seine

\footnotetext{
${ }^{1138}$ Zur weiteren Deutung von Goethes Ballade vgl. z.B. Becker-Cantarino: Liebestod, S. 23-28; Laufhütte, Hartmut: Formulierungshilfe für Haustyrannen? Goethe: Der Gott und die Bajadere. In: Wulf Segebrecht (Hg.): Klassik und Romantik. Stuttgart 1984 (Gedichte und Interpretationen; 3), S. 117-143; Wild, Reiner: Der Gott und die Bajadere. In: Otto, Regine u. Witte, Bernd (Hg): Goethe Handbuch. Herausgegeben von Bernd Witte u.a. Band 1: Gedichte. Stuttgart und Weimar 1996, S. 291293; die Frage, inwieweit christliche Motive eine Rolle spielen untersucht u.a. Reinhardt, Hartmut: Dem Fremden freundlich zugetan. Interkulturelle Bezüge in Goethes literarischem Werk. Nordhausen 2012, S.138-143
} 
Einwohner zu retten. Auch Idamor scheint zunächst ein solcher Krieger zu sein, als sich herausstellt, dass er ein Paria ist, wird ihm diese Rolle allerdings verwehrt. Ebenfalls zu dem Typus Krieger gehören die Herrscher Benascar („Der Paria“) und Nagor (,Magandola“). An ihnen werden allerdings auch die Schattenseiten dieses Typs thematisiert. Während Nagor jedoch sehr schnell den Wünschen und Belehrungen Magandolas, keine Gewalt mehr anzuwenden und andere Menschen nicht zu verletzen, folgt und seine Waffen fortwirft, ist Benascar bis fast ganz zum Schluss der Gegenspieler der Hauptpersonen. Er hält lange an seiner Ehre, seinen Wünschen und den gesellschaftlichen Gepflogenheiten fest und stellt diese über das Wohlergehen anderer. Erst als die Katastrophe eingetreten ist, bereut er sein Handeln und versucht zu retten, was noch zu retten ist.

Udohla („Udohla“), Rosami („Der Hindu“) und Fazir („Die Indianer in England“) gehören von ihrem Stand und Alter eigentlich ebenfalls zu dem Typus des jungen Kriegers/jungen Mannes. Allerdings können sie aus verschiedenen Gründen diese Rolle nicht ausfüllen. Sie selbst bzw. ihre Väter sind durch die Europäer, die MogulHerrscher oder Familienauseinandersetzungen ihrer Macht beraubt und - bis auf Rosami - vertrieben worden (das trifft auch auf Nagor zu, doch tritt er dezidiert als Krieger und König auf). Sie gehen allerdings sehr unterschiedlich damit um. Udohla versucht zunächst vergeblich, seinen wegen Aufruhr angeklagten Vater zu retten, dann schwankt er zwischen Selbstmord, Widerstand und Rückzug ins Private und zieht sich am Ende mit seiner Schwester zu seinem Onkel zurück. Wie Udohla verzweifelt auch Rosami an seinem Schicksal. Er lebt noch immer im Zentrum der Macht, am Hof des Gouverneurs, und hat dort auch noch einen gewissen Einfluss auf die indische Bevölkerung. Aber er hadert mit seiner Rolle. Zum einen trauert er der alten goldenen Zeit indischer Freiheit hinterher, zum anderen entspricht er in seinem Charakter weniger einem Krieger als vielmehr einem Naturkind. Er leidet an der Lautstärke und Rohheit der Europäer, zieht sich in die Natur zurück und möchte in die Natur und Träume Kaschmirs fliehen. Rosami ist ein Inbegriff des romantischen Indienbildes und in gewisser Weise eine männliche Variante der Śakuntalā. Er habe eine „,zartgestimmte Seele“1139 und sei „ein Wesen höh'rer Art, Das mehr Gott, als Mensch geboren, Nur im Himmlischen auf Erden Heimisch froh und stark kann werden. “1140 Sein europäischer

\footnotetext{
1139 Sondershausen: Der Hindu, S. 70

1140 Sondershausen: Der Hindu, S. 71
} 
Gegenspieler sieht in ihm allerdings ein „Weichthier ohne Schild und Schaale, Nerv und Muskel ohne Haut‘ ${ }^{\star 1141}$. Er lässt sich nur widerwillig zum Kämpfen überreden und ist auch im Kampf zögerlich. Fazir ist der Sohn des vertriebenen Nabobs von Mysore und musste ebenfalls aus Indien fliehen. Er zeigt allerdings keinerlei Ambitionen, seine vormalige Stellung wiederzuerlangen. Auch er entspricht weniger dem Typ des Kriegers als dem des Naturkindes. Er ist leidenschaftlich, drückt seine Emotionen sehr direkt aus und spricht hin und wieder in der dritten Person von sich selbst. Auch wird

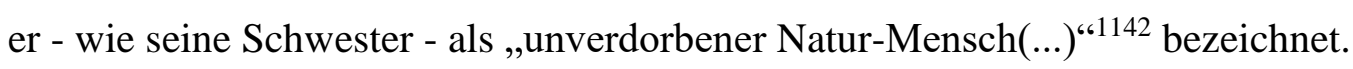

\subsection{Der (schwache) König}

Ein weiterer Figurentypus ist der oftmals schwache König. Diese Personen sind regierende Könige, die aber entweder sehr leichtgläubig sind oder aber dem Einfluss anderer nichts entgegenzusetzen haben. Insofern ist auch diese Figur nicht als typisch indisch zu bezeichnen. Der Samorin in Vulpius' „Die Portugiesen in Indien“ ist insgesamt sehr negativ gezeichnet. Er geht zwar zunächst auf die Portugiesen ein, ist aber von Anfang an sehr an Reichtümern interessiert und lässt sich immer wieder von seinem Katual und muslimischen Kaufleuten beeinflussen und zu Handlungen gegen die Portugiesen hinreißen. Er schafft es nicht, einen festen Standpunkt einzunehmen und diesen auch zu vertreten. Auch bei dem Samorin in „Das Schlangenfest“ haben die Berater einen relativ großen Einfluss. Anders als in dem Stück von Vulpius ist die Gesamtdarstellung des Samorins hier aber positiv. Seine Schwäche besteht nicht darin, dass er sich den Meinungen der Berater unbesehen anschließt. Vielmehr will er ihre Anschuldigungen zunächst prüfen. Aber er bemerkt ihre Intrigen zunächst nicht. Seine Schwäche liegt also vor allem in seiner Unwissenheit. ${ }^{143}$ Interessanterweise will er zwar die von einem als Propheten verkleideten Intriganten vorgebrachten Anschuldigungen gegen die Europäer erst prüfen lassen, aber von den Ausführungen des ebenfalls verkleideten Europäers lässt er sich sofort überzeugen. Im Deutungszusammenhang des Stücks beweist er damit allerdings eher Stärke, da er nun die ,richtige“ Ansicht unterstützt. In dem Stück „Die Pullichi“ sind es nicht die indischen Berater oder Priester, die großen Einfluss auf die Entscheidungen des Souba haben, sondern dessen Tochter sowie ein schiffbrüchiger Europäer, der das Vertrauen

\footnotetext{
1141 Sondershausen: Der Hindu, S. 71

1142 Kotzebue: Die Indianer in England, S. 127

${ }^{1143}$ Vgl. z.B. folgenden Dialog: „Beng. Malai Manao ist ein gerechter König - Mouba. Und würde noch gerachter seyn, wenn er allwissend wäre. Beng. Er liebt sein Volk! Mouba. Desto weniger lieben es seine Höflinge.“ (Hensler: Das Schlangenfest, S. 13)
} 
des Königs gewonnen hat und mit Hilfe seines Einflusses alte indische Traditionen verändern möchte. Die Schwäche des indischen Fürsten in „Padmana“ beruht interessanterweise auf seiner moralischen Stärke: Er hört - anders als die eben besprochenen Herrscher - zu wenig auf seinen Berater und vertraut leichtgläubig und naiv seinem Gegner, da er an das Gute im Menschen glaubt. Damit aber liefert er sich seinem Gegner aus und die Katastrophe nimmt ihren Lauf.

In gewisser Weise sind auch die Herrscher in „Udohla“ und „Die Bajaderen“ schwache Herrscher, da sie nicht ihren Willen vollstrecken können und in ihrer Meinung unsicher und schwankend sind. Die Ursache hierfür liegt in diesen Fällen allerdings nicht in einem schwachen bzw. leichtgläubigen Charakter und einer gewissen Naivität, sondern in äußeren Umständen und Gesetzen, die ihnen die Vermählung mit ihrer Auserwählten verbieten. Abgesehen von diesem problematischen Begehren sind sie in ihren Worten und Handlungen durchaus selbstbewusst und machtvoll.

Ein ganz anderer indischer Herrscher tritt dagegen in Bremers „Tippo-Saib und Laura“ auf. Er ist alles andere als schwach, sondern zeichnet sich durch seine Macht und Grausamkeit aus. ${ }^{1144}$

\subsection{Der vertriebene/ausgestoßene Vater}

In einigen Texten tritt der Vater der Hauptpersonen auf. Dieser Vater lebt mit seinen Töchtern (sofern er welche hat) zusammen, kann von seinem Sohn allerdings getrennt sein. Interessanterweise sind fast alle dieser Väter Vertriebene oder Ausgestoßene. Die Väter in „Die Pullichi“ und „Der Paria“ von Lewald sind als Kastenlose aus der Gesellschaft ausgestoßen. Die Väter in „Die Indianer in England“ und „Das Schlangenfest" sind dagegen aus politischen Gründen vertrieben worden. Allein der Vater in „Das Sonnenfest“ ist ein akzeptiertes Mitglied der Gesellschaft, was ihm allerdings auch nicht mehr Handlungsspielraum und Möglichkeiten zur Rettung seiner Tochter gibt.

\footnotetext{
${ }^{1144}$ Vgl. Bremer: Tippo-Saib und Laura, S. 104, $142 \mathrm{f}$.
} 


\subsection{Der Gott/die Göttin}

Eine zwar seltene, aber durch ihre Funktion und ihre enge Verbindung mit Indien interessante Figur ist die des Gottes bzw. der Göttin. Während in einigen Texten sich Brahmā indirekt durch ein Donnergrollen oder auch ein Wunder äußert, ${ }^{1145}$ gibt es auch ein paar wenige Szenen, in denen Götter direkt auftreten. In Goethes „Der Gott und die Bajadere“ kommt der Gott Mahadöh auf die Erde. Er gibt sich als einfacher Mensch aus, um die Hilfsbereitschaft und das Herz der Menschen zu prüfen. Seine Göttlichkeit beweist er am Ende, als er selbst nach seinem Tod lebendig aus den Flammen des Scheiterhaufens steigt und die Bajadere ebenfalls aus diesen Flammen rettet und in den Himmel aufhebt. In „Magandola“ erscheint am Ende des Stücks die Göttin des Ganges, verschlingt den ungläubigen Gegenspieler der Hauptpersonen in ihren Wasserstrudeln und verkündet, dass Magandola ihre Tochter sei. In den beiden hier geschilderten Fällen entsprechen die auftretenden Götter nicht den typischen Vorstellungen, die sich die meisten Leser von indischen Göttern machen dürften. Sie haben weder mehr als zwei Arme noch irgendwelche tierischen Attribute, was in den Sachtexten immer wieder fasziniert oder kritisch beschrieben wird. Vielmehr ähnelt Mahadöh in seinem Auftreten den griechischen Göttern, wenn diese auf die Erde kommen. Die Göttin des Ganges hat dagegen eher eine pantheistische, geheimnisvoll-wunderbare Aura.

Neben diesen beiden Texten, in denen ein Gott bzw. eine Göttin auftritt und direkt in die Handlung eingreift, gibt es auch in Mereaus „Serafine“ eine Szene, in der die Protagonisten einen heiligen Hain der Göttin Saraswati aufsuchen. Dort treffen sie allerdings nicht die Göttin selbst an, sondern den Liebesgott Kama. Dieser existiere, wie Mereau in einer Anmerkung ausführt, allerdings nur noch als geistiges Wesen, nachdem er von dem höchsten Gott verbrannt worden sei. Entsprechend wenig konkret ist auch sein Erscheinen. Er wird zwar als sichtbarer Gott mit Bogen und Blumenpfeil beschrieben, aber er geht in der überwältigenden Pracht der Natur und umgeben von Nymphen in dem Gesamtensemble des Hains auf. Er führt auch keine Handlungen aus und anders als bei tanzenden Nymphen, in deren Reihen sich die Protagonisten einreihen, wird von ihm nicht einmal die kleinste Bewegung beschrieben und es kommt auch zu keiner Interaktion mit den Protagonisten. Durch diese enge Verbindung, beinahe Verschmelzung mit der als belebt beschriebenen Natur erhalten die Götter und Nymphen in dieser Szene pantheistische Züge.

\footnotetext{
${ }^{1145}$ Vgl. z.B. Kanne: Padmana, S. 152; Heyden: Magandola, S. 249, 253f.; Hensler: Das Sonnenfest, S. 8
} 
Obwohl die indischen Götter in den Sachtexten zu den Aspekten der indischen Kultur gehören, die aufgrund der Ähnlichkeit mit den griechischen Göttern hinsichtlich ihrer Funktion vertraut sind, dient ihr Äußeres dazu, besonders augenfällig das Fremde dieser Kultur aufzuzeigen. In den literarischen Texten wird diese Fremdheit dagegen nicht dazu genutzt, dem Text eine besondere Exotik zu verleihen.

\section{Die Darstellung Indiens}

Im folgenden Kapitel möchte ich untersuchen, wie Indien in den literarischen Texten dargestellt wird. Dabei geht um die Frage, wie Indien und die Inder als solche kenntlich gemacht werden. Was kann die mit Indien assoziierten Bilder in einer Weise aufrufen, dass sich der Leser bzw. Zuschauer in Indien wähnt? Der Grad, in wieweit einzelne Texte den Schauplatz sowie auftretende Personen als indisch kennzeichnen, ist sehr verschieden. Während einige Texte nur durch die explizite Nennung Indiens als Schauplatz und indisch anmutende Namen ${ }^{1146}$ sowie typisch indische Figuren dem Leser mitteilen, dass die Handlung in Indien spielt, schmücken andere Texte dieses fiktive Indien weiter aus. Sie gehen z.B. auf einzelne Elemente der indischen Kultur ein - entweder als entscheidender Teil der Handlung oder lediglich als kleines untermalendes Detail - oder beschreiben die Szenerie ausführlicher.

Viele der Texte weisen durch die Nennung exotischer Pflanzen und (seltener) Tiere auf Indien als Schauplatz hin. Häufig genannte Pflanzen sind z.B. Palmen ${ }^{1147}$, Bananen ${ }^{1148}$, giftige Früchte ${ }^{1149}$ und natürlich immer wieder verschiedene Blumen. Bei den Tieren

\footnotetext{
${ }^{1146}$ De Zoysa stellt fest, dass einige Texte allein durch die Eigennamen deutlich machen, dass es sich um Indien und Inder handelt; ansonsten könnten sie auch irgendwo anders spielen (vgl. De Zoysa: "Blutrünstige Braminen am heiligen Strome“, S. 36f.). Allerdings sind keineswegs alle Namen, die Inder kennzeichnen sollen, tatsächlich indisch. So stellt De Zoysa weiter fest, dass die Namen vieler Brahmanen arabisch oder persisch seien (vgl. De Zoysa: "Blutrünstige Braminen am heiligen Strome“, S. 154).

${ }^{1147}$ Vgl. z.B. Hensler: Das Schlangenfest, S. 4, 23, 66; Kanne: Padmana, S. 39f.; Winter: Marie von Montalban, S. 37; Hensler: Das Sonnenfest, S. 43; Vulpius: Die Portugiesen in Indien. 1. Teil, S. 221; Vulpius: Die Portugiesen in Indien. 2. Teil, S. 76; Herklots: Die Bajaderen, S. 45; Heyden: Magandola, S. 183, 185; Gehe: Jessonda, S. 11; Günderrode: Geschichte eines Braminen, S. 313; Saint-Pierre: Die indische Hütte, S. 336 (auch andere exotische Bäume); Sondershausen: Der Hindu, S. 57

${ }^{1148}$ Vgl. z.B. Beer: Der Paria, S. 5; Hensler: Das Schlangenfest, S. 23; Tarnow: Die Prophetin von Caschimir. Erster Theil, S. 36, 81

${ }^{1149}$ Vgl. z.B. Hensler: Das Schlangenfest, S. 44; Beer: Der Paria, S. 29
} 
spielen vor allem Tiger ${ }^{1150}$, Schlangen ${ }^{1151}$ und Elefanten ${ }^{1152}$ eine Rolle. Es handelt sich also um genau die Tiere, die auch in den Sachtexten für Faszination sorgen. Zu einer indischen Szenerie gehören häufig auch der Ganges, der entweder genannt wird oder Teil des Bühnenbildes bzw. der beschriebenen Landschaft ist ${ }^{1153}$, sowie indische Tempel bzw. Pagoden ${ }^{1154}$ und Götterstatuen ${ }^{1155}$. Manche dieser Tempel werden nicht näher beschrieben. Andere werden dagegen als sehr groß und prachtvoll dargestellt. Der Tempel kann sich aber auch in einer düsteren Höhle befinden. Die meisten beinhalten verschiedene Götterbilder oder Statuen, die größtenteils als groteske Götzen charakterisiert werden („,colossale Götzenbilder, scheußliche, groteske Fratzen“1156). In den Opferstücken steht im Zentrum des Tempels häufig ein Opferaltar, an dem das Menschenopfer vollzogen werden soll. Auch der Ausschluss aus der Kaste kann im Tempel ausgesprochen werden. Der Tempel ist somit größtenteils ein Sinnbild für den indischen Aberglauben und dessen grausame Folgen. Lediglich in Vulpius’ „Die Portugiesen in Indien“ wird er zunächst neutral mit einer Kirche oder Moschee verglichen.

Die literarische Darstellung der indischen Landschaft ist also vor allem durch ihre Exotik geprägt, die mal gefährlich und düster, mal paradiesisch und prächtig sein kann. Großen Einfluss hat dabei das Drama Śakuntalā, in dem die indische Flora und Fauna (vor allem die von der Hauptperson umsorgten Blumen) eine wichtige Rolle spielen. Schauplätze, die im Inneren von Wohnräumen liegen, sind entsprechend der häufigsten Figurentypen (höhere Schichten oder Ausgestoßene) entweder prächtige Säle und Zimmer in Häusern oder Palästen oder aber ärmliche Hütten oder sogar Höhlen.

\footnotetext{
${ }^{1150}$ Vgl. z.B. Kanne: Padmana, S. 17; Beer: Der Paria, S. 7, 21; Sondershausen: Der Hindu, S. 111; Saint-Pierre: Die indische Hütte, S. 358

${ }^{1151}$ Vgl. z.B. Hensler: Das Schlangenfest, S. 21; Tarnow: Die Prophetin von Caschimir. Zweiter Theil, S. 61

${ }^{1152}$ Vgl. z.B. Kanne: Padmana, S. 40; Vulpius: Die Portugiesen in Indien. 2. Teil, S. 132; Tarnow: Die Prophetin von Caschimir. Erster Theil, S. 47, 140

${ }^{1153}$ Vgl. z.B. Hensler: Das Schlangenfest, S. 3; Kanne: Padmana, S. 39, 137; Beer: Der Paria, S. 10; Herklots: Die Bajaderen, S. 45; Heyden: Magandola, S. 183, 185f.; Günderrode: Geschichte eines Braminen; S. 311; Günderrode: Udohla, S. 220; Plümicke: Lanassa, S: 9; Saint-Pierre: Die indische Hütte, S. 329; Zumbach: Die Pullichi, S. 58

${ }^{1154}$ Vgl. z.B. Lewald: Der Paria, S. 1, 18, 74, 76; Winter: Marie von Montalban, S. 8, 63, 66; Hensler: Das Schlangenfest, S. 36, 81; Hensler: Das Sonnenfest, S. 57; Vulpius: Die Portugiesen in Indien. 1.Teil, S. 99, 103f.; Vulpius: Die Portugiesen in Indien. 2. Teil, S. 89; Plümicke: Lanassa, S. 5; SaintPierre: Die indische Hütte, S. 329, 335f.; Tarnow: Die Prophetin von Caschimir. Erster Theil, S. 36, 50; Tarnow: Die Prophetin von Caschimir. Zweiter Theil, S. 12

1155 Vgl. z.B. Lewald: Der Paria, S. 32; Winter: Marie von Montalban, S. 8

1156 Tarnow: Die Prophetin von Caschimir. Zweiter Theil, S. 12
} 
Reichtum und Pracht, wie sie bereits seit der Antike mit Indien verbunden sind, werden nicht nur bei der Ausstattung von Palästen, sondern auch in anderen Zusammenhängen hin und wieder betont, z.B. der Reichtum der Natur, der Handelsgüter, der Kleidung. ${ }^{1157}$

Die Inder selbst werden vor allem über ihre Namen und ihre gesellschaftliche Rolle (als Brahmanen, Könige und Krieger, Paria) als indisch gekennzeichnet. Ihre Kleidung wird zwar nicht allzu häufig beschrieben, aber auch sie kann genutzt werden, um deutlich zu machen, dass die auftretende Person ein Inder oder eine Inderin ist. Dabei sind die Beschreibungen oft nicht sehr genau, häufig werden aber Pracht und Reichtum betont. ${ }^{1158}$ Selten wird auch die dunklere Hautfarbe der Inder erwähnt. ${ }^{1159}$ Während also diese äußerlichen Merkmale zwar vorkommen, aber eher eine untergeordnete Rolle spielen, finden sich immer wieder Hinweise auf die innere Eigenschaften, die auch in den Sachtexten der Charakterisierung der Inder dienen: Sanftheit und Zartheit, ${ }^{160}$ Gastfreundlichkeit ${ }^{1161}$ und Toleranz ${ }^{1162}$, aber auch (geistige) Trägheit, Furcht und Erschlaffung. ${ }^{1163}$ Diese Eigenschaften werden häufig als natürlich und angeboren und eben nicht erlernt dargestellt. Einige Inder werden - wie oben anhand von Gurli beschrieben - auch anhand ihrer Sprache von den Europäern abgegrenzt. Dazu kommen indische Begriffe (vor allem Götternamen), die die Sprecher als Inder ausweisen. Auch das Kauen von Betel-Nüssen dient des öfteren dazu, der Szene einen indischen Anstrich zu verleihen. ${ }^{1164}$ Interessant ist auch, dass die Frauen - anders als in den Sachtexten - in einigen literarischen Texten als verschleiert und in ihren Gemächern oder Gärten eingeschlossen beschrieben werden und damit eher an die Traditionen der muslimischen Mogul-Herrscher erinnern. ${ }^{1165}$ Das wird in diesen Texten allerdings nicht

\footnotetext{
${ }^{1157}$ Vgl. z.B. Hensler: Das Schlangenfest, S. 23; Vulpius: Die Portugiesen in Indien. Teil 2, S. 34; Tarnow: Die Prophetin von Caschimir. Erster Theil, S. 49

1158 Vgl. z.B. Hensler: Das Sonnenfest, S. 25; Vulpius: Die Portugiesen in Indien. Teil 1, S. 110f; Heyden: Magandola, S. 206; Sondershausen: Der Hindu, S. 61, Tarnow: Die Prophetin von Caschimir. Erster Theil, S. 51; Kotzebue: Die Indianer in England, S. 129

${ }^{1159}$ Vgl. z.B. Vulpius: Die Portugiesen in Indien. Teil 1, S. 110; Saint-Pierre: Die indische Hütte, S. 360

${ }^{1160}$ Vgl. z.B. Sondershausen: Der Hindu, S. 65; Tarnow: Die Prophetin von Caschimir. Zweiter Theil, S. 34

${ }^{1161}$ Vgl. z.B. Tarnow: Die Prophetin von Caschimir. Erster Theil, S. 75

1162 Vgl. z.B. Tarnow: Die Prophetin von Caschimir. Erster Theil, S. 41, 125, 230; Kanne: Padmana, S. 26

${ }^{1163}$ Vgl. z.B. Tarnow: Die Prophetin von Caschimir. Erster Theil, S. 41, 58; Tarnow: Die Prophetin von Caschimir. Zweiter Theil, S. 146; Sondershausen: Der Hindu, S. 108; Günderrode: Udohla, S. 208

${ }^{1164}$ Vgl. z.B. Hensler: Das Schlangenfest, S. 23; Vulpius: Die Portugiesen in Indien. Teil 1, S. 108;

Kotzebue: Die Indianer in England, S. 30

${ }^{1165}$ Vgl. Kanne: Padmana, S. 16, 18; Hensler: Das Schlangenfest, S. 27, 37
} 
kritisiert, sondern es ist vielmehr so, dass gerade das Überschreiten dieses Gebots durch die Frau zur Katastrophe führt. Die „tyrannische (...) Herrschaft ${ }^{\star 1166}$ des Mannes wird allerdings in „Lanassa“ durch die Witwe und ihre Vertraute kritisiert und als Quelle des Leids im Leben der Frau ausgemacht.

Kulturelle Unterschiede spielen in den meisten Texten nur insofern eine Rolle, als einige der Inder durch Aberglauben und Traditionen an Handlungen festhalten, die aus Sicht der Europäer als grausam abzulehnen sind, oder Europäer in Indien eine ihnen sonst nicht zugängliche Weisheit suchen. Diese Unterschiede stellen jedoch keine problematische oder sogar unüberwindliche Grenze dar, da sie zumindest von einigen der Personen leicht überwunden werden können. So lernt der Europäer die Weisheit kennen und kann sogar selbst zu einer Art indischer Einsiedler werden. Und es sind nie alle Inder, die an den aus europäischer Sicht abergläubischen Vorstellungen festhalten. Einige scheinen diese Vorstellungen bereits vor dem Zusammentreffen mit Europäern nicht $\mathrm{zu}$ teilen, andere schwören ihnen aufgrund dieses Treffens ab. Die Schwierigkeiten, die es mit sich bringen kann, kulturelle Prägungen so weit zu überwinden, dass sie nicht zwischen Personen aus unterschiedlichen Kulturkreisen stehen, werden kaum thematisiert. Eine Ausnahme macht der Roman „Die Prophetin von Caschimir“. Hier versuchen die Hauptpersonen, eine indische Prophetin und ein christlicher Priester, sich aufgrund ihrer Liebe zueinander in den anderen hineinzuversetzen und sich aneinander anzunähern, aber ihre Versuche scheitern immer wieder aufgrund der tiefen kulturellen Prägung ihrer Erziehung und den Unterschieden in ihrer Weltanschauung.

In den meisten Texten genügen also kleine, aus den Sachtexten und anderen literarischen Texten vertraute Anspielungen, um in der Phantasie der Leser ein Bild von Indien entstehen zu lassen. Diese Anspielungen stammen dabei vor allem aus dem Bereich der bereits seit der Antike mit Indien in Verbindung gebrachten Attribute des Reichtums, der kindlich-naiven Natürlichkeit und des Monströsen. Anscheinend werden diese überlieferten Vorstellungen auch um 1800 von dem durchschnittlichen Leser noch als besonders typisch für Indien angesehen. Auf detailliertere Ausschmückungen wird zumeist verzichtet. Das ist zum einen für die Aussage und Funktion der Texte nicht nötig, zum anderen soll das Publikum auch nicht durch zu 
viele fremde Begriffe und Begebenheiten verwirrt und von der eigentlichen Handlung abgelenkt werden. Diese soll zwar einen exotischen Anstrich bekommen, aber dennoch verständlich bleiben. Auch muss eine Identifizierung der Leser mit den Hauptpersonen möglich bleiben. Denn anders als in den Sachtexten geht es den Autoren der literarischen Texte nicht um eine möglichst genaue und umfangreiche Repräsentation Indiens und seiner Kultur, sondern um eine bestimmte fest umrissene Handlung, mit deren Hilfe bestimmte Dinge, die nicht unbedingt etwas mit Indien zu tun haben müssen, thematisiert werden sollen. Die indische Einkleidung erfüllt im Wesentlichen drei Funktionen: Sie sorgt für Exotik, sie ermöglicht über kulturelle Besonderheiten (Witwenverbrennung, Paria) bestimmte Handlungsmotive und sie eröffnet eine Distanz, anhand derer eine indirekte Kritik an der eigenen Kultur und Gesellschaft leichter möglich wird.

\section{Aufgegriffene Themen}

In diesem Kapitel möchte ich aufzeigen, welche mit Indien verbundenen Themen, die nicht bereits bei der Darstellung der Handlungsschemata oder Figurentypen besprochen worden sind, in den literarischen Texten eine Rolle spielen und wie sie dargestellt werden. Unterscheiden sich Auswahl und Beurteilung der einzelnen Themen von denen der Sachtexte oder lassen sich Gemeinsamkeiten feststellen?

\subsection{Götter und Religion}

Während die Autoren vieler Sachtexte ein ernsthaftes Interesse an den indischen Religionen haben, dient sie in den meisten literarischen Texten entweder dazu, Aberglauben und grausame Traditionen zu legitimieren, oder aber die Religion wird als indische Weisheit verklärt. In vielen Texten besteht ihre Funktion auch lediglich darin, die Personen als Inder zu kennzeichnen.

Sowohl in der Funktion, Personen und Handlungen als indisch zu kennzeichnen, als auch als Ausgangspunkt für Aberglaube wird die Darstellung der indischen Religion in den meisten Texten auf die Anrufung oder Nennung verschiedener Götter reduziert. Sie werden in Notsituationen angerufen, um Beistand gebeten, dienen als Schreckensausruf entsprechend zu „oh Gott“, sind Empfänger von Opfern und werden als Herrscher und Gesetzgeber der Welt angesehen. Diese Götter werden zumeist nur mit Namen genannt und nicht näher beschrieben und sind in den meisten Fällen austauschbar. Häufig ist sogar nur allgemein von den Göttern die Rede und sie werden auch kollektiv angerufen 
(,ihr Götter“ oder „Heil'ge Götter“) ${ }^{1167}$. In einigen Texten wird lediglich von der „Gottheit“" oder „Gott“"1168 gesprochen, ohne dass präzisiert wird, um welchen Gott es sich handelt oder ob tatsächlich von nur einem Gott wie im Monotheismus ausgegangen wird.

Von den Göttern, die namentlich genannt werden, ist Brahmā der mit Abstand häufigste. ${ }^{169}$ Auch viele der beschriebenen Tempel sind Brahmā geweiht. In einigen Texten ist er auch der einzige Gott, der genannt wird. Teilweise wird er sogar als alleiniger bzw. höchster Gott inszeniert. ${ }^{1170}$ Manchmal finden dabei auch christliche Elemente ihren Eingang in die Darstellung Brahmās, wenn er z.B. als ein Richter beschrieben wird, der kommen wird, um die Menschen zu richten. ${ }^{171}$ Diese auffallende Bevorzugung Brahmās gegenüber den anderen Göttern ist besonders vor dem Hintergrund der in den Sachtexten immer wieder beschriebenen Einteilung der Hindus in Anhänger Viṣnus und Śivas interessant. Denn die Sachtexte betonen, dass Brahmā kaum direkt verehrt werde und keine eigenen Tempel besitze. Die meisten literarischen Texte scheinen sich in diesem Punkt nicht an den Erkenntnissen der Wissenschaftler und den Berichten der Reisenden zu orientieren, sondern nutzen den dem Begriff der Brahmanen sehr ähnlichen Namen Brahmā, um auf einfache Art und Weise deutlich zu machen, dass es sich um einen indischen Gott handelt. ${ }^{1172}$ Die in den Sachtexten so wichtigen Götter Viṣṇu und Śiva werden in den literarischen Texten kaum häufiger genannt als andere Götter, die in den Sachtexten eher eine untergeordnete Rolle spielen,

\footnotetext{
${ }^{1167}$ Kanne: Padmana, S. 94, 125; vgl. auch Gehe: Jessonda, S. 31, 36, 41; Goethe: Zahme Xenien II, S. 635; Günderrode: Udohla, S. 219, 221; Herder, Johann Gottfried: Indien. In: Johann Gottfried von Herder's sämmtliche Werke. Zur schönen Literatur und Kunst. Sechszehnter Theil. Stuttgart und Tübingen 1817, S. 51; Plümicke: Lanassa, S. 9; Zumbach: Die Pullichi, S. 102 1168 Vgl. z.B. Kanne: Padmana, S. 126; Jean Paul: Hesperus, S. 582, 605, 683ff., 886ff.; Plümicke: Lanassa, S. 5,8; Saint-Pierre: Die indische Hütte, S. 370, 376; Zumbach: Die Pullichi, S. 6, 59, 99, 153 (Weltrichter)

1169 Vgl. z.B. Hensler: Das Schlangenfest, S. 5, 7f., 24, 33, 64; Kanne: Padmana, S. 106,114, 122, 152; Beer: Der Paria, S. 8f., 11, 18, 23 und viele weitere; Hensler: Das Sonnenfest, S. 7f., 11, 13, 42, 58f.; Vulpius: Die Portugiesen in Indien. Teil 1, S. 126; Vulpius: Die Portugiesen in Indien. 2. Teil, S. 140,146 (Betrug); Herklots: Die Bajaderen, S. 8; 18, 23, 44; Lewald: Der Paria, S. 17, 34, 36, 40: Heyden: Magandola, S. 197, 247-254; Gehe: Jessonda, S. 3f., 41, 44; Goethe: Zahme Xenien, S. 635; Goethe: Der Paria, S. 450, 455; Günderrode: Udohla, S. 206; Kotzebue: Die Indianer in England, S. 34, 127; Plümicke: Lanassa, S. 7f., 14f.; Saint-Pierre: Die indische Hütte, S. 348; Sondershausen: Der Hindu, S. 110; Tarnow: Die Prophetin von Caschimir. Erster Theil, S. 31, 45, 56, 101 ${ }^{1170}$ Vgl. z.B. Hensler: Das Sonnenfest, S. 7; Lewald; Der Paria, S. 40; Plümicke: Lanassa, S. 7 ${ }^{1171}$ Vgl. Heyden: Magandola, S. 197; christlicher beeinflusst könnte der Hinweis auf Engel sein (vgl. Kanne: Padmana, S. 21, 34, 124; Gehe: Jessonda, S. 4)

${ }^{1172}$ Auch De Zoysa stellt fest, dass sich die Autoren weniger an den wissenschaftlichen Erkenntnissen, sondern vielmehr an an abenteuerlichen Reisebeschreibungen aus dem vorigen Jahrhundert orientieren (vgl. De Zoysa: "Blutrünstige Braminen am heiligen Strome“, S. 164)
} 
und ihnen wird auch keine so hohe Stellung eingeräumt wie Brahmā. ${ }^{1173}$ Neben diesen drei Göttern der Trimūrti ist es interessanterweise vor allem die Sonne, die in einigen Texten göttliche Verehrung erfährt. Manchmal wird sie dabei mit Brahmā gleichgesetzt. ${ }^{1174}$ Außerdem wird in einigen Texten ein Natur- bzw. Erdgeist erwähnt. ${ }^{1175}$ Weitere Götter werden in relativ wenigen Texten genannt und erfüllen dort unterschiedliche Funktionen. In „Das Schlangenfest“ wird dem positiv konnotierten Sonnengott der Opfergott „Jaka“1176 entgegengesetzt, um eine Einteilung in gut und böse zu ermöglichen. In „Magandola“ dienen dagegen die Götter (die Göttin des Ganges sowie Götter der Palmen und Blüten ${ }^{1177}$ ) vor allem dazu, die Natur als belebt und von Göttern durchwirkt zu schildern. Und in „Die Indianer in England“ wirkt die Aufzählung verschiedener Götter bei der Beschreibung einer Frau eher so, als sollte deren Vielzahl zum einen den Polytheismus der Inder zeigen und zum anderen die entsprechende Mannigfaltigkeit der Schönheit der ausgewählten Braut symbolisieren. ${ }^{1178}$ Der einzige der hier untersuchten Texte, der eine differenziertere Darstellung der indischen Götterwelt aufweist, ist „Die Prophetin von Caschimir“. Dort werden verschiedene, auch aus den Sachtexten bekannte Götter in durchaus unterschiedlicher Funktion genannt. Vor allem „Cama“, der Gott der Liebe, spielt als von der Prophetin besonders verehrte Gottheit eine Rolle. ${ }^{1179}$

Während die indischen Götter bei den meisten Autoren vor allem dazu dienen, dem Text ein indisches Lokalkolorit zu verleihen, und es kaum um die Götter als solche geht, setzt sich Goethe in seinen Xenien explizit mit den Göttern und ihren Darstellungen auseinander. Und obwohl die Form, in der er das tut, spöttische Elemente hat, ist es ihm mit dem Thema durchaus ernst und es ist ihm persönlich von großer Bedeutung. Er beschreibt die Götter als groteske Ungeheuer und „Bestien“. ${ }^{1180}$

\footnotetext{
${ }^{1173}$ Vgl. z.B. für Viṣnu Hensler: Das Sonnenfest, S. 8, 37; Herklots: Die Bajaderen, S. 22; Goethe: Zahme Xenien, S. 635; Tarnow: Die Prophetin von Caschimir. Erster Theil, S. 58, 108, 117; für Śiva bzw. Mahā-deva Goethe: Zahme Xenien, S. 635; Tarnow: Die Prophetin von Caschimir. Erster Theil, S. 109; Kanne: Padmana, S. 101,114; Goethe: Der Gott und die Bajadere, S. 150

${ }^{1174}$ Vgl. z.B. Hensler: Das Schlangenfest, S. 71, 81; Hensler: Das Sonnenfest, S. 57; Lewald: Der

Paria, S. 17; Tarnow: Die Prophetin von Caschimir. Erster Theil, S. 124, 126

${ }^{1175}$ Vgl. z.B. Hensler: Das Schlangenfest, S. 13; Günderrode: Briefe zweier Freunde, S. 354;

Günderrode: Geschichte eines Braminen, S. 312

${ }^{1176}$ Vgl. z.B. Hensler: Das Schlangenfest, S. 58, 81

1177 Vgl. z.B. Heyden: Magandola, S. 202, 256

1178 Vgl. Kotzebue: Die Indianer in England, S. 40

${ }^{1179}$ Vgl. z.B. Tarnow: Die Prophetin von Caschimir. Erster Theil, S. 48, 68, 117; aber auch Kanne:

Padmana, S. 68

${ }^{1180}$ Goethe: Zahme Xenien, S. 632
} 
Besonders die tierischen Elemente der Götter schrecken ihn ab. Gott habe den Menschen nach seinem Bilde geschaffen. ${ }^{1181}$ Also müssten, sofern man sich überhaupt eine bildliche Vorstellung von Gott machen möchte, diese Bilder am Menschen orientiert sein, wie es z.B. bei den Griechen der Fall ist. ${ }^{1182}$ Bei den indischen Figuren fühle man „weder Natur noch Gott“.${ }^{1183}$ Dabei ist es für Goethe besonders schlimm, dass die Götterbilder das „Absurde“ ${ }^{1184}$ nicht als etwas Abstraktes dem Menschen indirekt vermitteln, sondern es direkt „,vor's Auge“" ${ }^{1185}$ stellen und so durch die sinnliche Wahrnehmung direkt die Einbildungskraft beeinflussen, die für Goethe nicht nur in der Dichtung, sondern vor allem auch als Mittel der Erkenntnis von großer Bedeutung ist. Daher ist es für ihn ein wichtiges Bedürfnis, seine Einbildungskraft vor sie verzerrenden Elementen zu schützen. ${ }^{1186}$ Auch sind die indischen Götter für ihn eng mit den „leidigen hochmüthig-häßlichen Frömmlingen“ 1187 verbunden, den romantischen Verfechtern einer neuen Kunstreligion. Den indischen Göttern ist Goethe nur dann gewogen, wenn er die hinter ihrer verwirrenden Vielgestaltigkeit ruhende Einheit erkennen kann. Diese Einheit ist für Goethe - anders als für viele der anderen Autoren - allerdings keine monotheistische oder pantheistische Größe, sondern eine ästhetische: eine Einheit der Form. Das wird vor allem an seinem Gedicht „Howards Ehrengedächtnis“ deutlich, in dem der indische Gott „Camarupa“, der Wolkenbote, als Sinnbild für die den sich ständig wandelnden äußeren Formen zugrundeliegende Einheit inszeniert wird. ${ }^{1188}$ Goethe verfolgt die Forschungsergebnisse zu Indien mit Interesse, aber zum einen steht er der romantischen Vereinnahmung kritisch gegenüber und zum anderen nähert er sich fremden Kulturen weniger durch rationale Erkenntnis als vielmehr mittels Einfühlung in dieselben ${ }^{1189}$ (z.B. über die Verwendung indischer

\footnotetext{
${ }^{1181}$ Goethe: Zahme Xenien, S. 632

${ }^{1182}$ Vgl. Goethe: Napoleonische Zeit, S. 427 (Brief an Windischmann 1815)

1183 Goethe: Zahme Xenien, S. 635

${ }^{1184}$ Goethe: Zahme Xenien, S. 635

1185 Goethe: Zahme Xenien, S. 635

${ }^{1186}$ Goethe beklagt auch sich auch Humboldt gegenüber, dass Teile der indischen Kultur seine „Einbildungskraft ins Formlose und Difforme“ ziehe, wovor er sich fürchte (Goethe: Die letzten Jahre, S. 422; Brief an Humboldt 1826); zur Bedeutung der Einbildungskraft bei Goethe vgl. z.B. Shu Ching Ho: Über die Einbildungskraft bei Goethe. System und Systemlosigkeit. Freiburg i. Br. 1998

1187 Goethe: Die letzten Jahre, S. 542 (Brief an Boisseré September 1827)

${ }^{1188}$ Vgl. Goethe: Howards Ehrengedächtnis, S. 503f.; vgl. auch Lauer: Goethes indische Kuriositäten, S. 164f., 171-176; zur Ambivalenz in Goethes Beziehung zu Indien und zur besonderen Rolle von Einbildungskraft und Anschauung vgl. auch: Jenisch, Erich: Goethe und das ferne Asien. In: Deutsche Vierteljahresschrift für Literaturwissenschaft und Geistesgeschichte 1 (1923), S. 309-338

${ }^{1189}$ vgl. Bell: Goethe's Orientalism, S. 206
} 
Motive in seinen Balladen oder auch im west-östlichen Divan). Das aber ist ihm nicht möglich, wenn er keine emotionalen bzw. intuitiven Anknüpfungspunkte findet.

Konkrete Inhalte der indischen Religion(en) werden in den meisten Texten nicht angesprochen. In den wenigen Fällen, in denen es doch geschieht, orientiert sich diese Darstellung zumeist nicht an den tatsächlichen indischen Lehren, sondern die indische Religion fungiert eher als eine Hülle, in der eigene Vorstellungen vermittelt werden sollen. So verkündet Günderrodes Bramine die deutlich romantisch geprägte Ansicht, dass Religion die Anschauung des ewigen Urgrundes aller Dinge sei. ${ }^{1190}$ Die Weisheit, die der Paria in „Die indische Hütte“ verkündet, ist dagegen an Rousseau ${ }^{1191}$ angelehnt: Die Grundsätze der Wahrheit beruhten auf der Natur und müssten mit einfältigem Herzen gesucht werden. ${ }^{1192} \mathrm{Im}$ „Hesperus“ heißt es, Gott sei die Ewigkeit, er sei alles und müsse mit dem Herzen gesucht werden. ${ }^{193}$ Etwas anders ist es auch in diesem Fall in „Die Prophetin von Caschimir“. Deren Autorin muss neuere Forschungstexte zur indischen Religion gekannt haben. So finden sich bei ihr sowohl der Gedanke, dass die menschliche Seele göttlicher Natur sei und sich wieder mit dem Göttlichen vereinigen werde, als auch, dass sich der indische Polytheismus auf einen ihm zugrunde liegenden Monotheismus zurückführen lasse. ${ }^{1194}$

\subsection{Aberglaube}

Während die philosophisch-spirituellen Lehren der indischen Religion kaum thematisiert werden, spielen als Aberglaube empfundene Vorstellungen in den Texten eine deutlich größere Rolle. Sie reichen von dem Hinweis auf die Verehrung von Kühen, ${ }^{1195}$ über Astrologie ${ }^{1196}$ bis hin zum Glauben an Erscheinungen ${ }^{1197}$. Diese Formen des Aberglaubens finden in den Texten vor allem als kleine Hinweise Verwendung, die entweder lustig sein sollen oder die Personen näher charakterisieren. Handlungsrelevant sind sie meistens nicht. Der Aberglaube der Inder steht zumeist im

\footnotetext{
${ }^{1190}$ Vgl. Günderrode: Geschichte eines Braminen, S. 309

${ }^{1191}$ Vgl. De Zoysa: "Blutrünstige Braminen am heiligen Strome“, S. 118

1192 Vgl. Saint-Pierre: Die indische Hütte, S. 336

${ }^{1193}$ Vgl. Jean Paul: Hesperus, S. 891

${ }^{1194}$ Vgl. Tarnow: Die Prophetin von Caschimir. Erster Theil, S. 44f.

1195 Vgl. Kotzebue: Die Indianer in England, S. 30, 38; Saint-Pierre: Die indische Hütte, S. 340, Heine:

Den König Wiswamitra, S. 258

1196 Vgl. z.B. Kanne: Padmana, S. 100

${ }^{1197}$ Vgl. z.B. Tarnow: Die Prophetin von Caschimir. Erster Theil, S. 228; Band 2, S. 55; Jean Paul:

Hesperus, S. 1078
} 
Kontrast zu der aufgeklärten Rationalität der Europäer und hilft, diese zu unterstreichen. Er kann von den Europäern aber auch für deren Zwecke ausgenutzt werden. ${ }^{1198}$

Ganz anders ist es bei den bereits besprochenen Traditionen der Witwenverbrennung und des Menschenopfers, das anlässlich von Feiern für bestimmte Götter, als Ritus bei einer Hochzeit oder als Strafe bei Verweigerung einer Hochzeit stattfinden kann. Auch sie werden als direkte Auswirkungen des indischen Aberglaubens und als Anordnung der Götter inszeniert, die durch diese Opferungen versöhnt werden sollen. Aber sie dienen keinesfalls als lustige und $\mathrm{zu}$ verlachende Eigenheiten, sondern werden als grausame Traditionen kritisiert. In diese Kategorie gehört auch der versuchte Kindsmord, der etwas anders auch in den Sachtexten thematisiert wird. ${ }^{1199}$ Auch die Verachtung der Paria gilt in den Texten als ein göttliches Gebot und ist in den Augen der Europäer eine Folge des indischen Aberglaubens. Diese Legitimation durch die Religion wird allerdings durch einige Paria deutlich in Frage gestellt und als Lüge der Brahmanen entlarvt. ${ }^{1200}$ Die Paria sind sich darin mit vielen Autoren der Sachtexte einig, dass es die Brahmanen sind, die den Aberglauben aus Eigennutz aufrechterhalten. Es wird allerdings auch gezeigt, wie sehr sich diese Abscheu vor den Paria in den Köpfen der Menschen festgesetzt hat, so dass es ihnen sehr schwerfällt, sich von ihr loszusagen, selbst wenn sie sie als falsch erkannt haben. ${ }^{1201}$

Die grausamen Rituale und Traditionen werden in den meisten Texten von einem Großteil der Inder als richtig und wichtig angesehen. Zumeist gibt es eine oder mehrere treibende Kräfte (zumeist die Priester), die die Rituale um jeden Preis durchführen wollen, auch wenn sie sich damit selbst in Gefahr bringen. So wird wiederholt geschildert, wie versucht wird, das Opfer bzw. die Witwe noch im letzten Moment zu töten, obwohl die Europäer bereits in Sicht- oder Hörweite sind und den Indern klar ist, dass die Europäer die Opferungen nicht gutheißen. Ihnen gegenüber steht in den

\footnotetext{
${ }^{1198}$ Das ist z.B. der Fall, wenn Liddy Gurli zum Sprechen bringt, indem sie ihr vorspielt, ihr Schutzgeist habe ihr gesagt, dass Gurli ihr das Geheimnis verraten werden (vgl. Kotzebue: Die Indianer in England, S. 70), oder auch wenn die Europäer ein Mädchen vor dem Opfertod retten, in dem sie es durch einen Mann austauschen und den erstaunten Indern weismache, Bramā habe das Opfer selbst gerettet, indem er es in einen Mann verwandelt habe (vgl. Hensler: Das Sonnenfest, S. 59).

${ }^{1199}$ Vgl. Plümicke: Lanassa, S. 42

1200 Vgl. z.B. Lewald: Der Paria, S. 5; Beer: Der Paria, S. 10

${ }^{1201}$ Vgl. z.B. die Reaktionen von Neala in Lewalds Paria oder Tamajandris in Tarnows ,Die Prophetin von Caschimir", die sogar dann noch Abscheu gegenüber einem Paria empfindet, als sie selbst aus ihrer Kaste verstoßen und somit zum Paria wurde.
} 
meisten Fällen die kleine Gruppe der (indischen) Hauptpersonen, die die Bräuche als grausam ablehnen und sich dagegen auflehnen. Das geschieht in den allermeisten Fällen allerdings nicht deshalb, weil diese Personen bessere Menschen oder weniger abergläubisch sind (auch wenn es sich durchweg um gute und hilfsbereite Personen handelt), sondern weil sie selbst von diesen Traditionen betroffen sind (als Paria, als Witwe, als Opfer oder als deren Angehörige und Freunde). In einigen Texten werden sie von Europäern unterstützt, die zu ihrer Rettung eilen. Die Argumente, die diese Personen gegen Traditionen wie Witwenverbrennung, Opferungen, den Ausstoß der Paria und anderer grausamer Handlungen vorbringen, ähneln sich sehr. Häufig appellieren sie an die Menschlichkeit der anderen, berufen sich auf die Natur- und Menschenrechte und betonen die Unnatürlichkeit dieser Handlungen. ${ }^{1202}$ Damit berufen sich nicht nur die Europäer, sondern auch die entsprechenden Inder auf Werte und Konzepte der Aufklärung, die somit als universal gültig dargestellt werden können.

\subsection{Vergangene Herrlichkeit/fehlende Entwicklung}

Ein weiteres Thema, das neben Religion und Aberglauben in einigen Texten eine mehr oder weniger große Rolle spielt und das auch in den Sachtexten immer wieder diskutiert wird, ist die alte, nun aber vergangene Herrlichkeit Indiens. Nach diesen „Denkmälern der vergangenen Herrlichkeit“1203 suchen der Bramine und sein Schüler in „Geschichte eines Braminen“. Heyden stellt seiner dramatischen Novelle „Magandola“ sogar ein Gedicht voraus, in dem Indien als Heimat der Sagen beschrieben wird, wo „der Urwelt lichte Kunde“ von „heil'gen Palmenblättern“1204 gelesen werden könne. Damit stellt er das ganze Stück in den Kontext des Diskurses von Indien als der Wiege der Menschheit und Kultur. Das gilt auch für andere Texte. So wird in „Udohla“ diese alte Hochkultur der kulturellen Entwicklung der muslimischen Eroberer entgegengestellt: Während diese noch als Hirten durch die Steppen Asiens gezogen seien, sei Indien bereits ein „ruhmbegränzter Staat“ ${ }^{\text {"1205 }}$ gewesen. In „Der Hindu“ geht es dagegen vor allem um den Verlust der alten goldenen Zeit, die durch die Eroberung durch die Europäer ein Ende gefunden habe: Seit der Ankunft der Europäer seien die Tempel entweiht und das Land von Krieg überzogen. ${ }^{1206}$ Die Schuld an dem Verfall wird hier also den fremden

\footnotetext{
${ }^{1202}$ Vgl. z.B. Beer: Der Paria, S. 44; Hensler: Das Schlangenfest, S. 79; Plümicke: Lanassa, S. 10f., 65; Gehe: Jessonda, S. 24; Zumbach: Pullichi, S. 140 f.

${ }^{1203}$ Günderrode: Geschichte eines Braminen, S. 311

${ }^{1204}$ Heyden: Magandola, S. 183

1205 Günderrode: Udohla, S. 206

1206 Vgl. Sondershausen: Der Hindu, S. 68
} 
Eroberern gegeben. Anders ist es bei Hensler. Er beschreibt nicht die romantische Vorstellung vom Verlust der ursprünglichen Weisheit und Hochkultur, sondern führt (wenn auch nur in Andeutungen) die Unterschiede zwischen der indischen und europäischen Kultur im Sinne des Entwicklungsdenkens auf die fehlende Entwicklung der indischen Kultur in der neueren Zeit zurück. Zum Beispiel lässt er mit Keulen und Pfeilen bewaffnete Inder gegen mit Pistolen ausgerüstete Europäer kämpfen und verlieren. ${ }^{1207}$

Das Thema der fehlenden Entwicklung bzw. des Verfalls der indischen Kultur lässt sich also in verschiedenen literarischen Texten finden, wobei die romantische Sichtweise intensiver thematisiert wird. Allerdings ist es auch hier wie bei den meisten Themen, die aus den Sachtexten bekannt sind und Eingang in die literarischen Bearbeitungen finden: Diese Themen werden zwar angedeutet, jedoch nicht weiter vertieft.

\subsection{Europa im Spiegel Indiens}

Wie wir bereits bei den Sachtexten gesehen haben, zeigen die Texte über Indien nicht nur das Bild, das der betreffende Autor von diesem Land hat, sondern erlauben häufig auch Rückschlüsse auf dessen Sicht auf Europa. Das trifft auch auf die literarischen Texte zu. Vor allem in den Texten, in denen Europäer und Inder direkt aufeinander treffen, bleiben Vergleiche nicht aus. In „Die Prophetin von Caschimir“ findet sich in dem Aufeinandertreffen der Prophetin mit dem europäischen Missionar sogar eine Gegenüberstellung von Eigenschaften, die den von Said aufgestellten Dichotomien sehr ähnelt:

\footnotetext{
Sie, lieblich und anmuthvoll - er groß und Ehrfurcht gebietend; sie, schimmernd in all dem süßen Reiz, dem wundervollen Glanz des fabelreichen Orients - er in der Hoheit, Kraft und Stärke der Helden eines andern Welttheils; sie, ein Wesen, geschaffen zu lieben und zu gehorchen $\mathrm{er}$, geboren zu siegen, zu herrschen und zu befehlen [...]. ${ }^{1208}$
}

Der Orient erscheint hier als weiblich, reizend, liebevoll und märchenhaft, aber auch als passiv und dazu bestimmt zu gehorchen. Der Westen dagegen wird als starker Held beschrieben, der dazu geboren sei zu herrschen. ${ }^{1209}$ In den anderen Texten finden sich solche direkten Gegenüberstellungen nicht in so ausgeprägter Form, aber durch die

\footnotetext{
${ }^{1207}$ Vgl. z.B. Hensler: Das Sonnenfest, S: 34; Hensler: Das Schlangenfest, S. 12

1208 Tarnow: Die Prophetin von Caschimir. Erster Theil, S. 87f.

${ }^{1209} \mathrm{Vgl}$. auch Rajan, Balachandra: Under Western Eyes. India from Milton to Macaulay. Durham u. London 1999, S. 130f.
} 
Handlung spielen sie implizit gerade in den Opfer- und Witwenstücken ebenfalls eine Rolle. Die Opfer sind indisch, weiblich, schön, liebevoll, aber sie müssen gerettet werden und retten sich nicht aktiv selbst. Auch einige der männlichen Inder entsprechen eher diesem Bild, werden ebenfalls als zart und wenig tatkräftig beschrieben. Allerdings trifft das nicht auf alle Inder zu, es gibt auch andere. Die europäischen Retter hingegen sind kraftvoll, stark, mutig und sind gekommen, nicht nur um das Opfer zu retten, sondern um Indien sei es durch Handel, sei es durch militärische Präsenz zu beherrschen.

Die Europäer werden aber nicht durchgehend und nicht in allen Texten als den Indern moralisch und kulturell überlegen dargestellt. Es gibt auch Textstellen, in denen eine Gleichwertigkeit oder zumindest Ähnlichkeit beschrieben wird. Andere Textstellen äußern zudem direkte Kritik an dem Verhalten der Europäer in Indien und einigen Aspekten ihrer Kultur und Gesellschaftsordnung. Überlegenheit, Gleichwertigkeit und Kritik können in verschiedenen Texten überwiegen bzw. weniger vertreten sein, sie können aber auch in ein und demselben Text zum Ausdruck kommen, indem z.B. verschiedene Personen unterschiedliche Ansichten vertreten.

Als gleichwertige Gesprächspartner treten Inder und Europäer vor allem dann auf, wenn Abgesandte des portugiesischen Königs an den Hof eines indischen Herrschers kommen, um Handelsverträge zu schließen. Die Europäer passen sich bei ihren Treffen mit den Indern den indischen Gepflogenheiten an. So verbeugen sie sich z.B. nach Landessitte und erkennen damit ihr Gegenüber als ebenbürtigen Verhandlungspartner an. Gegenüber dem indischen Herrscher selbst nehmen die Europäer sogar eine untergeordnete Stellung ein, da sie lediglich Abgesandte eines Herrschers sind und nicht der Herrscher selbst. Das wird deutlich in der Art, wie sie den indischen Herrscher begrüßen und auf seine Anweisungen reagieren. Vulpius spielt in „Die Portugiesen in Indien“ mit dieser für die europäischen Leser ungewohnten Rollenverteilung, indem er deutlich macht, dass die Europäer in Indien die Fremden sind und sie als das Objekt der Neugierde der Inder darstellt. Diese betrachten die für sie exotischen Fremden unverhohlen und kommentieren ihre Verhaltensweisen, die aufgrund der ihnen fremden Gegenstände und Traditionen z.T. unbeholfenen wirken. ${ }^{1210}$ Vulpius hält so den 
Europäern den Spiegel vor und lässt sie erleben, wie es sich für andere anfühlen mag, Objekt der Lust am Exotischen zu sein.

Eine andere Möglichkeit, wie Inder und Europäer in den hier untersuchten Texten auf eine gleiche Ebene gestellt werden, ist die Betonung, dass sich ihre Sitten gar nicht so sehr voneinander unterscheiden: Auch in Europa gebe es grausame Sitten, ${ }^{1211}$ auch dort habe es das Recht der ersten Nacht gegeben, ${ }^{1212}$ die Mädchen in Indien seien wie die europäischen Mädchen ${ }^{1213}$ und überhaupt gebe es in allen Völkern seltsame Gebräuche, da alle Vorstellungen, die sich die Völker von der Welt machen, nicht in erster Linie auf der Natur, sondern auf Gewohnheiten beruhten. Das gelte auch für die Gesetze des Gewissens und den Vorstellungen von Gott. ${ }^{1214}$ Eine solche Engführung von auf dem ersten Blick ganz anderen, bei näherem Hinsehen aber sehr ähnlichen Traditionen findet sich z.B. in „Die Prophetin von Cashimir““ in der Parallelität der Verurteilungen der Prophetin bzw. des Missionars durch die offiziellen Vertreter ihrer Religion. ${ }^{1215}$ Die unterschiedlichen Kulturen werden hier also nicht in ihrer Gesamtheit bewertet und hierarchisch geordnet, sondern sie alle werden als zwar unterschiedlich, aber gerade in dieser Unterschiedlichkeit und in ihrer Ambivalenz (alle haben gute und weniger gute Aspekte) als gleichwertig dargestellt.

Kritik an den Europäern richtet sich vor allem gegen deren Geldgier und Machtansprüche. Sie gäben sich zwar zunächst freundlich, aber ihr Ziel sei es, das Land zu erobern, sich zu bereichern und die indische Religion und die indischen Bräuche zu verdrängen. Interessanterweise wird diese Kritik in den meisten Fällen dadurch entwertet, dass sie von den (bösen) Gegenspielern der Hauptfiguren geäußert wird. Der Leser identifiziert sich also nicht mit dem Sprecher und somit auch nicht mit dessen Aussage. Diese wird z.T. auch von anderen Personen des Textes direkt in Frage gestellt. So seien die Bräuche, die durch die Europäer bedroht würden, grausam und barbarisch, weshalb - wie man ergänzen könnte - ihre Abschaffung zu begrüßen sei. ${ }^{1216}$ Ausnahmen

\footnotetext{
${ }^{1211}$ Vgl. Plümicke: Lanassa, S. 11

1212 Vgl. Vulpius: Die Portugiesen in Indien. Band 2, S. 161 f. (Fußnote)

${ }^{1213}$ Vgl. Hensler: Das Schlangenfest, S. 60

${ }^{1214}$ Vgl. Vulpius: Die Portugiesen in Indien. Band 1, S. 93f., $97 f$.

${ }^{1215}$ Vgl. Botkin, Francis: Burning Down the [Big] House: Sati in Sydney Owenson's The Missionary. In: COLLOQUY text theory critique 15 (2008), S. 36-51, hier S. 42

1216 Vgl. Hensler: Das Schlangenfest, S. 21, 27, 44, 56f.; Vulpius: Die Portugiesen in Indien. Band 2, S. 123; Zumbach: Die Pullichi, S. 4; Winter: Marie von Montalban, S. $23 f$.
} 
sind Kotzebues „Die Indianer in England“, wo die Europäer nicht durch die Rede einer Person als geldgierig bezeichnet werden, sondern einige sich durch ihr Verhalten als geldgierig erweisen, und „Der Hindu“ von Sondershausen, wo die Hauptperson, die das Mitgefühl des Lesers auf sich ziehen soll, die Europäer als „kalte(...) und rohe(...) Männer ${ }^{\text {“1217 }}$ beschreibt. vor denen sogar die wilden Tiere fliehen. ${ }^{1218}$ Dieses Stück ist auch der einzige der hier untersuchten Texte (neben vielleicht noch Kotzebues „Die Indianer in England“), in denen ein Europäer als Gegenspieler der Hauptpersonen auftritt und somit nicht Identifikationsfigur für den Leser ist.

Im Großen und Ganzen lässt sich die Darstellung der Europäer in den hier untersuchten literarischen Texten also als positiv bezeichnen. Vor allem ihre moralische Überlegenheit und ihre vernünftige Sicht der Dinge werden indischem Aberglauben und grausamen Traditionen gegenübergestellt. Europa wird für einige der Opfer dieser Traditionen zum ersehnten Ort der Rettung und Freiheit. Dort könne man „unter dem Schutz menschlicherer Gesetze Tage der Wonne“"1219 erleben. Daraus ergibt sich für die Europäer häufig ein missionarischer Anspruch. Dieser bezieht sich natürlich zum einen auf die Verbreitung des Christentums, das als menschliche und milde Religion gefeiert wird, zum anderen aber auch auf eine Modernisierung der indischen Gesetze und Gesellschaft. Dabei stellt sich die Frage, ob man Rettung und Veränderung zunächst im Kleinen versuchen oder ob man große Reformen wagen sollte. Während die meisten Retter allein ihre Geliebte oder andere vertraute Personen retten und bekehren, sind einige Missionare darauf aus, möglichst viele Inder zu bekehren, was aber meistens nicht gelingt. Dieser Konflikt, ob Veränderung im Großen überhaupt möglich sei und daher gewagt werden dürfe und was diesen großen Plänen dafür im Kleinen geopfert werden dürfe, wird in dem Stück „Die Pullichi“ in den Fokus gerückt: Zwei befreundete Europäer mit ähnlichen Idealen sind in Indien gestrandet und verlieben sich in ihre Retterinnen. Doch während der eine sein Glück im Kleinen finden will und mit seiner Geliebten sein Glück sucht, verlässt der andere seine Liebe, um durch die Hochzeit mit der Herrschertochter die indische Gesellschaft zu reformieren. Zunächst scheint das auch zu glücken, aber am Ende muss er sich sein Scheitern eingestehen. Voller Reue kehrt er zu seiner Geliebten, die er durch sein Handeln in große Gefahr gebracht hat,

\footnotetext{
1217 Sondershausen: Der Hindu, S. 64

${ }^{1218}$ Vgl. Sondershausen: Der Hindu, S. 67f.

${ }^{1219}$ Hensler: Das Schlangenfest, S. 71
} 
zurück. Große Veränderungen können nicht auf Kosten des moralisch richtigen Verhaltens im Kleinen erreicht werden. ${ }^{1220}$ Auch der europäische General in „Lanassa“ beschreibt, wie er zunächst hoffte, ,einst die Fesseln zu zerbrechen, worin der blinde Aberglaube und die Tyrannei der Braminen dies Volk gefangen hält.“ Aber er musste feststellen, dass dieses Unterfangen vergeblich sei, denn an „Knechtschaft gewöhnt, schmäht es [das indische Volk] seinen Erretter und trotzt dem gewissen Untergang“. ${ }^{1221}$

\subsection{Christentum und Mission}

Mit der Frage nach den Möglichkeiten und Pflichten, Indien zu modernisieren und vom Aberglauben zu befreien, hängt das Thema Christentum und Mission eng zusammen, das auch in einigen der hier untersuchten Texten aufgegriffen wird. Vor allem in den Opfer- und Witwenstücken wird die Rettung der Opfer häufig mit deren Bekehrung verbunden. So wenden sich Lanassa, ihr Bruder und ihre Vertraute aus Dank für die Rettung Lanassas dem ihnen noch unbekannten Gott, der kein Blut verlangt, zu und werden Christen. ${ }^{1222}$ Auch in der sehr ähnlichen Oper „Jessonda“ wird die Sanftheit des christlichen Gottes betont, der nicht den Tod der Witwen verlange. Ziel der Europäer ist es hier, nicht nur die Witwe zu retten, sondern auch die „Götzenbilder“1223 zu stürzen. Das Stück endet mit der bangen Frage der Brahmanen, ob es einen größeren Gott als Brahmā gebe, und mit dem Preisen des christlichen Gottes. ${ }^{1224}$ Ähnlich ist es auch in „Das Schlangenfest“. Dort wird ebenfalls betont, dass der christliche Gott keine Menschenopfer verlange, sondern ,ein gutes, wohlthätiges Wesen“1225 sei. Einer der Inder ist bereits heimlich Christ. ${ }^{1226}$ Das Stück endet zwar nicht mit dem Preisen des christlichen Gottes, aber mit dem Sturz des Opfergottes und der Verehrung des Sonnengottes, die auch die Hauptpersonen (sowohl die Inder als auch die Europäer) als gut anerkennen. ${ }^{1227}$ In „Das Sonnenfest“ möchte dagegen eine Inderin aus Liebe und zu ihrer eigenen Rettung mit nach Europa fahren und Christin werden. ${ }^{1228}$ Und sogar in einem Stück, in dem Europäer überhaupt keine Rolle spielen (und somit auch das Christentum nicht thematisiert wird), findet sich eine Stelle, die in diesen Kontext

\footnotetext{
${ }^{1220}$ Vgl. Zumbach: Die Pullichi, S. 7, 27-32, 125

${ }^{1221}$ Plümicke: Lanassa, S. 38

${ }^{1222}$ Vgl. Plümicke: Lanassa, S. 31, 85

1223 Gehe: Jessonda, S. 36

${ }^{1224}$ Vgl. Gehe: Jessonda, S. 13, 44-46

${ }^{1225}$ Hensler: Das Schlangenfest, S. 77

${ }^{1226}$ Vgl. Hensler: Das Schlangenfest, S. 49

1227 Vgl. Hensler: Das Schlangenfest, S. 86

${ }^{1228}$ Vgl. Hensler: Das Sonnenfest, S. 24)
} 
gehört: In „Der Paria“ von Beer wendet sich die Frau des Parias an ihren sie bedrohenden Bruder mit den Worten: „Entweih’ ich diesen [indischen] Gott durch Lieb' und will/ Er Blut dafür, so sag' Dich los von ihm/ Und stell' Dir in dein goldnes Heiligthum/ Ein friedlich Lamm, es knieend anzubeten.“"1229 Obwohl die Frau das Christentum anscheinend nicht kennt und es auch sonst in dem Stück nicht erwähnt wird, wird mit dem Lamm als Sinnbild Christi dessen Überlegenheit über die indische Religion angedeutet.

Es gibt aber auch Texte, in denen das Verhältnis von indischer Religion und Christentum nicht so eindeutig ist und auch die Mission zumindest in einigen ihrer Formen durchaus ambivalent betrachtet wird. So wird (ähnlich wie in den Sachtexten) beschrieben, auf welche Schwierigkeiten die Missionare bei ihrer Tätigkeit stoßen und wie wenig sie von Erfolg gekrönt ist. Wie in den Sachtexten lassen sich die Inder entweder gar nicht erst auf ein Gespräch ein oder sie hören höflich zu, gehen aber nicht auf das Gehörte ein. Oder aber sie beginnen, den Missionar mit Argumenten unter Druck zu setzen. So wird ein Missionar in „Die Portugiesen in Indien“ mit dem Argument zurückgewiesen, dass er keine Wahrheiten erzähle, da Wahrheit das sei, was überzeuge. Da aber der Inder nicht überzeugt sei, könne es sich nicht um Wahrheiten handeln. Der Inder wolle nicht alles blind glauben, sondern selbst prüfen. Er sei der Ansicht, dass Hindus und Christen beide das gleiche Ziel hätten, allerdings auf unterschiedlichen Wegen versuchten, dorthin zu gelangen. ${ }^{1230}$ Auch der Missionar in „Die Prophetin von Caschimir“ hat wenig Erfolg bei seinen Missionsversuchen. Auf eine flammende Predigt vor Religionsgelehrten geht keiner der Anwesenden ein; sie wird vielmehr ignoriert. Einfache Inder, die er unterwegs trifft, hören ihm entweder gar nicht erst zu oder erklären ihm, dass jeder Stamm seinen eigenen Glauben habe. Diesen solle man ihm auch lassen und versuchen, gut mit seinen Nachbarn auszukommen. ${ }^{1231}$ Die Inder, die sich taufen lassen, tun das aus Liebe (damit die Liebenden sich auch nach dem Tod wiedersehen) oder aus Angst vor bestimmten indischen Traditionen und nicht, weil sie von der christlichen Botschaft überzeugt wären. ${ }^{1232}$ Einige der Hindus, die sich zum Christentum bekannt haben, rufen in Notsituationen doch ihre indischen Götter an,

\footnotetext{
${ }^{1229}$ Beer: Der Paria, S. 45

${ }^{1230}$ Vgl. Vulpius: Die Portugiesen in Indien. Band 2, S. 151f.

${ }^{1231}$ Vgl. Tarnow: Die Prophetin von Caschimir. Erster Theil, S. 55-58, 76, 82

1232 Vgl. z.B. Vulpius: Die Portugiesen in Indien. Band 2, S. 100f.; Tarnow: Die Prophetin von Caschimir. Erster Theil, S. 172f., Band 2, S. 23f., 28f.
} 
deren Verehrung weiterhin tief in ihnen verwurzelt ist. Sie wären auch viel eher dazu bereit, für diese Götter Leid auf sich zu nehmen als für den neuen christlichen Gott. ${ }^{1233}$

Wie schwierig und komplex die Mission sein kann (vor allem wenn auch persönliche Gefühle mit im Spiel sind), wird in „Die Prophetin von Caschimir“ ausführlich durchgespielt. Der Missionar verliebt sich in die indische Priesterin, die er bekehren möchte, und auch sie verliebt sich in ihn. Beiden ist körperliche Liebe aufgrund ihres priesterlichen Amtes allerdings untersagt. Hinzu kommt, dass der Missionar davon überzeugt ist, dass allein das Christentum den Weg in den Himmel eröffne, weshalb es für ihn von ungeheuer großer Bedeutung ist, seine Geliebte zu bekehren. Diese versteht diesen Eifer nicht, da ihre Religion die Auffassung vertritt, dass auch Andersgläubigen der Himmel offen stehe, und den Gedanken der Mission daher nicht kennt. ${ }^{1234}$ Vielmehr macht sie die Bedeutung der Bibel und der christlichen Lehren an der von ihr wahrgenommenen Heiligkeit des Missionars fest. ${ }^{1235}$ Außerdem ist es für sie selbstverständlich, die christlichen Lehren mit denen ihrer eigenen Religion zu vergleichen und sich zu freuen, wenn diese übereinstimmen. Der Missionar reagiert auf diese Vergleiche zumeist ungehalten, da er die Einzigartigkeit des christlichen Glaubens in Gefahr sieht. Ganz kann er sich den Vergleichen aber nicht entziehen und beginnt, über seine Religion neu nachzudenken. ${ }^{1236}$ Diese Ähnlichkeit religiöser Empfindungen wird auch in einem Moment ganz eigener und dennoch gemeinsamer Andacht deutlich, in dem beide „,von Einer Empfindung beseelt“"1237 sind. Es gibt aber durchaus Aspekte am Christentum, die die Prophetin kritisiert. So empfindet sie es als Gotteslästerung, Gott direkt anbeten und verstehen $\mathrm{zu}$ wollen, anstatt sich dem Göttlichen in seinen Schöpfungen zu nähern. Außerdem sind ihr einige Vorgaben zu streng und dogmatisch. So fragt sie sich z.B., warum man als Christ erst das Gebot der Nächstenliebe brauche, um sich um seine Mitgeschöpfe zu kümmern, da man doch selbst Ausfluss des göttlichen Urgeistes sei und Nächstenliebe daher selbstverständlich. ${ }^{1238}$ Trotz dieser auf ihrer religiösen Toleranz beruhenden Offenheit für christliche Lehren, hält sie dennoch zunächst an ihrer eigenen Religion fest - aus Überzeugung und aus Angst vor möglichen spirituellen und gesellschaftlichen Folgen

\footnotetext{
${ }^{1233}$ Vgl. Tarnow: Die Prophetin von Caschimir. Zweiter Theil, S. 142, 145; Sondershausen: Der Hindu, S. 110

${ }^{1234}$ Vgl. Tarnow: Die Prophetin von Caschimir. Erster Theil, S. 125, 230

1235 Vgl. Tarnow: Die Prophetin von Cashimir. Erster Theil, S. 152

1236 Vgl. z.B. Tarnow: Die Prophetin von Caschimir. Erster Theil, S. 119, 149f., 154, $176 f$.

1237 Tarnow: Die Prophetin von Caschimir. Erster Theil, S. 115

${ }^{1238}$ Vgl. Tarnow: Die Prophetin von Caschimir. Erster Theil, S. 112, 126f., Zweiter Theil, S. 64
} 
einer Konversion. Sie ist von den Lehren ihrer Religion überzeugt und lässt sich nur aus Liebe zu dem Missionar zu Christentum bekehren. Doch auch dann kniet sie vor Bildern ihrer indischen Götter nieder, verleugnet bei dem Hinweis, sie werde wegen ihres Übertritts aus ihrer Kaste verstoßen werden, wahre Christin zu sein, und kehrt aufgrund einer vermeintlichen Erscheinung Brahmās zwischenzeitlich zu ihrem alten Glauben zurück. ${ }^{1239}$ Es wird immer wieder gezeigt, dass sich seit der Kindheit verinnerlichte Lehren nicht durch kurze Unterweisungen verdrängen lassen. Interessant ist bei diesem Text auch, dass die christlichen und die indischen Lehren in der Art ihrer Darstellung und Bewertung kaum einander über- oder untergeordnet werden. Sie stehen vielmehr relativ gleichberechtigt nebeneinander. Und am Ende stirbt die indische Priesterin im festen Glauben sowohl an die Liebe zu dem Missionar als auch zu ihren Göttern. ${ }^{1240}$

In „Die Portugiesen in Indien“ wird an einer Stelle indirekt die Legitimation der Mission selbst in Zweifel gezogen. Es wird nämlich die Frage aufgeworfen, ob Heiden in den Himmel kommen können, wenn sie tugendhaft sind. Hierzu werden zwei unterschiedliche Positionen vorgestellt. Ein Portugiese ist der Ansicht, dass dem nicht so sei, da christliche Sünder besser als tugendhafte Heiden seien. Ein anderer vermutet dagegen, dass tugendhafte Heiden vielleicht sogar schneller in den Himmel kommen könnten als untugendhafte Christen. ${ }^{1241}$

Diskutiert wird in einigen Textstellen auch, welche Mittel zur Mission eingesetzt werden dürfen und ob Gewalt legitim sei. In „Die Portugiesen in Indien“ bekommen die portugiesischen Seefahrer den Auftrag, den christlichen Glauben notfalls mit dem Schwert durchzusetzen. Ein von der Mission überzeugter Portugiese vertritt die Ansicht, dass die christliche Lehre, dadurch dass sie die Wahrheit verkünde, alle überzeugen müsse. Inder, die sich trotz dieser zwangsläufig erfolgenden Überzeugung nicht taufen lassen wollen, handelten folglich aus bösem Willen heraus und müssten daher bekämpft werden. Auf den Einwand, was passiere, wenn die Inder stärker seien als die Europäer, erwidert er, das könne nicht geschehen, da die Christen aufgrund ihres wahren Glaubens stärker als alle Heiden sein müssten und nicht verlieren könnten. ${ }^{1242}$

\footnotetext{
${ }^{1239}$ Vgl. Tarnow: Die Prophetin von Caschimir. Erster Theil, S. 94-97, 206f., 224-227

${ }^{1240}$ Vgl. Tarnow: Die Prophetin von Caschimir. Zweiter Theil, S. 163

${ }^{1241}$ Vgl. Vulpius: Die Portugiesen in Indien. Band 2, S. $127 \mathrm{f}$.

1242 Vgl. Vulpius: Die Portugiesen in Indien. Band 2, S. 12, 61-63
} 
Es wird aber deutlich, dass der Autor des Textes diese Ansicht nicht unterstützt. In „Die Prophetin von Caschimir“ gibt es eine Diskussion, in der der Missionar, dessen Sicht auf die Dinge sich durch den engen Kontakt zu der indischen Priesterin etwas gewandelt hat, deutlich macht, dass es nicht darauf ankomme, möglichst viel zu predigen und zu missionieren, sondern dass man auch im Bewusstsein behalten solle, dass Mission ohne Aussicht auf Erfolg zu Fanatismus und Leid führen könne. Auch könne durch List und Gewalt keine wahre Bekehrung erzielt werden, allenfalls Lippenbekenntnisse. ${ }^{1243}$

Die Frage nach dem Einsatz von Gewalt zur Durchsetzung von Glaubensinhalten wird nicht nur anhand der Mission diskutiert, sondern auch hinsichtlich der europäischen Inquisition. Sowohl in „Die Portugiesen in Indien“ als auch in „Die Prophetin von Caschimir" wird der Schrecken der Inquisition der Toleranz der Inder gegenübergestellt. Während in dem Text von Vulpius nur erzählt wird, dass sowohl die christlichen als auch muslimischen Geistlichen große Macht hätten, sich zu rächen, und ein Europäer vor allem aus dem Grund als muslimischer Derwisch in Indien lebt, weil er in diesem Land seinen Glauben leben kann, ohne eine Inquisition zu fürchten, ${ }^{1244}$ werden die Hauptpersonen in „Die Prophetin von Caschimir“ direkte Opfer der Inquisition. Aufgrund ihres Verstoßes gegen religiöse Gebote der Hindus sind der Missionar und die indische Priesterin bereits von indischen Geistlichen zum Tode bzw. zur Verbannung verurteilt worden. Die Inder verfolgen die beiden Flüchtigen allerdings nicht weiter, da ihnen die Vollstreckung des Urteils aufgrund ihrer Sanftmut nicht so wichtig ist. ${ }^{1245}$ Nach einer langen Flucht erreichen sie die scheinbare Sicherheit einer europäischen Ansiedlung in Goa und werden dort von der Inquisition gefangen und verurteilt. Die indische Priesterin rettet den Missionar vor dem Scheiterhaufen, indem sie selbst stirbt.

Diese religiöse Toleranz der Inder, die auch in den Sachtexten erwähnt wird, wird auch durch Aussagen indischer Figuren veranschaulicht, die die Ansicht vertreten, dass es egal sei, welchem Glauben jemand angehöre, solange er ehrlich und tugendvoll sei. ${ }^{1246}$ Zwar wird in anderen Textstellen auch deutlich gemacht, dass die Europäer von den

\footnotetext{
${ }^{1243}$ Vgl. Tarnow: Die Prophetin von Caschimir. Zweiter Theil, S. 87-93

1244 Vgl. Vulpius: Die Portugiesen in Indien. Band 2, S. 154, 205

1245 Vgl. Tarnow: Die Prophetin von Caschimir. Zweiter Theil, S. 17f., $21 f$.

1246 Vgl. Vulpius: Die Portugiesen in Indien. Band 1, S. 118; Kotzebue: Die Indianer in England, S. 57
} 
Indern durchaus als ungläubige Heiden wahrgenommen werden können (so wird z.B. die Frage aufgeworfen, ob europäische Schiffbrüchige überhaupt vor ihrer Bekehrung gerettet werden sollten), ${ }^{1247}$ aber die auftretenden Inder versuchen an keiner Stelle, die Europäer zu missionieren oder ihnen ihren Glauben zu verbieten.

\section{Zusammenfassung}

Insgesamt kann man sagen, dass die Indienbilder in den literarischen Texten weniger differenziert und vielschichtig sind als die von den Sachtexten vermittelten Bilder, auch wenn einige der aus den Sachtexten vertrauten Themen aufgegriffen werden. Sowohl diese Themen als auch die auftretenden Personen und mögliche Handlungsabläufe sind deutlich eingegrenzter und schematisierter. Bestimmte Begriffe wie Ganges, Brahmane, Bajadere etc. genügen, um in der Vorstellung der Leser bzw. Zuschauer bestimmte Bilder von Indien zu erzeugen, die von einfachen Stereotypen geprägt sind und die von den Autoren nicht detaillierter beschrieben zu werden brauchen. De Zoysa nennt diese Begriffe, die Ketten von Assoziationen auslösen, „Codes““ ${ }^{1248}$ Diese so erzeugten Bilder entsprechen in den meisten Fällen nicht dem Stand der Wissenschaft, was weniger daran liegen dürfte, dass die Autoren diesen nicht kennen, sondern die Autoren versuchen vielmehr, den Geschmack und die Erwartungen des Publikums zu erfüllen. ${ }^{1249}$ Dabei entstehen vor allem zwei sich widersprechende Indienbilder: Zum einen wird ein Indien entworfen, das geprägt ist von Aberglaube und daraus resultierenden grausamen Traditionen. Dem steht ein modernes, aufgeklärtes Europa gegenüber. Zum anderen gibt es Texte, die Indien als Wiege der Menschheit und Quelle uralter Weisheit beschreiben, das so zum Sehnsuchtsort von Europäern wird, die durch die Entfremdungen der Moderne verunsichert und wurzellos geworden sind. Das erste Bild ist geprägt von einem Schwarz-Weiß-Denken: Es gibt entweder bösen Aberglauben oder aufgeklärte, christliche oder bei einigen Indern auch natürliche Menschlichkeit. Grautöne fehlen fast völlig. Auch das zweite Bild kennt diese Grautöne kaum. Es entspricht am ehesten dem von der Forschung (vor allem Willson) beschriebenen Mythos Indien und blendet die in den Sachtexten beschriebenen aktuellen gesellschaftlichen Lebenswelten und Probleme aus. Es gibt natürlich auch Texte, die sich keinem der beiden Hauptbilder zuordnen lassen, aber auch bei diesen wird Indien in der Regel nicht differenziert betrachtet. Das ist insofern nicht

\footnotetext{
${ }^{1247}$ Vgl. Hensler: Das Sonnenfest, S: 12; Tarnow: Die Prophetin von Caschimir. Erster Theil, S. $98 f$.

${ }^{1248}$ Vgl. De Zoysa: "Blutrünstige Braminen am heiligen Strome“", S. 238f.

1249 Vgl. auch De Zoysa: "Blutrünstige Braminen am heiligen Strome“, S.227f.
} 
verwunderlich, als es den meisten Autoren in ihren Texten nicht darum geht, Indien bzw. einige Aspekte der indischen Kultur zu thematisieren. Vielmehr dient Indien in den meisten Fällen entweder als exotische Kulisse, die die Texte interessanter macht und die Möglichkeit für bestimmte Handlungen (z.B. Opferungen) überhaupt erst ermöglicht, oder als Sinnbild für bestimmte Bereiche der europäischen Kultur, die stellvertretend an dem indischen Beispiel zur Diskussion gestellt und kritisiert werden können. Nur wenige Ausnahmen, wie z.B. „Die Prophetin von Caschimir“ und „Die Portugiesen in Indien“ gehen stärker auf die Ergebnisse der Indienforschung bzw. auf Berichte Reisender ein und schaffen so ein vielfältigeres Bild von Indien. 


\section{Phantasma Indien?}

Ziel dieser Arbeit ist es, die verschiedenen Diskurse, die um 1800 im deutschsprachigen Raum die Faszination Indien ausmachen, in ihren unterschiedlichen Facetten und hinsichtlich ihrer Argumentationsstrukturen zu untersuchen. Es geht vor allem darum aufzuzeigen, welche Bilder von Indien entworfen werden, inwieweit sich diese Bilder im Laufe der Zeit verändern, welche Themen und Begriffe diskursübergreifend von Bedeutung sind und welche anderen zeitgenössischen Diskurse in die Indiendiskurse mit hineinspielen und sie so beeinflussen. Dabei bin ich immer auch der Frage nachgegangen, warum gerade Indien eine solche Aufmerksamkeit zuteil wurde, wie die indische Kultur an die eigene angebunden worden ist, welche Funktion(en) Indien dabei ausfüllt und ob man im Zusammenhang mit der Indienrezeption von Projektionen oder sogar einem Phantasma sprechen kann. Auf diese Themen und Fragestellungen bin ich im Laufe der Arbeit immer wieder anhand entsprechender Beispiele eingegangen. Nun möchte ich sie in einer allgemeineren Zusammenfassung noch einmal aufgreifen und ihre Verbindungen untereinander aufzeigen.

\section{Warum gerade Indien?}

Seit im Zuge der Aufklärung und ihrer Folgen die Neugierde auf die Welt eine positive Aufwertung erfährt, zieht nicht nur Indien große Aufmerksamkeit auf sich. Viele Menschen in Europa sind geradezu begierig nach Kenntnissen über andere Länder und Kulturen. Das zeigt sich zum Beispiel an der großen Beliebtheit von Reiseberichten und daran, wie schnell neue Schriften aus diesem Themenfeld übersetzt werden. Die Ursachen für diese Hinwendung zu anderen Kulturen sind vielfältig. Eine wichtige Rolle spielt zweifellos das Bestreben der Aufklärung, alles kritisch zu hinterfragen und rational zu ergründen. Wenn dabei bislang gültige Weltbilder und Deutungen an Autorität verlieren, eröffnet das eine Vielzahl von Fragen. Gerade wenn das Eigene im Wandel ist und hinterfragt wird und dadurch ein großes Legitimations- und Reflexionsbedürfnis besteht, kann der Vergleich mit dem Anderen bei der Neudefinition des Eigenen helfen. ${ }^{1250}$ Wenn also z.B. die biblische Schöpfungsgeschichte nicht länger mit Gewissheit die eigene Herkunft erklären kann, ist es nicht verwunderlich, dass viele sich auf die Suche nach anderen, beweisbaren 
Erklärungen für den Ursprung der Menschheit und die Entstehung der unterschiedlichen Kulturen machen und daher ihren Blick über die Grenzen Europas hinaus richten. Die Neuentdeckung ${ }^{1251}$ Indiens fällt also in eine Zeit, in der sich viele Gelehrte aus unterschiedlichen Gründen mit der Suche nach Ursprüngen, Entstehungsund Entwicklungsgeschichten und Fragen nach möglichen Verwandtschaftsverhältnissen beschäftigen. Indien als eine noch kaum untersuchte, alte Hochkultur fasziniert die Menschen in großem Maße, da es aufgrund der noch weitestgehend unbekannten Fülle an anscheinend sehr alten Überlieferungen zu Spekulationen und Projektionen einlädt und Erwartungen und Hoffnungen weckt. Außerdem hat man mit Indien eine Kultur entdeckt, die nicht nur nahe an der Wiege der Menschheit zu liegen scheint, sondern die darüber hinaus Europa viel ähnlicher ist, als man es erwarten konnte, und sogar durch die entdeckte Verwandtschaft nicht nur Aufschlüsse über die Menschheit allgemein, sondern auch ganz konkret über die Geschichte des Eigenen verspricht. Hinzu kommt, dass Indien bereits seit der Antike als geheimnisvoll, unermesslich reich, als Land voller Wunder und Weisheit und zugleich auch als seltsam und monströs gilt, was zusätzliche Erwartungen weckt und zur großen Faszination beiträgt. Außerdem führen die bereits seit der Antike nebeneinander bestehenden Deutungsmöglichkeiten Indiens als Land der Weisheit auf der einen Seite oder als Land des Monströsen auf der anderen Seite, die auch um 1800 in veränderter Form weiter bestehen bleiben, dazu, dass sich an Indien wie an kaum einem anderen Land die Geister scheiden ${ }^{1252}$ und sich dieses Thema daher sehr gut eignet, bestimmte Kontroversen in der intellektuellen Landschaft um 1800 zuzuspitzen und auszutragen. Indien ist keineswegs die einzige alte Kultur, die die Neugierde vieler Menschen weckt, aber anders als z.B. die persische oder arabische Kultur wird es in deutlich stärkerem Maße zur Projektionsfläche für zeitgenössische Vorstellungen und zum Austragungsort für verschiedene Diskurse der Zeit.

\footnotetext{
1251 Natürlich gab es in Europa bereits seit der Antike Kenntnisse über Indien, die mit bestimmten Vorstellungen von dessen Kultur verbunden war. Dennoch kann man im Zusammenhang mit der Indienrezeption von einer bzw. genauer zwei Neuentdeckungen oder Erweiterungen sprechen: Da sind zum einen zu Beginn der frühen Neuzeit die ersten Augenzeugenberichte nach einer langen Zeit ohne direkten Kontakt zwischen Indien und Europa und da ist zum anderen die Entdeckung der alten indischen Schriftkultur.

1252 Vgl. Bhatti, Anil: Der deutsche Indiendiskurs. Ambivalenzen im deutschen Orientalismus des neunzehnten Jahrhunderts. In: German Studies in India. Aktuelle Beiträge aus der indischen Germanistik / Germanistik in Indien. München 2006, S. 23-38, hier S. 23
} 


\section{Der Einfluss anderer Diskurse}

Die Rezeption Indiens ist in besonders engem Maße mit verschiedenen zeitgenössischen Diskursen verbunden, wird von diesen angestoßen und beeinflusst, was bei ihrer Beurteilung in jedem Fall berücksichtigt werden muss. Dazu gehören vor allem die bereits genannten Diskurse über die Suche nach den Ursprüngen: nach dem Ursprung der Menschheit, der Kultur und der Sprache sowie die Suche nach einer möglichen Uroffenbarung. Polaschegg unterscheidet in diesem Zusammenhang für den deutschsprachigen Raum erstens die Suche nach einer eigenen nationalen Identität, die in Abgrenzung zu anderen europäischen Nationen konstituiert werden soll, zweitens die Frage nach der Entstehung von Kultur und ihr Verhältnis zur Natur und drittens die Frage nach der kulturellen Herkunft des christlichen Abendlandes. ${ }^{1253}$ Hinzu kommen weitere Diskurse wie die Frage nach menschlichen und kulturellen Universalien und Unterschieden, Vorstellungen von Naturrechten und Naturreligion, aber auch begrenztere Auseinandersetzungen wie der Pantheismus-Streit. Diese Diskurse beeinflussen nicht nur, was über Indien gesagt wird, sondern ordnen Indien auch in einen ganz bestimmten Kontext ein, der die Quellenauswahl und die Blickrichtung bestimmt. So ist es ein großer Unterschied, ob ein Autor sich mit Indien im Rahmen einer Menschheitsgeschichte beschäftigt, innerhalb derer Indien eine Kultur unter vielen ist, der auf einer postulierten Entwicklungsskala ihr Platz zugewiesen wird, oder ob Indien vor dem Hintergrund einer Suche nach den Uranfängen der Religion betrachtet wird, bei dem den indischen Überlieferungen aufgrund der vermuteten Nähe zur Uroffenbarung eine herausragende Stellung zukommt. Die unterschiedlichen Diskurse, innerhalb derer Indien thematisiert wird, geben bestimmte Prämissen und Fragestellungen vor, die zum Teil bereits Ergebnisse vorwegnehmen können. Diese einzelnen Diskurse wurden in den entsprechenden Kapiteln bereits ausführlich analysiert. Im Folgenden soll es um ihre Funktionen in einem größeren diskursiven Zusammenhang im späten 18. und frühen 19. Jahrhundert gehen.

\section{Anbindung und Funktionen Indiens}

Die Autoren gehen mit einem bestimmten Bild, bestimmten Fragen, Vorstellungen und erhofften Antworten im Rahmen eines bestimmten Diskurses und vor dem Hintergrund ihres eigenen Weltbildes an das Thema Indien heran. Die Anbindung der anderen Kultur an die Eigene geschieht dabei vor allem mithilfe des Vergleichs. In der eigenen 
oder einer anderen bereits vertrauten Kultur wird nach Ähnlichkeiten gesucht, die helfen sollen, die indische Kultur zu erklären und in das eigene Weltbild einzuordnen. So wird z.B. die zunächst seltsam erscheinende Götterordnung der indischen Religionen über den Vergleich mit den Heiligen oder Engeln des Katholizismus erklärt und in den Bereich des Vertrauten gezogen. Das Kastenwesen wird mit der mittelalterlichen Ständeordnung in Verbindung gebracht und die indische Literatur wird z.B. mit Shakespeare oder Ossian verglichen. Einzelne Aspekte der indischen Religion und Philosophie werden mit Begriffen, die anhand europäischer Konzepte entwickelt wurden (wie Monotheismus, Polytheismus und Pantheismus), zu fassen versucht. Auch die wissenschaftliche Herangehensweise an die indische Kultur, die vor allem von August Wilhelm Schlegel propagiert wird, soll über die Anbindung an bereits Vertrautes und an bereits vorhandene europäische Konzepte und Begriffe geschehen. In diesem Fall sind es die anhand der Auseinandersetzung mit der griechischen und römischen Antike entwickelten Methoden der klassischen Philologie, die auf Indien angewendet werden. Und sogar in Fällen, in denen Indien als ein negatives Gegenbeispiel zu Europa stilisiert werden soll, geschieht das häufig über Vergleiche entweder mit anderen als rückständig betrachteten Kulturen oder über Verweise auf rückständige Bereiche der eigenen Vergangenheit. Durch diese Anbindung über den Vergleich sowie mithilfe von Kategorien und Begriffen, die zur Beschreibung bestimmter Bereiche der eigenen oder anderer vertrauter Kulturen entwickelt worden sind, werden Teile der indischen Kultur (ohne dass in allen Fällen bewusst darauf hingewiesen wird) Diskursen zugeordnet, die dem europäischen Kontext entstammen. Das hilft, die Fremdheit abzubauen, und erleichtert das Verständnis. Auch fördert ein solches Vorgehen die Akzeptanz der Ergebnisse. Aber die Vorstellungen, die so an die andere Kultur herangetragen werden, verhindern oder erschweren es zumindest, dass die individuellen Besonderheiten des Anderen wirklich als solche wahrgenommen werden. So führen z. B. die Deutungsversuche des vielfältigen indischen religiösen Lebens und der indischen Lehren mithilfe europäischer Erklärungsmuster dazu, dass „die“ indische Religion als verwirrend und in sich widersprüchlich wahrgenommen und aufgrund dessen negativ beurteilt wird. Die Möglichkeiten, dass in Indien verschiedene Lehren und religiöse Traditionen nebeneinander und sogar miteinander eng verbunden existieren können oder dass sich das Besondere der indischen Lehren nicht mit bisherigen europäischen Begriffen fassen lassen kann, wird kaum in Betracht gezogen. Es gibt zwar Autoren wie Herder oder Forster, die darauf hinweisen, dass eigene Vorannahmen die Wahrnehmung Indiens beeinflussen, und die daher fordern, man 
solle indische Texte nicht im europäischen, sondern im indischen Geist lesen. Die Versuche, sich in diesen den Europäern unbekannten indischen Geist hineinzuversetzen, stehen aber vor einem ähnlichen Problem, wie die Annäherung über konkrete Vergleiche: Auch dabei werden unbewusst eigene Konzepte, die aus einem europäischen Diskurs stammen, auf Indien projiziert. ${ }^{1254}$

Das Eigene beeinflusst nicht nur über die Art der Anbindung die Indiendarstellungen, sondern auch über die Intentionen, mit denen sich die Autoren diesem Thema zuwenden. In einigen Fällen geht es den Autoren gar nicht darum, wirklich etwas über die andere Kultur zu erfahren; das Andere dient nur der Veranschaulichung bestimmter Aspekte des Eigenen. Bei vielen ist dagegen durchaus tiefergehendes Interesse vorhanden. Vor allem Humboldt versucht, möglichst genaue Einsichten in die Bhagavadgītā zu gewinnen und zeigt dabei nicht nur echtes Interesse, sondern auch den Wunsch, die Lehren wirklich zu verstehen. Die meisten dieser Autoren aber weisen Indien darüber hinaus - vielleicht auch unbewusst - bestimmte Funktionen zu, die bei einer Untersuchung so entstehender Bilder unbedingt mit angeschaut werden müssen, da sie die Art und Weise, wie die andere Kultur dargestellt wird, stark beeinflussen. ${ }^{1255}$

Eine dieser Funktionen ist es, als eine Art Spiegel die Kritik am Eigenen zu ermöglichen. So dient eine besonders positive, vielleicht auch überzeichnete Darstellung bestimmter Aspekte der indischen Kultur vor allem in Diskursen, die sich mit den Entwicklungen des modernen Europas befassen, dazu, die europäischen Entsprechungen im Glanze dieses Vorbildes als besonders kritikwürdig erscheinen zu lassen. Das ist vor allem bei den positiven Beschreibungen der Inder der Fall. Ein markantes Beispiel dafür ist die Darstellung durch Herder, aber auch in einigen Reiseberichten finden sich Gegenüberstellungen von indischen Tugenden mit europäischen Lastern. Andersherum zielt aber auch eine deutlich abwertende Schilderung indischer Begebenheit in vielen Fällen auf eine Kritik an ähnlichen Strukturen in Europa. Dabei geht es vor allem um gesellschaftliche bzw. politische Phänomene wie die Ausgrenzung von Minderheiten, die Ständegesellschaft oder die

1254 Vgl. auch Scheiffele, Eberhard: Affinität und Abhebung. Zum Problem der Voraussetzungen interkulturellen Verstehens. In: Wierlacher, Alois (Hg.): Das Fremde und das Eigene. Prolegomena zu einer interkulturellen Germanistik. München 1985, S. 29-46, hier S. 32

1255 Vgl. Mangold, Sabine: Anmerkungen zur deutschen Orientalistik. In: Hofmann, Michael u. Goer, Charis (Hg.): Der Deutschen Morgenland. Bilder des Orients in der deutschen Literatur und Kultur von 1770 bis 1850 . Paderborn 2007, S. 223-241, hier S. 241 
große Macht des Klerus. Diese Art der Kritik findet sich in vielen Reiseberichten, aber auch in literarischen Werken, die sich mit dem Schicksal der Paria auseinandersetzen.

Eine andere Funktion, die einige Autoren Indien zuweisen, ist die der Abgrenzung und Stärkung des Eigenen. Bei der Darstellung Indiens wird in diesem Fall vor allem das Andere und auch Fremde dieser Kultur herausgestellt. Dadurch wird das Eigene abgegrenzt und definiert. Geschieht diese Abgrenzung in einer abwertenden Art und Weise, versichern sich der Autor und seine Leser gleichzeitig der Überlegenheit und damit auch Legitimation des Eigenen. Das geschieht im indischen Kontext vor allem in Bezug auf Phänomene, die ein aufgeklärtes, modernes Europa überwunden zu haben glaubt, wie z.B. den Aberglauben mit all seinen (z.T. grausamen) Folgen.

Eine weitere Funktion, die Indien zuteil wird, ist die, als Projektionsfläche für Interpretationen $\mathrm{zu}$ dienen, die weniger Indien in seinen Besonderheiten zeigen, sondern im Rahmen bestimmter Diskurse eigene Thesen und Vorstellungen veranschaulichen und bekräftigen. Das geschieht vor allem im Kontext der Romantik. Dabei werden eigene Vorstellungen (z.B. von einem Urmythos oder einer ursprünglichen Weisheit) auf Indien projiziert. Dieses „Finden“ der eigenen Sichtweisen und Thesen in der indischen Kultur dient dazu, die Wahrheit dieser Thesen - vielleicht auch sich selbst gegenüber - zu beweisen. Zum Beispiel setzt sich Günderrode in ihren Texten nicht mit tatsächlichen indischen Lehren und Schriften auseinander, sondern projiziert eigene philosophisch-religiöse Vorstellungen wie die eines Erdgeistes auf den indischen Kontext. Diese Funktion als Projektionsfläche des Eigenen beeinflusst auch die Quellenauswahl stark. Das zeigt sich z.B. bei Görres, der seine Quellen anhand von Kriterien als authentisch oder gefälscht einteilt, die er anhand seiner Erwartungen, wie der Urmythos aussehen müsste, entwickelt hat. Diese Projektionen vermitteln zumeist ein sehr positives, häufig auch idealisiertes Bild von Indien. Aber auch negative Darstellungen der indischen Kultur erfüllen die Funktion, das eigenen Weltbild zu präsentieren und zu verdeutlichen. Das ist z.B. bei Hegel der Fall, der Indien nicht aus dem Grund von der eigenen Kultur abgrenzt, um die Identität der eigenen Nation herauszuarbeiten oder die Errungenschaften der Aufklärung deutlich zu machen, wie es viele andere Autoren tun. Hegel geht es vielmehr um seine Philosophie des Weltgeistes, die er anhand von bestimmten Aspekten der indischen Kultur verdeutlicht. Eine sehr ähnliche Funktion - wenn auch unter gegensätzlichem Vorzeichen - erfüllt Indien bei Herder und Forster, die deutlich machen wollen, dass 
alle Völker und Kulturen der Welt ihren Platz in der Geschichte haben und aufgrund von Universalien wie der Humanität und der menschlichen Gefühle miteinander verbunden sind. Jede Kultur habe in ihrer Zeit ihre Bedeutung und stehe gleichwertig neben den anderen. Diese Position bekräftigen Herder und Forster dadurch, dass sie sowohl die Gemeinsamkeiten Indiens und Europas als auch ihre lokalen Besonderheiten hervorheben und anerkennen.

Neben all diesen Rollen, die Indien innerhalb bestimmter Diskurse zukommen, erfüllt es noch eine weitere Funktion, die nicht an einzelne Diskurse gebunden ist: Der Bezug auf Indien dient auch dazu, die Lust am Exotischen und Unbekannten zu befriedigen. Das ist vor allem in Reiseberichten, Artikeln in populären Zeitschriften sowie in Schauspielen und Opern der Fall. Hier werden gerade die Aspekte der indischen Kultur in den Mittelpunkt gerückt, die aus europäischer Sicht am besten die Faszination am Fremden und Unerklärlichen mit der Lust an Grausamkeit und Schrecken verbinden. Prominentestes Beispiel dafür ist die Witwenverbrennung.

\section{Paradigmenwechsel: Distanz und Differenz}

Wie bereits in der Einleitung dargestellt, weist Polaschegg darauf hin, dass man bei der Untersuchung, wie andere Kulturen wahrgenommen werden, die Kategorien des Fremden und des Anderen, also der Dichotomien der Distanz und der Differenz, voneinander unterscheiden sollte. Außerdem beobachtet Polaschegg einen Wandel hinsichtlich dieser Kategorien, der um 1800 durch die Betonung des Historischen sowie die Entdeckung der klassischen indischen Texte eingeleitet werde. Vor dem Beginn der Erforschung durch die Asiatic Society seien Indien und Persien zwar als andere Kulturen, aber nicht als grundlegend fremd wahrgenommen worden. Seit ungefähr 1800 seien sie in den Bereich des Eigenen gewechselt, würden aber (aufgrund der postulierten historischen Distanz) als fremd empfunden. ${ }^{1256}$ Polaschegg meint damit, dass in der frühen Neuzeit Indien und Persien aufgrund der räumlichen Differenz einem anderen Kulturraum zugeordnet gewesen seien. Aber da sie noch nicht vor dem Hintergrund des späteren Entwicklungsdenkens betrachtet worden seien, hätten sie sich in der Wahrnehmung der Zeitgenossen auf dergleichen Zeit- und Entwicklungsebene wie die eigene Kultur befunden. Sie hätten also zwar als anders, aber nicht als fremd gegolten in dem Sinne, dass man $\mathrm{zu}$ ihrem Verständnis besondere 
Vermittlungsleistungen vorausgesetzt hätte. Die Distanz eines europäischen Fürsten zu seinen Untertanen wurde als größer empfunden als die zu einem indischen oder persischen Fürsten. ${ }^{1257}$ Um 1800 werde - so Polaschegg - die zu Indien empfundene Distanz aber immer weniger durch die Kategorie des Raumes, sondern vielmehr der Zeit definiert. Das Augenmerk werde auf das vergangene Indien gerichtet und auch das zeitgenössische Indien scheine in den Augen der europäischen Betrachter aufgrund fehlender Entwicklung auf der Stufe der Vergangenheit zu verharren. Durch diese unterschiedlichen Zeit- und Entwicklungsebenen, auf denen sich Indien und Europa zu befinden scheinen, betrachteten die europäischen und vor allem auch die deutschsprachigen Autoren Indien aus einer historischen Distanz heraus, die eine hermeneutische Distanz schaffe und die indische Kultur als fremd erscheinen lasse. Gleichzeitig würden viele Autoren Indien aufgrund der neu entdeckten (Sprach)Verwandtschaft als Teil der eigenen Vergangenheit ansehen und damit aus dem Bereich des Anderen in den des Eigenen überführen. ${ }^{1258}$

Obwohl sich Reste des frühneuzeitlichen Verständnisses von Indien als einem anderen, der eigenen Kultur aber vergleichbaren Land ${ }^{1259}$ auch um 1800 noch in den literarischen Bearbeitungen der ersten Begegnungen zwischen Europäern und Indern (z.B. bei Vulpius oder Hensler) finden lassen, trifft auf die überwiegende Mehrheit der Texte die von Polaschegg gemachte Beobachtung zu. In der Tat interessieren sich viele der (romantischen) Autoren nur für die Vergangenheit Indiens und rücken diese sogar noch in mythische Fernen. Andere Autoren beschäftigen sich zwar mit dem zeitgenössischen Indien, aber sie betrachten es unter der Prämisse, dass das, was sie dort sehen, nur die verfallenen Reste einer alten indischen Kultur seien. Das

\footnotetext{
${ }^{1257}$ Etwas Ähnliches beobachtet auch Reinhard, wenn er feststellt, dass ,,von einer ökonomischen, politischen und kulturellen Übermacht Europas gegenüber den asiatischen Hochkulturen in der Frühen Neuzeit noch keine Rede sein kann“, weshalb ,eine Art von Gleichzeitigkeit“ herrsche, ,dank der das Fremde als unvertraut und wundersam, aber nicht als gegensätzlich wahrgenommen werden kann.“ (Reinhard: Bornierter Blick?, S. 14f.)

${ }^{1258}$ Auch andere Autoren vertreten ganz ähnliche Ansichten, vgl. z.B. Amman: Östliche Spiegel, S. 32; Dharampal-Frick: Indien im Spiegel deutscher Quellen der Frühen Neuzeit, S. 11, 180f.

${ }^{1259}$ Wie deutlich sich dieser Wandel auch in kleinen Verschiebungen der Vergleiche (vor allem hinsichtlich der gewählten comparata) zeigt, führt Flüchter am Beispiel der indischen Nairen vor. Während diese zunächst als dem europäischen Adel vergleichbare Gruppe von Menschen verstanden worden seien, sei durch den Austausch der Vergleichsgröße „,europäischer Adel“ gegen ,indische Kasten“, also eines selbstreferentiellen Vergleichs durch einen fremdreferentiellen die Vergleichbarkeit der Nairen mit europäischen Gesellschaftsformen und -schichten als solche in Zweifel gezogen worden (Vgl. Flüchter, Antje: Die Nairen der Malabarküste zwischen Adelsstand und Kriegerkaste. Praktiken des Vergleichens und die europäische Weltaneignung. In: Klöber, Rafael und Ludwig, Manju (Hg.): HerStory. Historical Scholarship between South Asia and Europe: Festschrift in Honour of Gita Dharampal-Frick, Heidelberg u. Berlin 2018, S. 3-41)
} 
zeitgenössische Indien gilt also als eine Art lebendes Museum, aber es wird nicht als eigenständige, sich weiterentwickelnde Kultur anerkannt. Daraus entsteht eine hermeneutische Distanz, die dazu führt, dass nur noch Experten das Verstehen der Vergangenheit zugetraut wird. Möglich ist auch eine normative Distanz, die daraus entsteht, dass die moralischen Normen der Inder aufgrund ihrer Altertümlichkeit und ihres Verfalls nicht den europäischen zu entsprechen scheinen, weshalb einige Europäer sich dazu berufen fühlen, politisch einzugreifen und Traditionen wie die Witwenverbrennung zu beenden. Dieses Moment der Fremdheit wird in den Texten durch Vergleiche (in der eigenen oder zumindest vielen anderen Kulturen gibt oder gab es ähnliche Erscheinungen) entweder versucht zu relativieren und zu erklären oder aber besonders betont, um das Eigene von der anderen Kultur klar zu trennen und die eigenen Errungenschaften hervorzuheben. Umgekehrt dient Indien als ein Teil des Eigenen auch dazu, das Eigene über diese gemeinsame Vergangenheit neu zu definieren und - besonders im Fall des deutschsprachigen Raumes - von anderen europäischen Kulturen abzugrenzen.

\section{Argumentationsstrukturen und Begriffe}

Auch wenn sich die Autoren, die sich innerhalb der eng miteinander verbundenen und sich zum Teil überschneidenden Diskurse mit Verweis auf Indien geäußert haben, hinsichtlich ihrer Vorstellungen und Zielrichtungen sehr voneinander unterscheiden können, nutzen sie dennoch immer wieder dieselben Eigenschaften und Attribute zur Beschreibung Indiens und damit auch zur Stützung der eigenen Argumentation. Diese Attribute (wie z.B. ein hohes Alter, Sanftheit etc.) sind oben bereits ausführlich beschrieben worden. Durch unterschiedliche Bewertungen und Verknüpfungen werden dieselben Zuschreibungen innerhalb der Argumentation jedoch für ganz unterschiedliche, gegensätzliche Zielrichtungen und Thesen eingesetzt. Interessanterweise sind es nicht nur die verwendeten Attribute, die sich gleichen, sondern auch die Argumentationsstrukturen und -verläufe ähneln einander sehr. Dabei lassen sich zwei Hauptformen der Argumentation unterscheiden, die trotz ihrer Gegensätzlichkeit große Gemeinsamkeiten aufweisen und die in verschiedenen Variationen und immer wieder in Erscheinung treten.

Auf der einen Seite gibt es ein der Aufklärung und dem Entwicklungsdenken verpflichtetes Schema: Aufgrund des warmen Klimas sei in Indien eine sehr frühe Entwicklung menschlichen Lebens und menschlicher Kultur möglich gewesen. Doch 
aufgrund der Wärme und der damit verbundenen fehlenden Notwendigkeit, sich für den eigenen Lebensunterhalt übermäßig anzustrengen, seien die Inder weichlich und träge geworden, weshalb ihnen zum einen der Ansporn zur Weiterentwicklung fehle und sie zum anderen leicht das Opfer von Eroberung und Unterdrückung geworden seien. Das auf diese Weise entstehende despotische Herrschaftssystem trage seinerseits ebenfalls dazu bei, Entwicklung und Fortschritt innerhalb der indischen Gesellschaft und Kultur zu verhindern. Durch den Verlust alten Wissens, fehlende Entwicklung und die aus Machtgründen bewusst verhinderte Möglichkeit zu Bildung und Aufklärung habe vor allem innerhalb der unteren Schichten den Aberglauben gefördert, der wiederum grausame Rituale und Traditionen hervorgebracht habe. Die Aufgabe des höher entwickelten und vor allem aufgeklärten Europäers sei es, Indien und die Inder zu retten und ihnen den Fortschritt zu bringen und Aufklärung zu ermöglichen. Indien gilt innerhalb dieser Argumentationskette zwar als alte Kultur, die aber in eine Phase der Stagnation oder sogar des Verfalls geraten sei. Die Überlegenheit der Europäer wird betont, wobei einige Autoren davon ausgehen, dass die Unterlegenheit der Inder natürlich und schicksalhaft und daher unveränderlich sei. Viele andere trauen Indien dagegen durchaus zu, dass es sich (im modernen europäischen Sinne) entwickeln könne, wenn es die Hilfe der Europäer erhalte. Indien repräsentiert so einen Teil der Vorgeschichte des Eigenen und zwar nicht in erster Linie im Sinne einer direkten Verwandtschaft, sondern im Sinne einer Entwicklung der Menschheit von der anfänglichen Irrationalität hin zur Vernunft. Es befindet sich somit auf einer anderen Stufe der Entwicklungsleiter.

Auf der anderen Seite steht ein von der romantischen Vorstellung einer verlorenen goldenen Zeit geprägtes Argumentationsschema: Unter anderem wegen des warmen Klimas habe es in Indien beste Voraussetzungen für die Entstehung der Menschheit und Kultur gegeben. Da die Inder die Kindheit der Menschheit repräsentierten bzw. den Ursprüngen der Menschheit zumindest sehr nahe stünden, hätten sie auch an der Uroffenbarung und der ursprünglichen, natürlichen Weisheit teilgehabt. Da es in Indien kaum Entwicklung gegeben habe, habe sich die alte Lehre dort am reinsten erhalten. Allerdings fänden sich auch in Indien nur noch Spuren dieser Lehre (vor allem in den alten Schriften), die aber durch den später aufgrund von Eroberungen und Machtstreben (z.B. der Brahmanen) entstandenen und geförderten Aberglauben verunreinigt seien. Indien erhält in diesem Schema seine Bedeutung also gerade wegen seines hohen Alters und der fehlenden Entwicklung. Auch hier erscheint es in der Rolle der Vorgeschichte 
des Eigenen, allerdings in Form einer mythischen Urzeit und natürlichen Weisheit, die in Europa verloren gegangen seien und durch den Kontakt mit Indien wiederentdeckt werden sollen. Hinzu kommt die nicht so sehr mythische, sondern deutlich konkretere Vorgeschichte als Ursprung vieler Völker Europas, die aufgrund der festgestellten Verwandtschaft der Sprachen postuliert wird. Obwohl es hier zunächst den Anschein hat, als sei die indische Kultur der europäischen überlegen - was durch entsprechende Idealisierungen Indiens durch einige Autoren verstärkt wird -, ist es doch so, dass auch in diesem Argumentationsschema die hierarchische Anordnung zugunsten Europas ausfällt. Denn die alte reine Lehre, von der sich Reste in den indischen Überlieferungen erhalten haben, soll nicht etwa von den Indern selbst rekonstruiert werden, sondern durch europäische Gelehrte. Denn nur die hätten die nötige historisch-kritische Distanz, die reine Lehre von ihren späteren Zusätzen und Verfälschungen zu befreien. Damit aber wird den Indern die Fähigkeit zur Deutung und Repräsentation ihrer eigenen Kultur abgesprochen.

Darüber hinaus gibt es noch weitere Argumentationsschemata, die jedoch nicht ganz so markant und verbreitet sind. So gibt es z.B. Autoren wie Herder, Forster und Humboldt, denen es vor allem um die Frage nach Gemeinsamkeiten (Universalien) der Menschheit, lokalen Besonderheiten und der Gleichwertigkeit aller Kulturen sowie der Ausbildung der Menschlichkeit (Humanität) geht.

Autoren, die dem ersten, dem Fortschrittsdenken verpflichteten Schema, zuneigen, legen den Schwerpunkt ihrer Darstellungen vor allem auf den Zustand der zeitgenössischen indischen Gesellschaft und überlegen, ob und wie dieser verändert werden könnte. Die Vorgeschichte interessiert sie eher weniger. Autoren, die anhand des zweiten, romantischen Schemas argumentieren, richten ihre Aufmerksamkeit dagegen vor allem auf die Frühzeit der indischen Kultur und beachteten den auch von ihnen zumeist angenommenen späteren Verfall kaum. Es ist interessant zu sehen, wie sehr sich die beiden Hauptschemata trotz ihrer gegensätzlichen Thesen und ihrer oft als diametral entgegengesetzt empfundenen Zielrichtungen in ihrer Struktur ähneln. Hier finden sich also durchaus Regelmäßigkeiten in scheinbar (und in einigen Aspekten auch tatsächlich) Ungleichem. ${ }^{1260}$

\footnotetext{
${ }^{1260}$ Auch Lütt beschreibt innerhalb der Indienrezeption zwei Strömungen, die er das „,romantische“ und das „utilitaristische“ Indienbild nennt (Lütt, Jürgen: Deutschland, Indien und das deutsche Indienbild.
} 
Aber auch die gegenteilige Beobachtung gibt es: Brüche in scheinbar Gleichem. Denn natürlich finden sich die beiden hier vorgestellten Argumentationsschemata nicht in allen Texten und auch nicht immer in dem hier vorgestellten Umfang. Oftmals sind es nur kleine Ausschnitte und einzelne Elemente, die Verwendung finden, die übrigen Elemente schwingen aber oft mit. Dabei unterscheiden sich die unterschiedlichen konkreten Ausgestaltungen dieser Elemente zum Teil deutlich voneinander. So finden sich z.B. sowohl bei Claudius als auch bei Görres und Majer Merkmale des „romantischen“ Argumentationsmuster. Alle drei gehen davon aus, dass sich in Asien Reste einer alten, ursprünglichen Weisheit erhalten haben, die wiederentdeckt werden sollten. Aber während Görres diese Weisheit in einem traumähnlichen Zustand der frühesten Menschheit vermutet und anhand eines Vergleichs alter Mythen aus verschiedenen Kulturen rekonstruieren möchte, ordnet Majer diese Weisheit der seiner Ansicht nach ältesten Form des Hinduismus, dem Brahmaismus, zu und sucht sie in den ältesten Schriften der Veden. Claudius hingegen dient die Suche nach Spuren alter asiatischer Weisheit in erster Linie dazu, die Aussagen der Bibel zu bestätigen. Das Muster der Argumentation ist also bei allen dreien sehr ähnlich, die konkreten Aussagen sind es jedoch nicht. Auch die Thesen von Hegel, Meiners, einiger englischer Autoren und einiger Missionare unterscheiden sich trotz der gemeinsamen Annahme, dass Indien sich nicht wie Europa weiterentwickelt habe und daher die dortigen gesellschaftlichen und kulturellen Besonderheiten $\mathrm{zu}$ kritisieren seien, fundamental voneinander. So geht es vielen der englischen Autoren vor allem darum, die Indienpolitik ihres Landes zu legitimieren und sich als Retter der unterdrückten Inder zu inszenieren. Die Missionare wollen die Seelen der Inder retten (oder auch ihre eigene Seele). Meiners geht es um den Beweis, dass es verschiedene Menschenrassen gibt, die sich grundlegend in ihren Eigenschaften und Fähigkeiten voneinander unterscheiden. Hegel dagegen ordnet Indien konsequent in seine Philosophie des Weltgeistes ein, die durch die Verweise auf die Begebenheiten in Indien gestützt werden soll. Die verschiedenen den Zeitgenossen vertrauten Argumentationsmuster dienen den Autoren also als Vorlagen, mit deren Hilfe sie eigene Thesen und Vorstellungen darstellen und in einem bekannten Rahmen diskutieren. 
Doch nicht nur bei den verschiedenen Argumentationsmustern gibt es Brüche im scheinbar Gleichen, sondern auch bei der Verwendung und dem Verständnis bestimmter Begriffe. Denn hinter scheinbar gleichen Begriffen können sich trotz aller Ähnlichkeiten ganz unterschiedliche Konzepte verbergen. Ein markantes Beispiel dafür sind Begriffe wie „Wiege der Menschheit“, „Ursprung“, „Kindheit“. Während Fortschrittsdenker darunter etwas noch Unfertiges, Unentwickeltes, erst am Anfang Stehendes begreifen, verbinden Romantiker damit Vorstellungen von einer gerade für den modernen Menschen verlorenen Ureinheit und Urweisheit. Dieses Beispiel zeigt deutlich, dass auch im Zusammenhang mit der Indienrezeption Begriffe eine wichtige Rolle spielen, die im Sinne Kosellecks und Busses als „minimale Kristallisationskerne von Diskursen“1261 anzusehen sind. In Begriffen wie den genannten sowie in anderen wichtigen wie „Menschlichkeit“, „Natürlichkeit“, „Entwicklung“, „Vernunft“ oder „Einheit“ geht es nicht um etwas Konkretes, das einfach benannt werden kann, vielmehr verbergen sich dahinter ganze Konzepte, die das Ergebnis bestimmter Diskurse sind. Auf Indien angewandt implizieren sie jeweils unterschiedliche Kontexte, Argumentationsmuster und damit verbundene Wertungen. Dabei fällt auf, dass hier viele Begriffe nicht mehr nur Ausdruck bestimmter Erfahrungen sind, sondern - wie Koselleck es beschrieben hat - sich verstärkt auf von konkreten Erfahrungen unabhängige Konzepte beziehen, von denen einige erst in der Zukunft zu verwirklichen sind oder aber zwar bereits in der Vergangenheit verwirklicht waren, nun aber für die Zukunft auf einer anderen Ebene wieder mit Leben erfüllt werden sollen.

Für die Interpretation von Texten über Indien ist es wichtig, diese Unterschiede zu berücksichtigen und die jeweiligen Texte vor dem Hintergrund der verschiedenen diskursiven Rahmen einzuordnen und die verwendeten Begriffe hinsichtlich ihrer mitschwingenden Konnotationen zu bestimmen. Ob ein Text eher dem romantischen oder dem aufklärerischen Muster folgt, ist für die Aussagen, die er über Indien trifft, sowie für die Funktionen, die er Indien zuweist, von entscheidender Bedeutung.

\section{Das mythische Indienbild der Romantik}

Die Einteilung der Argumentationsstrukturen in die zwei Hauptrichtungen des aufklärerischen sowie des romantischen Schemas bedeutet aber keinesfalls, dass das letztgenannte Schema der von Willson geprägten These des mythischen Indienbildes 
der Romantik entspricht. In „A mythical image“ entwirft er ein Bild der Indienwahrnehmung, das auf der Arbeit von Paul Hoffmann fußt und das De Zoysa unter die Rubrik „,das mythische Indien als Ausdruck der romantischen Sehnsucht“ ${ }^{\star 1262}$ einordnet und das große Teile der Forschung zur Indienrezeption geprägt hat. Willson geht davon aus, dass die von Herder beeinflussten Romantiker Indien mit der Idee einer verlorenen goldenen Zeit, in der Poesie und Religion noch eins gewesen seien und die Menschen den Zugang zu naiver Weisheit noch nicht verloren hatten, verbinden und dadurch Indien zu einem Land der Sehnsucht stilisierten. Diese Idealisierung fuße jedoch nicht auf konkreten Kenntnissen, sondern auf Halbwissen, das mit bestimmten Vorstellungen verbunden werde. Daher müsse dieses mythische Indienbild zwangsläufig zerstört werden, sobald es im Zuge einer ernsthaften wissenschaftlichen Auseinandersetzung mit der Realität konfrontiert werde. Allein Hegel habe eine kritischere Einstellung und erkenne, dass Indien ein Land der Sehnsucht und der Phantasie sei. ${ }^{1263}$

Andere Autoren haben diese These eines im deutschsprachigen Raum vorherrschenden mythischen Indienbildes aufgegriffen. So schreibt Behler, dass das Interesse an Indien ein zutiefst romantisches sei. Mithilfe der östlichen Mystik solle der westliche Rationalismus überwunden werden. Innerhalb der romantischen Hinwendung zu Indien unterscheidet Behler zwei Gruppen: auf der einen Seite die Seher, für die Indien das Land der Poesie sei und die somit in der Dichtung Indien zu einem „mythischen Bild der Vollkommenheit“ ${ }^{* 1264}$ stilisierten, und auf der anderen Seite die Denker, die begonnen hätten, Indien im Rahmen der neu geschaffenen Indologie wissenschaftlich zu erforschen. Wie Willson geht auch Behler davon aus, dass sich der Enthusiasmus der Romantiker aufgelöst habe, sobald sie durch ernsthafte Forschungen den „wahren Gang der indischen Geistesgeschichte“ ${ }^{1265}$ erkannt hätten. ${ }^{1266}$ Auch Koch beschreibt ein romantisches Indienbild, das dadurch entstehe, dass die Romantiker auf den bereits von Herder idealisierten Inder ihre Wünsche und Sehnsüchte projizierten, wobei Herders kulturhistorisches Interesse bei den nachfolgenden Generationen in schwärmerische Indienbegeisterung umgeschlagen sei, die sich gegen das

\footnotetext{
1262 De Zoysa: "Blutrünstige Braminen am heiligen Strome“, S. 22

${ }^{1263}$ Vgl. Willson: A mythical image, S. 71, 84f., 90, 118

1264 Behler: Das Indienbild der deutschen Romantik, S. 26

1265 Behler: Das Indienbild der deutschen Romantik, S. 28

${ }^{1266}$ Vgl. Behler: Das Indienbild der deutschen Romantik, S. 21, 24-28
} 
Nützlichkeitsdenken der Aufklärung richte. Die wissenschaftliche Erforschung Indiens habe daher zu großen Desillusionierungen geführt. ${ }^{1267}$ Ganz ähnlich beschreibt Maráthe Herders idealisiertes, auf seiner Gefühlswelt beruhendes Indienbild, das die Atmosphäre geschaffen habe, in der das romantische Indienbild entstanden sei. Dieses habe trotz aller Wissenschaftlichkeit immer auch die Sehnsucht nach all dem, was Europa nicht mehr bieten konnte, beinhaltet. Oberflächlich sei diese erste Begegnung jedoch nicht gewesen. ${ }^{1268}$ Michaels geht davon aus, dass den Romantikern zwar bewusst gewesen sei, dass ihr Indienbild nicht dem wirklichen Indien entspreche, dass sie aber Indien romantisiert und so zu einem Symbol der Romantik gemacht hätten. Zuvor habe bereits Herder Indien aufgrund seiner tiefen Sehnsucht nach einem unschuldigen, unverdorbenen Land idealisiert. ${ }^{1269}$ Besonders deutlich betont auch Wilhelm das mystische Indienbild der Romantiker. Indien sei für die Romantik das, was für die Klassik Griechenland sei. Das romantische Indienbild sei überzeichnet durch Mystizismus und Schwärmerei, eine „Wunschlandschaft“ ${ }^{1270}$, in der die Romantiker ihre Ideale zu erkennen glaubten.

Es sind vor allem die älteren Forschungsarbeiten, die die von Willson bekannt gemachte Vorstellung eines mythischen Indienbilds aufgreifen, aber noch immer haben sie Einfluss ${ }^{1271}$. Es gibt jedoch vermehrt Kritik an dieser Annahme. So gibt es vielversprechende Ansätze, sowohl das Indienbild Herders ${ }^{1272}$ als auch der Romantiker ${ }^{1273}$ differenzierter zu betrachten. Die Ergebnisse der vorliegenden Arbeit

\footnotetext{
1267 Vgl. Koch: Deutschlands literarisches Indienbild. Teil 2, S. 3f., 5

${ }^{1268}$ Vgl. Maráthe: Spiegelungen Indiens in der deutschen Literatur des XIX. Jahrhunderts. S. 10-12, 16, 32,139

${ }^{1269}$ Vgl. Michaels: Wissenschaft als Einheit von Religion, Philosophie und Poesie, S. 328f., 333

1270 Wilhelm: Das Indienbild Heinrich Heines, S. 208

1271 Vgl. z.B. Cowan: The Indo-German Identification, S. 82

${ }^{1272}$ Herder habe sehr wohl für seine Zeit relativ gute Kenntnisse der indischen Kultur besessen. Zudem habe er Indien nicht nur idealisiert, sondern auch kritisch betrachtet. Mit seinen positiven

Beschreibungen ziele er nicht auf Indien als solches, sondern wolle den Europäern ein Gegenentwurf zur europäischen Kultur präsentieren (vgl. Halbfass: Indien und Europa, S. 88f.; Frank: Sanftes Gefühl und stille Tiefe der Seele, S. 16-18, 132, 238; Maillard: Beobachter, Weggenosse, Pionier, S. 52).

1273 So schreibt Inden, die Romantiker kritisierten zwar bestimmte Aspekte der westlichen Kulturen, aber sie sahen in den östlichen auch nicht einfach einen fertigen Ersatz dafür. Die menschliche Natur sei nicht in der einen oder der anderen Kultur vollständig verkörpert, sondern distributiv in allen, weshalb es wichtig sei, das jeweils andere zu verstehen (vgl. Inden: Imagining India, S. 67f.). Poltermann betont, dass sich zumindest die Frühromantiker aus dem Bewusstsein einer historischen Differenz heraus die indische Kultur durchaus kritisch aneignen wollten, auch wenn sie ihre Theorie einer Übersetzung, die zugleich Kritik sei, kaum in die Praxis überführten (vgl. Poltermann: Den Orient übersetzen, S. 88, 93). Talgeri kritisiert, dass die romantische Forschung in Schlegels Indienbild zu sehr das Esoterisch-Exotische und die „regressive zeitliche Struktur“ hervorgehoben habe, dabei aber dessen emanzipatorischenSeite übersehen habe (vgl. Talgeri, Pramod: Friedrich Schlegels Indien-Bild Forderung nach einer Epiphanie des Anderen. In: Zeitschrift für Kulturaustausch 37 (1987), 3 Vj. (Utopie - Projektion - Gegenbild. Indien in Deutschland), S. 418-423, hier S. 422)
} 
zeigen deutlich, wie berechtigt diese Kritik ist. So lässt sich zwar ein romantisches Argumentationsschema beschreiben, von dem einzelne Elemente bei den meisten dem Kreis der Romantik nahestehenden Autoren eine wichtige Rolle spielen. Vor allem Majers Darstellung der indischen Kultur entspricht am ehesten der These des romantischen, mythischen Indienbildes. Aber dennoch ist es keineswegs so, dass dieses Argumentationsschema eine feste Einheit ist, die immer auf die gleiche Art und Weise umgesetzt und interpretiert wird. Vielmehr unterscheiden sich die konkreten Konzepte der einzelnen Autoren zum Teil beträchtlich. Unterschiedliche Fragestellungen, Interpretationsansätze und Schwerpunkte stehen sich gegenüber. Daher ist es zwar durchaus sinnvoll, von einem romantischen Argumentationsschema zu sprechen, „das“ eine romantische Indienbild gibt es dagegen nicht. Zudem steht den romantisch geprägten Texten eine ganze Fülle von Reiseberichten, Lexikonartikeln, Abhandlungen und literarischen Werken gegenüber, die eine deutlich andere Wahrnehmung der indischen Kultur aufweisen. Gerade die Lexikonartikel, die den wissenschaftlichen Konsens der Zeit vermitteln sollen, und die Schauspiele, die den Erwartungshaltungen der Zuschauer gerecht werden müssen, zeigen deutlich, dass das romantische Indienbild nicht den Mainstream repräsentiert. Auch die Zeitschriftenartikel über Indien beschäftigen sich überwiegend mit Themen, die nicht in den Bereich des „romantischen Indienbildes“ gehören. ${ }^{1274}$ Und es sind nicht nur Übersetzungen englischer oder französischer Texte, die nichtromantische Indienbilder vermitteln. Auch Abhandlungen und Kommentare deutschsprachiger Autoren wie Ehrmann, Büsching, Danz, aber auch Heeren und Windischmann sowie von Rezensenten z.B. in der „Allgemeinen Literaturzeitung" entsprechen eindeutig nicht diesem Bild. Und auch Missionare wie Schwarz bewerten Indien anders. Natürlich berufen sich viele dieser Autoren auf englische Berichte. Doch obwohl sie deren Auffassung nicht immer teilen (vor allem im Hinblick auf die englische Kolonialpolitik gibt es auch deutlich kritische Stimmen, während ausgerechnet die Brüder Schlegel die Engländer in dieser Hinsicht in Schutz

\footnotetext{
1274 Tzoref-Ashkenazi hat über den „Index deutschsprachiger Zeitschriften“ die Themenverteilung der im Zeitraum 1750-1815 erschienenen deutschsprachigen Zeitschriften untersucht und kommt zu folgendem Ergebnis: über 100 Artikel beschäftigten sich mit Kolonialismus und Kolonialkriegen, 72 Artikel mit Sitten und Bräuchen, 55 mit Ethik und Religion, 45 mit indischer Politik, 28 mit Handel, 27 mit indischer Technik, 26 mit Naturgeschichte und 22 mit Geographie. Das zeige deutlich, dass die gelehrten Deutschen nicht nur an einem spirituellen und metaphysischen Indien interessiert gewesen seien (vgl. Tzoref-Ashkenazi: German Soldiers in Colonial India, S. 58).
} 
nehmen), stellen sie sich nicht gegen die allgemeinen Einschätzungen ihrer Gewährsleute. $^{1275}$

Interessant ist, dass sich viele der Forschungsarbeiten, die die These vom mythischen Indienbild vertreten, auf Autoren berufen, die sich bei genauerem Hinsehen eigentlich kaum mit Indien beschäftigen, Indien nicht in den Mittelpunkt stellen oder einen ambivalenten oder zumindest vielschichtigen Zugang zu Indien haben. Novalis, der immer wieder als ein typisches Beispiel genannt wird, hat Indien zwar erwähnt und als eine Art Symbol für Poesie bzw. die Einheit von Poesie und Religion verwendet, aber er hat sich in keinem seiner Texte näher mit dem Thema Indien auseinandergesetzt, weshalb ich auch im Rahmen dieser Arbeit nicht weiter auf ihn eingegangen bin. Indien oder Begriffe aus dem indischen Kontext tauchen in seinen Texten nur als vereinzelte Schlagwörter auf. Daher kann man zwar sagen, dass der Begriff Indien bei Novalis poetisch-symbolisch aufgeladen ist, aber das bedeutet noch nicht, dass er auch von dem realen Indien ähnliche Vorstellungen hat und lässt zudem die Frage offen, ob ihn das reale Indien überhaupt interessiert. Bei dem frühen Friedrich Schlegel ist es ähnlich. Die frühen Romantiker wollen zwar eine neue Mythologie erschaffen und beziehen sich dabei auch auf Indien, aber das Interesse an dieser Mythologie ist eher ästhetischer als mythischer Natur. Das Indienbild des späteren Schlegel, der sich dann tatsächlich mit der indischen Kultur auseinandersetzt, ist ein völlig anders. Indien ist hier nicht länger ein Symbol für Poesie und auch nicht mehr die Heimat des höchsten Romantischen. Es erfüllt vielmehr die Funktion, auf der einen Seite die Verwandtschaft der meisten europäischen Sprachen mit Sanskrit und die Überlegenheit dieser Sprachfamilie über andere Sprachen zu zeigen, und soll auf der anderen Seite das Christentum und die ständisch-monarchische Gesellschaft des europäischen Mittelalters propagieren. Auch die Texte seines Bruders August Wilhelm entsprechen nicht dem mythischen Indienbild. Indien wird bei ihm das Objekt wissenschaftlicher Untersuchungen, anhand dessen Schlegel sich als Experte in einem kleinen Kreis von Kollegen einen Namen machen kann. Die Mythologen Görres und Kanne versuchen zwar tatsächlich einen Urmythos zu konstruieren und idealisieren dabei die (indische) Frühzeit. Aber auch ihnen geht es nicht um Indien, sondern um die Uranfänge der Menschheit, die sie gar

1275 Auch Amman und De Zoysa vertreten die Auffassung, dass der romantische Indiendiskurs in der Gesamtwahrnehmung Indiens nur einen sehr kleinen Teil ausmache, der sich auf akademische Kreise beschränke und kaum einen Einfluss auf die große Masse der Leser gehabt habe (vgl. Amman: Östliche Spiegel, S. 33f.; De Zoysa: "Blutrünstige Braminen am heiligen Strome“, S. 24-29). 
nicht unbedingt in Indien direkt vermuten und zu deren Erforschung sie auch die Mythen anderer Kulturen heranziehen. Bei Creuzer spielt Indien sogar eine deutlich untergeordnete Rolle, da es ihm in erster Linie um die griechische Mythologie geht.

Natürlich wird Indien immer wieder in einzelnen Aspekten idealisiert, aber kaum einer der hier untersuchten Autoren tut dies durchgehend und uneingeschränkt. Auch Autoren der Romantik äußern Kritik an bestimmten Aspekten der indischen Kultur. Sogar Majer, der wenig Kritisches zu berichten weiß, kann die indische Kunst nicht vollends gutheißen. Und auch in den literarischen Werken Günderrodes, die größtenteils dem romantischen, mythischen Indienbild entsprechen, findet sich ein kritisches Moment (vgl. das oben besprochene Gedicht „Der Adept“"). Ebenso wenig stehen die wenigsten der nichtromantischen Autoren allen Aspekten Indiens ablehnend gegenüber. Die meisten finden durchaus Positives zu berichten, auch wenn negative Beurteilungen überwiegen mögen. Wie bereits beschrieben verteilen sich Lob und Kritik hauptsächlich auf einer zeitlichen Achse. Während die Frühzeit größtenteils als sehr bedeutend anerkannt wird und auch die Inder selbst in vielen Texten eher positiv gezeichnet werden (mit Ausnahme der Brahmanen), erfährt das gegenwärtige Indien überwiegend Kritik. Da sich aber Autoren, die romantisch geprägte Ansichten vertreten, mit dem zeitgenössischen Indien kaum beschäftigen, überwiegt bei ihnen die positive, oft auch idealisierende Darstellung Indiens. Dagegen gehen die übrigen Autoren deutlich seltener auf das alte Indien ein und zeigen daher vor allem eine kritische Einstellung. Das gegenwärtige Indien kann also durchaus auch in romantischen Kreisen Kritik erfahren. Allerdings scheint es ein gewagtes Unterfangen zu sein, sich nicht der dort verbreiteten Begeisterung über die Frühzeit Indiens anzuschließen, wie das obige Zitat von Humboldt, man sollte den Enthusiasten gegenüber nicht erwähnen, dass Sanskrit nicht zum vollendeten Ideengebrauch fähig sei, nahelegt. Maillard beschreibt die Begeisterung, die viele Autoren Indien gegenüber äußern, als „Indomanie“, als eine besondere Form der Indophilie. ${ }^{1276}$ Auf einige Autoren bzw. ihre Wahrnehmung bestimmter Aspekte Indiens trifft das auch zu. So gibt es Autoren, bei denen Indien im Mittelpunkt steht, eine große Begeisterung hervorruft und mit großen Hoffnungen verbunden wird. Als ein typisches Beispiel kann man - wie bereits erwähnt - Majer oder Günderrode ansehen. Bei vielen anderen 
Autoren steht Indien bei allem Enthusiasmus allerdings nur scheinbar im Mittelpunkt. Bei genauerem Hinsehen geht es ihnen um etwas Dahinterliegendes. Indien erhält seine Bedeutung dadurch, dass es den Zugang dazu zu ermöglichen verspricht. Dazu gehört für viele Autoren der Vergleich mit anderen alten Kulturen, da sie gerade in den Gemeinsamkeiten und Übereinstimmungen Hinweise auf das Ursprüngliche sehen. So geht es - wie beschrieben - Görres und Creuzer nicht in erster Linie um die indische Mythologie, sondern um Urmythen, die sie unter anderem auch aus indischen Mythen rekonstruieren wollen. Sprachwissenschaftler wie Bopp oder die Brüder Schlegel interessieren sich für die Sprachgenese, bei der Sanskrit aufgrund des hohen Alters zwar eine wesentliche Rolle zukommt, bloße Sanskritkenntnisse bei aller Begeisterung aber nicht das Ziel sind. Von einer „Indomanie“ im Sinne Maillards lässt sich also nur bei einem sehr kleinen Teil der Autoren sprechen.

$\mathrm{Zu}$ der These des mythischen Indienbild gehört auch die Annahme, dass dieses Bild eine Desillusionierung und Ernüchterung in dem Maße erfährt, in dem aufgrund der wissenschaftlichen Erforschung die Kenntnisse über Indien wachsen. ${ }^{1277}$ Abgeleitet wird sie vor allem von dem Wandel, der sich im Indienbild Friedrich Schlegels zeigt. Dieser Wandel des Indienbilds fällt allerdings in eine Zeit, in der sich auch andere Themen und Anschauungen Schlegels ändern. Er wendet sich verstärkt dem Christentum zu und zwar in seiner traditionelleren Form des Katholizismus. Dem Pantheismus, den er zunächst (neben erhofften Anregungen für das Projekt der neuen Mythologie) in Indien gesucht hatte, ${ }^{1278}$ steht er nun zunehmend ablehnend gegenüber. Auch ist für ihn nicht länger der Dichter der Mittler des Absoluten, sondern die Bibel. Schlegel ist also weniger enttäuscht, dass die Religion, die er in Indien gefunden hat, nicht der Pantheismus ist, den er sich erhofft hatte, sondern er wendet sich sowohl von Indien als auch vom Pantheismus ab, um sich dem Christentum zuzuwenden. Parallel dazu erfährt auch seine politische Einstellung eine Änderung. Ist für ihn zunächst die Freiheit des Individuums in einem republikanischen Staat ein politisches Ziel, ${ }^{1279}$ dient

\footnotetext{
${ }^{1277}$ Die These der Desillusionierung nach einem zuvor idealisierten Orientbild beschreibt auch Said für andere Teile des Orients. War der Orient zunächst für seinen Pantheimus und seine Konstanz verehrt, so erschien er nun als barbarisch und rückständig (vgl. Fuchs-Sumiyoshi, Andrea: Orientalismus in der deutschen Literatur. Untersuchungen zu WErken des 19. und 20. Jahrhunderts, von Goethes Westöstlichem Divan bis Thomas Manns Joseph-Tetralogie. Hildesheim u.a. 1984 (Germanistische Texte und Studien; 20), S. 54

1278 Vgl. Herling: The German Gītā, S. 125f.

1279 Vgl. Wanning, Berbeli: Friedrich Schlegel zur Einführung. Hamburg 1999, S. 123-125
} 
„Über die Sprache und Weisheit der Indier“ unter anderem dazu, die alte mittelalterliche Ständeordnung im Rahmen einer Monarchie als Gesellschaftsform zu propagieren. ${ }^{1280}$ Außerdem muss man berücksichtigen, dass die Frühromantik - bei aller Stilisierung Indiens als Symbol des Poetischen und Ort einer möglicherweise noch vorhanden Einheit von Religion, Poesie und Wissenschaft - in sehr viel stärkerem Maße als die spätere Romantik in Formen einer kritischen Ironie denkt. Man könne sich dem Gesuchten zwar annähern, aber es bleibe eine unendliche Bewegung, die das Ziel aufgrund der eigenen Reflexionen nicht erreiche. Der frühe Friedrich Schlegel und seine Freunde sind sich also dessen bewusst, dass Indien zwar zur Annäherung an das Gesuchte beitragen kann, dass es die neue Mythologie bereichern kann, aber nicht das Ende der Suche sein wird. Auch das spricht weniger für eine Desillusionierung der Frühromantiker als vielmehr für eine Hinwendung zu etwas Neuem.

Auch bei anderen Autoren der Romantik lässt sich die These der Desillusionierung nicht beweisen. Gegen sie spricht z.B., dass sich Friedrichs Bruder August Wilhelm Schlegel erst mit Beginn der wissenschaftlichen Erforschung Indiens überhaupt für dieses Thema $\mathrm{zu}$ interessieren beginnt. Er begegnet Indien von vornherein auf wissenschaftliche Art und Weise und zeigt in seinen Ausführungen keine Anzeichen einer Enttäuschung. ${ }^{1281}$ Indien ist für ihn vor allem ein wissenschaftlich neues Objekt, dessen Idealisierung die Bedeutung dieser neuen Forschungsrichtung unterstreicht. Die späteren Romantiker wie Creuzer, Görres oder Majer, die weniger stark die frühromantische Ironie und Kritik teilen und daher zum Teil in Indien viel direkter nicht nur eine Annäherung, sondern vielleicht auch ein Ziel zu finden hoffen, zeigen sich in den hier untersuchten Texten ebenfalls nicht desillusioniert. Zudem stellt sich die Frage, wann die Abkehr der Frühromantiker von Indien stattgefunden haben soll: 1808, als Friedrich Schlegels Faszination für Indien bereits deutlich nachlässt, haben viele der romantischen Mythologen oder auch Schlegels Bruder August Wilhelm ihre Texte zu Indien noch gar nicht veröffentlicht. Ein Anstieg der negativen Beurteilungen Indiens lässt sich vielmehr in den 1820er Jahren beobachten. Dieser Anstieg ist allerdings nicht die Folge einer Desillusionierung aufgrund der wachsenden wissenschaftlichen Kenntnisse, sondern geht einher mit dem Vordringen kolonialpolitischer Elemente in die Indiendiskurse, die die romantischen bzw. aufklärerischen Argumentationsschemata abzulösen beginnen und die das Ende meines 
Untersuchungszeitraums markieren. Darauf werde ich im folgenden Kapitel noch einmal zurückkommen.

Zusammenfassend lässt sich festhalten, dass sich ein romantisches, mythisches und zum Teil auch idealisiertes Indienbild zwar in einigen Texten und bei einigen Autoren erkennen lässt, aber es handelt sich dabei nicht um ein festes Konzept, die „die“ Romantiker genau so vertreten haben. Vielmehr unterscheiden sich die verschiedenen Indienbilder der romantischen Autoren in einigen Aspekten und vor allem auch den Gewichtungen sehr voneinander, so dass man zwar von romantisch-mythischen Zügen sprechen kann, von „dem“ romantisch-mythischen Indienbild aber keineswegs. Und auch die Idealisierung einiger Bereiche der indischen Kultur ist nicht vorbehaltlos, sondern immer wieder auch mit Kritik verbunden. Die These der Desillusionierung aufgrund der wissenschaftlichen Erforschung ist bezogen auf die hier untersuchten Texte nicht haltbar und muss in Folge dessen fallen gelassen werden.

\section{Aufklärung}

Auch die von den Diskursen der Aufklärung geprägten Indienbilder sind nicht einheitlich. Sie unterscheiden sich nicht nur hinsichtlich des diskursiven Kontextes, sondern Thesen und Themen können aufgrund unterschiedlicher Gewichtungen zu unterschiedlichen Bewertungen führen. Zum Beispiel kann die Bestimmung des Menschen als vernunftbegabtes Wesen zu der Feststellung führen, dass alle Menschen im Kern gleich sind (und dementsprechend auch gleich behandelt werden sollten). Die Ausrichtung an der Vernunft kann aber auch dazu führen, dass sie als ein Maßstab dienen kann, anhand dessen Kulturen und einzelne Traditionen eingeteilt werden in aufgeklärt-fortschrittlich bzw. abergläubisch-rückständig - verbunden mit entsprechenden Wertungen.

Projekte, die Welt mithilfe von Klassifikationen, Kategorien und zeitlichen Anordnungen zu erschließen, tragen dazu bei, die Aufmerksamkeit auf andere Kulturen zu lenken. Dabei können die Kulturen und Völker als gleichwertige Bestandteile der Welt wahrgenommen werden. Allerdings führen Versuche, die Menschen analog zur Klassifizierung des Pflanzen- und Tierreichs zu beschreiben, auch zur Einteilungen der Menschen in verschiedene Varietäten oder Rassen. Diese Einteilung wirkt sich auch auf die Beschreibung der Inder und Inderinnen aus. Zwar setzen sich die meisten der Autoren in den hier untersuchten Texten nicht direkt mit der Frage nach menschlichen 
Rassen bzw. Varietäten auseinander. Sie berufen sich aber häufig auf die von Buffon entwickelte Klimatheorie, um Besonderheiten der Inder zu erklären und versuchen, die Inder als Gruppe zu charakterisieren. Ansätze, die Völker anhand ihres Äußeren bestimmten Kategorien zuordnen, stoßen in Indien allerdings deutlich an ihre Grenzen. Denn Reisende finden auf dem Subkontinent eine Gesellschaft vor, die nicht nur kulturell, sondern auch hinsichtlich des Aussehens der Menschen nicht homogen ist. Die Verteilung verläuft dabei sowohl räumlich als auch entlang der gesellschaftlichen Hierarchie. Ebenso lässt die Beobachtung, dass die meisten Inder zwar von deutlich dunklerer Hautfarbe sind als die Europäer, ihnen aber ansonsten vom Aussehen her gleichen, sich nicht so einfach in auf äußere Merkmale festgelegte Rassen oder menschliche Varietäten einordnen. Auch aufgrund der sprachwissenschaftlich festgestellten Ähnlichkeiten können die Inder trotz ihrer dunkleren Hautfarbe nicht per se als von den Europäern unterschieden angesehen werden, was einige Autoren mit der Annahme verschiedener Rassen auf dem indischen Subkontinent zu erklären versuchen.

Ambivalente Auswirkungen auf die Wahrnehmung und Beurteilung Indiens erwachsen auch aus Diskursen der Aufklärung, die die Religion betreffen. Die Idee einer natürlichen Religion, eines auf der Vernunft beruhenden Minimalkonsens', den alle Religionen und Konfessionen teilen (Verehrung eines höchsten Wesens, die Pflicht zu einem tugendhaften Leben und zur Reue bei möglicher Schuld sowie die ausgleichende Gerechtigkeit durch einen jenseitigen Richter) ${ }^{1282}$, lassen viele Autoren auch in den fremden indischen Religionen Aspekte dieses Konsens' suchen (und finden). Anderseits erwächst daraus - neben der Kritik seitens der Kirche - eine zweite Säule der Verurteilung des indischen „Aberglaubens“. Diese richtet sich vor allem gegen rational scheinbar nicht erklärbare Glaubensinhalte und -praktiken sowie gegen die Vormacht der Priester. Deren Unterdrückung der Gläubigen unter anderem mithilfe von Aberglauben sei - nicht nur in Indien - Ursache von Leid und Glaubenskriegen. Das vielfach negative Bild der Brahmanen speist sich unter anderem auch aus dieser Quelle.

Diese Beispiele zeigen, dass verschiedene Ideen der Aufklärung das Potenzial haben, Impulse in ganz unterschiedliche Richtungen zu geben. Je nach Gewichtung können

\footnotetext{
${ }^{1282}$ Vgl. Barth, Ulrich: Religion. In: Thoma, Heinz (Hg.): Handbuch Europäische Aufklärung. Begriffe - Konzepte - Wirkung. Stuttgart u. Weimar 2015, S. 439 - 449, hier S. 440
} 
diese zu einer Auf- oder Abwertung der indischen Kultur bzw. bestimmter Aspekte dieser Kultur beitragen.

\section{Indienbilder im Wandel}

Aus dem Gesagten wird deutlich, dass es um 1800 nicht „das eine“ Indienbild gibt und auch nicht „die zwei“ sich gegenüberstehenden der Romantik und der Aufklärung. Auch andere Denkrichtungen und Strömungen haben großen Einfluss auf die Wahrnehmung Indiens. So beeinflusst der Klassizismus die Beurteilung der indischen Kunst, die zwar ebenfalls zu einer „klassischen“ Kultur gehört, sich in ihrer Art aber sehr von dem griechischen Maßstab des klar strukturierten und gegliederten Kunstbzw. Bauwerks unterscheidet. Religiöse Vorstellungen der Erweckungsbewegung tragen zu den ambivalenten Bildern, die sich europäische Autoren von den indischen Religionen machen ebenso bei wie das Konzept einer Naturreligion oder die romantische Suche nach einer Uroffenbarung. Utilitarismus und die sich mit zunehmender Vormachtstellung der Europäer nicht nur in Indien verschärfende Frage nach der Legitimation der Unterdrückung haben einen wesentlichen Anteil an der Häufung negativer Indienbilder ab den 1820er Jahren.

Statt von „dem Indienbild um 1800“ muss man also von einer Vielzahl an verschiedenen Indienbildern ausgehen, die sich in bestimmten Bereichen überschneiden und ähneln (z.B. in den Argumentationsstrukturen), in anderen aber deutlich voneinander abweichen. Dabei unterscheiden sich diese Indienbilder weniger in den verschiedenen Eigenschaften und Attributen, die Indien, den Indern und der indischen Kultur zugeschrieben werden, sondern vor allem durch die verschiedenen Diskurse, innerhalb derer Indien betrachtet wird, und hinsichtlich der Indien zugewiesenen Funktionen. So sind Aussagen wie die Folgenden um 1800 kaum umstritten: Die Inder seien sanft, weich und tolerant, aber auch passiv und zum Teil (vor allem die Brahmanen) auf den eigenen Vorteil bedacht; die indische Kultur ähnle vielen anderen Kulturen aufgrund des gemeinsamen Ursprungs und/oder späterer Beeinflussungen; die indische Kultur sei sehr alt und habe sich kaum weiterentwickelt. Positionen wie die von Meiners, dass Sanskrit erst in viel jüngerer Zeit entstanden sei, sind Außenseitermeinungen. Die Interpretationen dieser allgemein verbreiteten Bilder über Indien, die Bedeutung, die ihnen zugemessen wird, sowie die Art und Weise, wie sie instrumentalisiert werden, unterscheiden sich allerdings beträchtlich. Auch scheinbar sehr ähnliche Darstellungen Indiens weichen in kleinen, aber wichtigen 
Details voneinander ab. Die oben beschriebenen Hauptargumentationsrichtungen ${ }^{1283}$ sind ebenfalls nur Tendenzen und keine festen Größen.

Zur Vielfältigkeit der Indienbilder trägt zudem bei, dass sich das Indien, wie es in vielen literarischen Texten repräsentiert wird, deutlich von dem der wissenschaftlichen Texte unterscheidet, da diese bereits viele weitere Informationen und damit verbundene Neubewertungen Indiens vorlegen, die aber von den Autoren literarischer Texte nicht aufgegriffen und umgesetzt werden, um die Zuschauer bzw. Leser nicht zu enttäuschen. De Zoysa spricht hier von Anachronismen der Indienrezeption. ${ }^{1284}$ Auch kommen in der Literatur noch weitere Einflüsse zum Tragen, die in den Sachtexten keine oder eine deutlich geringere Rolle spielen wie z.B. die Tradition der Türkenopern und die Lust am Exotischen.

Die Indienbilder der Zeit sind ambivalent. Indien kann große Erwartungen und Sehnsüchte wecken, es kann viele Rätsel aufgeben, es kann aber auch als abstoßend empfunden werden. Diese Ambivalenzen wirken bis heute fort. Wie Ganeshan und Durzak betonen werde Indien heute noch als unterentwickelt und arm, gleichzeitig aber auch als heiliges Land, als Land der Wunder wahrgenommen. ${ }^{1285}$ Die Wirklichkeit Indiens mit seinen zum Teil gewalttätigen Ereignissen sei „der beunruhigende Untergrund des spirituellen Indien-Bildes, das in den literarischen Texten nach wie vor hervorgehoben wird“. ${ }^{1286}$

Hinzu kommt, dass sich auch das Bild, dass sich ein einzelner Autor von Indien macht, im Laufe der Zeit wandeln kann. Das prominenteste Beispiel ist sicherlich Friedrich Schlegel. Aber es lassen sich auch allgemeinere Tendenzen für verschiedene Wandel der Indienbilder erkennen. Der erste wurde bereits beschrieben: der Wandel Indiens vom vertrauten Anderen zum fremden Eigenen ab den 1780er Jahren. In den Jahren um 1820 lassen sich noch zwei weitere Wandel erkennen. So spaltet sich zum einen mit Beginn der Institutionalisierung als Wissenschaft die Indologie von dem übrigen Indiendiskurs ab. Dies geschieht, indem der neue wissenschaftliche Diskurs in

1283 Auch andere Autoren gehen von zwei verschiedenen Hauptrichtungen des Orientdiskurses aus, vgl. z.B. King: Orientalism and Religion, S. 116 1284 Vgl. De Zoysa: „Blutrünstige Braminen am heiligen Strome“, S. 227 1285 Vgl. Ganeshan: Das Eigene und das Fremde, S. 162 1286 Durzak, Manfred: Indien - Wahrnehmungen in einem Spiegelkabinett. In: Durzak, Manfred (Hg.): Bilder Indiens in der deutschen Literatur. Frankfurt a.M. 2011, S. 7-12, hier S. 11 
zweierlei Hinsicht Begrenzungen erfährt: Zum einen wird der Zugang zum Diskurs begrenzt, indem nur noch Wissenschaftler, die einer indischen Sprache (in der Regel Sanskrit) kundig sind, als qualifizierte Teilnehmer anerkannt werden. Und zum anderen schließt die (durch die Anbindung der Indologie an die klassische Philologie verstärkte) Konzentration auf die alte indische Schriftkultur das zeitgenössische Indien als Forschungsobjekt aus. Ein weiterer Wandel, der in den 1820er Jahren zu erkennen ist, besteht darin, dass die Tendenz zu negativen Beurteilungen Indiens in dieser Zeit zunimmt. Dieser Wandel ist von den drei beschriebenen der am wenigsten greifbare, da auch positive Indienbilder nach wie vor weit verbreitet sind. Dieser Wandel hängt eng mit Veränderungen der englischen Kolonialpolitik zusammen, die sich aufgrund von christlichen und utilitaristischen Einflüssen weg von dem Ansatz, indische Traditionen aufrechtzuerhalten, hin zu dem Versuch, die indische Gesellschaft im Sinne europäischer Vorgaben zu verändern, bewegt. Durch diesen kolonialpolitischen Einfluss häufen sich englische Texte, die die indische Kultur abwerten und darüber hinaus häufig die Rettung Indiens durch die Europäer propagieren. Diese Texte werden auch im deutschsprachigen Raum rezipiert und beeinflussen so auch die deutschen Indienbilder. Das macht sich zum Beispiel in den oben beschriebenen, deutlich kritischer werdenden Berichten über Witwenverbrennungen oder auch in dem bereits erwähnten Wandel der Themen in den Volksalmanachen bemerkbar. Auch die Kriege der Griechen gegen die Osmanen haben zu einem Wandel der Orientbilder allgemein beigetragen. ${ }^{1287}$

Die Indienbilder um 1800 sind also vielschichtig und häufig ambivalent. Während die Indien zugewiesenen Attribute kaum umstritten sind, ergibt sich ihre Bedeutung vor allem aus dem jeweiligen diskursiven Rahmen, in dem sie bestimmte Funktionen erfüllen. Allgemeine Tendenzen zu einem Wandel in der Indienwahrnehmung lassen sich um 1780 sowie in den 1820er Jahren erkennen und bilden so die Grenzen des Untersuchungszeitraums der vorliegenden Arbeit.

\section{Orientalismus und die besondere Rolle der deutschen Indienrezeption}

Eine Frage, die besonders vor dem Hintergrund der These eines Orientalismus' im Sinne Saids gestellt wird, ist die nach den Besonderheiten der deutschen Indienrezeption. Unterscheiden sich die deutschen Indienbilder von denen anderer 
Nationen aufgrund dessen, dass die deutschsprachigen Länder keine Kolonien in Indien haben? Und wie stehen die Zeitgenossen selbst zu diesem Thema? Auch diese Frage muss differenziert betrachtet werden, denn auch hier spielen die verschiedenen Indienbilder und die Funktionen, die Indien zugewiesen werden, eine entscheidende Rolle. Die deutschsprachigen Länder haben um 1800 zwar keine Kolonien in Indien, aber es gibt durchaus Interessen, die denen der Engländer oder Franzosen ähneln (z.B. ökonomische oder missionarische Interessen). Auch macht - wie bereits beschrieben der Kolonialismusdiskurs nicht an deutschen Grenzen halt. Das Fehlen einer Kolonialpolitik beruht also nicht unbedingt auf einer Ablehnung dieser Politik und einer bewussten Entscheidung, sich aus moralischen Gründen nicht daran zu beteiligen. Die fehlenden politischen Verflechtungen mit Indien erlauben es den deutschsprachigen Autoren aber dennoch, mit einer größeren Distanz und Offenheit über dieses Thema zu sprechen. Dabei kritisiert ein Großteil der Autoren zwar das konkrete Vorgehen der Europäer in Indien, aber das System des Kolonialismus an sich wird (außer von Herder) in der Regel nicht in Frage gestellt. Der größte Unterschied zur Indienrezeption Englands und Frankreichs ist vielmehr der, dass die deutschsprachigen Autoren sich gerade wegen der fehlenden politischen Perspektive im zeitgenössischen Indien noch sehr viel mehr auf das vergangene Indien fokussieren, was - wie beschrieben - häufig mit tendenziell positiven Indienbildern verbunden ist. Dabei entsteht bei Autoren wie Forster oder August Wilhelm Schlegel die Vorstellung, dass die Deutschen die geistigen Schätze Indiens sehr viel besser erkennen und würdigen könnten, gerade weil die deutschsprachigen Länder keine kolonialen Interessen in Indien hätten. Diese Autoren beanspruchen die Fähigkeit zur Sinnstiftung und Interpretation der indischen Kultur für sich und betonen die eigene wissenschaftliche Vorrangstellung. Bhatti spricht in diesem Zusammenhang von einem kompensatorischen Kolonialismus. ${ }^{1288}$

Aufgrund dieser anderen Rolle, die sich die deutschen Autoren zuschreiben, sowie der stärker verbreiteten positiven Indienbilder könnte man meinen, man könne im deutschsprachigen Raum nicht in demselben Maße von Orientalismus sprechen wie in England. Das ist im Sinne eines politischen Orientalismus auch richtig, auch wenn im deutschsprachigen Raum ebenfalls die Inder und die indische Kultur von einigen Autoren als negative Gegenbilder zur eigenen Kultur entworfen werden und dabei viele 
der Attribute eine Rolle spielen, die Said als typisch herausgearbeitet hat (wie z.B. die Darstellung der Inder als träge und irrational sowie die Zeichnung vieler indischer Figuren in der Literatur als weichlich). Aber wenn man unter Orientalismus versteht, dass der Rezipient sich ein festes Bild von seinem Objekt macht und diesem Objekt die Fähigkeit, sich selbst zu repräsentieren, abspricht, so trifft diese Annahme nicht zu. Denn auch wenn viele der deutschsprachigen Autoren Indien sehr wohlwollend schildern, so sehen sie sich doch in einer hermeneutischen Distanz zu Indien. Die indischen Überlieferungen müssen also interpretiert werden. Das gelte aber nicht nur für das Verhältnis der Europäer zu diesen Überlieferungen, sondern auch für das der Inder zu ihrer eigenen Vergangenheit. Denn auch die Inder hätten den Zugang zu den alten Texten und Lehren größtenteils verloren. Aufgrund ihrer Distanz, ihrer wissenschaftlichen Erfahrung und ihrer kritisch geschulten Vernunft sehen sich die europäischen und mit ihnen auch die deutschsprachigen Autoren als höchste Autorität und letzte Instanz in Fragen der Interpretation. ${ }^{1289}$ Den Indern wird diese Fähigkeit abgesprochen. Nicht nur in politischer oder philosophischer Hinsicht existiert also ein Überlegenheitsgefühl der Europäer, das auch von vielen deutschsprachigen Autoren geteilt wird. Auch viele der deutschen Gelehrten machen Indien und die Inder so zu einem Objekt, dem feste (und häufig auch stereotype) Eigenschaften zugeschrieben werden und dem sie die Fähigkeit, sich selbst zu repräsentieren und zu verstehen, absprechen. In diesem Sinne muss man also von einem deutschen Orientalismus sprechen, sofern man an diesem aus den oben genannten Gründen durchaus problematischen Konzept festhalten möchte.

\section{Phantasma Indien?}

Beruht die Indienwahrnehmung im deutschsprachigen Gebiet um 1800 auf Phantasmen? Während bei Projektionen dem Anderen Eigenes zugeschrieben wird, man also Eigenes im Anderen zu erkennen glaubt, kann man von Phantasmen sprechen, wenn die Bilder, die man sich vom Anderen macht, kaum noch auf wirklichen Erfahrungen beruhen. ${ }^{1290}$ Gerade im Zusammenhang mit dem sogenannten mythischen Indienbild der Romantik wurde dieses vielfach als bar jeglicher Erfahrungen der „Wirklichkeit“ beschrieben. Zutreffend ist, dass die deutschsprachigen Autoren in ihrer überwiegenden Mehrheit Indien nicht aus eigener Anschauung kennen, da sie nie dort

1289 Vgl. auch Bhatti: August Wilhelm Schlegels Indienrezeption, S. 193

1290 Vgl. Mecklenburg: Das Mädchen aus der Fremde, S. 239f. 
hingereist sind. Die vorliegende Arbeit hat aber gezeigt, dass man hinsichtlich ihres Bestrebens, sich anhand von verschiedenen Quellen ein möglichst realistisches Bild von Indien zu machen - wie bei den meisten der zuvor gestellten Fragen auch differenzieren muss. Bezieht man sich nur auf die Verwendung des Begriffs Indien in der Frühromantik als ein Symbol für die Poesie bzw. die Einheit von Poesie, Religion und Wissenschaft, wie er z.B. von Novalis oder auch dem frühen Friedrich Schlegel genutzt wird, dann ist eine Bezeichnung als Phantasma gerechtfertigt, da dieses imaginierte Indien tatsächlich auf keinerlei Faktenwissen beruht. Allerdings sollte man nicht vergessen, dass ein auf Fakten beruhendes Indienbild und eine konkrete Verbindung des Symbolisierten mit dem wirklichen Indien zunächst gar nicht das Anliegen der Frühromantiker ist. Ihr Bezug zu Indien ist ein ästhetischer. Es geht um die Schaffung einer neuen Mythologie und um Versuche, etwas eigentlich Unaussprechliches in Bilder zu kleiden. Als in der späteren Romantik alte indische Lehren die Aufmerksamkeit auf sich ziehen, als wirklich versucht wird, anhand dieser Quellen z.B. die Ursprünge der Menschheit, der Kultur, der Sprache, der Religion zu rekonstruieren, als sich folglich das Interesse an Indien von einem ästhetischen zu einem historischen bzw. mythischen wandelt, da beginnen die Autoren auch, sich tatsächlich mit den alten Überlieferungen auseinanderzusetzen. Da der Zugang zu diesen Texten zunächst nicht einfach ist, sind sie oftmals auf Berichte anderer angewiesen. Das bedeutet, dass die konkreten Fakten noch sehr dürftig sind. Hinzu kommt, dass viele Autoren Indien vor dem Hintergrund ihrer bereits im Vorfeld festgelegten Vorstellungen und Erwartungen untersuchen und dadurch Quellen, die nicht zu ihrem Bild passen, außer Acht lassen. Man muss hier ganz klar von Projektionen sprechen, die manchmal in den Bereich des Phantasmas hinüberreichen. Reine Phantasmen sind es aber nicht, da es eine Auseinandersetzung mit den Quellen gibt und immer wieder Bezug genommen wird auf tatsächliche indische Mythen, Lehren und Begebenheiten. Solche Projektionen bleiben nicht auf den Kreis der romantischen Autoren beschränkt. Auch negative Bilder von Indien beinhalten oft Projektionen. In diesen Fällen wird nicht etwas Eigenes in Indien gesucht (und gefunden), sondern das Gegenbild des Eigenen. Obwohl sich also auch Autoren, die sich z.B. vor dem Hintergrund von Diskursen der Aufklärung mit Indien beschäftigen, mehr oder weniger intensiv mit Texten aus oder zumindest über Indien auseinandersetzen, also durchaus den Zugang zu Quellenmaterial suchen, erfolgen sowohl ihre Wahrnehmung als auch ihre Quellenauswahl ebenfalls sehr selektiv, was das so gewonnene Bild von Indien verzerrt. 
Die Frage, ob und in welchem Maße die Indienbilder einzelner Autoren auf möglichst objektiven Untersuchungen basieren, Projektionen darstellen oder bereits als Phantasma zu bezeichnen sind, kann ebenfalls nicht so pauschal beantwortet werden, denn das kann sich sogar innerhalb ein- und desselben Textes immer wieder ändern. Abschnitte mit engem Bezug auf konkrete Fakten wechseln mit Abschnitten, in denen es mehr um das Eigene als um das tatsächliche Indien geht. Je mehr die Autoren um wissenschaftliche Erkenntnisse bemüht sind (wie z.B. August Wilhelm Schlegel und Humboldt), desto genauer und strenger auf die indischen Quellen bezogen sind ihre Untersuchungen. Wird Indien im Zusammenhang verschiedener Diskurse, die nicht primär mit Indologie oder verwandten Fächern zu tun haben, thematisiert, desto eher werden bestimmte Aspekte der indischen Kultur verallgemeinernd herausgegriffen und überzeichnet dargestellt. Auch Projektionen finden sich gehäufter. Ob sich die Autoren diesen Projektionen bewusst sind und ihre Lehren einfach in das populäre indische Gewandt kleiden oder ob sie gar nicht gewahr werden, dass sie Indien für ihr eigenes Weltbild vereinnahmen, ist in vielen Fällen kaum erkennbar. Am weitesten von einem Bezug auf konkretes Wissen entfernt, also am ehesten der Definition des Phantasmas entsprechend sind neben der frühromantischen Verwendung Indiens als Symbol einige mythologisch-vergleichende Texte und vor allem die meisten der literarischen Bearbeitungen. In ihnen wird ein Indien entworfen, dass nicht nur nicht auf eigener Anschauung beruht (wie das Indien der meistens Sachtexte auch), sondern dass auch die neuesten Erkenntnisse der Forschung ignoriert. Autoren literarischer Texte machen es sich jedoch auch nicht zur Aufgabe und zum Ziel, eine getreue Darstellung Indiens zu präsentieren. Ihre Indienbilder folgen ganz anderen Regeln als die Abhandlungen in Sachtexten. Nichtsdestotrotz beeinflussen diese durchaus phantastischen Indiendarstellungen in der Literatur natürlich auch das Indienbild der Leser oder Zuschauer.

Das Indienbild um 1800 hat also auch in dieser Hinsicht viele verschiedene Facetten und reicht von detaillierten, um wissenschaftliche Korrektheit bemühten Untersuchungen über das gezielte Herausgreifen und Vertiefen bestimmter Aspekte und dem Ignorieren anderen Bereiche zum Verfolgen eigener Ziele bis hin zur bloßem Verwendung des mit einigen stereotypen Attributen versehenen Indienbegriffs z.B. in literarischen Texten oder der Aufladung des Begriffs zu einem Symbol für etwas davon Losgelöstes. Unkenntnis aufgrund von mangelndem Zugang zu Quellen steht neben 
(bewussten oder unbewussten) Projektionen und gezielter Idealisierung (oder auch Abwertung) zu einem Phantasma.

\section{Resümee}

Man kann festhalten, dass die Indienbilder, die um 1800 im deutschsprachigen Raum existieren, sich zum einen durch sehr ähnliche, Indien zugeschriebene Attribute und Argumentationsweisen auszeichnen, die häufig bereits aus der Antike stammen und bis in unsere Zeit hinein fortgeführt werden. Zum anderen sind diese Indienbilder aber dennoch sehr vielschichtig und unterscheiden sich in ihrem Kontext und ihren Funktionen sowie in vielen kleinen Details. Die Autoren verarbeiten mehr oder weniger ausführlich Informationen, die sie entweder aus indischen Texten selbst oder aus Berichten über Indien gewonnen haben, aber die Auswahl dieser Quellen geschieht oft selektiv und richtet sich nach der Funktion, die Indien für diese Autoren erfüllen soll. Viele Autoren projizieren Eigenes auf bestimmte Aspekte der indischen Kultur oder entwerfen ein genaues Gegenbild zu ihren Vorstellungen des Eigenen. In einigen Fällen entfernt sich das durch solche Projektionen entstandene Bild so weit von den Quellen, dass von Phantasmen gesprochen werden kann. Anderen Autoren geht es tatsächlich darum, ihre Kenntnisse der indischen Kultur zu erweitern. Die literarische Darstellung Indiens unterscheidet sich dabei deutlich von der sachlich-wissenschaftlichen, da sie in anachronistischer Weise neue Forschungsergebnisse weitgehend ignoriert und verschiedene Vorstellungen überzeichnet. Auch wenn die Autoren von Sachtexten am Beispiel Indiens häufig bestimmte Weltbilder oder Anschauungen vermitteln wollen, tun sie das, indem sie die Leser informieren. In den literarischen Texten geht es dagegen in erster Linie nicht um Informationen über Indien, sondern um Unterhaltung der Leser auf der einen und das Durchspielen bestimmter Ideen, Fragen und (z.B. philosophischer oder gesellschaftlicher) Probleme auf der anderen Seite.

Für die wissenschaftliche Untersuchung der Rezeption anderer Kulturen ist es wichtig festzuhalten, wie entscheidend der Einfluss verschiedener, nicht direkt das Thema der Untersuchung betreffender Diskurse auf die Wahrnehmung und Darstellung dieses Themas ist. Dieser Einfluss darf bei der Interpretation entsprechender Texte keinesfalls außer Acht gelassen werden, da ansonsten die Gefahr besteht, dass durch eine allzu wörtliche bzw. auf das entsprechende Thema bezogene Interpretation die eigentliche, von diesem losgelöste Zielrichtung übersehen wird. Markantes Beispiel dafür ist die viel zu kurz greifende Interpretation der Indiendarstellung Herders als Idealisierung 
Indiens, die die Bezüge zu zeitgenössischen Diskursen z.B. über die Genese der Menschheit und Herders Stellungnahme am Beispiel Indiens missachtet. Bei der Bedeutung der zeitgenössischen Diskurse zu Themen, die zunächst unabhängig davon zu existieren scheinen, geht es nicht nur darum, dass - wie Foucault es beschreibt - die Diskurse sowohl die Menge derjenigen eingrenzen, die als kompetente Sprecher zugelassen werden, als auch die Aussagen, die sinnvollerweise innerhalb des Diskurses getroffen werden können. Das spielt natürlich mit hinein, wie der oben beschriebene Einwurf Humboldts, dass man bestimmte Dinge lieber nicht in bestimmten Kreisen sagen sollte, sowie die Ablehnung sprachunkundiger Gelehrter als kompetente Sprecher deutlich machen. Wichtig ist darüber hinaus aber auch, dass die Positionen, die die einzelnen Autoren innerhalb der Diskurse beziehen, bestimmte Erwartungen und Sichtweisen an das Thema herantragen und $\mathrm{zu}$ einer entsprechend selektiven Quellenauswahl sowie zur Projektion dieser Erwartungen und Thesen auf in diesem Fall Indien führen. Auch werden bestimmte Aspekte und Begriffe aus diesem Themenbereich, wenn sie immer wieder zur Stützung bestimmter Argumentationsstränge herangezogen werden, mit bestimmten Deutungen und Konnotationen, die aus anderen Diskursen stammen, aufgeladen. So können sie, ohne dass diese Mehrbedeutungen explizit erwähnt werden, bei ihrer Nennung deutlich mehr aussagen, als auf dem ersten Blick zu erkennen ist. Bei der Interpretation muss also nicht nur die Bedeutung der Begriffe und ihr möglicher Wandel in historischer Sicht berücksichtigt werden, sondern auch hinsichtlich der Verwendung innerhalb bestimmter Diskurse. Es ist ein großer Unterschied, ob vor einem romantischen oder aufklärerischen Hintergrund von der Ursprünglichkeit der indischen Kultur gesprochen wird.

Bei der Beschäftigung mit einem Thema wie der Rezeption Indiens ist die Einordnung der einzelnen Texte zu den entsprechenden Diskursen, an denen er teilhat, von großer Bedeutung. Umgekehrt kann die Untersuchung eines solchen Themas interessante Einblicke in die Vielzahl von Diskursen einer Zeit, ihre Vielfalt und ihre Verflechtungen untereinander gewähren. Einzelne Fragen und Themen, die am Beispiel Indiens diskutiert werden (wie z.B. die Frage nach den Ursprüngen der Menschheit und der menschlichen Kultur) können in vielen Bereichen beschrieben und veranschaulicht werden. In historischer Hinsicht kann aufgezeigt werden, wie bestimmte Annahmen und Vorstellungen, die zu bestimmten Zeiten als Teil bestimmter Diskurse mit Indien verknüpft worden sind, weiter fortwirken und später in anderen Zusammenhängen 
ähnliche oder auch ganz andere Funktionen erfüllen. So können frühneuzeitliche Deutungen der indischen Götterwelt als monströs und teuflisch in der Zeit der Aufklärung als monströs und irrational oder bei Goethe als monströs und die Einbildungskraft zerstörend wieder aufgegriffen werden. Denn auch wenn die entsprechenden Diskurse und Kontexte, innerhalb derer Indien mit bestimmten Bildern, Wertungen und Gefühlen verbunden worden ist, sich ändern, so bleiben diese Bilder, Wertungen und Gefühle häufig weiter bestehen und werden vor einem neuen Hintergrund (um)gedeutet.

Eine Untersuchung wie die Vorliegende kann über das konkrete Thema hinausweisend wichtige Einblicke in die Art und Weise, wie eine andere und in vielen Aspekten auch fremde Kultur wahrgenommen und rezipiert wird, ermöglichen. Bestimmte Strategien, wie dem Anderen begegnet wird, wie ein Verständnis gesucht und eine Integration in das Eigene versucht wird, können herausgearbeitet werden. Bei der Rezeption Indiens geschieht dies zumeist in Form eines (idealisierten oder negativen) Gegenbildes zum Eigenen, das mit Hilfe von Vergleichen konstruiert wird. Indien erhält seine Faszination und Bedeutung für viele der Autoren erst im Bezug auf das Eigene und häufig im Kontrast dazu. Ohne diesen Bezug wäre ein solches Interesse für Indien nicht zu erklären. Während die Verbindung mit dem Eigenen einerseits überhaupt erst die Aufmerksamkeit der Autoren und Leser in diesem Maße auf Indien lenkt und Anknüpfungspunkte für Deutungen liefert, verstellt sie andererseits gerade durch den Bezug auf das Eigene eine vorurteilsfreie Wahrnehmung des Anderen. Gerade im Hinblick auf die Frage, ob es auch im deutschsprachigen Raum Orientalismus im Sinne Saids gegeben habe, ist es sinnvoll nicht nur zu schauen, ob Indien mit bestimmten stereotypen Attributen versehen wird, sondern auch zu untersuchen, inwieweit den Autoren die gefilterte Sicht bewusst ist und wie sie mit ihr umgehen. So zeigt ein Autor, der diese europäische Prägung der Wahrnehmung als hilfreich und notwendig zu einem wirklichen Verständnis der indischen Kultur ansieht, eher orientalistische Züge als ein Autor, der diese Voreingenommenheit als hinderlich ansieht und sich bemüht, die indische Sichtweise zu berücksichtigen.

Die Untersuchung der Indienrezeption um 1800 in einem holistischen Ansatz, wie ihn diese Arbeit verfolgt, ermöglicht ein umfassendes Bild der Indienvorstellungen dieser Zeit. Die vor allem um Artikel aus Magazinen und Zeitschriften sowie um literarische Bearbeitungen erweiterte Quellengrundlage ergänzt und erweitert das bislang in der 
Forschung dominierende Bild einer romantischen Indiensehnsucht um politischaktuelle Interessen und der Lust am Exotischen auf der einen sowie eine häufig stereotype und spielerische Verwendung älterer Vorstellungen auf der anderen Seite. Durch die Orientierung an verschiedenen Diskursen anstatt an einzelnen Autoren wird die Bedeutung, die andere, nicht direkt dem Thema Indien zugehörige Diskurse auf die Wahrnehmung und Funktionalisierung dieses Themas haben, deutlich. Indem die vorliegende Arbeit sich darüber hinaus auf eine Vielzahl von Themengebieten bezieht, können Querverbindungen und strukturelle Ähnlichkeiten zwischen den unterschiedlichen (Sub-)Diskursen herausgearbeitet werden. Dadurch werden Erkenntnisse auf verschiedenen Ebenen ermöglicht: eine umfassende Beschreibung der Indienbilder um 1800 sowie Einblicke in die Themen und Strukturen der in dieser Zeit zahlreichen Diskurse über die menschliche(n) Kultur(en). Darüber hinaus werden zeitspezifische sowie allgemeine Muster und Vorgehensweisen im Umgang mit anderen Kulturen sowie Probleme bei deren Verständnis erfasst. 


\section{Literaturverzeichnis}

\section{Primärliteratur}

Abhandlungen über die Geschichte und Alterthümer, die Künste, Wissenschaften und Literatur die Künste, Wissenschaften und Literatur Asiens von Sir William Jones und andern Mitgliedern der im Jahr 1784 zu Calcutta in Indien errichteten gelehrten Gesellschaft. Aus dem Englischen übersetzt von Johann Christian Fick, Lehrer am ill. Gymnasium zu Erlangen, durchgesehen, und mit Anmerkungen, ausführlichen Erläuterungen und Zusätzen bereichert von D. Johann Friedrich Kleuker. 1. Band Riga 1795, 2. Band Riga 1795, 3. Band Riga 1797.(Teil 1: https://reader.digitalesammlungen.de/de/fs1/object/display/bsb11248614_00001.html; Teil 2:https://archive.org/details/bub_gb_I1thAAAAcAAJ)

Ansicht der Braminen über ein diesem Leben vorhergegangnes Daseyn. In: Morgenblatt für gebildete Stände 15 (1821; Nr. 129 Mai), S. 515. (https://reader.digitalesammlungen.de/de/fs1/object/display/bsb10531694_00005.html)

Asiatisches Magazin. Hrsg. von Julius Klaproth. Weimar 1802. (https://zs.thulb.unijena.de/receive/jportal_jpjournal_00000065;jsessionid=19129599747E778B0DE88E4F954071FC?XS L.toc.pos.SESSION=1\&XSL.view.objectmetadata.SESSION=true)

Aus dem Briefe eines deutschen Missionars im südlichen Indien. In: Indische Bibliothek 2 (1827), S. 162-180. (https://reader.digitale-sammlungen.de/de/fs1/object/display/bsb10250829_00003.html)

Beer, Michael: Der Paria. Trauerspiel in einem Aufzuge. Stuttgart und Tübingen 1829. (https://reader.digitale-sammlungen.de/de/fs1/object/display/bsb10944803_00005.html)

Bernardin de Saint-Pierre, J. H.: Die indische Hütte. In: Paul und Virginie und die Indische Hütte. Von J. H. Bernardin de Saint-Pierre. Neue Übertragung durch G. Fink. Pforzheim 1840, S. 311-412.

Beschreibung einer Indischen Jagd (Auszug aus dem Briefe eines Engländers). In: Asiatisches Magazin 1 (1802). 2. Stück, S. 169-174. (https://zs.thulb.uni-

jena.de/receive/jportal_jpjournal_00000065;jsessionid=19129599747E778B0DE88E4F954071FC?XS

L.toc.pos.SESSION=1\&XSL.view.objectmetadata.SESSION=true)

Best, C. C.: Briefe über Ost-Indien, das Vorgebirge der guten Hoffnung und die Insel St. Helene. Herausgegeben von Karl Gottlob Küttner. Leipzig 1807.

Beyträge zur Kenntnis der Länder und Völker im Nordwestlichen Indien. In: Minerva. Ein Journal historischen und politischen Inhalts 59 (1806), S. 193-241. (https://ds.ub.unibielefeld.de/viewer/image/1958318_059/201/LOG_0029/)

Bildungsanstalten für die Jugend in Hindostan. In: Morgenblatt für die gebildeten Stände 13 (1819, Januar, Nr. 17), S. 66-67. (https://reader.digitale-sammlungen.de/resolve/display/bsb10531678.html)

Blicke auf Indien. In: Literatur-Blatt 14/15 (1824), S. 53-55, 57-58. (https://reader.digitalesammlungen.de/de/fs1/object/display/bsb10531688_00699.html?contextType=scan\&contextSort=score $\% 2$ Cdescending \&contextRows $=10 \&$ context=Blicke+auf+indien)

Blumenbach, Johann Friedrich: Über die natürlichen Verschiedenheiten im Menschengeschlechte. Nach der dritten Ausgabe und den Erinnerungen des Verfassers übersetzt, und mit einigen Zusätzen und erläuternden Anmerkungen herausgegeben von Johann Gottfried Gruber. Leipzig 1798. (http://www.deutschestextarchiv.de/book/view/blumenbach_menschengeschlecht_1798?p=3)

Bopp, Franz: Über das Conjugationssystem der Sanskritsprache in Vergleichung mit jenem der griechischen, lateinischen, persischen und germanischen Sprache. Nebst Episoden des Ramajan und Mahabharat in genauen metrischen Uebersetzungen aus dem Originaltexte und einigen Abschnitten aus den Veda's. Herausgegeben und mit Vorerinnerungen begleitet von Dr. K. J. Windischmann. Frankfurt a.M. 1816. (https://reader.digitale-sammlungen.de/de/fs1/object/display/bsb10711905_00007.html) 
Botanik. In: Indische Bibliothek. Erster Band. Bonn 1823, S. 390-393. (https://reader.digitalesammlungen.de/de/fs1/object/display/bsb10250828_00005.html)

Brahmanen. In: Morgenblatt für gebildete Stände 2 (1808; Nr. 237), S. 945f. (https://reader.digitalesammlungen.de/de/fs1/object/display/bsb10531657_00005.html)

Bremer, Johann Gottlieb: Tippo-Saib und Laura oder Strafe und Rettung in den Folgen des jugendlichen Leichtsinns zweyer Militairpersonen. Eine authentische Geschichte. Berlin 1791. (https://digital.staatsbibliothek-

berlin.de/werkansicht?PPN=PPN638225876\&PHYSID=PHYS_0005\&DMDID=)

Brentano, Clemens: Einer Jungfrau bei dem Geschenk der Sakontala. In: Brentano, Clemens: Gesammelte Gedichte. Berlin 2017, S. 345f.

Brentano, Clemens: Godwi oder das steinerne Bild der Mutter. Stuttgart 1995.

Brentano, Clemens: Werke. Band 1. München 1963.

Briefe an Ludwig Tieck. Ausgewählt und herausgegeben von Karl von Holtei. Dritter Band. Breslau 1864.

Briefe auf einer Reise von Stade nach Madras in Ostindien und aus Ostindien geschrieben nach Stade von einem churhannöverschen Capitain der Infanterie. Bremen 1789. (https://digital.slubdresden.de/werkansicht/dlf/56020/1)

Briefe eines italienischen Reisenden. In: Ehrmann, Theophil Friedrich (Hg.): Neueste Beiträge zur Kunde von Indien. Aus dem Englischen und Italienischen. 3. Band. Weimar 1806. (https://gdz.sub.unigoettingen.de/id/PPN246763086?tify $=\{\% 22$ view\%22:\%22scan\%22\})

Briefe von und an August Wilhelm Schlegel. Gesammelt und erläutert durch Josef Körner. Erster Teil. Die Texte. Zürich u.a. 1930.

Briefwechsel des Herzogs-Großherzogs Carl August mit Goethe. Herausgegeben von Hans Wahl. II. Band 1807-1820. Mit einem Bildnis des Herzogs. Berlin 1916 (Carl August. Darstellungen und Briefe zur Geschichte des Weimarischen Fürstenhauses und Landes. Im Auftrag Seiner Königlichen Hoheit des Großherzogs Wilhelm Ernst von Sachsen zur Hundertjahrfeier des Großherzogtums.

Herausgegeben von Erich Marcks. IV. Abteilung: Briefwechsel des Herzogs-Großherzogs Carl August mit Goethe).

Büsching, D. Anton Friedrich: Erdbeschreibung. Fünften Theils. Zweite Abtheilung, Asien, nemlich Hindostan und Dekan. Ausgearbeitet von Matthias Christian Sprengel. Hamburg 1802.

Casimir Delavigne. In: Illustrirte Zeitung. Zweiter Band. Leipzig 1844, S. 145f.

Claudius, Matthias: Eine asiatische Vorlesung. In: ASMUS omnia SECUM portans, oder Sämmtlich Werke des Wandsbecker Bothen. 7. Teil. Wandsbeck 1802, S. 1-62. (https://reader.digitalesammlungen.de/de/fs1/object/display/bsb10924598_00021.html)

Conversations-Lexicon oder encyclopädisches Handwörterbuch für gebildete Stände. Band 4. Dritte Auflage. Leipzig und Altenburg 1815. (https://reader.digitalesammlungen.de/de/fs1/object/display/bsb11003693_00721.html)

Conversations-Lexikon oder kurzgefasstes Handwörterbuch für die in der gesellschaftlichen Unterhaltung aus den Wissenschaften und Künsten vorkommenden Gegenständen. Band 3. Amsterdam 1809. (https://reader.digitalesammlungen.de/de/fs1/object/display/bsb10400701_00324.html?contextType=scan\&contextSort=score $\% 2$ Cdescending \&contextRows $=10 \&$ contextStart $=10 \& \mathrm{zoom}=0.6500000000000001 \&$ context $=$ ostindien )

Creuzer, Friedrich: Symbolik und Mythologie der alten Völker, besonders der Griechen. In Vorträgen und Entwürfen. Leipzig und Darmstadt. 1. Band 1810. (https://digi.ub.uniheidelberg.de/diglit/creuzer1810ga) 
Creuzer, Friedrich: Symbolik und Mythologie der alten Völker, besonders der Griechen. In Vorträgen und Entwürfen. Leipzig und Darmstadt. 2. Band 1811. (https://digi.ub.uni-

heidelberg.de/diglit/creuzer1810ga)

Creuzer, Friedrich: Symbolik und Mythologie der alten Völker, besonders der Griechen. In Vorträgen und Entwürfen. Leipzig und Darmstadt. 3. Band 1812. (https://digi.ub.uni-

heidelberg.de/diglit/creuzer1810ga)

Creuzer, Friedrich: Symbolik und Mythologie der alten Völker besonders der Griechen. Erster Theil. Zweite völlig umgearbeitete Ausgabe. Leipzig und Darmstadt 1819. (http://digital.bibliothek.unihalle.de/id/2523625)

Creuzer, Friedrich: Symbolik und Mythologie der alten Völker besonders der Griechen. Zweiter Theil. Zweite völlig umgearbeitete Ausgabe. Leipzig und Darmstadt 1820. (http://digital.bibliothek.unihalle.de/id/2523625)

Creuzer, Friedrich: Symbolik und Mythologie der alten Völker besonders der Griechen. Vierter Theil. Zweite völlig umgearbeitete Ausgabe. Leipzig und Darmstadt 1821. (http://digital.bibliothek.unihalle.de/id/2523625)

Dalberg, F. H. von: Gita-govinda oder die Gesänge Jajadeva's eines altindischen Dichters. Aus dem Sanskrit ins Englische, aus diesem ins Deutsche übersetzt mit Erläuterungen. Erfurt 1802. (https://reader.digitale-sammlungen.de/de/fs1/object/display/bsb10250929_00007.html)

Danz, Johann Traugott Leberecht: Der Marsch der Franzosen nach Indien. Notizen zu Beurtheilung der neuprojectirten Landexpedition. Jena 1808. (http://digital.bib-bvb.de/R/?func=dbin-jumpfull\&object_id=4178727\&local_base=UBA\&pds_handle=GUEST\&bvb=suma)

Dapper, Olfert: Asia / oder Ausführliche Beschreibung Des Reichs des Grossen Mogols Und eines grossen Theils von Indien. Nürnberg 1681. (https://digi.ub.uniheidelberg.de/diglit/dapper1681/0005/image)

Darstellung der Brahmanisch-Indischen Götterlehre, Religionsgebräuche und bürgerliche Verfassung. Nach dem lateinischen Werke des Vaters Paullinus a St. Barthholomaeo bearbeitet. Gotha 1797. (https://reader.digitale-sammlungen.de/de/fs1/object/display/bsb11216176_00005.html)

Das alte Indien. In: Morgenblatt für gebildete Stände. 1 (1807; Dezember, Nr. 305), S. $1217 f$. (https://reader.digitale-sammlungen.de/de/fs1/object/display/bsb10531655_00005.html)

Das Fest zu Jaggernauth, im Jahr 1814. In: Morgenblatt für gebildete Stände 10 (1816; Nr. 21 Januar), S. 83. (https://reader.digitale-sammlungen.de/de/fs1/object/display/bsb10531673_00005.html)

Des Fra Paolino da San Bartolomeo Reise nach Ostindien. Aus dem Französischen. Mit Anmerkungen von Johann Reinhold Forster. Berlin 1798 (Magazin von merkwürdigen neuen Reisebeschreibungen, aus fremden Sprachen übersetzt und mit erläuternden Anmerkungen begleitet; 15). (https://gdz.sub.unigoettingen.de/id/PPN24461086X)

Die Hindus von F. Balthasar Solvyns. In: Morgenblatt für gebildete Stände 4 (1810; Nr. 95), S. 377 380. (https://reader.digitale-sammlungen.de/de/fs1/object/display/bsb10531660_00007.html)

Die Jagdpartien der Engländer in Indien. Nach der in den Asiatic Researches enthaltenen Erzählung des Obristen Ironside. In: Morgenblatt für gebildete Stände 6 (1812; Nr. 147+148; Juni), S. 585-587. (https://reader.digitale-sammlungen.de/de/fs1/object/display/bsb10531664_00005.html)

Die Tigerjagden in Indien. In: Morgenblatt für gebildete Stände 7 (1813; Nr. 284; November), S 1134f. (https://reader.digitale-sammlungen.de/de/fs1/object/display/bsb10531667_00005.html)

Dubois's Briefe über den Zustand des Christenthums in Indien, in welchen die Bekehrung der Hindus als unausführbar dargestellt wird. Aus dem Englischen übersetzt mit Anmerkungen und erläuternden Nachträgen von D. A. G. Hoffmann nebst einer Vorrede von D. Joh. Friedr. Röhr. Neustadt a.d. Orla 1824. 
Dubois, J.A.: Description of the Characters, Manners and Customs of the People of India; and of their Institution, religious and civil. London 1817.

Ehrmann, Theophil Friedrich (Hg.): Neuste Kunde von Asien. Erster Band. Asien überhaupt, WestAsien und Mittel-Asien. Weimar 1811 (Neueste Länder- und Völkerkunde. Ein geographisches Lesebuch für alle Stände; 10). (https://zs.thulb.uni-

jena.de/receive/jportal_jpvolume_00133050?XSL.view.objectmetadata.SESSION=false)

Ehrmann, Theophil Friedrich (Hg.): Neuste Kunde von Asien. Zweiter Band. Süd-Asien. Weimar 1811 (Neueste Länder- und Völkerkunde. Ein geographisches Lesebuch für alle Stände; 11). (https://reader.digitale-sammlungen.de/de/fs1/object/display/bsb10429552_00007.html)

Ehrmann, Theophil Friedrich (Hg.): Neueste Beiträge zur Kunde von Indien. Aus dem Englischen und Italienischen. Weimar 1806. (https://gdz.sub.uni-goettingen.de/id/PPN246762780)

Epochen der Kultur von Indien. In: Morgenblatt für gebildete Stände 2 (1808; Nr. 76 März). S. 301302. (https://reader.digitale-sammlungen.de/de/fs1/object/display/bsb10531656_00355.html)

Erinnerungen aus Ostindien. In: Morgenblatt für gebildete Stände 3 (1809; April Nr. 90), S. 357-359. (https://reader.digitale-sammlungen.de/de/fs1/object/display/bsb10531659_00059.html)

Ersch, Johann Samuel: Handbuch der deutschen Literatur seit der Mitte des achtzehnten Jahrhunderts bis auf die neueste Zeit, systematisch bearbeitet und mit den nöthigen Registern versehen. Neue mit verschiedenen Mitarbeitern besorgte Ausgabe. Zweiter Band enthaltend I. Literatur der Jurisprodenz und Politik mit Einschluss der Kameralwissenschaften. II. Literatur der schönen Künste. Leipzig 1840 sowie Vierter Band enthaltend Geschichte und deren Hülfswissenschaften. Leipzig 1827.

Forster, Georg: Reise aus Bengalen nach England, durch die nördlichen Theile von Hindostan, durch Kaschemir, Afganistan, Persien und Rußland. Aus dem Englischen übersetzt, und mit Anmerkungen begleitet von C. Meiners. Erster Theil. Zürich 1796. (https://reader.digitalesammlungen.de/de/fs1/object/display/bsb10470007_00007.html)

Forster, Georg: Briefe 1790 bis 1791. Bearbeitet von Brigitte Leuschner und Siegfried Scheibe. Berlin 1980 (Georg Forsters Werke. Sämtliche Schriften, Tagebücher, Briefe. Herausgegeben von der Akademie der Wissenschaften der DDR; 16).

Briefe an Forster. Bearbeitet von Brigitte Leuschner u.a. Berlin 1982 (Georg Forsters Werke. Sämtliche Schriften, Tagebücher, Briefe. Herausgegeben von der Akademie der Wissenschaften der DDR; 18).

Forster, Georg: Noch etwas über die Menschenracen. In: Forster, Therese (Hg.): Georg Forster's sämmtliche Schriften. Bd. 4: Kleine Schriften. Leipzig 1843, S. 280-306. (https://www.digitalesammlungen.de/de/view/bsb11246119?page=316)

Forster, Georg. Rezensionen. Bearbeitet von Horst Fiedler. Berlin 1977 (Georg Forsters Werke. Sämtliche Schriften, Tagebücher, Briefe. Herausgegeben von der Akademie der Wissenschaften der DDR; 11).

Forster, Georg: Sakontala oder der entscheidende Ring ein indisches Schauspiel von Kalidas. Aus den Ursprachen Sanskrit und Prakrit ins Englische und aus diesem ins Deutsche übersezt mit Erläuterungen. Mainz und Leipzig 1791. (https://reader.digitalesammlungen.de/de/fs2/object/display/bsb10251006_00007.html)

Frankreichs ehemalige Macht in Ostindien. In: Minerva. Ein Journal historischen und politischen Inhalts 87 (1813), S. 297-311.

Fundgruben des Orients. Bearbeitet durch eine Gesellschaft von Liebhabern. Wien 1809. (https://reader.digitale-sammlungen.de/de/fs1/object/display/bsb10210776_00009.html)

Gehe: Eduard Heinrich: Jessonda. Große Oper in 3 Aufzügen. München 1836. (https://reader.digitalesammlungen.de/de/fs1/object/display/bsb10577523_00005.html)

Georg Forster's sämmtliche Schriften. Herausgegeben von dessen Tochter und begleitet mit einer Charakteristik von G.G. Gervinus. In neun Bänden. Achter Band. Briefwechsel. Leipzig 1843. 
Georg Viscount Valentia's und Heinrich Salt's Reisen nach Indien, Ceylon, dem rothen Meere, Abyssinien und Ägypten, in den Jahren 1802, 1803, 1804, 1805 u. 1806. Aus dem Englischen im Auszuge übersetzt und mit einigen Anmerkungen begleitet von Friedrich Ruhs. Weimar 1811. (https://archive.thulb.unijena.de/collections/rsc/viewer/HisBest_derivate_00002833/BR_1811_44_0001.tif)

Görres, Joseph: Mythengeschichte der asiatischen Welt. Erster Band. Hinterasiatische Mythen. Heidelberg 1810. (https://reader.digitalesammlungen.de/de/fs1/object/display/bsb11096263_00001.html)

Goethe, Johann Wolfgang: Ästhetische Schriften 1824-1832. Über Kunst und Altertum V-VI. Herausgegeben von Anne Bohnenkamp. Frankfurt A.M.1999 (Sämtliche Werke. Briefe, Tagebücher und Gespräche. Herausgegeben von Friedmar Apel u.a.. I. Abteilung: Sämtliche Werke; 22).

Goethe, Johann Wolfgang: Das erste Weimarer Jahrzehnt. Briefe, Tagebücher und Gespräche vom 7. November 1775 bis 2. September 1786. Herausgegeben von Hartmut Reinhart. Frankfurt a.M.1997 (Sämtliche Werke. Briefe, Tagebücher und Gespräche. II. Abteilung: Briefe, Tagebücher und Gespräche. Herausgegeben von Karl Eibel u.a., Band 2 (29).

Goethe, Johann Wolfgang: Die letzten Jahre. Briefe, Tagebücher und Gespräche von 1823 bis zu Goethes Tod. Teil II: Vom Dornburger Aufenthalt 1828 bis zum Tode. Herausgegeben von Horst Fleig. Frankfurt a.M. 1993 (Goethe, Johann Wolfgang: Sämtliche Werke. Briefe Tagebücher und Gespräche)

Goethe, Johann Wolfgang: Goethes Gespräche. Zweiter Teil. Zürich1950 (Goethe, Johann Wolfgang: Gedenkausgabe der Werke, Briefe und Gespräche. Herausgegeben von Ernst Beutler).

Goethe, Johann Wolfgang: Indische Dichtungen. In: Goethes Werke. Herausgegeben im Auftrage der Großherzogin Sophie von Sachsen. Band 42,2. Fotomechanischer Nachdruck d. Ausg. Weimar, Böhlau 1907. München 1987, S. 50-53.

Goethe, Johann Wolfgang: Mit Schiller. Briefe, Tagebücher und Gespräche vom 24. Juni 1794 bis zum 9. Mai 1805. Teil II. Vom 1. Januar 1800 bis zum 9. Mai 1805. Herausgegeben von Volker C. Dörr und Norbert Oellers. Frankfurt am Main 1999 (Sämtliche Werke. Briefe, Tagebücher und Gespräche. II. Abteilung: Briefe Tagebücher und Gespräche. Herausgegeben von Karl Eibl u.a., Band 5, 32).

Goethe, Johann Wolfgang: Napoleonische Zeit. Briefe, Tagebücher und Gespräche vom 10.Mai 1805 bis 6. Juni 1816. Teil II: Von 1812 bis zu Christianes Tod. Herausgegeben von Rose Unterberger. Frankfurt a.M. 1994 (Sämtliche Werke. Briefe, Tagebücher und Gespräche. II. Abteilung: Briefe, Tagebücher und Gespräche. Herausgegeben von Karl Eibl u.a., Band 7/34).

Goethe, Johann Wolfgang von: Der Gott und die Bajadere. Indische Legende. In: Goethe, Johann Wolfgang: Gedichte 1800-1832. Herausgegeben von Karl Eibl. Frankfurt a. M. 1988 (Sämtliche Werke. Briefe, Tagebücher und Gespräche. Herausgegeben von Hendrik Birus u.a. I. Abteilung: Sämtliche Werke; 2), S. 150-153.

Goethe, Johann Wolfgang von: Howards Ehrengedächtnis. In: Goethe, Johann Wolfgang: Gedichte 1800-1832. Herausgegeben von Karl Eibl. Frankfurt a. M. 1988 (Sämtliche Werke. Briefe, Tagebücher und Gespräche. Herausgegeben von Hendrik Birus u.a. I. Abteilung: Sämtliche Werke; 2), S. 503f.

Goethe, Johann Wolfgang: Paria. In: Goethe, Johann Wolfgang: Gedichte 1800-1832. Herausgegeben von Karl Eibl. Frankfurt a. M. 1988 (Sämtliche Werke. Briefe, Tagebücher und Gespräche. Herausgegeben von Hendrik Birus u.a. I. Abteilung: Sämtliche Werke; 2), S.450-456.

Goethe, Johann Wolfgang von: West-östlicher Divan. Teil 1. Herausgegeben von Hendrik Birus. Frankfurt a. M. 1994 (Sämtliche Werke. Briefe, Tagebücher und Gespräche. Herausgegeben von Friedmar Apel u.a.I. Abteilung: Sämtliche Werke, Band 3/1).

Goethe, Johann Wolfgang: Zahme Xenien II. In: Goethe, Johann Wolfgang: Gedichte 1800-1832. Herausgegeben von Karl Eibl. Frankfurt a. M. 1988 (Sämtliche Werke. Briefe, Tagebücher und Gespräche. Herausgegeben von Hendrik Birus u.a. I. Abteilung: Sämtliche Werke. Band 2), S. 630640. 
Göttingische gelehrte Anzeigen unter der Aufsicht der königl. Gesellschaft der Wissenschaften. Der erste Band auf das Jahr 1808. 37. Stück. Göttingen 1808.

Günderrode, Karoline von: Briefe zweier Freunde. In: Günderrode: Sämtliche Werke, S. 350-362.

Günderrode, Karoline von: Der Adept. In: Günderrode, Karoline von: Sämtliche Werke. Frankfurt a.M. und Basel 2006, S. 49-51.

Günderrode, Karoline von: Die Malabarischen Witwen. In: Günderrode: Sämtliche Werke, S. 325.

Günderrode, Karoline von: Geschichte eines Braminen. In: Günderrode: Sämtliche Werke, S. 303-314.

Günderrode, Karoline von: Udohla in zwei Acten. In: Günderode: Sämtliche Werke, S. 203-231.

Hauptunterschied in den Lehren der Buddhisten und der Braminen. In Morgenblatt für die gebildeten Stände 20 (1826; Nr. 270 November), S. 1079. (https://reader.digitalesammlungen.de/de/fs1/object/display/bsb10531693_00477.html)

Heeren, Arnold Hermann Ludwig: Etwas über Studien des alten Indiens. Antwort an Herrn Prof. A.W.v. Schlegel auf dessen an mich gerichtete drei ersten Briefe in seiner Indischen Bibliothek. Göttingen 1827.

Heeren, Arnold H. L.: Geschichte des Europäischen Staatensystems und seiner Kolonien. Göttingen 1809. (http://www.deutschestextarchiv.de/book/show/heeren_staatensystem_1809)

Heeren, Arnold Hermann Ludwig: Ideen über die Politik, den Verkehr und den Handel der vornehmsten Völker der alten Welt. Erster Theil. Zweyte Abtheilung. Upsala 1818. (https://archive.org/stream/p2ideenberdiep01heer\#page/n3/mode/2up)

Hegel, Georg Wilhelm: Über die unter dem Nahmen Bhagavad-Gita bekannte Episode des Mahabharata; von Wilhelm von Humboldt. Erster Artikel. In: Jahrbücher für wissenschaftliche Kritik. Herausgegeben von der Societät für wissenschaftliche Kritik. Jahrgang 1827. Stuttgart und Tübingen 1827, Sp. 51-63. (https://reader.digitalesammlungen.de/de/fs1/object/display/bsb10501816_00007.html)

Hegel, Georg Wilhelm: Über die unter dem Nahmen Bhagavad-Gita bekannte Episode des Mahabharata; von Wilhelm von Humboldt. Zweiter Artikel. In: Jahrbücher für wissenschaftliche Kritik. Herausgegeben von der Societät für wissenschaftliche Kritik. Jahrgang 1827. Stuttgart und Tübingen 1827, Sp. 1441-1492. (https://reader.digitalesammlungen.de/de/fs1/object/display/bsb10501816_00007.html)

Hegel, Georg Wilhelm Friedrich: Vorlesungen über die Philosophie der Geschichte. Herausgegeben von D. Eduard Gans. Berlin 1837 (Georg Wilhelm Friedrich Hegel's Werke. Vollständige Ausgabe durch einen Verein von Freunden des Verewigten; 9).

Heine, Heinrich: Den König Wiswamitra. In: Heine, Heinrich: Buch der Lieder. Bearbeitet von Pierre Grappin. Hamburg 1975 (Historisch-kritische Gesamtausgabe der Werke. Herausgegeben von Manfred Windfuhr. Band I/1), S. 258

Heine, Heinrich: Die romantische Schule. Kritische Ausgabe. Herausgegeben von Helga Weidmann. Stuttgart 1997.

Hell, Theodor: M. Perrin's Reise durch Hindostan und Schilderung der Sitten, Einwohner, NaturProducte und Gebräuche dieses Landes nach einem sechszehnjährigen Aufenthalte dasselbst. Nach dem Französischen bearbeitet von Theodor Hell. Wien 1811. (https://reader.digitalesammlungen.de/de/fs1/object/display/bsb10467716_00018.html)

Hensler, Karl Friedrich: Das Schlangenfest in Sangora. Eine heroisch komische Oper in zwey Aufzügen. Wien 1797. (https://daten.digitalesammlungen.de/0006/bsb00061674/images/index.html?id=00061674\&groesser=\&fip=qrsxseayawqrse ayayztsxsxdsydenw\&no=3\&seite $=5$ ) 
Hensler, Karl Friedrich: Das Sonnenfest der Braminen. Ein heroisch komisches Original-Singspiel in zwey Aufzügen. In: Sammlung einiger Singspiele, aufgeführt auf der k. k. privil. Marinellischen Schaubühne in der Leopoldstadt. Wien 1790.

Herder, Johann Gottfried: Adrastea und das 18. Jahrhundert. Neu herausgegeben von Johann von Müller. Stuttgart und Tübingen 1829.

Herder, Johann Gottfried: Auch eine Philosophie der Geschichte zur Bildung der Menschheit. Frankfurt a.M. 1967.

Herder, Johann Gottfried: Blumenlese aus morgenländischen Dichtern. Herausgegeben durch Johann von Müller. Wien 1807 (Johann Gottfried Herder's sämmtliche Werke. Zur schönen Literatur und Kunst. Neunter Theil).

Herder, Johann Gottfried: Ideen zur Philosophie der Geschichte der Menschheit. Darmstadt 1966.

Herder, Johann Gottfried: Indien. In: Johann Gottfried von Herder's sämmtliche Werke. Zur schönen Literatur und Kunst. Sechszehnter Theil. Stuttgart und Tübingen 1817, S. 51.

Herder, Johann Gottfried: Über ein morgenländisches Drama. Einige Briefe. In: Johann Gottfried von Herder's Blumenlese aus morgenländischen Dichtern. Herausgegeben von Johann von Müller. Wien 1813, S. 259-298.

Herder, Johann Gottfried: Werke. Erster Theil. Gedichte. Berlin 1879.

Herklots: Die Bajaderen. Heroische Oper in drey Akten mit Ballet. München 1817.(https://reader.digitale-sammlungen.de/de/fs1/object/display/bsb10577346_00003.html)

Herrn Sonnerat, Kommussärs beym Seewesen (...) Reise nach Ostindien und Ssina (...). Aus dem französischen Original in einen freien Auszug gebracht. Frankfurt u. Leipzig 1784. (https://reader.digitale-sammlungen.de/de/fs1/object/display/bsb11095751_00005.html)

Heyden, Friedrich von: Magandola. In: Heyden, Friedrich von: Dramatische Novellen. Erster Theil. Königsberg 1819, S. 181-262.

Hindernisse, die den Missionen in Indien entgegenstehen. Aus dem Englischen. In: Minerva. Ein Journal historischen und politischen Inhalts 94 (1815), S. 161-168.

Hodges, Wilhelm: Reisen durch Ostindien während der Jahre 1780, 1781, 1782 und 1783. Aus dem Englischen. Hamburg 1793 (Neuere Geschichte der See- und Land-Reisen; 6). (https://gdz.sub.unigoettingen.de/id/PPN244608342)

Humboldt, Wilhelm von: Über die unter dem Namen Bhagavad-Gita bekannte Episode des Mahabharata. Gelesen in der Akademie der Wissenschaften am 30. Juni 1825 und 15. Juni 1826. In: Abhandlungen der Königlichen Preußischen Akademie der Wissenschaften zu Berlin 1825. 1828, S. 164. (http://bibliothek.bbaw.de/bibliothek-digital/digitalequellen/schriften/anzeige?band=07abh/1825\&seite:int=00000402)

Indische Bibliothek. Herausgegeben von August Wilhelm Schlegel. 1. Band Bonn 1823, 2. Band Bonn 1827. (https://reader.digitale-sammlungen.de/de/fs1/object/display/bsb10250828_00005.html)

Indische Dichtungen. In: Indische Bibliothek 1 (1823), S. 28-96. (https://reader.digitalesammlungen.de/de/fs1/object/display/bsb10250828_00005.html)

Jean Paul: Hesperus. In: Jean Paul: Sämtliche Werke. Abteilung I. Erster Band. Darmstadt 2000, S. 471-1236.

Jomard: Parallele zwischen den Alterthümern von Indien und denen von Ägypten. In: Journal für Literatur, Kunst, Luxus und Mode 34 (1819), S. 728-744. (https://zs.thulb.unijena.de/receive/jportal_jpjournal_00000029)

Jones, William: Über die Gottheiten Griechenlands, Italiens und Indiens. In: Kleuker, J.F. (Hg.): Abhandlungen über die Geschichte und Altertümer, die Künste, Wissenschaften und Literatur Asiens. 
1. Band Riga 1795, S.161-249. (https://reader.digitale-

sammlungen.de/de/fs1/object/display/bsb11248614_00001.html)

Jones, William: Über die Hindus. In: Kleuker, J.F. (Hg.): Abhandlungen über die Geschichte und Altertümer, die Künste, Wissenschaften und Literatur Asiens. 1. Band Riga 1795, S. 1-24.

(https://reader.digitale-sammlungen.de/de/fs1/object/display/bsb11248614_00001.html)

Kanne, Friedrich August: Padmana. Trauerspiel in fünf Aufzügen. Wien 1818.

Kanne, Johann Arnold: Pantheum der Ältesten Naturphilosophie, die Religion aller Völker. Tübingen 1811. (https://reader.digitale-sammlungen.de/de/fs1/object/display/bsb10254411_00003.html)

Klaproth, Julius: Asia polyglotta. Paris 1823. (https://reader.digitalesammlungen.de/de/fs1/object/display/bsb10691043_00005.html)

Klaproth, Julius: Einleitung. In: Asiatisches Magazin 1 (1802), erstes Stück, S. 3-8. (https://zs.thulb.unijena.de/receive/jportal_jpjournal_00000065;jsessionid=19129599747E778B0DE88E4F954071FC?XS L.toc.pos.SESSION=1\&XSL.view.objectmetadata.SESSION=true)

Klaußer: Die Hindus. In Neue Litteratur und Völkerkunde 1 (1791), S. 508-527.

Kleuker, Johann Friedrich: Das Brahmanische Religionssystem im Zusammenhange dargestellt und aus seinen Grundbegriffen erklärt: wie auch von den verschiedenen Ständen Indiens mit besonderer Rücksicht auf Fr. Paullini a S. Bartholomaeo Systema Brahmanicum etc. Nebst einem kurzen Auszuge aus eben desselben Sidharvbam oder Samskrdamischen Grammatik. Riga 1797. (https://reader.digitalesammlungen.de/de/fs1/object/display/bsb10435335_00005.html)

Knapp, Georg Christian (Hg.): Neuere Geschichte der Evangelischen Missions-Anstalten zu Bekehrung der Heiden in Ostindien. 5. Band. Halle 1804. (http://digital.bibliothek.unihalle.de/hd/periodical/pageview/678175)

Kotzebue, August von: Die Indianer in England. Frankfurt und Leipzig 1790. (https://reader.digitalesammlungen.de/de/fs1/object/display/bsb10104947_00001.html)

Langstedt, Friedrich Ludwig: Hindostanische Denkwürdigkeiten. Ein Lesebuch zur Beherzigung für jeden Kosmopoliten. Nürnberg 1799.

Lebendig begrabne Frau eines Hindu. In: Morgenblatt für gebildete Stände 13 (1819; Mai Nr. 121), S. 483. (https://reader.digitale-sammlungen.de/de/fs1/object/display/bsb10531678_00517.html)

Leitzmann, Albert (Hg.): Briefwechsel zwischen Wilhelm von Humboldt und August Wilhelm Schlegel. Herausgegeben von Albert Leitzmann. Mit einer Einleitung von B. Delbrück. Halle 1908.

Lewald, August: Der Paria. Tragödie in fünf Acten nach C. Delavigne frei für die deutsche Bühnen bearbeitet. Nürnberg 1825. (https://reader.digitalesammlungen.de/de/fs1/object/display/bsb10090068_00003.html)

Majer, Friedrich: Brahma oder die Religion der Indier als Brahmanismus. Leipzig 1818.

Majer, Friedrich: Der Bhaguat-Geeta oder Gespräche zwischen Kreeshna und Arjoon. In: Asiatisches Magazin 1 (1802), S. 406-453. (https://zs.thulb.unijena.de/receive/jportal_jpjournal_00000065;jsessionid=19129599747E778B0DE88E4F954071FC?XS L.toc.pos.SESSION=1\&XSL.view.objectmetadata.SESSION=true)

Majer, Friedrich: Gita-Govinda. ein indisches Singspiel. Von Jajadeva. aus der Ursprache ins Engl. von W Jones, und aus diesem ins Dt. übers., und mit einigen Erl. begleitet von Friedrich Majer. In: Asiatisches Magazin 2 (1802), 4. Stuick, S. 294-375. (https://zs.thulb.unijena.de/receive/jportal_jpvolume_00068755)

Majer, Friedrich: Über die mythologischen Dichtungen der Indier. In: Poetisches Journal. Erster Jahrgang erstes Stück. Von Ludwig Tieck 1 (1800), S. 165-216. (https://zs.thulb.uni- 
jena.de/receive/jportal_jpvolume_00058223?XSL.view.objectmetadata.SESSION=true\&XSL.toc.pos.S $\mathrm{ESSION}=1$ )

Majer, Friedrich: Zur Kulturgeschichte der Völker. Historische Untersuchungen. Zweiter Band. Leipzig 1798.

Mégha Doûta oder die verkündigende Wolke. Ein samskritanischs Gedicht von Kalidasa. In: Journal für Literatur, Kunst, Luxus und Mode (1817, März), S. 213-222. (https://zs.thulb.unijena.de/receive/jportal_jpjournal_00000029)

Meiners, Christoph: Grundriß der Geschichte der Menschheit. Lemgo 1785. (https://reader.digitalesammlungen.de/de/fs1/object/display/bsb10435503_00005.html)

Meiners, Christoph: Untersuchungen über die Verschiedenheiten der Menschennaturen in Asien und den Südländern, in den Ostindischen und Südseeinseln, nebst einer historischen Vergleichung der vormahligen und gegenwärtigen Bewohner dieser Continente und Eylande. Erster Theil. Tübingen 1811. (https://reader.digitale-sammlungen.de/de/fs1/object/display/bsb10255338_00005.html)

Meiners, Christoph: Untersuchungen über die Verschiedenheiten der Menschennaturen (die verschiedenen Menschenarten) in Asien und den Südländern, in den Ostindischen und Südseeinseln, nebst einer historischen Vergleichung der vormahligen und gegenwärtigen Bewohner dieser Continente und Eylande. Zweiter Theil. Tübingen 1813. (https://reader.digitalesammlungen.de/de/fs1/object/display/bsb10255339_00005.html)

Mereau, Sophie: Serafine. Ein Gedicht in sechs Gesängen. Berlin 1802 (Gedichte von Sophie Mereau. Zweites Bändchen). (https://reader.digitalesammlungen.de/de/fs1/object/display/bsb10114708_00006.html)

Merkwürdige Thierhetze zu Seringapatnam. Aus dem Essai sur l'Indoustan par Mr. Legoux de Flaix. In: Morgenblatt für gebildete Stände 2 (1808; Nr. 209; August), S. 835. (https://reader.digitalesammlungen.de/de/fs1/object/display/bsb10531657_00481.html)

M. Perrin's Reise durch Hindostan und Schilderung der Sitten, Einwohner, Natur-Producte und Gebräuche dieses Landes nach einem sechzehnjährigen Aufenthalte daselbst. Nach dem Französischen bearbeitet von Theodor Hell. Wien 1811. (https://opacplus.bsbmuenchen.de/Vta2/bsb10467716/bsb:BV035053714)

Müller, Niklas: Glauben, Wissen und Kunst der alten Hindus in ursprünglicher Gestalt und im Gewande der Symbolik mit vergleichenden Seitenblicken auf die Symbolmythe der berühmten Völker der alten Welt, mit hieher gehöriger Literatur und Linguistik. Erster Band. Mainz 1822.

(https://babel.hathitrust.org/cgi/pt?id=uc1.b4300573\&view=1up\&seq=3)

Nachricht von einer indischen Sutee. In: Morgenblatt für gebildete Stände 15 (1821; Juni Nr. 147), S. 587. (https://reader.digitale-sammlungen.de/de/fs1/object/display/bsb10531682_00609.html)

Orientalische Literatur. In: Allgemeine Literatur-Zeitung (1828), Band 2, Nr. 182, Sp. 601-608. (https://zs.thulb.uni-jena.de/receive/jportal_jpjournal_00000005?XSL.q=allgemeine\%20zeitung)

Plat, Peter Josef du: Brief vom 29. März 1784. In: Ahuja, Ravi u. Christof-Füchsle, Martin (Hgg.): A Great War in South India. German Accounts of the Anglo-Mysore Wars, 1766-1799. Berlin/Boston 2020, S. 345-355.

Plümicke, Carl M.: Lanassa. Nach der Veuve du Malabar des le Mierre. Berlin 1782. (https://reader.digitale-sammlungen.de/de/fs1/object/display/bsb11090316_00003.html)

Proben aus Ostindischen Zeitungen. Das Fest zu Jaggernauth, im Jahr 1814. In: Morgenblatt für gebildete Stände 10 (1816; Januar Nr. 21), S. 83. (https://reader.digitalesammlungen.de/de/fs1/object/display/bsb10531673_00091.html)

Religionsparteyen der Indier. In Morgenblatt für die gebildeten Stände 3 (1809; Nr. 150 Juni), S. 597598. (https://reader.digitale-sammlungen.de/de/fs1/object/display/bsb10531659_00309.html) 
Remer, Julius August: Handbuch der neuern Geschichte von der Kirchenverbesserung bis auf den Aachener Kongreß im Jahre 1818. Zweiter Band. Fünfte verbesserte und vermehrte Auflage vom Professor Saalfeld in Göttingen. Brauchschweig 1824.

Rezension zu: Der Krieg in Indien. In: Jenaische Allgemeine Literatur-Zeitung 18 (1819), Band 1, Nr. 29, Sp. 226-229. (https://zs.thulb.uni-

jena.de/receive/jportal_jpjournal_00000011?XSL.q=jenaer\%20allgemeine\%20literaturzeitung)

Rezension zu „Georg Viscount Valentia's und Heinrich Salts Reise nach Indien, Ceylon, dem rothen Meere, Abyssinien und Ägypten“ in Jenaische Allgemeine Literatur-Zeitung 119 (Juni 1812), Sp. 425432. (https://zs.thulb.uni-

jena.de/receive/jportal_jpjournal_00000011?XSL.q=jenaer\%20allgemeine\%20literaturzeitung)

Rezension von: Memoir of the War in India. In: Allgemeine Literatur Zeitung (1818), Band 3, Nr. 235, Sp. 182-184. (https://zs.thulb.uni-

jena.de/receive/jportal_jpjournal_00000005?XSL.q=allgemeine\%20zeitung)

Rezension zu: Neuere Geschichte der Evangelischen Missionsanstalten zu Bekehrung der Heiden in Ostindien 1791. In: Allgemeine Literatur-Zeitung (1792), Band 3, Nr. 224 Sp. 422.

(https://zs.thulb.uni-jena.de/receive/jportal_jpjournal_00000005?XSL.q=allgemeine\%20zeitung)

Rezension zu Rhode, J.G.: Über Alter und Werth einiger morgenländischen Urkunden. In: Allgemeine Literatur-Zeitung (1817), Band 2, Nr. 168, Sp. 505-510. (https://zs.thulb.unijena.de/receive/jportal_jpjournal_00000005?XSL.q=allgemeine\%20zeitung)

Rezension zu: Sakontala, oder: der verhängnißvolle Ring : indisches Drama des Kalidas in sechs Aufzügen / Kalidasa. Metrisch für die Bühne bearbeitet von Wilhelm Gerhard. In: Jenaische Allgemeine Literaturzeitung 18 (1821; Nr. 53 März); Sp. 420-422. (https://zs.thulb.unijena.de/receive/jportal_jpjournal_00000011?XSL.q=jenaer\%20allgemeine\%20literaturzeitung)

Roques, Carl de: Ein Tagebuch aus Südindien: Februar 1782 - Juni 1784. In: Ahuja, Ravi u. ChristofFüchsle, Martin (Hgg.): A Great War in South India. German Accounts of the Anglo-Mysore Wars, 1766-1799. Berlin/Boston 2020, S. 253-317.

Salt, Henry: Georg Viscount Valentia's und Heinrich Salts Reise nach Indien, Ceylon, dem rothen Meere, Abyssinien und Ägypten 1802,1803, 1804, 1805, 1806. Weimar 1811. (https://archive.thulb.unijena.de/collections/rsc/viewer/HisBest_derivate_00002833/BR_1811_44_0001.tif)

Scenen aus Indien. Erste. In: Morgenblatt für gebildete Stände 1 (1807; Mai Nr. 109), S. 435f. (https://reader.digitale-sammlungen.de/de/fs1/object/display/bsb10531654_00467.html)

Schiller, Friedrich: Über naive und sentimentalische Dichtung. Herausgegeben von Klaus L. Berghahn. Stuttgart 2005.

Schlegel, August Wilhelm: De l'origine des Hindous. In: Oeuvres. Écrites en Francais et publiées par Eduard Böcking. Hildesheim u. New York 1972, S. 24-94.

Schlegel, August Wilhelm: Observations sur la critique du Bhagavad-Gita (insérée dans le Journal Asiatique). In: Oeuvres. Écrites en Francais et publiées par Eduard Böcking. Hildesheim / New York 1972, S. 288-310.

Schlegel, August Wilhelm: Ramayana id est carmen epicum de Ramae rebus gestis [...]. In: Oeuvres. Écrites en Francais et publiées par Eduard Böcking. Hildesheim/New York 1972, S. 281-287.

Schlegel, August Wilhelm: Über den gegenwärtigen Zustand der Indischen Philologie. In: Jahrbuch der preußischen Rhein-Universität 1 (1819/21) Heft 2/3, S. 224-250. (http://digitale-sammlungen.ulb.unibonn.de/periodical/pageview/798962)

Schlegel, August Wilhelm: Über die Zunahme und den gegenwärtigen Stand unserer Kenntnisse von Indien. In: Berliner Taschenbuch auf das Gemein Jahr 1831, S. 1-160. 
Schlegel, Friedrich: Philosophie der Geschichte. In achtzehn Vorlesungen gehalten zu Wien im Jahre 1828. Erster Band. Wien 1828. (https://reader.digitale-

sammlungen.de/de/fs1/object/display/bsb10033630_00134.html?zoom=0.6500000000000001)

Schlegel, Friedrich: Über die Sprache und Weisheit der Indier. Ein Beitrag zur Begründung der Alterthumskunde. Nebst metrischen Übersetzungen indischer Gedichte. Heidelberg 1808. (http://www.deutschestextarchiv.de/book/view/schlegel_indier_1808?p=4)

Schlegel, Friedrich.: Vorlesungen und Fragmente zur Literatur. Erster Teil. Orientalia. Mit Einleitung und Kommentar herausgegeben von Ursula Struc-Oppenberg. Paderborn u.a. 2002 (Kritische Friedrich-Schlegel-Ausgabe; 15).

Schubert, F.: Sacontala. Vorgelegt von Manuela Jahrmärker (Notenteil) und Thomas Aigner (Libretto). Kassel u.a. 2008.

Schulze, Johann Ludwig (Hg.): Neuere Geschichte der Evangelischen Missions-Anstalten zu Bekehrung der Heiden in Ostindien. Vierter Band. Halle 1796. (http://digital.bibliothek.unihalle.de/hd/periodical/pageview/602327)

Selbstverbrennung einer indischen Wittwe. In: Morgenblatt für gebildete Stände 18 (1824; Februar Nr. 41), S. 163. (https://reader.digitale-sammlungen.de/de/fs1/object/display/bsb10531688_00181.html)

Seltsames Gefecht zwischen einem Tyger und mehreren englischen Soldaten. In: Verbesserter und Alter Voll-kommener Staats-Kalender, Genannt der Hinkende Bott. Lahr 1801. (https://digital.blbkarlsruhe.de/blbihd/periodical/pageview/4208477)

Skizzen aus Ostindien. In: Morgenblatt für die gebildeten Stände 22 (1828, Nr. 71, März), S. 281. (https://reader.digitale-sammlungen.de/de/fs1/object/display/bsb10531696_00293.html)

Sondershausen, Karl: Der Hindu. In: Dramatische Gedichte. Zweites Bändchen. Altenburg 1823, S. 55140 .

Sprengel, Matthias: Über die Sieks in Hindostan. In: Asiatisches Magazin 1,3 (1802) S, 181-200. (https://zs.thulb.uni-

jena.de/receive/jportal_jpjournal_00000065;jsessionid=19129599747E778B0DE88E4F954071FC?XS L.toc.pos.SESSION=1\&XSL.view.objectmetadata.SESSION=true)

Tarnow, Fanny: Die Prophetin von Caschimir oder Glaubenskraft und Liebesglut. Nach Lady Morgan. Erster Theil. Leipzig 1826.

Tarnow, Fanny: Die Prophetin von Caschimir oder Glaubenskraft und Liebesglut. Nach Lady Morgan. Erster Theil. Leipzig 1826.

Thorn, William: Der Krieg in Indien in den Jahren 1803 bis 1806, geführt von dem General Lord Lake, Oberfeldherrn, und dem General-Major Sir Arthur Wellesley, Herzog von Wellington. Gotha 1819. (https://reader.digitale-sammlungen.de/de/fs1/object/display/bsb10433793_00005.html)

Über den Charakter der Hindus. Aus dem Englischen. In: Journal für Literatur, Kunst, Luxus und Mode 32 (1817, November), S. 715-721. (https://zs.thulb.uni-jena.de/receive/jportal_jpjournal_00000029)

Über den Kindermord bei den Hindus. In: Minerva. Ein Journal historischen und politischen Inhalts 84 (1812), S.460-463. (https://ds.ub.uni-bielefeld.de/viewer/image/1958318_084/458/LOG_0030/)

Über die Bhagavad-Gita. Mit Bezug auf die Beurtheilung der Schlegelschen Ausgabe im Pariser Asiatischen Journal. Aus einem Briefe von Herrn Staatsminister von Humboldt. In: Indische Bibliothek 2 (1827), S. 218-258. (https://reader.digitale-

sammlungen.de/de/fs1/object/display/bsb10250829_00003.html)

Über Götterlehre, Feste und gottesdienstliche Gebräuche der Malabaren oder Tamuler. In: Neues Hannoversches Magazin 68 (1791), Sp. 1073-1120. (https://ds.ub.unibielefeld.de/viewer/image/2233746_001/558/LOG_0130/) 
Über Reformatoren unter den Hindus. In: Morgenblatt für gebildete Stände 15 (1821; Nr. 249

Oktober), S. 994f. (https://reader.digitale-

sammlungen.de/de/fs1/object/display/bsb10531683_00390.html)

Über Verfassung, Religion, Gebräuche und Sitten der Maratten. In: Minvera. Ein Journal historischen und politischen Inhalts 38 (1801), S. 311-341.

Unglückliche Lage des weiblichen Geschlechts in Indien. In: Morgenblatt für gebildete Stände 15 (1821; Oktober, Nr. 244), S. 975. (https://reader.digitalesammlungen.de/de/fs1/object/display/bsb10531683_00371.html)

Verbrennung indischer Frauen. Aus dem englischen Missionsjournal. In: Morgenblatt für die gebildeten Stände 21 (1827; Oktober Nr. 243), S. 970-972. (https://reader.digitalesammlungen.de/de/fs1/object/display/bsb10531695_00366.html)

Völker- und Sittenschilderung. Die Sitten der Hindus. In: Journal für Literatur, Kunst, Luxus und Mode 33 (Februar 1818), S. 73-90. (https://zs.thulb.uni-jena.de/receive/jportal_jpjournal_00000029)

Vulpius, Christian August: Die Portugiesen in Indien. Ein historisch-romantisches Gemälde. Hof 1793. (https://reader.digitale-sammlungen.de/de/fs1/object/display/bsb10122488_00003.html; https://reader.digitale-sammlungen.de/de/fs1/object/display/bsb10122487_00001.html)

Waiblinger, Wilhelm: Phaeton. Teil 1 und 2. Dresden 1920.

Wilhelm von Humboldts Briefe an F.G. Welcker. Herausgegeben von R. Haym. Berlin 1859.

Winter, Peter: Marie von Montalban. Eine Oper in vier Akten. München 1800. (https://reader.digitalesammlungen.de/de/fs1/object/display/bsb10376702_00001.html)

Zedler, Johann Heinrich: Grosses vollständiges Universal-Lexicon (...). Halle u. Leipzig 1735.

Zoologie. In: Indische Bibliothek. Erster Band. Bonn 1823, S. 393-399. (https://reader.digitalesammlungen.de/de/fs1/object/display/bsb10250828_00005.html)

Zumbach, K.A.: Die Pullichi auf Malabar. Schauspiel in fünf Aufzügen. Köln 1799.

(https://digital.staatsbibliothek-

berlin.de/werkansicht?PPN=PPN755274091\&PHYSID=PHYS_0005\&DMDID=)

Zur Geschichte des Elephanten. In: Indische Bibliothek. Eine Zeitschrift von August Wilhelm von Schlegel. Erster Band. Bonn 1823, S. 129-231.(https://reader.digitalesammlungen.de/de/fs1/object/display/bsb10250828_00005.html)

\section{Sekundärliteratur}

Ahmad, Aijaz: Between Orientalism an Historicism. In: Macfie, A.L. (Hg.): Orientalism. A Reader. Edinburgh 2000, S. 285-297.

Amman, Ludwig: Östliche Spiegel. Ansichten vom Orient im Zeitalter seiner Entdeckung durch den deutschen Leser 1800-1850. Hildesheim 1989.

Anemüller, Ernst, "Langstedt, Friedrich Ludwig" in: Allgemeine Deutsche Biographie 17 (1883), S. 692 [Online-Version]; URL: https://www.deutsche-biographie.de/pnd10030074X.html\#adbcontent).

Arens, Katherine: Said's Colonial Fantasies: How Orientalism marginalizes eighteenth-centaury Germans. In: Herder Jahrbuch 7 (2004), S. 11-29. 
Barth, Ulrich: Religion. In: Thoma, Heinz (Hg.): Handbuch Europäische Aufklärung. Begriffe Konzepte - Wirkung. Stuttgart u. Weimar 2015, S. 439 - 449.

Beachamp, Henry K: Vorwort des Herausgebers. In: Dubois, Jean Antoine: Leben und Riten der Inder. Kastenwesen und Hinduglaube in Südindien um 1800. Auf Grundlage der französischen und englischen Ausgaben von 1825 und 1906 übersetzt und herausgegeben von Thomas Kohl. Mit den Anmerkungen, Korrekturen und der Biographie von Henry k: Beauchamp sowie dem Vorwort von Friedrich Max Müller aus der dritten englischen Auflage von 1906. Mit Karten, Abbildungen, einem Register und einem Verzeichnis der wichtigsten Sanskritbegriffe sowie einem Essay „Dubois, Coeurdoux und die Jesuiten in Südindien“. Bielefeld 2002, S. 15-36.

Becker-Cantarino, Barbara: Liebestod: Goethe „Der Gott und die Bajadere“ und Günderrode „Die Malabarischen Witwen“. In: Arnold, Antja u. Pape, Walter (Hgg.): Emotionen in der Romantik. Repräsentation, Ästhetik, Inszenierung. Salzburger Kolloquium der Internationalen ArnimGesellschaft. Berlin u.a. 2012, S. 21-31.

Becker-Cantarino: Mythos und Symbolik bei Karoline von Günderode und Friedrich Creuzer. In: Strack, Friedrich (Hg.): 200 Jahre Heidelberger Romantik. Heidelberg 2008 (Heidelberger Jahrbücher; 51), S. 281-298.

Behler: Das Indienbild der deutschen Romantik. In: Germanisch-Romanische Monatsschrift N.F. 18 (1968), S. 21-37.

Bell, David: Goethe's Orientalism, In: Nicholas Boyle und John Guthrie (Hg.): Goethe and the English-Speaking World. Essays from the Cambridge Symposium for his 250th Anniversary. Rochester 2002, S. 199-212.

Bergunder, Michael: Die Bhagavadgita im 19. Jahrhundert. Hinduismus, Esoterik und Kolonialismus. In: Bergunder, Michael (Hg.): Westliche Formen des Hinduismus in Deutschland. Eine Übersicht. Halle 2006 (Neue Hallesche Berichte. Quellen und Studien zur Geschichte und Gegenwart Südindiens; 6), S. 187-211.

Bhatawadekar, Sai: Claims and disclaimers. Schopenhauer and the cross-cultural comperative enterprise. In: Cho, Joanne Miyang u.a. (Hg.): Transcultural Encounters between Germany and India. Kindred spirits in the nineteenth and twentieth centuries. London u. New York 2014, S. 37-51.

Bhatti, Anil: August Wilhelm Schlegels Indienrezeption und der Kolonialismus. In: Lehmann, Jürgen u.a. (Hg): Konflikt Grenze Dialog. Kulturkontrastive und interdisziplinäre Textzugänge. Festschrift für Horst Turk zum 60. Geburtstag. Frankfurt a.M. 1997, S. 185-205.

Bhatti, Anil: Der deutsche Indiendiskurs. Ambivalenzen im deutschen Orientalismus des neunzehnten Jahrhunderts. In: German Studies in India. Aktuelle Beiträge aus der indischen Germanistik / Germanistik in Indien. München 2006, S. 23-38.

Birus, Hendrik: Der „Orientale“ Jean Paul. Versuch über Goethes Vergleichung. In: Jahrbuch der JeanPaul-Gesellschaft 20 (1985), S. 103-126.

Blumenthal, Lieselotte: Goethes „Paria“. In: Jahrbuch des Wiener Goethe-Vereins 81/83 (1977/79), S. 185-200.

Böhm, Alexandra u. Sproll, Monika: Einleitung. In: Böhm, Alexandra und Sproll, Monika (Hg.): Fremde Figuren. Alterisierungen in Kunst, Wissenschaft und Anthropologie um 1800. Würzburg 2008, S. 7-26.

Borutta, Manuel: Der innere Orient: Antikatholizismus als Orientalismus in Deutschland, 1781-1924. In: Juneja, Monica u. Pernau, Margrit (Hg.): Religion und Grenzen in Indien und Deutschland. Auf dem Weg zu einer transnationalen Historiographie. Göttingen 2008, S. 245-274.

Bosse, Anke: Orientalismus im Frühwerk Ludwig Tiecks. In: Ludwig Tieck. Literaturprogramm und Lebensinszenierung im Kontext seiner Zeit. Herausgegeben von Walter Schmitz. Tübingen 1997, S. 43-62. 
Botkin, Francis: Burning Down the [Big] House: Sati in Sydney Owenson's The Missionary. In: COLLOQUY text theory critique 15 (2008), S. 36-51.

Brown, Clive: Louis Spohr. A critical biography. Cambridge 1984.

Brümmer, Franz, "Sondershausen, Karl" in: Allgemeine Deutsche Biographie 34 (1892), S. 621-622 [Online-Version]; URL: https://www.deutsche-biographie.de/pnd117478830.html\#adbcontent.

Buschmeier, Matthias u. Kauffmann, Kai: Einführung in die Literatur des Sturm und Drang und der Weimarer Klassik. Darnstadt 2010 (Einführungen Germanistik).

Busse, Dietrich: Begriffsgeschichte - Diskursgeschichte - Linguistische Epistemologie. Bemerkungen zu den theoretischen und methodischen Grundlagen einer Historischen Semantik in philosophischem Interesse anlässlich einer Philosophie der „Person“. In: Alexander Haardt und Nikolaj Plotnikov (Hg.): Diskurse der Personalität. Die Begriffsgeschichte der $>$ Person < aus deutsche und russischer Perspektive. München 2008, S. 115-142.

Busse, Dietrich: Begriffsgeschichte oder Diskursgeschichte? Zu theoretischen Grundlagen und Methodenfragen einer historisch-semantischen Epistemologie. In: Dutt, Carsten (Hg.): Herausforderungen der Begriffsgeschichte. Heidelberg 2003, S. 17-38.

Busse, Dietrich: Diskurs - Sprache - Gesellschaftliches Wissen. Perspektiven einer Diskursanalyse nach Foucault im Rahmen einer Linguistischen Epistemologie. In: Busse, Dietriche/Teubert, Wolfgang: Linguistische Diskursanalyse: neue Perspektiven. Wiesbaden 2013, S.147-185.

Busse, Dietrich: Historische Diskurssemantik. Ein linguistischer Beitrag zur Analyse gesellschaftlichen Wissens. In: Sprache und Literatur 86, 2 (2000), S. 29-53.

Busse, Dietrich: Historische Semantik: Analyse eines Programms. Stuttgart 1987.

Busse, Dietrich/Teubert, Wolfgang: Ist Diskurs ein sprachwissenschaftliches Objekt? Zur Methodenfrage der historischen Semantik. In: Busse, Dietrich u.a. (Hg.): Begriffsgeschichte und Diskursgeschichte. Methodenfragen und Forschungsergebnisse der historischen Semantik. Opladen 1994, S. 10-28.

Carson, Penelope: The East India Company and Religion, 1698 - 1858. Woodbridge 2012.

Chakkalakal, Silvy: Deutsch-indische Figurationen. Der bildhafte Stil der Ethnographie um 1800. In: Füssel, Marian u.a. (Hg.): Historische Anthropologie. Kultur, Gesellschaft, Alltag. 22 (2014). Heft 2, S. 250-277.

Christof-Füchsle, Martin: Two Hanoverian Lieutenants in the Tamil Plains: The Letters of Ferdinand Breymann and the Diary of Carl de Roques. In: Ahuja, Ravi u. Christof-Füchsle, Martin (Hgg.): A Great War in South India. German Accounts of the Anglo-Mysore Wars, 1766-1799. Berlin/Boston 2020, S. 201-221.

Cie'slik, Boleslaw: Das Bild Indiens in der deutschen Literatur von der Aufklärung bis zum Zweiten Weltkrieg. In: Colloquia Germanica Stetinensia 4 (1995), S. 153-162.

Cohn, Bernhard S.: Colonialism and its forms of knowledge. The British India. Princeton 1996.

Cowan, Robert: The Indo-German Identification. Reconciling South Asian Origins and European Destinies, 1765-1885. Rochester 2010 (Studies in German Literature Linguistics and Culture; 86).

Crusius, Irene, "Heeren, Arnold" in: Neue Deutsche Biographie 8 (1969), S. 195 f. [Online-Version]; URL: https://www.deutsche-biographie.de/pnd118773607.html\#ndbcontent.

Czapla, Ralf Georg: Annäherungen an das ferne Fremde. August Wilhelm Schlegels Kontroverse mit Friedrich Rückert und Franz Bopp über die Vermittlung von indischer Religion und Mythologie. In: Rückert-Gesellschaft :: Jahrbuch der Rückert-Gesellschaft e.V. 17 (2008), S. 131-141.

Däbritz, Walther: Anregungen aus der indischen Mythologie in Goethes Dichtung. In: Goethe N.F. 20 (1958), S. 99-117. 
Dallet-Mann, Véronique: "Nur das Wilde, Große, Glänzende gefällt mir": l'orient de Karoline von Günderrode. In: L'Orient dans la culture allemande aux XVIIIe et XIXe siècles. Actes du colloque organisé par le Centre d'Études Germaniques et Scandinaves (LIRA) de l'Université Nancy 2 (9 et 10 décembre 2004) / ouvrage publié sous la dir. de Philippe Alexandre. Nancy 2007, S. 61-72.

Dalmia-Lüderitz, Vasudha: Die Aneignung der vedischen Vergangenheit. Aspekte der frühen deutschen Indien-Forschung. In: Zeitschrift für Kulturaustausch 37 (1987), 3. Vj.: Utopie-ProjektionGegenbild, S. 434-443.

Dammann, Oswald, "Creuzer, Friedrich" in: Neue Deutsche Biographie 3 (1957), S. 414 f. [OnlineVersion]; URL: https://www.deutsche-biographie.de/pnd118677330.html\#ndbcontent.

Dammann, Günther: Antirevolutionärer Roman und romantische Erzählung. Vorläufige konservative Motive bei Chr. A. Vulpius und E. T. A. Hoffmann. Kronberg /Ts 1975.

D’Aprile, Iwan-Michelangelo u. Siebers, Winfried: Das 18. Jahrhundert. Zeitalter der Aufklärung. Berlin 2008.

Dean, Dennis R.: Morgan [née Owenson], Sidney, Lady Morgan. In: Oxford Dictionary of National Biography [Online-Version] URL:

https://www.oxforddnb.com/view/10.1093/ref:odnb/9780198614128.001.0001/odnb-9780198614128e-19234?rskey=3t1 VuM\&result=2.

De Zoysa, Asoka: "Blutrünstige Braminen am heiligen Strome". Indienbilder in der deutschen Unterhaltungsliteratur zwischen Aufklärung und Restauration. Frankfurt am Main u.a. 1997.

Dharampal-Frick: Castigating Company Raj. Georg Forster and Matthias Sprengel on British colonialism (1781-1802). In: Beck, Thomas: Barrieren und Zugänge. Die Geschichte der europäischen Expansion. Festschrift für Eberhard Schmitt zum 65. Geburtstag. Wiesbaden 2004, S. 195-207.

Dharampal-Frick, Gita: Indien im Spiegel deutscher Quellen der Frühen Neuzeit (1500-1750). Studien zu einer interkulturellen Konstellation. Tübingen 1994.

Dietz, Max, "Winter, Peter Ritter von" in: Allgemeine Deutsche Biographie 43 (1898), S. 470-474

[Online-Version]; URL: https://www.deutsche-biographie.de/pnd119055716.html\#adbcontent.

Dirks, Nicholas B.: Castes of Mind. Colonialism and the Making of Modern India. Princeton 2001.

Doering, Sabine: Persien im Märkischen Sand. Kleists Bild vom Orient. In: Kleist-Jahrbuch 1996, S. 171-186.

Durzak, Manfred: Indien - Wahrnehmungen in einem Spiegelkabinett. In: Durzak, Manfred (Hg.): Bilder Indiens in der deutschen Literatur. Frankfurt a.M. 2011, S. 7-12.

Dusche, Michael: Friedrich Schlegel's Writings on India. Reimagining Germany as Europe's True Oriental Self. In: Hodkinson, James u.a. (Hg.): Deploying Orientalism in Culture and History. From Germany to Central and Eastern Europe. Rochester N.Y. 2013, S. 31-54.

Ehrmann, Theophil Friedrich. In: Allgemeine Deutsche Biographie 5 (1877), S. 721 [Online-Version]; URL: https://www.deutsche-biographie.de/pnd115368337.html\#adbcontent.

Elschenbroich, Adalbert, "Kanne, Johann Arnold" in: Neue Deutsche Biographie 11 (1977), S. 105-107 [Online-Version]; URL: https://www.deutsche-biographie.de/pnd118776665.html\#ndbcontent).

Espagne, Geneviève: Orient-Bezüge in Jean Pauls „Hesperus“. In: Goer, Charis u. Hofmann, Michael (Hg.): Der Deutschen Morgenland. Bilder des Orients in der deutschen Literatur und Kultur von 1770 bis 1850. München 2008, S. 117-136.

Evans, David O.: A source of Hernani: Le Paria, by Casimir Delavigne. In: Modern Language Notes 47 (1932), 8, S. 514-519. 
Ewert, Michael: Interkulturelle Hermeneutik. Georg Forsters Rezeption altindischer Dichtung. In: Georg-Forster-Studien 9 (2004), S. 17-37.

Feilchenfeldt, Konrad, "Mereau, Sophie" in: Neue Deutsche Biographie 17 (1994), S. 129 f. [OnlineVersion]; URL: https://www.deutsche-biographie.de/pnd11858104X.html\#ndbcontent.

Festa, Aldo: Giudizi e considerazioni sulla Compagnia delle Indie dalle „Lettere“ di Lazzaro Papi. In: Rivista delle Colonie 16 (1942), 6, S. 548-552.

Fischer, Wolfdietrich: Die Wahrnehmung des Orients in der deutschen Literatur der ersten Hälfte des 19. Jahrhunderts. In: Jahrbuch der Rückert-Gesellschaft e.V. 17 (2008), S. 59-72.

Fludernik, Monika: Der „Edle Wilde“ als Kehrseite des Kulturprogressivismus. In: Fludernik, Monika u.a. (Hg.): Der Alteritätsdiskurs des Edlen Wilden. Exotismus, Anthropologie und Zivilisationskritik am Beispiel eines europäischen Topos. Würzburg 2002, S. 157-175.

Flüchter, Antje: Bajadere und Sati. Bilder der Inderin im deutschsprachigen Diskurs der Frühen Neuzeit. In: Ineichen, Martina u.a. (Hg.): Gender in Trans-it. Transkulturelle und transnationale Perspektiven. Beiträge der 12. Schweizerischen Tagung für Geschlechtergeschichte. Zürich 2009, S. 159-170.

Flüchter, Antje: ,Aus den fürnembsten indianischen Reisebeschreibungen zusammengezogen`. Knowledge about India in early modern Germany. In: Huigen, Seigfried u.a. (Hg.): The Dutch Trading Companies as Knowledge Networks. Leiden u. Boston 2010, S. 337-356.

Flüchter, Antje: Die Nairen der Malabarküste zwischen Adelsstand und Kriegerkaste. Praktiken des Vergleichens und die europäische Weltaneignung. In: Klöber, Rafael und Ludwig, Manju (Hg.): HerStory. Historical Scholarship between South Asia and Europe: Festschrift in Honour of Gita Dharampal-Frick, Heidelberg u. Berlin 2018, S. 3-41.

Flüchter, Antje: „Religions, Sects, and Heresy“. Religion on the Indian Subcontinent in Early Modern German Texts. In: Krämer, Martin u.a. (Hg.): Labeling Self and Other in Historical Contacts between Religious groups. Leipzig 2010 (Comparativ; 20,4), S. 58-74.

Flüchter, Antje: Weighing the Mughal. German Perception of Governmental Structures an the Staging of Power in the Early Modern Indian Mughal Empire. In: Flüchter, Antje u. Richter, Susan (Hg.): Structures on the Move. Technologies of Governance in Transcultural Encounter. Heidelberg 2012, S. $147-166$.

Förster, Stig: Die mächtigen Diener der East India Company. Ursachen und Hintergründe der britischen Expansionspolitik in Südasien, 1793 - 1819. Stuttgart 1992.

Foucault, Michel: Archäologie des Wissens. Frankfurt a. M. 1981.

Foucault, Michel: Die Ordnung des Diskurses. Mit einem Essay von Ralf Konersmann. Frankfurt a. M. 10. Auflage 2007.

Frank, Alexa: Sanftes Gefühl und stille Tiefe der Seele. Herders Indien. Würzburg 2009.

Frank, G., "Danz, Johann Traugott Leberecht" in: Allgemeine Deutsche Biographie 4 (1876), S. 752 [Online-Version]; URL: https://www.deutsche-biographie.de/pnd116025913.html\#adbcontent).

Fröschle, Hartmut: Goethes Verhältnis zur Romantik. Würzburg 2002.

Fuchs, Konrad u. Raab, Heribert: Wörterbuch der Geschichte. 13. Auflage. München 2002.

Fuchs-Sumiyoshi, Andrea: Orientalismus in der deutschen Literatur. Untersuchungen zu WErken des 19. und 20. Jahrhunderts, von Goethes West-östlichem Divan bis Thomas Manns Joseph-Tetralogie. Hildesheim u.a. 1984 (Germanistische Texte und Studien; 20).

Füssel, Merian u. Neu, Tim: Diskursforschung in der Geschichtswissenschaft. In: Angermüller, Johannes u.a. (Hg.): Diskursforschung. Ein interdisziplinäres Handbuch. Band 1: Theorien, Methodologien und Kontroversen. Bielefeld 2014, S. 145-161. 
Füssel, Marian: Panduren, Kosaken und Sepoys. Ethnische Gewaltakteure im 18. Jahrhundert zwischen Sicherheit und Stigma. In: Rogger, Philippe u. Hitz, Benjamin (Hg.): Söldnerlandschaften.

Frühneuzeitliche Gewaltmärkte im Vergleich. Berlin 2014 (Zeitschrift für historische Forschung;

Beiheft 49), S. 181-199.

Fulda, Hans Friedrich: G. W. F. Hegel. München 2003.

Ganeshan, Vridhagiri: Das Eigene und das Fremde in der Indienbegegnung deutscher Schriftsteller. In: Hardt, Dietrich (Hg.): Fiktion des Fremden. Erkundung kultureller Grenzen in Literatur und Publizistik. Frankfurt a.M. 1994, S. 161-179.

Gerhard, Anselm: Die Verstädterung der Oper. Paris und das Musiktheater des 19.Jahrhunderts. Stuttgart 1992.

Germana, Nicholas: India and Hegel's „scientific“ method in the Phenomenology of Spirit. In: Cho, Joanne Miyang u.a. (Hg.): Transcultural Encounters between Germany and India. Kindred spirits in the nineteenth and twentieth centuries. London u. New York 2014, S.25-36.

Göbell, Walter, "Kleuker, Johann Friedrich" in: Neue Deutsche Biographie 12 (1980), S. 56 f. [OnlineVersion]; URL: https://www.deutsche-biographie.de/pnd119021498.html\#ndbcontent.

Gipper, Helmut: Verstehen als sprachlicher Annäherungsprozeß. Am Beispiel des Begriffes Yoga in der indischen Bhagavad Gita und der Diskussion zwischen A. W. Schlegel, S. A. Langlois, W. v. Humboldt und G. W. Hegel. In: Sprachwissenschaft 12:1 (1987), S. 24-44.

Glasenapp, Helmut von: Das Indienbild deutscher Denker. Stuttgart 1960.

Gokhale, Anushka: Indien erzählen. Eine Studie zur deutschsprachigen Reiseliteratur. Würzburg 2011.

Ghosh, Pranabendra Nath: Johann Gottfried Herder's Image of India. In: Heinz Mode und H.-J. Peuke (Hg.): Indien in der deutschen literarischen Tradition. Halle 1979, S. 4-17.

Goldmann, Robert P.: Indologies. German and Other. In: McGetchin, Douglars (Hg.): Sanskrit and 'Orientalism'. Indology and Comparative Linguistics in Germany, 1750-1958. Delhi 2004, S. 27-40.

Gregor, Helmut: Das Indienbild des Abendlandes (bis zum Ende des 13. Jahrhunderts). Wien 1964.

Greilich, Susanne: Orientbilder in französisch- und deutschsprachigen Volksalmanachen des achtzehnten und neunzehnten Jahrhunderts. In: Jahrbuch der Rückert-Gesellschaft e.V. 15 (2003), S. 60-78.

Grenzmann, Ludger: Zur frühen deutschsprachigen Rezeption von Georg Forsters SakontalaÜbertragung von 1791. In: Hellfaier, Detlev u.a. (Hgg.): Der wissenschaftliche Bibliothekar. Festschrift für Werner Arnold. Wiesbaden 2009, S. 231-256.

Grotsch, Klaus: Das Sanskrit und die Ursprache. Zur Rolle des Sanskrit in der Konstitutionsphase des historisch-vergleichenden Sprachwissenschaft. In: Theorien vom Ursprung der Sprache. Hrsg. von Joachim Gessinger und Wolfert von Rahden. 2. Bd. Berlin/New York 1988, S. 85-121.

Guthke, Karl S.: Benares am Rhein - Rom am Ganges. Die Begegnung von Orient und Okzident im Denken A. W. Schlegels. In: Jb des FdH (1978), S. 396-419.

Halbfass, Wilhelm: Hegel, Schelling, Schopenhauer und Indien. In: Zeitschrift für Kulturaustausch 37. Jg. 3. Vj. (Utopie - Projektion - Gegenbild. Indien in Deutschland) (1987), S. 424-433.

Halbfass, Wilhelm: Indien und Europa. Perspektiven ihrer geistigen Begegnung. Basel u. Stuttgart 1981.

Heinrich Julius Klaproth. In: Brockhaus Enzyklopädie Online. Versionsdatum: 2021-07-10, https://brockhaus.de/ecs/permalink/4ED75CE3B5A8F2A2CA110D1FB8BAE90B.pdf.

Heizmann, Bertold: Im Schatten Goethes: Kotzebue. Röttenbach 2019. 
Hemron, Anand Sebeyan: Transmission of knowledge by christian missionarie among the indigenous people of central-eastern India in the 19th century. In: Heyden, Ulrich van der u. Feldtkeller, Andreas (Hg.): Missionsgeschichte als Geschichte der Globalisierung von Wissen. Transkulturelle

Wissensaneignung und -vermittlung durch christliche Missionare in Afrika und Asien im 17., 18. und 19. Jahrhundert. Stuttgart 2012, S. 155-171.

Herling, Bradley L.: The German Gītā. Hermeneutics and Discipline in the German Reception of Indian Thought, 1778-1831. New York u. London 2006.

Hilliard, Kevin F.: Orient und Mythos: Karoline von Günderrode. In: Frauen: MitSprechen, MitSchreiben. Beiträge zur literatur- und sprachwissenschaftlichen Frauenforschung. Herausgegeben von Marianne Henn. Stuttgart 1997, S. 244-255.

Hoffmeister, Gerhart: Deutsche und europäische Romantik. Zweite Auflage. Stuttgart 1990 (Sammlung Metzler; 170).

Hofmann, Michael u. Patrut, Iulia-Karin: Einführung in die interkulturelle Literatur. Darmstadt 2015.

Hoffmann, Paul: Der indische und der deutsche Geist von Herder bis zur Romantik. Eine literarhistorische Darstellung. Tübingen 1915.

Hoorn, Tanja van: Dem Leibe abgelesen. Georg Forster im Kontext der physischen Anthropologie des 18. Jahrhunderts.Tübingen 2004.

Ilany, Ofri: „Alle unsere Wanderungen im Orient“. Die deutsche Sehnsucht nach dem Orient Theologie, Wissenschaft, Rasse. In: Salaymeh, Lena u.a. (Hg.): Der Orient. Imagination in deutscher Sprache. Göttingen 2017 (Tel Aviver Jahrbuch für deutsche Geschichte; 45), S. 41-68.

Inden, Ronald B.: Imagining India. 2. Aufl. London 2000.

Jalal al-'Azm, Sadik: Orientalism and Orientalism in Reverse. In: Macfie, A.L. (Hg.): Orientalism. A Reader. Edinburgh 2000, S. 217-238.

Jamme, Christoph: „Göttersymbole“. Friedrich Creuzer als Mythologe und seine philosophische Wirkung. In: Heidelberger Jahrbücher 51 (2007), S. 487-498.

Jenisch, Erich: Goethe und das ferne Asien. In: Deutsche Vierteljahresschrift für Literaturwissenschaft und Geistesgeschichte 1 (1923), S. 309-338.

Jolles, Frank: India in England and Germany during the 18th century, - a synthesis? In: German studies in India 9 (1985), S. 191-204.

Jürgens, Hanco: German Indology avant la lettre: The Experiences of the Halle Missionaries in Southern India, 1750-1810. In: Douglas T. McGetchin u.a. (Hg.): Sanskrit and 'Orientalism'. Indology and Comparative Liguistics in Germany, 1750-1958. New Delhi 2004, S. 41-82.

Kade-Luthra, Veena: Einleitung. In: Kade-Luthra, Veena (Hg.): Sehnsucht nach Indien. Ein Lesebuch von Goethe bis Grass. München 1991, S. 10-21.

Kanne, Friedrich August. In: Österreichisches biographisches Lexikon, S. 217 [Online-Version]. URL: https://www.biographien.ac.at/oebl_3/217.pdf.

Karyekar, Madhuvanti: Fostering aesthetic tolerance through literary translation. Georg Forster's Śakuntalā. In: Cho, Joanne Miyang u.a. (Hg.): Transcultural Encounters between Germany and India. Kindred spirits in the nineteenth and twentieth centuries. London u. New York 2014, S. 13-24.

Kaufmann, Stefan u. Haslinger, Peter: Einleitung: Der Edle Wilde - Wendungen eines Topos. In: Fludernik, Monika u.a. (Hg.): Der Alteritätsdiskurs des Edlen Wilden. Exotismus, Anthropologie und Zivilisationskritik am Beispiel eines europäischen Topos. Würzburg 2002, S. 13-30.

Keller, Reiner: Diskursforschung. Eine Einführung für SozialwissenschaftlerInnen. 2. Auflage. Wiesbaden 2004. 
King, Richard: Orientalism and Religion. Postcolonial theory, India and "the mystic East“". London u. New York 1999.

Klawitter, Arne/Ostheimer, Michael: Literaturtheorie - Ansätze und Anwendungen. Göttingen 2008.

Kleinschmidt, Adolf, "Blumenbach, Johann Friedrich" in: Neue Deutsche Biographie 2 (1955), S. 329330 [Online-Version]; URL: https://www.deutsche-biographie.de/pnd116208503.html\#ndbcontent.

Klingenberg, Karl-Heinz: Iffland und Kotzebue als Dramatiker. Weimar 1962 (Beiträge zur deutschen Klassik).

Koch, Gerhard: Deutschlands literarisches Indienbild. Zur Indienrezeption der deutschen Literatur von den Anfängen bis zum Beginn des 20. Jahrhunderts. In: German studies in India 11 (1987), S. 175-183 und 12 (1988), S. 2-14.

Kocziszky, Éva: Das Konzept und die Rolle des Orients in Creuzers Werk im Vergleich zu Görres. In: 200 Jahre Heidelberger Romantik. Herausgegeben von Friedrich Strack. Berlin u.a. 2008, S. 299-320.

Kohl, Thomas: Dubois, Coeurdoux und die Jesuiten in Südindien. In: Dubois, Jean Antoine: Leben und Riten der Inder. Kastenwesen und Hinduglaube in Südindien um 1800. Auf Grundlage der französischen und englischen Ausgaben von 1825 und 1906 übersetzt und herausgegeben von Thomas Kohl. Mit den Anmerkungen, Korrekturen und der Biographie von Henry k: Beauchamp sowie dem Vorwort von Friedrich Max Müller aus der dritten englischen Auflage von 1906. Mit Karten, Abbildungen, einem Register und einem Verzeichnis der wichtigsten Sanskritbegriffe sowie einem Essay „Dubois, Coeurdoux und die Jesuiten in Südindien“. Bielefeld 2002, S. 577-588.

Komma, Karl Michael, "Dalberg, Friedrich Hugo Freiherr von" in: Neue Deutsche Biographie 3 (1957), S. 488 f. [Online-Version]; URL: https://www.deutschebiographie.de/pnd116028203.html\#ndbcontent).

Kosch, Wilhelm: Deutsches Literaturlexikon. Biographisches und bibliographisches Handbuch. Zweiter Band. Kosegarten - Zyrl. Halle 1930.

Koselleck, Reinhart: Begriffsgeschichten. Studien zur Semantik und Pragmatik der politischen und sozialen Sprache. Frankfurt a.M. 2010.

Koselleck, Reinhart: Die Geschichte der Begriffe und Begriffe der Geschichte. In: Dutt, Carsten (Hg.): Herausforderungen der Begriffsgeschichte. Heidelberg 2003, S. 3-16.

Kragl, Florian: Die Weisheit des Fremden. Studien zur mittelalterlichen Alexandertradition. Mit einem allgemeinen Teil zur Fremdheitswahrnehmung. Bern u.a. 2005.

Kramer: Verkehrte Welten. Zur imaginären Ethnographie des 19. Jahrhunderts. Frankfurt a.M. 1977.

Kratzsch, Siegfried: Goethe und Indien. In: Indien in der deutschen literarischen Tradition.

Herausgegeben von Heinz Model und Hans- Joachim Peuke. Halle 1979, S. 18-31.

Krusche, Dietrich: Literatur und Fremde. Zur Hermeneutik kulturräumlicher Distanz. München 1985.

Kuczynski, Ingrid: Verunsicherung und Selbstbehauptung - der Umgang mit dem Fremden in der englischen Reiseliteratur des 18. Jahrhunderts. In: Fuchs, Anne u. Harden, Theo (Hg.): Reisen im Diskurs. Modelle der literarischen Fremderfahrung von den Pilgerberichten bis zur Postmoderne. Tagungsakten des internationalen Symposiums zur Reiseliteratur University College Dublin vom 10.12. März 1994. Heidelberg1995, S.55-70.

Kürschner, Joseph, "Herklots, Karl Alexander" in: Allgemeine Deutsche Biographie 12 (1880), S. 115 [Online-Version]; URL: https://www.deutsche-biographie.de/pnd117519901.html\#adbcontent.

Kurz, Isolde: Vom Umgang mit dem anderen. Die Orientalismus-Debatte zwischen Alteritätsdiskurs und interkultureller Kommunikation. Würzburg 2000.

Landwehr: Historische Diskursanalyse. Frankfurt. a.M. 2008. 
Lauer, Gerhard: Goethes indische Kuriositäten. In: Kunz, Edith Anna u.a. (Hgg.): Figurationen des Grotesken in Goethes Werken. Bielefeld 2012, S. 159-179.

Lauer, Gerhard: Über Menschen, Schweine und andere Rassen. Die Varietäten der Menschen und ihre zoologische Kritik in der gelehrten Literatur des 18. Jahrhunderts. In: Gantet, C. u. Schock, F. (Hg.): Zeitschriften, Journalismus und gelehrte Kommunikation im 18. Jahrhundert. Festschrift für Thomas Habel. Bremen 2004, S. 221-232.

Laufhütte, Hartmut: Formulierungshilfe für Haustyrannen? Goethe: Der Gott und die Bajadere. In: Wulf Segebrecht (Hg.): Klassik und Romantik. Stuttgart 1984 (Gedichte und Interpretationen; 3), S. 117-143.

Lederle, Julia: Mission und Ökonomie der Jesuiten in Indien. Intermediäres Handesln am Beispiel der Malabar-Provinz im18. Jahrhundert. Wiesbaden 2009 (Studien zu Außereuropäischen Christentumsgeschichte (Asien, Afrika, Lateinamerika; 14).

Leifer, Walter: Indien und die Deutschen. 500 Jahre Begegnung und Partnerschaft. Tübingen und Basel 1969.

Lentz, Sarah: „Wer helfen kann, der helfe!“ Deutsche SklavereigegnerInnen und die atlantische Abolitionsbewegung, 1780-1860. Göttingen 2020 (Veröffentlichungen des Instituts für Europäische Geschichte Mainz; 261).

Lewis, Bernhard: The Question of Orientalism. In: Macfie, A.L (Hg.): Orientalism. A Reader. Edinburgh 2000, S. 249-270.

Lima Martins, Luciana de: George Forster. In: Oxford Dictionary of National Biography. [OnlineVersion]; URL: https://www.oxforddnb.com/view/10.1093/ref:odnb/9780198614128.001.0001/odnb9780198614128-e-9907?rskey=sMOoQ7\&result $=1$.

Linke, Angelika: Begriffsgeschichte - Diskursgeschichte - Sprachgebrauchsgeschichte. In: Dutt, Carsten (Hg.): Herausforderungen der Begriffsgeschichte. Heidelberg 2003, S. 39-49.

Linkenbach, Anje: Weltreligion Hinduismus: Zur Konstruktion des Indienbildes in deutschen Schulbüchern. In: Bultmann, Christoph u. Linkenbach, Antje (Hgg.): Religionen übersetzen. Klischees und Vorurteile im Religionsdiksurs. Münster 2015 (Vorlesungen des Interdisziplinären Forums Religion der Universität Erfurt; 11), S. 23-43.

Lotter, Friedrich: Christoph Meiners und die Lehre von der unterschiedlichen Wertigkeit der Menschenrassen. In: Geschichtswissenschaft in Göttingen. Eine Vorlesungsreihe. Herausgegeben von Hartmut Boockmann und Hermann Wellenreuther. Göttingen1987, S. 30-75.

Lüsebrink, Hans-Jürgen: Kolonialismus. In: Thoma, Heinz (Hg.): Handbuch Europäische Aufklärung. Begriffe - Konzepte - Wirkung. Stuttgart u. Weimar 2015, S. 289-299.

Lüsebrink, Hans-Jürgen: Von der Faszination zur Wissenssystematisierung: die koloniale Welt im Diskurs der europäischen Aufklärung. In: Lüsebrink, Hans-Jürgen (Hg.): Das Europa der Aufklärung und die außereuropäische koloniale Welt, S. 9-18.

Lütt, Jürgen: Deutschland, Indien und das deutsche Indienbild. Das romantische und das utilitaristische Indienbild Europas. In: Wehling, Hans-Georg (Hg.): Indien. Stuttgart u.a. 1998 (Der Bürger im Staat 48 (1998) Heft 1), S. 60-64.

Lütt: Einleitung. In: Zeitschrift für Kulturaustausch 37.Jg/3. Vj. (Utopie - Projektion - Gegenbild. Indien in Deutschland) (1987), S. 391-393.

Maillard, Christine: Beobachter, Weggenosse, Pionier: Herder und die Anfänge der europäischen Indologie. In: Cultura tedesca: revista semestrale 24 (2003), S. 49-62.

Maiilard, Christine: Entzauberungsphantasien. Indienrezeptionen und Seelenkunde in Johann Gottfried Herders Lyrik der 1790er Jahre. In: Eckel, Winfried u.a. (Hg.): Projektionen - Imaginationen Erfahrungen. Indienbilder der europäischen Literatur. Remscheid 2008, S. 109-127. 
Maillard, Christine: „Indomanie“ um 1800: ästhetische, religiöse und ideologische Aspekte. In: Goer, Charis u. Hofmann, Michael (Hgg.): Der Deutschen Morgenland. Bilder des Orients in der deutschen Literatur und Kultur von 1770 bis 1850. München 2008, S. 67-83.

Maillard, Christine: La "Bhagavad gîtâ": fortune(s) d'un texte en Allemagne de 1785 à 1825 ; les points de vue de Herder, A. W. Schlegel, W. v. Humboldt et Hegel. In: L'Orient dans la culture allemande aux XVIIIle et XIXe siècles. Actes du colloque organisé par le Centre d'Études Germaniques et Scandinaves (LIRA) de l'Université Nancy 2 (9 et 10 décembre 2004) / ouvrage publié sous la dir. de Philippe Alexandre. Nancy 2007, S. 131-143.

Maiworm, Heinrich, "Beer, Michael" in: Neue Deutsche Biographie 1 (1953), S. 737 [Online-Version]; URL: https://www.deutsche-biographie.de/pnd118657887.html\#ndbcontent.

Mangold, Sabine: Anmerkungen zur deutschen Orientalistik. In: Hofmann, Michael u. Goer, Charis (Hg.): Der Deutschen Morgenland. Bilder des Orients in der deutschen Literatur und Kultur von 1770 bis 1850. Paderborn 2007, S. 223-241.

Mangold, Sabine: Eine "weltbürgerliche Wissenschaft". Die deutsche Orientalistik im 19. Jahrhundert. Stuttgart 2004.

Manley, Deborah u. Rée, Peta: Henry Salt. In: Oxford Dictionary of National Biography. [OnlineVersion]; URL: https://www.oxforddnb.com/view/10.1093/ref:odnb/9780198614128.001.0001/odnb9780198614128-e-24563?rskey=TiiJeA\&result=8.

Maráthe, Mandakini: Spiegelungen Indiens in der deutschen Literatur des XIX. Jahrhunderts. Wien 1965.

Marchignoli, Saverio: Canonizing an Indian Text? A.W. Schlegel, W. von Humboldt, Hegel, and the Bhagavadgítá. In: McGetchin, Douglas (Hg.): Sanskrit and 'Orientalism'. Indology and Comparative Linguistics in Germany, 1750-1958. Delhi 2004, S. 245-270.

Marschall, Wolfgang: Verfremdung und autonome Konstitution. Zur Kategorie der Fremden im Denken des aufgeklärten Jahrhunderts. In: Schuster, Meinhard (Hg.): Die Begegnung mit dem Fremden. Wertungen und Wirkungen in Hochkulturen vom Altertum bis zur Gegenwart. Stuttgart u. Leipzig 1996 (Colloquium Rauricum; 4), S. 245-261.

Mayer, Mathias: Paria. In: Otto, Regine und Bernd Witte (Hgg.): Goethe-Handbuch. Band 1: Gedichte. Stuttgart u. Weimar 1996, S. 478-481.

Mecklenburg, Norbert: Das Mädchen aus der Fremde. Germanistik als interkulturelle Literaturwissenschaft. München 2008.

Meier, Albert, "Plümike, Carl Martin" in: Neue Deutsche Biographie 20 (2001), S. 551 f. [OnlineVersion]; URL: https://www.deutsche-biographie.de/pnd116246871.html\#ndbcontent.

Meier, Andreas (H.): Christian August Vulpius. Eine Korrespondenz zur Kulturgeschichte der Goethezeit. Band 1: Brieftexte. Berlin / New York 2003 (Quellen und Forschungen zur Literatur- und Kulturgeschichte).

Mendheim, Max, "Tarnow, Fanny" in: Allgemeine Deutsche Biographie 37 (1894), S. 399-402 [Online-Version]; URL: https://www.deutsche-biographie.de/pnd118837052.html\#adbcontent.

Mendheim, Max, "Vulpius, August" in: Allgemeine Deutsche Biographie 40 (1896), S. 379-381

[Online-Version]; URL: https://www.deutsche-biographie.de/pnd118770489.html\#adbcontent.

Menze: Das indische Altertum in der Sicht Wilhelm von Humboldts und Hegels. In: Welt und Wirkung von Hegels Ästhetik. Herausgegeben von Annette Gethmann-Siefert und Otto Pöggeler. Bonn 1986, S. 245-294.

Meyer, Annette: Die Epoche der Aufklärung. Berlin 2010, 
Michaels, Axel: Wissenschaft als Einheit von Religion, Philosophie und Poesie. Die Indologie als frühromantisches Projekt einer ganzheitlichen Wissenschaft. In: Romantische Wissenspoetik. Die Künste und die Wissenschaften um 1800. Herausgegeben von Gabriele Brandstetter und Gerhard Neumann. Würzburg 2004, S. 325-340.

Michel, Wilhelm, "Büsching, Anton Friedrich" in: Neue Deutsche Biographie 3 (1957), S. 3 f. [OnlineVersion]; URL: https://www.deutsche-biographie.de/pnd119003554.html\#ndbcontent.

Michelsen, Peter: Der Sog der Mythe: zu Johannes Joseph von Görres 'Mythengeschichte der asiatischen Welt'. In: Heidelberg im säkularen Umbruch. Traditionsbewußtsein und Kulturpolitik um 1800. Hrsg. von Friedrich Strack. Stuttgart 1987, S. 444-65.

Mitter, Partha: Much maligned monsters. A history of European reactions to Indian art. Chicago und London 1992.

Mommsen, Katharina: „Indisches“ im West-östlichen Divan. In: Goethe. Jahrbuch der GoetheGesellschaft. N.F. 22 (1960), S. 294-297.

Müller, Friedrich Max: Vorwort. In: Dubois, Jean Antoine: Leben und Riten der Inder. Kastenwesen und Hinduglaube in Südindien um 1800. Auf Grundlage der französischen und englischen Ausgaben von 1825 und 1906 übersetzt und herausgegeben von Thomas Kohl. Mit den Anmerkungen, Korrekturen und der Biographie von Henry k: Beauchamp sowie dem Vorwort von Friedrich Max Müller aus der dritten englischen Auflage von 1906. Mit Karten, Abbildungen, einem Register und einem Verzeichnis der wichtigsten Sanskritbegriffe sowie einem Essay „Dubois, Coeurdoux und die Jesuiten in Südindien“. Bielefeld 2002, S. 13f.

Mueller-Vollmer, Kurt: Mutter Sanskrit und die Nacktheit der Südseesprachen: Das Begräbnis von Humboldts Sprachwissenschaft. In: Athenäum 1 (1991), S. 109-133.

Murti, Kamakshi: India. The Seductive and Seduced „Other“ of German Orientalism. Westport, London 2001 (Contributions in Comperative Colonial Studies; 39).

Naundorf, Gert, "Klaproth, Heinrich Julius" in: Neue Deutsche Biographie 11 (1977), S. 706 f. [Online-Version]; URL: https://www.deutsche-biographie.de/pnd10082451X.html\#ndbcontent.

Oliver, S. P.: Pierre Sonnerat. In: The Gardeners' Chronicle. A Weekly Illustrated Journal of Horticulture and Allied Subjects. July-December 1892. London 1892.

Opitz, Alfred: Die Portugiesen in Indien (1793) von Christian August Vulpius oder Schwierigkeiten der deutschen Aufklärung mit den portugiesischen Entdeckungsreisen. In: Siepmann, Helmut (Hg.): Portugal, Indien und Deutschland. Akten der V. Deutsch-Portugiesischen Arbeitsgespräche (Köln 1998). Köln u. Lissabon 2000, S. 32-44.

Osterhammel, Jürgen: Die Entzauberung Asiens. Europa und die asiatischen Reiche im 18. Jahrhundert. München 1998.

Osterhammel, Jürgen: Distanzerfahrung. Darstellungsweisen des Fremden im 18. Jahrhundert. In: Hans-Joachim König u.a. (Hg.): Der europäische Beobachter außereuropäischer Kulturen. Zur Problematik der Wirklichkeitswahrnehmung. Berlin 1989, S. 9-42.

Panattoni, Emanuela: Il Malabar nelle „Lettere sulle Indie Orientali“ di Lazzaro Papi. In: Indologica Taurinensia 2 (1974), S. 199-233.

Park, Peter K. J.: A Catholic Apologist in an Pantheistic World: New Approaches to Friedrich Schlegel. In: McGetchin, Douglas u.a. (Hg): Sanskrit and ,Orientalism‘. Indology and Comparative Linguistics in Germany, 1750-1958. New Delhi 2004, S. 84-86.

Pausch, Oskar, "Hensler, Karl Friedrich" in: Neue Deutsche Biographie 8 (1969), S. 564-565 [OnlineVersion]; URL: https://www.deutsche-biographie.de/pnd119267659.html\#ndbcontent.

Pikulik, Lothar: Frühromantik. Epoche - Werke - Wirkung. Zweite Auflage. München 2000. 
Pille, René-Marc: À la fracture du classicisme et du romantisme. L'Inde, sujet de discorde entre Goethe et Friedrich Schlegel. In: La fascination de l'Inde en Allemagne 1800-1933. Herausgegeben von Marc Cluet. Rennes 2004, S. 25-45.

Polaschegg, Andrea: Athen am Nil oder Jerusalem am Ganges? Der Streit um den kulturellen Ursprung um 1800. In: Böhm, Alexandra / Sproll, Monika (Hg.): Fremde Figuren. Alterisierungen in Kunst, Wissenschaft und Anthropologie um 1800. Würzburg 2008, S. 41-65.

Polaschegg, Andrea: Der andere Orientalismus. Regeln deutsch-morgenländischer Imagination im 19. Jahrhundert. Berlin 2005.

Polaschegg, Andrea: Im Schatten der Pyramide. Achim von Arnims Ordnung des Orients. In: Regionalität und Fremde. Literarische Konstellationen, Visionen und Konzepte im deutschsprachigen Mitteleuropa. Herausgegeben von András F. Balogh, in Verbindung mit Magdolna Orosz. Berlin 2007, S. 89-102.

Pollock, Sheldon: Indology, Power, and the Case of Germany. In: Macfie, A. L. (Hg.): Orientalism. A Reader. Edinburgh 2000, S. 302-323.

Poltermann, Andreas: Den Orient übersetzen. Europäisches Zivilisationsmodell und die Aneignung orientalischer Weisheit. Zur Debatte zwischen den Gebrüdern Schlegel, Humboldt und Goethe. In: Kulturelle Identität. Deutsch-indische Kulturkontakte in Literatur, Religion und Politik. Herausgegeben von Anil Bhatti und Horst Turk. Berlin 1997, S. 67-103.

Prantl, Carl von, "Meiners, Christoph" in: Allgemeine Deutsche Biographie 21 (1885), S. 224-226 [Online-Version]; URL: https://www.deutsche-biographie.de/pnd116863498.html\#adbcontent.

Rajan, Balachandra: Under Western Eyes. India from Milton to Macaulay. Durham u. London 1999.

Reinhard, Wolfgang: Bornierter Blick? Gegenseitige Wahrnehmung von Europäern und Asiaten im 17. und 18. Jahrhundert. In: Liebau, Heike u.a. (Hg.): Mission und Forschung. Translokale Wissensproduktion zwischen Indien und Europa im 18. und 19. Jahrhundert. Halle 2010, S. 3-20.

Reinhard, Wolfgang: Die Unterwerfung der Welt. Globalgeschichte der europäischen Expansion 14152015. München 2016.

Reinhardt, Hartmut: Dem Fremden freundlich zugetan. Interkulturelle Bezüge in Goethes literarischem Werk. Nordhausen 2012.

Remy, Artur F. J.: The Influence of India and Persia on the Poetry of Germany. New York 1901.

Roedl, Urban, "Claudius, Matthias" in: Neue Deutsche Biographie 3 (1957), S. 266-267 [OnlineVersion]; URL: https://www.deutsche-biographie.de/pnd118521098.html\#ndbcontent.

Roegele, Otto, "Görres, Joseph von" in: Neue Deutsche Biographie 6 (1964), S. 532-536 [OnlineVersion]; URL: https://www.deutsche-biographie.de/pnd11854019X.html\#ndbcontent.

Rösch, Gertrud Maria, "Müller, Nikolaus" in: Neue Deutsche Biographie 18 (1997), S. 460 f. [OnlineVersion]; URL: https:/www.deutsche-biographie.de/pnd117608122.html\#ndbcontent;

Rommel, Gabriele (Hg.): Novalis und der Orient. Katalog der Ausstellung im Novalis-Schloß Oberwiederstedt; [vom 30. August 2007 bis zum 31. August 2008]. Wiederstedt 2007.

Rothermund, Dietmar: Carl August Schlegel's Military Geography of the Carnatic. In: Ahuja, Ravi u. Christof-Füchsle, Martin (Hgg.): A Great War in South India. German Accounts of the Anglo-Myysore Wars, 1766-1799. Berlin/Boston 2020, S. 79-91.

Rothermund, Dietmar: Geschichte Indiens. Vom Mittelalter bis zur Gegenwart. München 2002 (Wissen in der Beck'schen Reihe; 2194).

Rothermund, Dietmar: The German Intellectual Quest for India. Delhi 1986.

Safranksi, Rüdiger: Romantik. Eine deutsche Affäre. München 2007. 
Said, Edward W.: Orientalism. London 2003.

Salus, Peter H: Preface. In: Sir William Jones. A reader. Edited with Introduction and Notes by Satya

S. Pachori. Foreword by Rosanne Rocher and a Preface by Peter H. Salus. Delhi 1993, S. 3-10.

Scheiffele, Eberhard: Affinität und Abhebung. Zum Problem der Voraussetzungen interkulturellen Verstehens. In: Wierlacher, Alois (Hg.): Das Fremde und das Eigene. Prolegomena zu einer interkulturellen Germanistik. München 1985, S. 29-46.

Schillers Werke. Nationalausgabe. 36. Band, Teil II. Briefwechsel. Briefe an Schiller. 1.11.179531.3.1797. Anmerkungen. Herausgegeben von Norbert Oellers. Weimar 1976.

Schmitt, Anke: Der Exotismus in der deutschen Oper zwischen Mozart und Spohr. Hamburg 1988 (Hamburger Beiträge zur Musikwissenschaft; 36).

Schmitz-Emans: Monika: Einführung in die Literatur der Romantik. Darmstadt 2004.

Schmitz-Emans, Monika: Orientalisches bei Jean-Paul. In: Orientdiskurse in der deutschen Literatur. Herausgegeben von Klaus-Michael Bogdal. Bielefeld 2007, S. 81-123.

Schnädelbach, Herbert: „Zweite Abteilung: Der objektive Geist. In: Drüe, Hermann u.a.: Hegels „Enzyklopädie der philosophischen Wissenschaften“ (1830). Ein Kommentar zum Systemgrundriß. Frankfurt a. M. 2000 (Hegels Philosophie. Kommentare zu den Hauptwerken herausgegeben von Herbert Schnädelbach; 3), S. 289-316.

Schnorr von Carolsfeld, Franz, "Gehe, Eduard Heinrich" in: Allgemeine Deutsche Biographie 8 (1878), S. 497 [Online-Version]; URL: https://www.deutsche-biographie.de/pnd102522359.html\#adbcontent.

Schröder, Ulrike: Religion, Kaste und Ritual. Christliche Mission und tamilischer Hinduismus in Südindien im 19. Jahrhunder. Halle 2009 (Neue Hallesche Berichte. Quellen und Studien zur Geschichte und Gegenwart Südindiens. Im Auftrag der Franckeschen Stiftungen zu Halle.

Herausgegeben von Michael Bergunder und Helmut Obst; 8).

Schultz, Heiner: Begriffsgeschichte und Argumentationsgeschichte. In: Koselleck, Reinhart (Hg.): Historische Semantik und Begriffsgeschichte. Stuttgart 1979, S. 43-74.

Schulz, Eckhard, "Heyden, Friedrich von" in: Neue Deutsche Biographie 9 (1972), S. 67 f. [OnlineVersion]; URL: https://www.deutsche-biographie.de/pnd11678699X.html\#ndbcontent).

Schwab, Raymond: The Oriental Renaissance. Europe's Rediscovery of India and the East, 1680-1880. New York 1984.

Sedlar, Jean W.: India in the Mind of Germany. Schelling, Schopenhauer and their Times. Washington D.C. 1982.

Selbmann, Rolf, "Lewald, August" in: Neue Deutsche Biographie 14 (1985), S. 408 f. [OnlineVersion]; URL: https://www.deutsche-biographie.de/pnd119164035.html\#ndbcontent.

Sengupta, Indra: Shishyas of Another Order. Students of Indology at the Universities of Bonn and Berlin. In: Douglas T. McGetchin (Hg.): Sanskrit and 'Orientalism'. Indology and Comparative Linguistics in Germany, 1750-1958. Delhi 2004, S: 137-171.

Somerfeld, Susanne: Indienschau und Indiendeutung romantischer Philosophen. Diss. Zürich 1943.

Steiner, Gerhard: Kalidasas Sakontala oder die deutsche Entdeckung Indiens. In: Rasmussen, Detlef (Hg.): Der Weltumsegler und seine Freunde - Georg Forster als gesellschaftlicher Schriftsteller der Goethezeit. Tübingen 1988, S. 59-69.

Stemmrich-Köhler, Barbara: Zur Funktion der orientalischen Poesie bei Goethe, Herder, Hegel. Exotische Klassik und ästhetische Systematik in den "Noten und Abhandlungen zu besserem Verständnis des West-östlichen Divans" Goethes, in Frühschriften Herders und in Hegels Vorlesungen zur Ästhetik. Frankfurt a.M. u.a. 1992. 
Stollberg-Rilinger: Einleitung. In: Stollberg-Rilinger (Hg.): Ideengeschichte. Stuttgart 2010, S. 7-42.

Stuebe, Isabel Combs: The Life and Works of William Hodges. New York u. London 1979.

Talgeri, Pramod: Friedrich Schlegels Indien-Bild - Forderung nach einer Epiphanie des Anderen. In: Zeitschrift für Kulturaustausch 37 (1987), 3 Vj. (Utopie - Projektion - Gegenbild. Indien in Deutschland), S. 418-423.

Tautz, Birgit: Wackenroder's 'Ein wunderbares morgenländisches Mährchen von einem nackten Heiligen'. Autopoiesis of world, rhetoric of "the Orient". In: Monatshefte für deutschsprachige Literatur und Kultur 95 (2003), N.1, S. 59-75.

Tekinay, Alev: Zum Orient-Bild Bettine von Arnims und der jüngeren Romantik. In: Arcadia 16 (1982), H. 1, S. 47-49.

Trepp, Anne-Charlott: „Daher entsteht so viel naturhistorisches Unheil“. Wissens- und Kulturtransfer zwischen Indien und Europa: Die Halleschen Missionsberichte. In: Beck, Andreas u. Kaminski, Nicola (Hg.): Literatur der Frühen Neuzeit und ihre kulturellen Kontexte. Bochumer Ringvorlesung im Sommersemester 2011. Frankfurt a. M. 2012, S. 229-255.

Tzoref-Ashkenazi, Chen: Der romantische Mythos vom Ursprung der Deutschen. Friedrich Schlegels Suche nach der indogermanischen Verbindung. Göttingen 2009 (Schriftenreihe des Minerva Instituts für deutsche Geschichte der Universität Tel Aviv; 29).

Tzoref-Ashkenazi, Chen: German Soldiers in Colonial India. London 2014.

Tzoref-Ashkenazi, Chen: The Nationalist Aspects of Friedrich Schlegel's On the Language and the Wisdom of the Indians. In: Douglas T. McGetchin u.a. (Hg.): Sanskrit and 'Orientalism'. Indology and Comparative Linguistics in Germany, 1750-1958. New Delhi 2004, S. 107-130.

Tzoref-Ashkenazi, Chen: The Outsinder's Perspective on Colonial Conflict: A Hanoverian Officer's Narrative of the Second Anglo-Mysore War, 1783-1784. In: Ahuja, Ravi u. Christof-Füchsle, Martin (Hgg.): A Great War in South India. German Accounts of the Anglo-Mysore Wars, 1766-1799. Berlin/Boston 2020, S. 319-343.

Vetch, R.H.: Thorn, William [formerly Wilhelm]. In: Oxford Dictionary of National Biography [Online-Version]. URL:

https://www.oxforddnb.com/search?q=thorn\%2C+william\&searchBtn=Search\&isQuickSearch=true ).

Vogel, Claus: Die Anfänge des westlichen Studiums der altindischen

Lexikographie.Opladen/Wiesbaden 1999.

Waldenfels, Bernhard: Grundmotive einer Phänomenologie des Fremden. Frankfurt a.M. 2006.

Wanning, Berbeli: Friedrich Schlegel zur Einführung. Hamburg 1999.

Wengeler, Martin: „Gastarbeiter sind auch Menschen“. Argumentationsanalyse als diskursgeschichtliche Methode. In: Sprache und Literatur 86,2 (2000), S. 54-69.

Wengeler, Martin: Historische Diskurssemantik als Analyse von Argumentationstopoi. In: Busse, Dietrich/Teubert, Wolfgang: Linguistische Diskursanalyse: neue Perspektiven. Wiesbaden 2013, S. 189-215.

Wiehl, Reiner: Begriffsgeschichte zwischen theoretischem Mangel und theoretischem Überschuss. Philosophische Fußnoten zur historischen Semantik. In: Dutt, Carsten (Hg.): Herausforderungen der Begriffsgeschichte. Heidelberg 2003, S. 81-101.

Wild, Reiner: Der Gott und die Bajadere. In: Otto, Regine u. Witte, Bernd (Hg): Goethe Handbuch. Herausgegeben von Bernd Witte u.a. Band 1: Gedichte. Stuttgart und Weimar 1996, S. 291-293.

Willson, A. Leslie: A mythical image: The ideal of India in German Romanticism. Durham 1964. 
Windisch, Ernst: Geschichte der Sanskrit-Philologie und Indischen Altertumskunde. Berlin 1992.

Wüst, Walther, "Bopp, Franz" in: Neue Deutsche Biographie 2 (1955), S. 453-454 [Online-Version]; URL: https://www.deutsche-biographie.de/pnd118659332.html\#ndbcontent).

Wulfhorst, Martin, "Spohr, Louis" in: Neue Deutsche Biographie 24 (2010), S. 733-735 [OnlineVersion]; URL: https://www.deutsche-biographie.de/pnd118616366.html\#ndbcontent.

Zhang, Chunjie: German Indophilia, Feminity, and Transcultural Symbiosis around 1800. In: Fuechtner, Veronika u. Rhiel, Mary (Hg.): Imagining Germany Imagining Asia. Essays in AsianGerman Studies. New York 2013, S. 204-219.

Zimmermann, Paul, "Remer, Julius August" in: Allgemeine Deutsche Biographie 28 (1889), S. 198 [Online-Version]; URL: https://www.deutsche-biographie.de/pnd116436123.html\#adbcontent.

\section{Internetseiten}

https://brockhaus.de/ecs/enzy/article/indien (Stand 07.05.2019)

https://www.buddhaland.de/forum/thread/8966-schubladen-denkfaulheit-und-aversion/ (Stand 07.05.2019)

http://www.buddha-vs.de/Buecher/Meditation (Stand 07.05.2019)

https://www.chamaeleon-reisen.de/Asien/Indien/Thar (Stand 06.11.2015)

http://www.indien-reise.com/ (Stand 06.011.2015)

https://katholisches.info/2014/06/24/gewalttaetiger-buddhismus-vatikan-besorgt-wegen-papstbesuch/ (Stand 07.05.2019)

http://www.tourvital.de/tvrproduct/DEL01AA/?gclid=CLyfuqfJ-8gCFQs6GwodyRIJwQ (Stand 06.11.2015)

https://wiki.yoga-vidya.de/Indien (Stand 07.05.2019) 


\section{Eidesstattliche Versicherung}

Hiermit versichere ich an Eides statt, dass ich die schriftliche wissenschaftliche Abhandlung (Dissertation) selbstständig angefertigt und keine anderen als die angegebenen Quellen und Hilfsmittel verwendet habe und dass anderweitig keine entsprechende Promotion beantragt wurde und die hierbei eingereichte Dissertation oder Teile daraus vorgelegt worden sind.

Hirschberg, 18.07.2020 